\title{
MARITIME SAFETY IN EUROPE
}

A COMPARATIVE APPROACH

\author{
EDITED BY \\ JUSTYNA NAWROT
}

AND

ZUZANNA PEPŁOWSKA-DABROWSKA 
MARITIME SAFETY IN EUROPE 


\section{MARITIME AND TRANSPORT LAW LIBRARY SERIES}

Ship Building, Sale and Finance

Edited by Bariş Soyer and Andrew Tettenborn

The Modern Law of Marine Insurance Volume 4

Edited by D. Rhidian Thomas

Air Cargo Insurance

Malcom A. Clarke and George Leloudas

Offshore Oil and Gas Installations Security An International Perspective

Mikhail Kashubsky

International Trade and Carriage of Goods Edited by Bariş Soyer and Andrew Tettenborn

Maritime Law and Practice in China

Liang Zhao and Lianjun $\mathrm{Li}$

Maritime Cross-Border Insolvency

Lia Athanassiou

The Law of Yachts and Yachting Second Edition

Edited by Filippo Lorenzon and Richard Coles

Maritime Liabilities in a Global and Regional Context

Edited by Bariş Soyer and Andrew Tettenborn
New Technologies, Artificial Intelligence and Shipping Law in the 21st Century Edited by Bariș Soyer and Andrew Tettenborn

The Law of Wreck Nicholas Gaskell and Craig Forrest

Codification of Maritime Law Challenges, Possibilities and Experience

Edited by Zuzanna Pepłowska-

Dąbrowska and Justyna Nawrot

Transport Documents in Carriage Of Goods by Sea

International Law and Practice By Caslav Pejovic

Maritime Law

Fifth Edition

Edited by Yvonne Baatz

Ship Operations: New Risks, Liabilities and Technologies in the Maritime Sector

Edited by Bariş Soyer and Andrew Tettenborn

Maritime Safety in Europe

Edited by Justyna Nawrot and

Zuzanna Pepłowska-Dąbrowska

For more information about this series, please visit: www.routledge.com/Maritime-and-Transport-Law-Library/book-series/MTLL 


\title{
MARITIME SAFETY IN EUROPE
}

\author{
A COMPARATIVE APPROACH
}

EDITED BY JUSTYNA NAWROT

AND ZUZANNA PEPŁOWSKA-DĄBROWSKA 
First published 2021

by Routledge

2 Park Square, Milton Park, Abingdon, Oxon OX14 4RN

and by Routledge

52 Vanderbilt Avenue, New York, NY 10017

Routledge is an imprint of the Taylor \& Francis Group, an informa business

(C) 2021 selection and editorial matter, Justyna Nawrot and Zuzanna Pepłowska-Dąbrowska; individual chapters, the contributors

The right of Justyna Nawrot and Zuzanna Pepłowska-Dąbrowska to be identified as the authors of the editorial material, and of the authors for their individual chapters, has been asserted in accordance with sections 77 and 78 of the Copyright, Designs and Patents Act 1988.

With the exception of Chapter 14, no part of this book may be reprinted or reproduced or utilised in any form or by any electronic, mechanical, or other means, now known or hereafter invented, including photocopying and recording, or in any information storage or retrieval system, without permission in writing from the publishers.

Chapter 14 of this book is available for free in PDF format as Open Access from the individual product page at www.routledge.com. It has been made available under a Creative Commons Attribution-Non Commercial-No Derivatives 4.0 license.

All rights reserved. No part of this book may be reprinted or reproduced or utilised in any form or by any electronic, mechanical, or other means, now known or hereafter invented, including photocopying and recording, or in any information storage or retrieval system, without permission in writing from the publishers.

Trademark notice: Product or corporate names may be trademarks or registered trademarks, and are used only for identification and explanation without intent to infringe.

British Library Cataloguing-in-Publication Data

A catalogue record for this book is available from the British Library

Library of Congress Cataloging-in-Publication Data

A catalog record has been requested for this book

ISBN: 978-0-367-46584-1 (hbk)

ISBN: 978-1-003-03077-5 (ebk)

Typeset in Times

by Deanta Global Publishing Services, Chennai, India 


\section{CONTENTS}

Contributors vii

Foreword by Professor Henrik Ringbom Xv

Preface xvii

Table of cases $\quad$ xx

Table of legislation $\quad$ xxi

PART I INTERNATIONAL AND EUROPEAN PERSPECTIVE

CHAPTER 1 IMPLEMENTATION OF IMO TREATIES INTO

DOMESTIC LEGISLATION: IMPLEMENTATION AND

ENFORCEMENT AS THE KEY TO EFFECTIVENESS

OF INTERNATIONAL TREATIES

Dorota Lost-Siemińska

CHAPTER 2 EU MARITIME SAFETY RULES: RAISING THE BAR WITHIN EUROPE AND BEYOND

Lemonia Tsaroucha and Jacob Terling

CHAPTER 3 MARITIME SAFETY FROM THE PERSPECTIVE OF THE EEA EFTA COUNTRIES

Milagros Varela Chouciño

PART II NATIONAL PERSPECTIVE: EFFORTS TO ENSURE COMPLIANCE

CHAPTER 4 MARITIME SAFETY IN BELGIUM: AN OVERVIEW OF THE LEGAL FRAMEWORK

Eric Van Hooydonk

CHAPTER 5 MARITIME SAFETY: CROATIAN LEGAL FRAMEWORK

Igor Vio 
CHAPTER 6 FRENCH RULES CONCERNING MARITIME SAFETY

Cécile De Cet Bertin

CHAPTER 7 GERMAN MARITIME SAFETY LAWS:

COMPREHENSIVE BUT COMPLICATED

Henning Jessen

CHAPTER 8 BRIEF REFLECTIONS ON THE REGULATION

AND IMPLEMENTATION OF MARITIME

SAFETY IN THE UK

Filippo Lorenzon

CHAPTER 9 MARITIME SAFETY: GREECE

Lia I. Athanassiou

CHAPTER 10 THE ITALIAN LEGAL FRAMEWORK ON MARITIME SAFETY: RECENT DEVELOPMENTS AND FUTURE PERSPECTIVES

Anna Montesano, Alessandra Laconi and Lucrezia Pari

CHAPTER 11 AN OVERVIEW OF MARITIME

SAFETY LAWS IN MALTA

Elda Kazara-Belja and Sofiya Shvelidze

CHAPTER 12 COMPARATIVE MARITIME SAFETY: THE

NETHERLANDS

Frank Stevens

CHAPTER 13 NORWAY: PLAYING IT SAFE

Erik Røsag

CHAPTER 14 TAKING MARITIME SAFETY SERIOUSLY:

THE POLISH PERSPECTIVE

Justyna Nawrot and Zuzanna Pepłowska-Dąrowska

CHAPTER 15 MARITIME SAFETY AND SECURITY IN SPAIN Juan L. Pulido Begines and Achim Puetz

CHAPTER 16 MARITIME SAFETY IN TURKEY

Ahmet Gelgeç 


\section{CONTRIBUTORS}

\section{EDITORS}

DR JUSTYNA NAWROT is an Assistant Professor in the Maritime Law Department, Faculty of Law and Administration, University of Gdańsk, where she teaches Maritime Law. In 2015 she was nominated as a member of the Polish Codification Commission for Maritime Law. She is a vice president of the Polish Maritime Law Association and vice editor of Prawo morskie, a scientific journal edited by the Polish Academy of Science and an arbitrator in maritime disputes. She was awarded a scientific grant by the Polish National Science Center for research dedicated to the maritime safety legal system. She is also the main coordinator of scientific grants dedicated to the problems of contemporary maritime codes. She has conducted her research in leading maritime law centres in Europe, among others: the Scandinavian Institute of Maritime Law at University of Oslo, the IMO International Maritime Law Institute in Malta and IMO Knowledge Centre in London. She is also an author of many publications on maritime law in Polish and English, including Codification of Maritime Law (Informa Law from Routledge 2020, as a co-editor and contributor) and International Law of Maritime Safety (C.H. Beck 2019, in Polish).

DR ZUZANNA PEPLOWSKA-DĄBROWSKA is an Assistant Professor at the Commercial and Maritime Law Department of the Law and Administration Faculty at the Nicolaus Copernicus University in Toruń. Between 2015 and 2019 she was a member of the Polish Codification Commission for Maritime Law. She is Vice President of the Polish Maritime Law Association, a member of the Maritime Law Commission's board of the Polish Academy of Sciences and an arbitrator in maritime disputes. In 2017 she was awarded a scientific grant by the Polish National Science Center for research dedicated to the problems of contemporary maritime codes. She is an author of many publications on maritime law in Polish and English, including Codification of Maritime Law (Informa Law from Routledge 2020, as a co-editor and contributor) and Civil liability for oil pollution from ships (Wydawnictwo Naukowe UMK 2017, in Polish).

\section{CONTRIBUTORS}

PROFESSOR LIA I. ATHANASSIOU, LLB (Athens Law School), LLM (AixMarseille III), LLM (Paris II), PhD (University Paris I-Panthéon-Sorbonne) is a Professor of Commercial Law with senior full-time tenure at the Law School of the University of Athens, teaching mainly Shipping Law, Company Law and Competition Law. She is also 
the Director of the Post Graduate Program on Business Law and head of the LLM in Maritime Law at the above University. She holds a PhD Degree at the University of Paris I-Panthéon-Sorbonne as well as authorization by the University of Paris I-Sorbonne to supervise University research. Visiting Scholar-Harvard Law School (2007-08), Fulbright Scholar (2007-08) member of the Hellenic Competition Commission (2003-08), Member of the Hellenic Association of Maritime Law, President of the Organizing Committee of the International Conference of Maritime Law, held in Piraeus every three years. She has lectured and effectuated academic research in several foreign Institutions (USA, Malta, UK, Italy, France, Germany). Barrister at law entitled to plead before the Supreme Court with experience in consulting and arbitration. Registered arbitrator at the Hellenic Shipping Chamber. Member of Legislative Committees on various commercial law issues. In 2015, she was appointed member of the Committee of Experts of the International Labor Organization (ILO, Geneva). She has published extensively on Maritime, Competition, Industrial Property, Company, European and Transport law, and participated in and organized of numerous international and national Conferences and Congresses. Among the more recent books and monographs, Treatise on Maritime Law (2020, in Greek) by Antapassis/Athanassiou, Maritime Cross-border Insolvency (Informa 2018), Competition and Regulation in Shipping and Shipping Related Industries, ed. by A. Antapassis, L. Athanassiou and E. Røsæg (Martinus Nijhoff, 2009, in English), Shareholders' activism and corporate monitoring (Athens 2010, p. 423, in Greek by L. Athanassiou), Intellectual Property - Greece (Kluwer, 2014, co-author, in English). She is an author of more than 60 articles and contributions in collective works, in foreign and Greek reviews, in Greek, English and French. Director of two publication series for Maritime Law, in Greek.

DR ELDA KAZARA-BELJA is currently a Senior Lecturer at the IMO International Maritime Law Institute. Prior to joining the Institute in 2008, she served as Legal Officer, Department of Maritime Affairs at the Ministry of Transport and Public Works of Albania. She completed her law studies at the National and Kapodistrian University of Athens. Ms Kazara-Belja obtained her Master of Laws Degree in International Maritime Law, with distinction, from the IMO International Maritime Law Institute. She has been a visiting lecturer at the International Ocean Institute (IOI) and University of Malta and has acted as an examiner for the Faculty of Laws, University of Malta. She has also participated in several international conferences and workshops where she has delivered presentations on issues of the law of the sea, shipping law, marine environmental law, and migration at sea. Dr Kazara-Belja joined the International Maritime Organization's Roster of Experts in 2012 and the FAO's Roster of Experts in 2018. She is a contributor and co-editor of the Second Volume of The IMLI Manual in International Maritime Law.

MILAGROS VARELA CHOUCIÑO is a Spanish and Norwegian qualified lawyer, specialized in maritime/offshore matters. She holds two LLMs in Maritime Law from the Universities of Southampton and Oslo and an Executive MBA from Copenhagen Business School. She is the Head of Labour Relations in the Marine Human Resources division of APM Moller-Maersk in Copenhagen. Before taking up this post, she was working at the EFTA Surveillance Authority, an international organization tasked with the monitoring of the EEA Agreement, for six years. Her last position held in this organization was Deputy Director for the Transport Unit. Mila has also worked as a shipping lawyer in the Shipping 
and Offshore department of the Norwegian top-tier law firm, Wikborg Rein, and as a contractual advisor in offshore contracts for Equinor AS.

DR CÉCILE DE CET BERTIN is a Senior Lecturer in Private Law at the University of Brest (France). She is a member of an interdisciplinary research unit specialized in economics and law of the sea (UMR 6308 AMURE), and her research activity is focused on maritime law. She contributes on a regular basis to the biannual maritime chronicle of the Revue de l'Union européenne (Dalloz), and she has recently co-edited an interdisciplinary book dedicated to property rights in a marine context (La propriété à l'épreuve de la mer, Cécile De Cet Bertin and Jean Boncoeur Eds, PUAM, 2018).

DR AHMET GELGEÇ is a Master of Laws (LLM, University of Southampton, 2013) and holds a PhD in law (PhD University of Southampton 2018). He is currently a Lecturer in Maritime and Commercial law at Istanbul Medeniyet University, Law School. His research primarily covers shipping law, carriage of goods by sea law and international sale of goods law. Dr Gelgeç has a number of works published as book chapters and articles in international journals, including several in Lloyds' Shipping and Trade Law. He is also a member of Union of Turkish Bar Associations and Istanbul Bar Association.

PROFESSOR HENNING JESSEN, Associate Professor at the World Maritime University (WMU) is a fully qualified lawyer in his German home jurisdiction. He graduated from the University of Kiel in 2002 (First State Exam) and took the Second State Exam in 2006. Supported by a Fulbright Scholarship, he has undertaken postgraduate studies in Admiralty and Maritime Law in the United States (Tulane Law School, New Orleans) from 2003 to 2004. From 2006 to 2008, Henning Jessen worked for the German Federal Ministry for Economic Cooperation \& Development (focus areas World Trade Law, Aid for Trade). Since 2008, he has been working as a Professor of Maritime Law and the Law of the Sea, at two universities in the German maritime hubs of Bremen (2008-2012) and Hamburg (2012-2016). Henning Jessen has co-edited and authored an extensive commentary on the EU's regulatory activity in the maritime realm (Brussels Commentary on EU Maritime Transport Law). Since 2016, he has been an Associate Professor for Maritime Law \& Policy at the World Maritime University (WMU) in Malmö, Sweden. His main areas of teaching and research are legal aspects of IMO Conventions and related EU Law as well as the Law of the Sea; carriage of goods by sea law; marine insurance; international aspects of transport law; trade facilitation and related world trade (WTO) law.

ALESSANDRA LACONI has been a Lawyer since September 2013 and an Associate of the Zunarelli Law Firm since November 2017. She mainly works in the fields of Civil, Bankruptcy, Commercial, Insurance, International and Transport Law, and has gained significant experience in legal advice and judicial and extrajudicial assistance to insolvency administrators, insurance companies and other companies working, inter alia, in the fields of transport, fashion, import-export, hospitality and the music industry. She is also a $\mathrm{PhD}$ Candidate in Maritime Law at the Alma Mater Studiorum - University of Bologna. Her research interests are oriented towards the practical profiles of insolvency procedures in the transport field. She has taken part as a speaker in many international conferences on Maritime and Transport Law, and is author of many publications, in Italian and in English, 
for some of the main academic journals of the sector. She is a member of the Editorial Board of the Journal Il Diritto Marittimo (academic journal of class A) and of the Editorial Staff of The Aviation \& Space Journal, edited by the University of Bologna. She is a Teaching Assistant in Maritime, Transport and Air Law.

PROFESSOR FILIPPO LORENZON, LLD, Italy, LLM Soton, FCIL, Avvocato (Italy) and Solicitor in England and Wales, is Professor of Maritime and Commercial Law in the Faculty of Law of Dalian Maritime University in China. Filippo is a former Professor of Maritime and Commercial Law with the School of Law at the University of Southampton and has directed the Institute of Maritime Law from 2010 to 2014. He is qualified as an Avvocato in Italy and as a Solicitor in England and Wales and is a Member of the Italian and British Maritime Law Associations, the European Maritime Law Association (EMLO) and the International Bar Association (IBA). He is a consultant with Campbell Johnston Clark Ltd in London.

DR DOROTA LOST-SIEMIŃSKA is Deputy Director and Head of the Legal Affairs Office in the Legal Affairs and External Relations Division of the International Maritime Organization where she leads her team in the provision of legal advice in various complex subjects of international law, treaty law, maritime law and all other areas related to the activities of the Organization. Before joining the IMO in 2011 she was a Director of the Maritime Transport and Inland Navigation Department in the Ministry of Transport in Warsaw, Poland and, among other duties, led the Polish delegation to various UN and EU meetings. She obtained a Master of Law and PhD in International Maritime Law from the University of Gdańsk, Poland and a Master of Maritime Law from the IMO International Maritime Law Institute in Malta. She is also an advocate admitted to the Bar in Gdańsk and a member of the Polish Academy of Science and Polish Maritime Law Association.

DR ANNA MONTESANO graduated in Law magna cum laude at Alma Mater Studiorum - University of Bologna with a thesis in Commercial Law in 2008. She attended the Postgraduate School for Legal Professions E. Redenti in Bologna, obtaining the Diploma in 2010. In 2016, Anna pursued her PhD in State, individual and services in the European and International law system (curriculum: Transportation Law) at Alma Mater Studiorum - University of Bologna. In 2014, as part of the doctorate programme, she spent three months as visiting researcher at the University of Swansea. Her research focused on letters of credit and transport documents. Since 2013, Anna has been appointed named expert in Maritime and Transportation Law and in Tourism Legislation at the Department of Legal Studies of the Alma Mater Studiorum - University of Bologna. Member of the Bologna Bar Association, she is currently working as lawyer, providing legal advice and assistance with reference to civil, commercial, banking, insurance, maritime and transportation law. She has gained significant experience in domestic and international arbitrations and in the litigation practice area. She is author of articles concerning Maritime and Transport Law. She is a member of AIDIM, Italian Maritime Law Association, Regional Committee of Genoa, and member of the Editorial Boards of Il Diritto Marittimo and the International Transport Law Review (ITLR). Anna is Lecturer in Transportation Law at the University of Chieti-Pescara. 
LUCREZIA PARI graduated in Law at the University of Bologna in November 2017 with a final dissertation and thesis in Maritime Law entitled: The General average and the York Antwerp rules 2016. During the academic training she attended the University of Las Palmas de Gran Canaria for one year and spent three months at the CES Embassy Institute of Sydney. She is Trainee Lawyer of a well-known Italian Law firm operating in the field of Shipping and Transport Law and has been enrolled in the trainee register of the Bologna Bar Association since December 2017. She is author of case comments and articles concerning Maritime and Transport Law, for the scientific journal Il Diritto Marittimo - Quaderni, and speaks three languages, Italian, English and Spanish. She has taken part as a speaker in many national and international conferences on Maritime Law, and she is a member of AIDIM - Italian Maritime Law Association, Regional Committee of Genoa.

PROFESSOR ACHIM PUETZ is a German citizen resident in Spain. He holds a Law and a Masters degree in Transport Law and Administration (2006), as well as a European $\mathrm{PhD}$ (Law) from Jaume I University of Castellon (Spain) in 2008, for which he received the outstanding doctorate award. Bilingual in Spanish and German and with an advanced knowledge of English, French and Italian, has been an Associate Professor of Commercial Law at Jaume I University since September 2018. He has also lectured as a visiting professor, mostly on transport law, in degree, Masters and $\mathrm{PhD}$ studies at other higher education institutions in Spain (Complutense University, Madrid; Catholic University of Valencia; University of the Balearic Islands, European University of Valencia) and abroad (Université Catholique de Lille, Università degli Studi di Cagliari, Universidad de San Carlos de Guatemala, Università degli Studi di Bologna). He is the author of a monograph on rail wagon law (Madrid, 2012) and has co-authored the volume on Spain of the International Encyclopcedia of Laws - Transport Law (Netherlands, 2018). He has also published numerous research articles and contributions to collective works, both in transport matters and in other areas of commercial law (company law, antitrust and unfair competition law, insurance and factoring contract, insolvency law). Prof. Puetz holds the position of Academic Secretary of the Institute for Transport Law (IDT) at Jaume I University and is Director of its Master in Transport Law. He frequently participates as a speaker in conferences and seminars on transport law and has carried out research stays at renowned institutions in Germany, such as the Max Planck Institutes for Comparative and International Private Law (Hamburg) and for Intellectual Property, Competition and Tax Law (Munich), or Dr Ingo Koller's chair at Regensburg University; in Switzerland, at the Swiss Institute of Comparative Law (Lausanne); and in Italy (Università degli Studi de Bologna).

PROFESSOR JUAN L. PULIDO BEGINES has been a University Lecturer since 1992, becoming a Full Senior Professor of Commercial Law at the University of Cádiz in 2007. He holds a Law Degree (1989) and a PhD in Law (1995) from the University of Cádiz, for which he received the outstanding doctorate award. He has authored more than 60 publications (monographies, articles in law reviews, contributions to collective books) on different subjects of Commercial Law (Company Law, Banking Law, Insurance Law and mostly Maritime Law). These include the following monographs: Los contratos de remolque marítimo, Barcelona, 1996; El derecho de información del socio en la sociedad de responsabilidad limitada, Madrid, 1997; El derecho de información del accionista, 
Madrid, 1998; Seguro de mercancías y seguro de responsabilidad civil del porteador terrestre, Barcelona, 2001; Las averías y los accidentes de la navegación marítima y aérea, Madrid, 2003; La responsabilidad frente a terceros de las sociedades de clasificación de buques, Vitoria, 2006; Instituciones de Derecho de la navegación marítima, Madrid, 2009; El concepto de porteador efectivo en el Derecho uniforme del transporte, La transición incompleta, Madrid, 2012; Curso de Derecho de la navegación marítima, Madrid, 2015; Cruise Ships Law, in Hamburg Lectures on Maritime Law 2011-2013, Hamburg, 2015; International Encyclopcedia of Laws - Spain; Transport Law - Alphen aan den Rijn, 2018. Professor Pulido has been a speaker at numerous courses, masters, PhD courses, seminars and conferences in Spain and abroad and has been a visiting Professor at the Universities of Messina (Italy), La Habana (Cuba) and Gabriel René Moreno in Santa Cruz de la Sierra (Bolivia), among others. He is a member of the Editorial Board of the following journals: Anuario de Derecho Marítimo; Revista de Derecho del Transporte; Studia Iuridica Toruniensa and Diritto dei Trasporti.

PROFESSOR ERIK RØS EG was born in 1958, and has mainly been employed by the University of Oslo since 1982. He became Master of Laws 1986 and Doctor of Laws 1992; both degrees from University of Oslo. He currently works at the Institute of Private Law. He works with general commercial law, maritime law and law of the sea. He has extensive experience from maritime liability treaty negotiations and is the chair of the Norwegian Maritime Law Commission.

SOFIYA SHVELIDZE is currently serving as a Lecturer at the IMO International Maritime Law Institute in Malta. She obtained her Bachelor Degree (Hons) in Law from the University of Malta and her Master of Laws Degree in International Maritime Law, with distinction, from the IMO International Maritime Law Institute. Her areas of interest are law of the sea and marine environmental law.

DR FRANK STEVENS obtained his Law Degree from the University of Leuven (Belgium) in 1991. He also holds an LLM in Admiralty from Tulane University (1992), a 'Special Degree in Maritime Sciences' from the University of Antwerp (1993) and a Doctorate in Law from the University of Ghent (2017). Dr Stevens joined the Antwerp Bar in 1993, and has been practising transport and maritime law since then. Since 2016, he has been an Associate Professor at the Erasmus School of Law in Rotterdam, and of counsel to Roosendaal Keyzer, one of the leading maritime law firms in Antwerp. Dr Stevens is the author of textbooks on Carriage of Goods by Sea and on Limitation of Liability, and regularly publishes and speaks on issues of transport and maritime law. He is the Editor-in-Chief of the Journal for International Trade and Transport Law (Tijdschrift voor Internationale Handel en Transport) and is on the Board of Editors of two other legal journals. He is a member of the Belgian Maritime Law Association, and served as its President from 2015 to 2019 .

JACOB TERLING is Principle Administrator in the Maritime Safety Unit of the European Commission's Directorate General for Mobility and Transport, with responsibilities, among other areas, for the development of EU policy and legislation related to flag State as well as coastal State issues, including vessel traffic monitoring and situational 
awareness at sea (maritime surveillance) and related Port State Control issues. He holds a Double Degree in Law (LLM) from the University of Lund (Sweden) and in European Business Law (post-graduate) from the University of Amsterdam. He is also involved in work on EU external relations aspects of maritime transport, such as negotiations at the IMO. Jacob chairs the EU expert group on Autonomous Shipping and the expert group on ships in need of assistance seeking a place of refuge. He has over 20 years' experience in the maritime field and in particular with maritime safety issues. He has been working on maritime issues in the European Commission since 1996. After spending some time working for the Swedish Shipowners Association in Brussels, he spent seven years working for the European Maritime Safety Agency (EMSA), and was one of the pioneers in its initial setting up, also managing the 'inspectorate' unit.

DR LEMONIA TSAROUCHA is a Senior Legal Officer in the Transport Unit of the Internal Market Affairs Directorate of the EFTA Surveillance Authority. She has previously worked as a lawyer for the Maritime Safety Unit of the European Commission's Directorate General for Mobility and Transport. Dr Tsaroucha has extensive experience with maritime safety and security regulation, including safety and security audits and inspections. She has also worked on EU external relations aspects of maritime transport, such as negotiations at the IMO and EU restrictive measures. She holds a doctorate $(\mathrm{PhD})$ in International Law (Thesis on 'Justice and Finality in International Judgments and Awards') from University College London, with a scholarship from the Greek State Scholarships Foundation; an LLM in Public International Law from University College London; and has studied law at undergraduate level in Greece (Aristotle University of Thessaloniki) and France (Robert Schuman University of Strasbourg). She was admitted to the Bar in Greece in 2007.

PROFESSOR DR ERIC VAN HOOYDONK is the Senior Partner at the Eric Van Hooydonk Lawyers law firm. He holds a licentiate in Laws (UIA, 1988), a special licentiate in Maritime Sciences (UFSIA, 1988) and a doctorate in Laws (UIA, 1994). In 1988 he was called to the Bar at Antwerp. Since 1994 he has lectured on maritime and transport law, international law of the sea and related subjects at the University of Antwerp. He has written numerous books about maritime, port and transport law. Between 2000 and 2009 he was President of the European Institute of Maritime and Transport Law. In 2007, Eric was appointed chairman of the Royal Commission for the Review of Belgian Shipping Law. In 2009 Eric joined the Faculty of Law of the University of Ghent, where with the support of the College of Europe, based in Bruges, and the port authorities of Antwerp, Ghent and Zeebrugge he established Portius, an international and EU port law centre. He is a member of the management and editorial boards of several maritime law reviews. Eric is a Titulary Member of the Comité Maritime International and a member of various learned societies.

DR IGOR VIO is Lecturer of courses in Maritime Law, Law of the Sea and Transport Insurance at the University of Rijeka - Faculty of Maritime Studies. As a visiting lecturer, he has delivered courses at the IMO IMLI in Malta, IMO IMA in Trieste, and International Ocean Institute at Dalhousie University in Halifax, Canada. His legal education includes LL.B. degree at the University of Rijeka - Faculty of Law, LLM in Ocean and Coastal Law at the University of Miami School of Law, LLM in Maritime Law and Law of the Sea at the University of Split - Faculty of Law, and PhD degree in Maritime Law from 
the University of Split - Faculty of Law. As a UN fellow, he spent one year in the United States and worked in the United Nations Office of Legal Affairs in New York City. Dr Vio has published papers covering various fields of the international law of the sea and maritime law. He was editor of the volume Maritime Code of the Republic of Croatia and Recent Developments in the Area of Maritime and Transportation Law and member of the working group for drafting amendments of the Maritime Code. As an invited speaker, he participated with presentations at various national and international conferences. He is the Secretary General of the Croatian Maritime Law Association and a Titulary Member of the CMI. 


\section{FOREWORD}

Shipping represents a crucial element of the European economy and is key to the general prosperity of the region. The health of the industry depends on maintaining high standards of safety which, in turn, requires an adequate regulatory framework. The body of maritime safety legislation has increased exponentially over the past decades and now covers virtually every aspect of ships' activities. At the same time, the number of players involved in regulation and enforcement has increased, thereby altering traditional roles of institutions, but also increasing the risk of regulatory tension between different sets of rules.

Nevertheless, maritime safety has not received very much attention in legal research. The legality of individual safety rules at times receives some notice, in particular where they involve diversions from the global regulatory framework. The topic as a whole tends to get particular attention, by policymakers and academics alike, following high-profile accidents, which keep occurring, albeit - thankfully - ever more infrequently.

There is a particular shortage of broader, more analytical studies of maritime safety legislation in a historic perspective. In the absence of a systematic review of regulation and developments, not only worldwide, but also regionally and at national level, several interesting trends and developments remain largely unnoticed by legal research. How accurate really is, for example, the widespread truism that maritime safety is exclusively regulated at global level alone and that national rules in this field only replicate IMO standards? How has the purpose and focus of maritime safety regulation changed over time? What development has there been with respect to the content of maritime safety legislation and how has that development affected the roles and risks of various key players? What legal challenges has the increasing regional coordination of maritime safety in Europe given rise to? And what regulatory challenges do new technologies in the field give rise to, for law-makers, industry players and for society at large?

The current book touches upon those questions and is thus a notable exception to the general scarcity of legal studies of maritime safety. It specifically seeks to address more structural aspects of legislation and its enforcement. It does so through 16 regulatory case studies of selected jurisdictions, all undertaken by well-known experts in the field.

The book proves, again, that the maritime safety discipline is much more dynamic and multifaceted than merely a uniform worldwide implementation exercise of global rules. It highlights a variety of issues and perspectives of maritime safety regulation, ranging from procedural differences on how international rules are accommodated and incorporated in national systems, which are surprisingly significant, to independent national legal solutions for prescription and enforcement. As always, the interesting things lie in the details, but their significance can only be appreciated when related to the more general development. 
The global foundation of maritime safety regulation offers an unusually good basis for assessing - and understanding - developments and trends through national comparisons, which is exactly what this book does, added with the additional EU/EEA-dimension which adds an extra layer of regulatory dynamism into the field.

The editors, Dr Justyna Nawrot and Dr Zuzanna Pepłowska-Dąbrowska, are to be commended for putting together this volume, which represents a very welcome addition to European and global maritime safety literature. Hopefully the book can serve to spark further interest in legal research in this very fascinating, dynamic and important field.

Henrik Ringbom, March 2020

PROFESSOR II, SCANDINAVIAN INSTITUTE OF MARITIME LAW, UNIVERSITY OF OSLO, NORWAY

HEAD OF RESEARCH, DEPARTMENT OF LAW, ÅBO AKADEMI

UNIVERSITY, TURKU, FINLAND

PROFESSOR OF MARITIME LAW, UNIVERSITY OF TURKU, FINLAND 


\section{PREFACE}

Mythical Europe was born by the waters of the Mediterranean. The beautiful princess, loved by the king of ancient gods, Zeus, and kidnapped by him from Tyre, gave the name to the mighty continent. Had it not been for the favour of Poseidon, god of the seas and sailors and brother of Zeus, who knows whether Zeus would have been able to cross the Mediterranean Sea and reach Crete with Europe. This mythical tale allows us to root Europe's history in safe shipping and prove - even symbolically - its strong relationship with the sea.

The perils of the sea are the cause and unifying force of the entire human output regarding the principles of safe navigation. Attempts to remedy them have been undertaken since the beginning of human navigation activities. However, interest in maritime safety issues in the context of creating comprehensive global legal regulations appeared only at the beginning of the last century and as a consequence of the rise of new threats caused by human activity. Certain national pre-existing regulations concerning ship safety and the prevention of collisions at sea, such as the British Regulations for Preventing Collisions at Sea of 1863 or the obligation to mark ships' freeboard, were supported by a few other states, allowing them to be standardized internationally. It was only the Titanic disaster in 1912 that drew the international community's attention to the problem of the lack of international requirements regarding maritime safety and the need to create a comprehensive global regulation. Since then, maritime safety has undergone a significant evolution and has become one of the most dynamically developing branches of maritime law. Another crucial moment was the disaster of the Torrey Canyon tanker in 1967. It seems reasonable to claim that it accelerated the process of redefining the role of states involved in strengthening maritime safety. It made many countries, which had traditionally favoured the interests of ship operators, aware that strengthening control over the ship's safety was crucial for the protection of the marine environment, as well as the coast and its interests.

The concept of maritime safety has undergone considerable changes in recent years. Traditionally, it referred to the safety of human activities at sea and was focused only on increasing the safety of human life as well as reducing the risk associated with the loss of a ship or its cargo. It also related to navigation and technical aspects aimed at reducing the classic dangers at sea. A characteristic feature of regulations in the field of maritime safety is the wide application of technical standards, unusual for other legal branches. These standards usually concern the ship's construction issues in addition to its stability and equipment. Initially, the maritime safety regulatory standards only regulated issues related to the safety of the seagoing vessel in technical terms and in terms 
of its seaworthiness, nautical safety, proper manning and sea rescue. Those regulations, except for maritime rescue standards, were preventive and prescriptive in nature. For many years, there has been a trend in the international regulations to extend the concept of maritime safety to issues related to the protection of the marine environment. For the last several years, the concept of maritime safety has also been extended to issues related to preventing violations of law at sea as well as organizational and management issues related to setting standards for safe management, seafarers' qualifications and land personnel involved in the operation of marine equipment. Recent years brought the IMO to goal-based standards, which opens the prescriptive, technical requirements for innovations. At the same time, control mechanisms over ship safety compliance have intensified, which is reflected in the IMO Member State Audit Scheme.

This book aims to present the European approach to the challenges arising from the need to implement international standards of maritime safety, taking into account the relationship between international and EU law as well as the specificity of national interests. Despite significant unification of international safety law made in the field of international law, comparative legal research remains the underlying instrument for approximating national laws, seeking a common denominator and mapping potential sources of divergence in the application of the law by individual countries.

The book is divided in two parts. First, it presents the international perspective of the legislation adopted by the International Maritime Organization, the European Union and EFTA. This part of the book aims to summarize the information on the way in which international organizations anticipate and manage the challenges of maritime safety. The second part is devoted to national standpoints and presents the national framework for implementing internationally agreed standards and the specific national challenges that this involves. Adopting a harmonized structure for each national chapter allows one to easily compare the variety of national regulations.

The first chapter, by Dr Dorota Lost-Siemińska deals with the international maritime safety framework, addressing the challenges for national legislators. The second chapter, by Dr Lemonia Tsaroucha and Jacob Terling is also of an introductory nature and presents the EU's approach towards maritime safety regulation. In the third chapter, Milagros Varela Chouciño presents the perspective of the EEA EFTA countries as well as the interrelation between the international, EU and EEA EFTA regulations.

The main part of the book consists of the chapters dedicated to the following national maritime safety regulations (in alphabetical order): Belgian law presented by Professor Dr Eric Van Hooydonk, Croatian law presented by Dr Igor Vio, French law presented by Senior Lecturer Cécile de Cet Bertin, German law discussed by Professor Henning Jessen, British law assessed by Professor Filippo Lorenzon, Greek regulations presented by Professor Lia I. Athanassiou, the chapter on Italian law discussed by Dr Anna Montesano, Alessandra Laconi and Lucrezia Pari, Maltese law presented by Dr Elda Kazara-Belja and Sofiya Shvelidze, Dutch law assessed by Dr Frank Stevens, the Norwegian perspective presented by Professor Erik Røsæg, the Polish perspective discussed by Dr Justyna Nawrot together with Dr Zuzanna Pepłowska-Dąbrowska, the chapter on Spanish law submitted by Professor Juan L. Pulido Begines and Professor Achim Puetz and Turkish maritime safety law described by Dr Ahmet Gelgeç. All the national contributions follow a similar pattern, where the problems of implementation structure, prevention, system of control and surveillance as well as enforcement are 
addressed. The last element of national contributions is devoted to liability regulation supported by compulsory financial security. Despite the private nature of financial security instruments, they can be perceived not only as commercial tools, but also as the elements strengthening the maritime safety system. Maritime civil liability conventions incorporate an added value to their dominant compensatory function and thus they are included in the national contributions as an element supplementing the book's content.

We use this opportunity to thank all the contributors ${ }^{1}$ who made the book possible despite turbulent events during the last lap of our works. For the same reason, we are enormously grateful to our publisher, whose active role made it possible for the book to come into existence.

Gdańsk, 31st March 2020

DR JUSTYNA NAWROT, GDAŃSK UNIVERSITY, POLAND

DR ZUZANNA PEPŁOWSKA-DĄBROWSKA, THE NICOLAUS COPERNICUS UNIVERSITY IN TORUŃ, POLAND

1 Gathering the team of researchers as well as developing the concept of the book was possible due to research conducted within a scientific grant financed by the National Science Centre, Poland, under the contract UMO2016/23/D/HS5/02447 Maritime Safety Legal System. 


\section{TABLE OF CASES}

Athenian Tankers Management SA v Pyrena Shipping (The Arianna) [1987] ...........123n6 C-22/70 Commission v Council [1971] ECLI:EU:C:1971:32

C-45/07 Commission v Greece [2009] ECLI:EU:C2009:81 $27 \mathrm{n} 37,137$

C-188/07, ECR 2008, Commune de Mesquer, ECLI :EU :C :2008 :359 136 n12

C-308/06 The Queen on the application of International Association of Independent Tanker Owners (Intertanko), International Association of Dry Cargo Shipowners (Intercargo), Greek Shipping Co-operation Committee, Lloyd's Register, International Salvage Union v Secretary of State for Transport [2008] ECLI:EU:C:2008:312 .........27n35, 27n36 C-368/16 Assens Havn v Navigators Management (UK) Limited, Judgement of 13 July 2017 $.48 \mathrm{n} 145$

C-399-12 Germany v Council [2014] ECLI:EU:C:2014:2258 ..............................27n29

C-459/03 Commission v Ireland [2006] ECLI:EU:C:2006:345 .............................27n28

C-600/14 Germany v Council [2017] ECLI:EU:C:2017:935 ................................27n33

Case of Brudnicka and Others v. Poland ............................................................217n20

Marc Rich \& Co AGv Bishop Rock Marine Co Ltd (The Nicholas H) [1996] ........128n37 Riverstone Meat Co Pty Ltd v Lancashire Shipping Co Ltd (The Muncaster

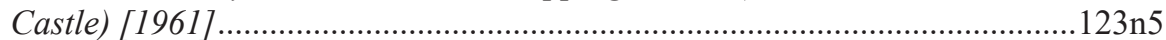

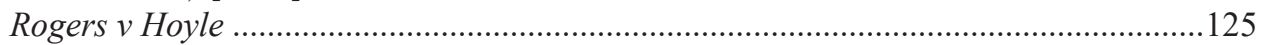

Sea Glory Maritime Co v Al Sagr anational Insurance Co (The Nancy).........................124

Slops Case

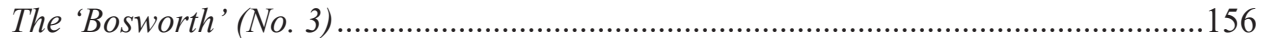

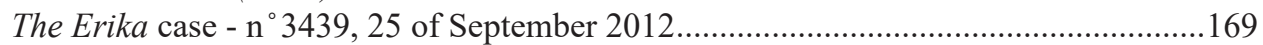

The Prestige - Reino de Espan̆a v. the American Bureau of Shipping ...........................169

Medellin v Texas, 552 U.S. 491, 505, n2 (2008) 


\section{TABLE OF LEGISLATION}

\section{International Legislation}

\section{European Economic Area/ \\ European Free Trade Association}

EEA (European Economic Area)

Agreement. 52-60, 207

Annex XIII .56

Article 108(1) .58

Article 109(2) 59

General Agreement on Tariffs and Trade (GATT) .52

North Atlantic Treaty Organization (NATO) .52

Treaty of Friendship, Co-operation and Mutual Assistance Between the Soviet Union and Certain East European Communist Governments

(Warsaw Pact) 52

\section{European Union Treaties, Directives, Regulations and Decisions}

Commission Regulation (EU) No

$788 / 2014$ $32 n 59$

Commission Regulation (EU) No

788/2014 $32 \mathrm{n} 59$

Directive 09/16/EC 258

Regulation 392/2009/

EC 119 n54, 135n 10

Regulation 3577/1992 140

Regulation (EC) 392/2009 ......... 48n150,

Commission Decision (EU) 190, 225n59, 227

2016/566 $57 \mathrm{n} 22$
Commission Decision 2009/83/EC ... 236

Commission Delegated Regulation

(EU) 2018/414 $168 \mathrm{n} 43$

Commission Delegated Regulation (EU)

2018/414 Regulation EU 2018/414 $168 \mathrm{n} 43$

Commission Implementing Directive 2014/111/EU $33 n 65$

Commission Implementing Regulation

(EU) 2018/608 $168 \mathrm{n} 43$

Commission Implementing Regulation (EU) 2018/608 Regulation EU 2018/608 $168 \mathrm{n} 43$

Commission Implementing Regulation (EU) 2018/773 $168 n 43$

Commission Implementing Regulation (EU) 2018/773 Regulation EU 2018/773 $168 \mathrm{n} 43$

Council Decision (EU) 2017/770 $45 n 133$

Council Decision 2002/762/EC $45 n 133$

Council Decision 2002/971/EC $45 n 133$

Council Decision 2004/246/EC $45 \mathrm{n} 133$

Council Decision 2012/22/EU $46 n 137$

Council Decision 2013/268/EU 33n64

Directive (EU) 1999/32 .................... 171

Directive (EU) 2016/1629 ................ 164

Directive (EU) 2017/2010 ............... 188, 219n27, 223n48 
Directive (EU) 2017/2108 $97 \mathrm{n} 12$

Directive (EU) 2017/2110 $97 \mathrm{n} 12,188 \mathrm{n} 124,219,247$

Directive (EU) 2017/2397 $169 \mathrm{n} 45$

Council Directive 1999/35/EC 33n66, 82n37, 93n71, 178n34

Council Directive 1999/38/EC

$146 n 103$

Directive 1996/98 168Directive

1999/63/EC 166n35, $177 \mathrm{n} 29$

Council Directive 1999/63/EC .....96n12

Directive 1999/95/EC 101,166 n35

Directive 1999/99/EC 164

Directive 2000/59/EC $56 n 19,92$

Directive 2000/60/EC $82 \mathrm{n} 37$

Directive 2001/105/EC ... 32n57, 129n41

Directive 2001/96/EC 139

Directive 2002/35/EC 164

Council Directive 2002/59/EC

$146 \mathrm{n} 103$

Directive 2002/59/EC ..... 29n42, 33n66, $41 \mathrm{n} 115,82 \mathrm{n} 37,86 \mathrm{n} 53,92 \mathrm{n} 68,96 \mathrm{n} 12$, 168, 178n34, 182n73, 198-200, 221n39, 223n42, 237-8, 240-1, 259

Directive 2002/6/EC . $96 \mathrm{n} 12,183$

Directive 2002/84/EC 139

Directive 2003/24/EC $93,165 \mathrm{n} 32$

Directive 2003/25/EC. $35,92-93,140-1$

Directive 2004/35/EC $47 \mathrm{n} 139$ $48 \mathrm{n} 154,49 \mathrm{n} 155$

Directive 2005/35/EC $27 \mathrm{n} 36$, $82 \mathrm{n} 34,150$

Directive 2005/65/EC 163 166n39, 198, 236

Directive (EU) 2008/106/EC 169

Directive 2008/106/EC $36 \mathrm{n} 84$, $38 \mathrm{n} 92,141,166,169$

Council Directive 2009/13/EC 177

Directive 2009/13/EC $82 \mathrm{n} 34$

Directive 2009/15/EC $32 n 58,128-9$

Directive (EU) 2009/16/EC . 223

Directive 2009/16/EC $38 \mathrm{n} 95$, 44n129, 96n12, 97n12, 100, $118 \mathrm{n} 49,145,163,167,187 \mathrm{n} 113$, $188 \mathrm{n} 122,247,258$
Directive 2009/17/EC $41 \mathrm{n} 115$, 146, 182, 232, 237, 259

Directive 2009/18/EC 33,82 , $88,146,162 \mathrm{n} 21,178$ Council Directive 2009/20/EC

$191 \mathrm{n} 146$

Directive 2009/20/EC .... 24n12, 39n104, 46n136, 47, 82n34, 135n9, 149, 197, 227

Directive 2009/20/EC .... $82 \mathrm{n} 34$

Directive 2009/21/EC 29n41, 37, 39n105, 96n12, 143

Directive 2009/45/EC .... 35, 48n151, 97n12, 165, 197, 204n72

Directive 2010/36/EU. $165 \mathrm{n} 32$

Directive 2010/65/EU $24 \mathrm{n} 12,57 \mathrm{n} 23,182,183 \mathrm{n} 74$ 201n63, 222

Directive 2012/32/EU $168 \mathrm{n} 43$

Directive (EU) 2012/33/EU ............... 171

Directive 2012/35/EU ............... 166, 169

Directive 2013/54/EU ................... 38n93

Commission Directive 2014/100/

EU 237

Directive 2014/111/EU ....33n65, 128n35

Directive (EU) 2014/90/EU ............... 220

Directive 2014/90/EU .... 42n120, 96n12, 164, 168n43, 179n37, 220n31

Directive 75/442/EEC. $136 \mathrm{n} 12$

Directive 89/392/EEC. $166 n 35$

Council Directive 93/75/EEC ........ 86n53

Directive 93/75/EEC. $86 \mathrm{n} 53$

Council Directive 94/57/EC 23n8, 57n26, 92n67, 129n41

Directive 94/57/EC . $31 \mathrm{n} 54,32 \mathrm{n} 57,57,128 \mathrm{n} 36$,

129 n38, 257

Directive 94/58/EC $169 n 44$

Council Directive 95/21/EC ....... 118n49

Directive 95/21/EC 199n46, 257

Directive 96/98/EC 164,168

Council Directive 96/98/EC ........ 97n12, 179 n 37

Directive 97/70/EC 59,164

Council Directive 97/91/EC .............. 176

Directive 98/18/EC..... 57,165 
Directive 98/41/EC 197

Regulation (EC) No 1049/2001 .......60n31 Regulation (EC) No 1371/2007 .....48n150 Regulation (EC) No 1406/2002........19n43, 55n14, 60n30, 86n53

Regulation (EC) No 1406/2002 .....36n83

Regulation (EC) No 2099/2002 .... 30n51, $93 \mathrm{n} 71$

Regulation (EC) No 219/2009 236

Commission Regulation (EC) No. 324/2008 236

Regulation (EC) No 336/2006 $38 \mathrm{n} 94,57 \mathrm{n} 24$

Regulation (EC) No 391/2009 $32 \mathrm{n} 58,128 \mathrm{n} 32$

Council Regulation (EC) No 392/2009 48n150, 119n54, 135n10, 190n142, 225n59, 227

Commission Regulation (EC) No

415/2004 $93 n 71$

Regulation (EC) No 417/2002 137

Regulation (EC) No 44/2001 ...... 46n137, 169-170

Regulation (EC) No 561/2006 .......25n18

Regulation (EC) No 725/2004 .....137, 236

Regulation (EC) No 725/2004 ........... 93, $166,198,235,258$

Regulation (EC) No 765/2008 ..... 42n122

Regulation (EC) No 782/2003 ........... 139

Regulation (EC) No 789/2004 ....... 29n40

Regulation (EEC) 3577/92/EC .82n 34,140

Regulation (EEC) No 339/93....... 42n122

Council Regulation (EEC) No 3820/85

$25 \mathrm{n} 18$

Council Regulation (EEC)

No 3821/85 $25 \mathrm{n} 18$

Regulation (EU) 2017/352.... 218

Regulation (EU) 2017/352 $218 \mathrm{n} 23$

Regulation (EU) 2019/1239 24n12

Regulation (EC) no. 725/2004 ........... 166

Regulation (EU) 2019/1243/

EU $128 \mathrm{n} 32$

Regulation (EU) 2019/1243........... 236-7

Regulation (EU) 2019/1896......... 40n111
Regulation (EU) No 100/2013 .......55n14

Regulation (EU) No 1177/2010......... 218

Regulation (EU) No 1215/2012 46n137, 169-170

Regulation (EU) No 1257/2013 ......... 172

Regulation (EU) No 182/2011 ....... 30n47

Regulation (EU) No 530/2012 ... 137, 140

Regulation (EU) No 530/2012 ........... 164

Commission Regulation (EU)

No 788/2014 .................................. 32n59

\section{IMO Resolutions and Codes}

Code for Recognized

Organizations (RO Code) (Resolution

MSC. 349(92)

Code of the International Standards and Recommended Practices for a Safety Investigation into a Marine Casualty or Marine Incident (MSC.255(84)) $6 n 14,178$

Code of Practice for the Safe Loading and Unloading of Bulk Carriers

(Resolution A.862(20)) 139 n37

Implementation of International

Instruments Code (III Code)

Resolution A.1070(28) 20, 37, 40n109, 43

International Code for Ships Operating in Polar Waters (Polar Code) Resolution MSC.385(94) Resolution MEPC.264(68) 207,210

International Maritime Dangerous

Goods (IMDG) Code (MSC.122(75)) . 6 n14, 182

International Maritime Solid Bulk

Cargoes (IMSBC) Code (Resolution MSC.268(85), 181 International Safety Management (ISM) Code (Resolution A.741(18)) $6 \mathrm{n} 14,38,57,111,168,180$, $183,197,216,220 ; 230,243,260-1$, 123,126

International Ship and Port Facility Security (ISPS) Code (Conference 
Resolution 2)

6n14, 94, 178, 180n53, 202,

209, 216, 231, 234-5, 258

Resolution A.158 (ES.IV) in

1968 259

Resolution A.572(14) 238

Resolution A.578(14) 259

Resolution A.682(17) 20n65

Resolution A.739(18) $3 \ln 55$

Resolution A.787(19) 223

Resolution A.851 (20) 240, 242

Resolution A.857(20) 259

Resolution A.898(21) ......135n9, 149n121

Resolution A.924(22) 234

Resolution A.950(23)

Resolution A.1052(27) 87

Resolution A.1054(27)

Resolution A.1067(28) 258

Resolution A.1110(30) $20 \mathrm{n} 67$

Resolution A.1131(31) 9n32 9 n32

\section{International Conventions}

Athens Convention relating to the Carriage of Passengers and their Luggage by Sea, 1974 (PAL Convention 1974) 26n26, 89, 96n10, 224, 225n $59,226-7$

Athens Convention relating to the Carriage of Passengers and their Luggage by Sea, 2002 (PAL Convention 2002) 119, 79, 82, 89, 46, 119, 190, 224, 225n59, 226-7

Accommodation of Crews Convention (1949) 255

Accommodation of Crews

(Supplementary Provisions) Convention (1970). 255

Convention on the Control of

Harmful Anti-fouling Systems on

Ships (2001) $6 n 16,199$

Convention on the International

Maritime Organization (1948) $3 n 2$

Convention on the International Regulations for Preventing Collisions at
Sea, 1972 (COLREGs) 5,85 , 102, 169, 175, 186-7, 209, 221, 245, 256 Convention on Limitation of Liability for Maritime Claims (LLMC, 1976) 12n44, 190, 212, 226, 254, 264

Convention for the Suppression of Unlawful Acts against the Safety of Maritime Navigation (SUA Convention) 255

Convention for the Unification of Certain Rules of Law with respect to Collisions between Vessels (Collision Convention 1910)..... $169,254,261$

Food and Catering (Ships' Crew)

Convention (1946) 255

The Hong Kong International

Convention for the Safe and

Environmentally Sound Recycling of

Ships, (2009), 261, 6n16, 9

International Convention on Certain

Rules Concerning Civil Jurisdiction in

Matters of Collision, 1952 169

International Convention on the Civil

Liability for Bunker Oil Pollution

Damage (Bunker Convention 2001) 6n19, 130n45, 131, 147-8, $203,213,255,265$

International Convention on

Civil Liability for Oil Pollution Damage 1969 (CLC 1969) 5-6, 13, 89-90, 103, 130n44, 147-8, 171, 190, 203, 212, 226, 249, 254-5, 265

International Convention on

Civil Liability for Oil Pollution Damage 1992 (CLC 1992) 212, 249

International Convention for the Control and Management of Ships' Ballast Water and Sediments 6n16, 199, 255

International Convention on the Establishment of an International Fund for Compensation for Oil Pollution Damage 1992 (FUND 1992). $212,254-5$ 
International Convention on Liability and Compensation for Damage in Connection with the carriage of Hazardous and Noxious Substance by Sea (HNS 1996) 10n37, 125, 171, 203, 250, 264

International Convention on Load Lines (1966) 12n43, 139,

169, 180, 196, 209, 255

International Convention on Oil

Pollution Preparedness, Response and

Co-operation (OPRC) $6 n 17,255$

International Convention for the

Prevention of Pollution from Ships

(MARPOL). $7 \mathrm{n} 21,163,241,256$

International Convention for the

Safety of Life at Sea (SOLAS) ..... 125-6, 139, 155, 160, 163, 168, 208-9, 255-6

International Convention on Salvage of 1989 6n18, 155, 170, 254, 261

International Convention on

Maritime Search and Rescue (1979), $79,96,155,156,178,215$

International Convention on Standards of Training, Certification and Watchkeeping for Seafarers (STCW 1978) 126, 141, 161, 166, 169, 209, 256

International Convention on Tonnage Measurement of Ships (1969) $175,196,209$

International Convention for the Unification of Certain Rules of Law

Relating to Bills of Lading $123 n 4$

Maritime Labour Convention (MLC)

(2006). $78-79,131,166,170$,

204, 210, 213, 230, 255

Merchant Shipping (Minimum

Standards) Convention 84

Nairobi International Convention on the

Removal of Wrecks (2007) .... 16n54, 82, 91, 118n52, 130n46, 131, 171-3, 191, 204, 212, 226, 250, 255, 265-6

Officers' Competency Certificates

Convention (1936) 255
Prevention of Accidents (seafarers)

Convention (1970) ............................. 255

Protocol of 2003 to the International

Convention on the Establishment of an International Fund for Compensation for Oil Pollution Damage, 1992: $89,46,147,171,212,225 n 59$,

250, 265

Protocol of 2010 to Amend the International Convention on Liability and Compensation for Damage to Connection with the Carriage of Hazardous and Noxious Substances by Sea, 1996 10n37, 89, 45n133, 103, 148, 213, 226, 264

Seafarers' Identity Documents Convention (1958) ............................ 255 Ship Owners' Liability (Sick and Injured Seamen) Convention (1936) .............. 255 United Nations Convention on the Law of the Sea (UNCLOS) 139, 221, $231,237,242-3,247,255$

\section{National Legislation}

\section{Austria}

Maritime Proclamation of 1774 .75

\section{Belgium}

Act of 3 November 1967 on pilotage of seagoing ships $73 n 71$

Act of 13 June 2014 for the implementation and monitoring of the application of the Maritime Labour Convention, 2006 70n33, 72n69

Belgian Shipping Code 69-73

Belgo-Dutch Agreement concerning the establishment of a shore radar chain along the Western Scheldt and its mouths $72 \mathrm{n} 62$

Cooperation agreement of 8 July 2005 between the Federal State and the Flemish Region on the establishment of 
and cooperation in a coastguard structure $72 n 63$

Decree of the Flemish Government of 3 June 2005 on the organisation of the Flemish administration $71 \mathrm{n} 49$

Decree of the Flemish Government of 26 October 2007 on vessel traffic services $71 \mathrm{n} 61$

Flemish-Dutch Treaty on joint nautical management in the Scheldt area ... 72n62 Flemish Shipping Decree 69

Legislative decree of 16 June 2006 on vessel traffic services on maritime access routes and the organisation of the Maritime Rescue and Coordination Centre $71 n 61,73 n 70$

Royal Decree of 20 July 1973 containing the maritime inspection regulations $70 \mathrm{n} 35$

Royal Decree of 20 June 1977 implementing the Act of 24 November 1975 approving and implementing the Convention on the International Regulations for Preventing Collisions at Sea, 1972 $70 \mathrm{n} 45$ Royal Decree of 4 August 1981 on police and shipping regulations for the Belgian territorial sea, the ports and the beaches of the Belgian coast $70 \mathrm{n} 46$ Royal Decree of 4 August 1981 on police and shipping regulations for the Belgian territorial sea, the ports and the beaches of the Belgian coast $71 \ln 58$

Royal Decree of 12 November 1981 on regulations for passenger ships not engaged on international voyages and operating exclusively within a limited coastal shipping area $.70 \mathrm{n} 41$

Royal Decree of 7 May 1984 implementing the Act of 12 July 1983 on ship measurement 70n36

Royal Decree of 7 January 1998 on medical assistance on board ships 70 n39
Royal Decree of 20 November 2001 establishing the Federal Public Service Mobility and Transport $71 n 49$ Royal Decree of 11 March 2002 on safety regulations and standards for passenger ships engaged on domestic voyages $70 \mathrm{n} 40$ Royal Decree of 12 March 2003 for the enforcement of compulsory working time for seafarers on board ships calling at Belgian ports $70 \mathrm{n} 38$

Royal Decree of 1 September 2004 on the delivery of ship-generated waste and cargo residues $71 \mathrm{n} 48$ Royal Decree of 21 November 2005 on specific stability requirements for ro-ro passenger ships $70 \mathrm{n} 43$ Royal Decree of 24 May 2006 on certificates of competency for seafarers $70 \mathrm{n} 37$

Royal Decree of 8 March 2007 on inland waterway vessels also used for non-international sea voyages ...... 70n44 Royal Decree of 21 April 2007 on maritime security $7 \ln 59$ Royal Decree of 27 April 2007 on the prevention of air pollution from ships and the reduction of the sulphur content of certain marine fuels $71 \mathrm{n} 47$ Royal Decree of 22 December 2010 on Port State Control $7 \ln 57$

Royal Decree of 15 June 2011 on compliance with flag state obligations $71 \ln 56$ Royal Decree of 26 September 2011 on the competent authority for the accommodation of ships in need of assistance $71 \mathrm{n} 60$

Royal Decree of 13 March 2013 implementing several International Conventions on civil liability for pollution by ships $72 n 68$ Royal Decree of 25 April 2016 on the equipment of seagoing ships and the 
organisation of market supervision $70 \mathrm{n} 35$

Royal Decree of 28 February 2019 on an inspection system for the safe operation of ro-ro passenger ships and high-speed passenger ships on regular services $70 \mathrm{n} 42$

Royal Decree of 6 April 2020 on the partial entry into force of the Belgian Maritime Code $69 n 24$

Special Act for the reform of the institutions 67-68n6-22

\section{France}

1984 Decree on safety of human life at sea, prevention of pollution, security and social certification of vessels .............. 97

French Transport Code ....................... 94

Parliament Act of 17 December 1926 101

\section{Germany}

Act on the Enforcement of Claims for

Wreck Removal 119

"Basic Law" 107-9

Federal Act on Ship Safety 109-10, 114-18

"Flaggenrechtsgestz" (1951) 109

"Ordinance on Ship Safety"

(Schiffssicherheitsverordnung) 114

"Schiffsicherheitsgesetz" (1998) 109

"Seeaufgabengesetz" 108-10, 117-18, 120

"Seelotsgesetz" (1954) 109

"Seesicherheitsgesetz" 120

"Seesicherheits-Untersuchungs-Gesetz" (2002) 109

"Wasserstrassengesetz" (1968) 109

\section{Greece}

Greek Code of Public Maritime Law (KDND) 136-7, 143, 156
Greek Code of Private Maritime Law

(KIND) 136

L. 187/1973 …............................... 136n15

L. $391 / 1968$.................................. 139n34

L. $743 / 1977$......................................... 148

L. 1045/1980 .............................. 139n36

L. 1269/1982 …........................... 139n35

L. 1373/1983 ............................... 136n16

L. 1650/1986 …................................... 148

L. $2172 / 1993$....................................... 138

L. $2321 / 1995$............................... 139n33

L. 2932/2001 ….................................. 140

L. $3816 / 1958$............................... 136n14

L. $4033 / 2011$....................................... 146

L. $4037 / 2012$.................................. 150-1

L. 4058/2012 …............................. 151-3

L. 4078/2012 …................................. 142

MD 128/2016 ….................................. 139

MD 222/2018 .............................. 140n50

MD 2222.1-1.2/90149/2016 ............. 139

OJ L 115, 9.5.2003 …................. 140n43

OJ L 172, 30.6.2012 .................. 140n44

OJ L 123, 170502003 ................. 141n52

OJ L 131, 28.5.2009 ................. 144n80,

144n81, 145n95, 146n100, 146n103

OJ L 255, 30.9.2005 ................ 150n137

OJ L 323, 3.12.2008 .................... 141n 60

OJ L 343, 14.12.2012 ….............. 141n61

PD 3/2017 ……................................. 142

PD 6/2012 ......................................... 149

PD 13/2018 .................................... 137-8

PD 16/2011 .......................... 145-6, 150

PD 17/2011 ........................................ 146

PD 52/2005 ......................................... 140

PD 66/2004 ........................................... 139

PD 102/2011 ...................... 143, 143n74

PD 103/2011 ...................................... 144

PD 113/2018 …................................... 142

PD 119/2014 .................................. 141-2

PD 171/2014 ..................................... 142

\section{Italy}

Criminal Code .................................... 168

L. Decree no. 25/2018 ...................... 165 
L. Decree no. $25 / 2018$

L. Decree 32/2016

L. Decree no. 45/2000

L. Decree no. 53/2011

L. Decree no. 58/2005

L. Decree no. 71/2015

L. Decree no. 81/2004

L. Decree no. 93/2012

L. Decree no. 108/2008

L. Decree no. 114/2018

L. Decree no. 136/2011

L. Decree no. 152/2006

L. Decree no. 169/2016

L. Decree no. 196/2005

L. Decree no. 203/2007

L. Decree no. 229/2017

L. Decree no. 271/1991

L. Decree no. 271/1999

L. Decree no. 291/2002

L. Decree no. 541/1999

Law no. 51/2001

Law no. 84/1994

Law no. 113/2013

Law no. 172/2003

Law no. 220/1992

Law no. 313/1980

Law no. 349/1986

Law no. 438/1982

Law no. 462/1980

Law no. 616/1962

Law no. 739/1985

Law no. 979/1982

Law no. 689/1994,

Ministerial Decree 154/2009

Ministerial Decree of 10 October 2005

Ministerial Decree of 12 October 2017

Ministerial Decree of 15 January 2003

Ministerial Decree of 28 January 2004

Ministerial Decree of 28 December 2017 $166 \mathrm{n} 35$ 172 164 167

165 $166 n 37$ 163,167 $165 \mathrm{n} 32$ $165 \mathrm{n} 32$ 166 n35 164 169 171 162 167,168

163,166 163 166,169 66,170 $165 n 32$ 164 167 $160,162,168$ 166 163 171 168 171 162 162 161 69 171 162 166

164
172
Navigation Code of 1942 ..... 160-1, 165, 168

Pleasure Sailing Code 163 Presidential Decree no. 231/2006, Law 300/1970 ........................................... 170 Presidential Decree no. 239/2017 ..... 164 Presidential Decree no. 407/1999 ..... 164 Presidential Decree no. 435/1991 161, 164-5, 168

\section{Malta}

Fisheries Conservation and Management Act ...................................................... 183 L.N. 22 of 2003 ................................... 181 L.N. 093 of 2019 ................................ 187 L.N. 411 of 2007 ............................... 180 Merchant Shipping Act ...... 176, 179-80, 182, 187

Merchant Shipping (Liability for Bunker Oil Pollution Damage) Regulations 2009 190

Oil Pollution (Liability and Compensation) Act (1999) ................ 190

Ratification of Treaties Act ............... 177 S.L. 234.16 191

S.L. 234.19 $176 \mathrm{n} 13$

S.L. 234.20 176n14, 186

S.L. 234.29 $176 \mathrm{n} 12$

S.L. 234.30 $176 n 11,189$ n 128

S.L. 234.32 $177 \mathrm{n} 24$

S.L. 234.33 191

S.L. 234.36 $176 \mathrm{n} 22$

S.L. 234.37

S.L. 234.38 $176 \mathrm{n} 15$

S.L. 234.45 176n18, 188

S.L. 234.46 $176 n 19$

S.L. 234.48

S.L. 234.49 $190 \mathrm{n} 136$

S.L. 234.50 $176 \mathrm{n} 17$

S.L. 234.51 91n147

S.L. 234.52 $177 \mathrm{n} 27$

S.L. 234.53 190n140

S.L. 499.23 $191 \mathrm{n} 145$

S.L. 499.34 183 185n107, 186 


\section{The Netherlands}

1839 Belgo-Dutch Treaty 200

1909 Ships Act $194-6,199$

1965 Decree to implement art . $195 \mathrm{n} 17$

1965 Ships Decree 195

1975 Liability of Oil Tankers Act .... 203

1981 Tonnage Certificate Act 196

1981 Tonnage Certificate Decree ..... 196 1988 Shipping Traffic Act

197, 199-201

1989 Decree to declare applicable the International Regulations for preventing collisions at sea, 1972 200n54 1989 Fishing Vessels Decree 196 1993 Decree containing administrative provisions on shipping traffic ...... 201n62 1993 Shipping Traffic Administrative Provisions Decree 197 1997 Decree regarding routeing and reporting systems for ships on the high seas off the Dutch coast 199n52 1997 Port State Control Act 199 1997 Seafarers Act 196-7

2001 Seafarers Decree 196

2002 Fishing Vessels Decree 196 2004 Decree establishing rules with regard to the safety and certification of sea-going vessels $195 n 18$

2004 Foreign Ships Act 195

2004 Port Security Act 198 2004 Ships Decree ....... 195-8, 202-3 2006 Financial Supervision Act ........ 203 2011 Insurance of Sea-going Vessels Act 204 2012 Decree reporting formalities and data processing in shipping 202 2013 Decree on training and powers of nautical professions .. 201

2015 Maritime Accidents Response Act 198

2015 Maritime Incidents Act 204 Merchant Navy Protection Act 198

\section{Norway}

Act Concerning Protection

Against Pollution and Concerning

Waste $212 \mathrm{n} 54$

Act Relating to Employment Protection

Etc. for Employees on Board Ships 206n7

Act Relating to Industrial Injury

Insurance $213 n 58$

Act Relating to Norway's Territorial

Waters and Contiguous Zone ...... 207n21

Act Relating to a Norwegian

International Ship Register $207 n 14$

Act Relating to Procedure in Cases

Concerning the Public Administration $208 \mathrm{n} 24$

Act Relating to Public Control of the

Seaworthiness of Ships 206n5

Act Relating to Ship Safety and

Security .......................................... 206n1

Harbor Act ........................................ 211

Petroleum Act .................................. 212

Pollution Control Act (1980) ............. 212

Seaworthiness Act (1903) .................. 206

Ship Labor Act .................................. 206

Ship Safety Act 2007 ............... 206-208

\section{Poland}

Act on International Treaties 224

Act for the Prevention of Pollution from

Ships 221,224

Criminal Code 224

Harbours and Marinas Act ................ 218

Labour at Sea Act of 2015 ................ 225

Marine Equipment Act .....219-220, 225

Maritime Code (1961) ..............214-215

Maritime Code (2001) ..... 214-215, 224, 226

Maritime Safety Act (2000) .............215, 218-219, 224, 227

Maritime Safety Act (2011).... 215-222, 224 
Maritime Zones and Administration Act (1991) $216,220,221,224$

Shipping and Port Security Act 216

\section{Republic of Croatia}

1994 Maritime Code $84 n 48$ 2004 Maritime Code $80-81$

2019 Maritime Code Amendments Act $82-83$

Act on Harbour Master's Offices 76

Act on Maritime Ship and Port Security 76

Act on Public Liner Coastal Maritime

Transport .76

Act on the Gradual Phasing-Out of

Single Hull Oil Tankers .76

Bankruptcy Act 82

Coast Guard Act (CGA) .88

Croatian Register of Shipping Act ......85 Harbour Master's Offices Act (Official Gazette 124/1197) $77 \mathrm{n} 10$

Hydrographic Activity Act .76

Maritime Code (MC 1994) $80 \mathrm{n} 22$

Maritime Domain and Seaports Act 76-77, 80n 25

Maritime and Inland Navigation Act

(1977) $80 \mathrm{n} 21$

Ordinance on Places of Refuge 87

Ordinance on Services of Armed Guards Protection on board Ships of Croatian

Nationality 83-84

Protection and Rescue Act .88

Ships and Port Security Act (SPSA) ... 83

\section{SPAIN}

2014 Maritime Navigation Act .....231, 248 Commercial Code of 1885, Book III ....229 Ministry of Development No. FOM/1194/2011 236 Royal Decree No. 91/2003 241
Royal Decree No. 201/2012 237 Royal Decree No. 210/2004 232-3, 237-9, 241-4

Royal Decree No. 638/2007 ............. 245

Royal Decree No. 733/2019 ............. 247

Royal Decree No. 804/2014 ............. 245

Royal Decree No. 877/2011 ............. 245

Royal Decree No. 1617/2007 ............ 236

Royal Decree No. 1737/2010 ........... 247

Royal Decree No. 1795/2008 ........... 250

Royal Decree No. 1837/2000 ........... 245

Royal Decree No. 1892/2004 ........... 250

Ships and Port Security Act

(SPSA) 237

State Ports and Merchant Navy Act, Spain $244-5,250$

\section{Turkey}

Act on Protection of Life and Property at Sea .................................................... 256

Act on the Principles of Emergency Action and Indemnification of Losses in the Pollution of the Marine Environment by Oil and Other Hazardous Substances 256,265

Act on the Turkish International Ship

Registry No. 4490 254

Cabotage Act No. 815 ....................... 254

Environment Act $255-256,265$

Maritime Traffic Regulations on the Turkish Straits 2019 260n 36 Ports Act No. 618 .............................. 254 Regulation on Port State Control ...... 258 Regulation on Seafarers .................... 256 Regulation on Selection and Authorization of Classification Societies Acting on Behalf of the State for Turkish-Flagged Ships ...................... 257 Turkish Commercial Act (TCA) ...... 254, 264

Turkish Criminal Act 256 


\section{United Kingdom}

1995 Merchant Shipping Act .... 122, 130

Marine Insurance Act (1906) 124

European Union (Withdrawal) Act 2018

European Union (Withdrawal

Agreement) Act 2020

\section{Yugoslavia}

Maritime and Inland Navigation Act

(1977) $80 \mathrm{n} 21$ 


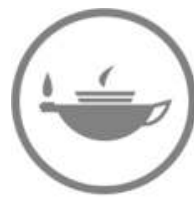
Taylor \& Francis

Taylor \& Francis Group http://taylorandfrancis.com 
PART I

INTERNATIONAL AND EUROPEAN PERSPECTIVE 
Taylor \& Francis

Taylor \& Francis Group

http://taylorandfrancis.com 


\title{
Implementation of IMO treaties into domestic legislation
}

\author{
Implementation and enforcement as the key to \\ effectiveness of international treaties
}

Dorota Lost-Siemińska ${ }^{1}$

\subsection{Background}

Given the key role that international shipping plays in the movement of goods from one country to another, there can be no doubt that ships and the seas and oceans in which they sail, no less than ports and cities, must be kept as safe and as clean as we can possibly make them. Due to the international dimension of shipping and its inherently dangerous nature, the international community has recognized the need for conformity and unity in standards through the global regulation of shipping.

Sixty-two years ago, the inaugural meeting of the International Maritime Organization (IMO) was held in London. ${ }^{2}$ As a specialized agency of the United Nations, the principal objective of the Organization is to

provide machinery for co-operation among Governments in the field of governmental regulation and practices relating to technical and related administrative and legal matters of all kinds affecting shipping engaged in international trade, [and] to encourage and facilitate the general adoption of the highest practicable standards in matters concerning maritime safety and efficiency of navigation.

Since its inception, the IMO has built a multifaceted legal regime for international shipping to ensure safe navigation on clean oceans.

1 The author is a staff member of the International Maritime Organization. The views expressed in this chapter are of the author alone and do not represent the views, decision or policies of the International Maritime Organization.

2 The Convention on the International Maritime Organization (Geneva, 1948) was adopted in Geneva in 1948 at a diplomatic conference held under the auspices of the United Nations Economic and Social Council. The Convention entered into force in 1958 (UNTS 4214). Originally the Organization was named Inter-Governmental Maritime Consultative Organization. This name was changed to International Maritime Organization (IMO) in 1982. Amendments to the title and the substantive provisions of the Convention on the International Maritime Organization, adopted by the Assembly of the Organization by Resolution A.358 (IX) of 14 Nov. 1975 and A.371 (X) of 9 Nov. 1977 (rectification of Resolution A.358 (IX)). A consolidated version of the Convention is available in Basic Documents Volume I, International Maritime Organization, 2018. 
The Organization, as of January 2020, has 174 Member States and three Associate Members (Hong Kong, China, Macau, China and the Faroe Islands). ${ }^{3}$ Numerous intergovernmental and non-governmental organizations enjoy an observer status with the IMO and take an active part in its work. ${ }^{4}$ Since the Organization doesn't have an operational arm, its role is primarily of a regulatory nature. In fulfilling its mandate, the IMO provides an international forum for Governments to consider issues of concern and to develop global standards which are then transformed by individual States into their national regulations. The global uniform standards may be formulated in treaty instruments which are legally binding on those States which commit to be bound by them, or they may be developed as regulations, rules, guidelines or recommendations of a non-mandatory nature. Over 50 treaties, hundreds of codes and guidelines that were developed under the auspices of the Organization, govern every aspect of the shipping industry: the construction, design, equipment of ships, the training of seafarers, protection of the marine environment from pollution emanating from ships and liability and compensation matters. Shipping is continuously environmentally friendly, and the main focus of the Organization in the second decade of the 21 st century is on the adoption of further measures to make shipping even cleaner. $^{5}$

Most IMO treaties are ratified by a high number of States and are binding for over $99 \%$ of the world's merchant fleet. In accordance with the principle of a 'no more favourable treatment' enshrined in many IMO treaties, even those ships which fly the flag of a nonState party must still comply with international regulations when coming to a port of a State party. However, the negotiation and adoption of a treaty, and then its ratification and global entry into force would be meaningless without national implementation and enforcement of its provisions. Even after a treaty has been implemented, subsequent frequent amendments create a need to continuously update domestic legislation to keep current with technological developments and changes in the shipping industry. States bound by treaties must ensure that the administration and the industry comply with the obligations that the regulations impose.

\subsection{IMO legal framework}

\subsubsection{Categories of IMO treaties}

Article 2 of the IMO Convention recognizes that in order to achieve its fundamental purposes, the Organization shall provide for the drafting of conventions, agreements and other

3 The United Kingdom of Great Britain and Northern Ireland was the first country that ratified the Convention on 14 February 1949. The newest Member, Armenia, joined the Organization in 2018. Membership of the Organization is regulated in Part III of the IMO Convention.

4 The participation of non-governmental organizations in the work of IMO is regulated in Rules and guidelines for consultative status of non-governmental international organizations with the International Maritime Organization. The Rules are adopted by the Assembly and its latest version was adopted on 4 December 2019 in resolution A.1144(31) available on IMODOCS (https://docs.imo.org/Category.aspx?cid=34, last accessed on 9 September 2020).

5 Rosalie P. Balkin, 'The IMO and Global Ocean Governance: Past, Present and Future' in D. J. Attard, R. P. Balkin and D. W. Greig (eds), The IMLI Treatise on Global Ocean Governance: Volume III (Oxford Public International Law, 2018), ch. 1. More information on the history of the IMO can be found on www.imo.org/en/About /HistoryOfIMO/Pages/Default.aspx. 
suitable instruments. ${ }^{6}$ Some important conventions, such as the International Convention for the Safety of Life at Sea (SOLAS) and the International Convention for the Prevention of Pollution of the Sea by Oil (OILPOL) had already been developed prior to IMO's creation in 1958, so the Organization was tasked with ensuring that they remained up to date. Others, in particular those treaties which relate to the enhanced protection of the marine environment and the liability and compensation for pollution damage, were developed once the need arose. Most conventions adopted under the auspices of the IMO can be divided into three general categories: maritime safety and security, prevention of marine pollution and liability and compensation, particularly for damage caused by pollution. There are, however, other related conventions dealing with matters such as salvage, facilitation and unlawful acts against the safety of navigation which also fall within the purview of the IMO.

The core IMO treaties, such as SOLAS $1974,{ }^{8}$ International Convention for the Prevention of Pollution from Ships (MARPOL), ${ }^{9}$ International Convention on Civil Liability for Oil Pollution Damage (CLC), ${ }^{10}$ Convention on the International Regulations for Preventing Collisions at Sea, 1972 (COLREG) ${ }^{11}$ and Convention for the Suppression of Unlawful Acts against the Safety of Navigation (SUA), ${ }^{12}$ are nearly universally accepted since they are ratified by States representing more than $99 \%$ of the world's merchant shipping fleet. Other IMO treaties, such as the Nairobi International Convention on the Removal of Wrecks which has 44 States parties, ${ }^{13}$ have entered into force but are not as universally accepted as the core treaties.

Generally, IMO treaties apply only to ships on international voyages and only to ships of certain tonnage and size. They have three main objectives: prevention, mitigation and compensation. Treaties like SOLAS and COLREG aim at ensuring safe navigation and preventing collisions at sea by providing for minimum standards for the construction, equipment, operation of ships and traffic separation schemes. SOLAS contains technical regulations that prescribe, among others, requirements for subdivision and stability, machinery and electrical installations, fire protection and life-saving appliances. Chapter

6 Art. 2 (a) of the IMO Convention provides that the Organization shall 'subject to the provisions of Art. 3, consider and make recommendations upon matters arising under Art. 1(a), (b) and (c) that may be remitted to it by Members, by an organ or specialized agency of the United Nations or by any other intergovernmental organization or upon matters referred to it under Art. 1(d)'.

7 The first version of SOLAS was adopted in 1914 in response to the Titanic disaster. It was further revised in 1929 and in 1948. IMO Member States considered and adopted SOLAS in 1960 but a completely new version of the convention was adopted in 1974.

8 International Convention for the Safety of Life at Sea (London, 1974), ((signed on 1974, entered into force on 1980) 1184,1185 UNTS 18961).

9 Protocol of 1978 relating to the International Convention for the Prevention of Pollution from Ships, (1973) ((signed on 1978, entered into force on 1983) 1340, 1341 UNTS 22484).

10 International Convention on Civil Liability for Oil Pollution Damage (Brussels 1969), ((signed on 1969, entered into force on 1975) 973 UNTS 14097). This Convention was amended in 1992 by a Protocol (UNTS 1956).

11 Convention on the International Regulations for Preventing Collisions at Sea (London 1972), ((signed on 1966, entered into force on 1968) 640 UNTS 9159).

12 Convention for the Suppression of Unlawful Acts Against the Safety of Navigation (Rome, 1988), ((signed on 1988, entered into force on 1992) 1678 UNTS 29004).

13 International Convention on the Removal of Wrecks (Nairobi, 2007), ((signed on 2007, entered into force on 2015) UNTS 55565), as of January 2020 there are 48 Contracting States to the Convention, representing $73.16 \%$ of the world merchant tonnage. 
XI contains special measures to enhance maritime safety and security. There are numerous codes, recommendations and guidelines adopted to address specific areas of safety. ${ }^{14}$

MARPOL's main objective is the prevention of pollution of the marine environment by ships from operational or accidental causes. Annex I of MARPOL covers the construction of oil tankers, their operation and equipment and record-keeping about any discharges. Other annexes of this treaty regulate prevention of pollution by noxious liquid substances, harmful substances carried in packaged form, sewage and garbage. The 1997 Protocol to MARPOL that added Annex VI, aims at preventing air pollution from ships by setting limits on sulphur oxide and nitrogen oxide emissions. ${ }^{15}$ It designates emission control areas and energy efficiency measures that are designed to reduce greenhouse gas emissions from ships. ${ }^{16}$

Treaties which aim at reducing the effects of casualties such as for example the International Convention on Oil Pollution Preparedness, Response and Cooperation (OPRC) require to establish measures for dealing with pollution incidents, either nationally or in cooperation with other countries. ${ }^{17}$ The Nairobi Wreck Removal Convention and the International Convention on Salvage ${ }^{18}$ are other examples of treaties containing measures to mitigate the results of casualties.

Compensation is the main objective of all treaties which relate to civil liability. Treaties like the CLC or the International Convention on the Civil Liability for Bunker Oil Pollution Damage (Bunker) ${ }^{19}$ relate to the aftermath of oil pollution incidents and are based on the polluter pays principle. They impose strict liability and channel all claims for compensation against the shipowner. The lability is limited, and the shipowner has an obligation to maintain insurance or other financial security covering the risk. To demonstrate that the insurance is in place, a certificate shall be carried on board each ship to which the treaties apply. Claimants have a right of direct action against the insurer. Finally, those treaties also set out rules as to jurisdiction and time limitation. ${ }^{20}$

14 There are various codes adopted in relation to safety and security, which are mandatory and form part of SOLAS, like for example the International Safety Management (ISM) Code (originally adopted by resolution A.741(18), the International Maritime Dangerous Goods (IMDG) Code (originally adopted by resolution MSC.122(75), the Code of the International Standards and Recommended Practices for a Safety Investigation into a Marine Casualty or Marine Incident (Casualty Investigation Code) (adopted by resolution MSC.255(84), or the International Ship and Port Facility Security (ISPS) Code (adopted by virtue of the amendments to the annex to SOLAS on 12 December 2002).

15 Protocol of 1997 to amend the International Convention for the Prevention of Pollution from Ships (London,1973) as modified by the Protocol of 1978 relating thereto (London, 1997), (signed on 1997, entered into force on 2005).

16 The IMO environmental regime is further complemented by treaties such as: the 2001 Anti-Fouling System Convention (AFS Convention, London, 2001) (London (IMODOCS AFS/CONF/26), the 2004 International Convention for the Control and Management of Ships' Ballast Water and Sediments (BWM Convention, London 2004), (IMODOCS BWM/CONF/36), or the Hong Kong Convention for the Safe and Environmentally Sound Recycling of Ships (Hong Kong, 2009) (IMODOCS SR/CONF/45).

17 International Convention on Oil Pollution Preparedness, Response and Cooperation (London, 1990), (signed on 1990, entered into force on 1995) 1891 UNTS 32194.

18 International Convention on Salvage (London, 1989), (signed 1989, entered into force on 1996), 1953 UNTS 33479 .

19 International Convention on Civil Liability for Bunker Oil Pollution Damage (London, 2001), (signed on 2001, entered into force on 2008).

20 Liability and Compensation for Ship-Source Oil Pollution: An Overview of the International Legal Framework for Oil Pollution Damage from Tankers, United Nations Conference on Trade and Development, Studies in Transport Law and Policy - 2012, No.1. 


\subsubsection{No more favourable treatment principle}

Enshrined in many of IMO's treaties is the above-mentioned principle of 'no more favourable treatment' (NMFT). When included in a treaty, this principle means that all ships, regardless of whether they fly the flag of a State which is party to that convention, must comply with that convention if they enter a port of a State Party. ${ }^{21}$ This has the practical effect of ensuring vessel compliance with many IMO conventions, particularly for those involved in international trade, requiring them to berth in ports of numerous States. The underlying motive behind the principle is to prevent ships of non-parties from gaining an economic or competitive advantage by not complying with IMO safety, security and environmental protection regulations, compared to ships that do comply. The NMFT principle is contained in numerous IMO instruments for the safety and security of ships, and for the protection of the marine environment. The comprehensive IMO liability and compensation regime uses a variant of the NMFT principle so that ships of non-parties will obtain the requisite insurance to cover any casualties that may occur. ${ }^{22}$

\subsection{Treaty-making process}

\subsubsection{IMO organs}

The IMO operates largely through its organs and bodies composed of representatives of Member States. ${ }^{23}$ The principal organs are: (1) the Assembly, ${ }^{24}(2)$ the Council ${ }^{25}$ and (3) the five main Committees, namely the Maritime Safety Committee (MSC), ${ }^{26}$ the Legal

21 The NMFT clause as provided for in Art. 5(4) MARPOL has been used in the development of subsequent conventions, for example: Art. 3(3) of the BWM Convention provides that 'With respect to the ships of nonParties to this Convention, Parties shall apply the requirements of this Convention as may be necessary to ensure that no more favourable treatment is given to such ships'. The same wording is contained in Art. 3(3) of the AFS Convention.

22 For example, Art. VII of the 1992 CLC provides that the owner of a ship registered in a Contracting State and carrying more than 2,000 tons of oil in bulk has an obligation to maintain insurance. To demonstrate that an insurance is in place the Contracting State shall issue a certificate and shall not permit a ship flying its flag to trade unless such certificate has been issued. Furthermore, a Contracting State shall ensure, under its national legislation, that every ship, wherever registered (also in a non-Party State), entering or leaving a port of that Contracting State maintains the insurance as required under Art. VII.

23 For more information on the composition of organs of an international organization see: H. G. Schermers and N. M. Blokker, International Institutional Law (Martinus Nijhoff Publishers 2003), p. 183, paragraph 237.

24 The Assembly, consisting of all Member States, is the highest governing body. It meets once every two years and is responsible for approving the Strategic Plan of the Organization, adopting the budget and electing the Council members. It is the responsibility of the Assembly to recommend to IMO Member States for adoption new treaties, which are developed by the committees. For this purpose, the Assembly decides whether to convene international conferences. In some cases, the Assembly would also be an appropriate body to adopt amendments, if that is the procedure prescribed in a treaty.

25 The Council consists of 40 Member States and meets usually twice a year in regular sessions. It is an executive organ of IMO and is mainly responsible for supervising the work of the Organization between Assembly sessions. Draft treaties or amendments thereto developed by the committees are submitted to the Council and then transferred to the Assembly.

26 The committees are composed of all Member States and meet at least once a year. Each committee is responsible for different subject matter. The MSC is a competent organ do develop draft proposals for safety regulations and amendments thereto. It also develops recommendations and guidelines, and considers any matters relating to navigational aids, the construction and equipment of vessels, manning from a safety standpoint, rules for the prevention of collisions, handling dangerous cargo, maritime safety procedures and requirements, hydro- 
Committee (LEG), ${ }^{27}$ the Marine Environment Protection Committee (MEPC), ${ }^{28}$ the Technical Co-operation Committee (TC) ${ }^{29}$ and the Facilitation Committee (FAL) ${ }^{30}$ In addition to the Committees, the MSC and MEPC have established several sub-committees, some of them highly specialized, the functions of which are to carry out preliminary work for the Committees. There are also working groups, drafting groups and correspondence groups, most of which are established to deal with specific issues as and when they arise these bodies are therefore generally of a limited lifespan. All IMO organs except for the TC play a role in the process of developing a treaty, or amendments thereto. While the TC is not involved in the treaty-making process, it plays a very important role in the implementation process, which will be explained below.

\subsubsection{Proposal and a compelling need for an IMO treaty}

The life of a treaty begins with a proposal. Proposals are developed by Member States, the Secretary-General, or intergovernmental and nongovernmental organizations sponsored by a Member State. A direct relationship exists between the prospect of widespread acceptance and effective implementation and a compelling need for a new convention. Where States provide a demonstrated need for a convention, widespread acceptance and implementation is highly probable. Therefore, it is vital that proponents consider practicality, feasibility, proportionality, costs and benefits in order to draft articles that can then be easily integrated into the domestic legislation.

At the first stage there must be a compelling need for a new treaty. Member States that want to initiate the process for a treaty must submit a proposal for a new output to the Committee (usually MSC, MEPC or LEG). The Committee assesses the need and, if there is sufficient support by other States, it approves the proposal for a new output. The proposal is subject to the 'Assessment of proposals for outputs' set out in the Resolution A. 1111(30) on Application of the Strategic Plan of the Organization, and 'Work Planning and Delivery Process' under the Organization and Method of Work of each Committee. ${ }^{31}$ The proposal must be verified and accepted as an output, and the Assembly that adopts the Strategic Plan of the Organization must include the proposal in the appropriate regulatory

graphic information, log books and navigational records, marine casualty investigation, salvage and rescue, and any other matters directly affecting maritime safety (Art. 28a) of the IMO Convention).

27 The Legal Committee considers any legal matters within the scope of the Organization (Art. 33a) of the IMO Convention). The IMO liability and compensation regime as well as treaties related to the suppression of unlawful acts against the safety of navigation were developed by this Committee.

28 The Marine Environment Protection Committee considers any matter within the scope of the Organization concerned with the prevention and control of marine pollution from ships. Seven environment-related treaties were developed by this Committee (Art. 38 of the IMO Convention).

29 The Technical Cooperation Committee oversees matters within the scope of the Organization concerned with the implementation of technical cooperation projects funded by the relevant United Nations programme for which the Organization acts as the executing or cooperating agency or by funds-in-trust voluntarily provided to the Organization, and any other matters related to the Organization's activities in the technical cooperation field (Art. 43 of the IMO Convention).

30 The Facilitation Committee considers any matter within the scope of the Organization concerned with the facilitation of international maritime traffic (Art. 48 of the IMO Convention).

31 MSC-MEPC.1/Circ.5, Organization and Method of Work of the Maritime Safety Committee and the Marine Environment Protection Committee and Their Subsidiary Bodies, 24 November 2016; and LEG.1/Circ.8, 'Organization and Method of Work of the Legal Committee', 14 July 2016. 
body's biennial or post-biennial agendas. The relevant committee will also determine the target completion schedule for each output. The list of outputs can be found in the annex of the Strategic Plan of IMO. ${ }^{32}$

\subsubsection{Development and adoption of an IMO treaty}

When the Plan with the new output is adopted, the Committee has a mandate to develop a treaty. The Committees have their own specialized subject matter and meet on a regular basis, often twice a year. Committee meetings provide a platform for Member States to discuss proposals and develop drafts. This early involvement by Member States in the regulatory process is one reason why IMO treaties generally enter into force within a reasonable time once they are adopted. The draft treaty, developed by the Committee, is submitted to Council and Assembly for approval. The Assembly will then recommend the draft to Member States for adoption and will also take a decision with regard to convening an international conference for this purpose.

IMO treaties are adopted at diplomatic conferences, which are held either at the Headquarters in London or in a host country. ${ }^{33}$ All Members States of the IMO and all United Nations and members of any of its specialized agencies are invited; therefore, such conferences are truly global. Moreover, intergovernmental organizations and nongovernmental organizations which have established a formal relationship with the IMO take part in the conferences as observers. Every conference adopts its own rules of procedure, which require the appointment of officers to chair the various committees and regulate, among other matters, voting. Usually, the conventions are adopted by consensus. The wider the consensus, the better the chance for the acceptance and implementation of a treaty. However, consensus does not mean unanimity, rather it demonstrates a lack of objection. At the end of the conference, the negotiating States adopt the final act. ${ }^{34}$

\subsubsection{Signature, ratification and acceptance of an IMO treaty}

The signatures of the final act have a non-binding nature. ${ }^{35}$ They reflect who participated in the conference and who negotiated its text but do not impose any direct obligations on signing States, unless otherwise provided in the treaty. The rules on the binding signature are contained in the final clauses of the treaty. Usually the treaty is open for signature at the Headquarters for several months after which it is open for accession. During the time when it is open for signature, all States may sign it without reservation as to the ratification or

32 Resolutions A. 1110(30), Strategic Plan for the Organization for the Six-Year Period 2018 to 2023, adopted on 6 December 2017 and A.1131(31) List of outputs for the 2020-2021 biennium, adopted on 4 December 2019.

33 IMO Member States are usually eager to offer hosting of a diplomatic conference, since it is customary that a treaty adopted outside the Headquarters would have the name of the host city in its title, as is the case with, for example, the Nairobi Wreck Removal Convention or the Hong Kong Ship Recycling Convention.

34 Anthony Aust explains that the term adoption is not defined in the Vienna Convention on the Law of Treaties, but is the formal act by which the form and content of the treaty is settled; and a state that takes part in the drawing up and adoption of the text is known as a 'negotiating state' (Art. 2(1)(e) of the VCLT). Unless the circumstances suggest otherwise, the act of adoption does not amount to authentication of, or consent to be bound by, the treaty or mean that the treaty has entered into force. A. Aust, Modern Treaty Law and Practice, Third Edition (Cambridge University Press 2014), p. 79.

35 Ibid, p. 85. 
subject to ratification. In most cases, IMO Member States sign treaties subject to ratification, unless they choose not to sign it but rather accede at a later stage.

After the period for signatures closes, the treaty is open for accession. It is important to note that the Vienna Convention on the Law of Treaties (VCLT) in Article 2 provides that 'ratification', 'acceptance, 'approval' and 'accession' mean in each case the international act so named whereby a State establishes on the international plane its consent to be bound by a treaty. ${ }^{36}$ Every treaty may regulate it slightly differently, but the Secretary-General, acting as the depositary, would accept an instrument with any of those names, as long as the intention of a State to be bound by a treaty is clear.

The instruments of ratification, acceptance or approval, signed by the head of State, the head of the Government or Minister of Foreign Affairs can be deposited by a representative of a State in person with the Secretary-General or the Legal Affairs Office of the Secretariat. Alternatively, they can be sent by post. Some instruments of ratification/accession must be accompanied by certain reservations, declarations or reports. For example, the 2010 Protocol to the International Convention on Liability and Compensation for Damage in Connection with the Carriage of Hazardous and Noxious Substances by Sea, 1996 (the 2010 HNS Convention) $)^{37}$ in Article 20 (4) provides that:

An expression of consent to be bound by this Protocol shall be accompanied by the submission to the Secretary-General of data on the total quantities of contributing cargo liable for contributions received in that State during the preceding calendar year in respect of the general account and each separate account. ${ }^{38}$

Article 20 (5) further provides that an expression of consent that is not accompanied by the data referred to in Article 20 (4) will not be accepted by the Secretary-General. This means that a ratifying State needs to adopt national legislation containing reporting regulations prior to ratification and therefore also prior to the entry into force of this Convention in this particular State.

The final clauses of each treaty provide for the entry into force requirements. Besides a specific number of States that need to ratify the treaty for it to enter into force, many IMO treaties also provide for tonnage requirement. Some treaties, although not universally ratified, still apply globally to all ships, if they are ratified by States with the largest fleets. ${ }^{39}$

36 For more information on the accession to international treaties see further: I. Sinclair, The Vienna Convention on the Law of Treaties, Second Edition, Melland Schill Monographs in International Law (Manchester University Press 1984), p. 42. On the conditions of effective consent, see further: M. Craven, 'The Ends of Consent' in M. J. Bowman and D. Kritsiotis (eds), Conceptual and Contextual Perspectives on the Modern Law of Treaties (Cambridge University Press 2018), pp. 119-131.

37 The original International Convention on Liability and Compensation for Damage in Connection with the Carriage of Hazardous and Noxious Substances was adopted in 1996, but has never come into force: ILM, 35 (1996), 1415-1436. This was mainly due to the complicated provisions on the reporting requirement, which needed to be met prior to entry into force. The 2010 Protocol to the 1996 International Convention on Liability and Compensation for Damage in Connection with the Carriage of Hazardous and Noxious Substances (HNS 2010) is designed to resolve the practical problems that had prevented many States from ratifying the original Convention. The full consolidated text of the 2010 Protocol may be found at www.hnsconvention.org.

38 The HNS workshop held at IMO Headquarters in 2012 adopted Guidelines on Reporting of HNS Contributing Cargo which were subsequently endorsed by the IMO Legal Committee at its 100th Session in April 2013. The text of the Guidelines may be found at www.hnsconvention.org.

39 The largest flag States in 2018 were Panama, Liberia, Marshall Islands, Singapore and Malta. An example of a convention ratified by the largest flag States is the 2007 Nairobi Wreck Removal Convention. As of October 


\subsection{Amendments of IMO treaties}

A treaty is open for amending once it has been adopted, accepted and entered into force. The Vienna Convention for the Law of Treaties provides a procedure for amending treaties by agreement between the parties; however, the treaty itself can designate a different procedure.$^{40}$ Generally, at the IMO, there are two ways of amending a treaty: (1) through the 'classical' amendment procedure and (2) through the tacit acceptance procedure.

\subsection{1 'Classical' amendment procedure}

The traditional manner of amending treaties requires that States that wish to be bound by amendments to a treaty express their consent to be bound. This will likely result in the adoption of a new protocol, but there is an alternative method of explicit acceptance which is utilized when the convention requires amendment, but a thorough protocol is not needed.

\subsubsection{Protocols to IMO treaties}

The first type of classical amendment procedure, protocols, are typically adopted either when the original convention couldn't enter into force (such as the original MARPOL of 1973) or when the original convention needs to be dramatically revised (such as the 2002 Athens Protocol to the Convention relating to the Carriage of Passengers and their Luggage by Sea (PAL)). ${ }^{41}$ Each protocol is in fact a new treaty with its own States Parties. Thus, if a State Party to the parent convention does not ratify a protocol, the amendments in the protocol would not apply to that State. Each protocol has its own entry into force requirements and within the IMO's structure, is adopted at a diplomatic conference. Most IMO treaties have protocols. For example, SOLAS 1974 has a 1978 Protocol, CLC 1969 has a 1992 Protocol and MARPOL 1973 has both a 1978 Protocol and a 1997 Protocol (also called Annex VI). Protocols are adopted either to help the parent convention to enter into force (for example Protocol of 1978 to MARPOL) or to introduce new principles or a new subject (for example Protocol of 1997 to MARPOL).

\subsubsection{Explicit acceptance procedure}

The other type of traditional amendment procedure, explicit acceptance, is used when a full protocol is not needed but the convention still requires amendment. In this case, consideration will take place first at a committee meeting, and once deliberation has taken place, the amendment is usually adopted by consensus. If there is no consensus, then it must be voted on and adopted by two-thirds majority of the Contracting Governments. Following adoption, the Secretary-General of the IMO communicates the text of the amendment to all Contracting Governments for acceptance. The amendment must be then explicitly accepted by a two-thirds majority to enter into force.

2019, this Convention was ratified by 47 States, including all five largest flags, and therefore applies to $74 \%$ of the world fleet.

40 See the Vienna Convention on the Law of Treaties, Arts. 39, 40, 1155 UNTS 331.

412002 Protocol to the Athens Convention relating to the Carriage of Passengers and their Luggage by Sea (London, 1974), (signed on 2002, entered into force on 2014) UNTS 24817. 
The inefficiency of the required amendment procedure combined with the frequency of modification has led to long delays in bringing amendments into force. In earlier conventions, amendments only came into force after a certain percentage of Contracting States representing a sufficient percentage of world gross tonnage (normally two-thirds) had accepted them. In some cases, only a small number of ratifications was required for a treaty to enter into force. If, subsequently, such a treaty was accepted by a large number of States, more acceptances were required to amend that treaty than was originally required to bring it into force. The result was an extremely time-consuming process with most of the amendments never entering into force. For example, the SOLAS 1960 required two-thirds of Contracting States, including two-thirds of the Governments represented on the Marine Safety Committee, ${ }^{42}$ to accept the amendments in order to bring them into effect. None of the amendments to SOLAS adopted between 1966 and 1973 received enough acceptances to satisfy the requirements to enter into force. To address this, in 1974 a completely new SOLAS Convention was adopted incorporating these amendments with some other minor changes and has been further modified on numerous occasions since.

\subsubsection{Tacit acceptance procedure}

To address the problem of non-expeditious acceptance and entry into force of the amendments, IMO adopted and incorporated the tacit acceptance procedure into the provisions of most conventions; e.g. COLREG 1972, SOLAS 1974, MARPOL 73/78, Load Lines 1966, ${ }^{43}$ CLC 1969, LLMC Convention $1976^{44}$ and others. Specifically, tacit acceptance is used to amend provisions of a technical nature such as annexes and appendices of treaties, whereas amendments to the primary articles of a convention are subject to the traditional amendment process. If an amendment is subject to tacit acceptance, it will enter into force at a specified date, unless a predetermined number of objections by States Parties are received. There is no requirement of a domestic ratification of an amendment subject to this procedure in order for it to become binding. ${ }^{45}$ Under tacit acceptance, an amendment will come into force once three conditions are met: the relevant organ of the Organization adopts the amendments; the amendments are circulated to all Contracting States for acceptance; and there is insufficient number of objections to prevent the amendment from entering into force. ${ }^{46}$

The tacit acceptance is an effective method to revise treaties, as demonstrated by SOLAS and MARPOL which have been amended numerous times. ${ }^{47}$ However, many States do not

\footnotetext{
42 See SOLAS 60, Art. IX, paragraph (d).

43 International Convention on Load Lines (London, 1966), ((signed on 1966, entered into force on 1968) 640 UNTS 9159).

44 Convention on Limitation of Liability for Maritime Claims (London, 1976), ((signed on 1976, entered into force on 1986) 1456 UNTS 24635).

45 C. A. Bradley, Unratified Treaty Amendments and Constitutional Process (6 February 2006), unpublished manuscript on file with the author, prepared from Duke Workshop on Delegating Sovereignty.

46 The regulatory conventions such as SOLAS, MARPOL, Load Lines, COLREG, etc., require the explicit objection not only from a certain number of State Parties but also a specified percentage of the gross tonnage of the world's merchant fleet. On the other hand, the liability conventions, e.g. CLC Protocol 1992, HNS 1996, require only a specified number of Contracting States.

47 MSC and MEPC, the Committees responsible for SOLAS and MARPOL (respectively), usually meet twice a year and new amendments are adopted almost every meeting.
} 
have a smooth method of incorporating amendments adopted tacitly into their domestic legislation. In some legal systems, such amendments still go through a separate national ratification procedure. From an international law point of view, this practice is unnecessary. A State that is a Party to a convention that contains the tacit acceptance procedure has already agreed and given consent to all future amendments, unless an objection by that State is raised. Therefore, the amendments enter into force for that State even without the national ratification process and subsequent consent. Once the amendments enter into force, all States Parties which did not object to it, are bound by the amendments, regardless of whether they implemented them into their national legislation. There are some cases in which the Secretary-General, as depositary, receives instruments of 'ratification' or 'acceptance' of such amendments 10-15 years after they entered into force. This is a reason for concern because it implies that for those years the amendments were absent from national legislation. Pursuant to Article 27 of the VCLT, a Party may not invoke the provisions of its internal law as a justification for its failure to perform a treaty. Ships flying the flag of a State that is a Party to a treaty which has been amended, must fulfil the standards and can be inspected for compliance with the treaty as amended, even though those amendments have not been incorporated into the domestic legislation.

\subsection{Interrelation between IMO treaties}

The IMO treaties create a global regime to ensure safe and environmentally sound shipping. Many of those treaties are interlinked and refer to each other. Therefore, in the ratification and implementation process this interrelation between treaties plays a vital role. One example of such treaty is the 1988 SUA Fixed Platform Protocol, which can be ratified only by the Parties to the 1988 SUA Convention. The 2005 SUA Protocols to the 1988 treaties are open only to Parties to those States which ratified the 1988 treaties. Similarly, for MARPOL the 1997 Protocol is open for ratification or accession only to those States which ratified MARPOL 73/78.

In some cases, the interrelation between treaties is their explicit opposition to one another. For example, unlike MARPOL and the SUA Fixed Platform Protocols, the 2002 Athens Protocol to the 1974 Convention required States to denounce the 1974 Convention and 1990 Protocol. ${ }^{48}$ Although the 1992 CLC does not explicitly provide for an obligation to denounce the 1969 CLC, many States Parties to the 1992 treaty denounced the preceding Convention in order to avoid having two conflicting liability regimes in place.

The Bunkers and the Nairobi Wreck Removal Conventions, which provide for compensation for bunker oil pollution damage, or damage caused by wrecks, do not have their own limits of liability in place but instead refer to the national limits of liability or the limits as provided for in the Convention on Limitation of Liability for Maritime Claims (LLMC). It is advised that States that ratify the Bunkers or the Nairobi Wreck Removal Conventions but have no national limits of liability in place for claims that fall under the scope of those treaties, ratify the LLMC. The original LLMC that was adopted in 1976 provides for extremely low limits of liability, depriving those who suffered damage from obtaining

48 Art. 19 of the Protocol provides that States may not become Parties to the 2002 Athens Protocol unless they denounce the 1974 Convention and the 1990 Protocol. 
an adequate compensation. Its successor, the 1996 Protocol, contains higher limits and the tacit acceptance procedure for the amendments of those limits. This procedure was first utilized in 2012 by the Legal Committee, who increased the limits and the new limits of liability entered into force in 2015. Many Parties to the 1996 Protocol denounced the parent Convention although the Protocol did not require denunciation. The Parties denounced the parent Convention to both avoid having conflicting liability regimes in place and to ensure higher compensation for claimants under the LLMC, the Bunkers and the Nairobi Wreck Removal Conventions.

\subsection{Implementation process}

As explained above, an IMO convention is valuable only if it is effectively and universally implemented. Implementation, also known as 'incorporation' or 'transformation' refers to the process by which a State that has expressed its consent to be bound by a treaty ensures that the domestic law gives effect and complies with the provisions of that treaty. The IMO, as an international organization and a specialized agency of the United Nations, has no enforcement power. Thus, the implementation, application and enforcement of the standards set in IMO's regulations, whether they are contained in binding treaty instruments or in recommendations or guidelines, are essentially a matter for the IMO's Member States. Most States use the time between signing a treaty and depositing their instrument of ratification to draft and pass the necessary law through their domestic parliaments. This is generally time well spent because it means the States can comply with their obligations as soon as the treaty enters into force. The lack of effective national legislation can make the enforcement of international standards impossible.

\subsubsection{Monism and dualism}

There are two prominent legal systems in the world for the hierarchy of law and implementation of international law: monism and dualism. The essence of the monist approach is that a treaty may, without any domestic legislation (meaning without the implementation process), become part of domestic law once it has been concluded, has entered into force for that State and has been published in an official gazette. ${ }^{49}$ In this system, the domestic law and the international law are two components of one body of law. Thus, if the instrument is a 'self-executing' treaty, States with monist legal systems may not need any domestic legislation to enforce the treaty's obligations within their jurisdiction. For example, while not a pure monist system, a treaty that is held by the United States' domestic courts to be self-executing becomes judicially enforceable upon ratification. ${ }^{50}$ As such, it can supersede prior acts of the U.S. Congress since it is effectively treated as domestic federal legisla-

49 For an interesting analysis of the monist system from the Albanian perspective see: F. Korenica and D. Doli, 'The Relationship between International Treaties and Domestic Law: A View from Albanian Constitutional Law and Practice' (2012) 24 Pace International Law Review, Art. 3.

50 See Medellin v. Texas, 552 U.S. 491, 505, n.2 (2008) ('What we mean by "self-executing" is that the treaty has automatic domestic effect as federal law upon ratification.'); Legal Information Institute, Cornell University Law School (self-executing treaty), www.law.cornell.edu/wex/self_executing treaty; U.S. Const., Art. VI, sec. 2 (Supremacy Clause: 'all Treaties made, or which shall be made, under the Authority of the United States, shall be the supreme Law of the Land.'). 
tion. ${ }^{51}$ However, if a treaty is 'non-self-executing', it would need implementing legislation in countries with the monist system, although treaties typically constitute supreme law and override inconsistent domestic legislation. ${ }^{52}$

Under the dualist approach, no special status is accorded to treaties. The rights and obligations created by treaties have no effect in domestic law unless legislation is in force to give effect to them. Thus, treaty provisions only have status once they become domestic law. This system presents the unique challenge that in certain scenarios, treaty provisions incorporated into domestic law could be repealed by later domestic legislation, possibly resulting in a breach of the treaty. The legal system in the United Kingdom is an example of a dualist approach.

\subsubsection{Non-self-executing nature of IMO treaties}

International instruments adopted under the auspices of the IMO are 'non-self-executing' treaties since they impose numerous obligations on administrations within a State Party. Consequently, the IMO Member State, when becoming a party to any IMO convention, needs to enact domestic legislation to give effect to the provisions of that instrument. ${ }^{53}$ Regardless of whether a State has a monist or dualist legal system, when drafting domestic legislation, it is critical that States Parties pay attention to those clauses provided for in the convention which require them to take action. The process of transposition of a treaty into the domestic system varies from State to State. At times, the domestic legislation must be ready even before ratification/acceptance, otherwise the Contracting Government will not give the consent to be bound. On other occasions, domestic legislation is drafted and implemented only after ratification and before the entry into force of the convention for the State.

\subsubsection{What legislative drafters need to know?}

To effectively implement an IMO treaty into national legislation, it is important to participate in committee meetings that develop treaties and amendments. It helps to understand how the Organization works, how treaties and amendments are developed, what their purposes are, and how practically they will be enforced. Unfortunately, in many jurisdictions, it is impossible for legislative drafters to be actively involved in IMO's efforts, as they usually draft various national legislation and not only maritime.

Ideally, legislative drafters should prepare draft national legislation and perform other preparatory work, before a convention comes into force. A consideration should be given to the nature of a treaty or an amendment. The first question that drafters encounter is whether the treaty should be implemented in the primary or secondary national legislation. In many States, primary legislation requires an act of a Parliament, whilst a secondary

51 Ibid.

52 R. Uerpmann, International Law as an Element of European Constitutional Law: International Supplementary Constitutions (New York University School of Law and Max Planck Institute for Comparative Public Law and International Law, Heidelberg, 2003), p. 26. www.jeanmonnetprogram.org/archive/papers/03/030901 -02.pdf.

53 See the provisions of Art. 1 - General obligations under the Convention, of SOLAS, MARPOL and the International Convention on Standards of Training, Certification and Watchkeeping for Seafarers, 1978 (STCW) (1361 UNTS 2). 
legislation would only require an act by a Government. Primary legislation would usually incorporate all substantive provisions of a treaty, while, in many cases the technical details can be incorporated in the secondary legislation, which is easier to subsequently amend, depending on the needs. The primary legislation often contains delegated powers to execute the treaty and any enforcement provisions. However, some administrative provisions, procedures for issuance of certificates, carrying out inspections and surveys, and administrative fees, could be regulated in the secondary legislation.

A State's status as flag, port or coastal is an important element to consider when enacting implementing legislation because most IMO treaties impose certain obligations on States based on their role. Some states only need to enact those provisions which are related to their obligations as flag States, and do not need provisions that would be applicable to coastal States. Another important element is national stakeholders, who should be consulted in the legislative process, like shipowners, seafarers or shipbuilders. Many jurisdictions also require environmental impact assessment of the legislation. These procedures make the legislative process complex and time-consuming.

Legislative drafters should carefully study the convention they are about to implement, devising an objective for the convention before embarking on the implementation steps outlined above. Understanding the objective of the convention would help legislative drafters determine where the convention should be placed in the national system or whether the domestic legislation already addresses the problem. If the problem that the convention aims to resolve is already addressed in the current legislation, other questions legislative drafters can answer include: what needs to be amended in the current legislation to align with the provision of the convention? Are the definitions in the domestic legislation still applicable or do they need to be revised? What would be the scope of application of the convention under the domestic legislation? ${ }^{54}$

National legislation should also regulate potential exceptions and exemptions from the requirements, if so provided by the treaty in question. Many IMO conventions provide for an obligation to carry on board of ships' certificates that document compliance with standards. Those certificates are issued by administrations, and national legislation should contain procedures related to the issuance of such certificates, such as the conditions of validity, the authority to issue, and certificates cost. Moreover, IMO treaties do not contain enforcement provisions. They merely provide that States Parties have an obligation to give effect to the standards contained in those treaties. It is the responsibility of the national legislation to regulate detection of violations and related sanctions.

Civil liability conventions contain provisions obligating Parties to assign a national court that would have jurisdiction to hear cases arising in connection with the damage suffered. When implementing an IMO convention, States Parties should be aware that some instruments require that domestic legislation ensure notification to the Organization. Notification is typically received by the Secretariat or by one of the committees. In order to facilitate implementation and application of highly technical instruments, committees adopt guidelines to give legislative drafters and technical officers in Member States a better

54 Some treaties, such as the Nairobi Wreck Removal Convention, have a flexible geographical scope of application which allows the provisions of the Convention to apply also in the territorial sea - this so-called opt-in clause is contained in Art. 3 of the Convention. 
understanding of their provisions, with an ultimate goal to effectively apply and enforce them.

\subsubsection{Implementation of amendments adopted by virtue of the tacit acceptance procedure}

Since IMO conventions are continuously amended to meet technological developments, the national legislation must inevitably keep up with the pace of change. Lack of effective implementation becomes an issue at the IMO as it reflects the inability of Member States to comply with international standards. As stated above, amendments adopted through the tacit acceptance procedure are binding on all Parties, unless they have objected to them. ${ }^{55}$ SOLAS and MARPOL have been amended hundreds of times and all relevant amendments need to be incorporated into the domestic legislation. This creates a challenge for many States, in particular for developing countries, that lack technical expertise and the resources to keep their legislation up to date. ${ }^{56}$

\subsubsection{Delegation of authority to issue secondary legislation}

One of the methods used to speedily comply with international obligations is through delegation of authority to issue secondary legislation. In the British legal system, secondary legislation is defined as law created by ministers (or other bodies) under powers given to them by an Act of Parliament. It is used to fill in the details of Acts (primary legislation). These details provide practical measures that enable the law to be enforced and operate in daily life. ${ }^{57}$ In some jurisdictions, acts of Parliament are rather skeletons that contain provisions empowering ministers to issue regulations, rules or bye-laws to add details required by the primary legislation. Secondary legislation can be amended without engaging Parliament.

In the Maltese law, entire treaties, like MARPOL or the Ballast Water Management Convention, are implemented through secondary legislation. Article 308A of Part VA of the Merchant Shipping Act, Prevention of Pollution from Ships, ${ }^{58}$ provides that the Minister may make regulations as appear necessary to give effect to any provision of any of the following which have been ratified or acceded to or accepted by the Government of Malta: (a) MARPOL (including protocols, annexes and appendices thereto); (b) the Intervention Convention; (c) the 1990 OPRC; (d) any international agreement not mentioned in paragraphs (a) to (c) which relates to the prevention, reduction or control of pollution of the sea or other waters by matter from ships or which regulates liability of any person arising from pollution of the sea or other waters. This article further provides that any reference to an international agreement or convention or protocol shall include reference to any amendment to such agreement or convention or protocol ratified, acceded to or accepted by the Government of Malta. It goes further, to conclude that the powers conferred include power to provide for the provision to come into force notwithstanding that the agreement may not be in force.

55 SOLAS Art. VIII and MARPOL Art. 16.

56 M. S. Karim, Prevention of Pollution of the Marine Environment from Vessels. The Potential and Limits of the International Maritime Organization (Springer 2015), p. 37.

57 www.parliament.uk/about/how/laws/secondary-legislation.

58 Act XI of 1973, Chapter 234, Merchant Shipping Act, as amended. 
Using this broad delegated authority, subsidiary legislation 234.55 (Regulations), incorporates into the Maltese law the Ballast Water Management Convention. Although Malta, similarly to Great Britain, is a dualist country, the Regulations make direct reference to the Convention without repeating its provisions. Paragraph 4 provides that the Convention, as may from time to time be in force, shall, unless otherwise provided in or in terms of these Regulations and notwithstanding the provisions of any other law, form part of and be enforceable as part of the Law of Malta. Furthermore, the Regulations authorise the Registrar-General to issue Merchant Shipping Notices in order to specify the requirements or to clarify the application or interpretation of the Convention, as well as to extend the application of the Convention to other classes of ships. ${ }^{59}$ The same provision also contains direct reference to, among others, circulars, codes, recommendations and guidelines of the IMO or any other body or organization with an appropriate knowledge or competence on the subject matter. The Regulations also provide for inspections and detentions and determine fines in case of non-compliance.

\subsubsection{Incorporation by reference}

The delegation of authority to issue secondary legislation is often supported by another method of implementation into the domestic legislation of international standards, namely incorporation by reference. The term 'incorporation by reference' is used to describe a technique that gives legal effect to provisions contained in a document without repeating those provisions in the text of the incorporating legislation. Incorporation by reference occurs more frequently in delegated legislation than in primary legislation. New Zealand legislation holds that incorporation by reference may be appropriate when the document is long or complex, covers technical matters only, and few citizens are likely to be directly affected, as well as when the document has been agreed with one or more foreign governments, cannot easily be recast into an Act of Parliament or delegated legislation, and deals only with technical or operational details of a policy already approved by Parliament. It is appropriate for the document to be formulated by a specialist government, inter-governmental agency, or private sector organization, rather than by Parliament or Ministers.

A copy of any material incorporated by reference in rules, including any amendment to, or replacement of, the material, must be certified as a correct copy of the material. Any material incorporated in a rule by reference is to be treated for all purposes as forming part of the rule; and unless otherwise provided in the rules, every amendment to any material incorporated by reference that is made by the person or organization originating the material is to be treated as being a part of the rule. All material incorporated by reference under subsection must be made available at the offices of the Authority for inspection by the public at no cost. The Authority must give notice in the Gazette and on the Authority's internet site. ${ }^{60}$

59 Chapter 249 of the Interpretation Act of the Laws of Malta, in Art. 6(d) provides that the power to legislate includes a power to rescind, revoke, amend or vary the rules, regulations or bye-laws, and such power shall be exercisable without prejudice to the making of new rules, regulations or bye-laws. Source: www.justiceservices. gov.mt.

60 Source: Legislation Design and Advisory Committee, Legislation Guidelines: 2018 edition, Chapter 15, Part 3, www.ldac.org.nz. 
Incorporation by reference is widely used in the Australian legal system. The Ballast Water Management Convention is incorporated into the Australian legislation by the Biosecurity (Ballast Water and Sediment) Determination 2017. ${ }^{61}$ Using the delegated authority provided for in the Biosecurity Act 2015, the Director of Biosecurity may, by legislative instrument, make a determination prescribing matters that are required or permitted by the Act. The Determination explains which IMO instruments are incorporated by reference into the Australian law and that includes also the text of the BWM Convention.

Similar implementation techniques are also used in monist systems. Article 87 of the Constitution of the Republic of Poland provides that ratified international agreements are sources of law in Poland. Once those ratified agreements are published in the Journal of Laws they compose part of the domestic legal system and are directly applicable. The Safety at Sea Act of 2011 provides that IMO conventions such as SOLAS or Load Lines are applicable. ${ }^{62}$ The Act contains direct references to other IMO instruments and gives authority to the Minister responsible for maritime affairs to issue regulations to give effect to those instruments. The weakness of the Polish system lies in the fact that there is no mechanism of smooth incorporation of all amendments adopted by the tacit acceptance procedure. Those amendments still need to be approved by the Parliament, which makes the process long and cumbersome.

As explained above, there are hundreds of amendments to treaties like SOLAS and MARPOL that are adopted by virtue of the tacit acceptance procedure. Moreover, there are 20 codes that became mandatory by virtue of the tacit acceptance procedure under SOLAS and that are frequently amended using this procedure. They are of a very technical nature and the most efficient way of incorporating them into the national legislation is by delegation of authority to issue secondary legislation, or by incorporation by reference. This author examined various legal systems to identify the most efficient ways of implementation of IMO instruments into the domestic legislation. In all cases, whether instruments are incorporated by reference, or whether they are contained in the secondary legislation, they must be publicly available to have a binding nature.

\subsection{Enforcement of IMO treaties}

Clearly, not all the instruments adopted by the IMO are ratified, implemented and enforced effectively by States. Lacking any enforcement power and respecting the principle of sovereignty, the IMO may not impose upon its Member States a requirement to become a party to each instrument it has adopted. However, to ensure that minimum standards are enforced across the globe, the concept of 'no more favourable treatment', discussed previously, was included as a provision in many IMO instruments.

Although the United Nations Convention on the Law of the Sea (UNCLOS), was adopted after most IMO treaties entered into force, it established a solid basis for enforcement of those treaties. ${ }^{63}$ Under UNCLOS Article 94, flag States have the primary duty to ensure that vessels flying their flag comply with applicable international rules and standards. In

61 The Determination is made under section 308A of the Biosecurity Act 2015; www.legislation.gov.au.

62 Safety at Sea Act, adopted on 18 August 2011, Journal of Laws 2011, No 228, item 1368.

63 More on the history of UNCLOS in: R. R. Churchill and A. V. Lowe, The Law of the Sea, 3rd edition (Manchester University Press 1999). 
particular, the flag State has a duty to maintain a register of ships flying its flag and assume jurisdiction under its internal law over each ship flying its flag and its master, officer and crew in respect of administrative, technical and social matters concerning the ship. The flag State has also several obligations which relate to safety at sea. To fulfil this obligation, States incorporate into their national legislation the provisions of SOLAS, and other IMO safety-related treaties, and provide for sanctions in cases where ships do not comply with those international regulations. In order to examine compliance, flag States conduct surveys and impose measures, such as penalties, and other administrative sanction, including withdrawal of registration. ${ }^{64}$

UNCLOS and IMO treaties also create a powerful basis for port States to intervene in cases where ships are in their ports or terminals. Port State Control (PSC) conduct inspections to verify that the condition of the ship and its equipment comply with the requirements of international rules and that the ship is manned and operated in compliance with these rules. ${ }^{65}$ In cases of non-compliance with international standards, port States impose sanctions, including detention of a ship. Over the years, PSC proved to be more effective than the flag State surveys in terms of enforcing compliance. ${ }^{66}$

Although the IMO has no enforcement power and, as an international organization, has no mandate to examine the level and the quality of implementation of IMO conventions into the national legislation, IMO Member States often voluntarily asked to be audited. The Voluntary Member States Audit Scheme (VIMSAS) ${ }^{67}$ was created and ultimately proved to be so successful that it became mandatory on 1 January 2016 (IMSAS), ${ }^{68}$ and the national legislation of each IMO Member State is subject to audits. The IMO Instruments Implementation Code, which provides the framework for the audit, reaffirmed that States have the primary responsibility to have in place an adequate and effective system to exercise control over ships entitled to fly their flag, and to ensure that they comply with relevant international rules and regulations in respect of maritime safety, security and protection of the marine environment. IMSAS is a powerful tool that enables the Organization to assess the compliance of Member States with the relevant treaties and assists them to identify gaps in their national legislation and to correct them.

\subsection{Concluding remarks}

States Parties to treaties have a legal obligation to comply with them. Principle pacta sunt servanda, codified in Article 26 of the Vienna Convention on the Law of Treaties, provides

64 More on Art. 94 of UNCLOS in: N. M. Hosanee, A Critical Analysis of Flag State Duties as Laid Down under Article 94 of the 1982 United Nations Convention on the Law of the Sea, publication by the Division for Ocean Affairs and the Law of the Sea Office of Legal Affairs, The United Nations (New York 2009).

65 www.imo.org. See also resolution A.682(17) adopted by the IMO Assembly on 6 November 1991 on regional cooperation in the control of ships and discharges.

66 To enhance effectiveness of PSC, States conclude regional agreement, known as Memoranda of Understanding (MoU). There are currently nine agreements in place: Paris MoU (Europe and the North Atlantic), Tokyo MoU (Asia and the Pacific), Acuerdo de Vina del Mar (Latin America), Caribbean MoU (Caribbean), Abuja MoU (West and Central Africa), Black Sea MoU (the Black Sea region), Mediterranean MoU (the Mediterranean), Indian Ocean MoU (Indian Ocean) and the Riyadh MoU (Bahrain, Kuwait, Oman, Qatar, Saudi Arabia and the United Arab Emirates). The United States Coast Guard maintains its own PSC regime.

67 IMO Assembly resolution A.1054(27) Code for the Implementation of Mandatory IMO Instruments.

68 IMO Assembly resolution A.1070(28) IMO Instruments Implementation Code (III Code). 
that: 'Every treaty in force is binding upon the parties to it and must be performed by them in good faith.' Pursuant to Article 27 of the VCLT, a State cannot excuse itself from not complying with an obligation in a Convention which it has voluntarily entered into by claiming that it conflicts with the State's national legislation. If a State Party fails to give effect to a treaty, it might be in breach of it. ${ }^{69}$

In the context of IMO treaties, on many occasions States, Parties to those treaties, fail to implement them into the domestic legislation, despite that ships flying their flag still comply with international obligations to be able to operate globally. The ultimate goal of the global maritime community is to ensure effective flag State and Port State Control in the interests of safe, secure and environmentally friendly shipping.

69 Art. 60.3 of the VCLT regulates a material breach of a multilateral treaty, defining that such a breach consists in a repudiation of the treaty, or the violation of a provision essential to the accomplishment of the object or the purpose of the treaty. See also: Ch. J. Tams 'Regulating treaty breaches', in M. J. Bowman and D. Kritsiotis (eds) Conceptual and Contextual Perspectives on the Modern Law of Treaties (Cambridge University Press 2018), pp. 440-467. 


\title{
EU maritime safety rules
}

\author{
Raising the bar within Europe and beyond
}

Lemonia Tsaroucha and Jacob Terling

\subsection{The EU as 'regulator' and 'global actor'1}

\subsubsection{Background and scope}

Maritime transport is one economic activity that saw the need for transnational principles and rules to be developed early on, before the birth of international law and the modern States. As a result, customary principles of law have been applied to maritime trade, consolidated by a centuries-old practice. These customary principles codified as 'law merchant' have been both a blessing ${ }^{2}$ and a burden when it comes to modernising maritime law. In the case of maritime safety law, the latter description fits better. Regulating maritime transport to make it safer has been a challenge, both for the international and the national regulators. They have had to fight the common perception that risk is inherent in shipping, and profit is made on the premise that shipping entails dangers for the people working in it and for the people benefiting from its service.

A series of serious accidents, however, in the post-war era of the 20th century attracted public attention to the cause of safety at sea. At the same time, the United Nations had established an international specialised agency on maritime law, ${ }^{3}$ whose mission as of 1958 has been increasingly focused on promoting the safety of navigation. The IMO, through the procedures described in another chapter of this volume, ${ }^{4}$ has adopted a number of safety conventions which define the responsibilities of States as flag State (or State of registration), port State, and coastal State. ${ }^{5}$ These international instruments provide comprehensive standards that serve as a basis for the formulation of domestic laws regulating the design, equipment, maintenance, manning, operation, management, and disposal of ships.

1 The views expressed in this paper are the authors' own and do not necessarily reflect the official positions of their employers at the time of publication. Responsibility for any errors remains with the authors themselves.

2 An example of the benefits the long history of admiralty law has brought to modern maritime law, including EU rules, can be found in the history of P\&I Clubs, or of classification societies, both born out of centuries of experience in maritime commerce. These two institutions are an excellent example of how private initiative was able to build on their experience and develop rules for their business.

3 The UN adopted in 1948 a Convention on the creation of the Inter-Governmental Maritime Consultative Organization (IMCO), which was renamed in 1982 as the International Maritime Organization (IMO).

4 See D. Lost-Sieminska, ch. 1 above.

5 See IMO list of conventions and related protocols at: www.imo.org/en/About/Conventions/ListOfConven tions/Pages/Default.aspx (last visited on 31 January 2020). 
The origin of the European Union maritime transport and maritime safety policy dates back to the early 1990s. The Communication issued by the European Commission in 1993, entitled 'A Common Policy of Safe Seas', ${ }^{6}$ contained a package of accident-driven response measures aiming at reinforcing implementation of international rules within the European Community. ${ }^{7}$ The focus of those measures was on Member States exercising their jurisdiction as coastal States regarding vessel traffic monitoring, especially for dangerous goods and hazardous material (HAZMAT), and as port States regarding Port State Control. The responsibilities of Member States as flag States regarding technical safety standards were covered to a lesser extent, mainly in relation to their use of classification societies. ${ }^{8}$

In the aftermath of the sinking of two oil tankers, the Erika in 1999 and the Prestige in 2002, the EU reinforced this set of measures with additional rules (known as the "Erika" legislative packages) to improve maritime safety and prevent pollution at sea from shipping. Vessel traffic monitoring in the EU was given a significant boost in 2002 with the creation of a vessel traffic monitoring and information system to oversee traffic along EU coasts, in order to be able to intervene as early as possible, saving life and mitigating any consequences of incidents, such as oil pollution.

In 2009 with the adoption of the third 'Erika' legislative package, the EU expanded its legal framework to cover the entire chain of responsibility in the maritime sector, with a view to combating substandard shipping in European waters. This included new legislation on flag State responsibilities, which largely reflects international obligations incumbent on Member States as flag States, with reinforced surveillance and enforcement capabilities for the European Commission.

Today the EU acquis on maritime safety comprises more than 60 legal acts. ${ }^{9}$ The focus has since 2009 shifted from enacting new legislation to implementing, enforcing, and evaluating existing rules ${ }^{10}$ to ensure that EU legislation remains fit for purpose and produces the intended effect.

It is important to note at the outset of this chapter that maritime safety policy in the EU covers safety of navigation, with a balanced focus on the protection of human life and values, as well as the protection of the environment, in connection with shipping activities. ${ }^{11}$ This chapter does not address EU actions in relation to environmental protection. Hence, the EU legislation and ongoing initiatives in relation to the reduction of polluting air emissions from shipping, sustainable recycling of vessels, and ship-generated waste do not form part of the following analysis. It is also worth noting that safety and security are distinguished as two different policy areas within the European Commission's work on

$6 \operatorname{COM}(93) 66$ final of 24 February 1993.

7 The European Union (EU) succeeded the European Community through the Treaty of Lisbon that entered into force on 1 December 2009. See, in particular, Art. 1 of the Treaty on the European Union (TEU).

8 Council Directive 94/57/EC of 22 November 1994 on common rules and standards for ship inspection and survey organisations and for the relevant activities of maritime administrations, OJ L 319, 12.12.1994, p. 20.

9 For a complete list of the EU maritime safety acts see: www.emsa.europa.eu/emsa-documents/legislative -texts.html (last accessed 31 January 2020).

10 Ex-post evaluation of EU rules was promoted by the European Commission in 2015, as a key to ensure that further regulation would rely on an assessment of what is already in place. See Better Regulation Guidelines: Chapter VI - Guidelines on evaluation (including fitness checks) at https://ec.europa.eu/info/sites/info/files/be tter-regulation-guidelines-evaluation-fitness-checks.pdf p. 52 (last accessed on 31 January 2020).

11 For an up-to-date overview of the European Commission's work on maritime transport policy, see https:// ec.europa.eu/transport/modes/maritime_en (last accessed 31 January 2020). 
maritime transport. Maritime security forms part of a broader transport security agenda, while maritime safety is more closely linked to shipping economic policy ${ }^{12}$ and is distinct from safety in other modes of transport. Maritime security legislation does not form part of the analysis in this chapter either.

\subsubsection{Objectives}

The aim is to eliminate substandard shipping, increase the protection of passengers and crews, reduce the risk of environmental pollution, and ensure that operators who follow good practices are not put at a commercial disadvantage compared to those prepared to take short cuts with vessel safety. ${ }^{13}$

This is how the European Commission defines its goals in relation to maritime safety. It is essential to note that maritime transport policy forms part of the broader transport policy of the EU; hence, it shares the same overall objectives. The EU aspires to a safe, sustainable, and connected transport sector, which can support the functioning of the EU internal market, and in particular the free movement of goods, persons, and services. ${ }^{14}$

Two principles that determine the goals the EU sets through its legislation are the principle of proportionality ${ }^{15}$ and the principle of subsidiarity. ${ }^{16}$ Any new rules have to satisfy both tests. Proportionality calls for measures that are proportionate to the objectives sought. Subsidiarity requires the Union to act only when an objective cannot be achieved through national rules alone.

In the light of the above, EU maritime safety rules have been adopted when national or international rules proved insufficient to address, or prevent, shipping accidents. They aspire to ensure that EU Member States can remain competitive within the EU internal market, and worldwide, while effectively enforcing international standards on ship safety and pollution prevention from shipping. Furthermore, while it is true that the EU policy on maritime safety was born in the aftermath of some tragic accidents involving ships in the previous century, it has moved forward to encompass preventive actions concerning navigation and ship safety.

12 One example of the close link that exists between maritime safety rules and financial regulation for shipping is the legislation that covers insurance for maritime claims, i.e. Directive 2009/20/EC of 23 April 2009 on the insurance of shipowners for maritime claims, OJ L 131, 28.5.2009, p. 128, which forms part of the EU actions on safety and environment protection. Another prominent example is legislation concerning digitalisation of shipping, in particular as regards reporting formalities for ships arriving in or departing from EU ports, i.e. Directive 2010/65/EU on reporting formalities for ships arriving in and/or departing from ports of the Member States, OJ L $283,29.10 .2010$, p. 218, which has now been repealed (end of validity 25.8.2025) by Regulation (EU) 2019/1239, OJ L 198, 25.7.2019, p. 64, establishing a 'European Single Window' for reporting relating to maritime transport. The latter has been developed bearing in mind its use for customs purposes.

13 European Commission, Directorate-General for Mobility and Transport, Maritime Safety and Environment: https://ec.europa.eu/transport/modes/maritime/safety_en (last accessed on 31 January 2020).

14 See 'Transport in the European Union - current trends and issues' (2018), published by the European Commission, Directorate-General Mobility and Transport, online at: https://ec.europa.eu/transport/sites/transport/fil es/2018-transport-in-the-eu-current-trends-and-issues.pdf (last accessed on 31 January 2020).

15 The principle of proportionality is explicitly protected, as a fundamental principle of EU law, in Art. 5 para. 4 of the Treaty on European Union (TEU).

16 The principle of subsidiarity is also enshrined in the fundamental treaties of the Union, namely Art. 5 para. 3 TEU. 
The first key objectives, maritime safety and pollution prevention in EU waters, are tackled through a reinforced and comprehensive layer of EU legislation addressing flag State, port State, and coastal State responsibilities. These three roles have been largely defined at international level, through UNCLOS. ${ }^{17}$ In the absence of an enforcement mechanism 'with teeth' on the international plane, the EU has adopted its own rules incorporating international standards. Contrary to international rules, which can only rely on national enforcement, under EU law, the Commission, supported by the European Maritime Safety Agency (EMSA), has the responsibility for checking the implementation of the relevant rules and taking the necessary measures, including through an infringement procedure before the European Court of Justice.

More specifically, as flag States, EU Member States have to ensure that all applicable rules at international and EU level are adhered to before granting a ship the right to enter into their national register. However, any ship flying a third country flag can enter EU waters with potentially dramatic consequences in case of substandard shipping. To address this risk, EU Member States are obliged to carry out Port State Control inspections of foreign ships calling at their ports, which aim to detect noncompliance with maritime safety requirements (stemming from international conventions) and any resulting threats to safety or environmental risks. Finally, as coastal States, Member States must fulfil their obligations under international law for the monitoring of maritime transport and maritime traffic for the avoidance of collisions, groundings, and the protection of people and cargo.

Beyond ensuring a high level of safety and pollution prevention, the incorporation into EU law of international obligations aims to achieve a second key objective, a level playing field between EU flags. This, again, relies on the powers of the Commission and relevant EU institutions to monitor implementation of the EU rules on the functioning of the internal market, which include, alongside safety rules, fair competition and freedom to provide services.

A third key objective of maritime transport legislation is to ensure the efficiency of maritime transport and thereby its competitiveness worldwide. By mirroring the international legal framework, there is less risk of out-flagging of EU shipping in search of more favourable conditions. At the same time, the stringent conditions imposed in EU waters irrespective of the flag prevent quality shipping suffering unfair competition from those operators and flag States willing to lower safety standards on their fleet to save on costs. The EU rules aim to ensure a level playing field within the EU between EU flagged ships, through uniform and effective application of international rules.

Finally, it is worth making reference to an objective that the EU upholds in many acts dealing with transport, which is to ensure fair competition among the different transport modes. This particular objective is often mentioned, for instance, in the case of harmonisation of social rights legislation for professionals employed in the different modes of transport, ${ }^{18}$ including shipping.

17 See in particular UNCLOS Art. 11 (definition of ports), 24 and 25 (duties and rights of coastal States), 94 (duties of the flag State), and 211 (pollution from vessels), the latter being the most elaborate example of how these three types of responsibility can apply to a State under the law of the sea.

18 See for instance Regulation (EC) No 561/2006 of the European Parliament and of the Council of 15 March 2006 on the harmonisation of certain social legislation relating to road transport and amending Council Regulations (EEC) No 3821/85 and (EC) No 2135/98 and repealing Council Regulation (EEC) No 3820/85, OJ L 102, 11.4.2006, p. 1, Art. 1. 


\subsubsection{Competence}

In view of the nature of the EU as a transnational legal entity, composed of sovereign States, the question of competence to act in an area of law is topical. Transport is an area where the Union and the Member States share competence, which then also applies to maritime safety law. ${ }^{19}$ Shared competence between the Union and the Member States means that both can legislate in an area of law. When the Union decides to legislate on a subject, the Member States shall follow this legislation in the future. However, this does not apply vice versa as the Union is not prevented from legislating in an area where there are already national rules in place. ${ }^{20}$ The competence of the Union to act applies both to adopting new EU regulation, and to adopting negotiating positions on behalf of the EU in international fora, including negotiations for the conclusion of international agreements.

The Treaty on the Functioning of the European Union (TFEU) establishes a discretion for the EU co-legislators, i.e. the European Parliament and the European Council, to lay down specific rules on maritime transport. ${ }^{21}$ This discretion is circumscribed by the principles of subsidiarity and proportionality. The EU has exercised its discretion, adopting a number of legislative acts which address different aspects of maritime safety. These acts are referred to as 'secondary legislation'22 and take the form of 'Regulations', 'Directives', or 'Decisions' under EU law. It is crucial to note that all three types of acts are directly binding in the EU, and can be invoked by citizens and entities against a Member State. ${ }^{23}$ The European Parliament and the Council adopt secondary legislation, acting in accordance with the ordinary legislative procedure, ${ }^{24}$ after consulting the European Economic and Social Committee and the Committee of the Regions. ${ }^{25}$ This procedure aims to ensure that the legislative process in the EU is as democratic as possible, including representatives of all layers of government in the Member States and in Brussels.

Competence to act on behalf of the Union on the international plane is particularly significant in the case of maritime safety, due to the role the IMO plays in developing new rules. The fact that the EU itself is not a party to most international conventions on maritime safety ${ }^{26}$ adds complication to the assessment of EU competence on maritime safety

19 Art. 4 para. 2, clause (g) TFEU lists transport specifically as an area of shared competence between the Union and the Member States.

20 See Art. 2 para. 2 TFEU; and Opinion 2/91 Convention $N^{\circ} 170$ of the International Labour Organization concerning safety in the use of chemicals at work [1993] ECLI:EU:C:1993:106, in particular para. 9.

21 Art. 100 para. 2 TFEU.

22 The term 'secondary' is meant to distinguish those acts from 'primary law', which is the Treaties of the European Union, i.e. TEU and TFEU.

23 The key distinction between a Regulation and a Directive is that the latter leaves a discretion to the Member States as to the form and methods of application of the rules, while the former is directly applicable in its entirety. A Decision is usually a measure of more limited scope, which can also mean limited addressees, but is also directly binding. See Art. 288 TFEU.

24 Art. 294 TFEU sets out how the 'ordinary legislative procedure' works in the EU.

25 Art. 13 TEU sets out the Union's institutional framework, including a list of EU institutions.

26 The only IMO Convention to which the Union itself is a contracting party is the Athens Convention on the Carriage of Passengers and their Luggage by Sea, see infra note 137. 
issues. On the other hand, UNCLOS was signed by the Community, ${ }^{27}$ thereby binding the EU and becoming an integral part of its legal order. ${ }^{28}$

The competence of the Union to act in the IMO encompasses both the negotiations for new international agreements to which the Union may potentially become a party, and more importantly - the positions to be adopted on behalf of the Union concerning acts having legal effects in the EU. ${ }^{29}$ The latter scenario is the most common in connection to the IMO, as the different IMO Committees discuss amendments to international conventions, to which the Union itself is not a party. However, these amendments produce legal consequences within the EU, to the extent that they affect existing EU rules on maritime safety. ${ }^{30}$ Therefore, an assessment of the extent of the Union's competence has to take place every time there is a discussion at the IMO concerning an international convention, be it on an amendment to a technical annex or the consideration of a new legal instrument.

The European Court has consistently ruled in favour of the Union's competence to undertake international commitments necessary for the attainment of an objective that is set out in EU legislation, even in the absence of an express provision thereon. ${ }^{31}$ At the same time, the European Court has upheld the "principle of conferral of powers" ${ }^{32}$ as a main condition for the assessment of the Union's competence both internally within the EU and externally in the Union's international actions. ${ }^{33}$ A duty of 'sincere cooperation' 34 applies to both the EU and its Member States in relation to external representation of the Union, ${ }^{35}$ and it is pertinent for the assessment of competence on IMO matters.

It is important to emphasise that the discussion on the extent of the Union's competence in the area of maritime safety covers both the power to adopt new rules within the EU, ${ }^{36}$ and the power to adopt common positions on behalf of the EU, which the Member States are obliged to follow. ${ }^{37}$ The necessity and added value of new EU rules on maritime safety

27 Council Decision of 23 March 1998 concerning the conclusion by the European Community of the United Nations Convention of 10 December 1982 on the Law of the Sea and the Agreement of 28 July 1994 relating to the implementation of Part XI thereof, OJ L 179, 23.6.1998, p. 1.

28 C-459/03 Commission v Ireland [2006] ECLI:EU:C:2006:345, para. 82.

29 See Art. 218 para. 9 TFEU; and C-399-12 Germany v Council [2014] ECLI:EU:C:2014:2258, para. 50.

30 Art. 3 para 2 TFEU allocates exclusive competence to the Union for the conclusion of international agreements in so far as that 'may affect common rules or alter their scope'.

31 See Opinion 1/13 Accession of third States to the Hague Convention [2014] ECLI:EU:C:2014:2303, para. 67.

32 Art. 5 para. 2 TEU.

33 C-600/14 Germany v Council [2017] ECLI:EU:C:2017:935, para. 80.

34 Art. 4 para. 3 TEU.

35 C-22/70 Commission v Council [1971] ECLI:EU:C:1971:32, para. 22; and C-308/06 The Queen on the application of International Association of Independent Tanker Owners (Intertanko), International Association of Dry Cargo Shipowners (Intercargo), Greek Shipping Co-operation Committee, Lloyd's Register, International Salvage Union v Secretary of State for Transport [2008] ECLI:EU:C:2008:312, para. 17.

36 C-308/06, The Queen on the application of International Association of Independent Tanker Owners (Intertanko), Inter-national Association of Dry Cargo Shipowners (Intercargo), Greek Shipping Co-operation Committee, Lloyd's Register, International Salvage Union v Secretary of State for Transport [2008] ECLI:EU:C:2008:312, at paras. 46-52 the Court of Justice analyses why Directive 2005/35/EC on criminal sanctions for ship-source pollution offences, OJ L 255, 30.9.2005, p. 11, cannot be assessed in the light of MARPOL 73/78, as the EU is not a party to MARPOL 73/78. Therefore, the latter does not form part of the Union's legal order. Also, in paras. 64-65 of the judgment, the Court found that the validity of Directive 2005/35/EC cannot be assessed on the basis of UNCLOS either. That is because UNCLOS and the Directive are not addressed to the same subjects, at least in so far as criminal sanctions are concerned.

37 C-45/07 Commission v Greece [2009] ECLI:EU:C:2009:81, esp. para. 30. 
is constantly scrutinised in relation to existing IMO rules. This scrutiny is both justified and necessary in view of constant developments in IMO rules. By the same token, the EU must act in unity on the international front in order to achieve its objectives concerning maritime safety.

\subsubsection{Complementarity of the EU maritime safety rules}

As noted above, EU rules have to abide by the principle of subsidiarity within the Union. At the same time, EU rules are subject to an 'EU added value' test. ${ }^{38}$ According to this test, the contribution of any piece of legislation to be adopted at EU level has to accomplish something further than the existing national and international rules. EU rules have to be complementary to other national and international rules, not simply compatible but also beneficial.

The EU does not have a register, a fleet, or ports of its own. It is a Union of sovereign States, and these States are the subjects of the rights and obligations of a coastal, a port, and a flag State under UNCLOS. ${ }^{39}$ While UNCLOS itself has been made a part of the EU legal order, this does not change the fact that the structure established thereunder does not include regional organisations like the European Union. International conventions on maritime safety rely on these obligations for States, and, in particular, the duty of the flag State to ensure safety at sea through appropriate oversight of the construction, manning, maintenance, and operation of its fleet. EU maritime safety rules have been promulgated bearing in mind that Member States will retain full responsibility for the enforcement of these rules, through their threefold role as flag, port, and coastal State.

The Commission has exercised its right of initiative to propose new legislation in this area of EU law, mostly prompted by evidence of gaps in the international rules or insufficient implementation thereof. This evidence always stemmed from accidents, which led to public pressure on the EU to take action. As a result, the EU system of maritime safety rules was built in 'waves', each time focusing on the part of international regulation that appeared to be the weakest. It took several rounds of legislative procedures to build what is today a comprehensive set of rules that is complementary to the IMO conventions, and focused on continuous improvement as well as enforcement.

The EU maritime safety legal framework works well within the EU single market, maintaining a delicate balance between international obligations and EU treaty obligations. In particular, the current maritime safety rules of the EU have been carefully constructed in accordance with the customary principle of freedom of navigation, the rights and duties established under UNCLOS, and the EU treaty principles of free and fair competition, freedom to provide services, freedom of establishment, free movement of persons, and free movement of goods.

It is important to note in this context that the maritime voyages between EU Member States are still 'international' voyages. Therefore, all international rules apply to this traffic, as well as national and EU rules. There are, however, some distinctions drawn in EU

38 EU added value is one of the main criteria listed for the assessment of existing legislation, and any new proposals, under the European Commission Better Regulation Guidelines. See supra note 10.

39 See supra note 17 on the list of provisions in UNCLOS referring to the three different roles the sovereign State must serve under the law of the sea. 
legislation between EU and non-EU registered vessels. This is to abide by the rules of the EU common market, and in particular free movement of goods and services therein.

Notably, transfer of cargo and passenger ships between registers within the EU is treated differently than transfers to or from a non-EU State. ${ }^{40}$ EU Member States are obliged to accept on their registers a ship that is already recognised in another Member State. That said, there are also rules in EU legislation, meant to install a safeguard against shipowners changing flag within the EU to avoid stricter safety rules. ${ }^{41}$

\subsubsection{EU special tools on maritime safety}

In order to understand how complementarity of EU rules works in practice, it is important to refer to the following three tools embedded in EU maritime safety legislation.

One key element EU rules added to bolster maritime safety in European waters is the EU-wide maritime common information and exchange system ('SafeSeaNet'). ${ }^{42}$ This system supports all national authorities in the EU as well as maritime operators, as it uses digitalisation to enhance the efficiency of maritime transport and maritime traffic.

The creation of the European Maritime Safety Agency (EMSA) in $2002^{43}$ was a direct consequence of the ERIKA and PRESTIGE accidents involving oil spills. The original idea behind its creation was to establish a body that would provide technical support to the Commission, with expertise to match those available in national administrations and the IMO. Since the start of its operation in January 2004, EMSA has provided technical, operational, and scientific assistance to the European Commission and to EU Member States that is key for the implementation of EU rules. EMSA's main tasks include the establishment of pollution preparedness stand-by vessels, ${ }^{44}$ the provision of integrated maritime services through integration and sharing of maritime traffic data and information, ${ }^{45}$ as well as training and capacity building activities within the EU and in its neighbouring States. Furthermore, EMSA provides a unique forum for Member States' experts to discuss and exchange best practices on the implementation of international rules, and to develop helpful guidance for their implementation. ${ }^{46}$

40 Regulation (EC) No 789/2004 of the European Parliament and of the Council of 21 April 2004 on the transfer of cargo and passenger ships between registers within the Community, OJ L 138, 30.4.2004, p. 19. See in particular Art. 4 and 5.

41 Directive 2009/21/EC of the European Parliament and of the Council of 23 April 2009 on compliance with flag State requirements, OJ L 131, 28.5.2009, p. 132. See in particular Art. 4.

42 The 'European Union's Maritime Information and Exchange System (SafeSeaNet)' was created under Directive 2002/59/EC of the European Parliament and of the Council of 27 June 2002, establishing a Community vessel traffic monitoring and information system and repealing Council Directive 93/75/EEC ('VTMIS Directive'), OJ L 208, 5.8.2002, p. 10.

43 Regulation (EC) No 1406/2002 of the European Parliament and the Council of 27 June 2002 establishing a European Maritime Safety Agency, OJ L 208, 5.8.2002, p. 1.

44 www.emsa.europa.eu/operations/pollution-response-services.html (last accessed 31 January 2020).

45 For more information on EMSA's Integrated Maritime Services ('IMS') see www.emsa.europa.eu/operat ions/maritime-monitoring.html (last accessed on 31 January 2020). This is further elaborated in Section 2. 'Preventive action in EU' below.

46 See for instance the 'EU States Claims Management Guidelines: Claims Arising due to Maritime Pollution Incidents' (last version 2019), developed by the EMSA Consultative Technical Group for Marine Pollution Preparedness and Response, available at: www.emsa.europa.eu/opr-documents/item/720-eu-states-claims-manage ment-guidelines-claims-arising-due-to-maritime-pollution-incidents.html (last accessed on 31 January 2020). There is also ongoing work for EU operational Guidelines for safe, secure, and sustainable trials of maritime 
Another proof of the complex nature of the EU's decision-making processes is the use of representative expert committees ${ }^{47}$ established to assist the European Commission in fulfilling its obligations with regard to implementation of EU rules. More specifically, EU legislation often lays down obligations for the European Commission to adopt implementing measures in areas where uniform conditions for implementation of EU rules are essential. ${ }^{48}$ In addition, EU legislation may also delegate powers to the European Commission to adopt non-legislative measures on specific non-essential elements of that legislation. ${ }^{49}$ In order to ensure Member States' participation in the drafting and adoption of these measures by the European Commission, EU legislation has set up committees composed of Member States' representatives with expertise in the respective policy areas. ${ }^{50}$

In the case of maritime safety, the relevant representative committee is the Committee on Safe Seas and the Prevention of Pollution from Ships (COSS). ${ }^{51}$ The role of COSS has grown over the years, in particular as the focus of the EU with regard to new legislation and improving implementation of existing rules. COSS votes on the draft Commission proposals for every measure that concerns the implementation of EU maritime safety rules, including exemptions to be granted by individual Member States in specific operators, or routes in their territory. COSS also discusses new developments in the international rules that may affect the implementation of EU rules at Member State level. Therefore, the role of COSS is crucial in ensuring complementarity of EU rules at the stage of their implementation.

COSS is not the only expert group advising the Commission in its work on maritime safety. A number of other expert groups are set up under EU maritime safety legislation. These technical experts groups include EMSA, and often also representatives of the relevant industry stakeholders. Their role often involves developing further guidance for Member States and shipping operators in the implementation of EU maritime safety rules. ${ }^{52}$ However, the role of those groups other than COSS is advisory/consultative on various technical issues, and they do not have the power to vote on Commission implementing measures ('comitology powers').

autonomous surface ships (MASS) done by an expert group on MASS. The expert group on MASS was established under the umbrella of the 'High Level Steering Group for the Governance of the Digital Maritime System and Services', in accordance with Commission Decision (EU) 2016/566 of 11 April 2016 on establishing the highlevel steering group for governance of the digital maritime system and services and repealing Decision 2009/584/ EC, OJ L 96, 12.4.2016, p. 46.

47 Regulation (EU) No 182/2011 of the European Parliament and of the Council of 16 February 2011 laying down the rules and general principles concerning mechanisms for control by Member States of the Commission's exercise of implementing powers, OJ L 55, 28.2.2011, p. 13.

48 The legal basis for the implementing powers of the Commission is Art. 291 para. 2 TFEU.

49 See Art. 290 TFEU on 'delegated acts'.

50 The procedures that refer to these committees and the role Member States play in checking the Commission's implementing and delegated powers are known as 'comitology'.

51 Regulation (EC) No 2099/2002 of the European Parliament and of the Council of 5 November 2002 establishing a Committee on Safe Seas and the Prevention of Pollution from Ships (COSS) and amending the Regulations on maritime safety and the prevention of pollution from ships, OJ L 324, 29.11.2002, p. 1.

52 See for instance the 'EU High Level Steering Group for Governance of the Digital Maritime System and Services (HLSG)' established under the VTMIS Directive, OJ L 208, 5.8.2002, p. 10. The HLSG has been instrumental in the development of the EU maritime information and exchange system (SafeSeaNet), and continues to play a key rule in the digitalisation of maritime transport in the EU, through its work on the 'European Maritime Single Window'. 
The next four sections of this chapter will focus on specific EU actions in the field of prevention, control and surveillance, enforcement, and liability and insurance in relation to maritime safety.

\subsection{Preventive actions at EU level}

\subsubsection{Recognised organisations}

It is not mandatory for flag States to use recognised organisations in order to fulfil their survey and certification obligations for their fleet under the international maritime safety conventions. That said, the vast majority of flag States now make use of the services of recognised organisations to a greater or lesser extent, and the role of the latter is undeniably key in ensuring safety at sea.

Flag States are responsible under international law for the activities recognised organisations carry out on their behalf. Therefore, flag States must ensure that recognised organisations have the requisite technical expertise, manpower, rules, and procedures in place to act on behalf of the State for maritime safety purposes and lay this down in an agreement. A number of accidents in the past have showed that poor performance of survey duties and lack of control can lead to catastrophic damages in shipping..$^{53}$ To that end, the EU has sought to strengthen the legal framework applicable to the relationship between the flag State and its recognised organisations, and to establish specific procedures for the monitoring of the organisations acting on behalf of EU Member States.

One of the first acts the EU adopted on maritime safety in 1994 was a Directive on recognised organisations ('ship survey and inspection organisations'). ${ }^{54}$ This was at the time a measure that had not mirrored any international conventions ${ }^{55}$ was aiming to impose for the first time common rules and standards on activities carried out by recognised organisations on behalf of flag States in the EU. EU Member States were obliged to make sure that any recognised organisation acting on their behalf fulfilled some minimum quality criteria, ${ }^{56}$ to monitor the work recognised organisations carried out on their behalf, and to inform the European Commission and other EU Member States of the results of this monitoring. At the same time, the Directive obliged Member States to recognise organisations that had already been recognised in another EU Member State, in line with the freedom to provide services in the EU internal market.

Following the accidents in European waters at the turn of the century, where the role of recognised organisations was directly called into question, the EU strengthened its rules on the monitoring of recognised organisations. The main changes brought about concerned the power to recognise organisations within the EU now exercised exclusively by the European Commission, minimum standards on the liability of recognised organisations in

53 This does not affect the shipowner's primary responsibility for the vessel.

54 Council Directive 94/57/EC, OJ L 319, 12.12.1994, p. 20.

55 The Directive was based on IMO Resolution A.739 (18) on guidelines for the authorisation of organisations acting on behalf of the administration, which was not binding and did not establish any obligations for flag States.

56 See Annex to Directive 94/57/EC, OJ L 319, 12.12.1994, p. 20. 
case of accidents, and regular assessments, based on EMSA inspections, of EU recognised organisations by the European Commission. ${ }^{57}$

In 2009 the EU further consolidated its legal framework on recognised organisations through two new legal acts. ${ }^{58}$ As a result of this consolidation of earlier amendments, EU rules are now presented in two sets of rules, a Regulation laying down the powers and obligations of the European Commission and a Directive laying down obligations for EU Member States in relation to the recognised organisations they choose to authorise to work on their behalf. A key addition to the legal framework was the possibility for the European Commission to impose fines against recognised organisations for serious breaches of the EU rules and criteria in the performance of their duties. ${ }^{59}$ Furthermore, the EU legislation imposed an obligation for recognised organisations to set up and maintain 'an independent quality assessment and certification entity in accordance with the applicable international quality standards'. ${ }^{60}$

It is worth making particular reference to the 'flag-blind' approach to the information concerning the recognised organisations' activities that have been adopted in the EU. This means that an EU-recognised organisation must provide to the EU Member States that have authorised it to act on their behalf and to the European Commission 'all relevant information about their classed fleet, transfers, changes, suspensions and withdrawals of class, irrespective of the flag the vessels fly' ${ }^{61,62}$ This was introduced in order to allow verification that the organisation performs to the same high level quality standards wherever a survey of a vessel takes place, as well as to ensure that any evidence of systemic failures of the recognised organisations' rules and procedures will be available to the European Commission and the Member States that work with these organisations. It is clear that

57 These changes happened through Directive 2001/105/EC of the European Parliament and of the Council of 19 December 2001 amending Council Directive 94/57/EC on common rules and standards for ship inspection and survey organisations and for the relevant activities of maritime administrations, OJ L 19, 22.1.2002, p. 9. EU Member States, in particular the Member State that originally requested the recognition of an organisation, also have a role in the periodic assessment of recognised organisations.

58 Directive 2009/15/EC of the European Parliament and of the Council of 23 April 2009 on common rules and standards for ship inspection and survey organisations and for the relevant activities of maritime administrations, OJ L 131, 28.5.2009, p. 47; and Regulation (EC) No 391/2009 of the European Parliament and of the Council of 23 April 2009 on common rules and standards for ship inspection and survey organisations, OJ L 131, 28.5.2009, p.11.

59 Commission Regulation (EU) No 788/2014 of 18 July 2014 laying down detailed rules for the imposition of fines and periodic penalty payments and the withdrawal of recognition of ship inspection and survey organisations pursuant to Art. 6 and 7 of Regulation (EC) No 391/2009 of the European Parliament and of the Council, OJ L 214, 19.7.2014, p. 12.

60 Art. 11 para. 1 of Regulation (EC) No 391/2009, supra note 58, establishes this obligation. Consequently, 'QACE - Entity for the Quality Assessment and Certification of Organisations Recognised by the European Union' was set up by the 12 EU recognised organisations in 2010. For further information on this entity see http: //qace.co/about-qace/\#post-foundation-of-qace (last accessed 31 January 2020).

61 Art. 15 para. 3 of Directive 94/57/EC as amended by Directive 2001/105/EC, OJ L 19, 22.1.2002, p. 9. Now this 'flag-blind' approach is included in Art. 10 para. 4 of Regulation 391/2009, OJ L 131, 28.5.2009, p.11.

62 This approach may be seen as challenging the exclusive jurisdiction of the flag State over its vessels that is established under Art. 91 para. 2, 92 para. 1, and 94 paras. 2 and 3 of UNCLOS. However, the EU is only concerned with the systemic failures in the recognised organisations' control and certification process, and this does not affect the flag State's jurisdiction. More to the point, commentators refer to this use by the EU of extraterritorial scope for its rules as being justified when their objectives reach beyond EU borders, such as in the case of EU financial regulations. For an analysis see J. Scott, 'The new EU extraterritoriality', (2014), 51(5) Common Market Law Review, 1343-1380. 
safety at sea and protection of the marine environment are driving the EU's efforts. The assessment of recognised organisations focuses on the survey work they perform on any vessel, in accordance with the required quality management system, to ensure they maintain control, and not on the flag of the vessels that are randomly selected during an inspection. This is the only way to take every necessary precaution against substandard shipping.

Further to the EU legal framework, the EU has been instrumental at IMO in pushing for an international instrument that would address the obligations of flag States and recognised organisations. The IMO adopted a 'Code on Recognised Organisations' in 2013, which collected in one instrument all the requirements that existed in the different maritime safety conventions for recognised organisations. ${ }^{63}$ The EU had to assess the impact of the Code on existing EU rules. Due to the fact that EU legislation is stricter on some aspects of the monitoring of recognised organisations, the EU Member States had to issue a declaration at IMO to exclude themselves from the application of certain provisions of the Code. ${ }^{64}$ The Code had been subject to an assessment by the Commission, with the positive opinion of the COSS, in order to determine which provisions of the Code were incompatible with existing EU rules. ${ }^{65}$

It is clearly evidenced in the abovementioned actions that the EU considers its rules on recognised organisations as a cornerstone of the maritime safety acquis with particular significance for the prevention of future accidents.

\subsubsection{Accident investigation}

In the context of prevention, it is also relevant to point to the EU legislation regarding accident investigation. ${ }^{66}$ Directive 2009/18/EC introduced a mandatory requirement for EU Member States to set up an independent accident investigation body, which must produce a report on the accident including safety considerations and advice. ${ }^{67}$ More to the point, the Directive established an EU database on marine casualties, known as the European Marine Casualty Information Platform (EMCIP).$^{68}$ EMCIP relies on the input by EU Member States in the form of accident reports produced by the national accident investigation bodies.

63 Resolution MSC.349(92), adopted 21 June 2013, available at www.imo.org/en/KnowledgeCentre/Inde xofIMOResolutions/Maritime-Safety-Committee-(MSC)/Documents/MSC.349(92).pdf (last accessed 31 January 2020).

64 Council Decision 2013/268/EU of 13 May 2013 on the position to be taken on behalf of the European Union within the International Maritime Organization (IMO) with regard to the adoption of certain Codes and related amendments to certain conventions and protocols, OJ L 155, 7.6.2013, p. 3, contains in Annex the Declaration made by EU Member States at IMO regarding the III and RO Codes.

65 The results of the conformity assessment process are reflected in detail in the Commission Implementing Directive 2014/111/EU of 17 December 2014 amending Directive 2009/15/EC with regard to the adoption by the International Maritime Organization (IMO) of certain Codes and related amendments to certain conventions and protocols, OJ L 366, 20.12.2014, p. 83.

66 Directive 2009/18/EC of the European Parliament and of the Council of 23 April 2009 establishing the fundamental principles governing the investigation of accidents in the maritime transport sector and amending Council Directive 1999/35/EC and Directive 2002/59/EC of the European Parliament and of the Council, OJ L 131, 28.5.2009, p. 114.

67 See Art. 8 of Directive 2009/18/EC, OJ L 131, 28.5.2009, p. 114.

68 EMCIP is managed by EMSA. See information available at www.emsa.europa.eu/emcip.html (last accessed 31 January 2020). 
There are two key elements to this set of rules in the EU. One concerns the obligation of EU Member States to adopt the relevant procedures and carry out their duties on a national level, as regards marine accident investigation. This ensures that an Accident Investigation actually takes place and concludes within a reasonable time. The second element concerns the EU-wide information platform that collects data and analyses them in order to come up with safety recommendations to avoid similar accidents in the future.

This approach to maritime accidents has a clear element of prevention built in. It constitutes important input for the decisions of the European Commission and EU Member States on the challenges and priorities that need to be addressed in different areas of maritime operations. EMCIP data are used more and more as a reference by the European Commission in its legislative proposals to improve maritime safety legislation. In addition, a permanent cooperation framework has been set up by the Directive for Member States to exchange best practices, and discuss their experience with marine accident investigation and reporting, learning from real cases and learning from each other. ${ }^{69}$ This is an excellent example of the inbuilt mechanism for continuous improvement of maritime safety policy in the EU, and an important part of prevention.

\subsubsection{Passenger ship safety}

The reason for the particular attention the EU has paid to passenger ship safety is easily deduced from the numbers for passenger ships and passenger traffic in EU ports. Figures for $2016^{70}$ indicate that among the EU/EEA flagged fleet, in terms of numbers of ships, passenger ships are the second biggest segment with $23 \%$ of the total fleet. ${ }^{71}$ For the world fleet, passenger ships hold a much less prominent position with $11 \%$ of the total. ${ }^{72}$ At the same time, Eurostat figures for seaborne passenger traffic in Europe in 2017 show 415 million passengers having travelled through ports in the EU, with the majority of seaborne passenger traffic being domestic traffic. ${ }^{73}$ More to the point, as regards domestic seaborne passenger traffic in the EU, the number of accidents reported in EMCIP on domestic passenger ships in the EU is over one thousand for the five-year period 2015-2019, bearing in mind the increase in reporting that has occurred in parallel. ${ }^{74}$

These numbers, coupled with the memory of past tragic accidents, such as the sinking of the Estonia in 1994 and the Express Samina in 2000, place passenger ship safety high

69 For more information on the work of the Permanent Cooperation Framework see www.emsa.europa.eu/ pcf.html (last accessed 31 January 2020).

70 Lloyds List Intelligence produced a report on 'EU flagged and controlled fleet' (December 2016) commissioned by the European Commission. The report is available at: https:/op.europa.eu/en/web/general-publications/ publications (last accessed 31 January 2020).

71 Lloyds List Intelligence's report on 'EU flagged and controlled fleet' (December 2016) commissioned by the European Commission. Tankers are the biggest vessel segment representing 26\% of the total EU/EEA fleet, while general cargo carriers represent $22 \%$, bulk carriers $14 \%$, and container carriers $11 \%$.

72 Lloyds List Intelligence's report on 'EU flagged and controlled fleet' (December 2016) commissioned by the European Commission.

73 EUROSTAT published 'Maritime ports freight and passenger statistics' based on data from May 2019, available at: https://ec.europa.eu/eurostat/statistics-explained/index.php/Maritime_ports_freight_and_passeng er_statistics\#Increase_in_number_of_seaborne_passengers (last accessed 31 January 2020).

74 See also 'Safety Analysis of $\bar{D}$ ata Reported in EMCIP - Analysis on Marine Casualties and Incidents involving Ro-Ro Vessels' by EMSA, available at: www.emsa.europa.eu/accident-investigation-publications/safet y-analysis.html (last accessed 31 January 2020). 
up on the list of priorities for the EU policy on maritime safety. As the lives of so many passengers travelling within or through Europe are at stake, the European Parliament in particular, as the body of elected representatives of EU citizens, has traditionally put particular emphasis on this objective.

As a result, international rules on the design and construction of passenger ships have been made mandatory through EU law to ships not covered by the international conventions. ${ }^{75}$ Directive 2009/45/EC extends the scope of application of these rules to passenger ships and high speed craft engaged in domestic voyages within the EU, irrespective of the flag they fly. The Directive defines 'sea areas' and corresponding 'classes' of domestic passenger ships based on their distance from the coast and significant wave height. ${ }^{76} \mathrm{EU}$ Member States are required under the Directive to take specific measures to ensure that the design and construction criteria of SOLAS and the High Speed Craft Code apply to the passenger vessels flying their flag, ${ }^{77}$ and to those operating on domestic voyages between their ports. ${ }^{78}$

In the case of ro-ro passenger ships, the EU has gone further than international rules by imposing stricter stability requirements. In fact, these stricter rules first applied regionally in the Baltic sea, and were adopted in the aftermath of the Estonia disaster. ${ }^{79}$ The EU, however, considered this to create uneven maritime safety levels among EU Member States, and hard to justify to EU citizens whose lives should be subject to the same protection across the EU. Therefore the European Parliament specifically requested the European Commission to examine the possibility of extending these stricter requirements to the whole of the EU. ${ }^{80}$ Directive 2003/25/EC on specific stability requirements for ro-ro passenger ships was adopted to extend the regional stricter rules to the whole of the EU, and established a system through which Member States would ensure implementation of these rules to ro-ro passenger ships operating to or from their ports, irrespective of the flag they fly. ${ }^{81}$

Finally, passenger ship safety rules also include specific requirements on the registration of passengers sailing onboard ships operating to or from EU MS ports. ${ }^{82}$ The objective of this act, adopted in the wake of the Herald of Free Enterprise and Estonia accidents, is to support Member States in Search and Rescue (SAR) activities in the aftermath of such accidents. The requirements involve registering and keeping, for the time of the voyage, information about all passengers. The Directive also foresees sharing such information in

75 Directive 2009/45/EC of the European Parliament and of the Council of 6 May 2009 on safety rules and standards for passenger ships, OJ L 163, 25.6.2009, p. 1.

76 Directive 2009/45/EC Art. 4, OJ L 163, 25.6.2009, p. 1.

77 Directive 2009/45/EC Art. 12, OJ L 163, 25.6.2009, p. 1.

78 Directive 2009/45/EC Art. 5, OJ L 163, 25.6.2009, p. 1.

79 Eight northern European countries, including seven EU Member States, agreed in Stockholm on 28 February 1996 to introduce a higher stability standard for ro-ro passenger ships in damaged condition in order to take into account the effect of water accumulation on the ro-ro deck and to enable the ship to survive in more severe states than the SOLAS 90 standard, up to $4 \mathrm{~m}$ significant wave heights. This agreement is known as 'the Stockholm Agreement'.

80 See recital (14) to Directive 2003/25/EC of the European Parliament and of the Council of 14 April 2003 on specific stability requirements for ro-ro passenger ships, OJ L 123, 17.5.2003, p. 22.

81 See Art. 3 to Directive 2003/25/EC, OJ L 123, 17.5.2003, p. 22.

82 Council Directive 98/41/EC of 18 June 1998 on the registration of persons sailing on board passenger ships operating to or from ports of the Member States of the Community, OJ L 188, 2.7.1998, p. 35. 
a safe manner should it become necessary, especially to authorities with SAR responsibilities, such as Maritime Rescue Coordination Centres (MRCC).

\subsubsection{EMSA}

The founding Regulation of EMSA establishes an obligation for EMSA to provide technical, operational, and scientific assistance to the Member States and the European Commission. ${ }^{83}$ EMSA fulfils this obligation in three phases or areas of operation, namely the pre-accident phase, the accident phase, and the post-accident phase.

Preventive actions at EU level are supported by EMSA - in the pre-accident phase in addressing any problems 'upstream' at flag State level. In practice, EMSA carries out visits to EU Member States to check in situ the implementation of the different maritime safety rules, such as passenger ship safety rules, marine equipment rules, or accident investigation rules. In addition, EMSA conducts inspections of the EU recognised organisations, in their offices all over the world where they carry out ship survey and inspection tasks to verify that they continue to fulfil the quality criteria stipulated in EU legislation. Inspections of maritime schools and maritime administrations responsible for the certification of seafarers in countries outside the EU are also carried out by EMSA. This is to ensure implementation of the STCW requirements for third country seafarers who wish to work on board a ship registered in an EU Member State. ${ }^{84}$ Visits and inspections are conducted, like audits, by EMSA's employees, as independent and impartial technical experts. ${ }^{85}$ They include document review, interviews, and on-site evidence gathering.

EMSA issues reports on their visits and inspections, which it shares with the States concerned, and in the case of EU recognised organisations with the organisations themselves. It is on the basis of these reports that the Commission then addresses the visited/ inspected party with requests for corrective action to remedy the identified shortcomings. EMSA reports may also be the underlying documentation, among other things, that informs the Commission's decision in taking legal action against a Member State for failure to implement EU maritime safety rules. In a way, when EMSA performs visits and inspections on behalf of the Commission, it is the 'eyes and ears' of the Commission.

The work of EMSA in prevention is essentially to 'control the controllers', the latter being EU Member States' competent authorities for the implementation of EU maritime safety rules. EMSA starts their visits and inspections every time there is a new piece of legislation in the EU, in order to ensure that EU Member States receive feedback from technical experts on their systems implementing EU rules early on, before there are any accidents confirming gaps in national systems. It is important to clarify also that EMSA

83 Regulation 1406/2002 Art. 1 para. 2, OJ L 208, 5.8.2002, p. 1.

84 The legal act implementing the STCW requirements into EU law is Directive 2008/106/EC of the European Parliament and of the Council of 19 November 2008 on the minimum level of training of seafarers, OJ L 323, 3.12.2008, p. 33. In accordance with Regulation 1406/2002, supra note 43, Art. 3 para. 3, EMSA is given the task of carrying out inspections of maritime schools in third countries for the purposes of Directive 2008/106/EC.

85 See Methodology for Visits to Member States adopted by the EMSA Administrative Board on 18 November 2015, available at www.emsa.europa.eu/visits-to-member-states/items.html?cid=130\&id=3065 (last accessed on 31 January 2020). 
does not carry out a second flag State inspection, or Port State Control inspection, or other statutory surveys. The obligation to exercise control on their fleet or their ports lies with the EU Member States under UNCLOS and the IMO Conventions.

Effective prevention requires monitoring and control measures. EU Member States as flag, port, and coastal States exercise control to ensure implementation of the relevant EU legislation and to support the operation of the entire EU maritime safety regime. This is the area where EU Member States have developed the most and where cooperation is the most advanced. In the EU context, monitoring and control is based on three key Directives: (i) the flag State Directive, ${ }^{86}$ (ii) the Port State Control Directive, ${ }^{87}$ and (iii) the vessel traffic monitoring and information system (VTMIS) Directive (covering coastal State obligations). ${ }^{88}$

\subsection{Control and EU-wide maritime surveillance systems}

\subsubsection{Flag State control}

International rules on maritime safety impose a twofold obligation on flag States. They have to adopt the necessary national regulation to ensure that international rules apply within their legal order. In addition, they have to ensure implementation of these rules in practice by exercising effective control over their registered fleet. This twofold obligation of flag State administrations cannot be delegated away. Hence, the flag State must have the necessary resources, financial, human, and technical, to inspect and control compliance of any ship on its register.

Flag State control over the fleet is necessary not only to ensure implementation of the relevant EU legislation, but also for the functioning of the entire maritime safety regime. It is closely interconnected with Port State Control, and the EU maritime surveillance system, but has a distinct role of its own to play.

Therefore, the EU adopted Directive 2009/21/EC, laying down in a binding form some specific obligations for EU Member States as flag States with regard to the implementation of international safety rules on their fleet. The Directive includes a requirement to have a quality management system in place for flag State related activities, and to have that certified in accordance with the applicable international quality standards (normally the ISO 9000 series).$^{89}$ This requirement has not been made mandatory under the IMO III Code. ${ }^{90}$ However, in practice, a quality management system is needed in order to fully meet the III Code requirements and in view of the IMSAS audits. ${ }^{91}$ A properly implemented and used flag quality management system aims to ensure a systemic approach to the flag State's duty to control its fleet.

86 Directive 2009/21/EC, OJ L 131, 28.5.2009, p. 132.

87 Directive 2009/16/EC of the European Parliament and of the Council of 23 April 2009 on port State control, OJ L 131, 28.5.2009, p. 57.

88 Directive 2002/59/EC, OJ L 208, 5.8.2002, p. 10.

89 Art. 8 para. 1 of Directive 2009/21/EC, OJ L 131, 28.5.2009, p. 132.

90 IMO Assembly Resolution A.1070(28) containing the 'IMO Code on the Implementation of IMO Instruments' ('III Code') was adopted on 4 December 2013.

91 IMO Member States Audit Scheme (IMSAS) began its mandatory audits in January 2016. 
Some examples of maritime safety rules, whose implementation in the EU is controlled through the flag State Directive are the requirements for seafarers' training and certification, ${ }^{92}$ the requirements on maritime labour conditions,,${ }^{93}$ and the requirements of the ISM Code. ${ }^{94}$

\subsubsection{Port State Control}

Port State Control rules ${ }^{95}$ were adopted in the EU to complement the role of the flag State in ensuring implementation of the maritime safety legislation (flag State inspections), and are known as the 'second line of defence'. EU rules have largely relied on the existing regional Port State Control systems, and in particular the Paris MoU system. ${ }^{96}$ The Paris MoU is based on a voluntary agreement among the States Parties to implement international rules relating to vessel safety, pollution prevention, and working and living conditions. The EU Port State Control system is mandatory and now monitors the implementation of most of the EU maritime safety legislation.

The main objectives of the Port State Control Directive are to (i) improve safety at sea, i.e. increase the protection of passengers and crews, (ii) enhance protection of the marine environment, i.e. reduce the risk of pollution, (iii) ensure maritime security, and (iv) improve on-board living and working conditions. The means the Directive uses to achieve these objectives are common criteria and harmonised procedures for control, as well as a system that takes into account the ship's risk profile. ${ }^{97}$ Ultimately, the Directive aims to increase compliance among vessels trading in European waters and eliminate substandard shipping in the area.

The effectiveness of the Directive depends on implementation and enforcement actions by the EU Member States and the European Commission. In this context, the Directive imposes an obligation on Member States to take all necessary measures in their national legal framework in order to carry out the inspections referred to in the Directive, and to maintain appropriate competent authorities with qualified inspectors performing the inspections required under the Directive. ${ }^{98}$ The assistance of EMSA is instrumental, having developed and maintained the database through which the results of Port State Control inspections are recorded, collected, and analysed. ${ }^{99}$

92 Directive 2008/106/EC of the European Parliament and of the Council of 19 November 2008 on the minimum level of training of seafarers, OJ L 323, 3.12.2008, p. 33.

93 Directive 2013/54/EU of the European Parliament and of the Council of 20 November 2013 concerning certain flag State responsibilities for compliance with and enforcement of the Maritime Labour Convention, 2006, OJ L 329, 10.12.2013, p. 1.

94 Regulation (EC) 336/2006 of the European Parliament and of the Council of 15 February 2006 on the implementation of the International Safety Management Code within the Community, OJ L 64, 4.3.2006, p. 1.

95 Directive 2009/16/EC, supra note 87. The predecessor to this Directive, Council Directive 95/21/EC of 19 June 1995 on Port State Control of shipping, OJ L 157, 7.7.1995, p. 1, was one of the first maritime safety acts to be adopted in the EU.

96 Paris Memorandum of Understanding (PMoU). All EU Member States with sea ports are parties to it, along with Canada, Russia, Norway and Iceland.

97 'Ship risk profile' is defined in Art. 10 and Annex I to Directive 2009/16/EC, OJ L 131, 28.5.2009, p. 57.

98 Directive 2009/16/EC, OJ L 131, 28.5.2009, p. 57, Art. 4.

99 THETIS is the information system which supports the New Inspection Regime for Port State Control and into which all inspection reports and detentions are reported. It is hosted at central level in EMSA. 
Ships sailing in 'EU waters' ${ }^{100}$ are subject to regular inspections by designated Port State Control officers (PSCO) to verify whether they meet the relevant international rules and standards. ${ }^{101}$ If a ship, after such an inspection, is deemed unfit by a PCO to continue its journey at sea, she must be detained and required to take the necessary corrective actions. The detention can be lifted only when the PSCO confirms to the port State administration, with an appropriate notification through the relevant database, that the corrective actions taken are satisfactory. ${ }^{102}$

If a ship is detained following Port State Control frequently, i.e. more than twice, within the EU the Directive obliges EU Member States to refuse access of that ship to their ports once it leaves the port where it was last detained. The refusal of access measures applies for a minimum period of time and until the ship provides evidence of full compliance. A ship can also be banned from sailing to EU ports in some cases where the record of detentions within the EU is more than three. ${ }^{103}$ The EU rules on mandatory insurance of shipowners provide for another possibility similar to access refusal, namely an 'expulsion order' to be issued against a ship that does not provide evidence of a valid insurance certificate on board during a Port State Control inspection. ${ }^{104}$

The EU Port State Control regime is today geared towards trying to identify substandard ships and to 'punish' them, while allowing good operators to go about their business as uninterrupted as possible - in fact, providing an incentive or 'reward' for quality shipping. This ensures the level playing field.

In this context, it should be noted that there are specific requirements in the flag State Directive that aim to close the loop between flag and Port State Control responsibilities. EU member states have to take direct action when they are informed that one of their vessels has been detained by Port State Control anywhere in the world. ${ }^{105}$ They are required to oversee that the ship is brought into compliance with the relevant IMO conventions. This is the essence of flag State responsibility. Often the relevant task is actually carried out by the recognised organisations on behalf of the flag State, i.e. additional surveys. EU Member States, however, are responsible for monitoring effective performance of the tasks delegated to their recognised organisations. Hence, the responsibility for compliance with international rules always remains with the flag State.

Moreover, if ships under EU flags are detained recurrently and end up on the 'grey list' or the 'black list' of the Paris MoU, ${ }^{106}$ each EU Member State whose ships are part of these lists has to do a root cause analysis on why this has happened. ${ }^{107}$ Following the analysis, EU flag States must produce an action plan on how to move their ships back onto the white list. This is to improve safety and, as a consequence, enable EU flagged vessels and shipowners

100 The Directive applies to ships calling at a port of an EU Member State. Directive 2009/16/EC, OJ L 131, 28.5.2009, p. 57, Art. 3 .

101 Directive 2009/16/EC, OJ L 131, 28.5.2009, p. 57, Art. 4.

102 Directive 2009/16/EC, OJ L 131, 28.5.2009, p. 57, Art. 19.

103 Directive 2009/16/EC, OJ L 131, 28.5.2009, p. 57, Art. 16 and Annex VIII.

104 Art. 5 para. 2 of Directive 2009/20/EC, OJ L 131, 28.5.2009, p. 128.

105 Art. 5 of Directive 2009/21/EC, OJ L 131, 28.5.2009, p. 132.

106 For more information on PMoU 'white', 'grey', and 'black' lists see www.parismou.org/detentions-ba nning/white-grey-and-black-list (last accessed 31 January 2020).

107 Art. 8 para. 2 of Directive 2009/21/EC, OJ L 131, 28.5.2009, p. 132. 
to continue enjoying lower risk profile, and less interruption in their operations because of a lower targeting factor in the EU Port State Control system.

The EU has progressively enlarged its Port State Control system to include almost all of the maritime safety rules. Doing so, it has remained in line with UNCLOS, whereby freedom of navigation does not apply inside a State's port. ${ }^{108}$

\subsubsection{Vessel traffic monitoring}

The other key EU legislation is the Vessel Traffic Monitoring and Information System (VTMIS) Directive, effectively implementing responsibilities incumbent on coastal States ${ }^{109}$ at EU level. Coastal states have a crucial need for accurate information regarding where a vessel is located, irrespective of its flag, in order to monitor and control traffic along their coast, and be able to intervene as early as possible in the event of an accident, to save life and mitigate any consequences. This was originally a system allowing exchange of information about ships carrying dangerous goods between all authorities involved within and between the EU MS. The system has since developed to become the Union maritime Information and Exchange System (SafeSeaNet) that now comprises all EU maritime safety legislation, directly or indirectly.

The system ensures interoperability between all national systems via a central node, hosted in EMSA, so that such information can be exchanged seamlessly 24/7, instead of having 27 different systems that are not interoperable, with limited or no informationsharing capability. This supports EU Member States for vessel safety monitoring and control, as well as any other activity pertaining to the maritime domain, such as customs, and security. This includes national Coast Guard functions, ${ }^{110}$ as well as the EU external border management at sea. ${ }^{111}$

Through the system, EMSA provides maritime authorities with the capabilities to monitor an incident or situation while it is developing. EMSA supports Member States and the Commission via the maritime surveillance system and the services providing situational awareness at sea, hosted and technically developed by EMSA. The system allows EU Member States to share pertinent information, in particular of dangerous goods carried on board, without delay.

108 See the analysis by H. Ringbom, The EU Maritime Safety Policy and International Law (Martinus Nijhoff Publishers, Leiden/Boston 2008), pp. 511-513.

109 The International Conventions define the obligations of the Contracting Parties. The implementation of coastal State (and flag and port State) obligations under IMO instruments are guided by the now mandatory IMO Implementation of International Instruments Code (III Code) [IMO Resolution A.1070(28)] and cover areas such as radio-communication services, search \& rescue services, ship's routing, ship reporting systems, vessels traffic services, and aids to navigation.

110 The system in its traffic monitoring aspects has been developed to provide Member States' authorities and Union bodies comprehensive information, a more complete maritime picture, enabling direct sharing (graphical interphase), supporting maritime situational operations in near real time.

111 See in particular the synergy between EMSA, the European Fisheries Control Agency (EFCA) and the European Border and Coast Guard Agency (EBCG). The mandate of the EBCG is defined in Regulation (EU) 2019/1896 of the European Parliament and of the Council of 13 November 2019 on the European Border and Coast Guard and repealing Regulations (EU) No 1052/2013 and (EU) 2016/1624, OJ L 295, 14.11.2019, p. 1. See in particular Art. 69 on the cooperation between EBCG, EMSA, and EFCA, including surveillance and exchange of information. 
There is no equivalent to this system at the international level. That said, SafeSeaNet does not deviate from the international rules; rather the opposite. It is an effective and efficient way to ensure that EU Member States are supported in their role as coastal States in meeting their international obligations for monitoring and control. Having only one system that is continuously used and improved, based on the operational needs of EU Member States, provides 'EU added value'. ${ }^{112}$ This is especially so when it comes to any incidents leading to oil pollution. ${ }^{113}$

For the cases where a ship finds itself in need of assistance, the EU Member States and the Commission, together with all industry stakeholders have developed a set of guidelines ${ }^{114}$ to assist national authorities and operators involved in accidents at sea. ${ }^{115}$ The main objective was to assist ships in distress and the authorities that have to respond to such incidents early on, to avoid smaller incidents turning into major accidents. The relevant provisions were placed in the VTMIS Directive, as traffic monitoring and sharing of information is 'key' in enabling monitoring and control in such situations, be it early on or at the postaccident phase. ${ }^{116}$ The main motto of the EU Operational Guidelines on places of refuge is 'no rejection without an inspection', meaning that EU Member States are obliged to assess the risks involved in an on-going incident before they decide on a request to accommodate a ship in need to assistance. ${ }^{117}$

On the request of all EU Member States and Industry stakeholders this work has been taken forward to the IMO with a draft text proposing to revise the IMO Guidelines drawing upon the experience in the EU context. ${ }^{118}$

That cooperation has been a very good exercise ${ }^{119}$ in developing a common understanding of all parties involved in such a situation and therefore ownership, especially for States in their capacity as coastal States and in fulfilling the requirement for, where possible, concerted actions. This development also illustrates how the EU can make useful contributions to work on the international level by 'exporting' tried and tested good practices.

112 See Section 1.4 above on 'Complementarity of the EU maritime safety rules'.

113 Oil spills are ranked among the major threats to the stability of the marine environment and can have longterm severe impacts on the shoreline, near-shore biological resources, and human-use resources.

114 EU Operational Guidelines on Places of Refuge, available at www.emsa.europa.eu/implementation-t asks/places-of-refuge.html (last accessed 31 January 2020).

115 Directive 2002/59/EC, OJ L 208, 5.8.2002, p. 10, as amended by Directive 2009/17/EC, OJ L 131, 28.5.2009, p. 101. Art. 20 para.3, 20a, 20b, 20c, 20 introduce an obligation for EU Member States to cooperate on this issue, by exchanging best practices related to a ship in need of assistance seeking a place of refuge (PoR), learning from the accidents, taking into account the IMO Guidelines on Places of Refuge for Ships in Need of Assistance, Resolution A.949(23) adopted on 5 December 2003.

116 EMSA's pollution response vessels may be called upon in such cases.

117 EU Operational Guidelines on Places of Refuge, available at www.emsa.europa.eu/implementation-t asks/places-of-refuge.html (last accessed 31 January 2020), at p. 30.

118 At the time of writing this chapter the IMO NCSR sub-committee has just discussed the draft text [e.g. ref MSC100/17/1 and NCSR7/13] and by and large endorsed it, with a view to updating the IMO GL via a new Assembly Resolution in 2021.

119 The EU Operational Guidelines on Places of Refuge won the Industry Innovation award at the international Salvage \& Wreck conference in London in 2016. See the 'Draft Summary Record' of the $6^{\text {th }}$ Meeting of the Cooperation Group on Places of Refuge taking place on 31 January 2017: https://ec.europa.eu/tran sparency/regexpert/index.cfm?do=groupDetail.groupDetailDoc\&id=31653\&no=2 (last accessed on 31 January 2020), at p. 1 . 


\subsubsection{Marine equipment}

Another area where the EU has used its internal market tools to ensure that maritime safety standards are effective and uniform is the market surveillance of marine equipment. EU rules on marine equipment ${ }^{120}$ aim to eliminate differences in the interpretation and implementation of international standards ${ }^{121}$ by means of a clearly identified set of requirements and uniform certification procedures. The difficulty in this case lies in the fact that equipment is placed on board ships at the time of their construction, during survey or repair all over the world.

Member States have to ensure that only compliant equipment is installed on board ships flying their flags and to issue, endorse, and renew the relevant certification of their ships. The EU market surveillance framework ${ }^{122}$ supports Member States in fulfilling their obligations, in particular as far as the assessment, notification, and monitoring of bodies authorised to carry out conformity assessment for marine equipment is concerned. The EU market surveillance framework also provides a platform for the sharing of information in relation to approved marine equipment, applications withdrawn or refused, and noncompliance of equipment.

EMSA provides technical assistance to the European Commission and Member States, in particular through the development and management of the database of EU approved marine equipment. ${ }^{123}$

As concerns control there are also provisions for situations of a transfer of ship into the flag of a Member State - Article 7 - which requires that the EU MS FS for a non-EU ship coming into its flag must during transfer inspect that the actual condition of the ship's marine equipment onboard complies with the EU Directive. If not, and the FS will or cannot consider the equipment equivalent, it has to be replaced or it can't flag in to that register. It is to be noted that this obligation is on the flag State and it is not accepted that this is done on behalf of the flag State by a recognised organisation (who may be in a conflict of interest, having certified the equipment in the first place). This is a strong control mechanism and as such effective for the preventive objective.

\subsection{Enforcement of EU rules}

\subsubsection{Enforcement at the international level}

To understand why the EU puts emphasis on correct implementation, application, and enforcement, it is important to first look at the assumption on which the international rules

120 Directive 2014/90/EU of the European Parliament and of the Council of 23 July 2014 on marine equipment and repealing Council Directive 96/98/EC, OJ L 257, 28.8.2014, p. 146.

121 International requirements for the approval of equipment to be placed aboard ships are set in the 1972 Convention on the International Regulations for Preventing Collisions at Sea (COLREG), the 1973 International Convention for the Prevention of Pollution from Ships (MARPOL), and the 1974 International Convention for the Safety of Life at Sea (SOLAS).

122 Regulation (EC) No 765/2008 of the European Parliament and of the Council of 9 July 2008 setting out the requirements for accreditation and market surveillance relating to the marketing of products and repealing Regulation (EEC) No 339/93, OJ L 218, 13.8.2008, p. 30. See in particular Chapter III.

123 MarED Product Database created pursuant to Art. 35 paragraph 4 of Directive 2014/90/EU, OJ L 257, 28.8.2014, p. 146. See www.mared.org/public_website (last accessed on 31 January 2020). 
are based. Maritime safety rules are international; however, States have to enforce these rules using the tools available in their national legal orders. The international rules also leave many aspects up to the discretion of the administration. However, as explained earlier, this may in some cases be incompatible with the internal market principles and the EU objective of harmonisation.

The IMO Audit Scheme, ${ }^{124}$ coupled with the entry into force of the III Code, has marked some progress towards a more harmonised approach to implementation and enforcement of maritime safety rules worldwide. IMO States have very different levels of capacity to give full effect to the rules. This can create distortion of fair competition. It may cost less for a shipowner to be registered under a certain flag State that does not or cannot fully enforce all the rules, while ships still compete for the same cargo and sail anywhere in the world.

The IMO Secretariat in 2018 did an analysis of the first consolidated audit summary report (CASR) based on the 18 (V)IMSAS audits in $2016 .{ }^{125}$ This analysis gave a very clear indication of major areas of concern. The results of the analysis revealed that audit findings were predominantly related to flag State issues. The five major areas identified were related to implementation (also for coastal and port State), initial actions (legislation, promulgation), enforcement (also for coastal and port State), strategy and delegation of authority, in particular lack of oversight of recognised organisations.

The shortcomings identified under the area of implementation concerned lack of implementation of policies through the issuance of national legislation and guidance; assignment of responsibilities; and, absence of guidance for the requirements that are left to the discretion of the administration. ${ }^{126}$ According to this analysis, as many as $40 \%$ of the IMO States have not promulgated in part or in full all the conventions to which they are party.

This analysis points to a fundamental issue, that of ensuring that all IMO MS actually promulgate and implement the Conventions into national law, to give them legal effect, and therefore to allow for any actions in situations where the rules have been breached. This is the underlying assumption for a level playing field for shipping internationally, which is the mantra of the IMO. However, even when 'failure' is established, neither the IMO nor its Secretariat are vested with enforcement powers.

This emphasises the critical need to further assist those IMO Member States that struggle with implementation, and whose statutory certification obligations are consequently affected. Delegation of the relevant tasks to a recognised organisation does not change that. The shipowners themselves may choose to cover this gap in legislation by actually making sure that their vessels fulfil international standards, for business reasons. However, this does not address the problem of enforcement as such.

124 IMO Assembly Resolution A.1067(28), adopted on 5 December 2013.

125 Note by IMO SECR to 5th III sub-committee, documents III 5/7 and III 5/INF.3.

126 The analysis revealed that the most frequent categories of root causes contributing to lack of effective implementation were: (i) lack of national provisions; (ii) lack of policies; (iii) lack of awareness, understanding, or interpretation of the requirements; (iv) lack of established written procedures; (v) lack of management system; (vi) lack of technical capability (trained personnel, hardware/equipment); and (vii) insufficient capacity to promulgate national legislation and to keep it updated. 


\subsubsection{Enforcement at the EU level}

At the EU level there is a need to ensure that the rules are implemented in a harmonised way in all EU Member States, taking into account the specificities of different national legal orders, and that they are enforced to ensure the harmonisation. In the EU context, there are two main types of enforcement.

The Commission may choose to initiate infringement proceedings, often on the basis of EMSA visits and inspections, among other information, against EU Member States for failure to implement EU rules. ${ }^{127}$ The first step of these infringement proceedings is a notification to the State of the suspected breach though a 'letter of formal notice'. If the State fails to respond or provide sufficient evidence addressing the suspected breach within a set period of time, the Commission will send a 'reasoned opinion' to the State. If the breach persists, the Commission can bring the case to the EU Court of Justice, which can issue a binding judgment against the relevant State, and impose pecuniary fines in case of failure of that State to comply with its judgment. ${ }^{128}$ The proceedings are public, and can also produce a counter-incentive as flag States do not wish to be seen as an offender - meaning a 'low quality flag' - to their customers. This is the first type of enforcement.

The second type of enforcement is through national law. EU rules on maritime safety adopted in the form of Directives contain a common provision that requires EU Member States to take the necessary measure to ensure that a system of effective, proportionate, and dissuasive penalties will apply nationally to any breaches. ${ }^{129}$ The enforcement of this provision on a national system of penalties may itself be subject to infringement proceedings before the EU Court of Justice, if a Member State fails to adopt and implement a national penalty system for the EU maritime safety rules.

The difference between international and EU enforcement is therefore this additional layer of supra-national enforcement that is present in the EU, through the European Court of Justice. The Commission has a dual role to play in this process. It is the guardian of the Treaties in the EU, and therefore has to ensure that obligations under EU law are complied with. At the same time, it will liaise with EU Member States directly, in order to ensure that appropriate corrective measures that are suitable for each Member State are adopted. It must also be noted that, in the case of maritime safety rules, EMSA's visits give Member States an opportunity to avoid proceedings for failure to implement EU rules. On the basis of EMSA's reports, which include recommendations for improvement, EU Member States can already adopt an action plan to address any potential breaches.

127 Art. 258 TFEU

128 Art. 260 TFEU.

129 For instance, Art. 34 of Directive 2009/16/EC, OJ L 131, 28.5.2009, p. 57. Art. 34 states: 'Member States shall lay down a system of penalties for the breach of national provisions adopted pursuant to this Directive and shall take all the measures necessary to ensure that those penalties are applied. The penalties provided for shall be effective, proportionate and dissuasive.' 


\subsection{Liability and insurance}

\subsubsection{The development of international civil liability and financial security rules}

In the area of civil liability and financial security, EU rules have followed international conventions adopted at the IMO. ${ }^{130}$ Mainly due to the advanced state of the marine insurance market, which had already been covering the needs of international maritime trade for over five centuries ${ }^{131}$ when the first international rules on civil liability entered into force in the late 1970s, EU legislation on marine liability and insurance had little to innovate on. More to the point, the cross-boundary nature of the risks involved in shipping is such that an international regime is the most effective. That said, international regulation on civil liability and marine insurance does not address the content or form of the marine insurance contract, which can vary from one jurisdiction to another. ${ }^{132}$

International conventions on civil liability and financial security were adopted, and further developed, in the aftermath of catastrophic accidents, such as the Torrey Canyon, which had raised questions about the effectiveness of national law in addressing the damages arising from international shipping activities. The same is true for EU rules. Accidents, such as the Erika (1999) and the Prestige (2002), have turned the attention of the European co-legislators and the Commission to the significant amounts needed to compensate the victims of such accidents, including compensation due for environmental damage to the adjacent coastlines. Contemplating action to ensure that damages resulting from shipping accidents would be covered to the fullest extent, the EU has embarked, since the early 2000 s, on a mission to promote ratification of the international conventions on liability and insurance. ${ }^{133}$

130 For a comprehensive list of IMO liability conventions see www.imo.org/en/OurWork/Legal/Pages/Liabi lityAndCompensation.aspx (last accessed 31 January 2020).

131 A. B. Leonard, Marine Insurance: Origins and Institutions 1300-1850 (Palgrave Macmillan 2016).

132 M. Pavliha, and A. Vincenca Padovan, 'The Law of Marine Insurance', in D. J. Attard et al. (eds), The IMLI Manual on International Maritime Law: Volume II: Shipping Law (Oxford 2016), Chapter 23; See also Legal and Documentary Aspects of the Marine Insurance Contract, Report by the UNCTAD Secretariat (1982), available at: https://unctad.org/en/PublicationsLibrary/c4isl27rev1_en.pdf (last accessed on 31 January 2020).

133 See Council Decision 2002/762/EC of 19 September $200 \overline{2}$ authorising the Member States, in the interest of the Community, to sign, ratify, or accede to the International Convention on Civil Liability for Bunker Oil Pollution Damage, 2001 ('the Bunkers Convention'), OJ L 256, 25.9. 2002, p. 7; Council Decision 2002/971/ EC of 18 November 2002 authorising the Member States, in the interest of the Community, to ratify or accede to the International Convention on Liability and Compensation for Damage in Connection with the Carriage of Hazardous and Noxious Substances by Sea, 1996 ("the HNS Convention"), OJ L 337, 13.12. 2002, p. 55; Council Decision 2004/246/EC of 2 March 2004 authorising the Member States to sign, ratify, or accede to, in the interest of the European Community, the Protocol of 2003 to the International Convention on the Establishment of an International Fund for Compensation for Oil Pollution Damage, 1992, and authorising Austria and Luxembourg, in the interest of the European Community, to accede to the underlying instruments, OJ L 78, 16.3.2004, p. 22; Council Statement by Member States on Maritime Safety (19 November 2008), including a commitment to ratify some of the above-mentioned instruments, where this was not yet done, by 1 January 2012; Council Decision (EU) 2017/769 of 25 April 2017 on the ratification and accession by Member States, in the interest of the European Union, to the Protocol of 2010 to the International Convention on Liability and Compensation for Damage in Connection with the Carriage of Hazardous and Noxious Substances by Sea ('the 2010 HNS Convention'), with the exception of the aspects related to judicial cooperation in civil matters, OJ L 115, 4.5.2017, p. 15; Council Decision (EU) 2017/770 of 25 April 2017 on the ratification and accession by Member States, in the interest of the European Union, to the Protocol of 2010 to the International Convention on Liability and Compensation for Damage in Connection with the Carriage of Hazardous and Noxious Substances by Sea, with regard to the aspects related to judicial cooperation in civil matters, OJ L 115, 4.5.2017, p. 18. 
At the same time, given that public opinion was heavily criticising States for not doing enough to address oil pollution risks from shipping, the EU saw an opportunity to lead the discussion on mitigating those risks through stricter liability and compensation rules. The European Commission launched two ambitious proposals in the early 2000s, ${ }^{134}$ whereby a compensation fund should be established in Europe for oil pollution damage, and, the liability of shipowners should be unlimited 'in the event of severe or deliberate infringement of their safety obligations', ${ }^{135}$ and always subject to mandatory insurance. The latter suggestion is the only one that is currently reflected in EU legislation. ${ }^{136}$ However, the pressure on Member States to take further action in the face of serious shipping accidents resulted in a number of amendments to existing international Conventions concerning liability and compensation. Prominent examples of the EU's successful efforts at IMO are the 2002 Protocol to the Athens Convention relating to the Carriage of Passengers and their Luggage by Sea, which is the only IMO convention to which the EU is a party itself, ${ }^{137}$ and the 2003 Protocol establishing an International Oil Pollution Compensation (IOPC) Supplementary Fund, which has raised the amount of compensation available for oil spills to 1 billion dollars.

\subsubsection{EU framework on liability and insurance}

In light of this background, the EU's policy on liability and financial security for maritime claims is premised on the following three principles: (a) strict liability of the shipowner, (b) mandatory insurance for maritime claims, and (c) prompt, adequate and effective compensation.

Strict liability of the operator in shipping is well established in the IMO liability conventions, with a reversed burden of proof, whereby the operator is responsible for contesting his liability for any third party damages arising out of the operation of a ship. Strict liability makes fault irrelevant. However, in shipping, strict liability has been agreed on the condition that the operator is always able to limit his liability. Limitation of liability applies unless the injured party proves fault on the part of the operator, consisting of a personal action or omission, committed with intent or a particularly severe gross negligence. ${ }^{138}$

134 Proposal for a regulation of the European Parliament and of the Council on the establishment of a fund for the compensation of oil pollution damage in European waters and related measures COM (2000) 802 final, OJ C 120 E, 24.4. 2001; and Proposal for a Directive of the European Parliament and the Council on the civil liability and financial guarantees of shipowners COM(2005) 593 final, OJ C 49, 28.2. 2006.

135 On 20 December 2000 the Council of EC Transport Ministers adopted conclusions on maritime safety calling for amendments to the shipowners' liability regime.

136 Directive 2009/20/EC, OJ L 131, 28.5.2009, p. 128.

137 Council Decision 2012/22/EU of 12 December 2011 concerning the accession of the European Union to the Protocol of 2002 to the Athens Convention relating to the Carriage of Passengers and their Luggage by Sea, 1974, with the exception of Art. 10 and 11 thereof, OJ L 8, 12.01.2012, p. 1; and Council Decision 2012/23/EU of 12 December 2011 concerning the accession of the European Union to the Protocol of 2002 to the Athens Convention relating to the Carriage of Passengers and their Luggage by Sea, 1974, as regards Art. 10 and 11 thereof, OJ L $8,12.01 .2012$, p. 13. The reason for adopting two separate Council Decisions concerning the accession of the EU to the 2002 Protocol are the EU rules on jurisdiction, and recognition and enforcement of judgments established in the 'Brussels I Regulation', namely Regulation (EC) No 44/2001 on jurisdiction and the recognition and enforcement of judgments in civil and commercial matters, OJ L 12, 16.01.2001, p. 1, now repealed by Regulation (EU) No 1215/2012, OJ L 351, 20.12.2012, p. 1.

138 For a concise overview of limitation of liability in its current form see N. A. Martinez Guttierez, 'Limita- 
Another key component of the strict liability regime is the channelling of liability to the shipowner. This makes the maritime liability conventions easier to apply before national courts, and ultimately also facilitates the calculation of third party liability costs for insurance purposes.

The discussions in Council on the 2005 Commission proposal regarding shipowners' liability made it clear that additional EU rules would undermine the international regime, which had recently been revised to satisfy also come of the EU's requests, such as - for instance - the revision of the liability regime for carriers of passengers. The preparatory works of the Environmental Liability Directive (ELD) ${ }^{139}$ also reveal the EU Member States' clear position at the time in favour of giving precedence to the international maritime liability conventions, whose system is intended to provide an exclusive forum for the settlement of maritime claims.

The EU has adopted rules making insurance for maritime claims obligatory for vessels registered in an EU Member State as well as vessels calling at EU ports. ${ }^{140}$ The key to the successful adoption of Directive 2009/20/EC, in its present form, ${ }^{141}$ is that it builds exclusively on international rules. The Directive makes reference to IMO Resolution A.898(21), which encourages States to adopt mandatory insurance rules. The limits of LLMC 1996 are used to define what constitutes adequate insurance, while the definition of insurance explicitly refers to P\&I cover, or self-insurance of a similar nature. ${ }^{142}$

EU rules go further than the international rules where they allow Member States to also require vessels operating in their territorial waters to have insurance in line with the Directive. This point had been subject to criticism on the part of Member States prior to the adoption of the Directive, as it can be seen as a restriction on the right of innocent passage, which is established in UNLOS and is binding on the Union and its Member States. A compromise between the European Parliament, the Council and the Commission was reached through the current wording that makes reference to international law, while leaving it to each Member State's discretion to apply the rules of the Directive to ships operating in its territorial waters. ${ }^{143}$ A recent report by the European Commission assessing the application of the Directive notes specifically on this point that it was not possible to ascertain how Member States which have transposed this requirement into their national law implement and enforce this in practice. ${ }^{144}$

Direct action against the insurer does not form part of the Directive for marine insurance. The European Court of Justice, however, has protected the right of injured parties, including victims in shipping-related incidents, to bring an action directly against the third

tion of Liability for Maritime Claims', in D. J. Attard et al. (eds), The IMLI Manual on International Maritime Law: Volume II: Shipping Law (Oxford 2016), pp. 551-575, esp. pp. 564-567.

139 Directive 2004/35/EC of 21 April 2004 on environmental liability with regard to the prevention and remedying of environmental damage, OJ L 143, 30.4. 2004, p. 56.

140 Directive 2009/20/EC, OJ L 131, 28.5.2009, p. 128.

141 The original Commission proposal, see supra note 134, was more ambitious, and included provisions on unlimited liability of the shipowner, and a scope of applications extending further than the territorial sea.

142 See Directive 2009/20/EC, OJ L 131, 28.5.2009, p. 128, Art. 3(b).

143 Directive 2009/20/EC, OJ L 131, 28.5.2009, p. 128, Art. 4 para. 2.

$144 \operatorname{COM}(2016) 167$ final, Report from the Commission to the European Parliament and the Council on the application of Directive 2009/20/EC on the insurance of shipowners for maritime claims, of 29.3.2016, para. 4.2. 
party liability insurer of the operator, based on the EU rules on jurisdiction ('Brussels I Regulation'). ${ }^{145}$

As far as compensation is concerned, following the Commission's unsuccessful proposal for a European compensation fund for oil pollution, ${ }^{146}$ the EU has consistently followed a deferential approach to the international conventions. More recently, in the context of ships in need of assistance, the Commission has issued a report on the adequacy of existing international instruments to cover relevant damages. ${ }^{147}$ The report contains a concise overview of the existing systems offering compensation for damages arising in connection to shipping. It concludes that there is not sufficient evidence to suggest a need for additional international instruments to cover liability for such incidents, while insisting on ratification - with the relevant opt-outs ${ }^{148}$ - of the existing conventions. ${ }^{149}$

One other element in the EU's regulatory actions on liability and financial security in maritime transport that is worth noting is the pull towards a cross-sectoral level playing field when it comes to the rights of citizens vis-à-vis operators. As a result, the right of passengers to a fair compensation is largely harmonised in terms of procedural requirements across the different transport modes, including maritime. ${ }^{150}$ The obligation of operators to provide clear and adequate information on their right to compensation is also harmonised across the different modes of transport. ${ }^{151}$

By the same token, environmental liability has been tackled at EU level, through the Environmental Liability Directive (ELD) ${ }^{152}$ for all 'occupational activities' ${ }^{153}$ including transport services. The polluter pays principle is reflected in Article $191 \mathrm{TFEU}$, and the ELD is the instrument that hammers out the key definitions necessary for its implementation in the EU, such as 'environmental damage', 'preventive measures', and 'remedial measures'. Maritime transport, however, is subject to a very specific exception in the ELD, whereby the existing international maritime conventions on liability and compensation shall apply instead of the ELD whenever there is an incident falling within their scope. ${ }^{154}$

145 Case C-368/16 Assens Havn v Navigators Management (UK) Limited, Judgment of 13 July 2017, published in the electronic Reports of Cases ECLI:EU:C:2017:546, esp. para. 42.

$146 \operatorname{COM}(2005) 593$ final, OJ C 49, 28.2. 2006.

$147 \mathrm{COM}(2012) 715$ final, Report from the Commission to the European Parliament and the Council on liability and compensation for financial damages sustained by places of refuge when accommodating a ship in need of assistance, of 30.11.2012. See also the Study Commissioned by EMSA to the Scandinavian Institute of Maritime law on "Liability and Compensation with Regard to Places of Refuge" of 12.10.2004, No. EMSA/ RES/001-2004, available at: www.emsa.europa.eu/implementation-tasks/places-of-refuge/items.html?cid=316 \&id=2642 (last accessed on 31 January 2020).

148 This point concerns in particular Art. 3 para. 2 of the Nairobi Wreck Removal Convention.

$149 \operatorname{COM}(2012) 715$ final, at pp. 10-11.

150 The right for an 'advance payment' by the operator in case of death or personal injury of a passenger is common in aviation, railway, and maritime transport, see Regulation (EC) No 2027/97 on air carrier liability in respect of the carriage of passengers and their baggage by air, OJ L 285, 17.10.1997, p.1, Art. 5; Regulation (EC) No 1371/2007 on rail passengers' rights and obligations, OJ L 315, 3.12.2007, p. 14, Art. 13; Regulation (EC) No 392/2009 on the liability of carriers of passengers by sea in the event of accidents, OJ L 131, 28.5.2009, p. 24, Art. 6.

151 Directive 2009/45/EC of the European Parliament and of the Council of 6 May 2009 on safety rules and standards for passenger ships, OJ L 163, 25.6.2009, p. 1, respectively: Art. 6 in Regulation (EC) No 2027/97, Art. 29 in Regulation (EC) No 1371/2007, and Art. 7 in Regulation (EC) No 392/2009.

152 Directive 2004/35/EC, OJ L 143, 30.4. 2004, p. 56.

153 'Occupational activities' are defined in Art. 2 para. 7 of Directive 2004/35/EC, OJ L 143, 30.4. 2004, p. 56.

154 Directive 2004/35/EC Art. 4 para. 2, OJ L 143, 30.4. 2004, p. 56. 
Also, the right of shipowners to limit their liability for maritime claims in accordance with LLMC remains unaffected by the ELD. ${ }^{155}$

These two unique exemptions granted to maritime transport operators under the ELD were the result of extensive negotiations within the EU, and successful lobbying on the part of shipowners and their P\&I Clubs, who pick up the tab of shipping accidents. The main arguments in favour of the existing international conventions prevailing have been the strict liability for the shipowner and the mandatory financial security schemes that already apply through them. However, in the recent evaluation of the ELD by the European Commission, the gap between the definition of 'pollution damage' under the conventions and 'environmental damage' under the ELD was highlighted, where the former has its focus on human interests while the latter encompasses also 'pure ecological damage' including damage to biodiversity. ${ }^{156}$

\subsection{Concluding remarks}

A common criticism against the EU and the European Commission in particular, especially at the IMO, has been that it is trying to undertake unilateral regional action, of no added value compared to the international conventions. This chapter has laid down the reasons why such an argument is of no real value. Some of these points are worth reiterating in the conclusions.

EU maritime safety rules are premised in the international conventions. Any actions taken at EU level going further than the IMO conventions have been subject to long, constructive discussions in the EU institutions. EU Member States, through the Council, and the EU citizen's representatives, through the European Parliament, ultimately decide on whether to adopt these actions. It is the European Commission's prerogative to propose new actions, and in some cases this prerogative is guided by specific requests of the European Parliament, as has been the case with passenger ship safety.

Only EU Member States have a flag (ship registers) and a fleet sailing under that flag, the EU itself does not. There is no internal market for intra-EU maritime transport. As soon as a ship crosses the sea border between two EU Member States it is treated as international transport under EU law too.

It is therefore not surprising that the EU has followed international rules and prioritised implementation of international instruments over adopting separate EU rules. It has pushed for a clearer and more stringent international legal framework in the IMO and ILO, but that is done in a coordinated way and with respect to the EU Treaties, to which the Member States are parties.

The EU subjects its own rules to quality checks, and the Commission has to take action under the 'Better Regulation Guidelines' to ensure that existing legislation is fit for purpose. ${ }^{157}$ Thus, the key pieces of EU maritime safety legislation related to port, flag, and

155 Directive 2004/35/EC Art. 4 para. 3, OJ L 143, 30.4. 2004, p. 56.

156 See BIO Intelligence Service (2014), ELD Effectiveness: Scope and Exceptions, Final Report prepared for European Commission - DG Environment, pp. 170-176, available at https://ec.europa.eu/environment/legal/1 iability/pdf/BIO\%20ELD\%20Effectiveness_report.pdf (last accessed on 31 January 2020).

157 See Better Regulation Guidelines: Chapter VI-Guidelines on evaluation (including fitness checks) at https://ec.europa.eu/info/sites/info/files/better-regulation-guidelines-evaluation-fitness-checks.pdf, p. 52 (last accessed on 31 January 2020). 
coastal State activities have been subject to a 'Maritime Fitness Check' in 2018. ${ }^{158}$ This involved several independent consultants, and addressed a number of questions to the public, through an open public consultation. Targeted consultations with the relevant industry representatives and EU Member States' administrations were also part of this exercise.

The key question of the Maritime Fitness Check was whether the EU legislative acts in question had any added value compared to the international rules. The Maritime Fitness Check came to the conclusion that effective and uniform enforcement of EU rules ensures a level playing field among Member States, and protects the economy and citizens within the EU. ${ }^{159}$ The overall conclusion based on all evaluation criteria ${ }^{160}$ was that the EU maritime safety policy and legislative framework have met the expectations of EU Member States, achieving EU-wide benefits.

More to the point, the EU plays a key role in implementing and enforcing IMO rules, regulations, and standards. EU legislation mirrors international obligations, which are then enforceable through the EU legal order. The distinctive roles of flag State, as the first line of defence, port State, as the second line of defence, and coastal State, for traffic monitoring and intervention, are now interconnected and complementary in the EU. This contributes to a safe, secure, and sustainable maritime transport.

The benefit of the EU intervention also lies in the cooperation of EU Member States in finding sustainable solutions at international, EU, or regional level. This supports EU Member States in meeting their international obligations, and performing their duties in the maritime domain. In addition, cooperation in implementation ensures a level playing field across the EU.

As the EU and its Member States are dependent on maritime transport for trade, ${ }^{161}$ there need always be consideration between too stringent rules and competitiveness of the EU Member States' flagged fleet. Therefore, in view of the current geopolitical challenges, EU legislation has to remain balanced and measured, only assuming regional action when there is evidence that international rules are not sufficient.

Enforcement is ultimately the main difference of the EU legal framework on maritime safety compared to the international framework. When an EU Member State does not implement or enforce EU rules, remedies are available to protect EU citizens and businesses at EU level, apart from national remedies. There are no such possibilities at the international level.

Importantly, there is a deterrent effect inherent in this system, as operators do not wish to be associated with a poor EU safety record. EU Member States are seen as quality registers in maritime terms, because of the stringent legal framework and the dual enforcement system that is in place.

Finally, an international sector of strategic importance for world trade like maritime transport needs international rules. However, the system is built on not only agreeing

158 Commission Staff Working Document - SWD (2018) 229 final.

159 SWD (2018) 229 final, page 45.

160 The five key criteria Better Regulation identifies for the evaluation of EU legislation are: (i) relevance, (ii) effectiveness, (iii) efficiency, (iv) coherence, and (v) EU added value.

161 Close to $90 \%$ of imports and exports to and from the EU are carried by sea, see https://ec.europa.eu/tran sport/modes/maritime_en (last accessed 31 January 2020). 
such international rules at IMO, but also on promulgating, implementing, monitoring, and enforcing these rules at a national level.

The EU has challenged the perception that the international level playing field in maritime safety terms should be that of the lowest common denominator. The bar must not be set by flag States who do not live up to what they have negotiated and reflected in the international conventions; either by not ratifying them, or by not implementing a convention to which they are party and not giving effect to the ratio legis of the convention's rules and regulations. The EU has insisted on ratification and implementation of the international conventions, and has adopted legislation to ensure that these are applied effectively to all relevant shipping activities within the EU.

One commentator concluded in 2008 that the EU and its maritime safety policy is 'a "sword in the hands of the IMO", rather than a competitor to it'. ${ }^{162}$ The authors wholeheartedly agree with this conclusion and, 12 years later, at the dawn of a 'European Green Deal' ${ }^{\prime 163}$ focusing also on shipping, suggest that this remains true.

162 H. Ringbom, The EU Maritime Safety Policy and International Law (Martinus Nijhoff Publishers, Leiden/Boston 2008), p. 503.

163 The European Commission has recently announced the 'European Green Deal', a package of measures that also encompass sustainable mobility, including shipping. More information available at: https://ec.europa.eu /info/strategy/priorities-2019-2024/european-green-deal_en (last accessed 31 January 2020). 


\title{
Maritime safety from the perspective of the EEA EFTA countries
}

\author{
Milagros Varela Chouciño
}

\subsection{Introduction}

Do passengers have the same rights on board a Norwegian flagged ferry as on an EU flagged one? Are maritime incidents happening in Icelandic waters investigated in the same manner as in EU waters? Are safety requirements on Norwegian and Icelandic vessels similar to EU requirements? The answer to those three questions should be 'yes' - or at least, the same yes that one would obtain if querying whether maritime safety requirements are the same or similar between Spain and Denmark, Greece and Finland, or between any other EU Member States.

The harmonization of maritime safety legislation in Norway and Iceland with the rest of the EU Member States came about thanks to the European Economic Area (EEA) Agreement. ${ }^{1}$ This chapter provides (i) a historical background for the existence of the EEA Agreement, (ii) a summarized review of the EEA rules in the field of maritime safety, and (iii) an analysis of the role and mandate of the EFTA Surveillance Authority ('the Authority') and the European Maritime Safety Agency (EMSA) in Norway and Iceland.

\subsection{Historical context of the EEA Agreement}

The origins of the European project can be traced back to the end of World War II. Rewinding to that historical context, Europe had to rebuild itself both literally and ideologically. Post-WWII Europe found itself in a polarized world, with an east and a west axis and the iron curtain shaping itself. At the same time, this trend brought about the flourishment of supranational agreements/structures such as the GATT, ${ }^{2} \mathrm{NATO}^{3}$ and the Warsaw Pact. ${ }^{4}$ The revolutionary idea that the integration of national States could be the key to greater stability and a faster economic recovery in Europe, has its roots in this particular moment in time. ${ }^{5}$

\footnotetext{
1 Agreement between the EFTA States on the establishment of a surveillance authority and a court of justice ('EEA Agreement'), OJ L344, 31.1.1994, p.3.

2 General Agreement on Tariffs and Trade (GATT), 30 October 1947, 61 Stat. A-11, 55 U.N.T.S. 194.

3 The North Atlantic Treaty Organization (NATO). 1950. [Place of publication not identified], [publisher not identified].

4 Treaty of Friendship, Co-operation and Mutual Assistance Between the Soviet Union and Certain East European Communist Governments, (The Warsaw Pact) signed at Warsaw, 14 May 1955. [Place of publication not identified], [publisher not identified].

5 R. Baldwin, 'The Economic Logic of EFTA Membership in the EEA and the EC', (1992), EFTA Occasional Paper 41.
} 
At its origins, different views already coexisted on how far-reaching European intergovernmental cooperation should be. The first milestone for European integration was taken in 1951 when six European neighbouring countries (Belgium, France, Germany, Holland, Italy and Luxembourg) agreed to sign the Treaty of Paris, forming the European Coal and Steel Community. ${ }^{6}$ Later, in 1958, the European Economic Community (EEC) aiming for even further economic integration between those same six countries, materialized.

The Stockholm or European Free Trade Association (EFTA) Convention, ${ }^{7}$ signed in 1960 by Austria, Denmark, Norway, Portugal, Sweden, Switzerland and the United Kingdom was created as an alternative to this framework. The model of integration agreed upon by the seven countries was based on a stronger emphasis on trade and economic cooperation, with its focus set on the reduction of tariffs and the elimination of quantitative restrictions on the imports of goods.

As increased trade proved apt to contribute to the faster economic recovery of Europe, the relationship between the groups of six and seven European countries - two neighbouring trade blocks - could soon not be disregarded. Thus, as early as in 1973, different initiatives were launched to bring both blocks closer. However, it was only in January 1989, when Jacques Delors in one of his speeches before the European Parliament advanced the idea of a 'new more structured partnership, with common decision making and administrative institutions', ${ }^{8}$ that concrete actions in this direction started to be taken. Negotiations began in 1990 and came to fruition in 1992 with the execution of the EEA Agreement.

The EEA Agreement is the framework, still in force today, by which three of the EFTA countries become part of the EU's internal market ${ }^{9}$ - without fully integrating themselves as EU members. By means of the EEA Agreement, the three EEA EFTA States are bound by the same obligations and ply the same rights as EU States with regard to the four fundamental freedoms (freedom to provide services, and freedom of movement of goods, capital and persons), competition and state aid rules, horizontal provisions relevant to the four freedoms, as well as certain areas of cooperation outside the scope of the four freedoms. ${ }^{10}$

\subsection{Same-same, but different: EU internal market law vs EEA law}

There is only one internal market, however, the institutional set up created to manage the EEA Agreement established a two-pillar system, with the EU and its institutions on one side, and the EEA EFTA States and its institutions on the other. The two-pillar structure, devised mainly for supervision and judicial control, entails that the Authority and the EFTA Court monitor and solve legal disputes for the EEA EFTA States, whilst the European Commission ('the Commission') and the European Court of Justice do the appropriate for their States.

6 Those were goods which at that moment in time were undoubtedly sources of great revenue and cornerstones of the military industries, thus reducing the chances of yet another war between France and Germany.

7 Convention establishing the European Free Trade Association (Stockholm, 4 January 1960).

8 J. Delors, Address to the European Parliament on the 17 January 1989.

9 The three EEA EFTA States are Norway, Iceland and Liechtenstein. The fourth EFTA State, Switzerland, did take part in the negotiations for the EEA Agreement and signed it on 2 May 1992; however, following a referendum held on 6 December 1992, the Swiss Federal Council stopped pursuing the country's EU and EEA membership.

10 Handbook of EEA EFTA procedures for incorporating EU Acts into the EEA Agreement (2016). 
The need for the two-pillar structure stems mainly from two reasons. The first one being, that the EEA EFTA States have not transferred any surveillance or judicial review competences to the relevant EU institutions, and the second, that EEA EFTA States are, as a general rule, ${ }^{11}$ constitutionally unable to accept binding decisions made by the EU institutions directly. In order to solve those issues whilst not hampering the functioning of the EEA Agreement, certain competences and tasks have been conferred pursuant to Article 108 EEA of the EEA EFTA institutions. Cross-pillar matters, nonetheless, are not uncommon and raise challenging issues that need to be solved either by the joint bodies established between the pillars or by ad hoc agreements reached by the EEA Contracting States. ${ }^{12}$

Summarizing the process, to a large extent EU law becomes EEA law in five main stages: ${ }^{13}$

- Stage 1: Decision shaping: The EEA EFTA States contribute to EU decision shaping by participating in expert groups and conducting early assessments of EEA/EFTA comments.

- Stage 2: Start of the incorporation process: The EFTA Secretariat launches the procedure to incorporate it into the EEA Agreement, assessing it together with the expert groups and adopting a Draft Joint Committee Decision (JCD).

- Stage 3: Draft JCD to the EU pillar: Once the EEA EFTA States approve the draft Decision, the EFTA Secretariat forwards it to the EU pillar for review and approval.

- Stage 4: Incorporation of the JCD into the EEA Agreement: When both pillars have finalized their approval process, the EEA Joint Committee adopts the JCD incorporating the act.

- Stage 5: Entry into force of the JCD: Decisions normally enter into force one day after adoption in the EEA Joint Committee, unless there are constitutional requirements to be lifted. When the decisions enter into force, the annexes or protocols to the EEA Agreement are updated accordingly and the EEA EFTA States are obliged to incorporate the acts into their national legal order.

Even if the cornerstone of the EEA framework is uniformity of rules, there are some features in the EEA framework that can allow for discrepancies between the EU internal market acquis and EEA law, the main ones being:

- Incorporation of EEA Acts in the EEA Agreement:

- Even early assessments of the need for incorporation of EU rules in the EEA are conducted in practical terms, the marking of an act as relevant by the Com-

11 Iceland and Norway have dualistic legal orders, meaning that international law and domestic law are distinct, meaning that EEA regulations and directives must be transposed into national legislation before they can have effect within the domestic legal system. Liechtenstein, however, has a monistic legal order. This means that provisions of international law are considered joined with and part of the internal legal order, meaning that EEA Regulations are applicable once incorporated in the EEA Agreement, but EEA Directives must be transposed.

12 For further information see: 'The basic features of the EEA Agreement', available at: www.efta.int/eea/eea -agreement/eea-basic-features; 'The two-pillar structure of the EEA Agreement - Incorporation of new EU acts', available at: [link]; and 'How an EU act becomes an EEA act and the need for adaptations', available at: www.e fta.int/media/documents/eea/1113623-How-EU-acts-become-EEA-acts.pdf.

13 For more information, please visit: https://eealaw.efta.int/. 
mission services is not final, and the EEA EFTA States assess the relevance of the acts independently. It is not uncommon that lengthy discussion can take place if both pillars do not reach a common understanding of the EEA relevance marking (i.e. the new amendments of the EMSA Regulation are still pending an agreement on whether to be deemed EEA relevant or not, even if the Regulation has been in force for 7 years in the EU pillar ${ }^{14}$ ). There are also large differences between the EEA EFTA countries in that a number of legal acts are not relevant to Iceland and Liechtenstein for geographical or infrastructural reasons. Lastly, Liechtenstein's bilateral agreements with Switzerland can also be a reason for discrepancies.

- There are three different procedures that aim at increasing the speed of incorporation of acts in the EEA Agreement. Nevertheless, it is not uncommon that EEA acts may experience delays in being incorporated in the EEA Agreement even after being marked as EEA relevant. This is typically the case if any of the EEA EFTA States intends to negotiate adaptation texts ${ }^{15}$ (i.e. a recent example is the EU Regulation for the provision of port services ${ }^{16}$ ). Furthermore, the publication of translated acts into Norwegian and, particularly, Icelandic may delay the incorporation of an act in the EEA Agreement. ${ }^{17}$

- Incorporation of EEA law in national legislation: Delayed or incomplete incorporation of EEA law into national legislation can be experienced. In this respect, the lifting of national constitutional requirements can delay the incorporation of an EEA Act into national law, but also the legislative processes in the EEA EFTA countries can delay the adoption of national legislation (i.e. parliamentary activity reduced under certain seasons or legislative packages delayed due to upcoming elections, etc). The Authority monitors and follows-up on the transposition deficit of EEA Acts and publishes twice a year in its Scoreboard an overview over the directives and regulations the EEA States have failed to communicate as transposed on time. Furthermore, judgments of the EFTA Court, where the EEA EFTA State has been compelled to improve compliance are yet another means of encouraging compliance. An example of late and partial incorporation of an EEA Act in the field of maritime safety is the case of Norway with regard to its

14 Regulation (EU) No 100/2013 of the European Parliament and of the Council of 15 January 2013 amending Regulation (EC) No 1406/2002 establishing a European Maritime Safety Agency Text with EEA relevance, OJ L 39, 9.2.2013, pp. 30-40.

15 Adaptation texts may be agreed to EU legal Acts applicable for the EEA EFTA States. Those could be of a technical or substantial nature given particular circumstances of one of the States, be used to adapt a legal measure to the scope of the EEA Agreement, or they can seek to compensate for a deficit of EEA/EFTA participation in the EU legislative process.

16 (EU) 2017/352 of the European Parliament and of the Council of 15 February 2017 establishing a framework for the provision of port services and common rules on the financial transparency of ports (Text with EEA relevance), OJ L 57, 3.3.2017, pp. 1-18.

17 An act can only enter into force in Iceland once it has been published either in the EEA Supplement or in the Government Gazette (Stjórnartíxindi). In Norway, the entering into force of an act does not depend on its publication. 
failure to comply for 34 months ${ }^{18}$ with the EFTA court judgment on the incorrect implementation of the old Directive on Port Reception Facilities. ${ }^{19}$

- Decisions adopted are based on EEA Acts: In the absence of coordination between the two pillars, there is a risk that decisions containing exemptions or derogations adopted in the EU pillar by the Commission and in the EFTA pillar by the Authority, may differ. However, close coordination and alignment between the pillars minimizes the materialization of this risk.

Hence, EU law and EEA law are not necessarily identical, but in order to guarantee the legal certainty and the efficiency of the EEA Agreement, any implementation and interpretation gaps between the two pillars must be minimized, and, if possible, eliminated.

\subsection{EEA substantial law in the field of maritime safety}

The main text of the EEA Agreement reflects the transport policy in force at the time it entered into force, namely a historical context in which progress in maritime transport policy at EU level was slow and national regulation was preferred to EU harmonization. ${ }^{20}$ At the time of the adoption of the EEA Agreement, merely a first maritime legislative package including three Council Regulations on maritime transport had been adopted. ${ }^{21}$

The main text of the EEA Agreement refers to transport as a service in its Article 38 and contains a specific chapter (Chapter VI) on transport. The articles of Chapter VI are only applicable to rail, road and inland waterways, but Article 48 (2) stipulates that Annex XIII contains specific provisions on all modes of transport. In addition, Protocol 19 to the EEA Agreement contains specific provisions on the field of maritime transport, namely referring to the first maritime legislative package.

Annex XIII of the EEA Agreement, more specifically Part V - maritime transport, of Annex XIII and the adaptations to the acts incorporated therein, contain the substantive regulation of EEA maritime transport legislation. With regard to the application of EEA maritime transport law, it is noteworthy that most of the acts are only applicable to two of the EEA EFTA States, Norway and Iceland, since Liechtenstein, a land-locked country with no ports or ship registry falls usually outside of the application of such acts. Currently, the chapter V of Annex XIII contains 101 acts in the field of freedom to provide transport services, maritime safety and maritime security, and five additional acts that the EFTA States should take note of.

The acts incorporated in the EEA Agreement dealing with the field of maritime safety have been incorporated respecting almost full harmonization with EU maritime safety.

18 Internal Market Scoreboard, July 2019. Available at www.eftasurv.int/da/DocumentDirectAction/outp utDocument?docId=4969.

19 Directive 2000/59/EC of the European Parliament and of the Council of 27 November 2000 on port reception facilities for ship-generated waste and cargo residues, EFT L 332 at 28.12.2000, s. 81-9.

20 A. Pallis, The Common EU Maritime Transport Policy: Policy Europeanisation in the 1990s (Ashgate, Aldershot UK 2002).

21 However, as the internal market became the centre of European policies, it became clear that the circulation of goods, services, persons and capital required a competitive and efficient transport sector. Last, but not least, the number of accidents which took place in European waters during the 1990s causing serious environmental disasters and numerous losses of lives significantly increased the focus of maritime safety. 
However, there are three noticeable matters that stand out, bearing in mind the principles of EEA law:

- Three maritime safety acts are incorporated with adaptations. Whilst one of them seems to be in line with the principles of EEA law and allows for a higher degree of integration of EFTA States in the Commission's comitology, the other two can potentially undermine the aspirations of homogeneity in EEA law:

- the Commission Decision with regard to the High-Level Steering Group for SafeSeaNet, ${ }^{22}$ which specifically grants the right to the EFTA States to appoint one observer for the meetings of the group.

- the Directive on reporting formalities ${ }^{23}$ includes an adaptation text related to its Article 9 by which the EFTA States could also invoke the exemption of submission of FAL forms for certain ships. Moreover, the exemption by means of the adaptation excludes from its scope reporting formalities related to custom matters.

- the Regulation incorporating the ISM Code ${ }^{24}$ excludes from its scope, with regard to Norway, passenger ships other than: (i) ro-ro passenger ferries, and (ii) passenger ships with more than 100 passengers flying the flag of Norway, in sea areas of Class C and D as defined in Article 4 of Directive 98/18/EC.

- The Commission decisions legally based on the list of certificates and the recognition of third countries with regard to Directive 2008/106/EC of the European Parliament and of the Council of 19 November 2008 on the minimum level of training of seafarers ${ }^{25}$ have been directly incorporated in the EEA Agreement as acts. Strictly speaking, that could arguably undermine the two-pillar structure, since Commission decisions are given direct effect in the EFTA pillar without a decision being adopted by the Authority on its pillar, and if Norway and Iceland had concerns on the recognition of a new third country, those concerns could not reach the Commission. On the positive side, this mechanism ensures a total homogeneity with regard to seafarer certification of third countries.

- The acquis on common rules and standards for ship inspection and survey organizations and for the relevant activities of maritime administrations ${ }^{26}$ in force in the EFTA pillar was repealed in the EU pillar in 2009. In addition, Directive 94/57/ EC was replaced by a new legislative framework, including both a Directive and a Regulation, that among other things set out new standards for recognition of survey organizations and the possibility to impose fines for non-compliance. It is

22 Commission Decision (EU) 2016/566 of 11 April 2016 on establishing the high-level steering group for governance of the digital maritime system and services and repealing Decision 2009/584/EC, OJ L 96, 12.4.2016, p. 46.

23 Directive 2010/65/EU of the European Parliament and of the Council of 20 October 2010 on reporting formalities for ships arriving in and/or departing from ports of the Member States and repealing Directive 2002/6/ EC, OJ L 283, 29.10.2010, p. 1.

24 Regulation (EC) No 336/2006 of the European Parliament and of the Council of 15 February 2006 on the implementation of the International Safety Management Code within the Community and repealing Council Regulation (EC) No 3051/95, OJ L 64, 4.3.2006, p. 1, as amended.

25 OJ L 323, 3.12.2008, p. 33.

26 Council Directive 94/57/EC of 22 November 1994 on common rules and standards for ship inspection and survey organizations and for the relevant activities of maritime administrations, OJ No L 319, 12.12.1994, p. 20, as amended. 
a matter of concern that discrepancies in this fundamental field within maritime safety can coexist between the two pillars and that more than a decade has passed without this issue being solved.

It can, thus, be concluded that EU and EEA maritime safety legislation are currently not identical, and that both by means of adaptation texts in the EEA incorporated acts and also due to implementation delays of the EU acquis in the EEA Agreement, a legislative gap exists.

\subsection{The role of the EFTA Surveillance Authority in maritime safety}

Once substantial EEA law has been touched upon, the next natural step is to approach EEA maritime safety law from the viewpoint of its watchdog, the Authority, in order to elucidate how compliance monitoring is pursued at national level.

According to Article 108(1) of the EEA Agreement, the Authority is an independent surveillance authority which shall monitor the EEA EFTA States' fulfilment of obligations under the EEA Agreement. In conducting its surveillance tasks, the Authority has powers and applies procedures similar to those applied by the Commission. In the 'two pillar system', the Authority has a fundamental role.

In the same manner as the Commission analyses compliance in the EU States between national legislation and the European maritime transport safety framework through both requests of documentation, notifications and conformity assessments, the Authority takes charge of assessing compliance of national legislation in Norway and Iceland. The Authority is empowered to launch own-initiative cases but may also receive complaints from external parties. Furthermore, in cases of non-compliance, the Authority is empowered to bring the EEA EFTA State to the EFTA Court.

The Authority's role is key to ensuring the consistency of the EEA maritime safety policy through its monitoring tasks in the EFTA pillar. It must cooperate closely with the officials in the Commission and EMSA and establish good cooperation with the national authorities in Iceland and Norway in order to succeed in this task.

The Authority's relationship with EMSA stems from the incorporation of the EMSA Regulations in the EEA Agreement. ${ }^{27}$ However, there are some discrepancies with regard to the Commission in this field, the main one being that the Authority is not represented in the Administrative Board of EMSA, even if the EEA EFTA States are. Also, the lack of incorporation of, particularly, Regulation 100/2013 in the EEA Agreement means that there is a weaker legal basis for assistance in all core and ancillary tasks mandated to EMSA in the EFTA pillar. Still, EMSA is generally empowered to assist the Authority in the performance of its tasks. ${ }^{28}$

With regard to tasks undertaken in collaboration with EMSA, the Authority ensures the inclusion of Norway and Iceland in the natural cycle of visits and inspections and horizontal assessments that EMSA conducts. Moreover, the Authority may also request ad hoc monitoring activities outside of the normal cycle of visits planned by the Commission, for

27 Annex XIII to the EEA Agreement, point 56.o.

$28 \mathrm{cf}$. Adaptation text to Annex XIII to the EEA Agreement, 56.o. 
example the two visits conducted in relation with the implementation of Directive 97/70/ EC of 11 December 1997 setting up a harmonized safety regime for fishing vessels of 24 metres in length and over. The first visit was conducted in 2016 in Norway, and the second one took place in Iceland in 2017. ${ }^{29}$ Findings from the visits can result in the opening of own-initiative cases for failure to correctly implement or incorporate maritime safety acquis.

It is also essential that the Authority strives to maintain close cooperation and good dialogue with its colleagues in the Commission, mainly to ensure that the interpretation of the acquis is aligned across the pillars. Article 109(2) EEA stipulates that in order to ensure a uniform surveillance throughout the EEA, the Authority and the Commission shall cooperate, exchange information and consult each other on surveillance policy issues and individual cases. Even if no formal fora have been established, collaboration is fruitful and stems from ad hoc meetings but also through participation of the Authority on Commission committees on the field of maritime safety, such as the Committee of Safe Seas.

The Authority also needs to establish a good working relationship with Norway and Iceland and holds annual meetings with relevant Ministry officials in both States in order to discuss pending items or on-going open cases in the field of maritime safety. These annual meetings, informally called Package Meetings, typically take place every year in June (Iceland) and October (Norway).

\subsection{The European Maritime Safety Agency and its work in Norway and Iceland}

The waves of internal market harmonization experienced during the 1990s, where an increase in technical and/or scientific harmonization was noticeable, generated a demand for technical expertise in order to assess compliance with the EEA rules. This trend prompted a bloom of EU agencies, created as centres of expertise in different policy areas.

In the field of transport, three agencies were founded: the European Maritime Safety Agency (EMSA), the European Aviation Safety Agency (EASA) and the European Rail Agency (ERA). The three agencies have been given quasi decision-making powers, i.e. they assist the Commission or the Authority on highly technical or scientific matters by providing advice and recommendations or draft legislative proposals. Both the Commission and the Authority rely heavily on the Agencies' expertise while taking decisions. Moreover, the Agencies have tasks related to research, collecting data and carrying out horizontal analysis, but also sharing best practices. Last but not least, their role in providing specialized training is key to keeping the specialized competence in the field of transport for staff of national administrations.

The majority of these agencies started their activities in 1994 or 1995, as the EEA Agreement came into force, and thus, the main text of the EEA Agreement fails to reflect this development. Now, given the fact that EU agencies are sources of technical expertise and were set up with the final purpose of advising the Commission, or in the case of the EFTA pillar the Authority, in its tasks, particularly in its decision-making processes, their role in the two-pillar structure is crucial. Any gaps observed in the incorporation of agencies' founding regulations in the EEA Agreement, create per se a serious gap between EU

29 http://emsa.europa.eu/visits-to-member-states/harmonised-safety-regime-for-fishing-vessels.html. 
and EEA law. This gap may, in the worst cases, affect the well functioning of the internal market.

The main text of the EEA Agreement may not specifically mention the Agencies in general, nor EMSA in particular, although the adaptation text included in point 56.0 of the EEA Agreement incorporating the founding EMSA Regulation ${ }^{30}$ does include following points:

- Notwithstanding the general horizontal adaptation of Protocol 1, Member States in the context of the EMSA Regulation shall be understood to include the EFTA States.

- Public access rules contained in Regulation 1049/2001 31 apply to any documents related to the EFTA States.

- Nationals of the EFTA States enjoying their full rights as citizens may be employed by EMSA, enjoying also the same indemnities and immunities as EU citizens.

- The EFTA States shall participate fully in the Administrative Board and shall within it have the same rights and obligations as EU Member States, except for the right to vote.

- The EFTA States shall participate in the financial contribution from the EU to EMSA.

There are currently no Icelandic or Norwegian nationals employed at EMSA; nonetheless, both Norway and Iceland do have a seat in EMSA's Administrative Board and their national administrations usually participate in any trainings and workshops organized by the agency on the same standing as EU States.

\subsection{Concluding remarks}

Considering the challenges that a globalized industry, such as the maritime industry, experiences in the context of international and intercontinental competition, adding Norway and Iceland to the already powerful EU Member State family by means of the EEA Agreement strengthens the EEA shipping industry, as well as contributing to improved safety standards in European waters and ports for the benefit of its citizens, its natural resources and the environment.

A dreamer could even envisage one fine day when EEA countries stand together flagging the same flag, supporting one position and speaking the same voice, while appearing at the International Maritime Organization and before the world. A fully harmonized EEA maritime safety policy, where all EEA countries agree upon its principles, coupled with an identical implementation and interpretation of maritime safety acquis, could bring about interesting opportunities, amongst them, an appealing business case for the benefit of all

30 Regulation (EC) No 1406/2002 of the European Parliament and of the Council of 27 June 2002 establishing a European Maritime Safety Agency, OJ L 208, 5.8.2002, p. 1.

31 Regulation (EC) No 1049/2001 of the European Parliament and of the Council of 30 May 2001 regarding public access to European Parliament, Council and Commission documents EFT L 145 at 31.5.2001, s. 43-48. 
EEA industry stakeholders, and the strengthening of EEA shipping industry's competitive advantage versus its international competitors.

However, as Calderon de la Barca wrote, 'dreams themselves are only dreams', and particularly, at this stage of European integration, solving the flaws and mitigating the risks embedded in the current set-up is the first step on the way.

Crucial improvements that must be undertaken are (i) closing any legislative gaps within the EEA, ensuring that EU acquis that is relevant is implemented promptly and fully, (ii) equal monitoring of EEA States in order to ensure that all countries within the EEA adhere to the adopted acquis on equal terms, (iii) ensuring that Iceland and Norway, being two key maritime nations, can proactively influence the direction of the EEA maritime safety policy and finally (iv) finding a place for the United Kingdom, yet another historical maritime nation, within this new EEA.

Furthermore, two features of the current set-up that must be sustained and aimed at further encouraging are: (i) the empowerment of the Authority as an independent monitoring body in the EEA EFTA States must be strengthened and a fruitful working relationship with its sister organization in the EU, the Commission, strived for, and (ii) the continuous use of the expertise found in EMSA in Lisbon, as a vehicle for best practice sharing and maritime expertise for the benefit of all EEA States.

Summarizing the main arguments of this chapter, one thing stands clear as a concluding remark: Homogeneity is a key success factor for the achievement of the goals of the international collaboration model proposed by the EEA agreement and, in fact, for an optimized enjoyment of its advantages. Full harmonization of the maritime transport acquis within the EEA is essential, as an equal level playing field for all EEA States, their citizens and their business is the ultimate goal of the internal market. Anything else, and anything less, is bound to disrupt EEA maritime safety policy. 
Taylor \& Francis

Taylor \& Francis Group

http://taylorandfrancis.com 
PART II

NATIONAL PERSPECTIVE

Efforts to ensure compliance 
Taylor \& Francis

Taylor \& Francis Group

http://taylorandfrancis.com 


\title{
Maritime safety in Belgium
}

\author{
An overview of the legal framework
}

\author{
Eric Van Hooydonk
}

\subsection{Introduction}

This chapter aims to provide an insight into the formal structure of maritime safety regulation in Belgium.

Belgian law provides no generally applicable definition of the concept of maritime safety. ${ }^{1}$ In accordance with the approach of the editors, we have understood the concept of maritime safety, for the purposes of the present chapter, in a rather broad sense, as an umbrella concept for matters such as the technical safety of the ship, labour law, nautical traffic regulations, vessel traffic services, maritime security, the prevention and sanctioning of environmental pollution caused by ships, and wreck removal.

In view of this broad definition and the complexity of the decision-making framework in Belgium, we will only provide a general overview of the policy levels and statutory and regulatory sources. In other words, the aim is to offer insight into the structure of Belgian law rather than to address specific application and interpretation problems. We hope this short chapter will also provide useful information on the Belgian experience with maritime law-making in a federal state and recent maritime codification attempts. Case law will not be discussed. Given the technical and public law nature of the subject-matter, court disputes about this branch of maritime law are rather rare, for that matter (with the exception of the quite common disputes relating to the division of legislative and regulatory powers). Legal doctrine on maritime safety is hard to find as well.

\subsection{National structure for the implementation of maritime safety and security law}

The regulation of the safety of shipping has a long history in Belgium. In the sixteenth century, Antwerp was the leading seaport city in Northern Europe. The Spanish government of the then Habsburg Netherlands (i.e. present-day Belgium and Holland) conducted a campaign to introduce central maritime legislation. It comprised one of the very first national legislations on the safe equipment of seagoing vessels ever. It had to be seen against the background of the defence against piracy and privateering and the avoidance of

1 Although maritime safety is of course distinguished from ship and port security, in accordance with the terminology of IMO and EU instruments. 
the need for maritime insurance, which was initially not very favourably regarded by the authorities. $^{2}$

Belgium, which saw the light of day as a separate kingdom in 1830, initially continued to apply maritime laws and regulations dating back to the French revolutionary period. As shipping technology evolved in the nineteenth century, it created specific maritime safety rules of its own. ${ }^{3}$

Today, Belgian maritime safety policy is primarily determined by the regulations established at the level of the IMO and the EU and, within the country, by the internal division of powers between the federal (or 'national') Belgian level and the regional level. As the implementation of IMO and EU rules is entirely self-evident, it will not be specifically addressed in this chapter. ${ }^{4}$ As regards the relationship between the federal and regional regulators, the latter are, more specifically, Flanders (the Dutch-speaking northern part), Wallonia (the French-speaking southern part) and the Brussels-Capital Region (the bilingual, centrally located capital). These regions enjoy political autonomy, which they exercise by means of their own government and parliament. Each region is exclusively competent for a number of explicitly listed policy matters (which have been extended through several consecutive stages of the state reform process). ${ }^{5}$ In order to understand the Belgian federal system properly, it is important to note that it is not the result of the amalgamation of previously independent states into a new, unified state system, but, on the contrary, of the splitoff, from the pre-existing unitary state, of newly created regions, whose exclusive powers are not subordinate or superior to those of the federal (national) level.

2 Maritime policy and regulation in this period has attracted the attention of historians: see L. Sicking, Zeemacht en onmacht. Maritieme politiek in de Nederlanden 1488-1558 (De Bataafsche Leeuw, Amsterdam 1998), 336 p.; L. Sicking, Neptune and the Netherlands. State, Economy, and War at Sea in the Renaissance (Brill, Leiden/Boston 2004), $551 \mathrm{p}$.

3 For a complete overview of Belgian maritime public law at the beginning of the twentieth century, see G. Van Bladel, Éléménts de droit maritime administratif belge (Ferdinand Larcier/Augustin Challamel, Brussels/ Paris 1912), $488 \mathrm{p}$.

4 See Chapters 1 and 2 above.

5 For a discussion of the distribution of maritime competences, see E. Van Hooydonk, 'De bevoegdheidsverdeling inzake zee- en binnenvaart, waterwegen en havens na de Zesde Staatshervorming' (i.e. 'The Distribution of Competences in relation to Maritime and Inland Navigation, Waterways and Ports following the Sixth Reform of the State' (2014) Tijdschrift voor het recht van netwerkindustrieën 428-435; E. Van Hooydonk, '2. Goederenvervoer algemeen - 2.1.3. Beleidsinstellingen en regelgevers - 5. Gewestelijk' (i.e. '2. Carriage of Goods in General -2.1.3. Policy Institutions and Regulators - 5. Regional'), in Transportgids (Kluwer Editorial, Diegem), looseleaf (1996), pp. 15-208; see also M. De Decker, 'De regionalisering van de binnenvaart na de zesde staatshervorming. Enige beschouwingen', in A. Cliquet and F. Maes K. (eds), Recht door zee. Hedendaags internationaal zee-en maritiem recht (Maklu, Antwerp/Apeldoorn 2015), pp. 291-315; Reybrouck and S. Sottiaux, De federale bevoegdheden (Intersentia, Antwerpen/Cambridge 2019), 657-659, paras. 1050-1053 and 691-698, paras. 1109-1126; J. Theunis, De bevoegdheidsverdeling in het federale België. Deel 3. Openbare werken en verkeer (die Keure, Bruges 1999), 123 pp.; J. Theunis, J. and D. Van Eeckhoutte, 'Openbare werken, vervoer, verkeer en verkeersveiligheid', in B. Seutin and G. Van Haegendoren (eds), De bevoegdheden van de gewesten (die Keure, Bruges 2016), pp. 403-463. 
The regional policy competencies include maritime affairs such as ports, ${ }^{6}$ dredging in the marine access channels to ports, ${ }^{7}$ inland waterways, ${ }^{8}$ pilotage, ${ }^{9}$ aids to navigation, ${ }^{10}$ rescue at sea, ${ }^{11}$ towage at sea, ${ }^{12}$ vessel traffic services, ${ }^{13}$ traffic rules on waterways (with a number of exceptions such as the carriage of radioactive materials and explosives), ${ }^{14}$ manning and safety requirements for inland vessels (including inland vessels that are also used for noninternational voyages at sea, which is a particularly important issue for the coastal port of Zeebrugge), ${ }^{15}$ the minimum technical safety norms for the construction and maintenance of waterways, ${ }^{16}$ and all works and activities in marine areas, including dredging, which are necessary in order to exercise the aforementioned competences relating to, inter alia, waterways, ports, pilotage and vessel traffic services. ${ }^{17}$ In practice, these powers are particularly important for the Flemish Region, which is the only one situated by the sea and has important ports such as Antwerp (the second biggest in the EU), Zeebrugge, Ghent and Ostend. In Wallonia there are important inland ports mainly serving barge traffic, including Liège, where, after a long voyage on a ship canal, small coasters can moor as well. Brussels also has an inland port that can be reached by small seagoing vessels.

All maritime matters that are not explicitly entrusted to the Regions by law remain the responsibility of the Belgian federal government, which has the 'residual' competence. There is therefore no exhaustive catalogue of the latter, federal maritime safety-related powers. In fact, the centre of gravity in the regulation of maritime safety still lies in any case at the federal Belgian policy level. Although the lion's share of maritime activities is located in Flanders, a double hard core of federal policy areas has so far prevented a complete transfer of maritime policy to Flanders. The first factor is the Belgian flag, under which, owing to the attractive fiscal regime, a considerable ship tonnage is operated. The flag state management and the relevant legislation (which includes most maritime safetyrelated rules dealt with in this paper) have therefore remained Belgian. Second, the marine areas (territorial sea, continental shelf, exclusive economic zone) have also retained federal

6 Art. $6, \S 1$, X, first paragraph, $3^{\circ}$ of the Special Act of 8 August 1980 for the reform of the institutions (as amended).

7 Art. $6, \S 1$, X, first paragraph, $2^{\circ}$ of the Special Act of 8 August 1980 for the reform of the institutions (as amended).

8 Art. $6, \S 1$, X, first paragraph, $9^{\circ}$ of the Special Act of 8 August 1980 for the reform of the institutions (as amended).

9 Art. 6, $\S 1$, X, first paragraph, $9^{\circ}$ of the Special Act of 8 August 1980 for the reform of the institutions (as amended).

10 Art. $6, \S 1$, X, first paragraph, $9^{\circ}$ of the Special Act of 8 August 1980 for the reform of the institutions (as amended).

11 Art. $6, \S 1$, X, first paragraph, $9^{\circ}$ of the Special Act of 8 August 1980 for the reform of the institutions (as amended).

12 Art. 6, $\S 1$, X, first paragraph, $9^{\circ}$ of the Special Act of 8 August 1980 for the reform of the institutions (as amended).

13 Implied in Art. 6, $\S 1, \mathrm{X}$, first paragraph, $9^{\circ}$ of the Special Act of 8 August 1980 for the reform of the institutions (as amended).

14 Art. $6, \S 1$, X, first paragraph, $10^{\circ}$ of the Special Act of 8 August 1980 for the reform of the institutions (as amended).

15 Art. $6, \S 1, \mathrm{X}$, first paragraph, $11^{\circ}$ of the Special Act of 8 August 1980 for the reform of the institutions (as amended).

16 Art. $6, \S 1$, X, first paragraph, $12^{\circ}$ of the Special Act of 8 August 1980 for the reform of the institutions (as amended).

17 Art. 6, § 1, X, second paragraph, of the Special Act of 8 August 1980 for the reform of the institutions (as amended). 
Belgian status. Wallonia, which has no sea coast, does not wish to give up its participation in the management of these areas. On the other hand, it should be noted that the Flemish authorities exercise important specific functional competences in these marine areas, such as, as we have just mentioned, dredging in the access channels to the ports, pilotage, vessel traffic services and rescue at sea.

The decision-making arrangements in maritime affairs include several consultation and involvement mechanisms. For example, the regional governments must consult each other on minimum technical safety rules for the construction and maintenance of waterways. ${ }^{18}$ The regional governments and the federal government (which latter is competent) must consult each other on minimum technical safety rules for the construction and maintenance of ports. ${ }^{19}$ Consultation is also expected with a view to the planning and the coherence of the waterway network ${ }^{20}$ and the adoption of waterway traffic rules. ${ }^{21}$ Finally, the federal authority (which is competent in this matter) must involve the regional governments in drawing up the general police rules (with the exception, however, of the police rules for waterway traffic, which are regional) and the regulations on traffic and transport, as well as the technical regulations on means of transport ${ }^{22}$ (including, for example, technical safety requirements for seagoing vessels).

It has to be admitted that the exact division of competences between the federal and regional levels in shipping and port matters is quite often the subject of legal disputes. New regulations always run the risk of being challenged by another regulator or an interested third party before the Constitutional Court, the Council of State or an ordinary court. Moreover, there are clear overlaps of competence. Some rules emanating from the IMO or the EU have to be transposed as many as four times: by the federal regulator and each of the three regional regulators. The reason is that parts of these new rules often relate to an aspect of the competence of different authorities, and require an adaptation of federal as well as regional rules. This requirement, as well as the consultation and involvement procedures mentioned above, often leads to delays in decision-making. For the implementation of international or EU rules, cooperation between the competent administrations is often indispensable. This is solved by the conclusion of so-called cooperation agreements, which are in fact a form of internal treaty-making between the federal government and/or the regional authorities.

Today, there is a growing political and social awareness that the gradual reform of the Belgian state, which started in 1970 and led to the peaceful and, from that perspective, quite successful settlement of sometimes heated disputes between the language communities, has led to an overly complex constitutional system. At the time of writing, in the midst of the complex national decision-making to control the Covid-19 epidemic, there was a renewed, broad public debate on how to simplify decision-making in the country by distributing competences more homogeneously among the different levels. It is not excluded that in the future these discussions will entail changes to the set-up for maritime affairs.

18 Art. $6, \S 2,4^{\circ}$ of the Special Act of 8 August 1980 for the reform of the institutions (as amended).

19 Art. 6, § 3, $4^{\circ}$ of the Special Act of 8 August 1980 for the reform of the institutions (as amended).

20 Art. $6, \S 3$ bis, $2^{\circ}$ of the Special Act of 8 August 1980 for the reform of the institutions (as amended).

21 Art. 6, $\S 3$ bis, $6^{\circ}$ of the Special Act of 8 August 1980 for the reform of the institutions (as amended).

22 Art. $6, \S 4,3^{\circ}$ of the Special Act of 8 August 1980 for the reform of the institutions (as amended). 
As regards the state of the legislation, the Belgian and Flemish legislators and governments have in the past created a multitude of specific laws and regulations on maritime safety aspects. Recently, the Belgian and Flemish legislators have attempted to bring these isolated regulations together into a larger, comprehensive whole.

In 2019, the federal Belgian parliament adopted the Belgian Shipping Code, ${ }^{23}$ which deals with both private and public maritime and inland navigation law and which incorporates most (but not all) of the pre-existing laws on maritime safety. This Code was prepared for a long time by an official reform commission, but in the final phase underwent a number of less fortunate amendments on the initiative of the administration concerned, so that the end result is open to serious criticism. In any case, the new Code is set to enter into force, based on a phased approach. ${ }^{24}$ In what follows, we will therefore no longer refer to the laws that preceded it.

For some years now, the Flemish government has been preparing a similar codification of the shipping laws that concern regional policy areas. This so-called Flemish Shipping Decree $^{25}$ may be adopted in the course of 2020. However, this act will not replace all Flemish shipping-related legislative decrees, ${ }^{26}$ but it will deal mainly with inland navigation and the management of inland waterways.

As will be seen below, the above statutory instruments are further implemented by more technical implementing provisions adopted by the respective governments. Various royal decrees implementing the new Belgian Shipping Code are in preparation. The royal decrees adopted on the basis of the old acts will continue to apply until they are replaced. We will therefore mention a selection of these existing royal decrees below.

Finally, it should be noted that the local port authorities enjoy a large degree of autonomy. These port authorities (or the municipalities) issue regulations that may also relate to maritime safety aspects. In what follows, however, we will not elaborate on this.

\subsection{Prevention}

Almost all of the substantive regulations concerning maritime safety within the federal policy sphere of statutory nature have been incorporated in the new Belgian Shipping Code. More specifically, this code contains provisions on the measurement of ships, ${ }^{27}$ the safety of seagoing vessels, ${ }^{28}$ the power to introduce nautical traffic regulations for the territorial

23 Act of 8 May 2019 introducing the Belgian Shipping Code.

24 In principle, the Code enters into force on 1 September 2020. See Art. 141 of the Act of 8 May 2019 introducing the Belgian Shipping Code as well as the Royal Decree of 6 April 2020 on the partial entry into force of the Belgian Maritime Code.

25 In the hierarchy of norms, a regional legislative 'Decree' (Dutch 'decreet', French 'décret', in Brussels 'ordonnantie' or 'ordonnance') operates at the same level as a federal Act of Parliament (called 'wet' in Dutch, and 'loi' in French). Hence, a federal statute cannot supersede a regional statute. In other words, the only difference is the level at which these instruments are enacted.

26 Such as the existing Flemish legislative decrees on ports, pilotage, and vessel traffic and rescue services.

27 Belgian Shipping Code, Book 2 (Maritime Shipping), Title 2 (Seagoing vessels), Chapter 2 (Measurement).

28 Belgian Shipping Code, Book 2 (Maritime Shipping), Title 2 (Seagoing vessels), Chapter 3 (Safety), Section. 
sea, ${ }^{29}$ the security of ships and ports, ${ }^{30}$ the prevention of pollution from ships ${ }^{31}$ and places of refuge. ${ }^{32}$ However, the legislation concerning the implementation of the Maritime Labour Convention $^{33}$ has not been integrated into the Belgian Shipping Code. ${ }^{34}$

Specific royal decrees implementing laws preceding the Belgian Shipping Code regulate matters such as technical safety requirements for ships, ${ }^{35}$ measurement of ships,${ }^{36}$ certificates of competency for seafarers, ${ }^{37}$ working time on board ships, ${ }^{38}$ medical assistance on board ships, ${ }^{39}$ safety regulations and standards for passenger ships engaged on domestic voyages,${ }^{40}$ regulations for passenger ships not engaged in international voyages and operating exclusively within a restricted coastal shipping area, ${ }^{41}$ an inspection system for the safe operation of ro-ro passenger ships and high-speed passenger ships on regular services, ${ }^{42}$ specific stability requirements for ro-ro passenger ships ${ }^{43}$ inland waterway vessels also used for non-international sea voyages, ${ }^{44}$ the implementation of the Convention on the International Regulations for Preventing Collisions at Sea, $1972,{ }^{45}$ the police and shipping regulations for the Belgian territorial sea, the ports and the beaches of the Belgian coast, ${ }^{46}$

29 Belgian Shipping Code, Book 2 (Maritime Shipping), Title 5 (Sea and ports), Chapter 1 (General provisions).

30 Belgian Shipping Code, Book 2 (Maritime Shipping), Title 5 (Sea and ports), Chapter 2 (Security).

31 Belgian Shipping Code, Book 2 (Maritime Shipping), Title 5 (Sea and ports), Chapter 3 (Prevention of pollution from ships).

32 Belgian Shipping Code, Book 2 (Maritime Shipping), Title 7 (Shipping incidents), Chapter 4 (Places of refuge).

33 Act of 13 June 2014 for the implementation and monitoring of the application of the Maritime Labour Convention, 2006.

34 There is no objective reason for this. Apparently, the explanation is that the labour ministry and the social partners are involved in the administration of the act in question.

35 Royal Decree of 20 July 1973 containing the maritime inspection regulations; Royal Decree of 25 April 2016 on the equipment of seagoing ships and the organisation of market supervision.

36 Royal Decree of 7 May 1984 implementing the Act of 12 July 1983 on ship measurement.

37 Royal Decree of 24 May 2006 on certificates of competency for seafarers.

38 Royal Decree of 12 March 2003 for the enforcement of compulsory working time for seafarers on board ships calling at Belgian ports.

39 Royal Decree of 7 January 1998 on medical assistance on board ships.

40 Royal Decree of 11 March 2002 on safety regulations and standards for passenger ships engaged on domestic voyages and amending the Royal Decree of 12 November 1981 on regulations for passenger ships not engaged on international voyages and operating exclusively within a limited coastal shipping area and the Royal Decree of 20 July 1973 containing the maritime inspection regulations.

41 Royal Decree of 12 November 1981 on regulations for passenger ships not engaged on international voyages and operating exclusively within a limited coastal shipping area.

42 Royal Decree of 28 February 2019 on an inspection system for the safe operation of ro-ro passenger ships and high-speed passenger ships on regular services.

43 Royal Decree of 21 November 2005 on specific stability requirements for ro-ro passenger ships.

44 Royal Decree of 8 March 2007 on inland waterway vessels also used for non-international sea voyages. This decree, which now concerns a regional policy matter, has been amended by the Flemish Government.

45 Royal Decree of 20 June 1977 implementing the Act of 24 November 1975 approving and implementing the Convention on the International Regulations for Preventing Collisions at Sea, 1972, its regulations and annexes.

46 Royal Decree of 4 August 1981 on police and shipping regulations for the Belgian territorial sea, the ports and the beaches of the Belgian coast. This decree, which now partly concerns a regional policy matter, has been amended by the regional governments. 
the prevention of air pollution from ships and the reduction of the sulphur content of certain marine fuels ${ }^{47}$ and the delivery of ship-generated waste and cargo residues. ${ }^{48}$

\subsection{System of control and surveillance}

Logically, the Belgian and regional authorities have their own administration. ${ }^{49}$

The Belgian Shipping Code contains provisions on the Shipping Control Service ${ }^{50}-$ the central enforcement agency within the federal Directorate-General for Shipping - the federal Shipping Police ${ }^{51}$ and the monitoring and enforcement powers of ship masters ${ }^{52}$ and various other authorities. ${ }^{53}$ It also regulates the activities of classification societies (recognised organisations) ${ }^{54}$ and maritime guards travelling on board Belgian ships to deter pirates..$^{55}$

Specific royal decrees govern the activities, within the federal Directorate-General for Shipping, of the Flag State Service (which monitors compliance with international and national laws and regulations concerning maritime labour, the safety of Belgian ships, the prevention of marine pollution caused by Belgian ships, and the manning of such ships $)^{56}$ and Port State Control. ${ }^{57}$ Supervisory powers are also included in the various shipping regulations. ${ }^{58}$ Yet other royal decrees govern the functioning of the National Authority for Maritime Security, local committees for maritime security and maritime security officers, ${ }^{59}$ and of the competent authority for the accommodation of ships in need of assistance. ${ }^{60}$

As we have mentioned before, the organisation of vessel traffic services and rescue at sea are regional matters. The Flemish Parliament has adopted extensive separate legislation on this subject. ${ }^{61}$ The provisions of the relevant legislative decree concerning the accommoda-

47 Royal Decree of 27 April 2007 on the prevention of air pollution from ships and the reduction of the sulphur content of certain marine fuels.

48 Royal Decree of 1 September 2004 on the delivery of ship-generated waste and cargo residues and amending the Royal Decree of 20 July 1973 containing the maritime inspection regulations.

49 Royal Decree of 20 November 2001 establishing the Federal Public Service Mobility and Transport; Decree of the Flemish Government of 3 June 2005 on the organisation of the Flemish administration.

50 Belgian Shipping Code, Book 4 (Enforcement), Title 2 (Establishment of infringements), Chapter 1 (The Shipping Control Service).

51 Belgian Shipping Code, Book 4 (Enforcement), Title 2 (Establishment of infringements), Chapter 2 (The Shipping Police).

52 Belgian Shipping Code, Book 4 (Enforcement), Title 2 (Establishment of infringements), Chapter 3 (Ship Masters)

53 Belgian Shipping Code, Book 4 (Enforcement), Title 2 (Establishment of infringements), Chapter 4 (Other authorities).

54 Belgian Shipping Code, Book 2 (Maritime Shipping), Title 2 (Seagoing vessels), Chapter 3 (Safety), Section 2 (Seagoing vessels).

55 Belgian Shipping Code, Book 2 (Maritime Shipping), Title 4 (People on board), Chapter 3 (Maritime security guards). See also Art. 185-207 of the Act of 2 October 2017 regulating private and particular security.

56 Royal Decree of 15 June 2011 on compliance with flag state obligations.

57 Royal Decree of 22 December 2010 on Port State Control.

58 See, for example, the Royal Decree of 4 August 1981 on police and shipping regulations for the Belgian territorial sea, the ports and the beaches of the Belgian coast.

59 Royal Decree of 21 April 2007 on maritime security.

60 Royal Decree of 26 September 2011 on the competent authority for the accommodation of ships in need of assistance.

61 Legislative decree of 16 June 2006 on vessel traffic services on maritime access routes and the organisation of the Maritime Rescue and Coordination Centre; Decree of the Flemish Government of 26 October 2007 on vessel traffic services. 
tion of ships in need of assistance in a place of refuge, which coexist with the relevant federal provisions, are an example of the complexity of the law, which inevitably results from the division of powers. As regards navigation on the waterways to the ports of Antwerp and Ghent, which are partly within the territory of the Netherlands (the Western Scheldt and the Ghent-Terneuzen Canal), Flanders has concluded a treaty with the Netherlands, which provides for joint vessel traffic management. ${ }^{62}$

With a view to coordination and consultation between the competent federal and Flemish regional services with regard to the sea, a joint Coastguard has been set up. It consists of a policy body, a consultative body and a secretariat. ${ }^{63}$

\subsection{Enforcement}

One of the important innovations of the Belgian Shipping Code is the introduction of a comprehensive and updated enforcement framework. ${ }^{64}$ Central to this is the systematic application of administrative sanctions, i.e. fines imposed by the enforcing agency itself (which belongs to the federal public service competent for maritime affairs) and not by a court of law (although an appeal to a court of law is of course possible).$^{65}$ Regarding the administrative organisation of enforcement actions, we refer to section 4 above.

\subsection{Liability}

As other EU member states, Belgium applies the main international regimes on liability for environmental damage laid down in the CLC, BUNKER and FUND Conventions. The relevant national legal provisions are incorporated in the new Belgian Shipping Code. ${ }^{66}$ This is also the case with the national legal provisions on wreck removal. ${ }^{67}$ The specific regime of limitation of the liability of the shipowner for wreck removal in the territorial sea was abolished by the Code. Further provisions on the environmental liability regime are laid down in a royal decree. ${ }^{68}$ As already mentioned, the regulation of maritime labour is excluded from the Code and continues to be governed by a separate Act. ${ }^{69}$

A quite original liability regime applies to vessel traffic services. The applicable Flemish legislative decree stipulates that the Vessel Traffic Service (VTS), the competent authority,

62 Flemish-Dutch Treaty on joint nautical management in the Scheldt area, done at Middelburg on 21 December 2005; see also the Belgo-Dutch Agreement concerning the establishment of a shore radar chain along the Western Scheldt and its mouths, done at Brussels on 29 November 1978.

63 Cooperation agreement of 8 July 2005 between the Federal State and the Flemish Region on the establishment of and cooperation in a coastguard structure.

64 Belgian Shipping Code, Book 4 (Enforcement).

65 Belgian Shipping Code, Book 4 (Enforcement), Title 1 (Penalties), Title 2 (Establishment of infringements) and Title 3 (Prosecution of infringements). See also the Act of 25 December 2016 on the imposition of administrative fines applicable in the event of infringements of the shipping laws.

66 Belgian Shipping Code, Book 2 (Maritime Shipping), Title 3 (Shipowners), Chapter 2 (Shipping), Section 1 (Compulsory insurance), and Title 7 (Shipping incidents), Chapter 3 (Pollution).

67 Belgian Shipping Code, Book 2 (Maritime Shipping), Title 7 (Shipping incidents), Chapter 6 (Wreck removal).

68 Royal Decree of 13 March 2013 implementing several International Conventions on civil liability for pollution by ships.

69 Act of 13 June 2014 for the implementation and monitoring of the application of the Maritime Labour Convention, 2006. 
the competent authority dealing with access to places of refuge and the Maritime Rescue and Coordination Centre (MRCC) may not be held liable, directly or indirectly, for damage sustained or caused by a vessel where such damage is caused by a fault of the VTS itself, of the competent authority or of the MRCC itself or of a member of its staff in the course of their duties, whether the fault lies in an act, decision or omission. These institutions may not be held liable either for damage caused by a malfunction or defect in the equipment used to send messages to vessels or from which the information on which the messages are based is obtained or which the staff members use in any way whatsoever in the performance of their duties, and which belong to or are used by the traffic management system, a competent authority or the MRCC. The relevant provision adds that the vessel shall be liable for any such damage. The staff member whose act, decision or omission has caused the damages shall not be liable unless there is intent or gross negligence on their part. However, the staff member shall be liable to pay compensation for any damage caused by their gross negligence up to a limited amount per damaging event. The Flemish Government has to determine the amounts for the various categories of staff members, without these amounts exceeding EUR 10,000 per damaging event. ${ }^{70}$ This specific liability regime is based on a similar one for pilotage, which has been in existence since 1988 and which remains, for that matter, fully applicable. ${ }^{71}$

\subsection{Concluding remarks}

Both as the seat of shipping companies and as a central European transit country with large sea and inland ports, Belgium is, despite the small surface of its territory, one of the most important maritime member states of the EU. The Belgian experience with the introduction and implementation of rules on maritime safety is specific due to the division of responsibilities between the federal and regional regulatory levels. This division of responsibilities is the result of major political compromises on the step-by-step reform of the state and, in particular, on the granting of autonomy to the regions, only one of which (Flanders) is located by the sea. While Flanders has obtained a large autonomy with respect to ports and inland navigation, key maritime policy fields such as flag state management, the management of marine areas and maritime safety regulation have largely remained part of the Belgian federal (national) domain. The transformation of Belgium into a federal state is undoubtedly an international best practice in the peaceful resolution of disputes between language communities. After more than 30 years of experience, it should also be noted, however, that the division of competences in maritime affairs is extremely complex and too often hampers the efficiency of decision-making. A simplification of this division of competence therefore seems worth exploring (in whatever direction the political decisionmakers would ultimately like to direct such an adjustment). At the same time, the Belgian experience can provide useful lessons for constitutional reform in other federal or confederal maritime countries.

70 See Art. 56-57 Legislative decree of 16 June 2006 on vessel traffic services on maritime access routes and the organisation of the Maritime Rescue and Coordination Centre.

71 Art. 3 bis of the Act of 3 November 1967 on pilotage of seagoing ships. 


\title{
Maritime safety
}

\author{
Croatian legal framework
}

Igor Vio

\subsection{Introductory remarks on maritime safety}

Many of the earliest instruments of the unification of maritime law were related to technical and other questions regarding the safety of navigation and the protection of human life at sea. Shipping has always had international characteristics and therefore the legal regulation of maritime safety as well as the problems of the seamen's profession, conditions of their life and work on board, and their social position could not be left exclusively to national legislation, but it was necessary to create international regulations in order to secure the improvement of standards on a global level. ${ }^{1}$

Safety may be defined as a condition in which crew members do not find themselves in any form of danger which may threaten their health and life, a positive feeling or a positive value where there are no negative and undesirable experiences and events as a result of accidents; or a rational insight into accidents and dangers possible in a certain working environment and safety measures which can minimize or prevent predictable dangers. ${ }^{2}$ In the shipping industry, safety is introduced and maintained by making adequate regulations. These regulations are made at international and national levels and on the levels of companies and trade unions. ${ }^{3}$ The majority of maritime accidents are caused by human factors. This means that they can be avoided if the right preventive measures are taken. These preventive measures can be taken through a system of maritime safety. The system of protection against maritime accidents can function well only as a part of a constantly coordinated whole. All parts of the system must function according to certain standards and regulations. The main parts of the system of protection against maritime accidents are: construction, building, equipping and maintaining a ship; education, professional training of the crew, taking care of their health, and filling up work posts with qualified and competent men; and services for firefighting, communications, watch keeping, pilotage, towing and salvage. If these safety components do not function, or if some of these services do not exist or do not work properly, more maritime accidents happen and more people will suffer from injuries

1 See more in: M. Biličić - I. Vio, 'Maritime Occupation and Safety’ (2000) 21 Zbornik Pravnog fakulteta u Rijeci 507-523.

2 'Safety' and 'security' do not have the two separate terms in the Croatian language so that single term 'sigurnost' which is used for both of them in national legislation sometimes causes confusion.

3 See more in: M. Učur, Pomorsko radno pravo (Maritime Labour Law), Pravni fakultet u Sveučilišta u Rijeci (Rijeka, 1997) et al. 
from various causes. ${ }^{4}$ The future of maritime occupation will also be influenced by the tendencies to develop autonomous vessels as a consequence of mechanization, automation and artificial intelligence. Naturally, this will cause important changes in the international and national maritime regulations on maritime safety, security and protection of the marine environment.

As for the maritime policy of the Republic of Croatia, having in mind its triple position as a coastal state, port state and flag state, its government has always considered that safety of navigation and pollution prevention are the most important aspects of its responsibility for the maritime sector. Due to an increased volume of maritime traffic in the Adriatic Sea, and particularly due to increased volumes of mineral oils and other dangerous and harmful substances carried by ships, the likelihood of maritime accidents in the Adriatic area has become more pronounced. It has to be emphasized that, because of the natural and geomorphologic features of the Adriatic Sea, any maritime accident involving harmful substances may result in catastrophic consequences for all countries in the region. The risks are increased because of a significant number of old and substandard ships entering the Adriatic area. At the same time, Croatian-flagged vessels, particularly vessels trading within the Croatian territorial sea, are also relatively old. Consequently, Croatian maritime authorities in coordination with other national responsible institutions and in cooperation with the authorities of the neighbouring coastal States are continuously working on improving safety, security and environmental protection.

The ports open for international transport face numerous obstacles while trying to satisfy the requirements concerning the port reception facilities for ship-generated waste and cargo residues. Accepting the fact that the human element is the most important factor contributing to the safety of navigation, particular attention is paid to the education and training of seafarers. Wishing to successfully prevent any terrorist act against the security of ships, persons or port facilities, the IMO ISPS Code has been implemented in the Republic of Croatia in due time and fully in accordance with international standards. A significant part of maritime safety and environmental protection issues relates to yachts and boats, mainly from EU countries (more than 60,000 per annum), sailing within Croatian internal waters and its territorial sea. Maritime authorities make significant efforts to ensure the safety of all persons aboard these craft and, at the same time, attention is paid to the impact of nautical tourism on the marine environment and its protection. Consequently, the Republic of Croatia will persist in assigning the highest importance to measures aimed at improving maritime safety, security and environmental protection.

\subsection{National structure for the implementation of maritime safety law in Croatia}

Traditionally, the Harbour Master's system in the territory of the Republic of Croatia has been in existence since the Austrian 'Maritime Proclamation' of 1774, while the relevant coordinating authority or harbour authorities (central governing bodies) have been in existence since 1850; for this reason the law retains the traditional identity and organization of the port authorities and central administration as the backbone of the maritime authorities

4 See more in: A.-M. Chauvel, 'Managing Safety and Quality in Shipping' in The Key to Success (The Nautical Institute, London 1997). 
and secures the status of the Republic of Croatia as a modern maritime state based on the 244-year tradition of the administrative system of port authorities. ${ }^{5}$ In addition, the proposed solutions of the Maritime and Inland Navigation Security Service, as related, are organized into a single navigational safety system of the Republic of Croatia, consisting of Harbour Master's Offices, search and rescue services at sea and a maritime and inland waterway management service. The principal public body in charge of all transport related sectors and policy (maritime transport included) is the Ministry of Maritime Affairs, Transport and Infrastructure. ${ }^{6}$

\subsubsection{Maritime Safety Directorate}

The Maritime Safety Directorate has the duty of carrying out inspections and administrative and expert activities related to navigation safety, protection of the maritime domain, search and rescue of human lives at sea, vessel traffic management, protection of marine waters and submarine areas from ship-source pollution, waterways and navigation safety objects, hydrographic activities, legal relations in navigation and marine casualties and misdemeanours on the maritime domain in Croatian internal waters, territorial sea and exclusive economic zone (protected ecological and fishery zone); and further, to carry out inspections, administrative and expert activities on the safety of Croatian vessels or maritime structures, and other activities prescribed by the Maritime Code, Act on Harbourmaster's Offices, the Maritime Domain and Seaports Act, the Act on Maritime Ship and Port Security, the Act on Public Liner Coastal Maritime Transport, the Act on the Gradual Phasing-Out of Single Hull Oil Tankers, the Hydrographic Activity Act, international agreements from the relevant fields and other regulations. It also undertakes activities in procedures before administrative courts and the High Administrative Court of the Republic of Croatia in its scope of work and performs activities assessing the impact of regulations. The Directorate coordinates the activities of other bodies and actively participates in advancing the system of monitoring and protection of the Adriatic Sea. The Directorate has to establish and maintain a quality management system. For the performance of the activities of the Maritime Safety Directorate, three specialized sectors have been established as the main functions, namely: (a) the Sector for Inspection Activities and Technical Standards with two Services distinguished within - the Service for Technical Standards of the Croatian Fleet and the Service for Navigation Safety ${ }^{7}$ and Maritime Domain Inspection; ${ }^{8}$ (b) the Sector of Administrative and Technical Expert Activities, and (c) Sector for Vessel Traffic Control and Management, Search and Rescue and Protection

5 See more in: I. Grabovac, Contemporary Croatian Maritime Law and the Maritime Code (Književni krug, Split 2005).

6 For details of its structure and functions see: Ordinance on Internal Organization of Ministry of Maritime Affairs, Transport and Infrastructure, Official Gazette No. 76/2017.

7 The TSCF Service monitors the operation of recognized organizations in activities of statutory certification of Croatian vessels or maritime structures, and monitors and analyses data in ship registers kept by recognized organizations including the statutory certificates and reports on inspections. The Service also monitors international (IMO and ILO) conventions and EU regulation from its scope of activities, and prepares plans for their application.

8 The NSMDI Service has the duties to coordinate and carry out the inspection and additional technical supervision of Croatian vessels or maritime structures, inspections of Croatian ships in foreign ports, as well as the supervision of foreign ships in Croatian ports. 
of Marine Waters. The Service for Technical Standards of the Croatian Fleet monitors the application of regulations in the field of navigation safety at sea and proposes measures for its improvement, monitors the adoption and amendments of international regulations, initiates amendments to acts and other regulations, participates in the drafting of acts and other regulations from its scope of work, and prepares plans, instructions and opinions related to the inspection of the implementation of acts and other regulations. ${ }^{9}$ It also has the duty to ensure the seaworthiness of Croatian vessels or maritime structures, carry out inspections and additional technical supervision of vessels or maritime structures, inspections of the maritime domain, ports, navigational safety facilities and port security open for domestic and international transport, and other activities of inspection in accordance with the Maritime Code, the Maritime Domain and Seaports Act, international agreements and other regulations, and coordinate and monitor the work of the harbourmaster's offices. The Service for Navigational Safety and Maritime Domain Inspection coordinates the activities of and offers support to regional units in the performance of administrative and expert activities that refer to the registration and deregistration of vessels or maritime structures, the management of registers and records of vessels or maritime structures, the issuing of seamen's discharge books and approvals for embarkation, as well as activities to determine the professional competence for the operation of boats and yachts, and keep records on: issued certificates of competency, embarkation and disembarkation of Croatian seafarers, and the registration/deregistration of Croatian seafarers in the pension and health-care system of the Republic of Croatia.

\subsubsection{The Harbourmaster's Offices}

The functions of the Harbour Master's Offices comprise carrying out vessel traffic services in internal waters and the territorial sea of the Republic of Croatia, search and rescue activities in accordance with the national plan of search and rescue of human lives at sea, navigation safety inspection activities, inspections of the maritime domain, registration and deregistration of vessels or maritime structures, keeping a register of vessels or maritime structures, determining the seaworthiness of vessels or maritime structures, registration and deregistration of boats, keeping a register of boats, and performing technical inspections of boats; as well as the issuing of seamen's discharge books and approvals for embarkation, determining the professional competence of seafarers for occupational titles in the maritime sector, registering and deregistering seafarers in the pension and health-care insurance system, issuing and keeping registers of issued authorizations for the performance of duties onboard ships, and other administrative, professional and technical activities regarding navigation safety in accordance with special acts and other regulations. ${ }^{10}$

The work of the Harbour Master's Office is managed by the Harbour Master, who has the position of Assistant Director of the Maritime Administration. He is appointed and

9 Art. 50 of the Ordinance on Internal Organization of Ministry of Maritime Affairs, Transport and Infrastructure, Official Gazette No. 76/2017.

10 The first Harbour Master's Offices Act (Official Gazette 124/1997) has been in force since 28 November 1997. This Act regulated the basic issues of the organization of maritime Harbour Master's Offices within the Ministry for Maritime Affairs, the scope of their tasks and powers in the control of navigation. The new Act was adopted in 2018 (Official Gazette 118/2018). 
dismissed by the Minister of Maritime Affairs at the proposal of the Director of Maritime Administration. Administrative and other acts within the scope of the Harbour Master's Office are performed by the Harbour Master, unless otherwise prescribed by a special law. The organizational units of the Harbour Master's Office are departments, headed by department heads. Harbour Master's Offices may have branches outside their seat, established by the Government of the Republic of Croatia. The work of the branch office is managed by the captain of the branch office appointed by the Harbour Master.

\subsection{Prevention}

\subsubsection{International Maritime Law instruments and their implementation in Croatia}

5.3.1.1 Conventions and recommendations of the International Labour Organization The Republic of Croatia became a member of the ILO in 1992, and a year before, on 25 June 1991, the Parliament of Croatia brought the Constitutional Decision on the Sovereignty and Independence of the Republic of Croatia, which contains the following provision:

The international agreements which SFRJ has signed and ratified, will be applied in the Republic of Croatia unless they are contrary to its Constitution and legal order, on the basis of the provisions of the international law on the succession of states, regarding international agreements. ${ }^{11}$

There is also a provision in the Constitution of the Republic of Croatia which envisages that international agreements which are signed, ratified and published constitute an integral part of the national legal system, with the legal force below the Constitution but above all other laws. $^{12}$

After the dissolution of the former Yugoslavia, Croatia decided that it would continue the status of state party to the numerous ILO conventions through succession. ${ }^{13}$ Thus, Croatia is bound to supervise effectively all ships registered on its territory regarding all enumerated standards and to make an official inquiry into any serious maritime accident in which these ships have been involved.

The next important step was Croatian ratification of the Maritime Labour Convention (MLC) ${ }^{14}$ By becoming a party to the MLC, Croatia has acquired an obligation to conduct a formal investigation into any serious maritime accident resulting in injury or death involving a ship flying its flag. As a rule, the final investigation report must be published. A significant role in the system of control of permanent compliance with the requirements of the MLC

11 Constitutional Decision, Art. 3 (Official Gazette No. 31/1991). An identical provision is to be found in Art. 33 of the Croatian Law on Concluding and Executing International Conventions (Official Gazette No. 53/1991).

12 The Constitution of the Republic of Croatia, Art. 134 (Official Gazette No. 56/1990).

13 By notifications on succession, since 8 October 1991 Croatia has been a party to the following ILO conventions: 8/1920, 9/1920, 16/1921, 22/1926, 23/1926, 27/1929, 32/1932, 53/1936, 56/1936, 69/1946, 73/1946, 74/1946, 91/1949, 92/1949, 109/1958 (Official Gazette - International Treaties No. 2/1994). Unlike the enumerated conventions to which Croatia became a party by succession, this ILO convention, which was probably the most important one before the adoption of the Maritime Labour Convention in 2006, is at the same time the first that the Republic of Croatia has ratified (Official Gazette - International Treaties, No. 4/1996).

14 Maritime Labour Convention (ILO 186) was adopted during the 94th session of the International Labour Conference held in Geneva from 7 to 23 February 2006. It entered into force on 20 August 2013. 
also belongs to Croatia as the flag state, which is obliged to ensure the application of the Convention in accordance with its powers. The effectiveness of the inspection will depend on the degree of cooperation achieved between the flag state of the ship and the port state to which the ship enters. As a state that has ratified the Maritime Labour Convention, Croatia undertook a duty to inspect ships entering its port even if flying the flag of a state that has not ratified it in the manner prescribed by the Convention. In this way, the possibility that ships flying the flag of a state that has not ratified the Convention enjoying a more favourable position than ships flying the flag of a state that is a party to the Convention has been successfully eliminated.

\subsubsection{Conventions and recommendations of the International Maritime Organization}

After gaining its independence in June 1991, Croatia became party to a multitude of IMO Conventions by succession from the former Yugoslavia, including the two main instruments SOLAS 1974/78, ${ }^{15}$ and MARPOL $1973 / 78,{ }^{16}$ whose role has always been to accomplish the principal goals of the IMO: safer navigation and cleaner seas. Other conventions on this 'succession list' included COLREG 1972, CSC 1972, Intervention 1969/73, FAL 1965, Loadlines 1966, Tonnage 1969 and STCW 1978.

Following the initial succession to the STCW, Croatia later adopted all successive amendments, ${ }^{17}$ and in conformity with the provisions of the revised Convention, and based on the Maritime Code, adopted Regulations on Professional Titles and Certificates of Competence of Seafarers on board Ships of the Merchant Navy of the Republic of Croatia. ${ }^{18}$

Besides becoming party by succession to the above enumerated IMO Conventions, Croatia ratified and acceded to many conventions afterwards, not only in the field of maritime safety, security and environmental protection (SAR 1979, SUA 1988, Salvage 1989, OPRC 1990, AFS 2001, BWC 2004) but also in the area of maritime law establishing liability regimes (CLC 1992, Fund 1992/2003, Bunkers 2001, PAL 2002, Wreck Removal 2007), ${ }^{19}$ and later implementing those liability regimes in the national legislation. ${ }^{20}$

15 The Republic of Croatia is a party to the Convention and the Protocol of 1978 on the basis of notification of succession and they have been in force since 8 October 1991 (Decision on the publication of multilateral international agreements to which the Republic of Croatia is a party on the basis of notification of succession, Official Gazette - International Treaties No. 1/1992). The Second SOLAS Protocol, adopted by the IMO in 1988, entered into force for the Republic of Croatia on 30 April 2000 (Decree on Accession to the Protocol of 1988, Official Gazette - International Treaties No. 13/1999 and Decision on Entry into Force of the Protocol, Official Gazette International Treaties No. 4/2000).

16 International Convention for the Prevention of Pollution from Ships, 1973, as amended by the Protocol of 1978 (MARPOL 1973/78). The Republic of Croatia is a party to the Convention and the Protocol on the basis of notification of succession and they have been force since 8 October 1991 (Decision on publication of multilateral international agreements to which the Republic of Croatia is a party on the basis of notification of succession, Official Gazette - International Treaties No. 1/1992). The 1997 Protocol amending MARPOL 1973/78 has been in force for Croatia since 4 August 2005 (Decree on the Publication of the Protocol of 1997, Official Gazette International Treaties No. 4/2005).

17 See more in: C. Young, 'Comprehensive Revision of the STCW Convention: An Overview' (1995) 26(1) Journal of Maritime Law and Commerce 1-4.

18 First edition of the Regulations was published in Official Gazette No. 103/1998, and the subsequent editions of the Regulations in Official Gazette Nos. 130/2013, 45/2014, 124/2015, and 72/2016.

19 D. Ćorić, Vessel-source Pollution of Sea: International and Domestic Regulation (Pravni fakultet Sveučilišta u Rijeci, Rijeka 2009).

20 See more on implementation of international conventions in Croatia in: G. Stanković, I. Vio, 'Croatia', in: W. Tetley (ed.), Maritime Liens and Claims, Blais (International Shipping Publications, Montreal 1994) pp. 1291-1294. 
According to the Maritime Code provisions, the flag of the Republic of Croatia is a sign of the vessel's domestic nationality, thus giving the Republic of Croatia rights and obligations concerning the supervision of all administrative, commercial and technical issues concerning the vessel, in accordance with the 1993/2000 ISM Code. Croatia did this by issuing the Regulations on Duties and Watchkeeping of Crew Members on board Seagoing Ships of the Merchant Navy of the Republic of Croatia ('Official Gazette' No.91/98). However, there is a provision in Article1 12 (6) of the Maritime Code which decrees that the technical supervision (performed by the Croatian Register of Shipping in accordance with its technical rules) also includes inquiring whether the shipping company has been properly organized to enable the safe operation of ships and protection of the environment during the ships' exploitation.

\subsubsection{Maritime Safety Legislation of the Republic of Croatia}

After Croatia had gained its independence in June 1991, it continued to apply the Maritime and Inland Navigation Act of the former Yugoslavia as its national law for the period of three years. $^{21}$

Whereas the former legislative act had regulated various aspects of both maritime and inland navigation, the first Croatian Maritime Code (adopted in 1994) ${ }^{22}$ focused exclusively on maritime law including, however, also provisions of the national law of the sea. ${ }^{23}$

Ten years after adopting the first Maritime Code, the Croatian Parliament adopted the second Maritime Code at its session on 8 December 2004, which entered into force on 29 December 2004. ${ }^{24}$ With its 1032 articles divided into 12 sections, the new Maritime Code (MC 2004) contains provisions on Croatian marine and submarine zones, safety of navigation, nationality and registration of vessels, property rights, maritime liens and mortgages, shipowners and ship operators and limitation of their liability, charter parties and other maritime contracts (including the areas of shipping, shipbuilding, maritime agency and marine insurance), collisions of ships, salvage, general average, wreck removal, liability for marine pollution, arrest and judicial sale of ships, conflict of laws, jurisdiction of Croatian national courts, and maritime offences. Basically, the MC 2004 regulated all significant legal relations related to the sea, maritime navigation and shipping, with the exception of issues concerning the maritime domain. ${ }^{25}$ It should be pointed out that the final adopted version of the 2004 Maritime Code relied substantially on the solutions of

21 The Maritime and Inland Navigation Act was passed in the Federal Assembly of Yugoslavia on 15 March 1977, and had been in force since 1 January 1978 (Official Gazette of the SFRY No. 13/1982, 30/1985, 80/1989 and 28/1990). It was adopted as a law of the Republic of Croatia by the Law on the Adoption of Federal Laws in the Fields of Maritime and Inland Navigation, which are applied in the Republic of Croatia as national laws, Official Gazette No. 53/1991. It ceased to be valid with the entry into force of the Maritime Code on 22 March 1994.

22 The first Maritime Code (MC 1994) entered into force on 22 March 1994 and was published in Official Gazette, No. 17/1994, while subsequent amendments were published in Official Gazette, Nos. 74/1994 and 43/1996.

23 See more in: I. Vio, 'Croatia and the United Nations Convention on the Law of the Sea: Five Years since the Notification of Succession’ (2000) 14 Pomorstvo (Maritime Affairs) 189-198.

24 The second Maritime Code was published in Official Gazette, No. 181/2004.

25 Maritime domain had been regulated by the provisions of the 1994 Code but during the preparations for the new legislation it was decided to have it regulated separately in the Maritime Domain and Seaports Act (Official Gazette, No.158/2003). 
the MC 1994, with appropriate amendments. The drafting of the second Code was initiated due to numerous and comprehensive necessary changes. Besides the desire to correct and supplement the omissions, inaccuracies and ambiguities of some provisions of the former Code that had been observed in the day-to-day application of that legislation, a significant part of the proposed solutions to the new Maritime Code was the result of the need to implement into Croatian maritime legislation the solutions of international unification instruments ratified by the Republic of Croatia after the first Maritime Code had entered into force. ${ }^{26}$

Beyond this necessary implementation, the 2004 Maritime Code even adopted various contemporary solutions from some international conventions that had not entered into force at the time, nor had they yet been ratified by the Republic of Croatia. ${ }^{27}$ Certain provisions were aligned with the various recommendations, guidelines and other instruments adopted by the International Maritime Organization (IMO) or the International Maritime Committee (CMI) ${ }^{28}$ It should be noted that a large part of the changes in the sections of the Maritime Code regulating maritime safety is due to the fact that the Republic of Croatia became a signatory to the Paris Memorandum of Understanding on Port State Control. ${ }^{29}$

On the other hand, some new solutions adopted by the 2004 Code were the result of the approaching membership of Croatia to NATO (provisions for the entry of foreign warships and foreign nuclear vessels) and the EU, creating the preconditions for the full harmonization of Croatian maritime legislation with the acquis communautaire. Namely, the MC 2004 harmonized the definitions of the basic terms, and provided for the authority of the Government of the Republic of Croatia and of certain Ministries to adopt ordinances, rulebooks and other by-laws of a technical nature, which were harmonized with European legislation. The new Code tightened sanctions for maritime offences, and especially for those offences that result in environmental damage.

One can conclude that the 2004 Maritime Code harmonized Croatian maritime legislation with contemporary and generally accepted solutions in international instruments and EU regulations in this field..$^{30}$ In this way, the MC 2004 provided the basic legal framework to continue the process of harmonization with EU regulations in the field of maritime affairs, by opening the possibility of adoption of various specific by-laws based on the

26 These international instruments were: the 1968 Protocol and 1979 Protocol amending the International Convention on the Unification of Certain Rules on the Bill of Lading, 1924 (Official Gazette - International Treaties, No. 3/1995), Protocols to the Athens Convention relating to the Carriage of Passengers and their Luggage by Sea, 1974, on the relevant Protocols of 1976 and 1990 (Official Gazette - International Treaties, No 2/1977), the 1992 Protocols to the CLC 1969 and the Fund Convention 1971 (Official Gazette - International Treaties, No 2/1997), the International Convention on Salvage, 1989 (Official Gazette - International Treaties, No. 9/1998), the 1995 and 1997 Amendments to the STCW Convention, and several amendments to the SOLAS and MARPOL.

27 These were, inter alia, the provisions of the 1993 International Convention on Maritime Liens and Mortgages, or those aimed at protecting the marine environment, such as Ballast Waters Convention, 2003, and the AFS Convention, 2001.

28 The CMI Uniform Rules for Sea Waybills and Rules for Electronic Bills of Lading 1990, the York-Antwerp Rules 1994, the IMO Guidelines on Places of Refuge, 2003, and the ISM Code.

29 The primary purpose of the Memorandum is to inspect foreign merchant ships entering ports of signatory states to determine whether they comply with the standards of the most important international conventions in the field of maritime safety.

30 See more on Maritime Code in: I. Vio (ed.): Pomorski zakonik Republike Hrvatske $i$ druge novine iz područja pomorskog i prometnog prava (Maritime Code of the Republic of Croatia-collected papers), HDPP (2005). 
Code. ${ }^{31}$ Since its adoption in 2004, the Maritime Code of the Republic of Croatia has been amended several times. ${ }^{32}$ During the year 2012, a Croatian legislator prepared a set of amendments regarding the MC 2004, ${ }^{33}$ having in mind an incorporation and/or adherence to EU norms. ${ }^{34}$ A major novelty is the decision of the Croatian Government to ratify the 2002 Protocol to the Athens Convention, having in mind Regulation 392/2009 concerning liability in connection to the carriage of passengers by sea. ${ }^{35}$ The last amendments were adopted by the Croatian Parliament on 8 February 2019. ${ }^{36}$ One of the main purposes of the 2019 Amendments was additional harmonization of the provisions of the Maritime Code with the acquis Communautaire. ${ }^{37}$ The other harmonization of national law was related to certain provisions of the 2007 Nairobi Wreck Removal Convention. The major changes are contained in Article 3 of the Amendments, with significant modifications of the definitions of ship, boat and yacht, also introducing entirely new concepts by determining definitions of autonomous vessel, traditional vessel and large passenger yacht. The 2019 Maritime Code Amendments Act has additionally regulated various aspects related to navigation safety, search and rescue service, inspection service, pollution response measures and pilotage. Furthermore, this Act has clarified dilemma concerning the precedence of application of the Maritime Code provisions on the judicial sale of vessels over the respective provisions of the Bankruptcy Act. The Amendments have also introduced new provisions on certain taxation issues in order to maintain the competitiveness of the Croatian shipping industry in the international market and to promote the development of the maritime economy. Thus the recent Amendments have introduced a unique centralized register of ships in electronic form with the possibility of submitting requests for entry into the register of ships in any Harbour Master's Office, and with this request it will no longer be necessary to submit numerous certificates since they will be available in electronic format, while the documents in English will no longer require a translation, except in case of doubt in the

31 See more in M. Mudrić, 'Croatian Maritime Law: Background and Recent Developments in Legislation, Case Law and Bibliography’ (2012) 29 Anuario de derecho maritimo 309-322.

32 Official Gazette, Nos. 181/2004, 76/2007, 146/2008, 61/2011, 56/2013, 26/2015.

33 The 6th Session of the Croatian Government, 2 February 2012, available at: https://vlada.gov.hr/sjednice/ 6-sjednica-vlade-republike-hrvatske/1027 (last accessed on 9 April 2020).

34 Namely: the Regulation 3577/92/EC on sea cabotage' Directive 2009/20/EC on mandatory insurance based on the LLMC regime (1976/1996), Directive 2005/35 on vessel-source pollution (as amended by the Directive 2009/123), Directive 2009/13/EC concerning the 2006 Maritime Labour Convention, Directive 2009/21 concerning the vessels' flag, Directive 2009/18 concerning the investigation of transport-related accidents - with plans to establish two independent services: (a) VTMIS service for supervision and administration of maritime transport in accordance with Directive no. 1406/2002 concerning the establishment of EMSA, and (b) Agency responsible for transport-related accidents investigation. It is important to mention that, according to the negotiated terms with the EU, the coastal line carriage between Croatian ports was reserved for Croatian ship operators until 2017, whereas the circular tourist-cruises between Croatian ports were reserved for Croatian ship operators until 2015.

35 For more see: M. Mudrić, 'Croatian Maritime Law: Recent Developments in Legislation, Case Law and Bibliography’ (2015) 32 Anuario de derecho maritimo 307-329.

36 The 2019 Maritime Code Amendments Act was published in the Official Gazette No. 17/2019 and entered into force on 28 February 2019, with the exception of certain provisions, which entered into force on 1 January 2020.

37 Namely with the Directive 2009/18/EC of the European Parliament and of the Council of 23 April 2009 laying down the basic principles for the investigation of accidents in the maritime transport sector and amending Council Directive 1999/35/EC and Directive 2002/59/EC of the European Parliament and of the Council and Directive 2000/60/EC of the European Parliament and of the Council of 23 October 2000 establishing a framework for Community action in the field of water policy. 
authenticity of the document. The minister in charge of maritime affairs will be authorized to determine the procedural provisions, the contents and the form of the entry list and all other documents and records. The 2019 Amendments introduced a new set of regulations with regard to certain issues of yachting and nautical tourism, creating preconditions for the sustainable development and easier operation of economic entities engaged in activities related to the Croatian nautical sector, increasing its competitiveness in relation to the European Union market by introducing yacht tonnage tax and encouraging the further development of nautical activity. In order to increase legal certainty, the Amendments Act regulates contracts of berth and yacht charter, as well as vessel-repair contracts related to yachts and pleasure boats, with the revision of maritime liens and claims related to the arrest of a pleasure vessel and application of provisions regulating wreck removal within the entire area of a marina. Finally, the Amendments have enabled the implementation of the seafarers' social reform facilitating income tax exemptions for seamen in international navigation, as well as regulating the status of agents in the employment of seafarers.

\subsubsection{Croatian regulations on maritime security}

Various aspects of the security of maritime ships and ports open to international traffic in the Republic of Croatia are regulated by the Ships and Port Security Act (SPSA) ${ }^{38}$ The introductory provisions of the SPSA define the scope of the Act and provide for its application to passenger ships and cargo ships on international voyages of $500 \mathrm{GT}$ and upwards, including high-speed crafts, mobile offshore drilling units for seabed exploration and exploitation if these units are registered in the appropriate registers in the Republic of Croatia, except when located in internal waters or territorial sea of the Republic of Croatia. The Act also applies to passenger vessels engaged in national navigation if sailing more than 20 nautical miles from the shoreline which persons in distress may safely access during the mid-tide, as well as the ports and port facilities serving such ships and crafts. ${ }^{39}$

The SPSA prescribes a number of obligations that the port authority or the concessionaire must fulfil in order to ensure the application and enforcement of security measures. Whether the port meets the security protection requirements prescribed by the Act is verified by the presence of the so-called statement of conformity of the port issued by the Ministry of Maritime Affairs with a validity of five years ${ }^{40}$ In accordance with provisions of the Act, the port authority or the concessionaire of a special purpose port shall establish a service responsible for the security of the port, which must be operational 24 hours a day and managed by the person responsible for the security of the port. The person responsible for the security of the port is appointed by the Director of the Port Authority or the authorized person of the entity having a concession of a special purpose port. ${ }^{41}$

Besides the Ships and Ports Security Act, another important source of security law is the Ordinance on Services of Armed Guards Protection on board Ships of Croatian Nationality, which prescribes the conditions that entities providing these services must fulfil, as well as

38 Published in Official Gazette No. 108/2017.

39 Ships and Port Security Act, Art. 5.

40 See more in: H. Jović, M. Mudrić, 'Sigurnosna i privatna zaštita morskih luka u Republici Hrvatskoj' (2018) 57 Comparative Maritime Law 205-252.

41 Ships and Port Security Act, Art. 6(3). 
the documents and information accompanying the application for authorization of embarkation of armed guards. ${ }^{42}$ In accordance with the provisions of the Ordinance, the embarkation of armed guards on ships of Croatian nationality may only be performed by domestic or foreign legal persons that have been issued a permit by the Ministry of Sea, Transport and Infrastructure, with the prior approval of the expert commission. ${ }^{43}$ The Ministry is obliged to keep official records of legal persons providing armed guards services to which it has issued a permit, and this list shall be published on the official website of the Ministry. ${ }^{44}$

It is important to emphasize that any foreign legal entity, which has been expressly authorized by a Member State of the European Union to provide armed guard services on ships of its nationality in accordance with its legislation and which has provided the Ministry with evidence of the existence of such explicit authorization, does not need the permit issued by the Croatian Ministry. ${ }^{45}$ The Ordinance also stipulates the conditions and reasons for revocation of the permit by the Ministry. ${ }^{46}$ In order to carry out armed guard services, the authorized entity should have employment contracts or other appropriate contracts concluded with at least ten persons previously determined to satisfy the requirements prescribed by the Ordinance. Besides employment contracts or other equivalent contracts, a legal entity providing these services must implement a prescribed procedure for selecting and hiring armed guards, as well as procedures for their continuous training and monitoring of their ability to perform their work properly.

In determining whether a ship meets the security requirements or not, the Croatian Register of Shipping as a recognized organization in Croatia applies the Rules for Statutory Certification of Ships, Part 31. - Ship Security.

\subsection{Control and surveillance in Croatia}

\subsubsection{Port State Control}

By ratifying the Merchant Shipping (Minimum Standards) Convention, and previously having become a party to other required international conventions, Croatia has fulfilled the conditions for joining the Paris Memorandum of Understanding on Port State Control of 26 January 1982. The Paris Memorandum demands its member states to sign and ratify a series of international conventions regulating safety of life at sea, standards of employment and shipboard conditions, and protection of the marine environment. These are, besides the above-mentioned ILO Merchant Shipping (Minimum Standards) Convention, the following IMO conventions: Loadlines 1966, Tonnage 1969, COLREG 1972, MARPOL 1973/78, SOLAS 1974/78 and STCW 1978/95. ${ }^{47}$ Besides becoming a party to the enumerated conventions, the Republic of Croatia has implemented their provisions into its national maritime law: the Maritime Code and other laws and regulations. ${ }^{48}$

42 Published in Official Gazette no. 123/2012.

43 Ordinance on Services of Armed Guards Protection on Board Ships of Croatian Nationality, Art. 3(1).

44 The list is currently unavailable.

45 Ordinance on Services of Armed Guards Protection on Board Ships of Croatian Nationality, Art. 3(5).

46 Ibid. Art. 17.

47 Official Gazette - International Treaties No. 1/1992.

48 The 1994 Maritime Code in the chapter regulating the safety of navigation prescribes the required conditions of the sea lanes in internal waters and the territorial sea of the Republic of Croatia, of its ports, ships, small 
Port State Control in Croatia is administered by the Harbour Master's Offices, which are supervised by the Ministry of Maritime Affairs, Transport and Infrastructure. The inspectors have quite broad and efficient powers, including the power to carry out inspections of vessels, impose sanctions, order detentions of the vessel, discontinuation of cargo operations, etc. In addition, if the shipowner has not removed the deficiencies as ordered by the inspector and the vessel poses a threat to the ports, or the navigable routes, or the environment, the Harbour Master shall order that the vessel be removed from her present location, or shall directly arrange for her removal at the owner's risk and expense. In any event, the inspectors may pursue misdemeanour proceedings and impose fines. ${ }^{49}$ As regards navigation, the Code adopted from the Convention on the International Regulations for Preventing Collisions at Sea (COLREG 1972) the obligation of applying the rules of navigation, as well as the signals and marks which must satisfy the conditions of safe navigation.

The Maritime Code confers an important role on the Croatian Register of Shipping, whose status, activities and organization are regulated in detail by the Croatian Register of Shipping Act, which in Article 1 states that the main function of this public institution is 'the public care regarding the protection of life and property at sea and in the internal waterways, as well as the protection of the marine environment and the environment of the internal waterways'. ${ }^{50}$ The activities of the Croatian Register of Shipping are to establish the seaworthiness and tonnage measurement of ships, of certain types of small boats and floating craft, ascertaining the safety of containers, ascertaining the adequacy of the shipowners' organization regarding safety at work and protection of the environment during the ship's exploitation, co-operation in investigating the causes of accidents at sea, as well as participation in work and fulfilment of the commitments to international organizations. The tonnage measurement and technical control while establishing the ship's seaworthiness are done by the Register according to technical rules which are in conformity with the Tonnage Convention, and comprise the provisions of the enumerated treaties (SOLAS, MARPOL, Loadlines) and other international conventions from the area of the safety of navigation which Croatia has joined. Among other things, this control applies to the safety of life at sea, safety at work and the conditions of accommodation of the crew and passengers. ${ }^{51}$

On the other hand, the Maritime Code provides that the inspectors of the safety of navigation from the Ministry of Maritime Affairs, Transport and Infrastructure also establish the ship's seaworthiness by means of an inspection control, checking whether there is a minimum number of qualified crew members on board and also whether the ship is loaded with cargo and whether the passengers are accommodated in conformity with the conditions according to the ship's documents and certificates. More detailed provisions are contained in the Regulations on the Safety of Navigation Inspection Control which, besides conforming to the international conventions (Loadlines and STCW), also represent

\footnotetext{
boats and floating craft registered in the Republic of Croatia, the crew, navigation and pilotage at sea (Official Gazette No.17/1994).

49 G. Stanković, 'The Legal 500 Country Comparative Guide', Croatia: Shipping (www.legal500.com)

50 Official Gazette No. 81/1996.

51 See more in: D. Bolanča, Hrvatsko plovidbeno upravno pravo (Croatian Navigational Administrative Law) University of Split (2015).
} 
the first Croatian regulations making possible the application of the Paris Memorandum of Understanding on Port State Control. ${ }^{52}$

\subsubsection{Vessel traffic management and information}

The National Coordination Centre for Vessel Traffic Management and Information using a technical system for vessel traffic management and information (VTMIS), or devices and equipment for the automatic identification of ships (AIS) or other equipment or devices, has a duty to carry out the activities of operational control and vessel traffic management, navigation and piloting in internal waters, the territorial sea and protected ecological and fishery zone of the Republic of Croatia, and monitor the implementation of navigation rules prescribed by international agreements, the Maritime Code, regulations adopted based on the Maritime Code and other regulations, and provide the availability of VTS services. ${ }^{53}$ It also has the function of carrying out the activities of monitoring and management through interaction with the Harbour Master's Offices. It performs inspection activities in accordance with authorizations prescribed by the Maritime Code and by-laws, provides VTS services to vessels or maritime structures in accordance with special regulations and the Rules of procedure of the VTS service, monitors the application of international and domestic regulations that refer to vessel traffic management and information, and prepares analyses and expert reports on the operation and proposes measures for their improvement. The head office of the National Coordination Centre for Vessel Traffic Management and Information (VTS Croatia) is established in Rijeka, while the other two VTS Centres are established in Split and Dubrovnik. VTS Centres provide users, vessels or maritime structures with VTSnavigation services in accordance with special regulations and the Rules of Procedure of the VTS service. Their task is also to participate in the preparation and updating of procedures, processes and operating instructions, and carry out professional training of employees. The Centres also monitor the application of international and domestic regulations that refer to vessel traffic management and information, prepare analyses and expert reports on the operation and propose measures for their improvement, and carry out other activities under the jurisdiction of the National Coordination Centre for Vessel Traffic Management and Information (VTS Croatia).

52 Official Gazette No. 34/1997.

53 The Croatian Vessel Traffic Monitoring and Information (CVTMIS) System in accordance with the requirements of Directive 2002/59/EC establishing a community vessel traffic monitoring and information system and repealing Council Directive 93/75/EEC. In accordance with international experience, this system is to encompass vessel routing and traffic separation schemes, vessel traffic monitoring and information system and emergency procedures. Functional requirements, duties and responsibilities, organizational and technical framework and project dynamics are outlined in a separate document of the CVTMIS Development Strategy. The information and communication system of the CVTMIS, being a part of the Integrated Maritime Information System, in respect of data export capabilities, has to be compatible with the specifications to be developed by the European Maritime Safety Agency, as provided for in Regulation (EC) No 1406/2002 establishing a European Maritime Safety Agency. Measures and obligations arising from the Directive 2002/59/EC which do not depend on the fully functional CVTMIS system, such as the fitting of Voyage Data Recorders on certain classes of ships, appointment of ports of refuge and designation and publication of a list of competent bodies, were implemented before the accession of Croatia to the EU (1 July 2013). 


\subsubsection{Maritime search and rescue system in Croatia}

The Maritime Rescue Coordination Centre (MRCC Rijeka) has been established to carry out the activities of the organization and the harmonization of search and rescue activities in accordance with the National Plan for the Search and Rescue of Human Lives at Sea; this involves following prescribed procedures for determining places of refuge, performing activities of the Maritime Assistance Service (MAS) in accordance with the IMO Resolution A.950 (23), carrying out activities and tasks in accordance with the Contingency Plan for Accidental Marine Pollution, performing activities of Long-Range Identification and Tracking of Ships (LRIT), carrying out activities and tasks in accordance with other regulations and monitoring the application of international and domestic regulations that refer to the indicated fields of jurisdiction. ${ }^{54}$

\subsubsection{Places of refuge}

Places of Refuge are regulated in Croatia in the Ordinance on Places of Refuge. ${ }^{55}$ This Ordinance is in accordance with the IMO Guidelines on Places of Refuge for Ships in Need of Assistance. The Ordinance prescribes the procedure for selecting and approving shelters for ships in need of assistance, competent authorities and persons responsible for selecting and approving shelters, conditions that must be met by shelters, conditions and manner of using shelters, content, and manner of adoption and amendments. It also oversees the plan for accepting a ship in distress, obligations regarding damages and costs, compulsory insurance or other financial guarantee for ships, and the procedure after the approval of the place of refuge. The Maritime Assistance Service (MAS) is established within the National Maritime Rescue Coordination Centre (MRCC) in Rijeka, based on the Plan for Acceptance of Ships in Distress. The request for approval and allocation of a place of refuge is submitted by the master of the ship in distress, which is received by the MRCC to assess its justification. Based on the proposal of the MRCC, the Deputy Minister in charge of navigation safety and protection of the sea from pollution makes a decision on allocating a place of refuge and sending the ship to a place of refuge, or a decision to reject the request for a place of refuge. The shipowner or the shipping company is obliged to reimburse all costs and all damage incurred in connection with the request for determining the place of refuge and provide assistance in accordance with this Ordinance. For the stated obligations, every ship seeking a place of refuge in the Republic of Croatia must have a valid insurance or other financial guarantee. With this Ordinance, Croatia has once again shown that complex and sensitive issues, such as the issue of places of refuge, can be resolved in a quality manner and thus fulfil a formal obligation under international and national regulations.

54 The head office of the Maritime Rescue Coordination Centre (MRCC Rijeka) was established in Rijeka. 55 Official Gazette Nos. 3/2008 and 101/2016. 


\subsection{Enforcement and liability}

\subsubsection{Croatian Coast Guard}

The Maritime Code states that the adoption of the law on the Coast Guard will determine the tasks and duties that will be performed by the Coast Guard. ${ }^{56}$ The Coast Guard Act (CGA) of the Republic of Croatia establishes the Coast Guard of the Republic of Croatia as an integral part of the Croatian Navy for the effective supervision and protection of the rights and interests of the Republic of Croatia at sea in accordance with international law and the regulations of the Republic of Croatia. ${ }^{57}$

The basic tasks and duties of the Coast Guard are the protection of sovereign rights and the implementation of the jurisdiction of the Republic of Croatia in its protected ecological fishery zone, the continental shelf and on the high seas. Part of these tasks relates to navigation safety, search and rescue, and protection of the marine environment. In the territorial sea and inland waters of the Republic of Croatia, the Coast Guard provides support to other competent state administration bodies in implementing laws and other regulations within their competence in accordance with the provisions of the Coast Guard Act. ${ }^{58}$ The Coast Guard participates in search and rescue operations at sea in accordance with the National Plan for Search and Rescue at Sea and a member of the Staff of the Search and Rescue Service, who is appointed by the Minister of Defence is a member of the Coast Guard. In cases of rescue operations prescribed by the Protection and Rescue Act, ${ }^{59}$ the Coast Guard coordinates its actions of protection and rescue of persons and property with the State Administration for Protection and Rescue. ${ }^{60}$ In accordance with international law and Croatian regulations, the Coast Guard monitors and protects the marine environment. In the event of sudden sea pollution, and extraordinary natural disasters, the Coast Guard shall act in accordance with the Contingency Plan for Marine Pollution in the Republic of Croatia A member of the Coast Guard is appointed to the Headquarters for the implementation of the said plan as a representative of the Ministry of Defence. ${ }^{61}$

\subsubsection{Maritime accident investigations}

In accordance with Directive 2009/18/EC, ${ }^{62}$ the Croatian Maritime Code in its 2019 amendments defines the terms of administrative and security investigation, prescribes when they are conducted and gives the authority to establish an independent body

56 Art. 1029 of the Maritime Code (Official Gazette, Nos. 181/2004, 76/2007, 146/2008, 61/2011, 56/2013, 26/2015 and 17/2019).

57 The new Coast Guard Act (Official Gazette, No. 125/2019) entered into force on 28 December 2019. Before that time the first CGA was in force from 1 November 2007 (Official Gazette, No. 109/2007).

58 CGA 2019, Art. 1, paragraphs 2 and 3.

59 Official Gazette, Nos. 174/2004, 79/2007, 38/2009 and 127/2010.

60 Ibid. Art. 35, para. 1.

61 For more see: P. Amižić Jelovčić, Ž. Primorac and N. Mandić, 'Pravni aspekt organizacije i djelokruga rada Obalne straže u Republici Hrvatskoj s posebnim osvrtom na Zakon o obalnoj straži’ (2010) 164 Poredbeno pomorsko pravo $372-382$.

62 Directive 2009/18 of the European Parliament and of the Council of 23 April 2009 laying down the basic principles for the investigation of maritime accidents and amending Directive 1999/35 / EC and Directive 2002/59/EC of the European Parliament and of the Council OJ L 131, 28.5.2009, p. 114. 
to conduct security investigations. An administrative investigation is conducted by the Ministry of Maritime Affairs in order to collect evidence and data for the purpose of determining misdemeanour and criminal liability. The safety investigation for the purpose of determining the cause of the accident and proposing measures to avoid maritime accidents and improve navigation safety, as an activity of interest to the Republic of Croatia, is conducted by an agency functionally and organizationally independent of all bodies responsible for maritime affairs. The agency responsible for conducting a security investigation is established by a special law, whereas the procedures and conditions for conducting a security investigation are prescribed by the Government of the Republic of Croatia which adopted the Decree on the procedure and conditions for conducting safety investigations into maritime accidents and incidents. ${ }^{63}$

The administrative investigation of a maritime accident is initiated and conducted ex officio regardless of the conduct of the safety investigation. As a rule, the administrative investigation is initiated and conducted by the competent Harbour Master's Office or the Ministry of Maritime Affairs, which appoints the head of the administrative investigation. An administrative investigation is conducted only when the basis of suspicion of committing a maritime offence in connection with the event of a maritime accident is established by a survey or inspection. It is not carried out if the competent state attorney initiates criminal prosecution for committing a criminal offence, which also includes a maritime misdemeanour in connection with a maritime accident. The administrative investigation shall be conducted in accordance with the provisions of this Ordinance and the law governing misdemeanour proceedings, insofar as that law refers to the powers of state administration bodies as authorized prosecutors. The administrative investigation of a maritime accident ends with the issuance of a misdemeanour order, the filing of an indictment or a decision not to initiate a misdemeanour prosecution. The head of the administrative investigation is obliged to compile a final report on the conducted administrative investigation.

\subsection{Liability}

After gaining its independence, Croatia became party through succession by the former Yugoslavia to some conventions regulating civil liability regimes (CLC 1969, Fund 1971, Athens Convention 1974) but later denounced them and ratified their new protocols as they were adopted by the IMO (CLC 1992, Fund 1992/2003, and PAL 2002). Croatia also became party to the LLMC (1976), Bunker (2001), Maritime Labour Convention (2006) and Nairobi Wreck Removal Convention (2007), implementing their liability and compensation regimes in the national maritime legislation. On the other hand, Croatia has never become party to Nuclear (1971), HNS (1996) and HNS Protocol (2010).

\subsubsection{Civil liability for pollution by oil transported by sea as cargo}

In this type of non-contractual liability, Croatian Maritime Code follows the provisions of the 1992 International Convention on Civil Liability for Oil Pollution Damage. In accordance with the provisions of CLC '92, the Maritime Code prescribes that a domestic or

63 Official Gazette, No. 69/2016. 
foreign ship carrying more than 2,000 tons of oil as cargo must have an insurance certificate or other financial security to cover liability for oil pollution damage. The certificate is issued by the Harbour Master's Office where the register of ships in which the ship is registered is kept, the certificate must be on board, and a copy kept in the ship's register. The legal provisions apply to damage caused by pollution in internal waters, the territorial sea and protected ecological-fishery zone of the Republic of Croatia, and to protective measures taken to prevent or reduce damage, regardless of where they are taken. The owner of a ship shall be liable for damage caused by a ship carrying oil as a bulk cargo by spilling or discharging that oil according to the principle of strict liability, unless he proves that the oil spill: (a) is a consequence of war, hostility, civil war, rebellion or force majeure, (b) arises entirely from the fact that a third party knowingly acted or failed to act with intent to cause damage, or (c) arises entirely from the act or omission of any state or other body responsible for maintaining the lighthouse, or other means to assist navigation in performing that function. The shipowner may limit his liability by establishing a limited liability fund for damages caused by oil spills or spills. ${ }^{64}$ The shipowner loses the right to limit liability if it is proved that the damage was caused by an act or omission committed by the shipowner, either with the intention of causing damage or recklessly knowing that the damage is likely to occur.

\subsubsection{Civil liability for marine pollution with bunker oil}

According to the Maritime Code, the owner of the ship shall be liable for damage caused by the ship by leakage or discharge of propellant oil if he does not prove that the leakage or discharge of propellant oil is: (a) a consequence of war, hostilities, civil war, rebellion or force majeure, (b) caused by an act or omission of a third party committed with intent to cause damage, or (c) wholly caused by the negligence or other harmful act of any state or other body responsible for the maintenance of lighthouses or other navigational aids in the performance of that function. Therefore, here too, it is a matter of strict liability. The solutions adopted in national law are in accordance with the International Convention on Civil Liability for Bunker Oil Pollution Damage from 2001. In accordance with the provisions of the BUNKER Convention, the Maritime Code stipulates that the owner of a ship with a gross tonnage greater than 1,000 entered in the Croatian Register of Ships must have insurance or other financial security to cover liability, as evidenced by a Harbour Master's Office certificate issued by the office keeping a register of ships in which the ship is entered.

\subsubsection{Civil liability for wreck removal}

The provisions of the Maritime Code apply to the extraction of wrecks and sunken objects located in the territorial sea and internal sea waters of the Republic of Croatia and to the removal of wrecks and sunken objects located in the territorial sea, internal waters and in the area of the protected ecological-fishery zone and continental shelf of the Republic of

64 The limit is calculated for each accident on the total amount of (a) 4.5 million units of special drawing rights for a ship not exceeding 5,000 tonnage units, (b) for ships over the specified tonnage, for each additional tonnage unit, 632 units of special drawing rights in excess of the amount referred to in point (a), provided that the total amount in no case exceeds the amount of $89,800,000$ units of account. 
Croatia. ${ }^{65}$ The owner is obliged to remove the wreck at his own expense, because if he does not do so he is liable for damage caused to third parties in connection with the wreck or sunken item. His liability is strict, because he is exonerated from liability only if he proves: (1) that the damage originates from some unpredictable cause that was outside the wreck or sunken object and which could not be prevented, avoided or eliminated, (2) that the damage was entirely caused by an act or omission of a third party person committed to the intention of causing damage, (3) that the damage was entirely caused by the harmful action of the competent public body. The owner is fully or partially released from liability if he proves that the damage was caused in whole or in part by an act or omission of the injured party committed with the intent to cause damage or through negligence. ${ }^{66} \mathrm{~A}$ wreck or sunken item that is not removed within two years from the day when it sank or ran aground becomes the property of the Republic of Croatia. It is also the property of the Republic of Croatia if the wreck or sunken item in nature represents money, valuables, archival material of general cultural interest and any other thing of value for which the owner of Croatian nationality can no longer be determined. Any person who acquires direct knowledge of the existence of a wreck or sunken item in a particular place is obliged to inform the competent Harbour Master's Office. It is forbidden to touch, move or relocate a wreck, or in any other way change its existing condition.

The competent Harbour Master's Office may remove the wreck (sunken item) which has become the property of the Republic of Croatia, and the Ministry of Maritime Affairs may sell it at public auction and pay all reasonable costs and fees related to extraction, advertising, storage and sale from the amount obtained by sale. The Maritime Code also regulates mandatory removal of wrecks and sunken items. The master of the maritime facility and the authorized person are obliged to inform the nearest Harbour Master's Office immediately when the maritime facility participated in the maritime accident in which the wreck occurred. The competent Harbour Master's Office may take measures to remove a wreck or sunken object that poses a danger and these measures must be proportionate to the danger. The owner shall be liable for the costs of locating, marking and removing the wreck, unless he proves that the maritime accident in which the wreck occurred is: (a) the result of war, hostilities, civil war, rebellion or force majeure; (b) wholly caused by an act or omission of a third party committed with intent to cause damage; or (c) entirely caused by negligence or other harmful action of the competent public body responsible for the maintenance of lights or other means of assistance to navigation in the performance of that function. The owner shall not be liable for the said costs, if the liability for such costs is in conflict with: (a) the applicable international convention or the provisions of the Maritime Code governing civil liability for damage due to oil pollution; (b) the applicable international convention or provisions of the Civil Code on civil liability for damage caused by oil pollution; or (c) the applicable international convention or domestic regulations governing civil liability for nuclear damage. In this matter, the Croatian legislator shall follow the decisions of the International Convention on the Removal of Wrecks (WRC 2007). One of the envisaged solutions is that the owner of a vessel with a gross tonnage of 300 tons or more entered in

65 V. Skorupan Wollf: 'Vađenje potonulih stvari u hrvatskom pravu de lege lata i de lege desiderata' (2012) 5-6 Zbornik Pravnog fakulteta u Zagrebu 700.

66 See more in: V. Skorupan Wolff - R. Petrinović: 'Međunarodna konvencija o uklanjanju podrtina' (2008) 162 Poredbeno pomorsko pravo 109-134. 
the Croatian Register of Ships must have insurance or other financial security to cover the costs of locating, marking and removing the wreck to the amount of general liability. The insurance or financial security certificate must be written in Croatian or English, and must be located on the vessel.

\subsection{Concluding remarks}

Taking into account the present status as well as the foreseeable overall development of the Republic of Croatia and the neighbouring countries, the Croatian Government in its Maritime Transport Strategy has set the following as the basic goals in the area of maritime safety, security and environmental protection: to increase the general level of safety on board Croatian-flagged ships and their inclusion in the White list of the Paris MOU, recognition of the Croatian Register of Shipping in accordance with Directive $94 / 57^{67}$ as amended, introduction of the Vessel Traffic Monitoring and Information System (CVTMIS), protection and maintenance of clean waters in the Adriatic Sea, installation of port waste reception facilities as required by MARPOL 73/78, as amended, and Directive 2000/5968; as well as improvement of the maritime education and training system of seafarers, continuous improvement of standards of living and work on board ships, increasing of the level of environmental protection in ports, in accordance with the highest practical standards, strengthening of administrative capabilities and operational effectiveness, particularly in respect of pollution prevention, pollution response and search and rescue operations, and the harmonization of Croatian legislation referring to shipping with the relevant part of Acquis Communautaire. In order to achieve these goals the Ministry of Maritime Affairs has decided to apply the following measures: to promote renewal of outdated vessels, applying a more rigorous survey and inspection procedure while inspecting Croatian-flagged ship, both in Croatian ports and abroad (based on the extended authorization granted to Port State Control inspectors), strict implementation of the requirements set out in the Maritime Safety Inspection Regulation, to perform additional hydrographical surveys and renew aids to navigation covering approaching routes to traffic separation schemes and other implemented routing measures, with digitalization of analogue hydrographical originals and establishment of the database of digital information as the main objectives, as well as the introduction of multi-beam echo-sounder hydrographical survey technique and its implementation on research ships of the Croatian Hydrographical Institute, all accompanied by the creation of a spatial database management system.

It is important to emphasize that, during the period before it became a member of the EU in July 2013, Croatia undertook to fulfil the requirements of the National Legislative Alignment Programme in the maritime transport sector with an obligation to define and implement the rules and regulations relating to places of refuge, in accordance with Maritime Code and Directive 2002/59/EC; and also to complete the measurements of wave heights necessary to define sea areas in accordance with Directives 2003/25/EC ${ }^{69}$

67 Council Directive 94/57/EC of 22 November 1994 on common rules and standards for ship inspection and survey organizations and for the relevant activities of maritime administrations, OJ L 319, 12.12.1994, p. 20.

68 Directive 2000/59/EC of the European Parliament and of the Council of 27 November 2000 on port reception facilities for ship-generated waste and cargo residues - Commission declaration OJ L 332, 28.12.2000, p. 81.

69 OJ L 123, 17.5.2003, p. 22. 
and 2003/24/EC, ${ }^{70}$ which are crossed by ro-ro passenger ships operating regular services to or from Croatian ports in these areas, in order to implement the requirements of Directive 2003/25/EC on the specific stability requirements for ro-ro passenger ships. The requirements also included an obligation to develop a Code for conducting marine accident investigations in accordance with the requirements of IMO Resolution A.849 (20) 'Code for the Investigation of Marine Casualties and Incidents', as amended by IMO Resolution A.884 (21) 'Amendments to the Code for the Investigation of Marine Casualties and Incidents' and Council Directive 1999/35/EC on a system of mandatory surveys for the safe operation of regular ro-ro ferry and high-speed passenger craft services. ${ }^{71}$

As regards maritime security, Croatia has undertaken to give full and complete effect to the special measures to enhance maritime security as defined in Regulation (EC) No $725 / 2004$ on enhancing maritime security as laid down by Regulation (EC) No 725/2004 on enhancing ship and port facility security. In order to improve passenger and cargo traffic between the Adriatic ports, the Ministry is to propose implementation of alternative security agreements or equivalent security arrangements to the neighbouring countries, in line with the provisions of Regulation (EC) No 725/2004 on enhancing ship and port facility security.

Finally, there are several issues that are continuously on the Croatian national maritime agenda: active participation in the work of Paris MOU bodies, implementing international and domestic regulations on ballast water management in order to minimize the risk of biological contamination, proposing to the IMO the proclamation of the Adriatic Sea as a Particularly Sensitive Sea Area, in accordance with the relevant IMO Resolution and in cooperation with other adjacent coastal states (Albania, Bosnia-Herzegovina, Montenegro, Italy and Slovenia), and continued cooperation with other countries within the Adriatic region in order to increase the level of maritime safety and protection of the common marine environment. Consequently, the Republic of Croatia will persist in assigning the highest importance to the measures aimed at improving maritime safety, security and environmental protection.

70 OJ L 123, 17.5.2003, p. 18.

71 The Croatian Government also accepted to implement into Croatian legal system the Community maritime legislation, as defined in Art. 2.2 of the Regulation (EC) No 2099/2002 establishing a Committee on Safe Seas and the Prevention of Pollution from Ships (COSS) and amending the Regulations on maritime safety and the prevention of pollution from ships, as amended by the Commission Regulation (EC) No 415/2004 amending Regulation (EC) No 2099/2002, with the system of mandatory surveys of ships operating on regular ro-ro ferry and high-speed passenger craft services established in accordance with Council Directive 1999/35/EC on a system of mandatory surveys for the safe operation of regular ro-ro ferry and high-speed passenger craft services. 


\title{
French rules concerning maritime safety ${ }^{1}$
}

\author{
Cécile De Cet Bertin
}

\subsection{Introduction}

According to French legal terminology, maritime safety and maritime security are two different concepts. Rules concerning maritime safety deal with topics such as the situation of vessels, seafarers' working conditions, or maritime traffic. Their major aim is to prevent accidents. According to the French government, "the aim of maritime and port facility security is to detect illegal actions causing threats to port facilities that are used in international shipping, and to take appropriate steps in order to prevent or to mitigate these threats". ${ }^{2}$

Maritime safety, as well as maritime and port facility security, has significantly changed under the influence of aviation law, which, in French transportation law, is the source of the distinction between safety and security. Major changes concerning security rules were adopted following the terrorist attacks of September 11, 2001 in the US, which, in the field of maritime law, resulted in the International Ship and Port Facility Security (ISPS) Code. ${ }^{3}$

The current French approach to maritime safety is rooted in the second half of the 19th century. While shipowners and their insurers had formerly managed the bulk of maritime safety, this approach emphasizes State involvement in the control of vessels. ${ }^{4}$ At the end of the 20th century, a new objective was added to the safety rules of vessels, concerning pollution prevention. This change was induced by maritime catastrophes such as the wrecks of the Amoco Cadiz (16 March 1978) and Erika (12 December 1999), both generating major oil pollution. As a result, regulations increased significantly, and became more stringent. Besides the French authorities, the International Maritime Organization (IMO) and the European Union (EU), both of which international organizations France participates in, also draw up regulations on maritime safety, and this diversity contributes to making changes in these regulations more frequent.

The scope of this chapter is limited to French rules concerning maritime safety, i.e. it will not deal with maritime security. As suggested by the French Transport Code, ${ }^{5}$ which is the main source of our study, we will assume that the expression "maritime safety" encompasses both vessel and navigation safety rules. Although the Code includes a chapter titled

1 Translated from the original French version by Jean Boncoeur.

2 www.ecologique-solidaire.gouv.fr/surete-maritime, 10 May 2019, accessed 16 January 2020.

3 Adopted by virtue of the amendments to the annex to SOLAS on 12 December 2002.

4 P. Boisson, Politique et droit de la sécurité maritime (Bureau Veritas, 1998), p. 29.

5 Hereafter 'C. transp.' 
"Vessels security and pollution prevention", ${ }^{6}$ rules concerning pollution prevention ${ }^{7}$ are detailed in another document, the Environmental Code, which will not be considered here.

The following survey consists of two parts. The first is dedicated to a general presentation of French law concerning maritime safety, and the second deals with the contents of the rules in this area.

\subsection{General presentation of French law concerning maritime safety}

This part presents the administrative organization, the sources, and the legal and regulatory contents of French maritime safety law.

\subsubsection{French administrative organization for the implementation of maritime safety law}

The French government body in charge of maritime safety is the Department of Transport (Ministère de la transition écologique et solidaire, chargé des transports). Within this department, maritime safety is managed by the Directorate of Maritime Affairs (Direction des affaires maritimes, DAM), a subdivision of the General Directorate of Infrastructure, Transportation and the Sea (Direction générale des infrastructures, des transports et de la mer, DGTIM). DAM includes a Maritime Safety Branch (Sous-direction de la sécurité maritime), in charge of: ${ }^{8}$

- elaborating administrative regulations on safety, security, and prevention of pollution by commercial ships, and looking after their implementation;

- organizing the inspection of vessels under Flag State control (for French commercial vessels), and Port State Control (for foreign commercial vessels calling at French ports);

- setting up general guidelines and regulations on marine signalling and aids to navigation, programs for the building and maintenance of relevant devices, and looking after the implementation of these programs;

- organizing sea rescue activities, and elaborating rules for the monitoring of maritime navigation.

In order to achieve these tasks, DAM relies on the Interregional Directorates of the Sea (Directions interrégionales de la mer, DIRM), and, in overseas territories, on the Directorates of the Sea (Directions de la mer, DM). These administrative bodies, which are major actors in the field of maritime safety, include the following specialized services:

- Regional Operational Monitoring and Rescue Centres (Centres régionaux opérationnels de surveillance et de sauvetage, CROSS), acting under the authority of maritime prefects, who are the representatives of the French State at sea, Government delegates and direct representatives of the Prime Minister as well

6 C. transp., Partie 5, Livre 2, Titre 4, chapitre 1.

7 C. transp. Art. L5241-9 \& L5241-10.

8 www.ecologique-solidaire.gouv.fr/lorganisation-securite-maritime, accessed 30 January 2020. 
as of each minister ${ }^{9}$ (there are three maritime prefectures in metropolitan France: Brest, Cherbourg, and Toulon);

- Lighthouses and Beacons Services (Services des phares et balises);

- Vessels Safety Centres (Centres de sécurité des navires), which are dedicated to the inspection of vessels, and are located along French shores in the cities of Dunkerque, Boulogne, Le Havre, Rouen, Caen, Saint-Malo, Brest, Concarneau, Lorient, Saint-Nazaire, La Rochelle, Bordeaux, Sète, Marseille, Fort-de-France, and Le Port (Reunion Island).

\subsubsection{Enforcement}

France has ratified most IMO conventions, ${ }^{10}$ and, according to the French constitution (article. 55), "treaties or agreements duly ratified or approved shall, upon publication, prevail over Acts of Parliament, subject, with respect to each agreement or treaty, to its application by the other party". ${ }^{11}$

French internal law refers, when applicable, to the regulations of the European Parliament and of the Council, and major EU directives on maritime safety have been transposed into French law. ${ }^{12}$

9 Maritime prefects are endowed with an authority in all areas of State action at sea. Their tasks are specified in an order given by the Prime Minister, dated 22 March 2007 (JORF 24 mars 2007), for the following zones: English Channel and North Sea, Atlantic Ocean, Mediterranean, West Indies, French Guyana, South Indian Ocean, and waters adjacent to French Southern and Antarctic Lands.

10 Convention on Facilitation of International Maritime Traffic (FAL, 1965), International Convention on Load Lines (LL, 1966), International Convention on http://www.imo.org/en/About/Conventions/ListOfConv entions/Pages/International-Convention-on-Tonnage-Measurement-of-Ships.aspx (TONNAGE, 1969), International Convention on Civil Liability for Oil Pollution Damage (CLC, 1969), Convention relating to Civil Liability in the Field of Maritime Carriage of Nuclear Material (NUCLEAR, 1971), Convention on the International Regulations for Preventing Collisions at Sea (COLREG, 1972), International Convention for Safe Containers (CSC, 1972), Convention relating to the Carriage of Passengers and their Luggage by Sea (PAL, 1974), International Convention for the Safety of Life at Sea as amended (SOLAS, 1974, 1978, 1988), International Convention for the Prevention of Pollution from Ships, 1973, as modified by the Protocol of 1978 relating thereto and by the Protocol of 1997 (MARPOL 73/78 and Annex I, II, III, IV, V, VI), Convention on Limitation of Liability for Maritime Claims (LLMC, 1976), International Convention on Standards of Training, Certification and Watchkeeping for Seafarers as amended (STCW, 1978), International Convention on Maritime Search and Rescue (SAR, 1979), International Convention on Salvage (SALVAGE), 1989 Protocol to the International Convention on the Establishment of an International Fund for Compensation for Oil Pollution Damage (FUND, 1992), International Convention on Standards of Training, Certification and Watchkeeping for Fishing Vessel Personnel (STCW-F), 1995, Protocol on Preparedness, Response and Co-operation to pollution Incidents by Hazardous and Noxious Substances, 2000 (OPRC-HNS Protocol), International Convention on the Removal of Wrecks (WRC, 2007).

11 France has also ratified an important number of ILO conventions. Ratification of Maritime Labour Convention in 28 February 2013 resulted in the automatic termination of the conventions prior to 28 February 2014.

12 Council Directive 1999/63/EC of 21 June 1999 concerning the Agreement on the organization of working time of seafarers concluded by the European Community Shipowners' Association (ECSA) and the Federation of Transport Workers' Unions in the European Union (FST) - Annex: European Agreement on the organization of working time of seafarers, OJ L 167, 2.7.1999, p. 33; Directive 2002/59/EC of the European Parliament and of the Council of 27 June 2002 establishing a Community vessel traffic monitoring and information system and repealing Council Directive 93/75/EEC, OJ L 208, 5.8.2002, p. 10, Directive 2009/16/EC of the European Parliament and of the Council of 23 April 2009 on port State control, OJ L 131, 28.5.2009, p. 57, Directive 2009/21/ EC of the European Parliament and of the Council of 23 April 2009 on compliance with flag State requirements, OJ L 131, 28.5.2009, p. 132, Directive 2010/65/EU of the European Parliament and of the Council of 20 October 2010 on reporting formalities for ships arriving in and/or departing from ports of the Member States and repealing Directive 2002/6/EC, OJ L 283, 29.10.2010, p. 1, Directive 2014/90/EU of the European Parliament and of the 
The French Transport Code includes Parliamentary Acts and most administrative regulations dealing with maritime safety. ${ }^{13}$ Two exceptions are the 1984 Decree on safety of human life at sea, prevention of pollution, security and social certification of vessels (Décret n॰84-810 du 30 août 1984 relatif à la sauvegarde de la vie humaine en mer, à la prévention de la pollution, à la sûreté et à la certification sociale des navires), and the 1987 Ministerial Order on vessels safety, pursuant to this decree (Arrêté du 27 novembre 1987 sur la sécurité des navires). A “General Regulation” (Règlement général) attached to this order specifies the provisions that vessels, their equipment and their cargo should comply with (arrêté, article. 1).

\subsubsection{Subject area}

The section of the Transport Code that is relevant to our study is named "Safety and pollution prevention" (Partie V, Livre II, Titre IV). It is composed of three chapters dedicated, respectively, to vessels safety and pollution prevention (chapter 1), navigation safety (chapter 2), and infringements recognition (chapter 3). Chapter 1 includes regulations concerning the maintenance and operation of vessels, marine equipment, safety titles, pollution prevention certificates and other certificates, Port State Control, actions for the prevention of pollution, and criminal penalties. Chapter 2 defines violations concerning the conduct of vessels and violations related to the polluting or hazardous character of cargoes. Chapter 3 deals with procedural rules, and provides answers to the following questions: who is entitled to recognize violations of maritime safety and pollution prevention rules, and how should this be performed?

The above-mentioned 1984 Decree $\left(n^{\circ} 84-810\right)$ is dedicated to the application of legislative decisions, and the 1987 Ministerial Order, which includes the "General Regulation", is dedicated to the application of the Decree. The content of these documents is detailed hereafter.

\subsubsection{Scope}

Transport Code rules apply to vessels flying the French flag, except warships, vessels used for troop transportation, and vessels that are requisitioned by French government, in accordance with the right of requisition covered by the Defence Code (article. L2211-1). They also apply to foreign vessels sailing within territorial waters or inland maritime waters, or calling at a French port. They do not apply to unmanned underwater or surface floating crafts that are controlled from a vessel flying the French flag (C. transp., article. L5242-1).

Council of 23 July 2014 on marine equipment and repealing Council Directive 96/98/EC, OJ L 257, 28.8.2014, p. 146, Directive (EU) 2017/2108 of the European Parliament and of the Council of 15 November 2017 amending Directive 2009/45/EC on safety rules and standards for passenger ships, OJ L 315, 30.11.2017, p. 40, Directive (EU) 2017/2110 of the European Parliament and of the Council of 15 November 2017 on a system of inspections for the safe operation of ro-ro passenger ships and high-speed passenger craft in regular service and amending Directive 2009/16/EC and repealing Council Directive 1999/35/EC, OJ L 315, 30.11.2017, p. 61.

13 This code may be accessed at www.legifrance.gouv.fr/. Legifrance is a government website designed for the dissemination of French law. 


\subsection{The content of safety rules: prevention, control and sanctions}

A basic line may be drawn between rules that aim at preventing shipping and pollution accidents on the one hand, and rules aiming at the compensation of these accidents on the other hand. Prevention includes technical rules, ships control, and places of refuge for ships in distress. Compensation includes civil and criminal liability rules, as well as administrative penalties.

\subsubsection{Prevention}

\subsubsection{Technical rules}

The set of technical rules aiming at preventing accidents may be found in Book 2 of the "General Regulation" (appendix to the 23 November 1987 Ministerial Order). This set is organized along various sections (named "divisions"), characterized by the content of the rules they deal with.

A first subset is made up of general technical rules applying to vessels, and covering the following topics: accessibility (section 190); gauging (section 210); stability (section 211); devices aiming at simplifying the conduct and operation of vessels (section 212); pollution prevention (section 213); worker protection and lifting gears (section 214); habitability (section 215); health and medical provisions (section 217); ballast water management (section 218); radio communication for the Global Maritime Distress and Safety System (section 219).

A second subset is made up of technical norms applying to specific categories of vessels: passenger vessels engaged on international voyages, and cargo-ships with a gross tonnage equal to or above 500 GT (section 221); passenger vessels engaged on domestic voyages (section 223); fishing vessels equal to or above 12 metres and under 24 metres (section 226); fishing vessels under 12 metres (section 227); fishing vessels equal to or above 24 metres (section 228); cargo-ships with a gross tonnage equal to or above $500 \mathrm{GT}$, and sailing in 4th or 5th category (section 229); fish-farming vessels under 24 metres (section 230); dredging and waste materials carrying units (section 231); mobile offshore drilling units (section 232); underwater vessels (section 233); special vessels (section 234); supply and offshore support vessels (section 235); safety rules for recreational sailing at sea on boats equal to or under 24 metres (section 240); pleasure boats with a hull equal to or under 24 metres, and operated with a commercial purpose (section 241); pleasure boats with a hull over 24 metres, and a gross tonnage under 3,000 GT (section 242); competition or experimental yachts (section 243); traditional pleasure boats (section 244); technical guidelines for pleasure boats not covered by EC labelling, and with a hull equal to or under 24 metres (section 245).

A third subset is made up of technical norms applying to marine equipment: approval rules (sections 310 and 311); fire prevention (section 321) and suppression (section 322); alarm devices for men overboard, and rescue actions (sections 332 and 334); rescue facilities (sections 333 and 337); Long Range Identification and Tracking (LRIT) of Ships (section 335); electronic chart display and information systems (section 341); miscellaneous alarm systems (sections 351 and 361). Moreover, marine equipment that is to be approved by Flag State according to international conventions is subject to the provisions of the Transport Code, which sets the supervisory rules for the marketing of this equipment (C. transp., article. L5241-2-1 to L5241-2-13). 
The last subset of technical norms is dedicated to cargoes: general rules relating to cargo stowage (section 410); carriage by sea of packages containing hazardous goods (section 411); road vehicles (section 412); timber deck cargoes (section 413); hydrocarbons (section 421); hazardous or noxious liquid substances, and liquefied gas transported in bulk (section 422); solid bulk cargoes (section 423); grain transportation (section 424); container safety (section 431).

\subsubsection{Ship control}

Ships are controlled in different ways. First, they are controlled prior to navigation. These controls result in the issuance of safety titles and certificates, without which a French vessel is not allowed to set sail (C. transp., article. L5241-3). A second set is the Port State Control, according to Directive 2009/16/EC of the European Parliament and of the Council of 23 April 2009 on port State control, ${ }^{14}$ and to the Paris Memorandum of Understanding signed on 26 January 1982.

\subsection{PRIOR CHECKS}

Prior to navigation, French vessels must hold safety titles and pollution prevention certificates (C. transp., article. L5241-3). These documents are: ${ }^{15}$ international safety, security, and pollution prevention certificates, or, when applicable, exemption certificates provided for in international conventions; safety, security, and pollution prevention titles and certificates provided for in EU rules; a national load-line certificate, if the vessel does not hold an international load-line certificate; a national tonnage certificate or a tonnage declaration, if the vessel does not hold an international tonnage certificate; a maritime labour certificate; a social certificate for fishing vessels, and a navigation licence.

Some regulatory provisions specify this legal list. Section 120 of the General Regulation, named "List of titles and certificates", contains a set of tables providing, for each certificate, the name of the document, the reference texts, and the vessels concerned. As an illustration, the following table is translated from article. 120.2.10:

\begin{tabular}{llc}
\hline Name of certificate & Reference texts & Concerned vessels \\
\hline Compliance & Résolution MSC.179(79). & All passenger vessels engaged on \\
Document & Règlement $(C E) n^{\circ} 336 / 2006$. & domestic voyages, including high- \\
& Règlement $(C E) n^{\circ} 540 / 2008$. & speed passenger crafts. All cargo- \\
& Résolution MSC.195(80). & ships and mobile offshore drilling \\
& & units with a gross tonnage equal to or \\
& & above 500 GT. \\
Safety & Résolution MSC.179(79). & All passenger vessels engaged on \\
Management & Règlement $(C E) n^{\circ} 336 / 2006$. & domestic voyages, including high- \\
Certificate & Règlement $(C E) n^{\circ} 540 / 2008$. & speed passenger crafts. All cargo- \\
& Résolution MSC.195(80). & ships and mobile offshore drilling \\
& Résolution MSC.273(85). & units with a gross tonnage equal to or \\
& & above 500 GT. \\
\hline
\end{tabular}

14 OJ L 131, 28.05.2009, p. 57.

15 Décret n ${ }^{\circ} 84-810$, Art. 3. 
These documents are issued by public authorities or by classification societies, in accordance with Section 130 of the General Regulation, which specifies the categories of vessels that are requested to hold the various certificates, and the validity period of these certificates. For vessels under 24 metres, these documents are valid indefinitely, except in the case of passenger vessels, and unless they have been issued by a classification society $(C$. transp., article. L5241-4). The issuance and the renewal of these documents are contingent upon surveys of the vessel and, when applicable, upon surveys of its blueprints and documents.

Section 130 of the General Regulation specifies the procedural rules related to the issuance of safety titles and certificates, as well as of the navigation licence. This licence must be held by all French vessels of the following categories: passenger vessels, cargo-ships, special vessels, underwater vessels, fishing vessels, pleasure boats used commercially, and mobile offshore drilling units. It certifies that the controls that were performed could not identify any apparent flaw such as to prevent the vessel from setting sail, due to at least one of the following considerations: safety, vessel habitability, prevention of maritime occupational risks, and prevention of pollution. An application for a licence must be submitted to the head of the Safety Centre with territorial jurisdiction. ${ }^{16}$

Section 130 also lays down the procedures for vessel visits and inspections (survey before the ship is put into service, periodical visits, special visits, surprise visits).

Section 140 of the General Regulation is devoted to technical bodies including authorized classification societies. These societies perform surveys, visits, and inspections of vessels, and issue, endorse, renew, prolong, interrupt, and revoke safety titles and certificates on behalf of the State (article. 140.1). Section 140 contains the rules related to the issuance, continuation, suspension and withdrawal, by the minister with responsibility for the sea, of the authorization that is to be held by classification societies. It also specifies the jurisdiction of these organisms. Attached to this section is a list of authorized classification societies. Prior to their authorization by the French government, these organisms must obtain recognition by the European Commission, according to Regulation (EC) No 391/2009 of the European parliament and of the Council of 23 April 2009 on common rules and standards for ship inspection and survey organizations. ${ }^{17}$ The French government has authorized the following classification societies: BUREAU Veritas, DET NORSKE Veritas, GERMANISCHER Lloyd, LLOYD'S Register of Shipping.

\subsection{Port State Control}

Sections 150 and 151 of the General Regulation contain provisions that are related to the inspections of ships by the Port State, both in metropolitan France and overseas (French Overseas Departments, French Polynesia, Wallis and Futuna Islands, French Southern and Antarctic Lands, New-Caledonia, Saint-Martin, Saint-Barthelemy, and Saint-Pierre-et-Miquelon).

These inspections are performed according to Directive 2009/16/EC of the European Parliament and of the Council of 23 April 2009 on port State control. ${ }^{18}$ Some major topics

16 This jurisdiction is defined in Art. 130.5 of the General Regulation.

17 OJ L 131, 28.5.2009, p. 11.

18 OJ L 131, 28.05.2009, p. 57. 
addressed by Sections 150 and 151 are provisions related to the refusal of access to ports and anchorages, special provisions applying to the control by the Port State of ships flying the flag of a State that is not party to an international convention (article. 150-2.01), and requirements of the Directive 1999/95/EC of the European Parliament and of the Council of 13 December 1999 concerning the enforcement of provisions in respect of seafarers' hours of work on board ships calling at Community ports. ${ }^{19}$

The following sections deal with safety management (section 160), registration of persons boarding passenger vessels (section 170), registration of $406 \mathrm{MHz}$ beacons (section 175), and the system of inspections for the safe operation of ro-ro passenger ships and high-speed passenger crafts in regular service (section 180).

\subsubsection{Places of refuge}

Article L5131-3 of the Transport Code sets the general rules concerning the accommodation of ships in distress. The French government holds the exclusive right to decide the conditions of this accommodation, and may order a port authority to accommodate a ship in need of assistance.

Except when they are ordered to accommodate ships in need of assistance, port authorities may refuse access to ships posing significant risks to maritime safety. They may also refuse access to ships that have been subject to an expulsion decision by a Member State of the EU, because their owner does not hold a certificate of insurance for maritime claims, as defined by the 1976 Convention on Limitation of Liability for Maritime Claims (C. transp., article. L5241-4-5 \& L5123-1).

According to French law, a shipowner or a ship operator may be required to remedy the damage caused by a ship in distress that has been accommodated in a port (C. transp., article. L5331-3, al. 3). Compensation for damage is a consequence of liability, which, in the field of maritime safety, may be considered as a sanction for safety breaches.

\subsubsection{Punishment and compensation}

First, French law includes punishment of maritime safety breaches. To this end it sets specific criminal sanctions, but also administrative sanctions, i.e. sanctions ordered by competent administrative authorities. It also sets rules for the compensation of damages. Some of these rules aim at reimbursing the expenses incurred by the public authority for the enforcement of safety rules. Other rules aim at compensating civil damages, as a consequence of shipowner's civil liability.

\subsubsection{Punishment}

\subsection{CRIMINAL LIABILITY}

Maritime criminal law is the subject of a specific legal document, the Parliament Act of 17 December 1926 concerning punishment in maritime affairs. This act defines maritime offences as well as the Maritime courts with jurisdiction for judging offences that are defined in the fifth part of the Transport Code, including offences to maritime safety, i.e. to

19 OJ L 14, 20.1.2000, p. 29. 
ship and navigation safety. Maritime criminal law also includes offences and penalties in case of damage to the marine environment (C. transp., article. L5242-7 et seq.).

Major offences concerning ship and navigation safety (i.e. maritime safety, strictly speaking) are defined in the Transport Code. Nowadays, this code may be considered as the "base of criminal policies in the field of maritime safety". ${ }^{20}$ These offences include the lack of documents that are required for navigation (C. transp., article. L5241-12), noncompliance with freeboard marks according to LL Convention (C. transp., article. L524111 ), and infringements of general rules concerning the conduct of vessels at sea (C. transp., article. L5241-1 et seq.).

In the field of maritime safety, French law assigns a fundamental role to the ship's master, who, in turn, bears a specific liability. For instance, according to the International French Registry ("RIF flag"), the ship's master is accountable for the safety of the ship and her crew (C. transp., article. L5612-3). In the same way, he is the first accountable person for the compliance with the 1972 Convention on the International Regulations for Preventing Collisions at Sea (COLREG) and Traffic Separation Schemes (TSS). He must follow instructions given by the maritime prefects and CROSS, in charge of controlling compliance with TSS under penalty of two years of imprisonment, and a fine of 30,000 euros (C. transp., article. L5242-1).

\subsection{AdMINISTRATIVE SANCTIONS}

Various administrative sanctions may follow non-compliance with maritime safety rules, and the acknowledgement, by the competent administrative authority, of a clear risk to maritime safety. Unlike criminal sanctions, which are imposed by courts, administrative sanctions are imposed by administrative authorities. French administrative sanctions are:

- suspension or withdrawal of safety documents that are required for navigation $(C$. transp., article. L5241-4);

- fines (C. transp., article. L524-4-1);

- refusal of access to a port (C. transp., article. L5241-4-5);

- detention, or postponement of the departure of a ship (C. transp., article. L5242-5);

- expulsion of a ship (C. transp., article. L5241-4-6);

- operating ban (C. transp., article. L5241-6);

- suspension or withdrawal of certificates referring to cargoes (C. transp., article. L5241-10-2).

\subsubsection{Compensation for damages}

6.3.2.2.1 REFUNDING OF EXPENSES INCURRED BY FRENCH AUTHORITIES FOR SHIPS CONTROL According to French law, shipowners or ship operators are charged for the costs associated to:

- visits of ro-ro passenger ships (C. transp., article. L5241-4-1 A);

- inspections of ships flying a foreign flag, and calling at a French port (C. transp., article. L5241-4-4);

20 A. Montas, in J.-P. Beurier (Ed.), Droits maritimes (Dalloz 2014), Ch. 383. 
- inspections of ships that have been detained, or whose departure has been postponed due to a risk to the safety or health of the crew, to passengers, to marine environment, or to other ships (C. transp., article. L5241-5).

\subsection{CiviL LIABILITY}

Regarding compensation of damages to property or to persons, general rules concerning the liability of the shipowner, based on the Convention on Limitation of Liability for Maritime Claims (LLMC), signed in London on 19 November 1976 and ratified by France, apply. Two special arrangements supplement these general rules. The first refers to the civil liability of the operators of nuclear ships (C. transp., article. L5122-1 et seq.), and the second to the civil liability of shipowners for the damages caused by oil pollution (C. transp., article. L5122-25 et seq.). In French domestic law, the treatment of the civil liability of shipowners in case of oil pollution remains close to the international model of the Civil Liability Convention (CLC) of 29 November 1969, which has been ratified by France. France has also ratified the convention of 18 December 1971, creating the International Oil Pollution Compensation Funds (IOPC Funds), as well as its protocols of 27 November 1992 and 16 May 2003.

Despite the Council Decision of 18 November 2002 (2002/971/EC) authorizing Member States, in the interest of the Community, to ratify or accede to the International Convention on Liability and Compensation for Damage in connection with the Carriage of Hazardous and Noxious Substances by Sea, 1996 (HNS Convention), ${ }^{21}$ France has not ratified the HNS convention, modified by a protocol in 2010 .

Shipowners or ship operators are subject to a general insurance requirement. They are requested to cover maritime claims under LLMC, by means of insurance or other financial security. This requirement refers to ships flying the French flag or entering a French port, and with a gross tonnage equal to or above 300 GT. Non-compliance with this obligation may result in the expulsion of the ship by the administrative authority ( $C$. transp., article. L5123-5), and a fine of 45,000 euros (C. transp., article. L5123-6).

\subsection{Concluding remarks}

Following the major oil pollution caused by the wreck of the Amoco Cadiz, off the coast of Brittany on 16 March 1978, maritime safety has become a high-level public policy objective in France. As an illustration of this preoccupation, it may be noticed that France was the instigator of an original international legal instrument, the Paris Memorandum of Understanding. This administrative agreement, which was signed by 14 States in 1982, and, up to now, has been signed by a total of 27 States, is the first agreement of this type setting out a coordinated control programme for foreign ships calling at EU ports.

Considered globally, French maritime safety law may be characterized by the following traits. First, a good part of its rules have an international origin. This is due to the fact that France ratifies most international conventions, and, as a Member State of the EU, applies relevant EU rules. Another important trait of French maritime safety law is its objective of environmental protection, which explains the association of rules concerning pollution

21 OJ L 337, 13.12.2002, p. 55. 
prevention with rules concerning maritime safety, strictly speaking. And finally, it is a technical law but also a punitive law, due to the criminal and administrative sanctions it includes.

Due to these traits, French maritime safety law is highly complex and shifting. Its complexity is due to the diversity of its levels, and of the matters it deals with. Its shifting character is related to the permanent evolution of international and EU rules, in order to fulfil the needs of maritime safety and environmental protection. Considering these needs, it may be noticed that the ship, being at the core of maritime law, is regarded by this law both as a subject of protection (maritime safety), and as a potential cause of environmental damage (pollution prevention). This duality has contributed to reshaping French maritime law, which has traditionally been the law of commercial shipment, motivated by the objectives of protecting ships, seafarers, and maritime trade. 


\title{
German maritime safety laws
}

\author{
Comprehensive but complicated
}

Henning Jessen

\subsection{Introduction: the strategic importance of maritime shipping for Germany}

Located in the geographical centre of Europe and as one of the most export-oriented countries of the world, Germany is deeply integrated in international trade patterns and supply chains. This applies both to intra-European Union (EU) trade as well as globally. Thus, it is no surprise at all that Germany regards the maritime industry as one of the essential sectors of its national economy: ${ }^{1}$ about 350 German-based ship-owning companies operate around 2,000 sea-going vessels (including: special purpose vessels, fishing vessels, floating platforms, etc.). As a result, Germany is still one of the biggest shipping nations. This general economic importance is also evidenced by the continuous presence of Germany as one of the 40 elected Members of the Council of the International Maritime Organization (IMO). ${ }^{2}$ Maritime shipping under the German flag (or at least controlled from shipping companies incorporated in Germany), German seaports and their efficient hinterland connections, specialized shipbuilding and all ancillary industries (such as building ship engines and machinery), as well as maritime research are of strategic importance to the country. Within the whole maritime cluster in Germany, a turnover of more than 54 billion euros is generated annually. ${ }^{3}$

To highlight the economic relevance of maritime shipping for Germany and the longstanding existence of a strong German maritime cluster underscores the necessity for a reliable and efficient legal framework for maritime safety and security. ${ }^{4}$ This chapter will explain the German regulatory approach to achieving and maintaining maritime safety. In this context, it is of vital importance to note that maritime safety also represents one of the major means to implement the strategic objectives of German National Maritime Policy. ${ }^{5}$

1 The most recent national maritime policy document is entitled "Maritime Agenda 2025 - The future of Germany as a maritime industry hub" and is published on the websites of the Federal Ministry for Economic Affairs and Energy: www.bmwi.de/Redaktion/EN/Publikationen/maritime-agenda-2025.html, accessed 01 May 2020. Evidently, such policy documents (and the strategic objectives) are subject to continuous adjustment intervals, with policy cycles for comprehensive updates ranging between five and ten years.

2 Germany is a so-called "Category (b)" Council Member (ten States with the largest interest in international seaborne trade).

3 See "In the service of maritime navigation and the seas", German Federal Maritime and Hydrographic Agency, www.bsh.de/DE/PUBLIKATIONEN/_Anlagen/Downloads/BSH-Informationen/Festschriften-und-Br oschueren/BSH-Imagebroschuere-englisch.pdf, accessed 01 May 2020.

4 See also P. Ehlers, Recht des Seeverkehrs, 5 (Nomos, Baden-Baden, 2017).

5 "Maritime Agenda 2025 - The future of Germany as a maritime industry hub", 30, ibid (note 1). 
It is not only in Germany, but the changing environmental conditions and the density of maritime traffic, including the increasing use of large container ships, have given rise to additional safety requirements in maritime transport worldwide. This also includes the protection of crews, ships, cargo and the marine environment. In fact, the regulatory challenges that Germany faces as a nation are comparable to many other IMO Member States: important areas of action include the development of traffic guidance systems (particularly on rivers and in seaports as well as inland waterway terminals) and methods for ensuring the minimum required power to maintain manoeuvrability in a seaway.

Other dangers to maritime safety and security include terrorism and piracy or armed robbery at sea - even if the latter threat does not exist in European waters, nevertheless, it frequently materializes as a major threat in other parts of the world and thus affects Germany as a flag State. The vulnerability and abuse of information systems (both offshore and onshore) represents another maritime safety challenge - for Germany as well as for all other flag, port and coastal States. The same can be said with regard to the clear identification of potentially dangerous or unlawful cargo in containers. Though containers with dangerous goods are usually declared, there are a range of potentially dangerous substances which do not have to be reported to shipping companies. ${ }^{6}$

In sum, the strategic objectives for Germany are to strengthen the maritime safety and security partnership between the private maritime industry and the national maritime safety and security authorities at the overarching federal level (the "Bund" which means the "Federation") and at the level of the different federal States (the "Bundesländer" or, in short, the "Länder"). This includes strong support for developing and continuously updating international regulations on the basis of current research findings and creating organizational structures (within the decentralized German federal system) that are fully capable of acting in the international context of interlinking maritime transport IT systems. It also includes the promotion of e-Navigation and maintaining a high professional quality of marine pilotage services (in times of declining numbers of qualified personnel); improving and developing traffic management systems and the availability of cargo details through a digitally interconnected information system; improving emergency preparedness on board ships using in-vehicle measures (improved fire detection, development of mobile and stationary fire extinguishing facilities, suitable towing equipment, targeted training for crews); and the availability of places of refuge for ships in distress including the necessary unloading and salvage facilities.

How can all of those complex regulatory tasks be achieved? Evidently, this is a continuous (never-ending) process. And while it is not possible to discuss each and every aspect of all the modern maritime policy challenges just raised, at the very least, the key regulatory framework of German maritime safety laws shall be introduced in this Chapter.

6 See generally "Rogue Shippers - The Bane of Box Shipping" available from Lloyd's List Intelligence: https ://lloydslist.maritimeintelligence.informa.com/LL1129256/Rogue-shippers-The-bane-of-box-shipping, accessed 01 May 2020. 


\subsection{The national structure for the implementation of maritime safety laws}

\subsubsection{The constitutional background and a selection of major federal maritime acts}

At the outset and in order to "set the scene", it is inevitable to start with the German constitution. This is the "Grundgesetz" of 1949 (which translates quite oddly as the "Basic Law"), representing the highest source of law within the German legal order. ${ }^{7}$ The "Basic Law" does not only establish constitutional and fundamental democratic rights and freedoms for the people, it also serves as the constitutional backbone of organizing German federalism. Any allocation of powers and competencies between the federal government (the Federation) and the "Länder" (the 16 federal States of Germany) ultimately originates from the articles of the "Basic Law" - and it should also never be forgotten that this decentralized approach reflects lessons learnt from German history.

Only a few articles of the "Basic Law" are directly relevant for German maritime law. First, Article 27 simply states that "all German merchant vessels shall constitute a unitary merchant fleet". Second, Article 73 identifies a carefully selected and limited number of matters which are under the exclusive legislative powers of the Federation (Article 73). It should be noted that Article 73 No. 5 of the "Basic Law" addresses "the unity of the customs and trading area, treaties regarding commerce and navigation, the free movement of goods, and the exchange of goods and payments with foreign countries, including customs and border protection" as under the exclusive legislative power of the Federation. However, and more importantly for the objectives discussed in this chapter, the "Basic Law" also identifies a much wider variety of matters which are under the concurrent legislative powers (Article 74) of the Federation and the federal States. For this reason, Article 74 para. 1 of the "Basic Law" includes an extensive catalogue of more than 30 different items which are subject to concurrent legislative powers. No. 21 of the catalogue refers explicitly to "maritime and coastal shipping, as well as navigational aids, inland navigation, meteorological services, sea routes and inland waterways used for general traffic". The general constitutional approach on concurrent legislative powers is that "the Länder shall have power to legislate so long as and to the extent that the Federation has not exercised its legislative power by enacting a law" (Article 72 para. 1 of the "Basic Law"). When it comes to maritime affairs, the Federation has exercised the granted legislative powers exactly. As a result and de facto, the Federation dominates the regulatory approach to all aspects of maritime affairs and shipping, including maritime safety laws.

Finally, it is also important to note Article 89 para. 2 of the "Basic Law" which states:

The Federation shall administer the federal waterways through its own authorities. It shall exercise those state functions relating to inland shipping which extend beyond the territory of a single Land, and those functions relating to maritime shipping, which are conferred on it by a law. Insofar as federal waterways lie within the territory of a single Land, the Federation on its application may delegate their administration to that Land on federal commission. If a waterway touches the territory of two or more Länder, the Federation may commission that Land which is designated by the affected Länder. ${ }^{8}$

7 An official English translation of the German "Basic Law" is available online, see www.gesetze-im-internet. de/englisch_gg/index.html accessed 01 May 2020.

8 It should be highlighted that Art. 89 para. 2 of the "Basic Law" must be read in conjunction with Art. 87 
The legal consequence of these quoted constitutional provisions is also known as a "facultative competence of the Federation". Authorized specifically by Article 74 para. 1 No. 21 and Article 89 para. 2 of the "Basic Law", the Federation is competent to regulate maritime affairs and shipping and it has executed this legal right. It is thus legally impossible for the "Länder" to enact any acts which would contradict or undermine the objectives of the Federation. However, all five "Länder" of the northern part of the country (where the German seaports are geographically located) have enacted additional, specific State laws to supplement and support the related federal acts.

Nevertheless, the most important legal acts to regulate the area of maritime safety under German law are exclusively federal laws, above all, the "Seeaufgabengesetz" (originally from 1950 and completely revised in 1965). ${ }^{9}$ An official English translation of that act does not exist. Mindful of that absence, the title could be translated as the "Federal Act on the Maritime Affairs-related Tasks of the Federation". One could argue that this act positions itself in the centre of all maritime laws in the German legal order. However, the thrust of the act is largely of an intra-organizational nature. For this reason and without being all-encompassing, the act has been labelled as the "basic law of the German maritime administration" 10 and as the "mother law" of all public maritime law in the German legal order. ${ }^{11}$ This legal categorization is correct. In particular, section 1 of this act includes a detailed enumerative catalogue of major maritime-related tasks which are specifically allocated to be administered by the Federation. ${ }^{12}$

In other words: the Federation is not only concurrently competent but it is even legally obliged to take legislative action in order to implement the tasks as listed by the catalogue of section 1 of the "Seeaufgabengesetz". ${ }^{13}$ Basically, all of the tasks of the catalogue have some (closer or more remote) relationship with establishing, upholding and enforcing maritime safety and security. Only tasks not explicitly mentioned in the enumerative catalogue would still leave some legislative flexibility for the "Länder" (which is the general rule under Article 83 of the "Basic Law"). ${ }^{14}$ Admittedly, for all maritime matters, not much concurrent legislative room is left open by the Federation. However, the "Länder" are still competent to regulate specific aspects of (local) port administration and (local) maritime security, to administer ship registries by (local) courts and to organize the approach to maritime education via (local) nautical academies and seafarer schools. ${ }^{15}$

para. 1 of the "Basic Law" which states - inter alia - that "in accordance with the provisions of Art. 89, the administration of federal waterways and shipping shall be conducted by federal administrative authorities with their own administrative substructures".

9 Federal Law Gazette 1949/1950, 767 and Federal Law Gazette 1965, Part II, 833 (the act has been amended numerous times since 1965, some of the most influential amendments are listed by P. Ehlers, Recht des Seeverkehrs (Nomos, Baden-Baden, 2017) p. 79. For the latest version of the text (in German) see www.gesetz e-im-internet.de/bseeschg/index.html, accessed 01 May 2020.

10 R. Herber, Seehandelsrecht - Systematische Darstellung (de Gruyter, Berlin, 1999, quote from the 1st edition), p. 69.

11 U. Jacobshagen, Seeschifffahrtsrecht und Öffentliches Seerecht (Lit. Verlag, Münster, 2016), p.170.

12 As a result of several amendments over time, the enumerative catalogue of section 1 of the "Seeaufgabengesetz" now incorporates more than 20 detailed tasks and cannot be reproduced in its entirety.

13 P. Ehlers, Recht des Seeverkehrs (Nomos, Baden-Baden, 2017), p. 84.

14 The Art. states that "The Länder shall execute federal laws in their own right insofar as this Basic Law does not otherwise provide or permit".

15 The latter competence is also explicitly delegated to the "Länder" by section 2 of the Federal "Seeaufgabengesetz". 
Arguably, the most important other federal acts that join the "Seeaufgabengesetz" in order to form a mutually interrelated set of high-ranking federal laws in the area of maritime affairs are (in chronological order):

- the "Flaggenrechtsgesetz" (originally from 1951) 16 - which regulates the law of the flag (including registration aspects);

- the "Seelotsgesetz" (originally from 1954) ${ }^{17}$ - which regulates all aspects of maritime pilotage;

- the "Wasserstrassengesetz" (originally from 1968) ${ }^{18}$ - which regulates the most important aspects to administer the federal waterways;

- the "Schiffsicherheitsgesetz" (originally from 1998) cifically to ship safety matters; and

- the "Seesicherheits-Untersuchungs-Gesetz (originally from 2002) ${ }^{20}$ - which is the main act with regard to marine casualty investigation.

It should be emphasized at this point that the above list of six major federal acts is far from complete. The German legal order provides many other legal acts which co-regulate more specific maritime matters as well, for example, in relation to all offshore-based activities (above all, when it comes to renewable energy generation and installations at sea).

However, given the thrust of both the chapter and the whole book, the following remarks will mostly concentrate on the material substance of one of the six German federal acts - the Federal Act on Ship Safety ("Schiffssicherheitsgesetz") - which broadly regulates maritime (ship-related) safety and which represents a more recent attempt (since 1998) to consolidate some of the most important rules as generated by the regulatory activity of both the IMO and the EU.

\subsubsection{The importance of allocating tasks and competencies under the "Seeaufgabengesetz"}

Even if the following analysis shall concentrate more specifically on the legal substance of the Federal Act on Ship Safety, it is nevertheless simply not possible to completely fade out other relevant federal laws. In particular, the central importance of the intraorganizational ("allocation-of-tasks-geared") "Seeaufgabengesetz" should never be underestimated for anyone more interested in how German public maritime law operates. In particular, sections 3, 5, 6 and 7 of the "Seeaufgabengesetz" serve as the legal basis for the establishment and organization of specialized administrative maritime agencies and

16 For the latest version (in German) see www.gesetze-im-internet.de/flaggrg/index.html, accessed 01 May 2020.

17 For the latest version (in German) see www.gesetze-im-internet.de/seelotg/index.html, accessed 01 May 2020.

18 For the latest version (in German) see www.gesetze-im-internet.de/wastrg/index.html, accessed 01 May 2020.

19 For the latest version (in German) see www.gesetze-im-internet.de/schsg/index.html, accessed 01 May 2020.

20 For the latest version (in German) see www.gesetze-im-internet.de/sug/index.html, accessed 01 May 2020. 
law enforcement bodies. ${ }^{21}$ The German Federal Ministry of Transport has legal oversight over those bodies; however, when it comes to the implementation and enforcement level, the Ministry depends on the professional execution of all maritime-related tasks to be performed by specialized agencies and bodies.

In addition, an enormously wide array of highly specific federal ordinances ("Rechtsverordnungen") is based on sections 7, 7a, 9-9c of the "Seeaufgabengesetz" and also on section 15 of the Federal Act on Ship Safety. ${ }^{22}$ One of those federal ordinances regulates technical aspects of maritime safety specifically ("Schiffssicherheitsverordnung"). ${ }^{23}$ This federal ordinance operates jointly with (and in implementation of) the Federal Act on Ship Safety since 1998.

\subsubsection{Monitoring, enforcement and the imposition of penalties}

Over the decades, and as a historic legacy, the legal power of the "Seeaufgabengesetz" (operating jointly with the other federal laws) has led to a comprehensive but complicated situation: historically speaking, German maritime safety law did not develop in a coherent and logical manner. Rather, German public maritime law is characterized by a rather tight meshwork of laws and ordinances which have been created and added over the last 60 years. To put it mildly, this historic development has not necessarily resulted in a transparent, uniform, consistent and systematic outcome. ${ }^{24}$

Generally, when it comes to German maritime public law, we are not dealing with an overly "user-friendly" area of German law. For example, there is also not one single, key German maritime implementation and enforcement agency. Rather, and leaving out the oversight powers of the Federal Ministry of Transport, there are at least five specialized administrative bodies which play an important maritime-related monitoring and enforcement role - each of those with a clearly defined mandate under German law. ${ }^{25}$ Just two of those five bodies shall be introduced shortly in accordance with their highlighted tasks pursuant to sections 5 and 6 of the "Seeaufgabengesetz".

21 Section 3 addresses a variety of police-related tasks. Section 5 details the tasks of the "BSH" which stands for the "Federal Maritime and Hydrographic Agency" as the "working arm" of the Federal Ministry of Transport for a number of maritime-related affairs (see note 3 for an internet link to the image brochure of that agency). Section 6 addresses the tasks of the "Occupational Accident Insurance Fund for Transport and Traffic" ("BG Verkehr") which - for historic reasons - performs a number of ship-safety-related enforcement tasks (via a specialized "Ship Safety Division") and is also the competent agency in all areas of maritime labour law. Section 7 serves a legal enabling clause for the inclusion of private legal persons to perform certain specialized tasks.

22 Generally, this is possible pursuant to Art. 80 of the German "Basic Law" which is entitled "Issuance of Statutory Instruments".

23 For the latest version (in German) see www.gesetze-im-internet.de/schsv_1998/index.html, accessed 01 May 2020.

24 P. Ehlers, Recht des Seeverkehrs (Nomos, Baden-Baden, 2017), p. 6.

25 These are (1) the "Federal Maritime and Hydrographic Agency" ("BSH"); (2) the "Occupational Accident Insurance Fund for Transport and Traffic" ("BG Verkehr") which has a specialized "Ship Safety Division"; (3) the "General Directory for Waterways and Shipping" which has a number of local offices in Germany; (4) the customs authorities of the Federation; and (5) the police authorities of the "Länder". Only under exceptional circumstances, for example for the purpose of providing administrative assistance, would the German Navy (which is exclusively tasked with military functions) be included as a sixth stakeholder in this broad picture of public maritime law-related enforcement agencies. 


\subsubsection{The tasks of the "Ship Safety Division"}

One might argue that the tasks of the highly specialized "Ship Safety Division" ("Dienststelle Schiffssicherheit") - which is incorporated under the auspices of the "Occupational Accident Insurance Fund for Transport and Traffic" 26 - stand out in the area of monitoring compliance with German maritime safety laws. The tasks of the "Occupational Accident Insurance Fund for Transport and Traffic" are specifically addressed and summarized in section 6 of the "Seeaufgabengesetz". Generally speaking, the "Ship Safety Division" is responsible for any German-flagged ship operating in commercial maritime shipping (including inshore and deep sea fishing). To execute its monitoring tasks, the division has a network of specially qualified surveyors at its disposal along the entire German coast (both the North Sea and the Baltic Sea). It ensures - via ship surveys - regulatory compliance of both German-flagged and foreign-flagged vessels. In particular, the division performs certain monitoring tasks on behalf of the Federal Government (i.e. the Federal Ministry of Transport) in the following areas:

- monitoring compliance with national and international rules and regulations concerning technical ship safety, including stability, fire protection and lifesaving appliances;

- monitoring compliance with rules and regulations concerning maritime pollution protection (in particular the MARPOL-Convention);

- determining minimum safe manning on seagoing ships;

- monitoring compliance with rules and regulations concerning the International Safety Management Code (ISM Code);

- verifying the living and working conditions of seafarers on board (in accordance with the requirements of the International Maritime Labour Convention)

- testing and certifying lifesaving, fire protection and marine pollution prevention equipment;

- monitoring training facilities regarding training in accordance with the STCW Convention; and

- Port State Control of foreign-flagged ships in German ports. ${ }^{27}$

\subsubsection{The tasks of the Federal Maritime and Hydrographic Agency ("BSH")}

Comparatively, in terms of available staff, the "BSH" is significantly larger than the "Ship Safety Division" and one might argue that its tasks are also spread out more broadly to cover other (but also interrelated) public maritime services. "BSH" staff frequently represent Germany in more than 20 international organizations. They also represent the Federation when it comes to most intra-state maritime affairs that need to be negotiated with the "Länder" and as part of specialized domestic committees. The tasks of the Federal Maritime and Hydrographic Agency are specifically addressed and summarized in

26 The history of this body dates far back to the 19th century when the first national occupational insurance schemes were developed. Over time, the "Occupational Accident Insurance Fund for Transport and Traffic" was also tasked with monitoring related aspects of safety - for all transport modes, including maritime shipping - and this approach has never been abandoned (although it leads to a significant split of competencies with other bodies).

27 See www.deutsche-flagge.de/en/german-flag/flag-state/bg-verkehr, accessed 01 May 2020. 
section 5 of the "Seeaufgabengesetz" (which represents a provision "loaded" with a multitude of legal cross-references). Generally, these tasks include:

- to protect the marine environment by following up on previously identified vessel-related deficiencies which would also include the imposition of administrative penalties (in relation to MARPOL, civil liability for oil pollution, the Ballast Water Convention and identifying the source of oil spills at sea);

- to perform hydrographic surveying and searching for wrecks;

- to set up and maintain navigational information systems;

- to provide document-related services for the shipping industry (flag State documents, certificates of competency for seafarers, promotion of the shipping sector);

- to issue "warnings" (water-level forecast, tide prediction, storm surge warning service, ice service);

- to monitor the status of the seas (with regard to climate and environmental changes);

- to serve as a maritime geospatial data centre;

- to execute maritime spatial planning in the German Exclusive Economic Zone; and

- to conduct approval procedures for offshore windfarms as well as underwater cables and pipelines. ${ }^{28}$

7.2.3.3 Non-compliance with ship safety laws - the imposition of administrative penalties In the past, the applicable rules for imposing administrative fines as a reaction to identified non-compliance with German ship safety laws were almost as fragmented as the material substance of the rules themselves. The application of criminal fines is a rare exception in that regard whereas the imposition of administrative penalties may occur more frequently. Generally, the law of administrative offences is far more relevant for practice when it comes to the question of how non-compliance with maritime safety laws could be penalized by the German authorities. ${ }^{29}$ Some degree of legal consolidation has been achieved in this area since 2014: the German legislator passed a Federal Ordinance that could oddly be translated as the "Ordinance on Environmentally Responsible Behaviour at Sea". ${ }^{30}$ This ordinance is now the reference act for the public reaction to any MARPOL-related offences but it also includes, for example, other offences in relation to antifouling, ballast water management and even ship recycling.

Generally, the Federal Maritime and Hydrographic Agency ("BSH") is the competent body responsible for imposing any administrative penalties resulting from non-compliance with marine environmental laws under MARPOL (see section 14 of the Federal Ordinance) or other environmentally relevant IMO Conventions. However, it should be noted that the maritime enforcement powers of the "BSH" are not completely exclusive under German

28 See www.deutsche-flagge.de/en/german-flag/flag-state/bsh-federal-martime-and-hydrographic-agency-1, accessed 01 May 2020.

29 A helpful summary of maritime-related administrative offences is available here (however, only in German): www.elwis.de/DE/Schifffahrtsrecht/Allgemeine-Informationen/BVKatBin-See/3-Zuwiderhandlungen-See schifffahrt/3-Zuwiderhandlungen-Seeschifffahrt-node.htm, last accessed 01 May 2020.

30 “See-Umweltverhaltensverordnung” of 13 August 2014, Federal Law Gazette, Part I, 1371. 
law. Rather, the allocation of enforcement powers of different public agencies depends on the specific nature of the maritime offence. For example, and in accordance with section 3 of the "Seeaufgabengesetz", all waterway-related compliance and enforcement competencies are assigned to another important German body which is the "General Directory for Federal Waterways and Shipping". ${ }^{31}$ In addition, the above-mentioned "Occupational Accident Insurance Fund for Transport and Traffic" is the competent body responsible for enforcing any applicable rules of maritime labour law and seafarer-related offences.

Finally, the general categorization of any non-compliance with German public maritime safety laws as administrative offences (see, for example, section 15 of the "Seeaufgabengesetz" and section 28 of the "Ordinance on Environmentally Responsible Behaviour at Sea") results in a direct financial consequence: ultimately, any administrative penalty (for a single offence) must be capped at a maximum of 50,000 euros (see section 15 para. 2 "Seeaufgabengesetz"). This stands in sharp contrast to the potentially much higher financial limitations to penalties in other domestic legal orders (particularly of the United States). It could be questioned whether a cap of 50,000 euros per offence is still appropriate in 2020 and beyond and whether some degree of procedural harmonization among port States should be coordinated. In Germany, only the introduction of criminal proceedings by a criminal prosecutor would carry the potential of imposing higher (criminal) penalties or even of resulting in an imprisonment of the perpetrator(s) in an extreme case. German criminal law provides the option to prosecute severe cases of "offences against the environment" (see Chapter 29, sections 324-330d, of the German Criminal Code). However, this would require the perpetrator(s) to actually "contaminate a body of water or otherwise negatively alter its properties" (see section 324 of the German Criminal Code) in accordance with the required "mens rea" standards under criminal law. There is some case law available in that regard under German law. However, most of these highly specific cases of criminally relevant offences against the environment dealt with the contamination of lakes or inland waterways but did not relate to any non-compliance with German public maritime safety laws - which is, effectively, confined to rules-compliance on the enforcement level of (minor) administrative penalties.

\subsection{Intermediate conclusions}

It will be quite hard to identify any real legal gaps where completely new regulation would be required from scratch or where no federal agency would be competent at all. The lack of user-friendliness in German public maritime law and the decentralized nature of allocating tasks to more than one competent agency is also not a purely maritime-specific issue. Rather, it exists also as a problematic phenomenon in many other areas of German law and one might venture to say that this effect could also be observed in other national legal orders, including the legal order of the EU.

At times, the German executive branch makes an enormous political effort in trying to consolidate and modernize the uncontrolled growth of legislative acts in certain regulatory

31 Generaldirektion Wasserstraßen und Schifffahrt, for a summary of the comprehensive responsibilities of this General Directory (in German) see www.gdws.wsv.bund.de/DE/schifffahrt/schifffahrt-node.html, accessed 01 May 2020. 
areas. Final success of such consolidation and modernization efforts cannot be taken for granted. Ultimately, it also depends on the legislative branch whether contentious political issues can be bridged and whether reasonable compromise solutions are possible. One example of a spectacular political failure in that regard is represented by the almost 20 -year-long uphill struggle to consolidate all German environmental laws in one massive environmental act (officially labelled as the "Umweltgesetzbuch"). This legislative project was originally initiated in the early 1990s, but ultimately, in 2009, the attempt had to be dropped because it resulted, obviously, in too many political and legal complications. In contrast, after many years of preparatory work, German private maritime law was, in fact, successfully modernized and consolidated in the fifth book of the German Commercial Code since 2013 (now sections 476-619). ${ }^{32}$

There have been some thoughts and ideas which have highlighted the necessity to harmonize, modernize and consolidate German public maritime law as well. Nevertheless, one single consolidation act of that kind does not yet exist in Germany - and it is highly doubtful whether such an act could ever be enacted. One major obstacle is the fact that German maritime safety laws are deeply embedded in a protracted system of legal cross-references with other public acts and ordinances. As a result, and backed up by the underlying legal system, the most promising approach of this chapter seems to be to concentrate the discussion predominantly on one legal act which gets as close as possible to the analytical objective of discussing German maritime safety law comprehensively - that is the Federal "Act on Ship Safety" ("Schiffssicherheitsgesetz"). It should not be forgotten that this Act is supplemented by the Federal "Ordinance on Ship Safety" ("Schiffssicherheitsverordnung"). However, an analysis of the ordinance seems to be too technical. Rather, the aim should be to provide some first orientation of how all of these laws form an integral part of the applicable meshwork of maritime safety laws in the German legal order.

\subsection{Prevention and compliance: the German federal act on ship safety ("Schiffssicherheitsgesetz")}

If translated literally, the titles of both the Act (and also the Ordinance) on Ship Safety are partially misleading: The regulatory substance of both laws does not concentrate exclusively on ships. Rather, both laws broadly cover the safety of maritime traffic, ${ }^{33}$ the general protection of the marine environment and related health and safety standards as well. ${ }^{34}$ The Federal Act on Ship Safety focuses broadly on concretizing implementation-related matters while technical details are left to be regulated by the parallel Federal Ordinance on Ship Safety - or by any other laws where the lex specialis rule applies (for example, specific acts to implement maritime labour law or offshore-related rules). ${ }^{35}$

As indicated above, both the Act and the Ordinance on Ship Safety were first enacted jointly in 1998, i.e., the same year when the ISM Code became mandatory by incorporation into the IMO's SOLAS Convention. Generally, both ship safety laws may well be taken

32 See generally R. Herber, Seehandelsrecht-Systematische Darstellung (de Gruyter, Berlin, 2016).

33 The understanding of maritime safety is broad as it includes aspects of maritime security and potential external threats to ships, see section 2 para. 3 of the Act.

34 P. Ehlers, Recht des Seeverkehrs (Nomos, Baden-Baden, 2017), pp. 187 and 192.

35 Section 1 para. 3 of the Federal Act on Ship Safety clarifies the scope of application in that regard. 
as the German domestic approach to partially implementing specific obligations under the United Nations Convention on the Law of the Sea (such as Article 94 paras. 3 and 5, 211 para. 2 and 217 UNCLOS) and to align and update German law to more specific IMOrelated and EU law-infused obligations.

Initially, the Federal Act on Ship Safety also represented a "slimmed down" approach to legal consolidation and modernization in this regulatory area. The Act definitely contributed to establishing some limited degree of user-friendliness that did not exist before 1998 . The enactment of the "Schiffssicherheitsgesetz" explicitly served the purpose of achieving more legal transparency and aimed to put an end to a continuously widening, earlier fragmentation of German ship safety laws which had developed over time as part of individually enacted ship-safety-related rules and regulations. In the spirit of the ISM Code, the Act also highlights the participatory inclusion of private operators aiming to achieve certain results and objectives (see in particular sections 7-9). Thus, at least partially, the act moves away from an enforcement-driven and predominantly prescriptive approach of the previous decades. ${ }^{36}$ The Act has also been amended and further updated numerous times since 1998, in particular, to focus more intensively on the protection of the marine environment.

\subsubsection{The Appendix-based integration of "applicable international regulations"}

The three core objectives of the act (achieving safety of maritime traffic, protecting the marine environment and upholding any related health and safety standards for seafarers) are explicitly mentioned by section 1 of the Federal Act on Ship Safety which defines the scope of application (paras. 1 and 3$).{ }^{37}$

Section 1 para. 2 of the Federal Act establishes a direct legal link to "international regulations applicable under this Act". This is a central provision to understand how the Act generally operates: section 1 para. 2 of the Act directly references the Appendix of the Act. This Appendix has five sections (A-E). It is instrumental to understand the legal system of the Appendix because there is hardly any individual section of the Federal Act on Ship Safety which does not - directly or implicitly - incorporate legal cross-references to the Appendix.

The first three sections of the Appendix (A-C) serve the declaratory function of incorporating all internationally and regionally agreed (legally binding) ship safety standards directly into the German legal order. These three sections include frequent references to all mandatory IMO Conventions and all mandatory regional rules (for example, as agreed under the auspices of the Helsinki Convention for the Baltic Sea) and they also incorporate EU Regulations (which are directly applicable).

In contrast to sections $\mathrm{A}-\mathrm{C}$, the fourth section (D) serves a rather specific function: section D lists all applicable secondary EU Directives which need to be implemented via further domestic legal acts. Further, in contrast to all previous sections of the Appendix, the fifth section (E) makes reference to potentially applicable "soft law", such as "best

\footnotetext{
36 P. Ehlers, Recht des Seeverkehrs (Nomos, Baden-Baden, 2017) p. 189.

37 Initially, section 1 para. 1 of the Federal Act defines the scope of application as broadly "positive" while section 1 para. 3 defines the scope of application in a "negative" manner, i.e., by highlighting which other legal areas are not covered by the Federal Act on Ship Safety.
} 
available technical standards" (and required skills of seamanship) and thus needs to be substantiated in further detail by other domestic laws. ${ }^{38}$

As a result, anyone who seeks a quick reference guide to all international ship safety rules and standards accepted and implemented by Germany may generally resort to studying the massive lists as incorporated by sections A-D of the Appendix to the Federal Act on Ship Safety. However, the reader should always be mindful of three different categories of interlinked legal sources in order to identify:

- whether the legal incorporation serves a rather declaratory purpose because the referenced acts of international law are part of the German legal order anyway (see sections $\mathrm{A}-\mathrm{C}$ of the Appendix in conjunction with section 4 of the Federal Act); or

- whether further domestic implementation is necessary as required by any applicable EU Directives (see section D of the Appendix in conjunction with section 5 of the Federal Act); or, finally,

- whether further domestic implementation and specific substantiation is necessary (see section E of the Appendix in conjunction with section 6 of the Federal Act).

The "technical" advantage for the German legislator - which results from this legal system of all 15 sections of the Federal Act on Ship Safety and its Appendix - should be quite evident: Frequent legal updates and amendments in international or regional fora or at the EU level - but in particular those agreed by the IMO - do not necessitate frequent changes of the material substance of the Federal Ship Safety Act itself. Rather, only the wide variety of legal instruments listed in the Appendix needs to be updated and (if necessary) expanded. This may be done directly by the German Federal Ministry of Transport which may take respective legislative action: the Ministry is legally empowered to issue Federal Ordinances to update and expand the Appendix of the Federal Act on Ship Safety, based on section 15 of the Federal Act on Ship Safety. ${ }^{39}$ As a result, frequent parliamentary discussions on the technicalities of applicable ship safety standards under federal law are neatly avoided. ${ }^{40}$

\subsubsection{Further prevention and compliance-related rules of the Act}

Section 2 of the Act provides further definitions and clarifications, in particular, in relation to all covered commercial vessels (which also include foreign-flagged vessels and, under certain conditions, inland waterway barges but which exclude, as is usually the case, foreign-flagged State vessels which operate exclusively for non-commercial purposes). ${ }^{41}$

38 Section E of the Appendix also makes reference to legally non-binding IMO Codes, guidelines and recommendations. Substantiation and legal incorporation of "soft law" into German law can be achieved via references and updates to the Federal Ordinance on Ship Safety (see section 4 of the Ordinance) which might ultimately result in highly specific proclamations of the Federal Ministry of Transport via the specialized federal gazette on traffic laws and regulations ("Bundesverkehrsblatt").

39 See details commented by P. Ehlers, Recht des Seeverkehrs (Nomos, Baden-Baden, 2017), pp. 223-224.

40 Art. 80 of the "Basic Law" establishes the constitutional benchmarks for any of those Federal Ordinances which are, unsurprisingly, a popular implementation instrument for the German executive branch.

41 See details commented by P. Ehlers, Recht des Seeverkehrs (Nomos, Baden-Baden, 2017), pp. 196-202. 
Section 3 is entitled "Elementary Principle" and broadly summarizes that anyone who operates a ship for commercial purposes must continuously and permanently ensure that those ship operations are entirely safe, including all design-, equipment- and manningrelated aspects. ${ }^{42}$ Section 3 of the Federal Act on Ship Safety truly mirrors the broad legal thrust of the ISM Code (which is specifically mentioned in section A (No. 1.9) of the Appendix to the Federal Act) ${ }^{43}$

Sections 7-9 of the Act substantiate the related legal obligations of the shipowner, the master and other responsible persons in a more sophisticated manner, focusing on safetyrelated details of organization, management, construction, design, equipment and specific behavioural responsibilities. In general, the "spirit" and the objectives of all safety-related mandatory IMO instruments (in particular under SOLAS, MARPOL and STCW) shines clearly through all of the provisions of the German Federal Act on Ship Safety. ${ }^{44}$ This assessment is also evidenced by section 12 of the Act which specifies that the legally required discretion of public authorities should take any guidelines and recommendations of the IMO (or any other competent organization) into additional consideration. ${ }^{45}$

Broadly speaking, sections 10-14 of the Act concentrate on rules aimed at monitoring and enforcing all ship safety-related rules as substantiated by the Act. A number of legal cross-references to other acts and ordinances become particularly relevant here. The Act on Ship Safety (only) sets out the general objective of monitoring and enforcement. However, section 10 para. 2 of the Act clarifies that all administrative details of specific monitoring and enforcement powers are delegated and organized under the legal framework of the task-oriented "Seeaufgabengesetz" (and under other highly specific laws, for example, in relation to enforcing MARPOL-related violations). ${ }^{46}$ The same is true for section 11 which is specifically dedicated to monitoring and enforcing all legal obligations "infused" under EU secondary law (the provision only relates to EU Directives). ${ }^{47}$ Section 10 para. 3 of the Act establishes a legal duty to cooperate efficiently with the enforcement authorities of other nations and with international organizations.

Section 13 of the Act is entitled "Measures to Be Taken with Regard to Violations". It is again a good example of the goal-oriented character of the Federal Act on Ship Safety which has to leave the details of any legal countermeasures to other acts and ordinances: section 13 para. 1 of the Act merely stipulates that the competent authorities (again, under the "Seeaufgabengesetz") will adhere to all legal obligations and limitations applicable under UNCLOS. The second paragraph of section 13 declares specifically that ISM-related certificates may be de-validated and may be withdrawn "by the competent authorities" if non-compliance is established. ${ }^{48}$

42 It should be noted that the reform of German private maritime law is quite helpful in this regard because sections 476-478 of the German Commercial Code provide new legal definitions for "persons involved in shipping", including legal definitions for "shipowner" (Reeder), "ship operator" (Ausrüster) and for anyone performing professional tasks on or on behalf of the ship (Schiffsbesatzung).

43 See details commented by P. Ehlers, Recht des Seeverkehrs (Nomos, Baden-Baden, 2017), pp. 202-203.

44 The reason why the International Maritime Labour Convention of 23 February 2006 (MLC) is not mentioned in the list is explained by the fact that Germany has a more specific domestic maritime labour law act ("Seearbeitsgesetz") which implements the spirit and objectives of the MLC in a comparable manner.

45 See details commented by P. Ehlers, Recht des Seeverkehrs (Nomos, Baden-Baden, 2017), pp. 218-219.

46 Ibid., pp. 215-216.

47 Ibid., pp.217-218.

48 Ibid., pp. 219-220. 
Section 14 of the Act addresses Port State Control (PSC) measures in relation to foreignflagged vessels. The system of the Act becomes relevant again because the provision has to acknowledge the fact that PSC is subject to legal harmonization under international rules and, in particular, PSC is subject to an EU Directive. ${ }^{49}$ The measures are listed in the Appendix to the Act (section D No. 8, for the EU Directive). Ultimately, section 14 para. 1 of the Federal Act on Ship Safety gives effect to the applicable EU law on Port State Control. Section 14 para. 2 of the Act generally incorporates the widely known "no more favourable treatment" principle. Thus, the sub-provision clarifies that any non-ratifying flag States would still have to comply with ship-safety standards of IMO Conventions as ratified by the German port State. However, the German authorities are still empowered with some degree of professional discretion in that regard (aiming at compliance with those generally accepted standards as listed under section A of the Appendix). ${ }^{50}$

\subsection{Issuing and monitoring compliance with mandatory liability insurance}

Germany has ratified all relevant IMO Conventions which address aspects of liability and compensation. Traditionally, the related legal instruments addressed civil liability for oil pollution and bunker oil pollution. ${ }^{51}$ Germany fully embraces the regulatory approach of integrating financial security instruments into the overall framework of maritime safety laws, including compulsory insurance for the carriage of passengers by sea. However, the best practical example for that acceptance is probably the fact that Germany was one of the initial "sponsoring" IMO Members to support the introduction of an IMO Convention on the Removal of Wrecks (Nairobi Convention): one legal backbone of that IMO Convention is the new introduction of mandatory liability insurance for wreck removal operations since 2015.52

Pursuant to section 5 para. 1 (second sentence) No. 1 of the "Seeaufgabengesetz", the Federal Maritime and Hydrographic Agency acts as the competent authority for issuing all IMO-driven liability and insurance certificates - at times even acting on behalf of other flag States. ${ }^{53}$ The insurance-related obligations and liability impacts of the CLC, the Bunker

49 Now Directive 2009/16/EC of the European Parliament and of the Council of 23 April 2009 on port State control, OJ L 131, 28.5.2009, p. 57.; initially: Council Directive 95/21/EC of 19 June 1995 concerning the enforcement, in respect of shipping using Community ports and sailing in the waters under the jurisdiction of the Member States, of international standards for ship safety, pollution prevention and shipboard living and working conditions (Port State Control), OJ L 157, 7.7.1995, p. 1.

50 See details commented by P. Ehlers, Recht des Seeverkehrs (Nomos, Baden-Baden, 2017) pp. 221-222.

51 The compensation and liability aspects of both the Civil Liability Convention of 1992 (CLC - Protocol of 1992 to amend the International Convention on Civil Liability for Oil Pollution Damage, 1969, adopted on 27 November 1992, entered into force on 30 May 1996, UNTS 1956) and the Bunker Oil Convention of 2001 (International Convention on Civil Liability for Bunker Oil Pollution Damage, 2001, adopted on 23 March 2001, entered into force on 21 November 2008) have been implemented via the German "Ölschadensgesetz" (originally from 1988, Federal Law Gazette, Part I, 1770).

52 Nairobi International Convention on the Removal of Wrecks, 2007 (adopted on 18 May 2007, entered into force on 14 April 2015). The 2007 Nairobi International Convention on the Removal of Wrecks entered into force internationally on 14 April 2015. The WRC applied for the Federal Republic of Germany as of this date because Germany had already ratified the WRC on 20 June 2013.

53 For example, it is possible to apply at the "BSH" for the issuance of a German wreck removal liability certificate, if (1) the ship flies the German flag; or (2) if the ship is registered in a German register but has changed to a foreign flag which is not a State Party to the Wreck Removal Convention and (3) even if the ship is neither registered in a shipping register of a State Party nor flying the flag of a State Party. The period of validity of the 
Oil Convention, the Athens Convention ${ }^{54}$ and the Wreck Removal Convention are now primarily implemented by modernized and consolidated legal acts which have been introduced since 2013, in implementation of Directive 2009/20/EC on the insurance of shipowners for maritime claims. ${ }^{55}$ As a result, the main source of law is now the German "Act on Particular Proof of Insurance in Maritime Transport. ${ }^{56}$ As it occurs frequently under German law, further technicalities are incorporated into a parallel Federal Ordinance (here: "On the Issuance of Liability Certificates"). ${ }^{57}$ A short summary of these acts and their legislative impact is available (in English) on the centralized website of the German Flag State administration. ${ }^{58}$

To complete the regulatory picture: An "Act on the Enforcement of Claims for Wreck Removal" now defines the shared competencies of the German maritime authorities with regard to wreck removal operations in accordance with the IMO's Nairobi Convention..$^{59}$ This act only has four provisions and those - essentially - establish a legal cross-reference to the rules of German civil law which is made applicable for the purposes of any potential cost recovery for EEZ-related wreck removal operations (i.e. $\S \S 670,683$ of the German Civil Code, as established already for decades in relation to the German territorial sea and German internal waters). ${ }^{60}$

The "Act on the Enforcement of Claims for Wreck Removal" defines the "General Directory for the Federal Waterways and Shipping" (and its sub-divisions) as the competent authorities for any kind of wreck removal-related recovery of costs. As a result, the issuing institution of the mandatory liability insurance (the "BSH") is not involved itself in the recovery of any costs, usually against the liability insurer. However, the actual existence of that insurance must be verified via the national wreck removal liability certificate which is, in fact, issued by the "BSH" (upon application). And the originals of the liability certificate (including the wreck removal liability certificate) must be carried on board the ships and must be presented (upon request) to the surveyors of the Ship Safety Division. To sum up (and further details will always depend on each and every regulatory topic specifically), it is, in fact, possible in Germany that three interrelated, maritime safety law-induced tasks of

- issuing the verification of existing mandatory insurance (documentary tasks);

- monitoring the existence of mandatory insurance (Flag/Port State Control); and

- recovering costs based on the existence of mandatory liability insurance

German wreck removal liability certificate is in principle the same as that of the insurance in place or other financial security provided; it does, however, not exceed one year.

54 However, as for all EU Members, not the Athens Convention but rather Regulation 392/2009/EC on the liability of carriers of passengers by sea in the event of accidents, OJ L 131, 28.5.2009, p. 24, was the driving legal source in that regard.

55 See OJ L 131, 28.5.2009, p. 128.

56 In German: "Seeversicherungsnachweisgesetz" (SeeVersNachwG), Federal Law Gazette 2013, Part I, 1471; see explicitly J. M. Hoffmann, G. Tüngler \& S. Kirchner, "Das neue Seeversicherungsnachweisgesetz", (2013) Recht der Transportwirtschaft, 264-267.

57 In German: "Seeversicherungsnachweisverordnung" (SeeVersNachwVO), Federal Law Gazette 2013, Part I, 1926; discussed by J. M. Hoffmann, G. Tüngler \& S. Kirchner, "Neue Entwicklungen im Seeversicherungsnachweisrecht - Die neue Seeversicherungsnachweisverordnung”, (2013) Recht der Transportwirtschaft, 420-423.

58 See www.deutsche-flagge.de/en/liability, accessed 01 May 2020.

59 In German: “Wrackbeseitigungskostendurchsetzungsgesetz", Federal Law Gazette 2013, Part I, 1478.

60 The general legal supremacy of the Nairobi Convention (in particular Art. 10 of the Wreck Removal Convention) remains untouched. 
are - institutionally - split between three different federal bodies. That list does not even include enforcement powers in actual emergency situations. It is quite evident that this system of splitting up competencies and powers can result in some loss of time and efficiency. Above all, it is difficult to understand, not only at first sight. On the other hand, this system works almost like a historically based, institutionalized application of "checks and balances" between the different competent public authorities.

\subsection{Conclusions}

One technical obstacle to truly embracing the variety of German maritime safety laws by any non-German reader is represented by the fact that official English translations only exist for selected legal acts, particularly in relation to modernized acts or new laws which have been passed over the last few years. For example, a number of German maritime labour laws (including more specialized ordinances and other seafarer-related acts) are, in fact, accessible in English. ${ }^{61}$ The evident translation gap will probably be closed over the next decades - possibly also as a result of Germany's next mandatory audit under the IMO Member State Audit Scheme (IMSAS) - otherwise it is a lot harder for any non-German third-party to understand how the applicable legal system works. ${ }^{62}$ For the moment, a lot of interpretation work yet remains to be done.

However, even if official English translations of the "Seeaufgabengesetz" and the "Seesicherheitsgesetz" (and all the other applicable acts of public maritime law) might be made available at some point, the non-German analyst would most probably still be quite stunned by the regulatory approach, in particular, if the reader originates from a centralistic (non-federal) system. In Germany, an "allocation-of-tasks-geared" Federal Act, the "Seeaufgabengesetz", stands in the organizational centre of all applicable German maritime laws, including those relating to maritime safety and security. This act lists more than 20 broad maritime tasks which create a legal obligation for the Federation to take further implementation measures. A meshwork of laws has grown wildly, originating historically from this approach over the decades. Neither is the catalogue of section 1 of the "Seeaufgabengesetz" systematically stringent nor has it resulted in a transparent, uniform, consistent and systematic outcome. Rather, the application in practice is quite protracted even for a professionally trained public or administrative lawyer.

As a result, when it comes to public maritime safety laws, Germany can hardly work as a fitting regulatory role model for other countries in the way it has (generally and historically speaking) for applying comprehensive codes in the areas of civil law, commercial law or criminal law. However, and ending on a positive note: the historically evolved legal system works quite well for Germany itself, both as a flag State as well as a port/coastal State. As a flag State, Germany is frequently a Top-10 country of the "PSC White Lists".

61 See, for example, the German Maritime Labour Law Act ("Seearbeitsgesetz"), for the English translation, see www.gesetze-im-internet.de/englisch_seearbg/index.html, accessed 01 May 2020. About ten other, highly specific German acts have been officially translated into English, almost all of them either relating to maritime labour laws or to the implementation of specific requirements under the IMO's STCW Convention.

62 For the background of the IMO's mandatory audit scheme, see H. Jessen \& L. Zhu, "From a Voluntary Self-assessment to a Mandatory Audit Scheme: Monitoring the Implementation of IMO Instruments", (2016) 3 Lloyd's Maritime and Commercial Law Quarterly 389-411. 
The domestic implementation, monitoring and enforcement bodies are aware of all the details of their respective maritime-related roles - both in relation to flag State control as well as to Port State Control - and any related competency-struggles between public maritime authorities can - in general - be resolved quite efficiently. Usually, legal updates and technical amendments can be incorporated quite quickly (by updating and expanding the existing legal meshwork and by the Federal Ministry of Transport frequently resorting to the issuance of Federal Ordinances).

Besides, since 1998, Germany's coastline has not been hit significantly by the results of any major maritime casualty affecting the country as a coastal State. The last example of such a threatening maritime casualty was the massive fire on board the timber-carrying cargo vessel Pallas (1998). Five years later, the institutional lessons learnt from this casualty scenario led to the foundation of the "German Central Command for Maritime Emergencies" (CCME) in 2003. ${ }^{63}$ The CCME (duly cooperating with competent authorities of the Federation and the "Länder") is now also the competent body which is, ultimately, legally empowered to select an appropriate German port of refuge in an individual maritime casualty scenario. ${ }^{64}$ In sum, and in the absence of any true major implementation problems, there is no compelling reason for Germany to change its traditional, often historically grown approach to regulating public maritime law. For the future, the domestic legal system discussed in this chapter will thus remain as indicated in the title: it will continue to be comprehensive but complicated.

63 The CCME is a joint institution of the German Federal Government and the Federal Coastal States. It was established to set up and carry out a mutual maritime emergency management in the North Sea and the Baltic Sea; for further information see www.havariekommando.de/EN/home/home-node.html, accessed 01 May 2020.

64 This decision would now be based on a specific domestic law ("Gesetz zur Notliegeplatzverordnung" (abbreviated as "NotLPIVbgG)"). This law and the coordinative role of the CCME serve as the German implementation of related legal expectations as generated on the international level, above all, by applicable IMO guidelines (see: www.imo.org/en/OurWork/Safety/Navigation/Pages/PlacesOfRefuge.aspx accessed 01 May 2020), as well as by the "EU Operational Guidelines on Places of Refuge" as coordinated by the European Maritime Safety Agency (EMSA). 


\title{
Brief reflections on the regulation and implementation of maritime safety in the UK
}

\author{
Filippo Lorenzon
}

\subsection{Introduction}

The United Kingdom has always put a significant effort into the development of international law on the safety of life at sea and the security of ships, crews, cargo and ports. Since joining the EU, the UK has played a key role in developing EU maritime legislation, implementing it at home and enforcing it in its ports and territorial sea, in compliance with international law. It is, however, important to remember that safety at sea cannot be achieved only through a network of international, regional and national pieces of safety legislation strictu sensu but requires significant cultural drive as well as considerable commercial pressure. UK-based P\&I clubs, H\&M underwriters, classification societies and trade associations have played an increasingly significant role in this process, not only by lobbying governments and European Institutions but - more effectively - insisting that full compliance with international safety standards (or evidence thereof) is a condition of the contract or a warranty of cover. Moreover, the responsibility imposed by English law on shippers, sellers, cargo interests and charterers in relation to the general safety of the adventure as a whole contributes significantly to the overall aim of keeping ships, seafarers and the environment safe.

English common law, with its absence of comprehensive codification and its strictly applied principle of stare decisis, makes the task of assessing "maritime safety" quite complex, even more so in the current Brexit "transition period". Currently, the sources of maritime law related to safety are very diverse and can be found mostly in the 1995 Merchant Shipping Act (as amended), supplemented by a number of other statutes and a large number of statutory instruments (through which EU directives are usually implemented) and EU regulations all with a common leitmotif: they all focus on the human and technical element of shipping, aiming at preventing human error, enhancing the working and living conditions of seafarers and - in the broadest sense - preserving life at sea.

This body of different instruments provides detailed regulations with which shipowners and operators are required to comply. Such compliance is achieved by a system of certification and control largely performed by classification societies on behalf of the flag State administration (or Flag State Control) and enforced by the port State (or Port State Control) according to very specific rules set by the International Maritime Organization (IMO). A system of mutual recognition of certification and - within the EU and currently still the 
$\mathrm{UK}^{1}$ - the important intervention of the European Maritime Safety Agency (EMSA) further enhance uniform compliance with the Conventions.

It is to follow this leitmotif that the following analysis will focus on the instruments that are obviously connected to safety: the 1974 International Convention for the Safety of Life at Sea (SOLAS Convention) and the International Safety Management (ISM) Code; the International Ship and Port Facility Security (ISPS) Code; the International Convention on Standards of Training, Certification and Watchkeeping (STCW 2010) and the Maritime Labour Convention 2006.

\subsection{The structure for the implementation of maritime safety law in the UK}

The ministry with competence for the strategic development, coordination and implementation of maritime safety law in the UK is the Department for Transport (DfT) in close cooperation with the Maritime and Coastguard Agency (MCA), the Marine Accident Investigation Branch (MAIB) and the three General Lighthouse Authorities (GLAs). The High Court in London has a specialist Admiralty Court ${ }^{2}$ with Admiralty jurisdiction $^{3}$ but matters of maritime safety can be heard in the Commercial Court, Labour Tribunals across the country and indeed in arbitration, depending on the way in which the issue arises, as the two examples below will illustrate in relation with the ISM Code.

When the Hague or Hague-Visby Rules apply to a claim for loss of or damage to cargo carried under a bill of lading, Article III rule 1 requires the carrier to exercise due diligence to make the ship seaworthy before and at the beginning of the voyage. ${ }^{4}$ Where the Hague or Hague-Visby Rules apply, carriers will be unable to benefit from the exclusion from liability for negligence in the navigation or management of the ship or the other exceptions contained in Article IV rule 2, if at any time the damage to the cargo is due to the unseaworthiness of the carrying vessel, unless they are able to prove the exercise of due diligence to make the ship seaworthy before and at the beginning of the contract voyage. This duty is non-delegable. ${ }^{5}$ The link between due diligence as to seaworthiness and an effective system of ship and safety management under the ISM Code is immediately apparent. The ISM Code in fact represents the internationally recognised standard of good ship and safety management, and failure to comply with its principles, as opposed to the simple failure to produce a valid certificate, could be argued to render the vessel unseaworthy on the basis that "there is something about it [...] which renders it legally or practically impossible for the vessel to go to sea or to load or unload its cargo", ${ }^{6}$ or at least negatively affect the

1 At the time of writing, the United Kingdom has left the European Union as from 31 January 2020. There follows a transition period until 31 December 2020. Pursuant to the European Union (Withdrawal Agreement) Act 2020 which amends the European Union (Withdrawal) Act 2018, EU legislation will still apply until the implementation completion day which is defined in section 39(5) of the 2020 Act as 31 December 2020 at $11 \mathrm{pm}$.

2 See www.gov.uk/courts-tribunals/admiralty-court, last accessed on 31 May 2020.

3 As defined in s.20 of the Senior Courts Act 1981.

4 The International Convention for the Unification of Certain Rules of Law Relating to Bills of Lading signed at Brussels on 25 August 1924 as amended by the Protocol signed at Brussels on 23 February 1968 and by the Protocol signed at Brussels on 21 December 1979.

5 Riverstone Meat Co Pty Ltd v Lancashire Shipping Co Ltd (The Muncaster Castle) [1961] 1 Lloyd's Rep 57.

6 Athenian Tankers Management SA v Pyrena Shipping (The Arianna) [1987] 2 Lloyd's Rep 376, at p 389 (Webster J); for the corresponding issue under the ISPS code see B. Soyer and R. Williams, "Potential Legal 
position of the operator qua carrier's ability to provide evidence of having exercised due diligence at the relevant time. $^{7}$

Similarly, ISM compliance may be relevant for the purpose of section 39(5) of the Marine Insurance Act 1906 to exclude liability of the insurer if the ship is sent to sea in an unseaworthy condition with the privity of the assured. It is, however, common for policies of insurance to contain specific ISM-related warranties. In Sea Glory Maritime Co v Al Sagr National Insurance Co (The Nancy), ${ }^{8}$ the words "Vessels classed and class maintained. Vessels ISM Compliant" were included in an amended hull and machinery policy concluded on Institute Time Clauses (ITC) - Hulls 95 terms for the M/V Nancy, a bulk carrier, which became a constructive total loss after a serious fire on board while in the port of Nokhodka, in Russia. The insured perils under the policy included fire but the insurers denied liability on a number of grounds including misrepresentation, nondisclosure and - most relevantly for present purposes - breach of the express ISM warranty. In the circumstances, the Safety Management System of the company managing the vessel was found to suffer from six areas of major non-conformity with the ISM Code. The claimants argued that the vessel possessed documentation certifying compliance with the Code. Blair J held that the insurers were liable for the sums claimed as the words "Vessels ISM Compliant" required only documentary compliance and that there was a distinction between compliance with the warranty and compliance with the Code.

In 2019 the DfT developed an interesting document titled "Maritime Safety Action Plan - Maritime safety matters. Moving Britain ahead" in which the DfT explains its role as one of having "overall responsibility for maritime safety policy, including leading some of the government's strategic international engagement and representation at relevant international forums such as the International Maritime Organization (IMO) and the International Labour Organization (ILO)" ${ }^{10}$

The Maritime and Coastguard Agency (MCA) is also on the front line of the government's safety work as its role is that of "developing and implementing safety policies as they apply to commercial shipping domestic passenger ships, fishing vessels and those working on these vessels". ${ }^{11}$

The Maritime Accident Investigation Branch (MAIB) ${ }^{12}$ is the permanent body within the DfT for the independent investigation of maritime accidents and its sole statutory objective is that of investigating an accident to determine its circumstances and causes, with the aims of improving safety and avoiding future accidents. The relationship between the MAIB and the DfT is regulated by a "Protocol governing the relationship between the Department for

\footnotetext{
Implications of the International Ship and Port Facility Security (ISPS) Code on Maritime Law" (2005) 2 Lloyd's Maritime and Commercial Law Quarterly 515.

7 See The Eurasian Dream (fn 16). See also Alize 1954 and Another v Allianz Elementar Versicherung AG and Others (The CMA CGM Libra) [2020] EWCA Civ 293.

8 [2013] EWHC 2116 (Comm); [2014] 1 Lloyd's Rep 14.

9 Hereafter the "Maritime Safety Action Plan", available on the DfT website at https://assets.publishing.serv ice.gov.uk/government/uploads/system/uploads/attachment_data/file/813274/maritime-safety-action-plan.pdf, last accessed on 31 May 2020.

10 Maritime Safety Action Plan, para 2.2.

11 Maritime Safety Action Plan, para 2.3. 2020 .

12 See www.gov.uk/government/organisations/marine-accident-investigation-branch, last accessed 30 May
} 
Transport and the accident investigation branches". ${ }^{13}$ The admissibility of MAIB reports in English civil cases may have been questioned as "inadmissible opinion evidence", since the relatively recent decision in the aviation case of Rogers $v$ Hoyle ${ }^{14}$ in which the Court of Appeal confirmed that Aviation Accident Investigation Reports are admissible in judicial proceedings.

\subsection{Prevention}

In maritime safety, prevention is considerably better than cure and a great deal of international work has gone into preventive legislation as well as preparedness and response. The UK is party to all the key international conventions on safety, with the notable exception of the 1996 Hazardous and Noxious Substances Convention and its 2010 Protocol.

The key international instrument on the prevention of maritime accidents is certainly the SOLAS Convention, ${ }^{15}$ the subject matter of which is to promote safety of life at sea by establishing rules which govern the safe construction of ships ${ }^{16}$ the safety equipment with which ships are required to be fitted and the standards to which they should be operated in order to avoid accidents. ${ }^{17}$ It is the role of the IMO to review the Convention regularly and to draft any necessary amendments, ${ }^{18}$ but the responsibility for enforcement of the provisions of the Convention lies, in respect of UK registered ships, with the UK Administration ${ }^{19}$ which must ensure that the ships which trade under its flag are surveyed when they are first registered, in order to establish compliance with SOLAS. ${ }^{20}$ The UK is permitted to delegate these responsibilities to a recognised body such as a classification society. ${ }^{21}$ As a port State, operating under administrative agreements such as the Paris Memorandum of Understanding on Port State Control - the Paris $\mathrm{MoU}^{22}$ - the UK has authority to inspect

13 Ibid.

14 [2014] EWCA Civ 257.

15 International Convention for the Safety of Life at Sea (London, 1974), ((signed in 1974, entered into force in 1980) 1184, 1185 UNTS 18961) with the Protocol of 1988 as amended (hereinafter "SOLAS"). A full list of amendments and ratifications is available at www.imo.org/About/Conventions/StatusOfConventions/Pages/Defa ult.aspx (accessed 25 February 2020). See The Merchant Shipping (Safety of Navigation) Regulations 2002, SI 2002/1473 as amended from time to time. In accordance with Regulation 5(4) of the MS (Safety of Navigation) Regulations, 2002, any changes to SOLAS Chapter V implemented through IMO Resolutions will be given effect in UK legislation by changes to this MCA document ("Safety of Navigation, Implementing SOLAS Chapter V, 2002"). Any such changes will be given effect by the promulgation of a Merchant Shipping Notice.

16 SOLAS, Chapter II.

17 See also SOLAS, Chapter III.

18 According to the procedure set up in Art. VIII.

19 SOLAS, Art. I.

20 See SOLAS, Art. I. For the EU see also Directives 2009/21/EC of the European Parliament and of the Council of 23 April 2009 on compliance with the flag State requirements, OJ L 131, 28.5.2009, p. 132, transposed into UK law by The Merchant Shipping (Flag State Directive) Regulations 2011 and 2009/15/EC of the European Parliament and of the Council of 23 April 2009 on common rules and standards for ship inspection and survey organisations and for the relevant activities of maritime administrations, OJ L 131, 28.5.2009, p. 47 (for transposition into UK law see The Merchant Shipping Notice MSN 1672 (M+F) Amendment 3 - Ship Inspection and Survey Organizations and European Directive 2009/15/EC), and Regulation (EC) No 391/2009 of the European Parliament and of the Council of 23 April 2009 on common rules and standards for ship inspection and survey organisations (as amended), OJ L 131, 28.5.2009, p. 11.

21 See below and SOLAS, Chapter I, reg 6.

22 The Paris MoU is an administrative agreement adopted in January 1982. Initially signed by 14 European countries at a Ministerial Conference held in Paris, it entered into operation on 1 July 1982. It now counts 27 Maritime Administrations. See www.parismou.org/about-us/organisation (accessed 31 May 2020). 
those ships on which they have grounds to believe they are not in compliance with SOLAS and if necessary detain them. ${ }^{23}$

Together with SOLAS, the UK has also adopted the ISM Code ${ }^{24}$ which has the objective of "ensur[ing] safety at sea, prevention of human injury or loss of life, and avoidance of damage to the environment in particular to the marine environment and to property" ${ }^{25}$ The ISM Code was adopted by the IMO in 1993 and in 1994 it was inserted into the SOLAS Convention as Chapter IX. On 1 July 1998, the code became mandatory for passenger ships, high speed ships, tankers and bulk carriers of more than 500 gross tonnes. Later, from 1 July 2002, it became mandatory for all other types of ship, excluding warships, auxiliaries or other government-operated ships, used for non-commercial purposes. ${ }^{26}$ The implementation was done through the Merchant Shipping (International Safety Management (ISM) Code) Regulations 1998, SI 1998/1561, since repealed by the Merchant Shipping (International Safety Management (ISM) Code) Regulations, SI 2014/1512, reg 3.

The UK is a party of the STCW 2010 the aim of which is to ensure seafarers worldwide are trained to consistent standards and that seafarers' certificates of competency are issued to similar acceptable and consistent standards. The training and certification of seafarers has always been the responsibility of flag administrations and before 1978 when the first STCW Convention ${ }^{27}$ was drafted, most of the recognised or traditional maritime administrations had in place their own established procedures in order to satisfy these requirements, always to the highest standards. The latest revision of the STCW Convention and Code came into force on 1 January 2012 under the tacit acceptance procedure and is aimed at ensuring precisely defined uniform standards of training, certification and competency; better procedures to guarantee that the STCW Convention is implemented and enforced worldwide; and the flexibility to meet the demands of the industry in the twenty-first century. The Convention is in force in the UK through the Merchant Shipping (Standards of Training, Certification and Watchkeeping) Regulations 2015, SI 2015/782 as amended.

Peculiar to the UK system in place for the prevention of maritime accidents is the SOSREP i.e. the Secretary of State's Representative, a civil servant specifically appointed by the government to oversee the national casualty response in order to reduce the environmental impact and financial cost of maritime disasters. The SOSREP has significant power when it comes to marine accidents; most remarkably: s/he has overall responsibility for monitoring response in offshore incidents with pollution risk. S/he can take control of incident management, and exercise intervention powers in incident response including offering ports of refuge to vessels in distress. This powerful figure was first introduced in 1999 following a recommendation in Lord Donaldson's "Safer Ships, Cleaner Seas"

23 Paris MoU, s 3.

24 The International Management Code for the Safe Operation of Ships and for Pollution Prevention, 2014 consolidated edition, as amended by resolutions MSC.104(73), MSC.179(79), MSC.195(80), MSC.273(85), which entered into force on 1 July 2002, on 1 July 2006, on 1 January 2009, and on 1 July 2010, respectively, and resolution MSC.353(92), which entered into force on 1 January 2015.

25 ISM Code, Art. 1.2.1.

26 On the ISM Code and Regulations see P. Anderson, ISM Code: A Practical Guide to the Legal and Insurance Implications (3rd edn, Informa Law from Routledge, 2015).

27 International Convention on Standards of Training, Certification and Watchkeeping for Seafarers 1978, as amended (adopted on 7 July 1978, entered into force on 28 April 1984, UNTS 1361) 2. 
report $^{28}$ and has so far proven a very successful experiment of the English administrative system related to maritime safety.

\subsection{Control and surveillance system}

The complexity of the legal framework involved and the technical background required to perform a thorough assessment in terms of safety compliance are such that in practice the duties of the UK flag to verify, certify and control its fleet for compliance with international standards are often delegated to specialist private bodies known as classification societies.

Classification societies are independent private bodies engaged in the study, development and surveillance of the technical side of ship structural safety and as such they have achieved a pivotal role within the shipping world. Generally speaking, the work of classification societies is based on service contracts with shipowners and shipbuilders alike. However, the importance of class certificates extends well beyond the interests of owners and builders since class documents are relied upon not only by flag States and Port State Control, but also by charterers and traders keen to see their products shipped on board staunch vessels and insurers who need to know the condition of the ships they insure in order to calculate the relevant risks and set the premium. ${ }^{29}$ Buyers of vessels may also need the classification certificates to ensure the future employability of the vessel and it does not stop there: other users of the sea, seafarers and coastal interests such as beach resorts and fishing reserves rely on class certificates almost as a form of guarantee for the safety of the world's fleet.

To better understand the work performed by classification societies and the different liabilities which may arise in respect thereof, it is necessary to divide it into two categories, (i) statutory work and (ii) non-statutory work.

i) Statutory surveys are performed by classification societies as representatives of the administration under formal authorisation granted by flag States. In performing these surveys, classification societies discharge obligations imposed on the flag State by international or national law. These functions comprise the assessment of the flag fleet in order to determine the compliance of registered vessels with the applicable requirements of the international conventions and codes, ${ }^{30} \mathrm{EU}$ Directives $^{31}$ and national legislation and the issue of statutory certificates.

ii) Non-statutory surveys include any other contractual work carried out by classification societies which does not involve the performance of statutory surveys or the issue of statutory certificates.

The distinction is extremely important and often misunderstood: for the purposes of this volume - i.e. safety and security compliance - only statutory work is relevant as the responsibility for the certificates issued is imposed by international conventions on the flag

28 Safer Ships, Cleaner Seas: Report of Lord Donaldson's Inquiry into the Prevention of Pollution from Merchant Shipping (Cm.: 2560).

29 This was, in origin, the raison d'être for the development of classification societies.

30 Some of which, such as the ISM Code, SOLAS etc., were discussed above.

31 Such as Directive 2009/13/EC, OJ L 124, 20.5.2009, p. 30. 
States and then delegated to the society. In fact, in order to perform statutory work, classification societies have to become "Recognised Organisations" ("ROs") and go through a special procedure now standardised within the European Union through Regulation (EC) 391/2009. ${ }^{32}$ Recognition will only be granted to organisations meeting specific "minimum criteria" 33 and may be withdrawn in case of serious failure in safety and pollution prevention performance. ${ }^{34}$

Once duly recognised, a RO may be contracted by the flag State to perform its certification duties. Such delegation, referred to as "authorisation", is dealt with by Directive 2009/15/EC, ${ }^{35}$ which in its latest recast attempts to create some degree of uniformity across Europe on the specific issue of liability between the authorising States and the classification societies in respect of damages arising from faults of the classification societies in performing statutory surveys. ${ }^{36}$ Unsurprisingly, within the scope of their various tasks and duties, classification societies may make mistakes that can cause damage either to the shipowner or to third parties. ${ }^{37}$ The extent of their liability in such events would vary depending on the type of survey that has been performed. Where the organisation is carrying out statutory work, its negligence may lead to third party claims against the State or the relevant Maritime Authority. In such cases the liability of the State or authority will depend on general principles of the national law concerned, whereas the recourse action against the organisation will depend entirely on the actual wording of the agreement in place between the society and the relevant administration.

When acting on behalf of national administrations, the vast majority of ROs in Europe have a contractual arrangement in place, generally called a "Model Agreement". Such agreements contain a schedule with a full list of all functions which are delegated to the organisations by the administration concerned. Generally speaking, the agreements impose a duty of care on the classification societies and a liability towards the Administration for breach of such duty, on the basis either of Directive 2009/15/EC or of IMO MSC Circular 710 and MEPC Circular 307. Of course, for a national authority to claim against a classification society under the relevant agreement there must be a breach of the agreement and there must be damage suffered as a consequence thereof. Damages may be suffered by the authorising State if the classification society has been negligent and the State sued

32 Regulation (EC) 391/2009 of the European Parliament and of the Council of 23 April 2009 on common rules and standards for ship inspection and survey organisations, OJ L 131, 28.5.2009 p. 11; as amended by Directive 2014/111/EU, OJ L 366, 20.12.2014, p. 83; and Regulation 2019/1243/EU, OJ L 198, 25.07.2019, p. 241.

33 Ibid., Annex I.

34 Regulation (EC) 391/2009, Art. 7.

35 Directive 2009/15/EC of the European Parliament and of the Council of 23 April 2009, on common rules and standards for ship inspection and survey organisations and for the relevant activities of maritime administrations (hereinafter "Directive 2009/15/EC"), OJ L 131, 28.05. 2009, p. 47; as amended by Directive 2014/111/EU of 17 December 2014 amending Directive 2009/15/EC with regard to the adoption by the International Maritime Organization (IMO) of certain Codes and related amendments to certain conventions and protocols, OJ L 366, 20.12.2014, p. 83 .

36 The attempt however can only be partly successful as demonstrated in a study by the Institute of Maritime Law of the University of Southampton; see Commission of the European Communities, "Commission Working Document on the Control of Recognised Organisations by the Commission and on the Impact of the Civil Liability Regime in Accordance with Directive 94/57/EC", COM (2006) 588 final, 11 October 2006.

37 As charterers or cargo owners, as happened in Marc Rich \& Co AG v Bishop Rock Marine Co Ltd (The Nicholas H) [1996] AC 211; [1995] Lloyd's Rep 299 (HL). 
and found liable to pay damages for such breach of statutory duty. This is where Directive 2009/15/EC had a major impact on the European liability regime of classification societies.

In its original text, the Directive imposed on the EU Member States the obligation to put in place a quality monitoring system ${ }^{38}$ for selecting classification societies to whom they were allowed to delegate, ${ }^{39}$ in full or in part, performance of statutory surveys. Only organisations which met the criteria to obtain recognition as set out in the Annex of the Directive could be authorised to carry out statutory work. ${ }^{40}$ The third amendment to this instrument ${ }^{41}$ and its 2009 recast require all EU Member States to insert in their agreements with such ROs the following clause concerning liability:

i) if liability arising out of any incident is finally and definitely imposed on the administration by a court of law or as part of the settlement of a dispute through arbitration procedures, together with a requirement to compensate the injured parties for loss or damage to property or personal injury or death, which is proved in that court of law to have been caused by a wilful act or omission or gross negligence of the recognised organisation, its bodies, employees, agents or others who act on behalf of the recognised organisation, the administration shall be entitled to financial compensation from the recognised organisation to the extent that the said loss, damage, injury or death is, as decided by that court, caused by the recognised organisation;

ii) if liability arising out of any incident is finally and definitely imposed on the administration by a court of law or as part of the settlement of a dispute through arbitration procedures, together with a requirement to compensate the injured parties for personal injury or death, which is proved in that court of law to have been caused by any negligent or reckless act or omission of the recognised organisation, its employees, agents or others who act on behalf of the recognised organisation, the administration shall be entitled to financial compensation from the recognised organisation to the extent that the said personal injury or death is, as decided by that court, caused by the recognised organisation; the Member States may limit the maximum amount payable by the recognised organisation, which must, however, be at least equal to EUR 4 million;

iii) if liability arising out of any incident is finally and definitely imposed on the administration by a court of law or as part of the settlement of a dispute through arbitration procedures, together with a requirement to compensate the injured parties for loss or damage to property, which is proved in that court of law to have been caused by any negligent or reckless act or omission of the recognised organisation, its employees, agents or others who act on behalf of the recognised organisation, the administration shall be entitled to financial compensation from the recognised organisation, to the extent that the said loss or damage is, as decided

38 Directive 94/57/EC, art 11(1) of the original text, OJ L 319, 12.12.1994, p. 20.

39 Art. 3(2).

40 Art. 4(1) of the original text.

41 Directive 2001/105/EC of the European Parliament and of the Council of 19 December 2001 amending Council Directive 94/57/EC on common rules and standards for ship inspection and survey organisations and for the relevant activities of maritime administrations, OJ L 19, 22.01.2002, pp. 9-16. 
by that court, caused by the recognised organisation; the Member States may limit the maximum amount payable by the recognised organisation, which must, however, be at least equal to EUR 2 million. ${ }^{42}$

The addition of this clause to the agreements between classification societies and the States may have very serious financial implications, indeed exposing classification societies to unlimited financial exposure for negligent acts or omissions. However - it is submitted - the clause cannot be triggered unless two conditions are satisfied: (a) the liability of the Maritime Administration is positively established through (b) the negligence of the class surveyor. If this is true, this situation can only arise in respect of statutory surveys where the surveyor is performing inspections by express authorisation of the maritime administration. On the other hand, where a non-statutory survey is performed, the liability of the Administration cannot arise and the classification society will be liable in contract and tort according to the ordinary rules of the law applicable to the relevant claim.

Whether this system of delegation and recognition will continue to underpin the working of classification societies in the $\mathrm{UK}^{43}$ after the post-Brexit transition period remains to be seen.

\subsection{Liability}

The proper distribution of liability for damage is part of the commercial framework for the implementation of safety regulations worldwide. The UK is a party to the CLC, ${ }^{44}$ the Bunker Convention, ${ }^{45}$ the Wreck removal convention ${ }^{46}$ and the $\mathrm{MLC}^{47}$ all of which require some sort of security or compulsory insurance to protect third parties from some damages specified in the conventions themselves. These are key provisions which should not be read in isolation as matters of mere compliance but rather as a further element of commercial pressure to ensure that safety is ensured in a uniform and effective manner with the involvement of liability underwriters, classification societies and in some instances the relevant unions.

The 1992 Civil Liability Convention for Oil Pollution Damage is expressly referred to in the 1995 Merchant Shipping Act (MSA) ${ }^{48}$ Chapter VI, Part III of which is designed to implement the convention and fine-tune its provisions into the English legal system. To satisfy the requirements of the Convention, s. 163 of the 1995 MSA provides that

42 Art. 5.2(b).

43 The current position is set out at www.gov.uk/guidance/uk-authorised-recognised-organisations-ros (accessed on 6 March 2020) but the page has not been recently updated.

44 International Convention on Civil Liability for Oil Pollution Damage (Brussels 1969), ((signed on 1969, entered into force on 1975) 973 UNTS 14097). This Convention was amended in 1992 by a Protocol (UNTS 1956).

45 International Convention on Civil Liability for Bunker Oil Pollution Damage (London, 2001), (signed on 2001, entered into force on 2008).

46 International Convention on the Removal of Wrecks, (Nairobi, 2007), ((signed on 2007, entered into force on 2015) UNTS 55565).

47 Maritime Labour Conventions (adopted on 23 February 2006, entered into force on 20 August 2013, UNTS 2952) 3.

48 1995, ch. 21. 
any ship carrying in bulk a cargo of more than 2,000 tons of oil [...] shall not enter or leave a port in the United Kingdom or arrive at or leave a terminal in the territorial sea of the United Kingdom nor, if the ship is a United Kingdom ship, a port in any other country or a terminal in the territorial sea of any other country, unless there is in force a certificate $[\ldots]$ showing that there is in force in respect of the ship a contract of insurance or other security. ${ }^{49}$

The UK is also a party to the International Convention on Civil Liability for Bunker Oil Pollution Damage, 2001, adopted in March 2001 and in force since 21 November 2008. The Bunker Convention was adopted through the Merchant Shipping (Oil Pollution) (Bunkers Convention) Regulations 2006, SI 2006/1244, which amend the 1995 Merchant Shipping Act so as to provide a liability, compensation and compulsory insurance system for the victims of oil pollution damage caused by spills of bunker oil. ${ }^{50}$

The Nairobi International Convention on the Removal of Wrecks has been part of the UK legal system since 14 April 2015 when it came into force. The Wreck Removal Convention Act $2011^{51}$ amended the 1995 MSA and inserted Part 9A, dealing with, among other things, the detailed requirements for the wreck removal insurance certificate. ${ }^{52}$ The master and operator of a ship are each guilty of an offence if the ship enters or leaves a port without the appropriate insurance cover.

The 2006 Maritime Labour Convention has been in force in the UK since 7 August 2014 by way of the Merchant Shipping (Maritime Labour Convention) (Minimum Requirements for Seafarers etc.) Regulations 2014, and provides for compulsory financial security in case of death, personal injury or abandonment of seafarers. ${ }^{53}$ P\&I Clubs from the International Group provide a letter worded thus:

THIS IS TO CERTIFY that there is in force a policy of insurance or other financial security in respect of the above-named ship while in the above ownership which meets the financial security requirements of Standard A4.2 paragraph 1(b) of the Maritime Labour Convention 2006 as Amended, where it is in force and applicable.

\subsection{Concluding remarks}

Shipping is a risky business and the safety of seafarers, ships, cargo and the environment has been at the very core of the IMO legislative effort for a long time. The UK, as a country with a very long shipping tradition, has been putting safety and compliance at the centre of its maritime agenda for a considerable time and has cooperated with EU institutions for decades. The resulting national legislation, mostly but not exclusively contained in the 1995 Merchant Shipping Act, is quite detailed and in line with international standards, with some occasional innovative twists.

The picture which emerges however is one of a sea swimming with codes, rules and regulations where - some may say - the purpose of safety is out of sight, swallowed by waves of bureaucracy and lost among piles of certificates. It seems indeed that the purpose

491995 MSA, s. 163.

50 The provision for compulsory insurance for Bunker Pollution is to be found in s. 163(A) of the 1995 MSA.

51 Ch. 8.

52 MSA 1995, s. 255j-255q.

53 The provisions regarding financial security were introduced with Merchant Shipping (Maritime Labour Convention) (Compulsory Financial Security) (Amendment) Regulations 2018, SI 2018/667. 
of enhancing safety through compliance could be better achieved if the rules to be followed were unified in a single and easily accessible instrument. We are certainly not there yet but the DfT's Maritime Safety Action Plan and the "Maritime 2050: navigating the future"54 vision are clear evidence that work is in progress, particularly in these extraordinary times.

54 See https://assets.publishing.service.gov.uk/government/uploads/system/uploads/attachment_data/file/8721 94/Maritime_2050_Report.pdf, last accessed on 31 May 2020. 


\section{Maritime safety}

\section{Greece}

\section{Lia I. Athanassiou}

\subsection{Introductive comments on maritime safety ${ }^{1}$}

Maritime safety has been the focus of continuous international attention from the mid20th century until today and a major challenge both at a regulatory and operational level. Being more a policy objective, it can be described rather than defined. In its stricto sensu conception, as designed by policymakers and academia and followed here, maritime safety encompasses, on one hand (and originally), the protection of the marine environment from casualties caused by the ship's operation (preventive measures, actions against spills, liability and compensation regimes), and on the other hand (and progressively), the protection of human life at sea. From the point of view of Greek doctrine, the term 'thalassia asfaleia' is lato sensu construed as a systemic whole protecting the maritime community, and covers both maritime safety as described above and maritime security. ${ }^{2}$

While taking maritime safety measures (that means measures relating to the construction, maintenance, crewing and operation of ships) is by definition within the powers of the flag state, very early on the issue was taken over by the international legislator: the International Maritime Organization (IMO), ${ }^{3}$ which has displayed remarkable productivity in this field and has become the main source of international instruments dealing with the protection of the marine environment and human life. The shift of the international community's interest in safety matters was due to several contributing factors: among others, the urge for greater cost efficiency and reduction of the ship's operating costs; the use of

1 Thanks are extended to Dr. Loukas J. Zygouros for his contribution to the first version of the present paper.

2 From a Greek point of view, there is no distinction between the concept of maritime safety and that of maritime security. Both fall within the same category, the so-called 'thalassia asfaleia'. In accordance with Greek legal literature, 'thalassia asfaleia' not only refers to the endangered 'values' of human life and the environment, but also focuses on the protection of the vessel's and cargo's interests from terrorist attacks, i.e. when the danger is external to the maritime casualty and the latter is used as a means for conducting illegal actions. A third, wider, aspect could potentially be added, focusing on the endangering of the abovementioned goods in relation to the imposition of unilateral trade restrictions and sanctions from one or more states to another when those measures result in physical damages and economic loss, see A. Antapassis, L. Athanassiou, Maritime law (2020) [in Greek], p. 62. The said sub-categories constitute as a whole the maritime safety in its lato sensu conception, which in the English literature may be found as maritime security.

3 One of its main purposes being to provide machinery for cooperation between governments on technical matters affecting shipping in order to encourage high safety standards; among its main areas of work are included the following: navigation from all aspects, ship design and equipment, stability and load lines, carriage of dangerous goods, marine pollution, training and certification, search and rescue, life-saving appliances etc. See, inter alia, B. Farthing, International Shipping (Lloyd's of London Press, London, 1987) pp. 81-84. 
greater - in size and carrying capacity - vessels and thus, the carriage of enormous quantities of dangerous cargoes greatly increasing the pollution risk; the unfair competition from ships usually registered in an open registry, and their non-compliance with international safety standards mainly as regards the composition and competence of the crew and the proper conduct of the vessel's maintenance operations; the unwillingness of some open registries to carry out their control duties as flag States, etc.

The development of international uniform regulation on maritime safety issues has further raised four points of concern and thought, from a policy point of view:

- The first is related to the right dosage between regulation and the industry's selfregulation. There is no doubt nowadays that protection of the marine environment and the human element at sea is a public interest goal which may only be adequately served by setting compulsory safety standards; otherwise, negative externalities and conditions of unfair competition would be generated by less conscious operators, to the detriment not only of prudent shipowners, but also of the maritime community as a whole. Still, the question remains as to how far such regulatory intervention should go, or in other words, how much risk should be tolerated in view of the importance of maritime transport to the functioning of international commerce. It goes without saying that the environment and human life are priceless goods, imposing precautionary behaviour and exposure to minimum risks; yet, the need for keeping a balance between profitability and sustainability, as well as between over-regulation and efficient implementation should not be overlooked. ${ }^{4}$

- The second is related to the requirement of uniform and efficient implementation. ${ }^{5}$ Modern maritime legal doctrine focuses indeed not (or not only) on the legislative process of harmonization, but also on the manner in which international conventions are implemented and interpreted in national legal systems. Accordingly, the first question examined ${ }^{6}$ is the impact of the methods of implementation in ensuring uniformity in practice, and then the extent to which the provisions of a convention require implementing legislation for uniform and satisfactory application to be achieved (i.e. provision of sanctions). In the same line, the examination should cover whether the international instrument, when becoming part of a national legal system, receives 'full' acceptance, is 'rejected' as unsuited to the principles of the implementing legal system or undergoes changes and alterations, due either to the coexistence with national provisions or to the nationally orientated interpretation favoured by domestic courts. This enhances regulatory completeness, as uniformity is not pursued only in the design of the substantive rules, but also in their actual implementation.

- The previous comment puts the accent on the divergence of flag States' compliance. It seems that, although the acceptance and ratification rate of international

4 See interesting comments by I. Christodoulou-Varotsi, Maritime Safety Law and Policies of the European Union and the United States of America: Antagonism or Synergy? (Springer, 2008), pp. 10-11.

5 Cf. L. Athanassiou, Maritime Cross-Border Insolvency (Informa Law from Routledge, 2018), pp. $93-94$.

6 See A. Antapassis, F. Berlingieri, 'Implementation and interpretation of international conventions' (20072008) CMI Yearbook 308 et seq. mainly 310-311. 
safety standards is very high, the degree of implementation varies considerably, some open registries being more reluctant to exercise effective control and supervision on their ships, for multiple reasons (i.e. lack of expertise, lack of personnel, unwillingness to disturb powerful clients etc.). The said compliance variation consequently distorts the level playing field by introducing unfair competition conditions, as it affects the exploitation cost of maritime operators. In order to address the distortion, the port State's control had to be empowered; the enhancement of the role of the port State, and the corresponding weakening of the flag State's power, should be considered as one of the most significant developments in maritime law in the course of the 20th century. The structure of this chapter will be largely based on the above described distribution of tasks.

- The last point refers to the tension between internationalism on one side, and regionalism or unilateralism on the other. Although the design of safety standards remains undoubtedly and predominantly within the scope of action of international organizations (the IMO and ILO), the EU as well as the US have developed in parallel, and to some extent their own policies, in the field. The European safety policy, which is of more interest here (taking into account that Greece has been an EU member since 1981), was gradually shaped, primarily as a reaction to major casualties. ${ }^{7}$ Envisaged from a macroscopic point of view, the relationship between international and European legislators could be qualified as more coordinated than conflictual, with some minor exceptions, ${ }^{8}$ Generally speaking, EU law (and more particularly the Common Shipping Policy) aims at: (a) complementing and strengthening international rules/guidelines by introducing regional standards or sanctions to strengthen them; ${ }^{9}$ (b) accelerating their entry into force; ${ }^{10}$ (c) extending their scope of application either geographically or ratione materiae. ${ }^{11}$ Only in a (fortunately) limited number of cases, this relationship proved to be inimical, with the characteristic example of the application of EU Waste legislation in matters relating to the compensation of damages from oil pollution at

7 The EU maritime safety policy may be divided in two main periods: the initial period extending from the Communication of 1993 regarding the 'Common Policy on Safe Seas' until the Erika accident, comprises a number of heterogenous measures, repeatedly amended at subsequent stages. In the second period beginning with the Erika spill, the EU affirms itself a major player in the safety field, with three sets of coordinated measures known as 'Erika I' (2000), 'Erika II' (2001) and 'Erika III' (2005). 'Erika I' contained proposals on port State control, the classification societies' regime and the phasing-out of single hulled tankers; 'Erika II' introduced a Community vessel traffic monitoring and information system and the creation of a European Maritime Safety Agency (EMSA); 'Erika III' addressed objectives related to the quality of flags, ship inspection procedures, port State control, traffic monitoring, accident investigation, liability of carriers (extension of the Athens Convention provisions) and insurance of shipowners for maritime claims. See the analysis under Chapter 2 above. For the EU action, in comparison with the US regulatory framework and policy, see I. Christodoulou-Varotsi, Maritime Safety Law and Policies of the European Union and the United States of America: Antagonism or Synergy? (Springer, 2008), pp. 33-38.

8 See also H. Ringbom, 'Maritime Liability and Compensation in EU Law', in B. Soyer, A. Tettenborn (eds) Pollution at Sea: Law and Liability (Informa Law from Routledge, 2012), p. 155 et seq.

9 E.g. Directive 2009/20/EC on the insurance of shipowners for maritime claims that implement the nonbinding IMO's Resolution A.898 (21).

10 E.g. Regulation 392/2009/EC on the liability of carriers of passengers by sea in the event of accidents, OJ L 131, 28.5.2009, p. 24-46.

11 H. Ringbom, 'Maritime Liability and Compensation in EU Law', in B. Soyer, A. Tettenborn (eds) Pollution at Sea: Law and Liability (Informa Law from Routledge, 2012), p. 156. 
sea. ${ }^{12}$ In the present chapter, measures with dual origin (both international and European) will be referred to in their most recent and complete version.

\subsection{National structure for the implementation of maritime safety framework}

\subsubsection{Legislative background}

Greece, being a traditional maritime country ${ }^{13}$ (with a high number of vessels flying its flag or controlled by Greek interests, an important number of national officers and a developed maritime cluster), has displayed sensibility and consistency regarding both the adoption and the implementation of maritime safety standards. Against this background, in terms of legislation, one may distinguish three closely interrelated levels.

The first pillar is composed of domestic legal instruments, such as the Greek Code of Private Maritime Law (KIND) ${ }^{14}$ and the Greek Code of Public Maritime Law (KDND), ${ }^{15}$ as well as other national legislative texts. The first Code (KIND) mainly governs private law issues arising from the commercial operation of the vessel and thus it covers only limited questions of safety, mainly by regulating liability and compensation issues arising from collision between ships (Articles 235 KIND et seq.), claims arising out of assistance at sea (Articles 246 KIND et seq), marine insurance (Articles 257 et seq.) etc.. The second Code (KDND) is the most relevant as it contains an extensive number of ex ante (preventive) and ex post rules (sanctions) on various safety related aspects of ships' operation. It covers, inter alia: (i) the tonnage measurement (Articles 21-30), ${ }^{16}$ (ii) the vessel's certificates (Articles 46-53), (iii) issues relating to the manning, the certification, the training, the duties and the protection of the seafarers, ${ }^{17}$ (iv) the policing of navigation, ports and

12 See C-188/07, ECR 2008, Commune de Mesquer, ECLI :EU :C :2008:359. In that case, a preliminary question from the French Cour de Cassation was submitted concerning the interpretation of Art. 1, Art. 15 of the Dir. 75/442/EEC on waste, as amended, in the context of the pollution damages resulting from the wreck of the Erika tanker. While the EU is not a member to the CLC-IOPC Fund regime, the CJEU tried to reconcile the EU directive and the international compensation scheme, with regard both to the liable parties and the limits of liability; it recognized the need for coordination of the concurrently applicable provisions, with a view to giving effect to the requirements of EU rules, without disrupting the autonomy of the international regime. In any case, it was held that EU law asserts full application (within the meaning of the broadest possible achievement of its legislative objectives), even if that requires the use of broad interpretation or alternative equivalent solutions, cf. L. Athanassiou, Maritime Cross-Border Insolvency (Informa Law from Routledge, 2018), pp. 99-102.

13 The Shipping sector is of a vital importance for the Greek economy and is considered a national pride. Greece is included between the top five shipowning economies owning more than half of the world fleet (together with Panama, China, Singapore and Hong Kong). In accordance with the latest UNCTAD's review (Review of Maritime Transport 2019, UNCTAD, https://unctad.org/en/PublicationsLibrary/rmt2019_en.pdf), 4,536 vessels of $349,195,189$ DWT in total are Greek owned, i.e. $17.79 \%$ of the world fleet; the fleet registered under the Greek flag comprises 670 ships, of $60,776,654$ DWT. In terms of the commercial value of the fleet, Greece is among the leading owners of oil tankers, bulk carriers and gas carriers (30,569 million dollars value of the oil tanker fleet, 37,218 of the bulk carrier fleet and 13,593 of the gas carrier fleet).

14 L. 3816/1958 which came into force on 1 September 1958.

15 LD 187/1973 which came into force on 4 April 1974.

16 See also LD 973/1971 (Gov. Gaz. 194/A/8.10.1971), on the tonnage measurement of merchant ships, L. 1373/1983 (Gov. Gaz. 92/A/8.7.1983), ratifying International Convention 1969 on Tonnage Measurement of Ships.

17 Arts. 65-72 (on seafarers' training), Arts 73-86 (on certificates of aptitude), Arts. 87-92 (on the manning requirements), Arts. 93-94 (on the seafarers' recruitment), Arts. 95-193 (public law measures on seafarers' employment and catering), 104-129 (on master's duties and powers), 130-135 (on the duties of the crew), 245-270 (on the disciplinary control of the master and the crew). 
coastal areas (Articles 135-163), (v) the regime of cabotage (Articles 164-180a), pilotage (Articles 181-187), towage and salvage (Articles 188-189), (vi) the regime of wrecks (Articles 195-201), (vii) the investigation of maritime accidents etc. As many of those chapters need further elaboration and/or continuous update, the KDND provide, on several occasions, legislative delegation for the Administration to issue detailed implementation rules or circulars. The said delegations have been repetitively used.

The second pillar comprises international uniform rules relating to maritime safety, which - once ratified and promulgated by law - enjoy legislative supremacy over domestic law, by virtue of Article 28 (1) of the Greek Constitution. ${ }^{18}$ Greece has ratified and implemented all major International Maritime Conventions, as will be revealed later on; the above articles of the KDND should, therefore, be read and interpreted in conjunction with legislation and regulations implementing comprehensive standards, and if conflict occurs, the international rule should prevail, while interpretation should by principle serve uniformity goals.

Last but not least, the third pillar has its roots in the evolving European Law. Since 1981, the country's adhesion year to the EC (later EU), Greece has not only been bound by the common shipping policy, but has also played a leading role in the shaping of such policy, given its position as the first maritime Member State in terms of tonnage. ${ }^{19}$ Finding a delicate balance between the commitment to international maritime regulation and the constraints resulting from EU membership has not always been an easy task for the national authorities; ${ }^{20}$ Greece was found, in Case C-45/07, ${ }^{21}$ to have violated its obligations under EU rules, ${ }^{22}$ merely through the submission to the IMO of a proposal relating to compliance checks of vessels and port facilities in relation to the requirements of Chapter XI-2 SOLAS 1974 and the ISPC Code, as internal common rules had been imposed on the same subject by Regulation 725/2004. On the other hand, Regulation 417/2002, as repealed and replaced by Regulation 530/2012 on the phasing-out of the single hulled oil tankers, was adopted under the Greek Presidency, despite the sensibility of the issue for the domestic shipping industry.

\subsubsection{The structure of the national Maritime Administration}

Greece disposes of a well-coordinated multidisciplinary administration that secures, amongst others, the implementation of maritime safety law. The pinnacle of the hierarchy is held by the Ministry of Maritime Affairs and Insular Policy, empowered with several competences and duties. In accordance with the Presidential Decree (PD) 13/2018, ${ }^{23}$ the

18 Art. 28 (1)(a): 'The generally recognized rules of international law, as well as international conventions as of the time they are ratified by statute and become operative according to their respective conditions, shall be an integral part of domestic Greek law and shall prevail over any contrary provision of the law'.

19 The two other important maritime countries (Cyprus and Malta) joined the EU later, on 1 May 2004.

20 As has been pertinently pointed out, the Greek authorities try to demonstrate a flexible attitude, balancing between publicly announced zeal for the IMO forum and eager support for common maritime safety, despite the fact that the shipowners' lobby is generally sceptical towards the increased interventions of Brussels. See I. Christodoulou-Varotsi, Maritime Safety Law and Policies of the European Union and the United States of America: Antagonism or Synergy? (Springer, 2008), p. 38.

21 ECR 2009, I-701.

22 Arts. 10, 71, 80 para 2 EC.

23 Gov. Gaz. 26/A/20.12.2018. 
Greek Ministry is responsible, inter alia ${ }^{24}$ for the design of maritime policy, the development of shipping and its linkage with the national economy, and for the protection of human life and property, the marine environment and the safety of navigation. A separate department of the Hellenic Coast Guard, ${ }^{25}$ the 'Directorate on the Safety of Navigation', deals solely with matters of this nature. The said Directorate is responsible ${ }^{26}$ for: the establishment of the proper terms and conditions in order to ensure the protection of human life and property at sea; the development and update of a national regulatory framework for safe navigation issues, ${ }^{27}$ including any technical issues concerning the shipbuilding and vessel's equipment; the adjustment of the domestic law to the applicable international and EU rules; the organization of ships' inspections and quality controls over the ships flying the Greek flag; the conduct of Port State Control over ships flying foreign flags, by virtue of the Paris MoU; the recognition and authorization of the Recognized Organizations (classification societies); the administrative control of marine casualties and accidents, as well as the design of the national perspective on maritime safety issues. Regarding the certification of ships and the conduct of inspections, the Ministry of Maritime Affairs and Insular Policy cooperates with the relevant recognized organizations that are entrusted ${ }^{28}$ with administrative duties, as long as they meet the minimum criteria set by the Greek legislator. ${ }^{29}$

At the judiciary level, L. 2172/1993 has established special judicial departments competent for maritime disputes in the Court of First Instance and the Court of Appeal of Piraeus, in order to ensure uniformity of judicial decision making. Those departments consist of judges with postgraduate studies or particular experience in maritime law and with satisfactory knowledge of at least one major European language and especially English $;^{30}$ there are competent departments for maritime claims, i.e. for private disputes arising from maritime trade operations, the use, operation or navigation of a ship or the maritime labour on board. ${ }^{31}$ In order to facilitate the process, in Article 51 (3) B, the

24 The development of seafarers training and maritime labour, the implementation of an integrated island and sea tourism policy, the facilitation of sea transport and sea communication services, the prevention and suppression of illegal actions in the areas of the Hellenic Coast Guard's responsibility, the control of maritime borders, the formulation of port policy, the supervision of port infrastructure, the promotion of the national port system.

25 In accordance with the PD 13/2018, the Hellenic Coast Guard is pertained to the Ministry's organizational structure. The Hellenic Coast Guard's mission is specified in Art. 5 of L. 4150/2013 (Gov. Gaz. 102/A/29.04.2013).

26 See Art. 21 (1) of the PD 13/2018. The Directorate is further subdivided in the following Departments: (a) the Department of Safe Navigation and Maritime Casualties, (b) the Department of Legislation and International Cooperation, (c) the Department of Maritime Surveillance and Traffic Management, (d) the Department of Organization and Supervision of Ship Inspections (Paris MoU).

27 The Hellenic Chamber of Shipping might be considered as part of the maritime administration, as it is the official advisor to the government on shipping matters, carrying out its work in close cooperation with, and under the supervision of, the Ministry of Maritime Affairs and Insular Policy. In brief, the Chamber may, as part of its major functions, offer opinion on draft legislation proposed by the Ministry or other government authorities, carry out research and studies on shipping related matters, offer expert advice on specialized shipping issues, propose measures for the protection and welfare of seafarers, attend meetings of international shipping organizations, monitor all legal and technical developments in the shipping field and conduct arbitration on maritime disputes.

28 See Art. 39 (1) KDND.

29 See infra, section III-C. At the administration level, there is a separate Directorate, responsible for the control of the recognized organizations' work on the compliance checks of shipping companies and vessels in the areas of maritime safety, prevention of pollution, safety management, compliance with the Maritime Labor Convention, and the inspectors' training (see Art. 26 (1) of the PD 13/2018).

30 See Art. 51 (7) of Law n. 2172/1993.

31 See Art. 51 (1) and (3) of Law n. 2172/1993. 
legislator lists a number of claims that fall within the meaning of 'maritime claims'. ${ }^{32}$ The said special judicial departments have local jurisdiction (ratione loci) throughout the Attica region (Article 51 (2)) and concurrent jurisdiction for maritime claims outside the Attica region (Article 51 (2) b).

\subsection{Prevention: Greece as a flag state}

\subsubsection{Measures relating to the construction and operation of vessels}

All major International Conventions setting uniform preventive rules (as a framework or in detailed form) for the construction and operation of vessels are ratified and implemented by Greece. The list includes, inter alia, the UNCLOS 1982, ${ }^{33}$ the Load Lines Convention, ${ }^{34}$ the Marpol 1973/77 35 and the SOLAS $1974 .{ }^{36}$ The same applies for EU measures, extending, accelerating or reinforcing, on a complementary basis, the international standards. When EU measures take the form of regulations, they apply directly and have binding force in the Greek legal order, without additional implementing legislation being in principle necessary. When EU measures take the form of a directive, domestic implementing legislation is needed within the timeframe as specified in each directive; the framework related to the safety requirements for the loading and unloading of Bulk Carriers ${ }^{37}$ provides an eloquent example from this point of view: PD 66/2004 incorporating Directive 2001/96/EC, ${ }^{38}$ as amended by Directive 2002/84/EC ${ }^{39}$ imposes harmonized requirements and procedures for the safe loading and unloading of bulk carriers, so that the risk of structural damage and losses due to improper loading and unloading operations is reduced; in case of non-compliance, criminal, disciplinary or administrative ${ }^{40}$ penalties are provided for.

Other worthy of mention EU legal acts, in relation to the construction and operation of vessels, with binding effect in the Greek legal system are, indicatively, the following: Directive 2016/802/EC relating to a reduction in the sulphur content of certain liquid fuels incorporated by virtue of MD 128/2016 $6^{41}$ and Directive 2014/90/EC on marine equipment, as incorporated by MD 2222.1-1.2/90149/2016;42 Regulation 782/2003 on the prohibition

32 Claims arising out of damage caused by collision or marine pollution, loss of life or personal injury caused by any ship or occurring in connection with the operation of any ship, the construction, repair, sale, mortgage or hypothecation of the ship, as well as disputes arising out of salvage, general average, pilotage, marine insurance or disputes between co-owners, etc.. The list closely resembles the list of Art.1 (1) of the International Convention Relating to the Arrest of Sea-Going Ships 1952.

33 Ratified by L. 2321/1995 (Gov. Gaz. 136/A/23.6.1995).

34 Ratified by L. 391/1968 (Gov. Gaz. 125/A/4.6.1968).

35 Ratified by L. 1269/1982 (Gov. Gaz. 89/A/21.7.1982).

36 Ratified by L. 1045/1980 (Gov. Gaz. 95/A/25.4.1980).

37 Greece is bound by Chapter XII of SOLAS, where additional safety measures for bulk carriers are specified and by the Assembly Resolution A. 862(20), through which the IMO adopted a Code of Practice for the Safe Loading and Unloading of Bulk Carriers ('the BLU Code'), with the aim of preventing accidents or loss of ships carrying solid bulk cargoes as a result of improper loading and unloading practices.

38 OJ L 13, 16.1.2002, p. 9.

39 OJ L 324, 29.11.2002, p. 55.

40 Art. 12 of PD 66/2004. Concerning the administrative measures, Art. 12 expressly refers to the penalties provided for under Art. 45 and 157 of the Greek Code for Public Maritime Law, (LD 187/1973).

41 Gov. Gaz. 3958/B/9.12.2016.

42 Gov. Gaz. 3454/B/26.10.2016. 
of organotin compounds on ships ${ }^{43}$ and Regulation 530/2012 on the accelerated phasing-in of double-hull or equivalent design requirements for single-hull oil tankers, ${ }^{44}$ with direct binding force into the Greek legal order.

\subsubsection{Measures relating to the human element}

High priority is given by the legislator and Administration to the protection of human life at sea, whatever the reason for their exposure to the perils of the maritime adventure; this covers both passengers and seafarers, for obvious reasons which need no further elaboration, if one takes into account the geographical particularities of Greece, the public policy goal of social cohesion and regional development, ${ }^{45}$ the need for ensuring continuous communication with the numerous islands, as well as the country's investment in the tourism and shipping sector.

Regarding the preventive measures for passengers in the ferry sector, application of the principle of freedom to provide services to domestic maritime transport services, i.e. the liberalization of maritime cabotage, has played a significant role. ${ }^{46}$ Regulation 3577/1992 introduced a realistic compromise for the gradual liberalization, according to a specific timetable for each type of transport service. For reasons of socio-economic cohesion, the derogation was extended for Greece until 1.1.2004 for regular passenger and ferry services and services provided by vessels less than $650 \mathrm{GT} .{ }^{47}$ However, the Greek legislator chose to accelerate the liberalization process for regular passenger and ferry services, by adopting L. $2932 / 2001^{48}$ entitled 'Freedom to provide maritime cabotage services etc.' . ${ }^{49}$

In light of the above, various measures have been adopted during the years in relation to the safety of ferries and roll-on/roll-off ('ro-ro') vessels. First, Greece is constantly ratifying all amendments of the SOLAS Convention related to ferries and ro-ro vessels. ${ }^{50}$ The same also goes for EU measures. For instance, PD 52/2005 51 incorporates Directive

43 OJ L 115, 9.5.2003, p. 1. The adoption of the Regulation in fact enhanced the ratification and implementation of the International Convention on the Control of Harmful Anti-fouling Systems on Ships 2001 (AFSConvention).

44 OJ L 172, 30.6.2012, p. 3. Its implementation is enhanced by the charterers' duty of vetting, i.e. a precautionary ship inspection in order to ensure that the ship is being properly operated and in a suitable condition to embark on the voyage in safety.

45 In the second Quarter of 2019, around 9 million passengers sailed between Greek ports. In fact, 9,578,242 passengers, in accordance with Hellenic's Statistical Authority press release (available at: www.statistics.gr/en/ statistics/-/publication/SMA06/-). Ferry traffic is of relevant significance and for the EU in general. According to the latest available data of Eurostat (https://ec.europa.eu/eurostat/statistics-explained/pdfscache/6652.pdf), in 2017 around 415 million passengers sailed in to, or out of, EU ports.

46 See also, A. Antapassis, L. Athanassiou, Maritime law (2020) [in Greek], p. 929 et seq.; L. Athanassiou, Aspects juridiques de la liberalization du cabotage européen, 1998 Diritto Marittimo 577; L. Athanassiou, 'Issues from the liberation of Greek cabotage', 2002 Epitheorissis Naftiliakou Dikaiou (END) 353.

47 See Art. 6 (3) of the Regulation.

48 Gov. Gaz. 145/A/27.6.2001.

49 The inland cruises have been liberalized by virtue of Art. 165 (3) of the Greek Code for Public Maritime Law (KDND).

50 For instance, under MD 222/2018, Resolution MSC. 404(96) was ratified, introducing an evacuation analysis for ro-ro passenger ships constructed on or after 1 July 1999 and other passenger ships constructed on or after 1 January 2020 carrying more than 36 passengers. The amendments entered into force on 1 January 2020.

51 Gov. Gaz. 79/A/31.3.2005. 
2003/25/EC, ${ }^{52}$ aiming at improving the survivability of the said type of vessels in case of collision damage and providing a high level of safety for the passengers and the crew. For this purpose, a specific department pertained to the Hellenic Ministry of Marine Affairs and Insular Policy is responsible for establishing a list of sea areas crossed by ro-ro passenger ships operating a regular service to or from Greek ports, ${ }^{53}$ together with the corresponding values of significant wave heights in these areas.$^{54}$ Certificates confirming compliance with stability requirements are issued for the Greek-flagged vessels, while the same requirements are imposed on third countries' vessels by Greece, in its position as host State. ${ }^{55}$

Crew measures mainly relate to training and working conditions, both of major importance from a safety point of view, in view of the well-established fact that human action remains the primary cause of marine casualties and incidents. ${ }^{56}$ Greece has ratified ${ }^{57}$ the International Convention on Standards of Training, Certification and Watchkeeping for Seafarers (STCW) 1978 and all the amendments over time; ${ }^{58}$ the said framework was further complemented by PD 119/2014, ${ }^{59}$ incorporating into the domestic legal order Directive $2008 / 106 / \mathrm{EC}^{60}$ on the minimum level of training of seafarers (as amended later on by Directive 2012/35/EU), ${ }^{61}$ which applies to seafarers serving on board seagoing ships flying the Greek flag. ${ }^{62}$ Under Article 5 of the PD, a special Division for the training of seafarers $^{63}$ shall ensure that the relevant certificates of competency and proficiency are granted only to candidates that meet the requirements, are issued ${ }^{64}$ in accordance with Regulation $\mathrm{I} / 2$, paragraph 1, of the STCW Convention and are drawn up both in English and Greek.

52 OJ L 123, 17.5.2003, p. 22. For a further analysis of the Directive, see also V. Power, EU Shipping Law (Informa Law from Routledge, 2019), p. 1468 et seq.; H. Ringbom, The EU Maritime Safety Policy and International Law (Nijhoff, Brill 2008), p. 305 et seq.

53 This list is published in a public database (internet site of the Ministry of Marine Affairs and Insular Policy).

54 Art. 5 (1) of PD 52/2005.

55 Certificates issued by EU members or third countries are recognized as far as they ensure compliance with the Directive.

56 In accordance with EMSA, from a total number of accident events within sub-sea areas around EU waters for the periods 2011 to 2018, 65.8\% were attributed to the human actions' category, see the Annual Overview of Marine Casualties and Incidents 2019, as available in: www.emsa.europa.eu/accident-investigation-publications/ annual-overview.html.

57 By virtue of L. 1314/1983.

58 The '1995 amendments' were ratified by PD 132/1997. The second revision of 2010 (The 'Manila amendments to the STCW Convention and Code') was ratified by PD 79/2012.

59 Gov. Gaz. 188/A/8.9.2014.

60 OJ L 323, 3.12.2008, p. 33.

61 OJ L 343, 14.12.2012, p. 78.

62 Art. 3 of the PD 119/2014. There are currently ten (10) National Marine Academies for Marine Deck Officers and four (4) National Marine Academies for Engineers operating under the supervision of the Ministry of Marine Affairs and Insular Policy. The studies usually include six (6) semesters of theoretical training and two (2) semesters of practical training on board, while particular emphasis is placed on the teaching of marine English terminology. For the year 2019-20 the total number of entrants in the National Marine Academies was 670 Marine Deck Officers and 487 Engineers. In accordance with L. 3153/2003, the training and education of seafarers may be entrusted to a four-year programme of private schools, which may not nevertheless be considered as Marine Academies (see Art.1 (2), L. 3153/2003).

63 Pertained to the old Ministry of Marine Affairs and Insular Policy and Aegean, now Ministry of Marine Affairs and Insular Policy (see PD 70/2015).

64 The certificates of competency may be issued by the Ministry's Division for the training of seafarers, by the Hellenic Merchant Marine Academies and by the Hellenic port authorities, following verification of the authenticity and validity of any necessary documentary evidence (see Art. 5(4) of PD 119/2014). 
Articles 10 and 11 of the PD 119/2014 lay down in detail the standards of quality and of medical fitness for seafarers respectively; penalties and/or disciplinary measures are prescribed to prevent fraud and other unlawful practices ${ }^{65}$ involving certificates of competency and certificates of proficiency and endorsements issued (Articles 9, 10) ${ }^{66}$ Foreign vessels visiting Greek ports are subject to control procedures aiming at detecting deficiencies on crew matters and may result to the detention of the vessel, if it poses a danger to persons, property or the environment (Articles 22, 23).

On the working conditions issue, the Maritime Labour Convention (MLC) is considered as the legal instrument of reference; its original version of 2006 was ratified by L. $4078 / 2012^{67}$ and the subsequent amendments of 2014 (entered into force on 18.1.2017) were introduced to the domestic legal order by PD $3 / 2017 .{ }^{68}$ The said instrument, structured on a multilevel basis, ${ }^{69}$ ensures both decent working and living conditions on board for all seafarers, regardless of their nationality and of the flag of the ships on which they sail, and fairer conditions of competition for operators respectful of rules and often disadvantaged by substandard shipping. The 2014 Amendments strengthened the protection, by introducing compulsory civil liability insurance coverage (subject to certification) in case of abandonment of seafarers, as well as in case of injury, sickness and death, with right of direct access by the seafarer to the insurance coverage. ${ }^{70}$ The 2016 Amendments (entered into force on 8.1.2019) that were introduced to the domestic legal order by PD 113/2018, ${ }^{71}$ deal mainly with the prohibition of harassment. EU Directive 2013/54 (PD 171/2014), ${ }^{72}$ on flag State responsibilities for compliance and enforcement of MLC 2006, ensures that Member States effectively discharge their obligations as flag States with respect to the

65 The Ministry's Division for Maritime Labour is competent to detect and combat fraud and other unlawful practices and exchange information with the competent authorities of other Member States and of third countries concerning the certification of seafarers (see Art. 9 (2) of PD 119/2014).

66 In accordance with Art. 10 (2) of the PD, within the context of prevention, criminal, disciplinary or administrative penalties might be imposed. Such penalties or disciplinary measures shall enforced in Greek flag seagoing ships cases in which: (a) a company or a master has engaged a person not holding a certificate as required by the PD; (b) a master has allowed a person not holding the required certificate or a valid dispensation or having the documentary proof required by Art. 20 to perform functions or services that under Greek law must be performed by persons holding the appropriate certificates; (c) a person has obtained by fraud or forged documents an engagement to perform any function or serve in any capacity which under the PD must be performed or fulfilled by a person holding a certificate or dispensation.

67 Gov. Gaz. A/179. 95 States have ratified the Convention representing 91\% of the world tonnage.

68 Gov. Gaz. 6/A/24.1.2017.

69 It is an instrument consolidating 37 Conventions and 31 recommendations, with an original multilevel structure, incorporating mandatory provisions (Articles, Regulations, Standards) and non-mandatory ones (Guidelines) and providing also for substantial equivalent provisions for mandatory standards.

70 For more on the MLC 2006 see also, A. Charbonneau, B. Vacotto, 'La Convention du travail maritime, 2006: renouveau et source d'inspiration du droit international du travail' in G. Politakis, T. Kohiyama, T. Lieby (eds), Law for Social Justice (ILO Geneva, 2019), p. 769 et seq.; G. Politakis, 'The Maritime Labour Convention 2006 - Implementation and challenges', 9th International Maritime Law Conference, Piraeus 2016, p. 551 et seq.; J. Lavelle, The Maritime Labour Convention 2006: International Labour Law Redefined (Informa Law from Routledge, 2013); P. Bolle, 'The ILO's new Convention on maritime labour: An innovative instrument' (2006) International Labour Review 135 et seq.

71 Gov. Gaz. 222/A/31.12.2018.

72 Gov. Gaz. 2491/B/18.9.2014. Directive 2013/38/EU (adopted by PD 166/2014, Gov. Gaz. 250/A/ 20.11.2014), amending Directive 2009/16/EC on port State control, obliges Member States to ensure, through their inspection mechanism, that the treatment of ships and their crew flying the flag of a State which has not ratified MLC 2006 is not more favourable than that of a ship, and its crew, flying the flag of a MLC 2006 ratifying State. 
implementation of the relevant parts of the MLC by setting out effective and appropriate enforcement and monitoring mechanisms.

\subsubsection{Empowerment of flag state's authorities}

The KDND contains numerous provisions relating to the powers and duties of the authorities when discharging flag state's obligations. The said regulatory framework was rendered more transparent, efficient and accountable, by virtue of PD 102/2011 incorporating Directive 2009/21/EC, ${ }^{73}$ serving thus more consistently the goals of enhancing maritime safety and preventing pollution from ships flying the Greek flag. PD 102/2011 explicitly requires compliance with the applicable international rules and regulations, ${ }^{74}$ prior to a ship being allowed to fly the Greek flag. In the same line, when a Greek-flagged vessel is detained by a port State, then the national administration shall oversee the ship in order to bring it into compliance with the relevant IMO Conventions. ${ }^{75}$ Accompanying measures focus on the transparency and accessibility of information relating to ships. ${ }^{76}$ Although an extended publicity system for a wide range of information and acts concerning ships (particulars, mortgage, transfer of ownership, operation agreements etc.) has been adopted by Greece for many decades, the legislation governing the functioning of the Ship's Registry is fairly outdated; ${ }^{77}$ that means that information is kept in paper form, written by hand in large books where two-pages are dedicated to each ship, while other relevant information regarding certification is kept by other departments of the Ministry; obviously, digitalization and rationalization is urgently needed. The quality management system required for the operational parts of the flag State-related activities (Article 8) had already been developed and implemented by Greece before the Directive, as acknowledged in the Report of the Commission to the EP and EC on the application of Directive 2009/21/EC. Besides, no performance report has been required until today, since Greece has consistently appeared in the white list of Paris MoU performance lists. ${ }^{78}$

Classification societies are important constituents assisting national authorities in discharging monitoring obligations. Article 39 of the KDND had provided that the certification of ships, of shipowners and of ships' operators may be delegated in whole or in part, to organizations, which are authorized ${ }^{79}$ by Greece. Following the adoption of EU rules on

73 On compliance with flag State requirements, OJ L 131, 28.5.2009, p. 132.

74 See Art. 4 (1) of PD 102/2011. The competent bodies shall verify the safety records of the ship by all reasonable means and, if necessary, consult with the losing flag State in order to establish whether any outstanding deficiencies or safety issues identified by the latter remain unresolved. Respectively, whenever another flag State requests information concerning a ship which was previously flying the Greek flag, domestic authorities shall promptly provide details of outstanding deficiencies and any other relevant safety-related information to the requesting flag State (Art. 4 (2)).

75 See Art. 5 of the PD 102/2011 and of Directive 2009/21/EC respectively.

76 Art. 6 (such as particulars of the ship, namely, the name, the IMO number, etc., dates of surveys, identification of the recognized organizations involved in the certification and classification of the ship, etc.).

77 Royal Decree 10/17-7-1910 (Gov. Gaz. 241/A/17.7.1910) on ship registries and ship mortgage register's books.

78 Accordingly, in the Paris MoU Performance List 2018, as published on 17 June 2019, Greece holds place 23 in the white list. The performance lists since 2010 are available from the Paris MoU website, see www.parism ou.org/publications-category/performance-list.

79 The organization's authorization, together with the relevant terms and conditions, is given by decree of the Minister of Shipping and Aegean (now Ministry of Marine Affairs and Insular Policy). 
the matter (Regulation 391/2009/EC, ${ }^{80}$ PD 103/2011 incorporating Directive 2009/15/EC ${ }^{81}$ on common rules and standards for ship inspection and survey organizations), the classification societies, before being delegated public certification powers, must be 'recognized' by the European Commission; recognition implies that the minimum criteria set by the above provisions are fulfilled. ${ }^{82}$ Consequently, Administration may authorize by virtue of PD 103/2011, those recognized organizations to undertake fully or in part inspections and surveys related to statutory certificates and, where appropriate, to issue or renew the related certificates. ${ }^{83}$ The 'working relationship' between the Ministry of Marine Affairs and the recognized organization providing inspection services is based on a Model Agreement, published by MD 411/2013; ${ }^{84}$ by such Agreement, the contracting organization is authorized to perform statutory certification services for ships flying the Greek flag and their companies on behalf of the flag states, within the framework, scope, terms, conditions and requirements of this authorization. The financial liability of the recognized organization in case of a marine casualty is also regulated. As prescribed in the Model Agreement, ${ }^{85}$ if liability arising out of any marine casualty is irrevocably imposed on the Administration, ${ }^{86}$ together with a requirement to compensate the injured parties for loss or damage to property or personal injury or death, which is proved to have been caused by a wilful act or omission or by gross negligence of the organization, its employees, agents or others who act on its behalf, the Administration shall be entitled to full financial compensation, from the relevant Organization. The non-regulated issue, which remains unanswered or unclear in various national legal orders, is whether classification societies may also incur tort liability against third parties for acts or omissions related to their certification duties. The main available legal basis establishing tortious liability in Greek Law is Article 914 of the Civil Code, according to which any person having caused harm to another against the law and with fault shall compensate the latter ${ }^{87}$ The evidence of the unlawfulness is not so challenging: the infringement of a maritime safety rule, for instance, may evidence the unlawful act or omission of the classification society. The most difficult part for the injured party to prove is the causation between the unlawful act and the damage. The final outcome is probably to be determined by whether the act or the omission of the classification society was likely to cause such damage. ${ }^{88}$

80 OJ L 131, 28.5.2009, p. 11. For a detailed analysis of the Regulation, see V. Power, EU Shipping Law (Informa Law from Routledge, 2019), p. 1350 et seq.

81 OJ L 131, 28.5.2009, p. 47.

82 See Art. 2 (e) Reg. 391/2009. See also Annex I of the Regulation, where the European legislator sets out two (2) categories, the general and the specific minimum criteria.

83 See Art. 3 of PD 103/2011. However, Hellenic administrations may restrict the number of organizations they authorize, in accordance with their needs, provided there are transparent and objective grounds for so doing (see Art. 4 (1) of PD 103/2011). In accordance with the latest data, the following are included in Greece's list of Recognized Organizations: American Bureau of Shipping (ABS), Bureau Veritas S.A. (BV), China Classification Society (CCS), DNV GL AS (DNV GL), Korean Register (KR), Lloyd's Register Group LTD (LR), Nippon Kaiji Kyokai General Incorporated Foundation (ClassNK), RINA Services S.p.A., Russian Maritime Register of Shipping (RS).

84 MD 4113.311/01/2013 (Gov. Gaz. 3049/B/29.11.2013).

85 See provision 7.7 et seq.

86 Imposed either by a court of law or as part of a settlement through arbitration procedures.

87 M. Stathopoulos, A. Karampatzos, Contract Law in Greece (Wolters Kluwer, 2014), p. 48.

88 For more on the classification societies' liability issues from a comparative and Greek Law point of view, see, L. Athanassiou, The role and responsibility of classification societies (1999) [in Greek]. Regarding other 


\subsection{Control and surveillance: Greece legislative weapons enhancing port control}

As mentioned in the Introductory remarks, the enhancement of Port State Control (PSC), in order to partly remedy flag states' failures and inadequacies (mainly those of the open registries), has been one of the major developments of maritime law in the course of the last century. ${ }^{89}$ Greece has been one of the 14 European Administrations- signatories ${ }^{90}$ of the Memorandum of Understanding on Port State Control, concluded in Paris, in 1982 ('Paris MoU'). ${ }^{91}$ As is well known, the Paris MoU requires that the participating national authorities maintain an effective system of PSC and also comply with the main international safety and pollution conventions, regardless of whether the flag State of the concerned ship is a party to these conventions or not. ${ }^{92}$ A great part of the success of Port State Control measures is based on the 'name and shame' principle, under which the participating port authorities may - in cooperation with other Administrations - develop lists of flag States (either positive or negative), as well as tables illustrating the performance of classification societies. ${ }^{93}$

The Greek regime on Port State Control is complemented with a package of rules of European origin. First, PD 16/201194 embodies the primary EU PSC regime, i.e. Directive 2009/16/EC ${ }^{95}$ on port State control. By incorporating the Directive, Greece contributes towards the objective of the EU, ${ }^{96}$ in reducing drastically substandard shipping in the

legal orders; see also M. Ferrer, La responsabilité des sociétés de classification (PUAM, 2004); J. Basedow, W. Wurmnest, Third-Party Liability of Classification Societies (Springer 2005); N. Lagoni, The Liability of Classifcation Societies (Springer, 2007); A. Tettenborn, 'The Liabilities of Classification Societies - More Awkward than it Looks?' in R. Thomas (ed.), Liability Regimes in Contemporary Maritime Law (Informa Law from Routledge, 2007); A. Antapassis, L. Athanassiou, Maritime law (2020) [in Greek], p. 163 et seq.

89 For more on Port State Control see, A. Blanco - Bazan, 'Implementation of IMO Conventions by Flag and Port States' in A. Couper, E. Gold (eds.) The Marine Environment and Sustainable Development: Law, Policy and Science (1991-1993), pp. 448-475; G. C. Kasoulides, Port State Control and Jurisdiction (Martinus Nijhoff Publishers, 1993); N. Ready, 'Port State Control' (1995) 2 Journal of International Maritime Law 6; A. Clarke, 'Port State Control or Sub- Standards ships: Who is to blame? What is the cure?' (1994) LMCLQ 202; A. Fall, 'Le controle par l'état du port en matière de sécurité de la navigation et de protection de l'environnement marin' (2000) Droit Maritime Français 601; P. Chaumette, Y. Tassel, 'Le controle des navires par l'état du port: Regime et consequences commerciales' (1999) Annuaire de Droit Maritime et Océanique 237 et seq.; I. ChristodoulouVarotsi, 'Port State Control of labour and social conditions: Measures which can be taken by Port States in keeping with international law' (2003) Annuaire de Droit Maritime et Océanique 251.

90 Since the group of 14 nations was comprised mostly of countries within the European Economic Community (the EU now), it might be alleged that the Paris MoU is one of the first steps in the EU's ambition to have an influence in maritime regulation.

91 Counting nowadays 27 members, i.e. Belgium, Bulgaria, Canada, Croatia, Cyprus, Denmark, Estonia, Finland, France, Germany, Iceland, Ireland, Italy, Latvia, Lithuania, Malta, the Netherlands, Norway, Poland, Portugal, Romania, the Russian Federation, Slovenia, Spain, Sweden and the United Kingdom.

92 The port States have the control competences that are given by the various conventions.

93 Following the example of the Paris MoU, eight other regional PSC regimes have been established: Tokyo MoU; Vina del Mar Agreement; Caribbean MoU; Abuja MoU; Black Sea MoU; Mediterranean MoU; Indian Ocean MoU; Riyadh MoU. The United States Coast Guard maintains the tenth PSC regime.

94 Gov. Gaz. 36/A/4.3.2011.

95 OJ L 131, 28.05.2009, p. 57. The Directive, part of the Erika III measures, has been amended several times since, through Directive 2013/38/EU (OJ L 218, 14.8.2013, p. 1), as incorporated in Greek Law by virtue of PD 166/2014 (Gov. Gaz. 250/A/20.11.2014), Regulation 1257/2013/EU (OJ L 330, 10.12.2013, p. 1) and Regulation 2015/757 (OJ L 123, 19.5.2015, p. 55). However, it was not the first EU legislative text on PSC (see for instance Directive 95/21/EC). Hence, it has been alleged that the said Directive is on the one hand a recast/consolidation measure, whilst on the other hand it also takes the law further on various issues, see V. Power, EU Shipping Law (Informa Law from Routledge, 2019), p. 1307.

96 See also Art. 1 of the Directive. 
waters under the jurisdiction of Member States by, among others, increasing compliance with international and relevant Community legislation on maritime safety, maritime security, protection of the marine environment and on-board living and working conditions of ships of all flags, by carrying out inspections on a frequent basis and by improving the quality of PSC administrations. The PD 16/2011 is applicable to any ship and its crew calling at a port or anchorage of Greece to engage in a ship/port interface, or in waters within national jurisdiction, other than at a port. It prescribes in detail measures for the training and empowerment of inspectors, as well as for the organization of the inspection system (frequency of the inspections, ${ }^{97}$ selection criteria for choosing the ships under inspection, ${ }^{98}$ conditions of ship's detention, ${ }^{99}$ reporting obligations and exchange of information, inspection database, penalties etc.).

In the same line, PD 17/2011 incorporated Directive 2009/17/EC, ${ }^{100}$ establishing a Community vessel traffic monitoring and information system. To that purpose, Greece took all reasonable steps for the development of a data exchange network, named SafeSeaNet, ${ }^{101}$ and of a long-range system for identification and tracking of ships ${ }^{102}$ ('LRIT'). Furthermore, the said PD provides for places of refuge that shall accommodate ships in distress and sets the authorities which are competent to decide about the accommodation of ships in need of assistance.

Lastly, reference should be made to L. 4033/2011, which incorporates Directive 2009/18/ $\mathrm{EC}^{103}$ establishing the fundamental principles governing the investigation of accidents in the maritime transport sector. In this context, the Hellenic Bureau for Marine Casualties Investigation (HBMCI) was established, as the independent and impartial national organization, competent for conducting safety investigations ${ }^{104}$ for marine casualties and incidents that take place on Greek-flagged vessels, other vessels within national territorial waters or within the Hellenic Search and Rescue (SAR), region provided that the SAR services were delivered by Greek Authorities, as well as any casualty or incident involving the substantial interests of Greece. ${ }^{105}$ Penalties are provided for, in case of non-compliance with the legislation, depending on the breach detected. ${ }^{106}$

97 See Art. 11

98 See Art. 12

99 See Art. 19. In the case of deficiencies which are clearly hazardous to safety, health or the environment, a detention order or stoppage of an operation shall not be lifted until the hazard is removed or until the competent authority establishes that the ship can, subject to any necessary conditions, proceed to sea or the operation be resumed without risk to the safety and health of passengers or crew, or risk to other ships, or without there being an unreasonable threat of harm to the marine environment.

100 OJ L 131, 28.5.2009, p. 114. The Directive, also part of the Erika III package, aims - in its reformed version - at improving the collection and sharing of information in order to respectively improve the knowledge of maritime traffic.

101 See Art. 22a and Annex III of PD 17/2011.

102 See also Art. 6 b of the PD 17/2011.

103 OJ L 131, 28.5.2009, p. 114. The Directive amends Council Directive 1999/35/EC and Directive 2002/59/ EC. It is also known as the Accident Investigation Directive.

104 The investigations conducted by the HBMCI are independent from criminal or other administrative investigations which are held to apportion blame or determine liability, and focus on identifying the causal and contributing factors that led to the marine accident or incident, with the objective of preventing future marine accidents or incidents, enhancing maritime safety. See also, Art. 4 of L. 4033/2011.

105 Two more important aspects of Directive 2009/18/EC that were incorporated by virtue of L. 4033/2011 are the so-called 'early alert system' and the European Marine Casualty Information Platform (EMCIP).

106 Depending on the infringement, Art. 22 provides either for the penalties described in Art. 45 or in Art. 223 (3) of KDND. 
Applying and enforcing the above rules in a way that ensures uniform protection of safety, without provoking disproportional hindrance to maritime commerce and generating a 'port-shopping' phenomenon, is more than a difficult task. Occasionally, a sense of unease is expressed by shipowners and flag States, worried that the ships might be unduly targeted, with the inspectors of port States imposing unreasonable demands before permitting their departure. ${ }^{107}$ In order to avoid these deficiencies, Directive 2009/16/EC on PSC provides examples of clear grounds for a more detailed inspection. ${ }^{108}$ However, besides the case of 'wake-up call' incidents, the execution of a more detailed inspection is up to the professional judgement of the inspector. As a result, albeit the existence of a harmonized PSC system, the results of the control inspections in fact differ, depending on the port State carrying out the inspection. ${ }^{109}$ For all these reasons, the inspectors' impartiality, professional quality and expertise, as well as the number of inspectors engaged in the inspection process are of utmost importance. ${ }^{110}$ A horizontal study is thus recommended at European level to assess the impact of the common control measures on safety as well as how they affect competitive conditions among ports.

\subsection{Enforcement and liability: remedies}

\subsubsection{Specific compensation regimes}

Greece has ratified and implemented into the domestic legal order most international specific compensation regimes. More precisely, it has ratified ${ }^{111}$ the International Convention on Civil Liability for Oil Pollution Damage (CLC) $(1992 / 2000)^{112}$ and the IOPC Fund Convention (1992/2000). ${ }^{113}$ It has ratified the Supplementary Fund Protocol as well, which provides an optional third tier of compensation up to 750 million SDR. ${ }^{114}$ The Bunkers

107 Thus, resulting in delays and therefore huge economic consequences to the shipowner.

108 See Annex V of the Directive. Among the key incidents that may lead to more detailed inspections are: information or evidence that the master or crew is not familiar with essential shipboard operations relating to the safety of ships or the prevention of pollution, or that such operations have not been carried out, the absence of principal equipment or arrangements required by the Conventions, detected inaccuracies in the certificates or other documentation, evidence that the certificate has been fraudulently obtained or the holder of a certificate is not the person to whom that certificate was originally issued, evidence that the working and living conditions are not in compliance with the provisions of MLC 2006, etc.

109 See, M. Tsakiri, 'Port State Control in Europe: Objectives and malfunctions' (2019) 102 PeirNom 110 [in Greek].

110 Although the Paris MoU (Section 3, para 3.3.) and Dir. 2009/16 (Art. 22) set out rules to prevent conflicts of interest, the experience and expertise of each individual is of the utmost importance. The port State's bureaucracy, administrative and political support may also affect the inspector's work and the uniform application of the established procedures. In accordance with a recent paper, see, A. Graziano, P. Cariou, F. C. Wolff, M. Q. Mejia, J. U. Schröder-Hinrichs, 'Port state control inspections in the European Union: Do inspector's number and background matter?' (2018) Marine Policy 230 et seq.; the number of inspectors engaged per inspection is of significance, since with the participation of several inspectors, the execution of inspection is more careful and thorough.

111 After denouncing both the International Convention on Civil Liability for Oil Pollution Damage (CLC) (1969) and the 1971 Fund Convention on 2.5.1997.

112 By virtue of PD 197/1995 and PD 286/2002 respectively.

113 By virtue of PD 270/1995 and PD 291/2003 respectively.

114 L. 3482/2006 (Gov. Gaz. 163/A/2.8.2006). 
Convention (2001) is equally incorporated into the domestic legal order, ${ }^{115}$ while this is not the case for the HNS Convention (1996), as amended in 2010.

It is shortly reminded that CLC (1992) was adopted to ensure that adequate compensation is available to persons who suffer oil pollution damage resulting from maritime casualties involving oil-carrying ships. It establishes a system of strict, exclusive and limited liability of the ship's registered owner, accompanied by compulsory civil liability insurance and a right of direct action against the insurer. The owner's liability is doubly canalized: on one hand, no claim for compensation for pollution damage may be made against him, on a different legal basis than that provided for in the Convention; ${ }^{116}$ therefore, from the Greek perspective, the injured parties cannot invoke the tortious liability provisions (AK 914 et seq.) or the provisions of L. 743/1977 'for the protection of marine environment' (as codified by PD 55/1998) or L. 1650/1986 'for the protection of environment' unless in a case of damage not falling within the scope of the CLC. On the other hand, no claim for compensation for pollution damage under the Convention or otherwise may be made against any of the persons covered by Article III (4), unless the damage resulted from their personal act or omission, committed with the intent to cause such damage, or recklessly and with knowledge that such damage would probably result. In the latter case, the above domestic legal bases may be used to sue persons deprived of the protection of Article III (4). The constitution of limitation fund by the owner or its insurer, the submission and verification of claims and the distribution of the amounts due are governed by PD $666 / 1982$ and organized as a quasi-collective judicial procedure ${ }^{117}$ at the CFI in the territory of which the incident that caused the pollution took place. ${ }^{118}$ Posterior insolvency of the owner-debtor does not affect the continuance of the procedure.

Worth mentioning at this point is the Greek Supreme Court's case-law on the definition of the term 'ship' under both CLC and IOPC Fund conventions, such jurisprudence being not just the first one on the matter but also highly controversial and criticized. The so-called 'Slops Case' was about an oil spill provoked by a Greek-flagged tanker, having undergone major conversion, permanently at anchor and used as a waste-oil reception facility; due to the lack of insurance and to the owner's insolvency, victims claimed compensation by the Fund, but the latter objected that the accident was not recoverable under the Fund Convention. The claimants filed an action before the Greek courts, provoking a series of contradictory decisions at various jurisdictional degrees. ${ }^{119}$ In the final proceedings, the Supreme Court (Areios Pagos) held that the Slops was a ship for the purposes of the CLC, on the basis of the construction criterion, as it had been built as a tanker and was still generally in a condition to carry oil as cargo. ${ }^{120}$ Although the Fund complied with the

115 L. 3393/2005 (Gov. Gaz. 242/A/4.10.2005).

116 Art. III§4.

117 See A. Antapassis, L. Athanassiou, Maritime law (2020) [in Greek], pp. 860-861, L. Athanassiou, The debate on the limitation of liability for maritime claims [in Greek] (2005), p. 342 et seq.

118 Arts. $1 \S 1 \mathrm{a}$ and 2.

119 Piraeus Multi-member CFI (PPrPeir) c. 5887/2002, Piraeus CoA (EfPeir) c. 103/2004, Supreme Court (Areios Pagos) c. 14369/2005, Supreme Court (Areios Pagos) Assembly (OlAP) c. 23/2006, Piraeus CoA (EfPeir) c. $133 / 2008$.

120 See A. Antapassis, L. Athanassiou, Maritime law (2020) [in Greek], p. 844 et seq. See also J. Harrison, 'Conflicting interpretation - The "Slops" incident and the application of the international oil pollution liability regime to offshore and storage operations' (2008) Journal of Environmental Law 454-464, T.A. Mensah, 'Can the "Slops" be considered as a ship for the purposes of the 1992 Civil Liability Convention and the 1992 Fund Con- 
final decision of the Supreme Court, it implicitly continued to apply its own interpretation guidelines.

Quite recently, the Fund had again to intervene in Greece regarding the oil spill from the 'Agia Zoni II' incident; the so-named double-hulled tanker, of 1587 gt, sank in the Saronic Gulf of Greece, on 17 September 2017, provoking a spill of approximately 500 tons of oil. The physical and environmental damages as well as the economic losses were considerable, since 20-25 km of coastline of the 'Athens Riviera' was affected and 3-4 km of Salamina island, while several operations took place in order to limit the effects of the spill (onshore and offshore clean-up operations). As a response, hundreds of claims were thereafter raised, 377 of them being submitted to the local Bureau of the Fund, operating in Piraeus. By 7 May 2019, the IOPC Fund had already paid claims amounting approximately $11,000,000 €$. The assessment is still ongoing.

\subsubsection{Compulsory insurance}

Compulsory insurance is a powerful tool for achieving maritime safety goals, both at the preventive and the compensatory level. Greece is primarily implementing compulsory insurance as regulated in several maritime International Conventions, i.e. the CLC 1992, the Bunkers Convention and the MLC. In addition to those international texts, ${ }^{121}$ already mentioned above, Greece is applying PD 6/2012 ${ }^{122}$ incorporating Directive 2009/20/EC C $^{123}$ on the insurance of shipowners for maritime claims. ${ }^{124}$ By virtue of the said PD, persons owning or operating ${ }^{125}$ a Greek-flagged ship of 300 gross tonnage or more, ${ }^{126}$ including passenger ferries, ${ }^{127}$ are obliged to insure their liabilities for maritime claims ${ }^{128}$ for an amount equal to the LLMC 1996 limits per incident. ${ }^{129}$ Owners or operators of ships flying a flag other than Greek are also required to have insurance in place when entering a Greek port and when operating in Greek territorial waters. ${ }^{130}$ The existence of the insurance may be

vention?' (2010) Aegean Review of the Law of the Sea and Maritime Law 145-155; Z. Peplowska-Dabrowska, 'What is a ship? The policy of the International Fund for Compensation for Oil Pollution Damage: the effect of the Supreme Court judgment in the Slops case', (2010) Aegean Review of the Law of the Sea and Maritime Law 157-164; S. F. Gahlen, Civil Liability for Accidents at Sea (Springer, 2015), p. 85 et seq.

121 See also IMO Resolution A. 898 (21) that invited the Member Governments to urge shipowners to implement several measures in order to ensure that there is an effective insurance cover or other financial security to provide full and prompt payment of such claims. The incorporated Resolution Guidelines also contain recommendations for certification and provide a model receipt and release form for claims for personal injury or death.

122 Gov. Gaz. 7/A/20.1.2012.

123 OJ L 131, 28.5.2009, p. 128.

124 See also, M. Pimm, 'Commentary on Directive 2009/20/EC on the Insurance of Shipowners for Maritime Claims' in H. Jessen, M. J. Werner, EU Maritime Transport Law (Hart Publishing, 2016), p. 1015 et seq. Although PD 6/2012 does not provide for a direct claim against the insurer, it introduces a most welcome extension of compulsory civil liability insurance for all maritime claims.

125 E.g. the bareboat charterer.

126 In accordance with Art. 2 (2), the legislation is not applicable to warships, auxiliary warships or other State owned or operated ships used for a non-commercial public service.

127 See opinion n. 542/2012 of the Hellenic Legal Council of State, according to which passenger ferries with a capacity of 300 or more that are operating on ferry routes and executing voyages within a port area are subject to insurance.

128 The insurance coverage might be provided by P\&I Clubs, as well as any other effective form of insurance (including proven self-insurance) or a financial guarantee providing similar terms of coverage (Art. 4b).

129 Art. $4 \S 3$.

130 Art. $4 \S 2$. 
proved by one or more certificates issued by her insurer and carried on board the ship. ${ }^{131}$ If the certificate or certificates referred to in Article 6 are not carried on board the ship, under a foreign flag, referred to in para 3 and without prejudice to PD 16/2011, ${ }^{132}$ which provides for detention of ships when safety issues are at stake, the competent authority ${ }^{133}$ shall issue an expulsion order to the ship. ${ }^{134}$ Respectively, the competent authority shall refuse entry of a ship into a Greek port, for which an expulsion order has been issued by the Competent Authorities of the other EU Member States until the shipowner serves the Certificate or Certificate of Insurance referred to in Article 6. The process of issuing the expulsion order is determined by the competent Ministry and the Hellenic Coast Guard and is posted up to the Port Authorities. ${ }^{135}$

\subsubsection{Criminal penalties}

Maritime safety is further enhanced through criminal penalties for pollution offences, complemented by European rules. ${ }^{136}$ Following the adoption of Directive 2005/35/ $\mathrm{EC}^{137}$ on ship-source pollution and on the introduction of penalties for infringements, ${ }^{138}$ L. 4037/2012 ${ }^{139}$ adopted criminal sanctions related to pollution offences. In a nutshell, L. 4037/2012 applies $^{140}$ in cases of discharges of polluting substances in internal waters (including ports) or the territorial sea of a Member State, the straits used for international navigation subject to the regime of transit passage ${ }^{141}$ (to the extent that a Member State exercises jurisdiction over such straits) and the high seas. A distinction is made between the cases where, due to the severity of the deterioration, there is a risk of death or serious injury or widespread environmental disturbance or destruction (a), and all the other cases (b). In the former scenario, the discharge of polluting substances is punishable by imprisonment for up to ten years and a fine ranging from 3,000 euros to 300,000 euros. ${ }^{142}$ In case of negligence, the provision provides for imprisonment of at least six months and a fine

131 Art. $6 \$ 1$.

132 Off Gaz. N. 36/4.3.2011. It implements the Directive 2009/16/EC on Port State Control.

133 The Ministry of Marine Affairs and Insular Policy and the Headquarters of Coast Guard.

134 Art. $5 \S 4$. The order shall be notified to the Commission, the other Member States and the flag State concerned.

135 Art. $5 \$ 5$.

136 See, inter alia, A. Mandaraka- Sheppard, Modern Maritime Law, Vol. II (Informa Law from Routledge 2014), p. 54.

137 OJ L 255, 30.9.2005, p. 11. See also, H. Jessen, 'Commentary on Directive 2005/35/EC on ship-source pollution and on the introduction of penalties, including criminal penalties, for pollution offences (as amended by Directive 2009/123/EC)', in H. Jessen, M. J. Werner, EU Maritime Transport Law (Hart Publishing 2016), p. 667 et seq., V. Power, EU Shipping Law (Informa Law from Routledge, 2019), p. 1114 et seq.

138 The Directive has given rise to multilevel tensions: (a) between the EU institutions regarding the allocation of powers, but also (b) between the EU and the Member States regarding the extent of the Union's criminal jurisdiction, (c) between EU and international maritime law as to whether MARPOL's international standards are minimum or maximum and whether EU regulations are in conflict with the compliance with the international obligations of the Member States, as well as (d) regarding the aim of the common maritime policy, with more maritime states (Greece, Cyprus, Malta) pointing out the risk of criminalizing seafarers' work.

139 Gov. Gaz. 10/A/0.01.2012.

140 See in detail Art. 3 of L. 4037/2012 and of the Directive 2005/35/EC respectively.

141 As laid down in Part III, section 2, of the 1982 UNCLOS.

142 Art. $6 \$ 1$ (a). 
ranging from 1,000 euros to 15,000 euros. ${ }^{143}$ In the latter scenario (i.e. all other cases), the offence is punishable by imprisonment of at least one year and a fine between 1,500 euros and 50,000 euros. ${ }^{144}$ Respectively, cases of negligence are punished with imprisonment of at least three months and a fine ranging from 200 euros to 3,000 euros. ${ }^{145}$ However, the legislator provides a form of relief to the wrongdoer who, with prompt notice to the competent authority, substantially addresses the material reduction of the adverse effects of the pollution or the water quality deterioration caused by his action or omission. In such cases, the court may impose a reduced sanction in accordance with Article 83 of the Criminal Code ${ }^{146}$ or may acquit the wrongdoer of any sentence. ${ }^{147}$

Lastly, L. 4037/2012 also regulates the accountability of legal entities. In particular, responsible for complying with the provisions relating to the prevention of marine pollution are considered to be: (a) the managers of partnerships, limited liability companies and cooperatives and (b) members of the management body and persons exercising control over the company in shareholding companies, shipping companies and yachting maritime companies. ${ }^{148}$

\subsection{Instead of conclusions: new challenges}

Due to its dynamic and continuously evolving character, a discussion on maritime safety cannot be closed. For that reason, instead of (temporary) conclusions, we dedicate the fifth and last section to some special safety issues of current interest, which affect several branches of law and raise sensible socio-political and economic concerns, as faced by Greece.

\subsubsection{Armed guards and maritime safety}

Following the increase of piracy incidents, ${ }^{149}$ Greece was one of the first States that adopted a regulatory framework specifically addressing the deployment of armed security personnel on board ships. L. 4058/2012 on the 'Provision of security services by armed guards to

143 Art. $6 \$ 2$ (a). In accordance with Art. $6 \S 5$, whoever, in any way contributes to the committing of the offence, without being qualified as a participant, is punished with the same penalties, but reduced in accordance with Art. 83 of the Greek Criminal Code, which means that instead of a term of up to ten years, a term of up to six years or imprisonment of at least one year is imposed and, in any other case, the judge freely reduces the penalty up to the minimum limit of the penalty.

144 Art. $6 \$ 1$ (b). In accordance with Art. $6 \S 5$, whoever in any way contributes to the committing of the offense, without being qualified as a participant, is punished with the same penalties, but reduced in accordance Art. 83 of the Greek Criminal Code.

145 Art. $6 \$ 2$ (b). Additionally, the framework regulates repeated minor cases that do not individually but in conjunction, in view of the local and temporal unity, result in deterioration in the quality of water $($ Art. $6 \S \S 3,4)$.

146 Ibid.

147 Art. $6 \S 6$.

148 Art. $7 \S 1$.

149 From an international law point of view, see UNCLOS (Art. 101) as ratified by L. 2332/1995. Regarding penal sanctions, Art. $215 \mathrm{KDND}$ provides for the imprisonment of persons having conducted acts of piracy, while Art. 8 of the Penal Code establishes the universal jurisdiction of Greek penal courts when it comes to acts of piracy. Lastly, in accordance with Art. 2 of L. 3922/2011, combatting piracy is included within the Hellenic Coast Guard competences. 
commercial ships ${ }^{\prime 150}$ achieves a dual goal: it enables the existence of armed guards, reducing thereby the external risks for the ships, while preserving the principle of proportionality, at various levels. The main pillars of the system may be summarized as follows: (a) security services are allowed on board merchant vessels that sail seas exposed to the risk of piracy, and only upon authorization to be issued by the Chief of the Hellenic Coastguard ${ }^{151}$ for a period of up to 12 months, with the possibility of extension ${ }^{152}$ and/or renew; ${ }^{153}$ (b) several minimum requirements must be met by the armed guards, relating to the age, the professional integrity, status and experience; ${ }^{154}$ (c) provision of the services is based on a contract concluded between the shipowner or operator and the security service provider, ${ }^{155}$ the latter being a company licensed and quality certified (ISO); (d) the private guards are employed by the company above and do not constitute part of the ship's crew; ; 156 (e) crew members have a recognized right to disembark after notifying the captain in writing, ${ }^{157}$ if they do not wish to provide work on board, after the issuance of the authorization; (f) proportionality applies also regarding the safekeeping and use of armed forces: on one hand, the armed guards' weapons and ammunition are kept in premises accessed solely by the captain or his substitute and the head of private armed guards or his substitute; on the other hand, use of weapons shall be allowed within high-risk areas to address imminent risks for the passengers, the ship or its cargo, exclusively by order of the master and only to the extent required to avert the risk. ${ }^{158}$ Additional notification obligations towards the competent authorities of coastal states as well as to flag State authorities are clearly prescribed.

Final but yet important, L. 4058/2012 (Article 9) prohibits any use of weapons and ammunition, including the maintenance thereof, carried or located aboard ships flying foreign flags within Greek territory, while the weapons and ammunition on board shall be kept in special locked premises thereof when the ship is within Greek territory. Article 10 states the penalties imposed when non-compliance is detected. In particular, imprisonment of up

150 Adoption of the Law came after taking into account the gradual increase in piracy attacks mainly in the Gulf of Aden and the need to avoid any possible leakage from the Greek registry due to the absence of an adequate legal framework ensuring for protection against the piracy. See Part II of the explanatory notes of L. 4058/2012 (available in the site of the Hellenic Parliament: www.hellenicparliament.gr/UserFiles/2f026f42-950c-4efc-b950340c4fb76a24/p-ploia-eis.pdf).

151 See Arts. 1, 2(3)(4) of L. 4058/2012. The authorization is issued within 15 days of the submission of the relevant request, accompanied by an analysis of the estimated risk and the views of the master. It is drafted in Greek and in English and its original version is kept on the ship.

152 See Art. 3 (1). Extension is granted ipso facto if it expires while the ship is on a voyage until its arrival at a port where private guards and their equipment are allowed to disembark.

153 Authorization may be renewed at the request of the shipowner or the manager prior to its expiry, provided that the terms and conditions of its issuance are still in force (Art. 3(2)). Art. 3 (3) provides also for the possibility of amending the authorization which is still valid. Revocation by the Chief of the Hellenic Coastguard is possible, if any one of the terms and conditions required for issuance is no longer valid. In case of violation of the terms and conditions of the authorization, administrative penalties may be imposed in conformity with Art. 45 KDND.

154 According to Art. 2, they must be at least 21 years old, not have been irrevocably sentenced to a custodial sentence longer than six months for any offence committed intentionally and being employed by a licensed company.

155 See Art. 2 (2).

156 The same approach is adopted by the BIMCO's Standard Contract for the Employment of Security Guards on Vessels ('GUARDCON'), in cl. 7 (j): 'ensuring that the Security Personnel are entered onto the Vessel's crew list as supernumeraries upon embarkation'.

157 In such a case, the employment contract is considered terminated without the fault of the parties and the sailor is entitled to be repatriated, at the shipowner's or manager's expense, see Art. 5.

158 See Art. 6 (2). 
to nine months or a monetary fine shall be imposed on: any private armed guard aboard a ship without authorization and any private armed guard who violated his obligations as prescribed in L. 4058/2012; the legal representatives of the shipowner or the manager or the security service provider and the captain, if they otherwise approved or consented to the boarding of unauthorized private armed guards; the legal representatives of the shipowner or manager, if false or inaccurate information was submitted for the issuance or renewal of the authorization; the captain of a ship flying a foreign flag, in case of violation of his obligations as mentioned and analysed above. Lastly, by virtue of para 2 of Article 10, the Hellenic Coastguard may confiscate and seize any weapons and ammunition of private armed guards' on board ships flying a Greek or foreign flag within Greek territory, which are not authorized or approved by the authorities of the flag State.

Briefly evaluating the effectiveness of armed guards, it may be alleged that their presence on board has been successful as a precaution for Greek vessels crossing risk areas. The assertion is borne out by the low rates of successful hijacks to Greek vessels when armed guards have been present on board. ${ }^{159}$ Apart from the obvious 'safety' reasons, there are looming economic benefits when having security forces on board, since the greater the level of security and safety a vessel possesses, the fewer route diversions will be needed, while the presence of armed guards on board may also reduce the premium required when crossing risk areas. ${ }^{160}$ In any case, the presence of armed guards on board is favourable provided that the personnel are chosen for their expertise, training and understanding of the relevant rules for the use of force on board. In other words, it is essential for an armed guard to understand that his/her presence is primarily preventive oriented, while using the minimal force necessary to do so and in no case should the use of force exceed what is strictly necessary and reasonable in the circumstances. ${ }^{161}$

\subsubsection{Massive migration flow and maritime safety}

During recent years, the EU and especially Greece have sought to handle and properly control migratory flows, usually originating from African or Middle East States, fleeing to Europe in search of safety and prosperity. Illegal migrants seek to cross the Mediterranean Sea, as a matter of course, mostly organized by smugglers. In the majority of cases, the perilous journey to Europe is undertaken in small unseaworthy vessels, thus increasing the likelihood and possibility of maritime accidents. In this special section, the analysis mainly concentrates on the existing regulations applied in this special area of safety - humanitarian safety.

159 The sole well-known attack was the hijacking of the Greek oil tanker Elka Aristotle off the coast of Togo's capital city Lome on 9 November 2019, where the pirates kidnapped four sailors and one of the security guards on board was shot in the incident.

160 Unarmed vessels are definitely more vulnerable when crossing areas well known for piracy attacks, and therefore they are either not covered while crossing those risk areas or the premium is greatly increased or the insurers themselves recommend the use of armed guards for keeping the premium low.

161 Currently, there are no international legislative texts that define what force and measures can be used lawfully to defend against a pirate attack. As a result, in international waters, the laws governing the use of force will be those of the flag state of the vessel, which must be complied with by the master, crew and security personnel at all times. It is advisable that shipowners ensure that the flag State is consulted at an early stage in their consideration of the decision to place armed guards on board to ensure that any statutory requirements are met (See MSC.1/ Circ.1405/Rev.2, Annex, 3.1.). 
So far there is no Treaty dedicated solely to issues arising from the rescue or operation of migratory flows. However, dispersed provisions in several international instruments do exist and may apply when it comes to the rescue of migrants and refugees. In particular, the obligation to assist vessels in distress at sea and to provide rescue of persons on board has always been considered a duty under any legal order ${ }^{162}$ and is reflected in several International Conventions, which were adopted in the first place in order to reduce the perils of the sea for commercial vessels and seafarers and to enhance maritime safety in general. ${ }^{163}$ The following short developments attempt to systematize the available legal tools, while pointing out insufficiencies and lacunas. ${ }^{164}$

The general obligation of assisting vessels in distress is primarily established in UNCLOS; Article 98 (Duty to render assistance) ${ }^{165}$ clearly establishes the positive obligation of flag States ${ }^{166}$ to require the master of the ship flying their flag to provide assistance. However, in practice, although imposed on the Member States, the obligation is fulfilled by the masters. ${ }^{167}$ Besides, although the said article is part of Part VII of UNCLOS under the title 'High Seas', the duty of assistance applies to all maritime zones and in fact constitutes a mere implementation of the safety of life at sea principle. ${ }^{168}$ The obligation applies to all masters equally, irrespective of whether it is a military, merchant or recreational ship. Furthermore, the duty of assistance applies to all persons at risk, irrespective of the nationality of the ship or the persons in danger, their legal status or activity. ${ }^{169}$ Thus, the fact that persons in distress might be involved in a form of illegal activity does not affect or nullify the duty of assistance. ${ }^{170}$ In this context, the duty is triggered when the persons in danger are migrants or refugees, although the Convention's initial scope is not the regulation of the rescue of mass migratory flows. ${ }^{171}$

162 It may be characterized as a customary rule of international law, see F. Munari, 'Salvage and rescue of human lives and migrants and EU Law: An urgent need for re-assessment' in 9th International Maritime Law Conference, Piraeus 2016, p. 569.

163 Regulations related to the protection of migratory flows are also found in international texts for the protection of refugees, such as the 1951 Convention Relating to the Status of Refugees, in European law concerning the Common European Asylum System (CEAS) and in the Protocol against the Smuggling of Migrants by Land, Sea and Air (2000). However, those texts will not be a subject of further analysis herein, since they fall outside the scope of the chapter that concentrates on texts related to maritime safety.

164 See also the analysis of the framework eventually applicable when dealing with migration at sea, from a Greek perspective, by A. Vidalis, 'Maritime law and migration. Framework, challenges, developments and concerns' in 9th International Maritime Law Conference, Piraeus 2016 [in Greek], p. 600 et seq.

165 Para 1 of Art. 98 provides that contracting States are bound to ensure that the master of a ship flying their flag will act appropriately in order to assist and rescue any person in danger, and will proceed with all possible speed for this purpose.

166 For the flag State's obligations, see Art. 94 UNCLOS and D. Rothwell, T. Stephens, The International Law of the Sea, 2nd ed. (Hart Publishing, 2016), p. 169.

167 For the State's measures for assuring the compliance of merchant ships with the duty of assistance see also, R. Kilpatrick, A. Smith, 'The international legal obligation to rescue during mass migration at sea: Navigating the sovereign and commercial dimensions of a Mediterranean crisis', (2015) 28(2) U.S.F. Maritime Law Journal 160-167.

168 S. Trevisanut, 'Which Borders for EU Immigration Policy?' in L. Azoulai, K. de Vries (eds.), EU Migration Law, Legal Complexities and Political Rationales (Oxford, 2014), p. 129.

169 See R. Barnes, 'Refugee law at sea', (2004) International \& Comparative Law Quarterly 53(1) 50.

170 See I. Papanicolopulu, 'The duty to rescue at sea, in peacetime and in war: A general overview' (2016) 98(2) International Review of the Red Cross 495.

171 See D. Rothwell, T. Stephens, The International Law of the Sea, 2nd ed. (Hart Publishing, 2016), pp. $170-171$. 
In addition, the second paragraph of Article 98 requires that every coastal State promotes the establishment, operation and maintenance of an adequate and effective Search and Rescue (SAR) system regarding safety on and over the sea, which in practice makes the link with the Convention on Maritime Search and Rescue system (SAR Convention), signed in Hamburg in 1979. ${ }^{172}$ This brings us to the second legal basis under scrutiny, ${ }^{173}$ i.e. the SAR Convention, by virtue of which the contracting States are under the obligation to cooperate and establish regional SAR Rescue and Coordination Centers (RCCs), with regard to facilitate rescue missions that are taking place in their region. ${ }^{174}$ In accordance with its provisions, the State Parties are obliged to "ensure that assistance [is] provided to any person in distress at sea ... regardless of the nationality or status of such a person or the circumstances in which that person is found' 175 and to "provide for their initial medical or other needs, and deliver them to a place of safety'. ${ }^{176}$ In this context, the RCCs shall provide medical advice, initial medical assistance, or medical evacuation, through the use of public and private resource, including cooperating aircraft, vessels and other craft and installations, ${ }^{177}$ to any person in distress without discrimination.

Furthermore, the duty of assistance is directly imposed on the master of a ship by the SOLAS Convention; Chapter V, Regulation 33, under the title 'Distress situations: obligations and procedures', para 1 provides that the master of a ship at sea which is in a position to be able to provide assistance on receiving information from any source that persons are in distress at sea, is bound to proceed with all speed to their assistance, if possible informing them or the search and rescue service that the ship is doing so. Such obligation to provide assistance applies regardless of the nationality or status of such persons or the circumstances in which they are found.

The same obligation is imposed on the master by Article 10 (1) of the Salvage Convention 1989. Under Article 10, 'the master is bound, so far as he can do so without serious danger to his vessel and persons thereon, to render assistance to any person in danger of being

172 And counting 113 Contracting States, including Greece (ratification by virtue of L. 1844/1989).

173 The efficiency of this tool to deal with the issue of vessels or boats full of migrants under distress has been contested because of its rationale (see F. Munari, op. cit., p. 574 et seq.). The SAR Convention considers rescue as ' $[\mathrm{a}] \mathrm{n}$ operation to retrieve persons in distress, provide for their initial medical or other needs, and deliver them to a place of safety' (See Chapter 1.3.2.), while in Chapter 3.1.2. 'a Party should authorize, subject to applicable national laws, rules and regulations, immediate entry into or over its territorial sea or territory of rescue units of other Parties solely for the purpose of searching for the position of maritime casualties and rescuing the survivors of such casualties'. In consequence it might be alleged that the SAR CV assumes that the States in whose region the rescue operation was carried out have the sole obligation to organize the rescue operation and bring the persons safely ashore. The States continue to exercise full sovereignty as to the entrance of foreign vessels carrying rescued persons in their territorial sea or in their ports, which may be used for disembarking purposes. Therefore, once the rescue has been accomplished, the States have no other obligation and therefore those persons shall thereafter return to their homes, their places of origin.

174 See Chapter 2.2.3.

175 See Chapter 2.1.10.

176 See Chapter 1.3.2. The Convention does not define what is considered as a place of safety. In accordance with para 6.12 of the Guidelines on the treatment of persons rescued at sea (adopted on 2004), a place of safety is a location where (i) rescue operations are considered to terminate, (ii) the survivors' safety of life is no longer threatened and where their basic human needs (such as food, shelter and medical needs) can be met, (iii) a place from which transportation arrangements can be made for the survivors' next or final destination.

177 See Chapter 1.1.3. It seems that States are not obliged to directly send their coastguard of military vessels. When organizing their SAR services, they might also call merchant vessels to approach the ship in distress and provide assistance. 
lost at sea'. Although the salvor is in principle entitled to reward if his assistance is successful, when it comes to human life salvage, then ' $[\mathrm{n}]$ o remuneration is due from persons whose lives are saved'. ${ }^{178}$ The only case where human life salvage may be accompanied by a reward is when persons are salved together with property. In such a case, the 'salvor of human life, who has taken part in the services rendered on the occasion of the accident giving rise to salvage, is entitled to a fair share of the payment awarded to the salvor for salving the vessel or other property or preventing or minimizing damage to the environment'.

Despite what has been exposed above, the use of the 1989 Salvage Convention for establishing the duty of assistance to migrants in distress might be proved problematic for more than one reason: first, the master is bound to render assistance, only if this can be accomplished without serious danger to his vessel and persons thereon. Thus, embarking dozens of migrants on a merchant vessel and providing them with food and shelter is primarily of a dangerous nature and incidentally a hindrance for the master due to the costs and potential liabilities for cargo interests that may arise when the vessel is diverted for rescuing migrants. ${ }^{179}$ Second, disembarking the rescued persons to a port of a coastal state willing to accept them proves often to be an additional peril for the shipowner who remains exposed to unpredictable delays and impasses, with the cost associated to them. Third, no reward (even a symbolic one) is provided to encourage proactive behaviour from commercial vessels, although Article 16 (2) of the Convention does not prevent national legislations from making such a provision; indeed, an effective approach would probably be to give commercial vessels a financial incentive so as to assist persons in need, through the constitution, for instance, of a Fund financed by Member States' contributions, which would offer an adequate award to those having saved human lives at sea.

The above described framework being inadequate to address the specific issue at stake, new initiatives are needed. Indicatively, the Maritime Safety Committee took the initiative to amend and revise both SOLAS and SAR Conventions ${ }^{180}$ by adding that the contracting States shall coordinate and cooperate to ensure that masters of ships providing assistance by embarking persons in distress at sea are released from their obligations with minimum further deviation from the ships' intended voyage and that the survivors are disembarked from the assisting ship and delivered to a place of safety. In addition, the IMO together with the International Chamber of Shipping (ICS), and the Office of the United Nations High Commissioner for Refugees (UNHCR) have published a guide with regard to principles and practices applied to refugees and migrants in distress at sea. ${ }^{181}$ Further, with the assistance of the IMO, the UN agencies are regularly working together on the lack of safety of migration flows at sea by hosting relevant meetings.

178 See Art. 16 (1). The fact that saving lives in danger is not considered a 'useful result' under the Salvage Convention is supported by the relevant case-law, see The 'Bosworth' (No. 3), 1 Lloyd's Rep. 483.

179 See also, J. Coppens, E. Somers, 'Towards new rules on disembarkation of persons rescued at sea?' (2010) 25 International Journal of Marine \& Coastal Law 380.

180 See Resolution MSC. 153(78) and Resolution MSC. 155(78), both adopted on 20 May 2004.

181 'Rescue at sea: A guide to principles and practice as applied to refugees and migrants', 2010 (available at: www.unhcr.org/publications/brochures/450037d34/rescue-sea-guide-principles-practice-applied-migrants-refu gees.html). The ICS further published a complementary supplement to the said leaflet Guidance under the title 'Large scale rescue operations at sea guidance on ensuring the safety and security of seafarers and rescued persons' (available at: www.ics-shipping.org/docs/default-source/refugee-migrant-rescue/large-scale-rescue-operati ons-at-sea33E6D8E4E3B2.pdf?sfvrsn=0 ). 
The enhancement and enforcement of the aforementioned rules lie on the States, mainly by means of criminal or civil remedies. Criminal sanctions are imposed by several jurisdictions, including Greece; thus, in accordance with Article 227 KDND, the master not offering assistance at sea is punished with imprisonment of three months at least and a monetary fine. Relevant criminal penalties are also envisaged in $\mathrm{UK}^{182}$ and USA ${ }^{183} \mathrm{Law}$. It has to be noted, however, that imposing criminal penalties might be challenging, especially when it comes to the collection of evidence. Civil sanctions might also be triggered, at least theoretically, by giving the right to the affected persons to seek compensation against the shipowner and/or the crew of the vessel omitting to render assistance, on the basis of tortious liability rules (Article 914 of the Civil Code); in realistic terms it is unlikely that such an action would ever be exercised, as persons who finally accomplish finding a place of refuge or asylum primarily seek to cover their basic necessities, without counting the costs related to such claims. In this framework, the proposition of offering (State) financial incentives to the potential salvors surfaces once again. Indeed, such a project may not be implemented overnight and indeed the idea has its weak spots. However, the end justifies the means and in this case the end is of supreme value: human life.

182 Merchant Shipping Act 1995 (Schedule 11, part II, Art. 3 'Assistance to persons in danger at sea').

183 In accordance with 46 U.S. Code $\S 2304$ under the title 'Duty to provide assistance at sea' the master or individual violating his obligation to render assistance to any individual found at sea in danger of being lost, shall be fined not more than $\$ 1,000$, imprisoned for not more than 2 years, or both. 


\title{
The Italian legal framework on maritime safety
}

\author{
Recent developments and future perspectives
}

Anna Montesano, Alessandra Laconi and Lucrezia Pari

\subsection{Introduction}

Maritime navigation has always been characterized by risks and dangers that derive from the surrounding environment, creating the need to establish a cross-border legal framework, based more on conflict prevention rather than on purely reactive operations. Maritime safety is unanimously considered as a complex transnational issue that has given rise to the importance of international cooperation for developing an integrated defence policy and appropriate safeguards which take into account the multiplicity of economic and legal aspects involved.

The evolution of traffic over the last few decades and the scientific and technological progress in the global shipping market have profoundly affected the methods of protecting navigation safety, translating results from research development into a cross-sectoral defence strategy and implementing measures, in the context of a legislative process that is currently on-going. In this perspective, new navigation techniques and more sophisticated methods of shipbuilding have been developed to improve maritime safety with the aim of protecting the marine environment and human life at sea. ${ }^{1}$ In light of what has just been said, the safeguarding of navigation safety is of general public interest and recognized as worthy of protection at both internal and international level.

Trying to provide a definition of the term 'maritime safety', in common parlance, the term typically refers to the ability to safeguard goods, people on board and the ship itself from the risks deriving from navigation and transport activities, through the implementation of specific preventive measures and also appropriate actions to combat harmful events. ${ }^{2}$ Speaking more precisely, today, at international level, the issue is closely linked to two distinct and fundamental concepts: safety and security.

The concept of safety was developed first and is intended as a set of measures aimed at guaranteeing safety in navigation: it is, in the strict sense, generally understood as the safeguarding of human life at sea against the dangers arising from navigation activities. In other words, this concept should be read as referring to 'operational-technical safety', ${ }^{3}$ focusing on several aspects concerning the safety of the ship with particular regard to its

1 E. Papi, P. Viglietta, 'Safety e security: aspetti evolutivi della sicurezza marittima' (2005) 1 Diritto dei trasporti 117.

2 Ibid., 118-119.

3 Ibid. 
construction, buoyancy, stability, propulsion, manning, safety equipment, fire protection and preparation of the crews.

Security, on the other hand, concerns a combination of preventive, but also responsive, measures aimed to protect maritime transport and port facilities against threats and intentional unlawful actions and possible terrorist actions. ${ }^{4}$ The security measures have resulted in a set of rules that affect the prevention of and reaction against terrorist events, including new technical rules, such as those that have made security devices mandatory for ships, passengers and goods, as well as regulating the behaviour of the crew, including provisions relating to the phenomenon of piracy. ${ }^{5}$

In line with what has been said above, the term has been defined as

the security from terrorism, piracy and similar threats, as well as effective interdiction of all illicit activities at sea such as pollution of the marine environment; illegal exploitation of sea resources; illegal immigration; smuggling drugs, persons, weapons and other things that can be used for terrorist activities. ${ }^{6}$

As already noted, the concept of 'safety' is accompanied by that of 'security', which was developed $^{7}$ following some terrorist actions. Reference is made, for example, to the hijacking (by a group belonging to the Palestine Liberation Front) of an Italian-flagged cruise ship, the $M / V$ Achille Lauro, in 1985, and to the attacks of 11 September 2001 in the United States, that have underlined the need to provide for effective counter-terrorism measures, whilst also complying with human rights standards. Moreover, new measures have also been increased in the security realm following the "rise of piracy off the coast of Somalia between 2008 and $2011^{\prime 8}$ that further stressed the importance of safeguarding strategic maritime security interests against a broad range of risks and threats, by also collecting and sharing information to improve safety practices and responses for an adequate counterterrorist collaboration.

As we will see in more depth later, safety and security measures are increasingly linked and often complementary,

given that the maritime industry, shipping companies and their employees are simultaneously potential targets (e.g. of pirates, terrorists, or criminals) as well as potential perpetrators (by engaging in maritime crimes such as trafficking of persons, illicit goods or weapons or in collaborating with violent actors). ${ }^{9}$

For this reason, the legal initiatives that were born to regulate only maritime safety aspects have been integrated over time with provisions concerning the security profile, with a view to increasing the effectiveness of the global defence system.

4 S. K. Kim, Global Maritime Safety \& Security Issues and East Asia (Brill Nijhoff Leiden/Boston, 2019), p. $3 \mathrm{ff}$.

5 G. M. Boi, Principi e tendenze nel diritto marittimo (Torino, 2016), p. 39.

6 J. Urbanski, W. Morgas \& M. Miesikowski, 'The present and expected changes in maritime safety, security and defense functions' (2009) International Journal on Marine Navigation and Safety of Sea Transportation 11.

7 G. M. Boi, Principi e tendenze nel diritto marittimo (Torino, 2016), p. 38.

8 C. Bueger, 'What is maritime security?' (2015) Marine Policy 159.

9 Ibid. 161. 


\subsection{The Italian legal framework for the implementation of the maritime safety/security law}

The matter of maritime safety/security is characterized by a legal framework based on several sources, both at international and national level. At the beginning of the last century, maritime safety became an increasingly important topic for political and legislative discussion, in particular following the Titanic accident in 1912, that led to the adoption in 1914 of the SOLAS Convention (International Convention for the Safety of Life at Sea).

The above Convention is generally deemed as the most important of all international treaties concerning maritime safety, aimed to specify minimum standards for the construction, equipment and operation of ships. The Convention in force today is referred to as SOLAS 1974, as amended, ratified by Italy with the law of 23 May 1980, no. 313. Originally, the main objective of the SOLAS Convention was to specify minimum technical-operational standards for the ship and its crew, compatible with their safety, including control provisions to inspect ships; however, over the years, new provisions have been introduced, concerning, for example, requirements for life-saving appliances and arrangements, including requirements for lifeboats, rescue boats and life jackets according to type of ship, and provisions for the carriage of dangerous goods. Moreover, after the terrorist attacks that took place in New York on 11 September 2001, on the assumption that maritime navigation could also have suffered such attacks, a new security chapter was introduced in the SOLAS Convention, despite the fact that this Convention only addressed maritime safety. ${ }^{10}$ Therefore, at the beginning, the concept of safety was mainly focused on the 'ship' and on the concept of seaworthiness, deemed as a set of conditions which the ship must meet to carry out safe navigation.

With specific regard to the current Italian regulatory framework, the matter of maritime safety is governed by general rules contained in the Navigation Code of $1942^{11}$ (Articles 164-202) and in the Regulation for the implementation of the Navigation Code ('Regolamento per l'esecuzione del codice della navigazione (navigazione marittima)') ${ }^{12}$ (Articles 347-348), and by special rules, ${ }^{13}$ in order to ensure coherence between domestic law and internationally agreed rules, standards and recommended practices and procedures in the matter of safety of maritime navigation.

The Italian Navigation Code, in its original structure, was based on an overall view of the protection of all public maritime interests and, first and foremost, of those related to safety, including not only the safety of maritime navigation, but also safety in ports and safety of the ship, understood both under the objective profile (relative to the seaworthiness of the ship) and the subjective one, in relation to the crew members on board. ${ }^{14}$ Over the years, special laws have been enacted in the field of maritime safety, such as Law no. 84/1994 on port governance, and many legislative initiatives were taken in Italy for

10 R. Tranquilli Leali, 'La sicurezza in ambito portuale e poteri dell'Autorità marittima' (2017) 2 Rivista del diritto della navigazione 518.

11 Royal Decree, 30 March 1942, no. 327.

12 It has been approved by decree of the President of the Italian Republic of 15 February 1952, no. 328.

13 E. Turco Bulgherini, 'Sicurezza della navigazione' in Enc. Dir., vol. XVII (Milano 1990), p. 472.

14 R. Tranquilli Leali, 'La sicurezza in ambito portuale e poteri dell'Autorità marittima' (2017) 2 Rivista del diritto della navigazione 515 . 
implementing international and European legal measures, which will be analysed in detail in the following sections.

That said, as mentioned previously, the concept of 'maritime safety' is focused on the notion of seaworthiness, as laid down in Article 164 of the Italian Navigation Code, according to which: 'the ship that is undergoing navigation must be in a navigable state, suitably armed and equipped, suited to the use for which it is intended'. ${ }^{15}$

It should also be added that ships must also meet further legal requirements relating to the hull, buoyancy, stability, hygiene conditions of the accommodation for crews, rescue measures, fire prevention means and so on. Accordingly, it is clear that the seaworthiness requirement has a complex content, which affects the technical and structural profiles of the ship, both human (with reference to the crew, shipboard living and working conditions) and documental, meaning that the existence of the technical requirements and the ship's equipment must be shown by the prescribed documents ${ }^{16}$ (reference is made, inter alia, to Articles 150-154, $168 \mathrm{ff}$. of the Italian Navigation Code). In the context of the domestic regime, the provisions relating to maritime safety refer to different phases, namely the construction of the ship and its operation.

In particular, Article 233 of the Navigation Code provides technical control activities during the phase of construction of the ship. In this regard, it is worth mentioning that the Italian classification society RINA is entrusted with the tonnage measurement of ships, separately from their classification.

In addition, the Italian discipline also provides for controls for the safe operation of the ship, in relation to its 'suitability' for navigation. In fact, Article 165 of the Navigation Code attributes to maritime and consular authorities the competences concerning compliance with safety requirements, providing that they must also carry out inspections and visits for this purpose. Moreover, given that numerous accidents at sea are due to human error deriving from the inadequate training of the crew on board, subjected to heavy on-board living and working conditions ${ }^{17}$ in relation to the vessel's operating phase, particular importance is also given to the discipline of the composition and the professional qualification of seafarers, that, pursuant to Article 317 of the Navigation Code, must be equipped to perform services on board.

As explained below, in this regard, specific provisions are contained in the Navigation Code (Articles 113-135) in Law no. 616/1962 and in the implementing Regulation approved with Decree of the President of the Republic no. 435/1991. Moreover, International standards for maritime education and training of seafarers are laid down in the International Convention on Standards of Training, Certification, and Watchkeeping for Seafarers (STCW) of 1978, that has been ratified by Italy with Law no. 739/1985.

That said, it should be highlighted that from the original approach based on the close connection between 'navigation, port and ship', over time the term 'maritime safety' has been interpreted broadly as including the concept of environmental sustainability for the preservation of the seas and of the marine environment. ${ }^{18}$ In other words, if, at the begin-

15 'La nave che imprende la navigazione deve essere in stato di navigabilità, convenientemente armata ed equipaggiata, atta all'impiego al quale è destinata'.

16 G. M. Boi, Principi e tendenze nel diritto marittimo (Torino, 2016), pp. 40-41.

17 E. Turco Bulgherini, 'Sicurezza della navigazione' in Enc. Dir., vol. XVII (Milano, 1990), p. 474.

18 Ibid., p. 516. The Italian rules for the protection of the marine environment are contained in Law no. 979 of 31 December 1982. 
ning, the core concerns of maritime safety were in rescue and the protection of the life of seafarers and passengers in order to achieve an appropriate level of safety on board, this has gradually shifted to environmental concerns and the prevention of collisions, accidents and the environmental disasters these may cause.

Despite past efforts, in fact, increased economic activities on coasts and seas have created a deterioration in the quality of the marine environment, whose protection represents the main purpose of many International Conventions: reference is made to the International Convention for the Prevention of Pollution from Ships (MARPOL Convention) of 1973/1978, ratified in Italy by Laws no. 462/1980 and 438/1982; the Montego Bay Convention of 10 December $1982,{ }^{19}$ ratified by Italy with the Law of 2 December 1994 , no. 689 , that also contains provisions requiring technical conditions, as, for example, the double-hull requirements for oil tankers. For what concerns the domestic regime, the same approach led, in 2015, to the so-called Piano Strategico Nazionale della Portualità e della Logistica (National Strategic Plan for Ports and Logistics) ${ }^{20}$ that is a strategic planning tool aimed at improving the competitiveness of the port and logistics system, in compliance with the criteria of energy and environmental sustainability, which was also implemented through Legislative Decree no. 169/2016, concerning the reform of Italian port governance. In this context it is worth mentioning Legislative Decree no. 165/2011, ${ }^{21}$ whose purpose is to improve the safety of maritime navigation and the prevention of pollution caused by ships, by means of maritime safety investigations, in order to reduce potential future risks.

Finally, as regards the competent Authority in the maritime safety realm, it should be noted that Articles 17.2 and 18 of the Italian Navigation Code assign to the Maritime Authority ('Corpo delle Capitanerie di porto') all administrative functions related to navigation and maritime traffic. ${ }^{22}$ Reference should also be made to Article 1235 of the Code which states that commanders and officers of the 'Corpo delle Capitanerie di porto' are judicial police officers.

Another source of the tasks assigned to the Maritime Authority in the field of maritime safety is represented by Law no. 84/1994 governing port matter ('Riordino della legislazione in materia portuale'), and also what concerns the performance of technical-nautical services such as mooring, pilotage and towage. Moreover, Article 3 of the same law reads that the Comando generale del Corpo delle capitanerie di porto - Guardia costiera 'also exercises the competences in matters of navigation safety that are attributed to the Ministry of Infrastructure and Transport', involving, therefore, a substantial identification with the Ministry. ${ }^{23}$

19 United Nations Convention on the Law of the Sea, that was opened for signature on 10 December 1982 in Montego Bay.

20 Approved by decree of the President of the Council of Ministers (d.P.C.M.) of 26 August 2015.

21 Legislative Decree 6 September 2011, no. 165, has implemented Directive 2009/18/EC laying down the fundamental principles concerning the investigation of accidents in the maritime transport sector and amending Directives 1999/35/EC and 2002/59/EC.

22 P. Gallerano, 'Compiti e responsabilità delle Capitanerie di porto' (1985) Trasporti 37.

23 See, on this point, Consiglio di Stato, 7 February 2014, no. 586: 'Negli scali marittimi, in linea generale, all'autorità marittima spettano le funzioni di polizia e di sicurezza previste dal codice della navigazione e dalle leggi speciali, e le rimanenti funzioni amministrative non devolute all'autorità portuale (legge 28 gennaio 1994, $n$. 84)' ('In maritime ports, in general, the Maritime Authority is in charge of the police and security functions provided for by the Navigation Code and special laws, and of the remaining administrative functions not devolved to the Port Authority (Law 28 January 1994, no. 84)'). 
With specific regard to port safety, many control activities are also performed by the Port System Authority in coordination with the Maritime Authority, but it should be highlighted that the Italian regime tends to privilege the role of the latter. ${ }^{24}$

Further control activities concerning maritime safety are assigned to the Maritime Authority by the Legislative Decree of 24 March 2011, no. 53, which implemented Directive 2009/16/CE of 23 April 2009 on port State control, and by Legislative Decree no. 203/2007, which implemented Directive 2005/65/EC of 26 October 2005 on enhancing port security, which provides an extension of judicial police duties and of security inspections of the Authority.

Further confirmation of the competences of the Maritime Authority in the maritime safety field derives also from the Law of 8 July 2003, no. 172, governing tourism and pleasure sailing, ${ }^{25}$ whose Article 9.1 states that 'The controls relating to navigation safety fall within the prominent competence of the Corpo delle capitanerie di porto - Guardia costiera', ${ }^{26}$

With reference to the maritime safety concerning the nautical tourism and pleasure crafts, it should be noted that the reform of the code for pleasure $\mathrm{craft}^{27}$ (has increased control activities in the field of safety of the pleasure navigation.

In particular, the Legislative Decree of 3 November 2017, no. 229, introduced Article 26-bis in the Italian Pleasure Sailing Code, which established a system of preventive checks, providing that the planning, management and coordination relating to controls on the safety of pleasure navigation fall within the exclusive responsibility of the Corpo delle capitanerie di porto-Guardia costiera. In addition to the aforementioned, in Italy many legislative interventions have followed in order to create a framework for a uniform and compulsory application of the safety standards laid down in international and EU regulations, whose complete analysis is outlined in the following sections.

\subsection{Prevention}

The Italian legislative framework on maritime safety adheres to international principles according to which the prevention of marine accidents and/or accidents of personnel on board ships relates first and foremost to adequate planning, construction and maintenance of ships according to the safety of navigation and safety of work on board.

\subsubsection{Prevention in the construction of ships}

The Italian legislator by ratifying both the SOLAS and MARPOL Conventions has shown the intention to adhere strictly to international principles aimed at enhancing safety and

24 R. Tranquilli Leali, 'La sicurezza in ambito portuale e poteri dell'Autorità marittima' (2017) 2 Rivista del diritto della navigazione $519 \mathrm{ff}$.

25 'Disposizioni per il riordino e il rilancio della nautica da diporto e del turismo nautico'.

26 'I controlli relativi alla sicurezza della navigazione rientrano nella preminente competenza del Corpo delle capitanerie di porto - Guardia costiera'.

27 Legislative Decree no. 171/2005 'Codice della nautica da diporto e di attuazione della direttiva 2003/44/ CE a norma dell 'articolo 6 della legge 8 luglio 2003, $n$. 172' ('Italian Pleasure Sailing Code and implementation of Directive 2003/44/CE under Art. 6 of the Law of 8 July 2003, no. 172'). 
pollution prevention through the establishment of common ship's construction standards. That said, national discipline relating to the requirements of the construction of ships is established mainly by Presidential Decree no. 435/1991, which shall be analysed, in any case, together with the extended set of rules established by the European Union. ${ }^{28}$

With regard to merchant ships' construction requirements, the relevant discipline is provided by Regulation (EU) no. 530/2012 on the accelerated phasing-in of double-hull or equivalent design requirements for single-hull oil tankers, which is directly applicable in Italy. As concerns fishing vessels, Directives 97/70/EC and 1999/99/EC were implemented in Italy by L. Decree no. 541/1999 and the amendments introduced by Directive 2002/35/ EC have been subsequently implemented by the Decree of the Minister of Transport and Infrastructure dated 15 January 2003. With reference to inland waterway vessels, the technical requirements provided by Directive 2016/1629 (EU) were implemented in Italy by L. Decree no. 114/2018. Finally, it seems relevant to underline the discipline which has been developed by the IMO first and subsequently by the European Union related to the technical requirements of marine equipment.

In this context, by creating a common framework on the design, construction and efficiency of marine equipment, the harmonized system developed with Directive 96/98/EC, first, and with the current Directive 2014/90/EU has been directed to the implementation of international rules established by the IMO in a uniform manner throughout the European Union.

In Italy, Directive 2014/90/EU was implemented by Presidential Decree no. 239/2017 on maritime equipment, which repealed the former Presidential Decree no. 407/1999 referring to the former Directives 96/98/EC and 98/85/EC. The above Decree identifies the essential safety requirements of marine equipment to be installed or already installed on board merchant vessels, which are subject to the approval of the flag State according to international conventions. ${ }^{29}$ Pursuant to Article 4 par. 2 , the above requirements correspond integrally to those established at the European level by Article 35 of Directive 2014/90/EU. Notwithstanding, the same Article provides at par. 4 that marine equipment for which the European Commission has not indicated the requirements and test standards must comply with the requirements established by the Ministry of Infrastructure and Transport together with the competent administration, based on the type of equipment.

In Italy, the Ministry of Infrastructure and Transport represents the public entity responsible for both the implementation of rules concerning the equipment's compliance with international standards as well as the control, coordination and planning of the inspection and certification activities carried out by the maritime authority through authorized inspectors, in order to verify the respect of the discipline related to that issue. ${ }^{30}$

28 See in particular Arts. 57-79 included in the II Book entitled 'Ship Construction and arrangement'.

29 According to Art. 2 of Presidential Decree 239/2017: 'The provisions of this decree apply to marine equipment to be installed or already installed on board merchant ships used for maritime transport for which international conventions require approval by the flag State.'

30 See Art. 5 of Presidential Decree 239/2017 which describes the functions of the competent administrations. 


\subsubsection{Construction and equipment requirements for passenger ships}

With specific reference to passenger ships' safety requirements, the Italian legislative framework is composed, together with the relevant norms provided by Presidential Decree no. $435 / 1991,{ }^{31}$ of the following Legislative Decrees which have gradually implemented the relevant European rules. ${ }^{32}$

Thus, following the implementation of Directive 98/18/EC through L. Decree 45/2000, the Italian discipline was subsequently amended by a set of legal instruments aimed at introducing into the national legal system the amendments and updates established at European level.

The Italian legislative framework was finally integrated by L. Decree no. 25/2018 that implemented Directive 2016/844/EU, amending Directive 2009/45/EC of the European Parliament and of the Council on safety rules and standards for passenger ships. Through the introduction of the above L. Decree, the discipline established by Annex I of the former L. Decree no. 45/2000 has been integrally replaced and a new set of construction's requirements introduced ${ }^{33}$ in the national system.

\subsubsection{Human factor: implementation of the rules relating to work on board}

As previously anticipated, one of the elements that contributes to the safety of maritime navigation is certainly represented by the crew, both in terms of numerical presence and in terms of qualification, professional experience and working conditions on board. Indeed, it is estimated that a large percentage of maritime accidents are due to human factors. With reference to the national system, the Italian Navigation Code, in particular Articles 113 to 135 , provides a set of rules aimed at specifying the categories of maritime workers, as well as the requirements for the registration in the relevant registries and the conditions for the issuing of licenses for maritime professional qualifications. In this context, the legislative system is also integrated by the relevant norms of Presidential Decree 435/1991, which dedicates the entire book IV to the discipline relating to the training and certification of the ship's crew. ${ }^{34}$

31 With specific reference to passenger ships see Art. 174.

32 Legislative Decree dated 4 February 2000, no. 45 which implemented Directive 98/18/EC on safety rules and standards for passenger ships; Legislative Decree no. 291 of 23 December 2002 replacing Annex I to Legislative Decree no. 45 of 4 February 2000 and implementing Directive 2002/25/EC on safety provisions and standards for passenger ships; Legislative Decree no. 52 of 8 March 2005 implementing Directive 2003/24/EC on safety requirements for passenger ships; Legislative Decree no. 93 of 2012 implementing Directive 2009/45/EC on safety rules and standards for passenger ships as amended by Directive 2010/36/EU.

33 The above requirements refer, inter alia, to

- constructive rules relating to protection against noise;

- technical rules relating to the rudder and its operational capacity;

- characteristics of fire and smoke dampers;

- characteristics of the self-contained breathing apparatus included in the fireman's equipment;

- presence on board of two radiotelephone devices, portable transceivers for each firefighter;

- fire resistance characteristics of bulkheads and decks;

- technical characteristics of ducts and ship ventilation system.

34 On this point, see in particular, Arts. 201-224 and Arts. 232-244 specifically relating to the training of the crew. 
The Maritime Labour Convention was ratified by Italy with Law. no. 113 of 23 September 2013. Moreover, together with L. Decree no. 271/1999 concerning the adaptation of the Legislation on safety and health of seafarers, a set of Legislative Decrees has implemented the European Directives that are applicable to seafarers working on board EU flagged vessels relating to: health and safety, ${ }^{35}$ working time ${ }^{36}$ and port State obligations for the Member States. ${ }^{37}$ With reference to the standards of the seafarers training, the International Convention on Standards of Training, Certification, and Watchkeeping for Seafarers (STCW) of 1978 was ratified by Italy with Law no. 739 of 1985 . In this context, the discipline has been subsequently integrated by L. Decree $71 / 2015^{38}$ which implemented Directive 2012/35/EU amending Directive 2008/106/EC on the minimum level of training of seafarers.

\subsubsection{The 'National Maritime Security Program (PNSM) against any illegal actions': enhancing maritime security in the national system}

The Italian Legislative framework on maritime security is composed from one side by L. Decree 203/2007, which identifies measures aimed at improving security in ports and ensuring that the measures adopted pursuant to Regulation (EC) no. 725/2004 are respected, and from the other side by the 'National Maritime Security Program (PNSM) against any illegal actions' integrated by Ministerial Decree 154/2009 concerning regulation on subsidiary security services. ${ }^{39}$ The main objective of the 'National Maritime Security Program (PNSM) against any illegal actions' is to ensure, in a framework of international cooperation, the safety of passengers, crews, port operators, the public and port infrastructures, as well as the regularity and efficiency of maritime transport towards any intentional unlawful actions. Pursuant to the abovementioned purpose, the Program provides for the coordinated application of the rules and procedures on maritime security and defines roles, tasks and synergetic links between the Authorities, Police Forces, Entities and operators of maritime transport. The drafting and updating of the Program is delegated to the Interministerial Committee for maritime security (CISM) $)^{40}$ which is also responsible, on one

35 Directive 89/391/EEC of 12 June 1989 on the introduction of measures to encourage improvements in the safety and health of workers at work which has been implanted in the Italian system by L. Decree no. 81/2004 concerning the protection of health and safety in the workplace.

36 Directive 1999/95/EC concerning the application of the provisions relating to the working time of seafarers on board ships calling at Community ports, implemented by the Decree of the Transport and Infrastructure Minister dated 10 October 2005 and 1999/63/EC concerning the Agreement on the organization of working time of seafarers concluded by the European Community Shipowners' Association (ECSA) and the Federation of Transport Workers' Unions in the European Union (FST) implemented by L. Decree no. 108/2008.

37 See, in particular, L. Decree 32/2016 which introduced specific obligations for the General Command of the Corps of Port Authorities relating to the audits and inspections procedure.

38 The Decree provides rules on training and competency standards for seafarer certification, as well as on specialist training. Moreover, the discipline concerns the requirements on both the communication between crew members and the verification of crew member's certificates.

39 In Italy, the L. Decree 203/2007 implemented the Directive 2005/65/EC of the European Parliament and of the Council of 26 October 2005 on enhancing port security on enhancing port security.

40 The Inter-ministerial Committee for maritime security is composed by the representative of the following administrations: Ministry of Foreign Affairs, Ministry of the Interior, Fire Department Public rescue and civil defense, Department of Public Security, Central Directorate of Immigration and Border Police, Ministry of Communications, Ministry of Defense, Ministry of Transport; Assoporti (Association of the Italian Ports), RINA, Confitarma (Association of the Italian shipowners), Confetra (Italian General Confederation of Transports and Logistics), Assologistica, Fedepiloti (Pilots in ports), Federagenti (National Federation of Maritime Agents). 
side, for the examination of the international provisions relating to maritime security, and on the other side, for the analysis of the case studies which are not covered by the current international legislation.

\subsection{Control and surveillance system}

\subsubsection{The role of Port State Control in the Italian Legal System}

As a Member State of the European Union, Italy is required to apply EU legislation relating to Port State Control as a priority with respect to the Paris MoU regime. Directive 2009/16/ EC on port State control was implemented in Italy by L. Decree. no. 53/2011. The competent authority is the General Command of the Corps of Port and Coast Guard Offices which operates under the coordination of the Ministry of the Environment and the Protection of the Territory and Sea. Pursuant to Article 4 of L. Decree 53/2011, the General Command of the Corps of Port and Coast Guard Offices is entrusted with the control and coordination of inspections as well as with the constant transmission of the acquired data to the Ministry of the Environmental and the Protection of the Territory and the Sea. Within the Corps of Port Authority Offices, the activities connected to Port State Control concretely fall within the attributions of the 6th Department - Safety of Navigation.

The 6th Department coordinates the activity of the local authorities and forwards the relevant provisions relating to the control activity. The latter is also responsible for the inspections of Italian ships which are carried out abroad. On the other hand, the inspections on foreign ships in Italian ports are carried out by specialist officers of the Coast Guard Corps who are duly authorized and formally appointed by the General Command of the Corps of Port and Coast Guard Offices. ${ }^{41}$

\subsubsection{Control and surveillance system: implementation of VTS and others}

In Italy, the detailed regulation of the VTS system took place with the Law of 7 March 2001, no. 51, 'Provisions for the prevention of pollution deriving from maritime transport of hydrocarbons and for the control of maritime traffic', which deals with the control of maritime spaces of national interest, and is assigned to the Ministry of Transport and Navigation (now the Ministry of Infrastructure and Transport); together with the Ministry of the Environment, it has the task of establishing, with its own decrees, the implementing provisions of the VTS and the operational management of the VTS service.

The subsequent Decree of the Ministry and Infrastructure dated 28 January 2004 regulates the operational management of the VTS, which is carried out, at central level, by the General Command of the Corps of Port and Coast Guard Offices (National Competent Authority, NCA) and, at local level, by the maritime offices located along the Italian coasts on the basis of what is established by the General Command (Local Competent Authority, LCA).

41 More on THETIS see supra 99, chapter 2 above. Pursuant to Annex I to the L.D. 53/2011, the inspector's appointment is subject to the possession of a set of professional requirements. The inspections' modalities established by the Italian regime correspond integrally to that provided by Directive 2009/16/EC. Finally, following the inspections, the inspectors shall transmit the relevant data to THETIS, while any measure taken shall be communicated to the competent local authority and to the master of the ship. 
According to Article 5 of L. Decree 196/2005 which has implemented Directive 2002/59/ EC, the NCA provides, through the LCAs, the management of the compulsory monitoring and reporting systems called Bonifacio Traffic and Adriatic Traffic. Moreover, the above Decree establishes the adoption at national level of the Automatic Identification System (AIS).

\subsection{Enforcement}

As was noted in the previous sections, the Italian legislative framework for maritime safety/ security law (as defined above) consists of international, EU and domestic legislation. In general, the Italian Code of Navigation establishes the main rules for both maritime and air navigation. Moreover, some complementary laws offer particular disciplines (inter alia, one of the most relevant is Law no. 84/1994, the 'Port Law'). Therefore, not all national rules concerning maritime safety/security law are part of a unique code (either the Italian Code of Navigation, or any other code), being regulated in separate legal acts, as will be better explained later (in relation to prevention and control and surveillance systems, please see sections $10.3-10.4$ ).

In the field of maritime safety, Italian law provides for both criminal and administrative sanctions. Relevant criminal offences (and sanctions) are provided in the Criminal Code (in particular, in relation to environmental aspects), as well as in the Code of Navigation. For what concerns administrative sanctions, the competent administrative authorities are enabled to issue preventive and/or financial measures, as established by the Code of Navigation and by the relevant pieces of legislation mentioned in the following text.

\subsubsection{Safety of navigation}

The SOLAS Convention 1974 was enacted by Law no. 313/1980, which was subsequently amended by Presidential Decree no. 435/1991. The current chapter IX requires every shipowner and any person or company that has assumed responsibility for a ship to comply with the International Safety Management Code (ISM), which purpose is to provide an international standard for the safe management and operation of ships and for pollution prevention. ${ }^{42}$ From the EU perspective, Directive 1996/98 on marine equipment was aimed to ensure the uniform application of the SOLAS Convention on equipment for commercial vessels, making the related IMO resolutions binding in the EU. ${ }^{43}$

42 The ISM Code in its mandatory form was adopted in 1993 by IMO resolution A.741(18) and entered into force on the 1 July 1998.

43 EU Directive 2012/32 has amended the previous EU Directive 1996/98 adapting its Annex A to the supervening international conventions. Directive 1996/98 has been repealed by EU Directive 2014/90 on marine equipment, which harmonized the safety rules relating to marine equipment on board EU flagged ships through the uniform application of the international instruments. See also:

- Commission Delegated Regulation EU 2018/414 supplemented Directive 2014/90 as regards the identification of specific items of marine equipment which can benefit from electronic tagging;

- Commission Implementing Regulation EU 2018/608 which laid down technical criteria for electronic tags for marine equipment;

- Commission Implementing Regulation EU 2018/773 on design, construction and performance requirements and testing standards for marine equipment repealed Implementing Regulation EU 2017/306. 
In the meantime, the President of the Italian Republic ratified the Convention on International Regulations for Preventing Collisions at Sea, 1972 (COLREGs) on the 27 December 1977. As concerns the International Convention on Standards of Training, Certification and Watchkeeping for Seafarers (STCW) of 1978, it was ratified by Italy with Law no. 739 of 1985. As is known, the STCW Convention has been amended twice, in 1995 and in 2010 (in the latter case, with the 'Manila Amendment'). Furthermore, the STCW Convention has been the subject of various EU Directives,${ }^{44}$ and in particular of Directive 2008/106, transposed into national law by Legislative Decree no. 136 of 2011, and EU Directive 2012/35, transposed into Italian law by Legislative Decree no. 71 of 2015.45

Moreover, Italy also ratified the IMO 1966 Load Lines Convention, which offers the relevant rules for the determination of the freeboard of ships by subdivision and damage stability calculations. ${ }^{46}$ Then, following major accidents involving polluting cargos (i.e., the MV Erika and the MV Prestige disasters, which occurred in 1999 and in 2002), the EU adopted its own rules to improve maritime safety in its waters.

In the described scenario, the provision of two sets of standards gave rise to some interpretative difficulties (and tensions), lacking a sufficient level of legal certainty at international level. ${ }^{47}$ On the other hand, EU shipping operators (including Italian ones) have been (and are) concerned about the competitive disadvantage arising from the stricter rules provided at EU level (which are not applicable to shipping companies not falling within the scope of application of EU law). Hence, the relevant domestic provisions concerning safety of work on board are contained in Legislative Decree no. 271/1999.

\subsubsection{Collisions}

In the field of collisions, the Collision Convention of 1910 is still in force, ${ }^{48}$ as well as the Collision Convention of $1952,{ }^{49}$ which established the rules concerning civil jurisdiction in matters of collision. In relation to the Collision Convention of 1952, the Italian Court of Cassation (Corte di Cassazione), with the judgment no. 4686 of 9 March 2015, affirmed that this Convention establishes some special criteria to identify the jurisdiction, thus it must prevail over the general discipline contained in Regulation no. 44/2001 (Brussels I Regulation), now replaced by EU Regulation no. 1215/2012 (Brussels I bis Regulation).

44 Directive 1994/58 on the minimum level of training of seafarers gave the 1978 STCW Convention the force of EU law.

45 EU Directive 2017/2397 on the recognition of professional qualification in inland navigation and repealing Council Directives 1991/672 and 1996/50 provides measures (also transitional) to extend professional qualification requirements beyond the level of boat masters to cover all crew in inland navigation in the EU.

46 The 1988 Protocol of November 1988 entered into force on 3 February 2000. It was aimed at harmonizing the Convention's survey and certification requirement with those contained in the SOLAS and MARPOL Conventions, and it also revised some regulations provided in the technical Annexes to the Load Lines Convention.

47 The comparison between the Erika and the Prestige judgments is emblematic: while the NY Court, in the Prestige case, stated the exemption from any liability in favour of the competent Classification Registry (the ABS), applying the principles established in the MARPOL Convention, the French Judicial Authority (in the Erika case) condemned the Italian Classification Registry (the RINA), pointing out the incompatibility of national regulations with the supranational ones.

48 Ratified by Italy on 2 June 1913.

49 Ratified by Italy on 9 November 1979. 
The reason of this statement is that the Brussels I Regulation (like the current Brussels I bis Regulation) does not affect any convention that governs jurisdiction in relation to particular matters to which the Member States are parties.

\subsubsection{Salvage}

Italy has ratified the London Convention on Salvage of 1989 with Law no. 129 of 12 April 1995. The Italian Code of Navigation contains some rules in the field of salvage, in the wake of the Brussels Convention of 1910. At any rate, following the ratification by Italy of the London Convention of 1989, these rules are de facto inapplicable, considering that - according to Article 2 of this latter Convention - the same shall apply whenever judicial or arbitral proceedings relating to matters dealt with in it are brought in a State Party. Consequently, the provisions of the Italian Code of Navigation assume a residual value, being applicable only to salvage services rendered by an Italian vessel to another Italian vessel.

In Italy, there are no specialized courts dealing with salvage proceedings, but the national courts are used to uphold the 'no cure, no pay' principle.

\subsubsection{Seafarers' rights}

Italy ratified the MLC on 19 November 2013, and the Convention entered into force on 19 November 2014 (in relation to financial security instruments related to the maritime labour field, see section 10.6).

For what concerns national legislation, as for other categories of workers, seafarers' rights are granted by National Collective Labour Agreements and by some specific laws, among which we mention Legislative Decree no. 271/1999 on the security and health of seafarers on board merchant ships, and Presidential Decree no. 231/2006 concerning seafarers' placement regulation.

In general, it has to be underlined that Article 18 of Law 300/1970 ("Workers'Statute") still protects all categories of employees, providing for some strict rules in relation to the termination of the employment agreement by the employer (the provision, albeit subject to several reforms that have reduced its scope of application, is still in force). ${ }^{50}$

With a judgment of 1991 (no. 364/1991), the Italian Constitutional Court pointed out that Article 18 of the Workers' Statute is also directly applicable to seafarers. At any rate, it has to be highlighted that many Italian political representatives often argue about a possible further review of labour law legislation, thus the protection rule provided at Article 18 of the Workers' Statute may be amended in the near future.

50 The provision is applicable to companies with more than 15 employees. 


\subsection{Liability}

\subsubsection{Environment and pollution}

In relation to oil pollution potentially deriving from cargo, Italy has ratified the Civil Liability Convention, 1969 (CLC), as well as the 1992 Protocol..$^{51}$ Moreover, Italy is a contracting party to the Convention establishing the International Fund for compensation for oil pollution, 1971, and to the 1992 and 2003 related Protocols. Furthermore, Italy has ratified the 2001 Bunker Oil Convention through Law no. 19 of 1 February $2010 .^{52}$ Nevertheless, Italy has not ratified the International Convention on Liability and Compensation for Damage in Connection with the carriage of Hazardous and Noxious Substance by Sea (1996 HNS Convention). As anticipated above, EU Directive 2012/33 regulating the sulphur content of marine fuels amended the EU Directive 1999/32 to be in line with the new standards set by the IMO in 2008 (the revised Annex VI to the MARPOL Convention introduced, inter alia, stricter sulphur limits for marine fuel).$^{53}$

For what concerns national legislation, Laws no. 979 of 31 December 1982, no. 220 of 28 February 1992 and no. 349 of 8 July 1986 offer the definition of protection of the environment, and lay down a set of measures to be implemented/adopted both by the administrative bodies/public administrations involved and by the private parties. Hence, Legislative Decree no. 152/2006 ('Environmental Code') is the main piece of legislation ruling the environmental subject in general. In particular, Part 6 of the Environmental Code deals with the rules on protection against environmental damages. At any rate, as set forth at Article 303, paragraph 1, letter b), of the Environmental Code, Part 6 does not apply to environmental damages arising from accidents subject to the discipline provided by an international convention.

\subsubsection{Wreck removal}

Italy has not ratified the Nairobi Wreck Removal Convention of 2007 yet. Therefore, the matter is still governed by a specific provision of the Italian Code of Navigation, i.e. Article 73 , according to which the owner of the vessel has the duty to remove a wreck. In particular, in case of submersion of vessels, if the maritime authority (which is the "Capitaneria di Porto") considers that the presence of the wreck could lead to danger or hindrance to navigation, the head of the maritime authority shall order the owner of the vessel to provide at his own expense the wreck removal, setting the deadline for the execution.

51 Pursuant to the Decree of the Ministry of Economic Development of 12 January 2012, Consap - Concessionaria Servizi Assicurativi Pubblici S.p.A., i.e. the Italian Public Insurance Services Concessionaire, has been authorized to certify the existence of an insurance or financial guarantee validly in force to cover civil liability for damage due to oil pollution referred to by Art. VII, paragraph 1, of the CLC Convention of 1992 on damage due to oil pollution and its annex, in modification to the Convention on the same subject, as adopted in Brussels on 29 November 1969, ratified by the Italian government by Law no. 185 of 6 April 1977.

52 According to the Decree of the Ministry of Economic Development (MISE) of 20 May 2010, Consap Concessionaria Servizi Assicurativi Pubblici S.p.A. - has been authorized to certify the existence of an insurance or financial guarantee validly in force to cover civil liability for bunker oil pollution damage, referred to by Art. 7, paragraph 1 of the Civil Liability Convention for damage due to oil pollution and its annex, made in London on 23 March 2001.

53 Italy transposed EU Directive no. 2012/33 through Legislative Decree no. 112/2014. 
If the owner does not execute the order within the set deadline, the maritime authority is responsible for the removal and sale of wrecks on behalf of the State. For ships of gross tonnage over 300 tons, if the proceeds from the sale are not sufficient to cover the costs, the owner is obliged to pay the difference to the State. In urgent cases, the maritime authority can provide for the removal on behalf and at the expense of the owner. However, for ships of gross tonnage not exceeding 300 tons, the owner is obliged to pay the removal costs only within the limits of the value of the wrecks recovered. Moreover, Article 92 of the Regulation for Maritime Navigation (Decree of the President of the Republic no. 328 of 15 February 1952) established that, if the maritime authority removes a submerged ship, this becomes State property.

Furthermore, it has to be underlined that ship recycling has to be done in respect of the standards provided by EU Regulation no. 1257/2013; in particular, this Regulation offers a list of recycling facilities authorized to carry out ship-recycling operations. The Regulation has been in force from the 31 December 2018, as set forth in Article 32, paragraph 1, letter b) of the Regulation itself.

With the Ministerial Decree of 12 October 2017, the Ministry of Infrastructure and Transport, in concert with the Minister of the Environment and the Protection of the Territory and the Sea, has designated the competent authorities and the administrations responsible for the application of EU Regulation no. 1257/2013, also determining the procedures for ship recycling authorization. According to the mentioned Ministerial Decree, the maritime authority (i.e., the "Capitaneria di Porto") is required to monitor the correct application of the EU Regulation, adopting the necessary measures (Article 3, paragraph 2 ), as well as to receive the statements concerning the intention of the owner who intends to proceed with the demolition of the vessel (Article 5).

\subsubsection{Seafarers' rights}

As anticipated before, Italy ratified the MLC on 19 November 2013. Pursuant to Decree of the Ministry of Infrastructures and Transports (MIT) and of the Ministry of Economic Development no. 559 of 28 December 2017, a register of the certificates of insurance and of the financial securities issued in respect of seafarers as required under Regulation 2.5.2 - Standard A2.5.2 (in respect of seafarers' repatriation costs and liabilities) and of Regulation 4.2 - Standard A.4.2 (in respect of shipowners' liability) of the Maritime Labour Convention 2006 as amended was held with Consap - Concessionaria Servizi Assicurativi Pubblici S.p.A., i.e. the Italian Public Insurance Services Concessionaire. MIT and Consap entered into an agreement on 18 January 2018, in order to define the terms and procedures for the keeping and operation by Consap of the aforementioned register, as well as the amount of the fee due to Consap for the said activity.

\subsection{Concluding remarks}

In view of the foregoing, the general issue of maritime safety (including the aspects of maritime security that are increasingly interlinked), given its transnational character, requires a shared responsibility of the institutions, at international and national levels, whose strategies stressed the importance of multilateralism and joint coordinated responses to find an appropriate balance of cross-sectoral policies. 
We have seen that in Italy the term 'maritime safety' refers to the measures of prevention and controls related, on one hand, to technical issues of maritime safety, such as the reliability of the ship's characteristics (impermeability, stability, manoeuverability etc.), of its services (nautical, firefighting, anti-flooding) as well as of the navigation assistance services (meteorological, signalling), and on the other a hand, to public issues of maritime safety, elsewhere defined as 'maritime security'.

Considering technical navigation safety, and in particular the provisions relating to the structural characteristics of the ships, the training of seafarers, the regulation of working hours, the powers of the flag States and the systems of information and monitoring of vessel traffic, we can conclude that the measures implemented in the Italian legal system reflect more or less integrally those established at international and European level. This circumstance confirms the intention of the Italian legislator to adhere strictly to the principles established at international level that are aimed at guaranteeing the development of a common maritime safety culture.

Moreover, as previously illustrated, the majority of the European rules on maritime safety are introduced by Directives that, unlike the Regulations, are not directly applicable in the Member States. The use of the Directive can lead to some problems related to the time needed by each Member State to implement the rules in the national legal system. In Italy, for example the European Court of Justice denounced the delays of the Italian legislator in the adoption of legislative measures to implement Directive 95/21/EC on Port State Control, which was only implemented 5 years after the introduction at European level, as well as Directive 1999/95/EC on the working time of seafarers. That said, the latter being a critical issue relating mostly to the efficiency of national legal systems, the great efforts carried out by the international organizations and European entities operating in the field of maritime safety in order to create a uniform standard of maritime safety shall in any case be recognized.

At any rate, in this multilevel legal framework, the other side of the coin has to be duly considered: in particular, the provision of different sets of safety standards (i.e., international and EU ones) has given rise to some interpretative difficulties, lacking a sufficient level of legal certainty. This is the main reason why EU shipping operators (including Italian ones) expressed their concern for the competitive disadvantage arising from the stricter rules provided at EU level (which are not applicable to shipping companies not falling within the scope of the application of EU law).

Furthermore, the application profiles of the relevant provisions of domestic law and their overlapping with the main EU Directives could also potentially lead to uncertainties and/ or disputes, if the EU Directives provide for stricter requirements than the international conventions (and the national rules explicitly recall the latter, as we have seen in relation to the Italian Environmental Code).

As concerns liability issues, we acknowledged that Italy has not ratified the Nairobi Wreck Removal Convention of 2007 yet, so the matter is still governed by Article 73 of the Italian Code of Navigation. Nevertheless, this non-ratification could lead to interpretative doubts in case of cross-border wreck removal cases, thus leading to delays (with the risk of relevant environmental damages) and posing a potential hazard to navigation.

That said, it should be considered that - despite the efficiency of the current legal framework in this sector - marine research, technology innovation, rapid globalization and climate change will give the matter of safety a greater worldwide role and present it with new challenges. 
In view of the abovementioned considerations, new initiatives may also be required at national level, in order to adapt the safety and security regime to the evolving role of the International and European maritime industry and to create an efficient regulatory system in full adherence to the growing shipping market, in view also of the increasing concerns about the risk of terrorism.

To this end, the need to promote a cost-efficient approach to maritime safety/security by improving cross-sectoral cooperation between national and international/EU systems must not be forgotten, in order to reconcile the protection of the public safety interest with the high costs required by its pursuit. 


\title{
An overview of maritime safety laws in Malta
}

\author{
Elda Kazara-Belja and Sofiya Shvelidze
}

\subsection{Introduction}

Maritime activities have long provided great economic value to Malta's welfare. This is not surprising considering the Island's strategic position in the middle of the Mediterranean. ${ }^{2}$ With the opportunities of industrial exploitation of the sea and its resources, however, comes the concern of maritime safety, which may be affected in light of the increasing number of shipping activities. These concerns relate not only to safety issues in waters under Maltese jurisdiction but also to any ship entitled to fly the Maltese flag.

Safety at sea is undoubtedly a necessary condition for national economic growth, and the core principles adopted by internationally recognized maritime institutions will always be 'set high on Malta's political agenda and the Government will be instrumental in ensuring that any future maritime related policies are aligned closely with international standards'. ${ }^{3}$ Thus, the effective implementation and enforcement of international uniform standards and rules, particularly those adopted by the International Maritime Organization (IMO) and International Labour Organization (ILO), remain a priority for the country.

Malta is a party to the key maritime safety conventions, including: SOLAS; ${ }^{4}$ Load Line Convention; ${ }^{5}$ Tonnage Convention; ${ }^{6}$ STCW Convention; ${ }^{7}$ and COLREGs ${ }^{8}$ and ships flying the flag of Malta are obliged to strictly comply with the provisions of these instruments and of the national legislation implementing the same.

1 All websites are confirmed as at 18 February 2020.

2 National Integrated Maritime Policy issued by Parliamentary Secretariat for Competitiveness and Economic Growth of the Republic of Malta with the objective of establishing the ideal business environment for the blue economy and blue jobs (2015) https://economy.gov.mt/en/public_consultation/documents/integrated $\% 20$ mariti me\%20policy.pdf.

3 Marine Security and Safety, Malta Marittima, Ministry for Tourism of the Republic of Malta www.maltam arittima.org.mt/index.php/what-is-clustering/the-policy/marine-security-safety.

4 International Convention for the Safety of Life at Sea 1974, as amended (adopted on 1 November 1974, entered into force on 25 May 1980, UNTS 1184,1185) 2.

5 International Convention on Load Lines 1969, as amended (adopted on 5 April 1966, entered into force on 21 July 1968, UNTS 640) 133.

6 International Convention on Tonnage Measurement of Ships 1969, as amended (adopted on 23 June 1969, entered into force on 18 July 1982, UNTS 1291) 3.

7 International Convention on Standards of Training, Certification and Watchkeeping for Seafarers 1978, as amended (adopted on 7 July 1978, entered into force on 28 April 1984, UNTS 1361) 2.

8 Convention on the International Regulations for Preventing Collisions at Sea 1972, as amended (adopted on 20 October 1972, entered into force on 15 July, UNTS 1050) 16. 
Adopted in 1973, the Merchant Shipping Act (the Act) $)^{9}$ launched the Malta flag. The Act has been amended numerous times and today contains nearly 400 sections in its ten parts. It has been supplemented by numerous Legal Notices (L.Ns.) which have been promulgated under the Act in the form of subsidiary legislation (S.L.) dealing with the various merchant shipping-related subjects. The Act and the L.Ns. form together a comprehensive body of robust legal framework which ensures that the success story of the Maltese registry continues.

Part V of the Act is dedicated to Safety of Life at Sea. ${ }^{10}$ This part is divided into six sections, namely Construction and Equipment of Ships, Load Lines and Loading, Unseaworthy Ships, Carriage of Dangerous Goods, Prevention of Collisions, and Miscellaneous Provisions. These maritime safety regulations are further elaborated in domestic law through a number of S.L., such as the Merchant Shipping (Safety Convention) Rules (S.L. 234.30), ${ }^{11}$ the Merchant Shipping (Load Lines Convention) Rules, 2003, ${ }^{12}$ Tonnage Regulations, 2003 (S.L. 234.19), ${ }^{13}$ Prevention of Collisions Regulations, 2003 (S.L. 234.20),${ }^{14}$ the Merchant Shipping (Ship Inspection and Survey Organisations) Regulations (S.L. 234.37), ${ }^{15}$ the Merchant Shipping (Accident and Incident Safety Investigation) Regulations (S.L. 234.49), ${ }^{16}$ Merchant Shipping (Flag State Requirements) Regulations (S.L. 234.48); ${ }^{17}$ Merchant Shipping (Port State Control) Regulations (S.L. 234.38); ${ }^{18}$ and the Merchant Shipping (Certification of Commercial Yachts and Commercial Cruising Vessels) Regulations, to mention a few. ${ }^{19}$

Moreover, the Torremolinos Protocol ${ }^{20}$ addressing fishing vessels safety is applicable to Malta due to the Council Directive 97/70/EC. ${ }^{21}$ The implementation was made through the Merchant Shipping (Fishing Vessel Safety) Rules (S.L. 234.36) ${ }^{22}$ which set a safety regime for fishing vessels of 24 metres in length and over.

Considered a pillar of the shipping industry, together with SOLAS and STCW, MARPOL $^{23}$ is the main instrument which covers pollution prevention by ships from operational or accident causes. Malta effectively implemented MARPOL by means of the

9 Merchant Shipping Act (Chapter 234) www.justiceservices.gov.mt/DownloadDocument.aspx?app=lo m\&itemid $=8734$.

10 Whereas the Maltese legislator has been prolific in the adoption of rules and prescriptions covering every facet of safety, due to the brevity of this contribution, not all of them can be covered. Attempts are made however that reference is made to their majority.

11 S.L. 234.30 www.justiceservices.gov.mt/DownloadDocument.aspx?app=lom\&itemid=9615.

12 S.L. 234.29 www.justiceservices.gov.mt/DownloadDocument.aspx?app=lom\&itemid=9614.

13 S.L. 234.19 www.justiceservices.gov.mt/DownloadDocument.aspx?app=lom\&itemid=9605.

14 S.L. 234.20 www.justiceservices.gov.mt/DownloadDocument.aspx?app=lom\&itemid=9606\&l=1.

15 S.L. 234.37 www.justiceservices.gov.mt/DownloadDocument.aspx?app=lom\&itemid=9622.

16 S.L. 234.49 www.justiceservices.gov.mt/DownloadDocument.aspx?app=lom\&itemid=11689\&1=1.

17 S.L. 234.48 www.justiceservices.gov.mt/DownloadDocument.aspx?app=lom\&itemid=11669\&l=1.

18 S.L. 234.38 www.justiceservices.gov.mt/DownloadDocument.aspx?app=lom\&itemid=9623\&l=1.

19 S.L. 234.45 Merchant Shipping (Certification of Commercial Yachts and Commercial Cruising Vessels) Regulations, 2006 www.justiceservices.gov.mt/DownloadDocument.aspx?app=lom\&itemid=9630.

20 Torremolinos Protocol relating to the Torremolinos International Convention for the Safety of Fishing Vessels 1977 (adopted on 2 April 1993, not in force).

21 Council Directive 97/70/EC of 11 December 1997 setting up a harmonized safety regime for fishing vessels of 24 metres in length and over, OJ L 34, 9.2.1998, p.1.

22 S.L. 234.36 www.justiceservices.gov.mt/DownloadDocument.aspx?app=lom\&itemid=9621.

23 International Convention for the Prevention of Pollution from Ships, 1973 as amended by the 1978 Protocol thereto (adopted on 17 February 1978, entered into force on 2 October 1983, UNTS 1340) 61. 
Merchant Shipping (Prevention of Pollution from Ships) Regulations 2004 (S.L. 234.32). ${ }^{24}$ In these Regulations, the duty to ensure compliance with the applicable requirements of MARPOL is assigned to "the owner of the company which assumed the operation of the ship and the master of the ship'. ${ }^{25}$ The Regulations also provide for the penalties, which in this case are a monetary fine to be calculated according to the offence committed. ${ }^{26}$

Taking into full consideration the human dimension of shipping, the Merchant Shipping (Maritime Labour Convention) Rules (S.L. 234.51) ${ }^{27}$ implemented MLC, ${ }^{28}$ STCW (in terms of watchkeeping) and Council Directive 2009/13/EC. ${ }^{29}$ These Rules ensure that the labour force which operates ships has safe and decent working conditions and is adequately trained and skilled so that accidents at sea which jeopardize life, property and the marine environment are avoided.

\subsection{National structure for the implementation of maritime safety legislation}

The Minister responsible for shipping, including any person acting under his authority (e.g. the Registrar-General of Shipping and Seamen), is empowered to make regulations for the effective implementation of any treaties or conventions adhered to by the Government of Malta in compliance with the Ratification of Treaties Act. ${ }^{30}$ Article 374 empowers the Minister to promulgate any regulations, rules or orders for the carrying into effect of the provisions of the Act as well as for other purposes in accordance with its provisions.

The Merchant Shipping Directorate (MSD) within Transport Malta is headed by the Chief Officer responsible for Merchant Shipping who in terms of law is also the RegistrarGeneral of Shipping and Seamen. In addition to ship and yacht registration, the MSD is responsible for the regulation, control and administration of all matters related to merchant shipping, the certification of seafarers, the fostering of Malta's relations in international shipping fora, and the administration and implementation of international maritime conventions and agreements. The Directorate gives fundamental importance to safety of life at sea and compliance with international maritime conventions. Transport Malta is the National Competent Authority for matters relating to pollution at sea and for any other emergencies at sea, including the allocation of a Place of Refuge.

Transport Malta is also the Maltese Designated Authority for security measures. In this capacity, it ensures that with respect to each port facility within the ports and territorial limits of Malta, port facility security assessments are carried out, reviewed and approved;

24 S.L. 234.32 www.justiceservices.gov.mt/DownloadDocument.aspx?app=lom\&itemid=9617.

25 Ibid., Art. 6 (1).

26 Ibid., Art. 12.

27 S.L. 234.51 www.justiceservices.gov.mt/DownloadDocument.aspx?app=lom\&itemid=12086\&l=1. On the implementation of S.L. 234.51 see Merchant Shipping Notice 105 Rev 1 of 8 January 2015 www.transport. gov.mt/MS-Notice-105-Rev-1-Guidelines-for-the-Implementation-of-the-Maritime-Labour-Convention-2006.p df-f3853.

28 Maritime Labour Conventions (adopted on 23 February 2006, entered into force on 20 August 2013, UNTS 2952) 3 .

29 Council Directive 2009/13/EC of 16 February 2009 implementing the Agreement concluded by the European Community Shipowners' Associations (ECSA) and the European Transport Workers' Federation (ETF) on the Maritime Labour Convention, 2006, and amending Directive 1999/63/EC, OJ L 124, 20.5.2009, p. 30.

30 Merchant Shipping Act, Art. 375. Paragraph 2 or this Article lists all the safety conventions to which Malta is a party as well as many other international instruments. 
and port facility security plans are developed, implemented, maintained and approved. The Maritime Security Compliance Monitoring Unit is responsible for compliance monitoring of port facilities as per the requirements of the ISPS Code ${ }^{31}$ as well as implementation of EU Regulations and Directives on port security.

The Registrar-General is the appropriate authority to issue certificates as required by the safety conventions and the respective national implementing legislation. Such duty may be delegated to an organization or body duly authorized in terms of Article 367 of the Act by the Registrar-General who shall determine the conditions of issues and validity of the certificates.

The Ports and Yachting Directorate within Transport Malta is tasked with responsibilities which include vessel traffic services (VTS), management of all vessel traffic in Maltese territorial waters, safety of navigation, overall control of port work and provision of port workers, prevention and control of pollution and emergency response, provision of pilotage, firefighting facilities, as well as regulating, controlling and promoting yachting centres.

The Armed Forces of Malta (AFM) conduct a wide range of operations in the maritime domain, including protection of Malta's maritime claims such as territorial seas and Fisheries Conservation and Management Zone and suppression of illegal activities at sea. AFM is also responsible for general maritime law enforcement, the implementation of the SAR Convention ${ }^{32}$ in addition to the Global Maritime Distress and Safety System (GMDSS) used to increase safety at sea and facilitate the rescue of distressed ships, boats and aircraft, and the provision of safety and security information to commercial shipping.

Merchant Shipping (Accident and Incident Safety Navigation) Regulations (S.L. 234.49) 33 established the Marine Safety Investigation Unit (MSIU) as an independent government investigation unit to carry out safety investigations into accidents and incidents and participate in safety studies and academic research. The Regulations comply with the measures contained in Directive 2009/18/EC ${ }^{34}$ and the Casualty Investigation Code. ${ }^{35}$ On completion of the safety investigation, the Unit prepares the safety investigation report with the sole scope of disseminating safety lessons and preventing the occurrence of similar accidents and incidents. The MSIU has an active role and is a member of the Maltese delegation at the IMO's Sub-Committee on Implementation of IMO Instruments. The MSIU is also a member of the European Commission's Permanent Co-operation Framework, the Marine Accident Investigators International Forum, and the European Maritime Investigators Forum.

\footnotetext{
31 The International Ship and Port Security Code entered into force under SOLAS chapter XI-2 on 1 July 2004.

32 International Convention on Maritime Search and Rescue, 1979, as amended (adopted on 27 April 1979, entered into force on 22 June 1985, UNTS 1405) 97.

33 S.L. 234.49 www.justiceservices.gov.mt/DownloadDocument.aspx?app=lom\&itemid=11689\&l=1.

34 Directive 2009/18/EC of the European Parliament and of the Council of 23 April 2009, establishing the fundamental principles governing the investigation of accidents in the maritime transport sector and amending Council Directive 1999/35/EC and Directive 2002/59/EC of the European Parliament and of the Council, OJ L131/114, 28.5.2009, p. 114.

35 Code of the International Standards and Recommended Practices for a Safety Investigation into a Marine Casualty or Marine Incident adopted by the IMO Maritime Safety Committee as Resolution MSC.255(84) (16 May 2008), www.imo.org/en/OurWork/MSAS/Casualties/Documents/Res.\%20MSC.255(84)\%20Casualty\%20 Iinvestigation\%20Code.pdf.
} 


\subsection{Prevention}

Article 206A of the Act gives force of law to SOLAS and ensures the applications of its provisions to all Maltese flagged ships as all other ships while in Maltese waters. ${ }^{36}$ In accordance with Article 207, the Minister may make rules (construction and survey rules)

prescribing the requirements for the hull, equipment $\left.{ }^{[37}\right]$ and machinery of ships to which this article applies and requiring any such ships to be surveyed to such extent, in such manner and at such intervals $\left[{ }^{38}\right]$ as may be prescribed by the rules.

Paragraph 2 of the article lists the categories of ships to which it applies, while paragraph 3 empowers the Minister to adopt further rules in relation to Maltese passenger ships.

The Minister is further empowered by the Act to make rules with regard to life-saving appliances,${ }^{39}$ radio equipment, ${ }^{40}$ direction-finders, ${ }^{41}$ openings in passenger ship's hulls and water tight bulk heads, ${ }^{42}$ as well as any rules to implement the SOLAS Convention as amended. ${ }^{43}$

Articles 217 to 222 prescribe the certificates (including exemption certificates subject to the provisions of the Act) issued in respect of ships showing that the ship complies with the requirements of SOLAS. The duration of the certificates corresponds to the provisions of SOLAS, namely one year for passenger ships and not more than five years for all other ships. $^{44}$

36 See also S.L. 234.30

37 In relation to marine equipment, on 18 September 2016, the Merchant Shipping (Marine Equipment) Regulations (S.L. 234.40) were adopted, www.transport.gov.mt/Sea-Ship-Registration-LegiS.L.ation-Merchant -Shipping-marine-Equipment-Regulations.pdf-f282. These Regulations adopt measures in relation to Maltese ships as contained in Directive 2014/90/EU of the European Parliament and of the Council of 23 July 2014 on marine equipment and repealing Council Directive 96/98/EC, OJ L257/146, 28.8.2014, p. 146 in its up-to-date version. Equipment placed on board a Maltese ship and for which the approval of the flag State administration is required shall comply with these Regulations. No certificate as required by international conventions shall be issued, renewed or endorsed unless the marine equipment placed on board the Maltese ship complies with these Regulations as well as international conventions. The Regulations also provide for an EU declaration of conformity covering the equipment concerned (in this respect see Merchant Shipping Notice 153 entitled Marine Equipment Directive - EU Declaration of Conformity, www.transport.gov.mt/include/filestreaming.asp?fileid=4 117), exemptions, and offences.

38 See, for example, Technical Notice IRO.2 entitled Harmonised System of Survey and Certification SOLAS Certification for Cargo Ships; Technical Notice S.L.S.20 entitled Periodical Bottom Inspection of Passenger Ships other than Ro-Ro Passenger Ships. See also S.L. 234.37.

39 Merchant Shipping Act, Art. 208. See, for example, Technical Notice S.L.S.17 on 'Embarkation Arrangements for Remotely Located Survival Craft' www.transport.gov.mt/include/filestreaming.asp?fileid=2242 and Technical Notice S.L.S.24 on 'Launch Test of Rescue Boat', www.transport.gov.mt/include/filestreaming.asp?fil eid=2255. It is the duty of the owner or the master of the ship to ensure that the ship is provided with life-saving appliances which have regard to the nature of the service on which the ship is engaged and avoid any undue encumbrance on the ship's deck and which are best adapted for securing the safety of crew and passengers.

40 Ibid., Arts. 209, 211.

41 Ibid., Art. 210.

42 Ibid., Art. 212.

43 Ibid, Art. 213. See also Technical Notice S.L.S.5 Rev.1 on 'Fire and Abandon Ship Drills' www.transp ort.gov.mt/include/filestreaming.asp?fileid=2246 and Technical Notice S.L.S.6 Rev.3 on 'Fire Protection Systems, Appliances and Compressed Gas Cylinders Periodic Maintenance, Inspection and Testing', www.transport. gov.mt/include/filestreaming. asp?fileid=2262.

44 Ibid., Art. 226. 
Articles 250-277 of the Act stipulate the applicable requirements for load lines and loading which shall apply to all ships save for warships, ships solely engaged in fishing and pleasure yachts. ${ }^{45}$ Article 251 empowers the Minister to make load lines rules which shall give due consideration to the Load Line Convention. Said Rules were promulgated in 2003 as S.L. 234.29. The Rules give force of law to the Load Line Convention, as amended, as well as any other instruments, standards and specifications of a mandatory nature adopted by the $\mathrm{IMO}^{46}$ which shall be applicable ${ }^{47}$ to all Maltese ships ${ }^{48}$ and any other ship to which the Convention applies when in Maltese waters. ${ }^{49}$ The Registrar-General is empowered to issue the certificates in terms of the Convention. ${ }^{50}$

The proper calculation of tonnage of the ship may also be considered as part of the requirements for the adequate implementation of cargo safety techniques. In this regard, the Tonnage Regulations (L.N. 391 of 2002), as amended by L.N. 411 of 2007 were promulgated with the purpose of incorporating the Tonnage Convention into the Laws of Malta. The Regulations revoked the Merchant Shipping (Tonnage) Regulations, 1989 (L.N. 78 of 1989) and apply to different types of ships of different size (including foreign ships when in Maltese waters ${ }^{51}$ ) which shall be duly certified in accordance with the provisions of the Tonnage Convention and of the Tonnage Regulations.

The obligation to comply with the ISM Code ${ }^{52}$ for the Malta flagged vessels stems from the adherence of Malta to SOLAS. However, to ensure that everyone is aware about its application, the MSD issued the Merchant Shipping Directorate Notice $42^{53}$ informing the stakeholders that compliance with the ISM Code (including the ISM certification) for both the company and the ship is a statutory requirement in terms of the SOLAS as is the safety construction, equipment and radio certification. Moreover, by means of Technical Notice S.L.S.26, ${ }^{54}$ the MSD reviewed its procedures relating to the filing of the ISM declaration forms. The purpose of this document is to provide guidance to owners and management companies of Maltese registered vessels.

It should be noted that SOLAS provides a comprehensive system of technical rules and regulations when it comes to carriage of goods by sea, in particular in Chapter VI which covers carriage of cargoes and oil fuels as well as requirements for stowage and securing of cargo and cargo units and Chapter VII covering transport of dangerous goods in various forms. As already mentioned, the SOLAS Convention is implemented fully in Malta and, hence, all the rules prescribed by it are applicable to Maltese ships or ships within the jurisdiction of Malta. The general regulations concerning cargo together with the mandatory

45 Ibid., Art. 250.

46 S.L. 234.29 , rule 3.

47 Ibid.

48 See also Art. 252-254 in relation to offences.

49 See also Merchant Shipping Act, Arts. 261-263.

50 Ibid., Arts. 252-259 on certificates and Art. 260 on inspections of ships.

51 Ibid., Part V, regulations 19-20.

52 International Management Code for the Safe Operation of Ships and for Pollution Prevention, adopted by the IMO Assembly as Resolution A.741 (18) (4 November 1993), www.imo.org/en/KnowledgeCentre/IndexofIM OResolutions/Assembly/Documents/A.741(18).pdf.

53 Implementation of the International Safety Management (ISM) Code for the Safe Operation of Ships and for Pollution Prevention www.transport.gov.mt/include/filestreaming.asp?fileid=2881.

54 Guidance to Registered Owners and Management Companies on the Filing of International Safety Management (ISM) Joint Declaration Forms, www.transport.gov.mt/include/filestreaming.asp?fileid=3886. 
codes are directly applicable due to the nature of the Convention and the wording of the national law ${ }^{55}$ incorporating the international instrument.

Despite the 'safe' wording of the law, the Maltese Government and responsible authorities further implement the instruments of mandatory and not mandatory nature into national legislation by means of laws and by-laws. Such active functioning of the legislature might also be an effect of the obligation undertaken by the Republic of Malta upon joining the European Union.

The International Maritime Solid Bulk Cargoes (IMSBC) Code ${ }^{56}$ provides requirements for the safe carriage of bulk cargoes and covers loading and discharge; safety of ship personnel; trimming procedures; and carriage of cargoes which may liquefy, or which represent a chemical hazard. The Code is applicable to Malta by means of L.N. 22 of 2003. On the basis of the same Rules, particularly Article 3(2), the Registrar-General issues merchant shipping notices confirming the mandatory nature of the Code, its application in Maltese waters and for Malta flagged ships and informing the stakeholders about the amendments in the Code. ${ }^{57}$ Apart from that, the L.N. 22 of 2003 in Article 6 revokes the previously existing Maltese legislation (Dangerous Goods Rules ${ }^{58}$ and Grain Rules ${ }^{59}$ ) in order to eliminate inconsistencies with the relevant instruments under the SOLAS.

Furthermore, the Registrar-General, in terms of Regulation 3(2) of L.N. 22 of 2003 and by means of Merchant Shipping Notice No. $60^{60}$ confirmed the applicability of the BLU Code $^{61}$ to all Maltese ships wherever they are, and all other ships when they are within a port in Malta.

When it comes to the safe transport of containers, Chapter VI of SOLAS, which is applicable in Malta, covers requirements for stowage and securing of cargo units (such as containers). The only explicit reference to the containers as such is made in regard to the Requirements for the Verified Gross Mass of Containers (amendments made to Chapter VI, Part A, Regulation 2 of the SOLAS) in force from 1 July 2016, which were introduced by the Ports and Yachting Directorate through the Port Notice No. 03/16. ${ }^{62}$ The amendments have as their objective the gross mass verification of packed containers prior to stowage on board a ship by expanding on how such gross mass of cargo carried units is to be verified. The shipper is provided with two possible options: weighing the packed container using calibrated and certified equipment; ${ }^{63}$ or weighing all packages and cargo items, including the mass of pallets dunnage and other securing material to be packed in the

55 See S.L. 234.30.

56 The International Maritime Solid Bulk Cargoes (IMSBC) Code adopted by the IMO Maritime Safety Committee as Resolution MSC.268(85) (4 December 2008), www.imo.org/en/KnowledgeCentre/IndexofIMOReso lutions/Maritime-Safety-Committee-(MSC)/Documents/MSC.268(85).pdf.

57 See Notice No. 28 of Merchant Shipping Directorate on 'Fire Safety Hazards Associated with Wood Pellets' issued on 1 February 2018, www.transport.gov.mt/include/filestreaming.asp?fileid=2974.

58 Legal Notice 90 Merchant Shipping (Dangerous Goods) Rules, 1974.

59 Legal Notice 91 Merchant Shipping (Grain) Rules, 1974.

60 Merchant Shipping Notice No.60 Safe Loading and Unloading of Bulk Carriers issued by Merchant Shipping, www.transport.gov.mt/include/filestreaming.asp?fileid=2886.

61 The Code of Practice for the Safe Loading and Unloading of Bulk Carriers (BLU Code) adopted in 1997 by the IMO Assembly through Resolution A. 862(20).

62 TM/PYD/83/96 VII, www.transport.gov.mt/Sea-Official-Notices-amp-Marine-Weather-Information-PortNotices-New-Solas-Requirements-for-the-Verified-Gross-Mass-of-Containers-03-16.pdf-f154.

63 SOLAS, Chapter VI, Carriage of Cargoes and Oil Fuels, Part A, Regulation 2, Paragraph 4.1. 
container and adding the tare mass of the container to the sum of the single masses, using a certified method approved by the competent authority of the State in which the packaging of the container was completed. ${ }^{64}$

Carriage of dangerous goods is covered by the Act in its Part 4 (Articles 284 to 291). The Act defines 'dangerous goods' by providing a list of substances to be considered as such. ${ }^{65}$ The Act gives power to the Minister to issue the rules as to the carriage of the said dangerous good. ${ }^{66}$ The Act restricts the carriage of dangerous goods without distinctly marking their nature on the outside of the package containing the same and giving written notice of the name and address of the sender or carrier thereof to the master or owner of the vessel.

Carriage of Grain is also covered by Part 4 of the Act. ${ }^{67}$ Shipowners are to take all the necessary precautions in the situation where the grain is loaded either on board the Maltese ship, or when loading is carried out in one of the ports of Malta to prevent grain from shifting. Failure to abide by the prescribed regulation will constitute an offence under the laws of Malta and the person liable will be fined. Apart from that, the Act requires any ship carrying a cargo of grain and arriving at any port in Malta from a port outside Malta, to give notice, stating: (a) the draught of water and freeboard of the ship after the complete loading of cargo at the final port, (b) particulars of the grain carried, namely: kind of grain and quantity, mode of stowage and type of precautions taken to prevent grain from shifting.

Additionally, the Dangerous Cargo Ships, Marine Terminals and Facilities and Bunkering Regulations (S.L. 499.12) as amended further covers dangerous cargo ships, by regulating the movement, transfer, storage and handling of dangerous cargoes ${ }^{68}$ on all ships and at all marine terminals and facilities within or connected to the internal and territorial waters of Malta ${ }^{69}$ (with exceptions mentioned in Article $4^{70}$ of the said Regulations). Throughout the Regulations, reference is made to the 'relevant instruments' ${ }^{71}$ which, according to the definition in the Regulations means not only all the relevant IMO Conventions to which Malta has acceded, or may accede to from time to time, but also the relevant IMO Codes of Practices, the relevant guides and current rules of ship classification societies. Furthermore, Article 11(2)(b) requires that any ship carrying dangerous packaged cargoes 'shall comply with all the requirements laid down in the IMO IMDG Code and other Relevant Instruments'. ${ }^{72}$ These Regulations also transposed the provisions of EU Directives concerning dangerous and polluting goods; ${ }^{73}$ and the provisions of Directive 2010/65/EU on

64 Ibid., Paragraph 4.2.

65 Merchant Shipping Act, Art. 284.

66 Ibid., Art. 285.

67 Ibid., Art. 291.

68 'dangerous cargoes' as per Art. 3 of the S.L.499.12 includes goods classified in the IMDG Code, dangerous liquid substances listed in Chapter 17 of the International Bulk Chemical Code, liquefied gases listed in Chapter 19 of the International Code of the Construction and Equipment of Ships Carrying Liquefied Gases in Bulk Code and solids referred to in Appendix B of the Solid Bulk Cargo Code.

69 S.L.499.12, Regulation 2.

70 Ibid., Regulation 4.

71 Ibid., Regulation 3.

72 Ibid., Regulation 11 (2)(b).

73 Directive 2002/59/EC of the European Parliament and of the Council of the 27 June 2002, as subsequently amended by Directive 2009/17/EC of the European Parliament and of the Council of the 23 April 2009 and Directive 2011/15/EU of the European Commission of the 23 February 2011, OJ L 208, 5.8.2002, p. 10. 
reporting formalities for ships arriving in and or departing from ports of the Member States and repealing Directive 2002/6/EC. ${ }^{74}$

Transport Malta issued the Code of Practice for the Safety of Commercial Vessels ${ }^{75}$ in terms of Commercial Vessels Regulations, 2002 (S.L. 499.23). ${ }^{76}$ The Code forms part of these regulations and is enforceable as part of the Laws of Malta. ${ }^{77}$ The main aim of the Regulations, together with the Code, is to regulate the owners of commercial vessels certified to be used or operated for hire or reward within the ports, internal waters and territorial waters of Malta, and the safety and manning requirements for such vessels. The Code contains 34 Articles and 7 Annexes (as per latest edition 13th issued in May 2017) addressing various issues, including inter alia manning, ${ }^{78}$ construction $^{79}$ and structural strength ${ }^{80}$ weathertight integrity, ${ }^{81}$ water freeing arrangements, ${ }^{82}$ machinery, ${ }^{83}$ electrical installations, ${ }^{84}$ freeboard and freeboard marking, ${ }^{85}$ life-saving appliances, ${ }^{86}$ fire safety,${ }^{87}$ radio equipment ${ }^{88}$ navigation equipment, ${ }^{89}$ accommodation, ${ }^{90}$ protection of personnel,,${ }^{91}$ certification, survey, maintenance, ${ }^{92}$ prevention of marine pollution ${ }^{93}$ and International Safety Management (ISM) Code compliance. ${ }^{94}$

In accordance with S.L. 499.23, the Regulations and the Code of Practice are applicable to all vessels engaged in any trade, business or calling within the territorial or internal waters or within any port of Malta with the exception of pleasure craft; 95 fishing boats when engaged, operated and used solely in licensed fishing activities in terms of the provisions of the Fisheries Conservation and Management Act; ${ }^{96}$ ships owned or operated for non-commercial service ${ }^{97}$ and ships of war or official vessels unless used on a commercial service..$^{98}$

74 Directive 2010/65/EU of the European Parliament and of the Council, OJ L 283/1, 29.10.2010, p. 218.

75 Code of Practice for the Safety of Commercial Vessels (13th ed., May 2017), www.transport.gov.mt/SeaPassenger-Transport-by-sea-Commercial-Vessel-Operations-in-Local-Waters-Code-of-Practice-CommercialVessels.pdf-f121.

76 S.L. 499.23 www.justiceservices.gov.mt/DownloadDocument.aspx?app=lom\&itemid=11345.

77 Commercial Vessels Regulations, regulation 1(2).

78 Code of Practice for the Safety of Commercial Vessels, Arts. 4-6.

79 Ibid., Art. 7.

80 Ibid., Art. 7.2.

81 Ibid., Art. 8.

82 Ibid., Art. 9.

83 Ibid., Art. 10.

84 Ibid., Art. 11.

85 Ibid., Art. 15.

86 Ibid., Art. 16.

87 Ibid., Arts. 17,18 (Structural Fire Protection) and 19 (Fire Appliances).

88 Ibid., Art. 20.

89 Ibid., Art. 21 (Navigational Lights, Shapes and Sound Signals) and 22 (Navigation, AIS and VDR Equipment).

90 Ibid., Art. 25.

91 Ibid., Art. 26.

92 Ibid., Art. 31.

93 Ibid., Art. 32.

94 Ibid., Art. 34

95 S.L. 499.23, Regulation 4(a).

96 Ibid., Regulation 4(b).

97 Ibid., Regulation 4(c).

98 Ibid., Regulation 4(d). 
The Code in its foreword requires the compliance of the vessels with the various regulations issued under the Act which are relevant to the class of vessel to which they belong. ${ }^{99}$ Moreover, compliance with the Code does not exclude application of any other additional local requirements where such are required to be complied with under relevant legal authority. ${ }^{100}$

Another important feature of the Code is the requirement for the owner of a vessel to obtain a policy of insurance for all persons who are part of the vessel's complement, and such insurance should provide cover for reasonable for claims which may arise in the course of vessel's commercial operation. The insurance certificate is required to be either displayed or available for inspection by persons on board the vessel. ${ }^{101}$ Annex 1 of the Code gives a full list of certificates to be issued for the vessels that are covered by the Code of Practice. If a vessel is exempted from application of any of the requirements prescribed by any convention which is applicable in Malta, an Exemption Certificate has to be issued by the Authority for Transport in Malta and such certificate should cover the exemption from the regulations relative to the subject. ${ }^{102}$

With regard to places of refuge, Malta is fully compliant with the obligations under international and EU law. By means of Vessel Traffic Monitoring and Reporting Requirements Regulations (S.L. 499.34), ${ }^{103}$ Malta transposed the obligations imposed by Directive EU 2002/59 as amended. Regulation 5(3) appoints Transport Malta as the competent authority responsible for the implementation of the provisions of the Regulations. In this regard, the Pollution and Incidence Response Unit (PIRU) within Transport Malta is the unit designated to assess the situation regarding the accommodation of ships in need of assistance.

Article 20 of the Directive imposes on all Member States a requirement to set up national plans in order to be able to accommodate a ship in distress with a place of refuge. In 2014, Transport Malta issued a notice ${ }^{104}$ which gives an outline on the decision process to allocate or refuse a vessel a place of refuge. Internal guidelines which provide the Authority with a decision-making process so that it can decide whether a vessel can be allocated a place of refuge, together with a framework for developing pre-incident information on potential places of refuge as well as charts of different such places, were also adopted.

\subsection{Control and surveillance system}

The responsibilities of Malta in its capacity as flag, port and coastal State are defined in a number of international instruments to which it is a party as well as under its obligations under EU legislation. ${ }^{105}$ These international instruments developed under the auspices of

99 Ibid., preambular 1.3

100 Ibid., 1.12 .

101 Ibid., Annex 6.

102 Ibid., Annex 1.

103 S.L. 499.34, www.justiceservices.gov.mt/DownloadDocument.aspx?app=lom\&itemid=11356.

104 PoR.TM-General/07.2014/rev3, www.transport.gov.mt/Sea-Maritime-Polution-Prevention-and-Control-PoR -General.pdf-f206.

105 S.L. 499.34 . 
IMO and ILO elaborate on the provisions of UNCLOS, ${ }^{106}$ referred to as 'the constitution for the oceans'.

In line with the EU maritime policy, control and surveillance refers to safe use of the sea (safety) and securing the EU's maritime borders (security). As mentioned in section 2, national authorities have been tasked, under national safety legislation, with compliance with these obligations..$^{107}$

It is the obligation of coastal States to alert interested parties of dangers to navigation within areas under their jurisdiction of which they have knowledge. This obligation aligns with the provision of Article 24(4) of UNCLOS. Information requisite for safe navigation within a given region is promulgated through coastal warnings. Coastal warnings are broadcast by the International NAVTEX service, or by the International SafetyNET service when implemented in lieu of NAVTEX.

Navigational warnings are promulgated by the AFM through NAVTEX and VHF transmissions. Since 2015, the NAVTEX service area has been reassigned to cover the west coast of Tunisia. This was agreed with Tunisia and the NAVAREA III Coordinator in 2015. Weather Bulletin and Navigational Warnings are issued daily by Malta Radio (9HD) Maritime Coast Radio Station on VHF, MF/RT.

Mariners should refer to SOLAS Chapter V regulations 31 and 32 which lay down the masters' obligations to report dangers to navigation (regulation 31) and provide the correct reporting format (regulation 32). ${ }^{108}$ Indeed, Notice to Mariners No. 02 of 2020 advises all concerned parties operating along the foreshore that

the Chief Officer \& Harbour Master is to be notified as early as possible when new or suspected dangers to navigation are discovered or any changes to aids to navigation are observed within the territorial and internal waters of Malta, in any port and in the land and sea approaches to any port, and on wharves.

The Maltese Hydrographic Office (MHO) which forms an integral part of the Ports and Yachting Directorate is responsible, inter alia, for gathering and providing hydrographic data, compiling and disseminating navigational charts, and providing maritime safety information to mariners, in compliance with the requirements of SOLAS. Digital charts are produced by the MHO which also undertakes the update of the electronic navigational charts to support the VTS system.

The increase in size, speed and number of vessels plying maritime routes and the attendant increase in marine accidents, stimulated the conceptualization of a single ship traffic management system. The Ports and Yachting Directorate through the Valletta Ports Vessel Traffic Service (Valletta VTS) and the Traffic Management section provides assistance to vessels navigating within Maltese territorial and internal waters.

106 United Nations Convention on the Law of the Sea, 1982 (adopted on 10 December 1982, entered into force on 16 November 1994, UNTS 1833) 3.

107 S.L. 499.34, Regulation 5.

108 Indeed, Notice to Mariners No. 02 of 2020 advises all concerned parties operating along the foreshore that 'the Chief Officer \& Harbour Master is to be notified as early as possible when new or suspected dangers to navigation are discovered or any changes to aids to navigation are observed within the territorial and internal waters of Malta, in any port and in the land and sea approaches to any port, and on wharves'. 
The Traffic Management section deals mainly with the terminal operators and ship agents and handles the pre-arrival and pre-departure notifications and berth planning. The operator, agent or master of a ship bound for a port or an anchorage in Malta or to enter the territorial waters to receive a service shall provide Transport Malta with the required information at the time and in such manner and format as required. S.L. 499.34 provides for the establishment of a maritime information management system which conforms to the EU directives and the FAL Convention. ${ }^{109}$ Transport Malta is tasked with the obligation to cooperate with competent authorities of other EU States and ensure the interconnection and interoperability of their respective systems and to develop and update SafeSeaNet.

The VTS department handles shipping movements by providing information services, traffic organization services and when deemed necessary a navigational assistance service. These services are provided on a round the clock basis by personnel trained in line with International Association of Marine Aids to Navigation and Lighthouse Authorities (IALA) standards.

Participation in the Malta VTS and Valletta VTS is compulsory for all vessels regardless of size. The master of a ship shall, prior to entering the territorial waters, make all the required reports, including reporting of deficiencies, and shall ensure that, when the ship enters the territorial waters of Malta, the ship shall participate in and comply with the rules which apply in the territorial waters. ${ }^{110}$

The AFM which operates the coastal station in Malta (MALTA VTS) is responsible for monitoring shipping and receiving vessel information within territorial waters. In terms of Regulation 8 of S.L. 499.34, the coastal station may request additional information even from ships beyond the territorial waters. In addition, the coastal station in Malta, when possessing information about ships which pose a potential hazard to shipping or a threat to maritime safety, the safety of individuals or the environment, shall transmit such information to the costal stations of States located along the planned route of the ship.

Further, pursuant to S.L. 499.34, ships fitted with an Automatic Identification System (AIS) shall maintain the system in operation at all times save where international agreements, rules or standards provide for the protection of navigational information. In addition, S.L.499.34, Regulation 9(f) makes mandatory the carrying of Long Range Identification and Tracking (LRIT) equipment which comply with regulation 19/1 for any ship to which this SOLAS regulation applies and that calls at a port in Malta. The same piece of legislation requires all passenger ships, irrespective of size, and all other ships with a gross tonnage of 3,000 and above, which are engaged on international voyages and call at ports in Malta, to be fitted with a voyage data recorder.

Other important instruments include the COLREGs, which make provisions on navigation rules to be followed by ships and other vessels at sea to prevent collisions and which were incorporated into Maltese law through Prevention of Collisions Regulations (S.L. 234.20); ${ }^{111}$ and the STCW Convention, which makes mandatory the observation of princi-

109 IMO Convention on Facilitation of International Maritime Traffic, 1965 as amended (adopted on 9 April 1965, entered into force on 5 March 1967, UNTS 591) 265.

110 See S.L. 499.34.

111 S.L. 234.20. Pursuant to Regulation 3, the Convention covering any amendment or Protocol related thereto as may from time to time be ratified, acceded to or accepted by the Government of Malta and other instruments, standards and specifications of a mandatory nature related thereto adopted or developed by the Interna- 
ples and guidance set out in the STCW Code so as to ensure that a safe continuous watch or watches appropriate to the prevailing circumstances and conditions are maintained in all seagoing ships at all times. ${ }^{12}$

Local Notice to Mariners No. 093 of 2019 strictly prohibits the misuse of distress signals. Whereas the Signal Distress Rules (S.L. 234.21) have made it mandatory for all Maltese ships, subject to the requirements stated therein, the use or exhibition of the signals described in Annex 4 of COLGREGs, Notice No. 093 is very important as it has introduced in the Maltese legislation the most up-to-date signals which are to be used or exhibited in situations of distress or need of assistance.

Undoubtedly, the responsibility for monitoring the compliance of ships with the international standards for safety, pollution prevention and on-board living and working conditions lies primarily with the flag State. ${ }^{113}$ In this regard, Malta is mindful that the principal responsibility for the effective application of the international standards rests upon the authorities of the State whose flag a ship is entitled to fly, but yet also recognizes the key role port States have in preventing the operation of substandard ships.

The obligation on the flag State to perform necessary inspections in order to ensure compliance with the established safety standards and regulations on board the vessels flying the Maltese flag is discharged by the Administration (MSD). The inspections are carried out by inspectors approved by the Administration specifically for these purposes on a regular basis. The list of inspectors (appointed ship surveyors) is available online. ${ }^{114}$ The surveys are conducted in addition to the regular statutory surveys performed by the recognized classification societies and only on the specific instructions of the MSD.

A surveyor of ships may inspect any ship for the purpose of verifying that the ship complies with the rules made under the Act. ${ }^{115}$ When the surveyor concludes that any of the said rules have not been complied with, 'he shall give written notice to the owner or master stating in what respect the said rules have not been complied with and what, in his opinion, is required to rectify the matter'. Such notice shall be communicated to the officer in charge of giving the ship clearance to proceed to sea. Clearance to proceed to sea may not

tional Maritime Organization form part of and are enforceable as part of the Law of Malta and apply to all Maltese ships and to all other ships while they are in Maltese waters as determined by the Convention. See also Merchant Shipping Act, Articles 292-297.

112 Regulation 33 of Merchant Shipping (Maritime Labour Convention) Rules, 2013 (S.L. 234.51), www. justiceservices.gov.mt/DownloadDocument.aspx?app=lom\&itemid=12086\&l=1, obliges the master of any ship to ensure that the watchkeeping arrangements for the ship are at all times adequate to maintain safe navigation. The same obligation is imposed on the master in case the ship is safely moored or safely at anchor under normal circumstance in port. Additional requirements for watchkeeping are imposed in case of a ship carrying hazardous cargo. See also Merchant Shipping Notices 129 and 144 on the 'Implementation of the International Convention on Standards of Training, Certification and Watchkeeping of Seafarers, as amended', www.transport.gov.mt/incl ude/filestreaming.asp?fileid=3547, www.transport.gov.mt/include/filestreaming.asp?fileid=3854 and Merchant Shipping Notice 135 of the 'Revised format of Certificates issued in terms of the International Convention on Standards of Training, Certification and Watchkeeping for Seafarers, as amended (STCW Convention)', www.t ransport.gov.mt/include/filestreaming.asp?fileid=2944.

113 Directive 2009/16/EC of the European Union Parliament and of The Council of 23 April 2009 on port State control (Recast (6)), OJ L 131, 28.5.2009, p. 57.

114 www.transport.gov.mt/list-of-authorised-ship-surveyors-October-2019-21-10-2019.pdf-f4587.

115 Ibid., Art. 241. 
be granted and the ship may be detained until the required certificate(s) is/are produced ${ }^{116}$ or the matter has been rectified. ${ }^{117}$

Since 1993, MSD (as part of the monitoring process) conducts random inspections of Maltese ships worldwide using the services of its own global network of inspectors. These inspections are in addition to the regular statutory surveys carried out by the classification societies and are undertaken on the specific instructions of the Directorate. The results and the performance of the inspectors is closely monitored by the Technical Department.

Whilst flag State inspections are performed on Malta flagged ships, Port State Controls (PSC), performed by the MSD, ${ }^{118}$ aim to ensure that international standards on board the ships coming into and leaving ports of Malta are properly maintained. The effectiveness of the PSC is further enhanced through a number of legislative instruments and various cooperation initiatives between port States.

One such instrument is the Memorandum of Understanding on PSC in the Mediterranean Region (MMoU) to which Malta has been a party since 11 July 1997 (with effective date applicable to Malta being 25 February 1998 $)^{119}$ in an effort to increase maritime safety and to prevent pollution and to establish a PSC System for southern and eastern Mediterranean countries.

Another important international instrument for the PSC regime in Malta is the Paris Memorandum of Understanding on Port State Control (PMoU) $)^{120}$ adhered to by Malta on 12 May 2006. Since then, the MSD has been obliged to give effect to the provisions of the $\mathrm{PMoU}$ and the Annexes thereto ${ }^{121}$ including the most recent $42 \mathrm{nd}$ amendment, adopted 17 May 2019 with effective date being 21 December 2019.

Following the Erika and Prestige accidents off the European coasts, EU legislation on PSC was adopted in $2009^{122}$ under the third maritime safety package. ${ }^{123}$ The Directive reinforced, as of 1 January 2011, Member States' obligations to inspect vessels calling at their ports, requiring more frequent inspections on ships posing a higher risk and extends the ban on substandard ships.

In this respect, S.L. 234.38 (adopting the measures contained in Directive 2009/16/ EC), to be read together with the Merchant Shipping (Port State Control) (Amendment) Regulations, 2019 (L.N. 344 of 2019) which partially transposed the measures contained in Directive (EU) 2017/2110 (in force from December 2019), ${ }^{124}$ establishes the responsible

116 Ibid., Arts. 232, 241

117 Ibid., Art. 241.

118 Art. 2(1), S.L. 234.38

119 Agreement on the Establishment of a PSC in the Mediterranean Region, 11 July 1997.

120 Paris Memorandum of Understanding on Port State Control, Text including 42nd Amendment, adopted 17 May 2019 (effective date: 21 December 2019).

121 Ibid., Art. 1.1.

122 Directive 2009/16/EC of the European Union Parliament and of The Council of 23 April 2009 on port State control (Recast (6)) [2009] OJ L 131, 28.5.2009, p. 57.

123 MEMO/05/438 Third Maritime Safety Package adopted in Brussels, 23 November 2005; amendment of the Port State Control Directive.

124 Directive (EU) 2017/2110 of the European Parliament and of the Council of 15 November 2017 on a system of inspections for the safe operation of ro-ro passenger ships and high-speed passenger craft in regular service and amending Directive 2009/16/EC and repealing Council Directive 1999/35/EC, OJ L 315, 30.11.2017, p. 61 . 
authorities, ${ }^{125}$ applicability of the PSC regulations, ${ }^{126}$ nature of the surveys to be conducted, their performance and punishments ${ }^{127}$ in cases where deficiencies constitute an offence under the said Regulations.

\subsection{Enforcement}

Article 375 of the Act empowers the Maltese Government, for the purposes of the Ratification of Treaties Act, to ratify or accede to the international instruments referring to merchant shipping which are listed in paragraph 2 of the same Article. The list covers almost every facet of shipping and, in accordance with paragraph 5 , any reference in Article 375 to a treaty or a convention or a protocol shall include reference to any of their amendments which have been accepted by the Government of Malta. ${ }^{128}$ The Minister has the obligation upon the ratification of any such treaties or conventions to publish a notice in the Gazette stating the date on which these instruments shall enter into force for Malta. Thereupon, such instruments are enforceable within the Maltese jurisdiction. In case of a discrepancy between the provisions of the treaty or of national legislation, unless stipulated otherwise, the treaty rules shall prevail.

The Act and the various S.L. adopted under it stipulate for a wide range of administrative penalties which are to be fixed and imposed by the Registrar-General. ${ }^{129}$ For example, Article 230 of the Act provides that it is the obligation of every owner or master to ensure that the certificate(s) issued to the ship in accordance with Part V of the Act are posted in a conspicuous place on board the ship and remain so posted for the entire duration of the certificate. Failure to comply with this obligation constitutes an offence and the owner or master of the vessels is liable to the fine provided for in Article 230. Considering that no Maltese ship shall proceed to sea unless the respective certificate(s) is/are in force, ${ }^{130}$ the owner or the master who fails to comply with this obligation shall be liable to the fines prescribed in Article 232. Similar provisions are found in relation to contraventions to load line regulations, tonnage regulations and other safety measures as well as marine pollution prevention measures and labour standards.

Although most of the penalties imposed are of a financial nature and constitute an executive title for the purpose of their execution, the Maltese legislation also provides for criminal penalties which are to be imposed by a court of law in accordance with the provisions of law. ${ }^{131}$

125 S.L. 234.38, Regulation 2.

126 Ibid., Regulation 3.

127 Ibid., Regulation 22.

128 In accordance with S.L. 234.30 'The Safety Convention as may from time to time be in force, shall, unless otherwise provided in these rules and notwithstanding the provision of any other law, form part of and be enforceable as part of the Law of Malta and shall apply to all Maltese ships and to all other ships while they are in Maltese waters as determined by the said Convention'; At the same time Rule 2(1) defines the Safety Convention to mean: '[t] he International Convention for the Safety of Life at Sea signed in London on 1st November, 1974, including any amendment or Protocol related thereto as may from time to time be ratified, acceded to or accepted by the Government of Malta and other instruments, standards and specifications of a mandatory nature related thereto adopted or developed by the International Maritime Organization or in terms of regulation 3(2)(a) hereof.'

129 Merchant Shipping Act, Art. 372A.

130 Ibid., Art. 232.

131 Environment Protection Act (Cap.549), Art. 84; Port and Shipping Act (Cap. 352), Arts. 35, 37-42. 
To deter the occurrence of safety measures violations, the responsible authorities may also refuse clearance to proceed to sea to non-conforming ships as well as subject such ships to detention until the necessary actions have been taken to rectify any deficiencies. ${ }^{132}$

\subsection{Liability}

In order to ensure that the country's maritime laws reflect the exigencies of the maritime industry, Malta has successfully domesticated a number of international instruments dealing with the rules and procedures governing liability and remedies available in cases of various marine accidents.

In respect of oil pollution, the Oil Pollution (Liability and Compensation) Act 1999 (Chapter 412 of the Laws of Malta) gave effect to CLC $1992^{133}$ and Fund Convention $1992^{134}$ while the Bunkers Convention ${ }^{135}$ was implemented through the Merchant Shipping (Liability for Bunker Oil Pollution Damage) Regulations 2009 (S.L. 234.46). ${ }^{136}$ Both regimes provide for strict liability of the shipowner and compulsory insurance coverage (applicable to vessels of certain size) up to the limits applicable. ${ }^{137}$

Since the Bunkers Convention does not have its own limits of liability (contrary to the CLC Convention) but makes reference to the applicable national limits, the Maltese legislator, while domesticating the instrument, in Article 3(6) of the Regulations indicated that 'the applicable limitation regime for the purposes of the Bunkers Convention shall be that provided for in the Merchant Shipping (Limitation of Liability for Maritime Claims) Regulations'. These Regulations ${ }^{138}$ made applicable to Malta the Convention on Limitation of Liability for Maritime Claims, 1976, as amended (LLMC Convention). ${ }^{139}$

The key provisions applicable to the passenger claims under Maltese law are found in the Merchant Shipping (Carriage of Passengers by Sea) Regulations (S.L. 234.52). ${ }^{140}$ The Regulations incorporated the Athens Conventions ${ }^{141}$ and, at EU level, Regulation (EC) No. 392/2009, ${ }^{142}$ which provide for a harmonized regime of liability and insurance for the carriage of passengers by sea. As per S.L. 234.52, 'a ship may not enter or leave a port

132 Merchant Shipping Act, Art. 241.

133 Protocol of 1992 to amend the International Convention on Civil Liability for Oil Pollution Damage, 1969 (adopted on 27 November 1992, entered into force on 30 May 1996, UNTS 1956).

134 Protocol to the International Convention on the Establishment of an International Fund for Compensation for Oil Pollution Damage, 1992 (adopted on 27 November 1992, entered into force on 30 May 1996).

135 International Convention on Civil Liability for Bunker Oil Pollution Damage, 2001 (adopted on 23 March 2001, entered into force on 21 November 2008).

136 S.L. 234.46, www.transport.gov.mt/Sea-Ship-Registration-LegiS.L.ation-Merchant-Shipping-liability-forBucker-Oil-Pollution-Damage-Regulations.pdf-f288.

137 See below discussions under wreck removal since both conventions have similar provisions.

138 Merchant Shipping (Limitation of Liability for Maritime Claims) Regulations (S.L. 234.16), www.transp ort.gov.mt/Sea-Ship-Registration-LegiS.L.ation-Limitation-of-liability-for-Maritime-Claims-Regulations.pd f-f258.

139 Protocol to the Convention on Limitation of Liability for Maritime Claims, 1976 (adopted on 2 May 1996, entered into force on 13 May 2004).

140 SL234.52, www.transport.gov.mt/Sea-Ship-Registration-Legislation-Merchant-Shipping-cariage-of-Pass engers-by-Sea-_regulations.pdf-f294.

141 The Protocol of 2002 to the Athens Convention relating to the Carriage of Passengers and their Luggage by Sea, 1974 (adopted on 1 November 2020, entered into force on 23 April 2014).

142 Council Regulation 392/2009 of 23 April 2009 on the liability of carriers of passengers by sea in the event of accidents, OJ L 131, 28.5.2009, p. 24. 
in Malta, nor, if the ship is a Maltese ship, a port in any other country, unless there is an insurance cover in force'. ${ }^{143}$

The Nairobi International Convention on the Removal of Wrecks $2007^{144}$ became part of the laws of Malta by virtue of the Merchant Shipping (Wreck Removal Convention) Regulations (S.L. 234.33). ${ }^{145}$ The purpose of the Nairobi Convention was to harmonize the regulations on wreck removal. To enable an application encompassing wrecks located in the territorial sea, the Convention includes an opt-in clause in Article 3.2 allowing a State Party to extend the scope of application to wrecks located within its territory including the territorial sea. In this regard, Malta, when depositing the instrument of accession in 2015, notified the IMO Secretary-General that it was extending the application of the Convention to its territory, including the territorial sea. Hence, if a wreck is located on or near the Maltese coast and the minister responsible believes that it is or is likely to become an obstruction or danger to navigation, the Government of Malta is

entitled to take possession of, remove or destroy the wreck, or to sell the wreck and any property recovered from it in order to be reimbursed for the expenses related to wreck removal, subject to any surplus of funds being held for the benefit of those persons entitled thereto.

S.L. 234.33 also imposes strict liability on the shipowner and makes it mandatory for the shipowner to obtain compulsory insurance.

The insurance or security shall cover liability under the Convention in an amount that equals the limits of liability under the applicable national or international limitation regime. In all cases the amount shall, however, not exceed the limitation amount calculated in line with Article 6.1.b of the LLMC Convention as amended.

The appropriate authority for the purpose of issuing the certificate attesting that an insurance cover or other financial security is in force, as required by the instruments discussed above, in respect of ships registered in Malta, shall be the Registrar-General who shall determine the conditions of issue and validity of such certificate. In respect of ships registered in a State not party to these instruments, the Registrar-General shall have the same powers.

Apart from the compulsory insurance requirement provided for in the abovementioned instruments, Malta is also bound, being a Member State of the EU, to properly implement measures required by EU Directive 2009/20/EC. ${ }^{146}$ In this regard, the Merchant Shipping (Insurance For Maritime Claims) Regulations (S.L. 234.50) ${ }^{147}$ were issued requiring all Maltese ships of 300 gross tonnage or more (with exception to warships, auxiliary warships or government ships used for non-commercial purposes) to have an insurance covering maritime claims subject to limitation under S.L. 234.16. The provisions of these

143 SL 234.52, Art. 4

144 Nairobi International Convention on the Removal of Wrecks, 2007 (adopted on 18 May 2007, entered into force on 14 April 2015) https://treaties.un.org/doc/Publication/UNTS/No\%20Volume/55565/Part/I-55565 $-080000028053 \mathrm{c} 3 \mathrm{a} 0 . \mathrm{pdf}$.

145 S.L. 234.53, www.transport.gov.mt/Merchant-Shipping-Wreck-Removal-Convention-Regulations.pdf-f2830.

146 Council Directive 2009/20/EC of 23 April 2009 on the insurance of shipowners for maritime claims, OJ L 131, 28.5.2009, p. 128.

147 SL 234.50, https://www.transport.gov.mt/Sea-Ship-Registration-Legislation-Merchant-Shipping-Insureance -for-martime-labour-convention-Rules.pdf-f292. 
Regulations also apply to any ship entering Maltese ports irrespective of the State of registration. As from 1 January 2012, vessels that do not have in place such an insurance cover may be denied entry into Maltese ports and may be subject to detention.

\subsection{Conclusion}

Malta's identity is steeped in maritime heritage. Situated in the middle of the Mediterranean Sea at the crossroads of three continents, Malta has relied on the sea for its survival for millennia. ${ }^{148}$ The vital importance the maritime sector still holds today is undeniable and it affirms the importance of Malta as a maritime hub. Being the largest ship registry in Europe and the sixth largest ship registry in the world, demands of the country a robust legal regime to ensure safe, clean and secure seas. Malta has lived up to these expectations and, as showcased above, has created a legislative framework which ensures compliance of ships with international rules and prescriptions promoting safety of ships and protection of the environment while safeguarding the lives of passengers and of the workforce operating them.

148 Integrated Maritime Policy, 'Making Malta a Centre of Maritime Excellence', https://economy.gov.mt/en /public_consultation/documents/integrated $\% 20$ maritime $\% 20$ policy.pdf. 


\title{
Comparative maritime safety
}

\author{
The Netherlands
}

\author{
Frank Stevens
}

\subsection{Introduction}

The Netherlands has a long and impressive maritime history. In the 17th century, the Dutch merchant fleet was one of, if not the largest fleet in the world, consisting amongst others of the famous 'East Indiamen', large sailing ships trading with South Asia. Today, the Dutch fleet is still sizeable, with Dutch shipping companies at the forefront of the industry in certain specialized trades such as cooled and reefer carriage, ocean towing, heavy lift and project cargo, etc. In addition, the port of Rotterdam is in the top 10 of ports in Europe and worldwide. Given the major economic significance of the Dutch maritime and port industry, it is hardly surprising that the Dutch government takes an active interest in maritime matters and strives to develop and maintain a legal framework to support or even boost the Dutch maritime ambitions.

In practice, this means that the Dutch government ratifies most maritime conventions, and tries to amend the Dutch legislation in light of new conventions, new IMO or EU rules or guidelines, etc. within as short a period as possible. Within this general context, rules and conventions that relate to maritime safety and security take on a special importance, given their subject matter.

In the English language, 'safety' can be distinguished from 'security', with safety referring to the technical characteristics and conditions of vessels and their equipment, and security referring to the protection against unwanted intrusions and interventions. ${ }^{1}$ In Dutch, the word most commonly used is 'veiligheid', which can refer to both safety and security. A similar word, 'beveiliging', generally refers to security ${ }^{2}$ and is not commonly used to refer to safety aspects. ${ }^{3}$ On a legal and regulatory level, however, the difference between maritime safety and maritime security is not very relevant, as often the same authorities are competent for both.

1 The distinction is not always carried through, though. The full title of the SUA Convention for example is 'Convention for the Suppression of Unlawful Acts against the Safety of Maritime Navigation', even though this Convention clearly deals with security issues.

2 The 2004 Ships Decree, for example, uses the term 'beveiliging' where it refers to ship security and the ISPS Code (see Arts. 9, 50 and 63).

3 The Dutch translation of Safety of Life at Sea (SOLAS), however, reads 'beveiliging van mensenlevens op zee'. 


\subsection{National structure for the implementation of maritime safety law}

The implementation of maritime safety law in the Netherlands is the competency of the Ministry of Infrastructure and Water Management. ${ }^{4}$ The Ministry consists of several divisions, the most important of which in this context are the legal department and the Inspectorate for Human Environment and Transport. ${ }^{5}$ The legal department is in charge of developing policy and implementing international rules into Dutch law. The Inspectorate performs inspections and audits and issues certificates to the shipping sector, which includes both ocean and inland shipping. ${ }^{6}$ The 'Shipping Inspectorate', ${ }^{7}$ a name that is still used in several Acts and regulations, used to be an independent department, but has in 2001 been merged into the Inspectorate for Transport and Water Management, ${ }^{8}$ which in turn in 2012 became the current Inspectorate for Human Environment and Transport.

The Netherlands also has a Safety Investigation Board. ${ }^{9}$ This is an 'independent administrative authority', ${ }^{10}$ created by the Safety Investigation Board Act of 2 December 2004. ${ }^{11}$ This Board investigates and reports on incidents or potential incidents ${ }^{12}$ on Dutch territory or in Dutch waters, including (but not limited to) those in the shipping sector. The Board can also investigate incidents that involve a Dutch vessel, regardless of where they have occurred, as well as incidents involving ro-ro ferries or high speed passenger vessels that started the voyage on which the incident occurred from a Dutch port. ${ }^{13}$ The purpose of the investigation and report is exclusively to learn from the incident in order to prevent similar incidents in the future, and not to establish liability.

For maritime incidents, the current Safety Investigation Board is the successor of the 'Maritime Council', ${ }^{14}$ which is still referred to in Chapter 4 of the 1909 Ships Act. The disciplinary powers of the Maritime Council have been taken over by the Maritime Disciplinary Board. ${ }^{15}$

4 Ministerie van Infrastructuur en Waterstaat, previously named the Ministry of Transport and Water Management (Ministerie van Verkeer en Waterstaat).

5 Inspectie Leefomgeving en Transport (ILT).

6 In addition to Shipping, the Inspectorate is also competent for the other transport modes (Rail \& Road, Air carriage), as well as for the industry (Waste, Industry \& Companies), for products (Water, Products \& Substances) and for the supervision of Housing Corporations.

7 Scheepvaartinspectie.

8 Inspectie Verkeer en Waterstaat (IVW). This name is also still used in some legislation (see for example Art. 5.1 of the 2010 Foreign Ships Act).

9 Onderzoeksraad voor de Veiligheid.

10 Zelfstandig bestuursorgaan.

11 Rijkswet van 2 december 2004 houdende instelling van een Onderzoeksraad voor veiligheid, Stb. 2004, 677.

12 An 'incident' is defined as an occurrence causing personal injury or death, or damage to goods or to the environment (Art. 1.1.f Safety Investigation Board Act).

13 Art. 14.1 Safety Investigation Board Act.

14 Raad voor de scheepvaart.

15 Tuchtcollege voor de scheepvaart. 


\subsection{Prevention}

\subsubsection{Ship construction}

The rules with regard to the construction and equipment of ships are primarily to be found in the 1909 Ships Act and the secondary legislation based on this Act. Article 3 of the Ships Act provides that a Dutch ship is not allowed to operate unless all of the required certificates have been issued and are still valid at the time of commencement of the voyage. The concept of a 'Dutch ship' is defined rather broadly and is not linked to the Dutch flag (Article 2.3). It includes any ship that is operated by a Dutch company, as well as any ship that is provisioned in the Netherlands and of which at least half of the crew are Dutch nationals. In addition, the 2004 Foreign Ships Act $^{16}$ provides the possibility to extend the safety requirements of the Ships Act to non-Dutch flagged vessels when that is required to enforce EU regulations on maritime safety (Article 3).

The Ships Act is further implemented by two Royal Decrees, the 1965 Ships Decree $^{17}$ and the 2004 Ships Decree. ${ }^{18}$ Substantial parts of the 1965 Decree have been abolished and replaced by the 2004 Decree, but a number of provisions of the 1965 Decree remain in force. Both Decrees start with the list of certificates that vessels must have and the initial and follow-up surveys that are required to obtain those certificates and to keep them valid. Many of these certificates are today based on international conventions such as SOLAS and the Load Lines Convention. In such case, the Ships Decree simply provides that the ship must comply with the convention requirements that correspond to a particular type of certificate. ${ }^{19}$ Further (technical) details are to be found in the Safety of Sea-going Vessels Regulation. ${ }^{2021}$

Article 3a of the 1909 Ships Act provides that a ship can only be certified if it meets all requirements set by secondary legislation. By way of implementation, both the 1965 and the 2004 Ships Decrees provide that the competent Ministry will identify classification societies whose rules will count as the requirements meant in Article 3a of the 1909 Ships Act. ${ }^{22}$ In practice, therefore, the statutory safety requirements for vessels are developed and updated by the recognized classification societies.

16 Wet van 6 juli 2004 houdende een voorziening om ter uitvoering van besluiten van instellingen van de Europese Unie regels te kunnen stellen ten aanzien van buitenlandse schepen (Wet buitenlandse schepen).

17 Decree of 5 August 1965 to implement Art. 3, 4bis, 5, 9, 17, 66 and 73 of the Ships Act (Besluit van 5 augustus 1965, tot uitvoering van de artikelen 3, 4bis, 5, 9, 17, 66 en 73 van de Schepenwet).

18 Decree of 18 June 2004 establishing rules with regard to the safety and certification of sea-going vessels (Besluit van 18 juni 2004, houdende regels met betrekking tot de veiligheid en certificering van zeeschepen).

19 See, for example, Art. 40 of the 2004 Ships Decree: 'A ship for which a safety certificate for passenger ships or safety certificate for cargo ships is required must comply with the requirements that apply to that ship pursuant to Chapters II-1, II-2, III, IV, V and XII of the SOLAS-convention.'

20 Regeling veiligheid zeeschepen. The full name of this Regulation is: Regeling houdende nadere regels met betrekking tot de veiligheid en certificering van in Nederland geregistreerde zeeschepen, alsmede regels met betrekking tot de veiligheid van buitenlandse schepen in Nederlandse wateren (Regulation introducing additional rules with regard to the safety and certification of sea-going vessels registered in the Netherlands, as well as with regard to the safety of foreign vessels in Dutch waters).

21 In the Dutch legal system, a 'Regulation' (Regeling) is a set of generally binding provisions, issued by a public body other than a formal legislator.

22 See the Decree recognized organizations Ships Act (Besluit erkende organisaties Schepenwet) of 17 March 2006, Stcrt. 2006, 60. At the time of writing, the following classification societies are recognized: American Bureau of Shipping (ABS), Bureau Veritas (BV), DNV-GL, Lloyd's Register (LR), Nippon Kaiji Kyokai (ClassNK), RINA and Indian Register of Shipping. 
Warships, naval auxiliary vessels and other vessels used for military purposes are excluded from the scope of both the 1909 Ships Act and the 2004 Foreign Ships Act.

The Netherlands is a party to the 1966 Load Lines Convention, ${ }^{23}$ the 1988 Load Lines Protocol $^{24}$ and the 1969 Tonnage Convention. ${ }^{25}$ All ships, except the smallest ones, are required to have an international load line certificate (Article 3.2.a of the 1965 Ships Decree \& Article 4 of the 2004 Ships Decree), and the smallest ships are required to have a domestic load line certificate ${ }^{26}$ (Article 3.2.b of the 1965 Ships Decree). With regard to the requirements that have to be met to obtain an international load line certificate and the surveys that have to be passed, the 2004 Ships Decree simply refers to the Convention (Article $13 \& 39$ of the 2004 Ships Decree). The Tonnage Convention has been implemented by the 1981 Tonnage Certificate $\mathrm{Act}^{27}$ and the 1981 Tonnage Certificate Decree. ${ }^{28}$

As regards vessel equipment, the 2016 Ship Equipment Act ${ }^{29}$ and the 2016 Ship Equipment Regulation ${ }^{30}$ implement Directive 2014/90/EU. Every piece of equipment that is installed on an EU ship must comply with the requirements of the international instruments applicable to that type of equipment. Further (technical) details are to be found in the Safety of Sea-going Vessels Regulation. ${ }^{31}$

Fishing vessels are subject to an extensive set of specific safety requirements, contained in two Decrees. The first, the 1989 Fishing Vessels Decree, ${ }^{32}$ was based on the 1977 Torremolinos Convention for the Safety of Fishing Vessels (which never entered into force). The second, the 2002 Fishing Vessels Decree, ${ }^{33}$ adds a further set of rules to the 1989 Decree, implementing the EU Directives on this matter (93/103/EC, 97/70/EC and 99/19/EC).

\subsubsection{Manning}

The Netherlands is a party to the SOLAS, STCW and MLC Conventions. The more technical requirements and provisions regarding the manning of ships are primarily to be found in the 1997 Seafarers Act ${ }^{34}$ and the 2001 Seafarers Decree, ${ }^{35}$ while the labour law aspects

23 Verdrag inzake de uitwatering van schepen (Trb. 1966, 275).

24 Trb. 1990, 57.

25 Verdrag inzake de meting van schepen (Trb. 1970, 122).

26 The standards and requirements for this domestic load line certificate are set out in Annex I to the 1965 Ships Decree.

27 Wet van 12 februari 1981 houdende bepalingen betreffende de meting van schepen, Stb. 1981, 122 (Meetbrievenwet).

28 Besluit van 24 juni 1981 houdende bepalingen voor de meting van schepen, Stb. 1981, 479 (Meetbrievenbesluit).

29 Wet van 23 augustus 2016 houdende regels met betrekking tot de productie, de conformiteitsbeoordeling en het plaatsen aan boord van scheepsuitrusting, Stb. 2016, 322 (Wet scheepsuitrusting 2016).

30 Regeling van de Minister van Infrastructuur en Milieu van 22 augustus 2016 houdende regels met betrekking tot de productie en conformiteitsbeoordeling van scheepsuitrusting (Regeling scheepsuitrusting 2016).

31 Regeling veiligheid zeeschepen.

32 Besluit van 5 augustus 1989, houdende nadere regelen voor de veiligheid van Vissersvaartuigen (Vissersvaartuigenbesluit).

33 Besluit van 11 januari 2002, houdende veiligheidsvoorschriften voor vissersvaartuigen (Vissersvaartuigenbesluit 2002).

34 Wet van 11 december 1997 houdende regels omtrent de bemanning van zeeschepen (Wet zeevarenden).

35 Besluit van 23 augustus 2001 houdende bepalingen omtrent de bemanning van zeeschepen in de handelsvaart en de zeilvaart (Besluit Zeevarenden). 
are dealt with in a separate Part (12) of the general labour law code (Title 10 of Book 7 of the Dutch Civil Code).

\subsubsection{ISM Code}

The Netherlands being a party to the SOLAS Convention, the ISM Code, as part of that Convention, is of mandatory application. In this respect, Article 49 and 50 of the 2004 Ships Decree provide that a vessel owner must develop and implement a Safety Management System for his organization and a Ship Safety Plan for each of his vessels, and that he must appoint safety officers. The resulting compliance documents, the Document of Compliance for the organization and the Safety Management Certificates for the vessels, are a necessary precondition for a vessel to be able to obtain the other certificates required to be allowed to operate (Article 3.1 of the 1965 Ships Decree).

\subsubsection{Passenger ships}

The SOLAS Convention has specific provisions for passenger ships, and also the EU has legislated on the subject with Directive 2009/45/EC (as amended) dealing with safety rules and standards and Directive 98/41/EC (as amended) dealing with the registration of passengers. The SOLAS provisions have mainly been implemented - in the Dutch fashion of merely referring to them - by the 2004 Ships Decree, with the Directives provisions being implemented by the Safety of Sea-going Vessels Regulation. ${ }^{36}$

\subsubsection{Safety of navigation}

The issue of safety of navigation and aids to navigation is, at the top level, governed by the 1988 Shipping Traffic Act. ${ }^{37}$ The actual navigation and collision rules are found in secondary legislation based on this Act. There are different 'Shipping Regulations ${ }^{38}$ for the different nautical regions: the territorial sea, the Western Scheldt, the Ems estuary, the communal Meuse and the Ghent-Terneuzen Canal. These Regulations are essentially based on the COLREGS, with locale-specific rules added in where necessary. The Shipping Regulations also define which aids to navigation can be used. The actual decisions as to which aids to navigation will be installed are made by the authority that is competent with regard to a particular waterway. These authorities can issue a 'Traffic Order' ${ }^{39}$ pursuant to the 1993 Shipping Traffic Administrative Provisions Decree. ${ }^{40}$ For example, the Harbour Master Rotterdam issues Traffic Orders for the waterways in the port of Rotterdam.

\footnotetext{
36 Regeling veiligheid zeeschepen.

37 Wet van 7 juli 1988 houdende algemene regeling met betrekking tot het scheepvaartverkeer op de binnenwateren en op zee (Scheepvaartverkeerswet).

38 Scheepvaartreglementen.

39 Verkeersbesluit.

40 Besluit van 13 december 1993 houdende vaststelling van administratieve bepalingen inzake het scheepvaartverkeer (Besluit administratieve bepalingen scheepvaartverkeer).
} 


\subsubsection{Places of refuge}

Article 20 of Directive 2002/59/EC ${ }^{41}$ requires all EU Member States to prepare plans to accommodate ships in distress. In the Netherlands, Article 23 of the 2015 Maritime Accidents Response Act ${ }^{42}$ provides that the competent Minister must prepare a plan to respond to dangers on the North Sea. This plan is known as the 'Incident Response Plan North Sea' ${ }^{43}$ and provides detailed rules and procedures on how to deal with incidents. Places of refuge are also touched upon in the Plan. Given the characteristics of the Dutch coastline, however, the Dutch government decided that there is no point in pinpointing specific places of refuge and that, in principle, all Dutch sea ports can be used as a place of refuge.

\subsubsection{Maritime security}

The Netherlands, as a State party to the SOLAS convention and EU Member State, is bound by the ISPS Code, as enhanced by Regulation (EC) No. 725/2004 on enhancing ship and port facility security and Directive $2005 / 65 /$ EC on enhancing port security. The ship's part of the Code is implemented by the 2004 Ships Decree, which provides that all ships that require a safety certificate also require an ISPS security certificate (Article 9). For the certification process and requirements, the Ships Decree simply refers to the ISPS Code (Article 19, 28 and 50 of the 2004 Ships Decree). The port's part of the Code and Directive 2005/65/EC are implemented by the 2004 Port Security Act. ${ }^{44}$

For a long time, the use of private armed guards to secure ships against attacks was not allowed under Dutch law. Dutch shipowners could only use a 'Vessel Protection Detachment' provided by the military. Since 2019, however, the Merchant Navy Protection $\mathrm{Act}^{45}$ does allow private armed guards.

\subsection{Control and surveillance}

\subsubsection{Port State Control}

In 1982, the Netherlands was one of the original signatories of the Paris MOU, and the secretariat of the organization is to this day established in The Hague. The EU Directives on

41 Directive 2002/59/EC of 27 June 2002 establishing a Community vessel traffic monitoring and information system and repealing Council Directive 93/75/EEC, OJ L 208, 5.8.2002, p. 10.

42 Wet van 14 oktober 2015 houdende regels ten aanzien van de bestrijding van maritieme ongevallen, met inbegrip van wijziging van Boek 8 van het Burgerlijk Wetboek en enige andere wetten, ter uitvoering van het op 18 mei 2007 tot stand gekomen Verdrag van Nairobi inzake het opruimen van wrakken (Wet bestrijding maritieme ongevallen),

43 Incidentbestrijdingsplan Noordzee, which is available (in Dutch) at the 'North Sea Counter' (Noordzeeloket) website (www.noordzeeloket.nl).

44 Wet van 6 juli 2004 tot uitvoering van Verordening (EG) nr. 725/2004 van het Europees Parlement en de Raad van de Europese Unie van 31 maart 2004 betreffende de verbetering van de beveiliging van schepen en havenfaciliteiten (PbEU L 129), alsook van andere besluiten van volkenrechtelijke organisaties met betrekking tot de beveiliging van havens (Havenbeveiligingswet).

45 Wet van 15 mei 2019 houdende regels voor de inzet van gewapende particuliere maritieme beveiligers aan boord van Nederlandse koopvaardijschepen, Stb. 2019, 186 (Wet ter Bescherming Koopvaardij). 
Port State Control ${ }^{46}$ were implemented by the 1997 Port State Control Act (as amended) ${ }^{47}$ Article 1.b.10 of this Act explicitly allows the competent authorities to add further conventions, in addition to those listed in the Directive. Currently, the 2001 Convention on the Control of Harmful Anti-fouling Systems on Ships and the 2004 Ballast Water Management Convention have been added to the list. ${ }^{48}$

\subsubsection{Ship routeing}

Both the 1909 Ships Act (Article 4a) and the 1988 Shipping Traffic Act (Article 21.1) provide, in general, that the competent authority is entitled to impose ship routeing measures. On the international level, however, pursuant to Regulation V/10 of SOLAS, the IMO is the only body recognized to develop routeing systems. Article 5a of the Shipping Regulations for the territorial sea ${ }^{49}$ further provides that the competent authority can set routeing or reporting systems in line with the IMO guidelines and criteria.

In line with Article 3(9) of Directive 2002/59/EC ${ }^{50}$ and Article 2.1.1 of IMO's General Provisions on Ships' Routeing, ${ }^{51}$ Dutch law defines routeing systems as a system of one or more routes or routeing measures aimed at reducing the risk of casualties, including traffic separation schemes, two-way routes, recommended tracks, areas to be avoided, inshore traffic zones, roundabouts, precautionary areas and deep water routes. ${ }^{52}$ Pursuant to Article 7.1 of Directive 2002/59/EC, the EU Member States must ensure that all mandatory IMO routeing systems are indeed complied with. The routeing systems of prime importance to Dutch shipping are repeated and confirmed in the 'Regulation routeing and reporting systems for ships on the high seas off the Dutch Coast', ${ }^{53}$ which currently covers two deep water routes (from North Hinder to the traffic separation scheme 'Off Brown Ridge', and from the traffic separation scheme 'Off Brown Ridge' to the traffic separation scheme 'West Friesland'), three traffic separation schemes ('Off Brown Ridge', 'West Friesland' and 'East Friesland'), a precautionary area ('Friesland') and two areas to be avoided (Ijmuiden and Maas North).

46 Initially Directive 95/21/EC concerning the enforcement, in respect of shipping using Community ports and sailing in the waters under the jurisdiction of the Member States, of international standards for ship safety, pollution prevention and shipboard living and working conditions (Port State Control), OJ L 157, 7.7.1995, p. 1, later replaced by Directive 2009/16/EC on port State control, OJ L 131, 28.5.2009, p. 57.

47 Wet van 6 november 1997 houdende regels betreffende het toezicht aan boord van schepen onder buitenlandse vlag in Nederlandse havens op de naleving van internationale voorschriften op het gebied van de veiligheid, voorkoming van verontreiniging en leef- en werkomstandigheden (Wet Havenstaatcontrole).

48 Besluit van 21 november 2003 houdende aanwijzing van een verdrag als bedoeld in artikel 1, onderdeel b, onder $10^{\circ}$, van de Wet havenstaatcontrole.

49 Scheepvaartregklement territoriale zee.

50 Directive 2002/59/EC of 27 June 2002 establishing a Community vessel traffic monitoring and information system and repealing Council Directive 93/75/EEC, OJ L 208, 5.8.2002, p. 10.

51 IMO Resolution A.572(14), as amended.

52 Art. 1 of the Decree of 6 October 1997 regarding routeing and reporting systems for ships on the high seas off the Dutch coast (Besluit van 6 oktober 1997 houdende vaststelling van routerings- en meldingssystemen voor schepen in volle zee voor de Nederlandse kust); Art. 2 of the Shipping Regulations for the Territorial Sea (Scheepvaartreglement territoriale zee).

53 Regeling van 3 juli 2013 houdende vaststelling van een regeling met betrekking tot routeringssystemen voor schepen op volle zee voor de Nederlandse kust (Regeling routerings- en meldingssystemen voor schepen in volle zee voor de Nederlandse kust). 
One of the possible measures with regard to ships' routeing is traffic separation schemes. Pursuant to Rule 1.d of the COLREGS, such schemes can be adopted by the IMO. All such schemes are published in the Staatscourant, the official Dutch Journal, and are binding on all Dutch ships and all foreign ships in Dutch territorial waters. ${ }^{54}$

Since the Netherlands shares two important rivers with neighbouring countries - the river Scheldt with Belgium, and the river Ems with Germany - it has entered into bilateral conventions with these countries to regulate the nautical aspects of these waterways. With Belgium, there is the 1978 Convention regarding the construction of a shore based radar chain along the borders of the Western Scheldt and its estuary ${ }^{55}$ and the 2005 Convention regarding the common nautical management of the Scheldt area. ${ }^{56}$ The former provided for the construction of a shore-based radar system to monitor and guide shipping traffic on the river Scheldt, with a central Coordination Centre in Flushing and regional centres in Zeebrugge, Flushing, Terneuzen and Hansweert. The radar images are recorded and kept for some time, and are often very useful in dealing with collision and other maritime incident cases. The 2005 Convention confirmed and reinforced the duties and powers of the already existing 'Permanent Commission', created by the 1839 Belgo-Dutch Treaty. The Permanent Commission, assisted by the 'Common Nautical Authority', is charged with developing and maintaining a common nautical management in order to ensure the safety and expediency of the shipping traffic in the Scheldt area. With Germany, the Netherlands has concluded the 1980 Convention regarding common information and guidance of shipping in the Ems estuary by means of shore-based radar and high-frequency radio installations. ${ }^{57}$

\subsubsection{Vessel Traffic Services}

Vessel Traffic Services (VTS) are defined in Article 3(o) of Directive 2002/59/EC as services designed to improve the safety and efficiency of vessel traffic and to protect the environment, which has the capability to interact with the traffic and to respond to traffic situations developing in the VTS area. In general, vessel traffic services consist of information provided to ships on the one hand, and (binding) instructions given to those ships on the other hand.

Article 1.(i) of the 1988 Shipping Traffic Acts defines 'traffic guidance' (verkeersbegeleiding) as the combination of personal and infrastructural facilities to create and maintain safe and expedient shipping traffic in a structured and interactive way. Article 1 further defines 'traffic information' (verkeersinformatie) and mandatory 'traffic instructions'

54 Art. 3.2 and Art. 1 of the Decree of 7 November 1989 to declare applicable the International Regulations for preventing collisions at sea, 1972 (Besluit van 7 november 1989 houdende het van toepassing verklaren van de Internationale Bepalingen ter voorkoming van aanvaringen op zee, 1972).

55 Overeenkomst inzake het aanleggen van een walradarketen langs de Westerschelde en haar mondingen, signed at Brussels on 29 November 1978.

56 Verdrag inzake het gemeenschappelijk nautisch beheer in het Scheldegebied, signed at Middelburg on 21 December 2005.

57 Overeenkomst tussen het Koninkrijk der Nederlanden en de Bondsrepubliek Duitsland inzake de gemeenschappelijke informatie en begeleiding van de scheepvaart in de Eemsmonding door middel van walradar- en hoogfrequent-radio-installaties, signed at Bonn on 9 December 1980. 
(verkeersaanwijzing). Both of these must be given by a competent person. ${ }^{58}$ The 2013 Decree on the training and powers of nautical professions ${ }^{59}$ provides that these competent persons are primarily the VTS operators (Article 5.1). In certain circumstances however, police officers, the Coast Guard Director and pilots can also provide traffic information or give traffic instructions (Article 5.7, 5.8 and 5.9). The implementing Regulation on the training and powers of nautical professions ${ }^{60}$ provides that for these matters the competent authority is not, as is generally the case, the Ministry of Infrastructure and Water Management, but the mayor and aldermen of the City of Rotterdam for the Rotterdam port area, the Director of the Central Nautical Management of the North Sea Canal Area for the Ijmuiden area, and the Royal Navy for the Den Helder area (Article 5). Finally, the Shipping Regulations (Scheepvaartreglementen) for the different areas and waterways all provide that ship masters are obliged to comply with traffic instructions. ${ }^{61}$ Failure to do so is a criminal offence (Article 31.4 of the Shipping Traffic Act).

\subsubsection{Traffic signs}

A traffic sign is defined as an object that is placed in, next to or over a waterway to provide information or to give instructions to the shipping traffic (Article 1.(g) of the 1988 Shipping Traffic Act). The decision to install (or to remove) a traffic sign must be taken by the competent authority by means of a 'traffic order' (verkeersbesluit), which must indicate the goals that are intended by the traffic sign. ${ }^{62}$ Not complying with a traffic sign is a criminal offence (Article 31.4 and 31a.(4) of the Shipping Traffic Act).

\subsubsection{Reporting obligations}

With Directive 2002/59/EC, the EU has created a maritime information exchange system known as SafeSeaNet (SSN). Additional rules on the exchange of information were introduced by Directive 2010/65/EU on reporting formalities for ships arriving in and/or departing from ports of the Member States. ${ }^{63}$ The Netherlands, as an EU Member State, participates in the exchange system.

Article 4.1.e of the 1988 Shipping Traffic Act provides that the competent authority can introduce rules on the collecting, storing and sharing of shipping information. This

58 Art. 9 of the Shipping Traffic Act provides that implementing legislation must define which persons are competent in this respect.

59 Besluit van 11 december 2013 houdende regels voor de opleiding van registerloodsen, noordzeeloodsen en VTS-operators en de bij die functies behorende bevoegdheden en verplichtingen (Besluit opleidingen en bevoegdheden nautische beroepsbeoefenaren).

60 Regeling van 6 december 2013 (nr. IENM/BSK-2013/283192) houdende vaststelling nadere regels met betrekking tot de opleiding en bevoegdheden van nautische beroepsbeoefenaren (Regeling opleidingen en bevoegdheden nautische beroepsbeoefenaren).

61 See, for example, Art. 11 of the Shipping Regulation for the Territorial Sea, Art. 35 of the Shipping Regulation for the Ems Estuary, Art. 54 of the Shipping Regulation for the Western Scheldt, etc.

62 Art. 5 of the 1993 Decree containing administrative provisions on shipping traffic (Besluit van 13 december 1993 houdende vaststelling van administratieve bepalingen inzake het scheepvaartverkeer (Besluit administratieve bepalingen scheepvaartverkeer)).

63 Directive 2010/65/EU of 20 October 2010 on reporting formalities for ships arriving in and/or departing from ports of the Member States and repealing Directive 2002/6/EC, OJ L 283, 29.10.2010, p. 1. 
provision has been implemented by the 2012 'Decree reporting formalities and data processing in shipping', ${ }^{64}$ which has detailed provisions in this respect. The Decree is further implemented by the 'Regulation reports and communication in shipping'. ${ }^{65}$

The SafeSeaNet 'National Competent Authority' (NCA) in the Netherlands is the Director-General of the Directorate-General for Public Works and Water Management (Rijkswaterstaat). ${ }^{66}$ All reports, for SafeSeaNet as well as for Customs and police purposes, must be filed through a single platform, the 'Maritime Single Window'. Today, this platform is known as the Single Window for Maritime and Aviation, as it is currently also used for air cargo.

\subsection{Enforcement}

In matters of public maritime law, the Dutch legislator is generally very open about the international origins of certain rules or provisions, and will, if at all possible, simply refer to the international rules. Article 28 of the 2004 Ships decree, for example, provides that for a new ship, a six-month temporary ISPS security certificate can be issued, 'if the ISPSCode requirements for the issuance of a temporary certificate are met'. Similarly, Article 4 of the 2011 Insurance of Sea-going Ships Act provides that Dutch ships and foreign ships calling at Dutch ports must prove that they are properly insured by having on board the certificates as meant in Article 3 of Directive 2009/20/EC and that these certificates must contain the information listed in Article 6 of the Directive. This approach is less convenient for the reader, who has to piece together two (or more) sets of rules, but on the other hand avoids discrepancies or contradictions between the international rules as such and the domestic incorporation thereof. Also, by simply referring to the international instruments rather than incorporating them full text, keeping up with modifications of the international instruments is easier.

In matters of private maritime law, such as the liability conventions, the international instruments are generally incorporated in Book 8 of the Dutch Civil Code. Like many other countries, the Netherlands originally had both a Commercial Code and a Civil Code. Since the 1980s, however, it has been decided to abandon the distinction between commercial and civil law and to concentrate all private law rules in the Dutch Civil Code. The Commercial Code still exists, but only a few limited parts are still in force today. Most of the private transport law has been moved to Book 8 of the Dutch Civil Code. Here, the Dutch legislator has aimed to make Book 8 the single source of all rules and provisions of private maritime law, rather than requiring the reader to use other instruments in combination with Book 8. The fact that private maritime law instruments change less frequently

64 Besluit van 4 mei 2012 houdende regels voor de scheepvaart over meldingsformaliteiten en over de verwerking van de ontvangen gegevens door organisaties en personen die niet aan het scheepvaartverkeer deelnemen (Besluit meldingsformaliteiten en gegevensverwerkingen scheepvaart).

65 Regeling van 27 april 2012 (nr. IENM/BSK-2012/60134) houdende vaststelling van nadere regels voor de scheepvaart en organisaties en personen die niet aan het scheepvaartverkeer deelnemen betreffende meldingen en communicatie (Regeling meldingen en communicatie scheepvaart).

66 Art. 16 of the Regulation reports and communication in shipping. 
than the technical, safety-related conventions, and thus do not often require amending the domestic legislation, helps of course.

\subsection{Liability}

The Netherlands is a party to most of the liability conventions. Most of these conventions have been incorporated into Book 8 of the Dutch Civil Code, which is the Book that deals with maritime and transport law.

The Netherlands was a party to the 1969 Civil Liability Convention (CLC), and has ratified the 1976 and 1992 Protocols. On ratifying the 1992 Protocol, however, the Netherlands has denounced the original 1969 Convention, to avoid possible issues in its relations with other States that are also party to the original 1969 Convention but have not ratified the 1992 Protocol. Contrary to the usual Dutch approach, the CLC was not incorporated in Book 8, but implemented through a separate Act, the 1975 Liability of Oil Tankers Act ${ }^{67}$ (as amended). In principle, the financial security that the owner of a tanker is required to have must be provided by an insurance company, a bank or another financial institution that is subject to the 2006 Financial Supervision Act, but the competent authority can also accept other persons if it judges the financial resources of this person to be sufficient (Article 13.(a) of the Liability of Oil Tankers Act). If the security is provided by a nonDutch entity, it must be certain that the money can be made available in the Netherlands (Article 13.(b) of the Liability of Oil Tankers Act).

The Netherlands is also a party to the 2001 Bunkers Convention. This Convention has been incorporated in Book 8 of the Dutch Civil Code, as Part 5 of Title 6 on Maritime Incidents (Article 8:639 to 8:653 DCC). The requirements for the financial security (Article 8:646) are largely the same as in the 1975 Liability of Oil Tankers Act, except for the reference to the 2006 Financial Supervision Act.

The Netherlands is not a party to the 1996 HNS Convention or the 2010 HNS Protocol. Book 8 of the Dutch Civil Code, however, has a set of rules on dangerous goods aboard ships (Part 4 of Title 6 on Maritime Incidents, Article 8:620 to 8:627 DCC) which is clearly inspired by the liability provisions of the CRTD Convention ${ }^{68}$ (inland carriage of dangerous goods) and the HNS Convention. As in the HNS Convention, liability is channelled to the shipowner (Article 8:623 DCC). The Dutch scheme, however, adds a defence that does not exist in the HNS Convention. If dangerous goods cause damage during their loading or discharging, and the loading or discharging is performed under the sole responsibility of someone other than the shipowner (such as the shipper or the consignee), only that other person can be held liable (Article 8:624.(1) DCC). If the loading or discharging is performed under the joint responsibility of the shipowner and another person, the shipowner and that other person are jointly liable (Article 8:624.(2) DCC). The Dutch dangerous

67 Wet van 11 juni 1975 tot uitvoering van het op 29 november 1969 te Brussel tot stand gekomen Internationaal Verdrag inzake de wettelijke aansprakelijkheid voor schade door verontreiniging door olie, met Bijlage (Trb. 1970, 196) alsmede regeling van die aansprakelijkheid in overeenstemming met dat Verdrag (Wet aansprakelijkheid olietankschepen).

68 Convention on Civil Liability for Damage caused during Carriage of Dangerous Goods by Road, Rail and Inland Navigation Vessels, done at Geneva on 10 October 1989 (not in force). 
goods regime does not have compulsory insurance and does not provide for a specific limitation of liability, but a shipowner who is held liable for damage caused by dangerous goods will generally be able to invoke the general LLMC limitation regime (incorporated in Title 7 of Book 8 DCC).

The Netherlands is a party to the 2007 Wreck Removal Convention. The Convention provisions on the liability for the costs of localizing, marking and removing wrecks have been incorporated into Part 6 of Title 6 (Maritime Incidents) of Book 8 DCC. The other provisions were incorporated in a separate Act, the 2015 Maritime Incidents Act (Wet bestrijding maritieme ongevallen) ${ }^{69}$ The compulsory insurance provisions are to be found in Chapter 6 of the Maritime Incidents Act, and are largely similar to those that apply in the context of the CLC and Bunkers Conventions.

The Netherlands is also a party to the 2006 Maritime Labour Convention. The provisions of this convention have partly been incorporated in Part 12 (Specific provisions regarding the maritime labour contract) of Title 10 (The labour contract) of Book 7 DCC, and partly in the 1997 Seafarers Act. ${ }^{70}$ The principle of compulsory insurance covering abandoned seafarers and the requirements that this insurance must comply with are to be found in Articles 7:738a and 7:738c DCC.

Finally, there is the general obligation for shipowners to carry insurance against maritime claims, introduced by Directive 2009/20/EC. ${ }^{71}$ In the Netherlands, this Directive has been implemented by the 2011 Insurance of Sea-going Vessels Act. ${ }^{72}$ In essence, the Act simply refers back to the Directive, providing in Article 3 that the insurance carried must comply with the requirements of Article 4.3 of the Directive, and in Article 4 that the insurance certificate must contain the information listed in Article 6.2 of the Directive.

\subsection{Concluding remarks}

The Netherlands has a rich maritime tradition and to this day, the Dutch government remains interested in the maritime sector, ratifying and implementing maritime conventions and protocols. Often, the Dutch legislator simply refers to a convention or to EU legislation. ${ }^{73}$ If the provisions of a convention are incorporated in Dutch legislation, it is a literal translation of the original provisions that is incorporated. The Dutch legislator is not in the habit of rephrasing or rearranging convention provisions.

69 Wet van 14 oktober 2015 houdende regels ten aanzien van de bestrijding van maritieme ongevallen, met inbegrip van wijziging van Boek 8 van het Burgerlijk Wetboek en enige andere wetten, ter uitvoering van het op 18 mei 2007 tot stand gekomen Verdrag van Nairobi inzake het opruimen van wrakken (Wet bestrijding maritieme ongevallen).

70 Wet van 11 december 1997 houdende regels omtrent de bemanning van zeeschepen (Wet zeevarenden).

71 Directive 2009/20/EC of 23 April 2009 on the insurance of shipowners for maritime claims, OJ L 131, 28.5.2009, p. 128.

72 Wet van 27 oktober 2011 tot invoering van de verplichting voor scheepseigenaren om een verzekering te hebben voor het schip en hiervan een bewijs aan boord te hebben ter uitvoering van Richtlijn nr. 2009/20/EG van het Europees Parlement en de Raad van de Europese Unie van 23 april 2009 betreffende de verzekering van scheepseigenaren tegen maritieme vorderingen (PbEU L 131) (Wet verzekering zeeschepen).

73 See, for example, Art. 10 of the Safety of Sea-going Vessels Regulation: 'Passenger ships for which the safety certificate for passenger ships within the meaning of Directive 2009/45/EC is required, are subjected to the surveys prescribed by Art. 12 of Directive 2009/45/EG to obtain that certificate and during the period of validity thereof.' Directive 2009/45/EC of the European Parliament and of the Council of 6 May 2009 on safety rules and standards for passenger ships, OJ L 163, 25.6.2009, p. 1. 
The different rules and regulations regarding maritime safety have not been concentrated in a single code or Act, but are dispersed over several Acts, Decrees and Regulations. Through the Netherlands Regulatory Framework (NeRF) ${ }^{74}$ however, the government does make an effort to provide at least a single point of entry to all of the regulatory information.

74 https://puc.overheid.nl/nsi/. 


\section{Norway}

Playing it safe

Erik Røsceg

\subsection{Introduction}

Norway takes ship safety and security legislation seriously and thus tends to fulfill expectations to the extent that there is not much to write about. In particular, this is so in respect of international cargo shipping, which is the focus here. Norway passed its first comprehensive Seaworthiness Act in 1903, which was replaced by the Ship Safety Act 2007. ${ }^{1}$ While the 1903 Act was controversial, particularly in respect of load lines, ${ }^{2}$ the 2007 Act was an uncontroversial revision and a follow-up to the EU Erika safety packages ${ }^{3}$ in the aftermath of the sinking of the tank vessel Erika in $1999 .{ }^{4}$

The 1903 Act was based on the concept of seaworthiness, defined as follows:

A ship is deemed to be unseaworthy if by reason of defects in hull, equipment, machinery or complement, or by reason of overloading or defective loading, or for other reasons it is in such state that, with due regard to the trade for which the ship is destined, it must be deemed to be attended by greater risk for human lives to put to sea in the ship than the voyage would normally involve. $^{5}$

By contrast, the 2007 Act does not utilize this concept; instead, it attempts to define each standard separately. The concept therefore lacks a definition in Norwegian law, although it is still used as a general reference, for example, in the Maritime Code. ${ }^{6}$

The Ship Safety Act mainly authorizes statutory instruments in the field of ship safety and security, and it includes the statutory basis for criminal and administrative sanctions. The Maritime Code mainly deals with private law, but it includes a chapter on maritime investigations. The Ship Labor Act ${ }^{7}$ is also important in this context.

1 Act Relating to Ship Safety and Security (Ship Safety and Security Act), LOV-2007-02-16-9. English translation: https://tinyurl.com/y343vd5u. All URLs in this paper were last accessed on 16 January 2020.

2 The chapter on load lines was not added until 1909, see LOV-1909-09-18-9.

3 See https://tinyurl.com/y5frlb46.

4 See https://en.wikipedia.org/wiki/MV Erika.

5 Act Relating to Public Control of the Seaworthiness of Ships (The Seaworthiness Act) LOV-1903-06-09-7 $\S 2$, translated in Sjøfartsdirektoratet, Regler for Flyttbare Innretninger. Regulations for Mobile Offshore Units (2003) p. 34.

6 Maritime Code, LOV-1994-06-24-39. English translation: http://folk.uio.no/erikro/WWW/NMC.pdf. See, for example, $\S 489$.

7 Act Relating to Employment Protection Etc. for Employees on Board Ships [Ship Labor Act], LOV-201306-21-102. English translation: www.sjofartsdir.no/en/legislation/laws/ship-labour-act/. 
Norway is not a member of the EU. However, pursuant to the Agreement on the European Economic Area, 1994 (the EEA Agreement), Norway is committed to implementing a number of EU regulations and directives,${ }^{8}$ including many relating to maritime safety and security. ${ }^{9}$ Norwegian courts tend to interpret national legislation so that it agrees with international obligations of these kinds; ${ }^{10}$ there is even a rule that statutory instruments implementing EU legislation pursuant to the EEA Agreement, to some extent, have precedence over Acts of Parliament. ${ }^{11}$

Norway cooperates with the International Maritime Organization (IMO) and the International Labour Organization (ILO), as well as with the European Maritime Safety Agency (EMSA). In preparing the Polar Code, ${ }^{12}$ even the Arctic Council was an important forum for maritime safety.

Norway has two ship registers, the Norwegian Ordinary Registry (NOR) ${ }^{13}$ and the Norwegian International Registry (NIS). ${ }^{14}$ The policy is apparently for the application of international rules for ships in both registries without the addition of national requirements. Norway also permits flagging in or flagging out of ships by registering bare boat charterparties. ${ }^{15}$ In this case, foreign safety and security legislation apply to those ships actually flying the Norwegian flag. ${ }^{16}$

Norwegian waters are open to foreign commercial vessels, even in cabotage. ${ }^{17}$ Foreign vessels are subject to Port State Control. ${ }^{18}$

The Ship Safety Act applies to Norwegian ships, even if not in international trade. ${ }^{19}$ It also applies to foreign ships in the territory (including the territorial sea and ports) of the Norwegian mainland, its Exclusive Economic Zone (EEZ), and its continental shelf ${ }^{20}$ (the reference to ships at the continental shelf is presumably a reference to ships involved in petroleum activities or other activities subject to the continental shelf regime in international law). Foreign ships in the territory of the Svalbard archipelago and in Jan Mayen are also subject to the Act; a 12-nautical mile territorial sea is declared. ${ }^{21}$ No explanation is given as to why the geographic scope of the Act is less extensive around Svalbard and Jan Mayen than around the mainland, but it is well in line with Norway not declaring an EEZ in these areas (only a fishery protection zone). In the possessions in the Antarctic (the Bouvet

8 See www.efta.int/Legal-Text/EEA-Agreement-1327.

9 Ibid., Annex VIII, https://tinyurl.com/y635kfdr.

10 F. Arnesen and A. Stenvik, Internasjonalisering og juridisk metode: Scerlig om EØS-rettens betydning $i$ norsk rett (2nd edn., Universitetsforlaget, 2015) p. 54 ff.

11 Lov om gjennomføring i norsk rett av hoveddelen i avtale om Det europeiske økonomiske samarbeidsområde (EØS) m.v. (EØS-loven), LOV-1992-11-27-109, § 2.

12 See below in Section 3.

13 Maritime Code, Chapter 2.

14 Act Relating to a Norwegian International Ship Register (NIS Act), LOV-1987-06-12-48. English translation: https://tinyurl.com/yy5ssdgu.

15 Maritime Code, Chapter 2 VII.

16 Ibid.

17 There are some exceptions in respect of carriage of passengers, see Act on Professional Transport by Motor Vehicle and Vessel [Professional Transport Act] LOV-2002-06-21-45, § 7. English translation: https://tinyurl.com/ yyq8eexq.

18 See below in Section 5 .

19 Ship Safety Act $\S 3$.

20 Ship Safety Act $\S 3$.

21 Act Relating to Norway's Territorial Waters and Contiguous Zone, LOV-2003-06-27-57. English translation: http://extwprlegs1.fao.org/docs/pdf/nor38370.pdf. 
Island and the contested possessions Queen Maud Land and Peter I Island), there are no ports, and in any event special rules apply. They will not be discussed here. ${ }^{22}$

\subsection{National structure for the implementation of maritime safety law}

The Norwegian Maritime Authority is the government agency responsible for ship safety and security. It reports to the Ministry of Trade, Industry and Fisheries.

The Maritime Authority has its own inspectors at a number of locations. In addition, it employs selected classification societies to perform inspections on its behalf. ${ }^{23}$ The Authority is located in Haugesund on the West Coast of Norway.

In addition to the Maritime Authority, the Norwegian National Coastal Administration, the Coast Guard, and the police play important roles in connection with ship safety and security.

\subsection{Prevention}

The Norwegian rules on the prevention of accidents at sea as related to security issues are compiled in the Ship Safety Act, enacted by the Storting (Parliament). The purpose of the Act is to provide a legal basis for more detailed statutory instruments and to give some indication of the areas to be regulated. The power of issuing statutory instruments is regularly given to the King (that is, the Government). The King (the Government) usually delegates these powers to the relevant ministry, and the ministry may delegate the powers further to, for example, the relevant agency. There are formalized procedures, including public consultations, which must be adhered to when issuing statutory instruments. ${ }^{24}$

There is a significant number of statutory instruments issued pursuant to the Ship Safety Act, even if amendments are consolidated into existing instruments. The scope of the different statutory instruments often, to some degree, corresponds with the departmental divisions of the issuing ministry or institution.

The structure of the Ship Safety Act corresponds with neither the structure of international instruments nor that of statutory instruments. Therefore, identifying how a specific provision in a convention is implemented in the Act and in statutory instruments, ascertaining whether it is not implemented, or identifying national provisions not based on international instruments is not a simple task. However, the leading commentary on the Ship Safety Act, written by the chair and the secretary of the drafting committee, is of great value in identifying these links. ${ }^{25}$

The international conventions relevant to safety and security are often amended. The International Convention for the Safety of Life at Sea (SOLAS), 1974 has been amended 172 times. In most cases, the amendments are made via tacit amendment procedures, but in some cases, a protocol requiring ratification has been thought necessary. It is beyond the

22 Statutory Instrument Relating to the Protection of the Environment and Safety in Antarctica, FOR-201304-26-412. English translation: https://tinyurl.com/y7xqmmex.

23 See https://tinyurl.com/y6dztz5w.

24 Act Relating to Procedure in Cases Concerning the Public Administration (Public Administration Act), LOV-1967-02-10, Chapter VII. English translation: https://lovdata.no/dokument/NLE/lov/1967-02-10.

25 H. Jacob Bull and T. Hernes Pettersen, Skipssikkerhetsloven - med kommentarer (Fagbokforlaget, 2010). 
scope of this chapter to document each amendment, its entry into force internationally and, for Norway, its implementation into Norwegian law by primary or secondary legislation, and the entry into force of the implementing legislation.

The structure of the following more detailed comments generally follow the common structure of this book.

Norway is a party to the SOLAS 1974, which entered into force for Norway on 25 May $1980 .{ }^{26}$ The Protocols of 1978 and 1988, as well as the amendments of 2000 and 2004, are accepted, and so are the amendments adopted by the tacit amendment procedure. ${ }^{27}$ The provisions of SOLAS are supplemented by the EU legislation included in Annex XIII of the EEA Agreement, which is continuously revised. ${ }^{28}$

A number of sections of the Ship Safety Act adds provisions in this respect, and there are dozens of statutory instruments pursuant to the Act.

The Protocol of 1978 Relating to the International Convention for the Prevention of Pollution from Ships, 1973, with annexes (MARPOL 73/78), entered into force for Norway on 2 October 1983. The Protocol of 1997, the optional annexes, and Annex IV and VI have also been accepted together with a number of amendments under the tacit amendment procedure. International rules are implemented in national law by Chapter 5 of the Ship Safety Act and statutory instruments. ${ }^{29}$

In respect of tonnage measurement, the International Convention on Tonnage Measurement of Ships, 1969 entered into force for Norway on 18 July 1982. There is also a tacit amendment of 2013. The internal basis for the rules is $\S 10$ of the Ship Safety Act with a statutory instrument pursuant to it. ${ }^{30}$

Load lines are regulated by the International Convention on Load Lines, 1966, which entered into force for Norway on 21 July 1968. In addition, the Protocol of 1988 is in force for Norway, as well as the amendments agreed by the tacit amendment procedure. There is an internal basis for the rules in a number of provisions of the Ship Safety Act with statutory instruments pursuant to them.

The Convention on the International Regulations for Preventing Collisions at Sea, 1972 (COLREG) entered into force for Norway on 15 July 1977 and is in force with a number of tacit amendments. The internal basis is $\S 14$ of the Ship Safety Act. The COLREG, with some additions for internal waters, is adopted as a statutory instrument. ${ }^{31}$

Instruments particularly concerning the human factor include SOLAS Chapter V, Safety of Navigation, and Chapter IX, Management for the Safe Operation of Ships (the International Safety Management Code). The International Convention on Standards of Training, Certification and Watchkeeping for Seafarers, 1978 came into in force for

26 The information on entry into force for Norway here and in the following is from the Registry of the Ministry of Foreign Affairs, Norges traktater https://ovdata.no/register/traktater, unless otherwise stated.

27 The information on ratifications and others with regard to IMO instruments here and in the following is, unless otherwise stated, from IMO: Status of IMO Treaties. Comprehensive Information on the Status of Multilateral Conventions and Instruments in Respect of Which the International Maritime Organization or Its SecretaryGeneral Performs Depositary or Other Functions, 5 August 2019, https://tinyurl.com/zugqm6n.

28 See: https://tinyurl.com/y635kfdr; https://www.efta.int/Legal-Text/EEA-Agreement-1327.

29 The main statutory instrument is forskrift om begrensning av forurensning (forurensningsforskriften), FOR-2004-06-01-931.

30 Forskrift om måling av skip og flyttbare innretninger FOR-2015-06-30-823.

31 Forskrift om forebygging av sammenstøt på sjøen (sjøveisreglene), FOR-1975-12-01-5. 
Norway on 28 April 1984. The International Labour Convention, 2006 has been in force since 10 February 2010, including the 2014 amendments. ${ }^{32}$ These instruments are implemented in national law by the Ship Safety Act and the Ship Labor Act with statutory instruments pursuant to them.

In respect of navigational aids and aids to navigation, this is a matter for the Norwegian National Coastal Administration. Their tasks in this regard are carried out without a framework and performance standards set out in legislation. However, for example, the standards of SOLAS Chapter V, Safety of Navigation, apply.

Ships in distress are advised to seek a place of refuge in one of the designated emergency ports. ${ }^{33}$ Crises will be handled by the Norwegian National Coastal Administration as soon as life-saving operations are completed.

Maritime security issues are addressed in SOLAS Chapter XI-2 (International Code for the Security of Ships and of Port Facilities, ISPS). The rules are implemented in national law by the Ship Safety Act $\S \S 39$ and 40 and a statutory instrument pursuant to those provisions. ${ }^{34}$

A special concern for Norwegian ship safety legislation is the Norwegian Arctic and Antarctic areas. The main instrument in this respect is the Polar Code, implemented in SOLAS and MARPOL. ${ }^{35}$

\subsection{Control}

In addition to the control of Norwegian ships, there is also Port State Control of foreign ships in Norwegian ports. Norway is a party to the Paris Memorandum of Understanding on Port State Control with a number of annexes and amendments, as well as corresponding EU legislation. ${ }^{36}$ In national law, the basis for these controls is $\S \S 44$ and 53 of the Ship Safety Act and statutory instruments. ${ }^{37}$ The provisions do not require that a ship is actually in port as long as it is subject to Norwegian jurisdiction pursuant to international law.

Vessels have to report to the authorities before arrival. The report duties include reports on hazardous and noxious cargoes and ship-to-ship transfers. All the reporting duties are compiled in one statutory instrument. ${ }^{38}$

There are half a dozen vessel traffic service (VTS) centers in Norway. They are all run by public authorities. The Harbor $\mathrm{Act}^{39} \S 17$ outlines their functions and provides a basis for statutory instruments, including duties to apply to the VTS before arrival. ${ }^{40}$ In several

32 See https://tinyurl.com/y57qnvys.

33 See locations at https://tinyurl.com/y4gqtvno.

34 Forskrift om sikkerhet, pirat- og terrorberedskapstiltak og bruk av maktmidler om bord på skip og flyttbare boreinnretninger (sikkerhetsforskriften), FOR-2004-06-22-972. See also EEA Agreement, Annex VIII, Nos. 56bb f, https://tinyurl.com/y635kfdr.

35 For a detailed discussion, see Erik Røsæg 'Norway and the Polar Code' (2018) 24 Journal of International Maritime Law 461.

36 EEA Agreement, Annex VIII, Nos. 56ba f, https://tinyurl.com/y635kfdr.

37 Forskrift om havnestatskontroll, FOR-2014-11-24-1458, and forskrift om undersøkelse, stansing og bording av utenlandsk skip ved mistanke om miljøovertredelse, FOR-2007-07-02-850.

38 Forskrift om fartøys meldeplikter etter havne- og farvannsloven, FOR-2015-12-21-1790.

39 Lov om havner og farvann (havne- og farvannsloven), LOV-2009-04-17-19.

40 Forskrift om bruk av sjøtrafikksentralenes tjenesteområde og bruk av bestemte farvann (sjøtrafikkforskriften), FOR-2015-09-23-1094. There are also application requirements in special areas for other purposes than ship 
incidents, the actions and advice of VTS operators have been questioned, but so far, criminal charges have not been brought, and no liability has been incurred. ${ }^{41}$

The Harbor Act Chapter 3 also provides the necessary legal basis for ship routing and traffic separation schemes, which are implemented in an increasing number of areas, also outside territorial borders. The provisions may require advanced notice of vessels. ${ }^{42}$ The Barents Ship Reporting System (Barents SRS) for the areas north of Norway is of particular importance. ${ }^{43}$

Inspired by regulations on petroleum activities, Norway tends to favor goal-based rules in respect of ship safety and security. In line with this, control measures tend to focus on the Safety Management System of the responsible party rather than individual safety and security measures. ${ }^{44}$

\subsection{Enforcement}

International rules generally also apply internally in Norway, and the enforcement procedures are generally the same regardless of the nationality of the ship and the persons involved. However, incarceration may be more burdensome for a foreign seafarer than for a local one, ${ }^{45}$ and this may influence the use of such a sanction in relation to foreign masters and crew members. The enforcement of Norwegian sanctions may also be impractical, particularly if the vessel cannot immediately be seized legally.

In Norwegian law, shipowners may be subject to criminal sanctions even when their company is organized as a limited company, ${ }^{46}$ and they may be considered to be under Norwegian criminal jurisdiction even if their company is a foreign one. ${ }^{47}$

Administrative sanctions, such as fees, coercive fines, detention, and denied access, are preferred over criminal sanctions. ${ }^{48}$ In addition, certificates issued by the Norwegian government can be revoked. ${ }^{49}$ These are easier procedurally than criminal sanctions, and they do not involve the police or the public prosecutor. The sanctions may be less stigmatizing than criminal sanctions, for good and for worse. However, in more serious cases, criminal sanctions are available, ${ }^{50}$ including forfeiture ${ }^{51}$ and loss of right to carry on as a master or a shipowner. ${ }^{52}$

safety and security purposes.

41 See, for example, Statens havarikommisjon for transport, Rapport sjø 2013/08, Rapport om Sjøulykke MV Full City grunnstøting ved Såstein 31. Juli 2009, 2013, www.aibn.no/Sjofart/Rapporter/2013-08.

42 Se Sjøtrafikkforskiften l.c. and Forskrift om farleder, FOR-2009-11-30-1477.

43 IMO Circular SN.1/Circ.318, 4 December 2012.

44 Ship Safety Act $\S 7$; Regulations on safety management for small cargo ships, passenger ships and fishing vessels, etc., FOR-2016-12-16-1770. English translation: https://tinyurl.com/y5ux6xwg.

45 United Nations Convention of the Law of the Sea, Art. 230 and Norwegian Supreme Court HR-1992-137-A Arisan.

46 Penal Code, LOV-2005-05-20-28, Chapter 4. English translation: https://tinyurl.com/y2umz2hu. Ship Safety Act $\$ \S 56$ and 59 .

47 See, for example, Norwegian Supreme Court HR-1996-55-A. A vessel can be detained until the owners have paid their fines, see Ship Safety Act $\S 57$ and 70 .

48 Ship Safety Act, Chapter 8 and 9.

49 Ship Safety Act $\S 51$.

50 Ship Safety Act, Chapter 10.

51 Penal Code, Chapter 13.

52 Penal Code, Chapter 10. 
These sanctions are based on the Ship Safety Act and the Criminal Code. Investigations are carried out by the Norwegian Maritime Authority and the police. In addition, there are rules on the investigation of marine accidents in Maritime Code 1994 Chapter 18.

These inquiries are carried out by the Accident Investigation Board Norway after a serious accident involving Norway, as well as incidents involving foreign ships. The purpose of the investigation is to determine the cause of the incident and not to clarify whether there is a basis for criminal sanctions, administrative sanctions, or civil liabilities. However, the investigation report is made public.

\subsection{Liability}

Norway is a State Party to the latest version of all liability conventions, except the Nairobi International Convention on the Removal of Wrecks, 2007 (Nairobi WRC 2007). Accession is under way, and legislation is implemented (but not in force) in Chapter 10a of the Maritime Code. Meanwhile, there is an agreement that Norwegian ships can obtain the insurance certificates required under the Convention from Danish authorities. ${ }^{53}$ In national law, there are currently provisions in respect of wreck removal in the Pollution Control Act $1980 .{ }^{54}$ Norway has made a reservation to the Convention on Limitation of Liability for Maritime Claims, 1976 (LLMC 1976), as amended, so that it does not apply to certain wreck removal claims. There is a special national limitation fund for wreck removal in $\S \S 172 \mathrm{a}$ and $175 \mathrm{a}$ of the Maritime Code. In any event, the limitation rules in Norway are held not to mitigate the obligations of the shipowner to remove wrecks, but only concern the financial reimbursement to others. ${ }^{55}$

In respect of oil pollution, Norway is a State Party to the latest versions of the international system for shipowner liability supplemented by international compensation funds financed by levies on cargo discharges:

- International Convention on Civil Liability for Oil Pollution Damage, 1992 (CLC 1992), in force for Norway on 30 May 1996

- International Convention on the Establishment of an International Fund for Compensation for Oil Pollution Damage, 1992 (FUND 1992), in force for Norway on 30 May 1996

- Protocol of 2003 to the International Convention on the Establishment of an International Fund for Compensation for Oil Pollution Damage, 1992 (FUND PROT 2003), in force for Norway on 3 March 2005.

These rules are implanted in Chapter 10 II of the Maritime Code with related statutory instruments. There are also supplementary national rules for oil pollution there, in the Pollution Control Act, and in the Petroleum Act. ${ }^{56}$

53 See https://tinyurl.com/yyyj6b8b.

54 Act Concerning Protection Against Pollution and Concerning Waste (Pollution Control Act), LOV-198103-13-6. English translation: https://tinyurl.com/hywz7ph.

55 Norwegian Supreme Court HR-2017-331-A Server.

56 Act Relating to Petroleum Activities (Petroleum Act), LOV-1996-11-29-72. English translation: https:// tinyurl.com/y3o946wb. 
The International Convention on Civil Liability for Bunker Oil Pollution Damage, 2001 (BUNKERS 2001) entered into force for Norway on 21 November 2008. It is implemented by Chapter $10 \mathrm{I}$ of the Maritime Code.

The Protocol of 2010 to Amend the International Convention on Liability and Compensation for Damage in Connection with the Carriage of Hazardous and Noxious Substances by Sea, 1996 (HNS 2010) has not entered into force. The implementing legislation is ready in Chapter 11 of the Maritime Code but will not be entered into force before the international instrument enters into force.

The amendments of 2014 to the Maritime Labour Convention regarding financial security abandonment or the personal injury or death of a seafarer entered into force 18 January $2017^{57}$ and have been implemented by an amendment to $\S 4-7$ of the Ship Labor Act. These provisions partially overlap provisions in national $\mathrm{law}^{58}$ and EU legislation. ${ }^{59}$

\subsection{Concluding remarks and recommendations}

As suggested in the introduction, the general impression is that Norway is serious in complying with international standards for ship safety and security, as well as in adhering to its obligations. There are few national rules not based on international law, and there are few conflicts concerning maritime safety and security in terms of substance, implementation failure, or conflicts between national and international rules.

The Norwegian Government seeks to play an active role in the IMO and other international fora. One basis for the engagement is the 2014 safety analysis of Norwegian Shipping Maritime Safety in Norwegian Waters - Today and Towards $2040 .{ }^{60}$ The engagement has been followed up by regular reports to the Storting (Parliament). In 2019, both an updated ocean strategy ${ }^{61}$ and a white paper on maritime safety ${ }^{62}$ were submitted.

57 https://tinyurl.com/yxe8bwuq.

58 Act Relating to Industrial Injury Insurance, LOV-1989-06-16-65. English translation: https://tinyurl.com/ $\mathrm{y} 33 \mathrm{sc} 74 \mathrm{x}$.

59 EEA Agreement, Art. 29.

$60 \mathrm{https}: / /$ tinyurl.com/yybrx7fs.

$61 \mathrm{https}: / /$ tinyurl.com/y3nh4uko.

62 Meld. St. 30 (2018-2019) Samhandling for betre sjøtryggleik https://tinyurl.com/y2ce782c. 


\title{
Taking maritime safety seriously
}

\author{
The Polish perspective
}

Justyna Nawrot ${ }^{1}$ and Zuzanna Peptowska-Dąbrowska ${ }^{2}$

\subsection{Introduction}

Polish maritime law does not have long-lasting traditions because, despite the efforts of the Polish monarchs to maintain access to the Baltic Sea, the Polish raison d'état was associated historically with the development of agriculture. However, since Poland regained independence in 1918, maritime safety issues have been treated with great care. The regulation of the President of the Republic of Poland of November 24, 1930, on the safety of maritime vessels was the first act of statutory rank which dealt with the issue of maritime safety. ${ }^{3}$ That regulation was part of a legislative package aimed at rebuilding Poland's maritime identity and strengthening the administrative ties of the coast, which was attached to Poland in 1920 as a consequence of the Treaty of Versailles. Due to the adoption of such goals, the inter-war maritime legislation mainly boiled down to the issue of strengthening maritime administration. ${ }^{4}$ In post-war times, throughout the entire period of the People's Republic of Poland, no coherent regulation of maritime safety was adopted. This subject was regulated by executive acts of maritime administration authorities adopted in the period from 1963 to $2000 .^{5}$ The basis for their enactment was formulated by the first Polish Maritime Code adopted in 1961. A large number of those acts and their diversified scope undoubtedly led to undesirable effects. Therefore, the need to develop a coherent and comprehensive law on safety was repeatedly expressed in the doctrine. The adoption of the first Polish statute on maritime safety in the post-war period ${ }^{6}$ coincided with the adoption of the new Maritime Code in 2001, which was predominantly of a private law nature. ${ }^{7}$

1 Research conducted by J. Nawrot was funded by the National Science Centre, Poland, under the contract UMO-2016/23/D/HS5/02447 Maritime Safety Legal System.

2 Research conducted by Z. Pepłowska-Dąbrowska was funded by the National Science Centre, Poland, under the contract UMO - 2016/22/E/HS5/00050 Problems of contemporary maritime codes.

3 Consolidated text in Journal of Laws 1938 No. 46, item 367.

4 Private legal issues related to shipping were regulated by the Act of 1 of August, 1919, maintaining German legislation in the areas of the former Prussian Partition (Journal of Laws 1919 No. 64, item 385).

5 M. Koziński, 'Ustawa o bezpieczeństwie morskim - stan de lege lata i postulaty de lege ferenda', (2012) XXVIII Prawo Morskie 53 et al.

6 Journal of Laws 2000 No. 109, item 1156.

7 For more, see: M. Dragun-Gernter, 'Polskie ustawodawstwo morskie a prawo międzynarodowe' in E. Kustra (ed.), Przemiany polskiego prawa (Toruń, 2002) vol. II, p. 133. 
Thus, in the current Maritime Code, unlike the first Maritime Code of 1961, there is no regulation on maritime safety. At the same time, regulation on maritime safety has greatly expanded and the initial assumption that a single 'maritime safety law' will be adopted has been abandoned. ${ }^{8}$ The Maritime Safety Act adopted in 2000 was, however, of a framework nature. In 2011, it was replaced by a more extensive regulation currently in force - the Maritime Safety Act. ${ }^{9}$

For years, Poland has been a party to the vast majority of international maritime conventions and all of them have been traditionally associated with maritime safety as it is broadly understood, comprising four essential elements: navigational safety, constructional safety, marine environment protection and the human factor. ${ }^{10}$

Pursuant to the Constitution of the Republic of Poland of April 2, 1997, the ratified international agreements constitute a part of the universally binding law in Poland. Moreover, an international agreement ratified upon a prior consent granted by a Polish statute takes precedence over Polish statutes in case of collision. As a consequence, such ratified international agreements have priority over Polish laws in case of possible discrepancies. ${ }^{11}$ After correct promulgation, they become part of Polish law and are to be applied directly (unless their application depends on the enactment of a statute). ${ }^{12}$ Notwithstanding the aforementioned constitutional regulation, the Polish system lacks a direct reference to the tacit acceptance procedure, which is characteristic of the IMO Convention. ${ }^{13}$ The wording used in the Polish legal acts referring to the tacit acceptance method varies. In order to avoid unnecessary connotation with the ratification procedure (which is the ordinary procedure provided for in Polish law for international legal instruments) and at the same time to ensure proper publication of amendments introduced under the tacit acceptance procedure, the Maritime Code uses the term 'public disclosure in an appropriate manner' (e.g. Article 97 of the Maritime Code). On the other hand, in the Maritime Safety Act of 2011, the term 'announcement of amendments' was adopted (Article 2 of the Maritime Safety Act of 2011). Lack of uniform solutions results in either no publications or significant delays in the publication of the current IMO texts in Polish.

Ratified conventions concerning maritime safety have been introduced into Polish law in numerous acts, often in the form of executive acts issued by the minister competent

8 J. Lopuski, 'Prawo morskie w dobie reformy ustawodawstwa' (1996) 3 Kwartalnik Prawa Prywatnego 566.

9 Journal of Laws 2011 No. 228, item 1368.

10 The International Convention for the Safety of Life at Sea, signed in London on November 1, 1974 (hereinafter: SOLAS), the International Convention on Load Lines, signed in London on April 5, 1966 (hereinafter LL), the International Regulations for Preventing Collisions at Sea (hereinafter COLREG), the International Convention for Safe Containers, signed in Geneva on December 2, 1972 (hereinafter CSC), the International Convention on Standards of Training, Certification and Watchkeeping, signed in London on July 7, 1978 (hereinafter STCW), the International Convention on Maritime Search and Rescue signed in Hamburg on April 24, 1979 (hereinafter SAR), the Convention for the Suppression of Unlawful Acts against the Safety of Maritime Navigation signed in Rome on March 10, 1988 (hereinafter SUA), the Maritime Labor Convention of February 23, 2006 (hereinafter MLC 2006).

11 In accordance with Arts. 87 and 91 of the Constitution of the Republic of Poland, Journal of Laws 1997 No. 78, item 483 .

12 J. Łopuski, The new Polish Maritime Code, in: Maritime Law in the second half of the 20th century. Selected articles (Wydawnictwo Naukowe UMK, Torun 2008), p. 90; J. Nawrot., Z. Pepłowska Dąbrowska, 'Maritime legislation in Poland and the Proposals of the Codification Commission for Maritime Law' (2017) 23 Journal of International Maritime Law 220-227.

13 See D. Lost-Siemińska, ch.1 above. 
for maritime affairs. As stated earlier, the Maritime Safety Act of 2011 is of fundamental importance. The Act is of a framework nature and implements numerous acts of international law. Adoption of the reference mechanism allows for flexible application of the convention without the need for constant amendment of the national law. This solution should be considered as correct, given the frequent amendments introduced into international conventions, usually within the framework of the tacit acceptance procedure. The Act, accompanied by executive legislation, constitutes the body of maritime safety law in Poland. At the same time, it should be emphasized that the issues related to the concept of maritime security have been regulated separately in the Shipping and Port Security Act, which implements the ISPS code. ${ }^{14}$ Therefore, the matter of the SOLAS was divided in the Polish legal order according to the source of the threat criterion. Nevertheless, the broad concept of safety at sea in Poland undoubtedly consists of elements of both maritime safety and security, which reflects the international concept. ${ }^{15}$ The so-called human factor is also an essential element of maritime safety. This issue is regulated by the ISM Code, which has been part of the SOLAS since 1988, as well the STCW, whose main goal was to standardize the principles of training seafarers globally, helping to reduce the number of marine casualties and disasters caused by human error. The MLC 2006, ratified by Poland in 2011 with its social output, should also be considered as an important factor enhancing safety at sea. Both of the aforementioned acts (the ISM Code and the STCW) were introduced by referral to the Polish Maritime Safety Act of 2011.

Despite some kind of division of the safety matter between multiple regulations in the Polish legal system, the Maritime Safety Act of 2011 remains the linking legal instrument.

\subsection{National structure for the implementation of maritime safety and security law}

In Poland, the minister responsible for the maritime economy is obliged to implement maritime safety and security standards. Currently, it is the responsibility of the Minister of Maritime Economy and Inland Navigation. ${ }^{16}$ The legal framework for the functioning of the Polish maritime administration is set out in the Polish Maritime Zones and Administration Act adopted in 1991). ${ }^{17}$ The Polish maritime administration has two levels. The central authority is represented by the minister competent for the maritime economy, while directors of maritime offices in Gdynia and Szczecin constitute the local level. ${ }^{18}$

14 Ustawa o ochronie żeglugi portów morskich, Journal of Laws 2008 No. 171, item 1055. It is also important to note that in Polish there is no such clear and intuitive distinction between 'safety' and 'security' as in English. The Maritime Safety Act of 2011 uses the Polish term 'bezpieczeństwo żeglugi', while the second of these acts uses the term 'ochrona żeglugi'. It seems that these two terms reflect precisely the Anglo-Saxon division into safety and security used in international acts.

15 Analysis of the international legal order and EU maritime law shows that the concept of maritime safety rather refers to standards concerning the 'internal' rules (e.g. regulations concerning the construction of ships or their equipment), while standards regarding security refer to principles aiming at the reduction of potential external sources of risks or threats. In relation to the former, the regulations contained in the SOLAS and MARPOL as well as relevant secondary law acts introducing them into the EU legal order are of crucial importance. In the field of international law, the latter include regulations on combating piracy and terrorism (SUA, ISPS Code). In the area of EU law, they include regulations on freedom, security and justice.

16 This office was established in 2015 and its department includes four branches of government administration: maritime economy, water management, fisheries and inland navigation.

17 Ustawa o obszarach morskich RP i administracji morskiej, Journal of Laws 1991 No. 32, item 131.

18 In April 2020, the third of the existing maritime offices in Słupsk was abolished. From $1^{\text {st }}$ of April, 2020, 
Additionally, maritime chambers - special quasi-judicial bodies - have jurisdiction over the professional responsibility of seafarers and maritime pilots. However, these quasijudicial bodies operating at the regional courts in Gdańsk and Szczecin should not be considered as a substitute for maritime courts. Generally, maritime matters are heard by common courts. The chambers, operating pursuant to the Act of $1961,{ }^{19}$ have retained to this day individual competences in the disciplinary proceedings of seafarers and pilots, but they operate alongside the State Marine Accident Investigation Commission (hereinafter SMAIC). To reduce duplication of their activities, the chambers' jurisdiction was limited to matters that would be reported at the request of the interested entities. The latter aims at explaining the causes of an accident in order to formulate appropriate recommendations for the future which will minimize the risk of similar accidents. However, SMAIC does not prejudge any issue of criminal or civil liability. Regardless of the EU regulation concerning investigation of the causes of maritime accidents, Polish law has contained provisions on severe professional responsibility of seafarers since the early 1960s. As a result, Polish seafarers display a high level of both knowledge and skills as well as diligence in performing their professional duties.

It is also worth mentioning that the functioning of marine chambers was the subject of a judgment of the European Court of Human Rights in 2005. ${ }^{20}$ The ECHR found that Poland had violated Article 6 of the Convention on Human Rights and Fundamental Freedoms by not providing an opportunity to appeal against the decisions of maritime chambers to a common court of law. As a consequence of the ECHR's judgment, the judicial control over the decisions of marine chambers was introduced into Polish law.

Maritime chambers also keep a register of vessels, which includes information on the ships flying the Polish flag. Notwithstanding the ship register run by the maritime chambers, maritime offices also keep a so-called 'administrative' register of ships which are not subject to the obligation of being entered in the register of vessels. ${ }^{21}$ Concluding, the maritime chambers should not be considered part of the maritime administration and their quasi-judicial functions and nature also allow them to deal with the real rights on ships.

Furthermore, under the Maritime Safety Act of 2011, it is possible for the proper minister to entrust the tasks of maritime administration bodies to a recognized classification society. In Poland, the classification society is the Polish Register of Shipping. Additionally, Polish law provides for the possibility of entrusting recognized foreign classification societies with the application of the said rights.

In the structure of the Polish maritime administration, the competent minister is responsible for preparing the implementation of international and EU standards and regulations within the national law. Inspection bodies, however, are placed within the structure of local maritime administration bodies, i.e. maritime offices. Three types of inspections were identified: maritime control, Flag State Control and Port State Control.

the scope of its activity was taken over by the other two maritime offices. Ordinance on the abolition of the Maritime Office in Słupsk, dated $15^{\text {th }}$ January, 2020, Journal of Laws 2020 item 91. It should be considered as a part of further reform of the Polish maritime authorities.

19 Ustawa o izbach morskich, Journal of Laws 1961 No. 51, item 320.

20 Case of Brudnicka and Others v. Poland, 03.06.2005.

21 Ships subject to the obligation to enter in the ship's register are specified in the Maritime Code. According to the latest proposal of Maritime Code's amendments (dated $17^{\text {th }}$ August 2020), "administrative" register is planned to be ceased. 
Local maritime administration authorities are also responsible - after appropriate prior control - for issuing certificates of ships required under international conventions to which Poland is a party. They issue ship safety and financial security certificates. Additionally, they have other obligations not directly related to ensuring maritime safety. Under the Harbours and Marinas Act, ${ }^{22}$ directors of maritime offices can manage small ports that are not crucial to the national economy. As a consequence, a strong connection between Polish ports and maritime administration can be observed. Moreover, the directors of maritime offices are competent to handle complaints of port users arising from the application of Regulation 2017/352 by the managing body of the port or other entity that provides port services $^{23}$ as well as complaints of passengers against carriers or terminal operators arising from the application of Regulation 1177/2010. ${ }^{24}$ Thus, in addition to traditional obligations related to the safety of navigation and ports, regional maritime administration bodies fulfil a number of other obligations. The scale of these obligations has significantly increased in recent years.

\subsection{Prevention}

Following the concept adopted by the Maritime Law Codification Commission relating to the private character of the Maritime Code of 2001, the matter concerning maritime safety was regulated in a separate Maritime Safety Act in 2000 repealed by the new Maritime Safety Act in 2011. The Maritime Safety Act of 2011 contains the regulatory framework regarding preventive standards.

In the preceding Maritime Safety Act of 2000, contents similar to that of SOLAS was adopted, ${ }^{25}$ taking into account the provisions of the other most crucial maritime safety conventions to which Poland is a party. As a result, the backbone of the Act was composed by Chapters 2-5 regulating the following issues: ship construction, installations and equipment, qualification of the crew and proper manning, navigational safety as well as search and rescue service. The Act incorporated the provisions of the conventions to which Poland is a party, supplementing them with delegations to introduce executive acts for the competent minister and directors of maritime offices.

Relatively soon after the adoption of the first Maritime Safety Act in 2000 in Poland, it became clear that it required revision. The most urgent reason was the need to implement numerous EU laws. Poland became a member of the European Union on May 1st, 2004. Work on the content of the new law was completed with the adoption of the new Maritime Safety Act in 2011. ${ }^{26}$ This Act is more extensive than its predecessor, although its internal systematics is based on the previously adopted solutions. The Act of 2011 concerns ship

22 Art. 25 of Ustawa o portach i przystaniach morskich adopted on 20 December, 1996, Journal of Laws 1997 No. 9, item 44.

23 Regulation (EU) 2017/352 of the European Parliament and of the Council of 15 February, 2017 establishing a framework for the provision of port services and common rules on the financial transparency of ports, OJ L 57, 3.3.2017, p. 1 .

24 Regulation (EU) No 1177/2010 of the European Parliament and of the Council of 24 November, 2010 concerning the rights of passengers when travelling by sea and inland waterways and amending Regulation (EC) No 2006/2004, OJ L 334, 17.12.2010, p. 1.

25 Journal of Laws 1984 No. 61, item 318.

26 Consolidated text in Journal of Laws 2016 item 281. 
construction, installations and equipment, qualification of the crew and proper manning, inspections, navigational safety as well as search and rescue service.

The Maritime Safety Act of 2011 applies to vessels flying the Polish flag. It is also applicable to vessels flying foreign flags located in Polish internal waters or the territorial sea in relation to Port State Control and navigational safety as well as to ro-ro passenger ships and high-speed passenger craft in regular service, regardless of their flag in relation to an inspection provided for them under Directive (EU) 2017/2110. ${ }^{27}$ Foreign vessels found in other Polish maritime zones are subject to the provisions of the Act only within the scope of its provisions on vessel traffic monitoring and information.

According to the Maritime Safety Act of 2011, a ship flying the Polish flag is not allowed to engage in navigation if it does not meet the safety requirements in terms of its construction, installations and equipment as well as living and working conditions on the ship specified in those international agreements to which Poland is a party, in the regulations of the Marine Equipment Act and in the additional provisions of the Maritime Safety Act of 2011. The ship's operator is also obliged to meet the requirements set out in the MLC. Non-convention vessels, for which national requirements have been established in a separate executive act, are exempted from the obligation to meet the requirements specified in the Maritime Safety Act of $2011 .^{28}$ Since 2015, the Act's provisions have also been partly applicable to fixed platforms. ${ }^{29}$ It incorporates multiple international conventions: LL, COLREG, MARPOL, TONNAGE 1969, AFS Convention 2001, MLC, STCW, STCW-F, BWM 2004 as well as EU legal acts. ${ }^{30}$

The Act also allows the proper minister to increase requirements for vessels subject to international agreements in the field of ship construction, its installations and equipment in relation to the requirements set out by international conventions ratified by Poland. In addition, the minister is allowed to exclude the vessels subject to these international agreements from specific provisions of these agreements. So far, the minister has not taken advantage of this possibility. The Act also reserves the possibility of exemption from the requirements set out in Chapter V of the SOLAS in relation to ships whose construction does not allow compliance with the convention's requirements or when it is justified due to the area or navigation conditions, provided that the level of safety is not reduced. Such a decision is taken by the director of a maritime office.

27 Directive (EU) 2017/2110 of the European Parliament and of the Council of 15 November 2017 on a system of inspections for the safe operation of ro-ro passenger ships and high-speed passenger craft in regular service and amending Directive 2009/16/EC and repealing Council Directive 1999/35/EC, OJ L 315, 30.11.2017, p. 61-77.

28 They must meet the requirements set out in the following executive act: Regulation of 2014 on requirements for the ship construction, installations, and equipment for ships not covered by the international agreement, Journal of Laws 2014, No. 1335.

29 A floating platform is considered a ship while in a move. Warships, Border Guard and Police vessels are basically excluded from the scope of the Maritime Safety Act of 2011. Furthermore, the rules for controlling and monitoring ship traffic are to be applied to special State purposes vessels and small vessels.

30 Directives: 92/29, 96/98, 97/70, 98/41, 99/35, 2002/59, 2003/25, 2008/106, 2009/15, 2009/16, 2009/17, 2009/21, 2009/42, 2009/45, 2010/36, 2010/65, 2011/15, 2017/2109, 2017/2110. 
Moreover, Poland implemented Directive (EU) 2014/90 on marine equipment ${ }^{31}$ in the Marine Equipment Act. ${ }^{32}$ According to this Act, international regulations are understood not only as the provisions of international conventions and EU standards but also as research standards, including soft law, technical standards, etc.

Furthermore, the Maritime Safety Act of 2011 defines the scope and procedures for issuing certificates required for ships flying the Polish flag and a list of certificates required for foreign ships entering Polish internal waters or the territorial sea. Certificates related to ship safety may be issued, after inspection, by a recognized classification society, which has been authorized to do so by the minister competent for maritime economy.

On the other hand, the Polish law does not specify in detail the issue of safe manning requirements. According to Articles 61 and 62 of the Maritime Safety Act of 2011, a ship is not allowed to operate if it is not properly manned. At the same time, the Maritime Safety Act of 2011 refers to the safe manning requirements set out in Chapter V of SOLAS as well as in STCW, STWC - F and MLC 2006 in relation to proper manning, without its own understanding of the term. As a consequence, the Polish requirements allow for a flexible interpretation of the 'safe manning' term, which follows the interpretation agreed internationally. It should also be noticed that, according to Article 80 of the Maritime Safety Act of 2011 and the Regulation on proper manning, ${ }^{33}$ the director of a maritime office has the right to reduce or increase standards, taking into account different circumstances, for example, the level of a ship's automatization, when the composition of the crew is being determined. Such possibility clearly refers to SOLAS.

The Maritime Safety Act of 2011 contains an extensive regulation regarding the ISM Code and possession of the maritime safety certificate is one of the premises of the initial inspection carried out in relation to Polish ships.

Navigational safety regulations are one of the critical elements of the Act. Its entire, extensive Chapter $\mathrm{V}$ is devoted to regulations regarding navigational safety. The bodies competent to exercise control in this area are directors of maritime offices, who establish local regulations for navigation in Polish internal waters. On the other hand, navigational safety in the territorial sea is regulated, in principle, in the Polish Maritime Zones and Administration Act of $1991 .^{34}$

Polish law meets the international and EU requirements in the field of places of refuge. The legal bases for places of refuge are included in Article 94 of the Maritime Safety Act of 2011 supplemented by the executive act. ${ }^{35}$ The decision to grant a place of refuge to a ship lies with the local maritime administration authorities, competent for the place of the ship's location. However, this means that, in Poland, there is basically no single national plan for granting places of refuge and such plans are of a regional nature. Demand for changes in this area has been present in the Polish doctrine for many years. ${ }^{36}$ This problem

31 Directive 2014/90/EU of the European Parliament and of the Council of 23 July 2014 on marine equipment and repealing Council Directive 96/98/EC, OJ L 257, 28.8.2014, p. 146-185.

32 Ustawa o wyposażeniu morskim, dated 2nd December, 2016, consolidated text in Journal of Laws 2019 item 255 .

33 Regulation on proper manning on ship dated on 9th December, 2015, Journal of Laws 2015 item 2104.

34 See more in section 4 of this chapter.

35 Journal of Laws 2012 item 575.

36 M. Koziński, 'Miejsce schronienia (place of refuge)' (2013) XXIX Gdańskie Studia Prawnicze 103-114. 
was partially addressed with the adoption of the regulation regarding the organization of the efforts to combat threats and pollution at sea by the Council of Ministers. ${ }^{37}$ However, this act is not strictly dedicated to the institution of places of refuge, nor does this concept appear in its text. It concerns the organization and coordination of maritime administration bodies and SAR services in the event of a threat to or pollution of the Polish maritime areas and obliges SAR services to develop a national plan to combat threats and pollution. The regulation was issued on the basis of a delegation contained in the Act for the Prevention of Pollution from Ships, ${ }^{38}$ which essentially implements the provisions of the MARPOL and relevant EU legislation in the field of the protection of the marine environment. Thus, since the issue of places of refuge is regulated in the Maritime Safety Act of 2011 and not in the Act for the Prevention of Pollution from Ships, it still does not exhaust the requirement of comprehensive and transparent regulation regarding places of refuge. However, it should be noted that the said regulation does refer, although not explicitly, to the obligation to establish a maritime assistance service (MAS), introduced by the IMO.

\subsection{System of control and surveillance}

The primary role assigned to maritime surveillance in new EU maritime policy is the safe use of the sea (safety) and securing the EU's maritime borders (security) as well as, more broadly, the entire European continent. Maritime surveillance is generally carried out by national authorities and is a primary tool used by States to exercise superior authority over maritime areas. A great advantage of the EU regulations is the ability to combine the results of national supervisory and monitoring activities in order to provide a regional picture of the situation at sea. ${ }^{39}$

In the said field, two legal acts are crucial in Polish law: the Polish Maritime Zones and Administration Act of 1991 and the Maritime Safety Act of 2011. The former defines the structure of maritime administration, including the structure of local maritime administration bodies with their scope of responsibilities and competences. Maritime offices consist of the following organizational units: maritime inspection, Flag State Control, Port State Control, VTS service, Security Office and local harbour masters' offices. Essentially, they are assigned with a leading role in the supervision of maritime safety. The latter act extensively regulates and clarifies control tasks and surveillance of maritime safety issues. Ship traffic on the territorial sea is subject to the COLREG regime and the Polish maritime zones regulations, determined in accordance with the provisions of the UNCLOS in the Polish Maritime Zones and Administration Act of 1991. In contrast, the regulations regarding ship traffic on internal waters and ports are regulated in the ordinances of directors of maritime offices. The Act refers extensively to Chapter V of the SOLAS Convention as well as international regulations and documents, including the obligation to use IAMSAR.

37 Journal of Laws 2017 item 1631.

38 'Ustawa o zapobieganiu zanieczyszczania morza przez statki' of 16th March, 1995, Journal of Laws 2019 item 2302 .

39 It follows from Directive 2002/59/EC of the European Parliament and of the Council of 27 June 2002 establishing a Community vessel traffic monitoring and information system and repealing Council Directive 93/75/EEC, OJ L 208, 5.8.2002, p. 10-27. The directive forms a basis for building Europe-wide SafeSeaNet. 
Moreover, the provisions on vessel traffic service reflect the provisions arising from the SOLAS and EU directives. VTS services are located within the structure of maritime offices and are subject to the directors of maritime offices in Gdynia and Szczecin. The Maritime Safety Act of 2011 does not define the concept of traffic service; however, it understands the VTS tasks quite broadly. They relate not only to ship traffic monitoring but also to providing relevant information, maintaining contact with ships, collecting and analysing information about the situation at sea, providing maritime service assistance, disseminating information about the meteorological and hydrographic situation and providing navigational warnings. Moreover, VTS functions as a Central Contact Point according to the ISPS code. The shipmasters of the vessels in the Polish maritime zones are required to comply with the orders, warnings, instructions and recommendations of the VTS Service. Failure to comply with them will result in a financial penalty imposed on the ship's master. ${ }^{40}$

VTS is also an essential component of the SafeSeaNet provided for in Article 91 of the Maritime Safety Act of 2011. That Act also established the function of the National SafeSeaNet System Coordinator, who was given the status of the National Competent Authority (NCA) under the Interface and Functionalities Control Document (IFCD). The National Coordinator is supported by the local maritime authorities in Gdynia and Szczecin. The Polish SafeSeaNet system contains two technical subsystems. The first one is responsible for the monitoring of maritime traffic (AIS, LRIT and data from radars). The second subsystem is designed to transfer information and includes two elements: the Polish Harbours Information \& Control System (PHICS) and the Maritime Safety and Security Exchange Information System (SWIBŻ). ${ }^{41}$ Basically, the local maritime authorities are also the competent authority to whom the required reporting information and documents should be submitted by the shipmaster or any other person assigned by the ship operator. SWIBŻ was designed in 2003, long before the approval of Directive 2010/65 and is one of the oldest such systems in the EU. At the beginning, it was designed only for the local Maritime Authority in Gdynia, but now this is a national system used to distribute information between various Polish authorities, including other local maritime authorities in Poland, the Polish Navy, SAR, Meteorology Institute, Hydrographical Office of the Polish Navy, the Polish Coast Guard, the National Emergency Centre, the Customs Office, the Police as well as port managements, European Agency of Maritime Safety (EMSA) and NATO's Allied Maritime Command in Northwood, UK. The main function of SWIBŻ is gathering, classifying and distributing maritime safety information and important security information.

PHICS was launched in 2004 in the Maritime Office in Szczecin and since then it has served as a system of basic information exchange about the cargo and passengers on the ships entering or departing from the Polish ports. PHICS has also become a Polish single window, fulfilling the requirement imposed in Article 5 of Directive 2010/65. As a single window, PHICS is a system through which the shipmaster or the ship operator can fulfil all the reporting obligations in relation to the State authorities and other entities (the port management, for example). After completing the required formalities at PHICS, all the interested entities are able to get access to the collected data as participants of the

40 Art. 128 of the Maritime Safety Act of 2011.

41 System Wymiany Informacji Bezpieczeństwa Żeglugi. 
PHICS system. This system meets the State obligations under both EU law ${ }^{42}$ and the FAL Convention. ${ }^{43}$

In the scope of establishing ship routing systems in accordance with Article 97 of the Maritime Safety Act of 2011, the Minister competent for maritime economy cooperates with the relevant IMO and EU bodies. There are several ship traffic separation zones in Poland, generally in areas with approach fairway to ports in Gdańsk, Świnoujście and Szczecin $^{44}$ and recently also in the Polish economic zone - TSS Ławica Stupska. ${ }^{45}$

Poland is also a member of the Paris MOU. Port State inspections are carried out by the competent units - Port State Control (PSC) operating within the structures of the local maritime authorities. PSC performs tasks in this respect in accordance with the procedures developed by the Paris MoU based on IMO Resolution A.787 (19) (as amended) and EU Directive 2009/16. The Polish PSC enters the data and information obtained during the inspection into the THETIS ${ }^{46}$ database containing information on Port State inspections carried out in the Paris MoU region. Furthermore, to fulfil the obligations additional to those arising from the Paris MoU, the THETIS EU information database has been in operation since December 2019. This is an information system developed and operated by EMSA which supports the implementation of PSC and FSC tasks, in particular in the field of the inspection of ro-ro passenger ships and high-speed passenger ships. ${ }^{47}$ As a consequence, passenger and ro-ro ships are also inspected in accordance with the inspection schedule set out in Directive 2017/2110.48

A few years ago, the fisheries policy became the responsibility of the minister competent for maritime affairs. Earlier, it had been the responsibility of the Ministry of Agriculture for many years. Thus, the sea fisheries policy and sea fisheries administration ${ }^{49}$ are concentrated in the same ministry together with the maritime issues. Regardless of the register of seagoing vessels, a register of fishing vessels is also kept. ${ }^{50}$ Unlike the register of ships flying the Polish flag, it is run directly by the ministry.

\subsection{Enforcement}

As for making international maritime safety standards binding in Polish law, the Polish legal system operates in a correct and relatively open manner. The Polish legislator decided to adopt the method of incorporating international conventions into the Polish legal order. ${ }^{51}$ In case of doubt, the authentic text of the Convention shall prevail.

42 This is essentially Directive 2002/59/EC establishing the maritime information exchange system known as 'SafeSeaNet' (SSN) as well as Directive 2010/65/EU of the European Parliament and of the Council of 20 October 2010 on reporting formalities for ships arriving in and/or departing from ports of the Member States, OJ L 283, 29.10.2010, p. 1-10.

43 Journal of Laws 2019 item 384.

44 Traffic Separation Schemes operate on the Gdańsk Bay, the Pomeranian Bay, and the Szczecin Lagoon.

45 Approved by MSC in 2010, taking into account the environmental fragility of the mentioned area.

46 See supra 99, chapter 2.

47 Art. 5 point 26a of the Maritime Safety Act of 2011.

48 Directive (EU) 2017/2110, see supra 27.

49 It should be noted, however, that local fisheries administration bodies - district sea fishery inspectors operate separately from local maritime administration bodies.

50 It is a modern register and, unlike the register of sea-going vessels, it is kept in electronic form.

51 See more in section 6 of this chapter. 
Therefore, this view presented by the doctrine of Polish maritime law assumes the need for comparative legal research, which significantly strengthens the idea of the unification of maritime law. ${ }^{52}$

The Maritime Code of 2001 remains the core of Polish maritime law. As part of a significant reform of the maritime law initiated with the change of the Polish system at the end of the 1980s and at the beginning of the 1990s, the maritime code in force since 1961 was amended by incorporating Athens Convention 1974, LLMC 1976, CLC 1969 and FUND 1971. The reform of Polish public maritime law began with the adoption of the Maritime Zones and Maritime Administration Act in 1991, which adapted Polish legal order to the principles arising from the UNCLOS. Exclusive economic zone and contiguous zone ${ }^{53}$ were also established as ones of the Polish maritime zones. The regulations adopted in the Act mentioned above are basic principles, while the specification of the issues of protection of the marine environment and maritime safety was made at a later stage by adopting the Act for the Prevention of Pollution from Ships in 1995 and the first Maritime Safety Act in 2000. Together with the adoption of the Act for the Prevention of Pollution from Ships the following conventions were incorporated into Polish law: MARPOL Convention 1972, Intervention Convention 1969 with the Protocol from 1973 and the first Convention on the Protection of the Marine Environment of the Baltic Sea Area 1974. The reform of Polish maritime law was completed by the adoption of the new Maritime Code in 2001.

The currently applicable Maritime Code does not include the provision of the previous maritime code of 1961 regarding the priority of international agreements. Such a norm is unnecessary considering the wording of the Polish Constitution. Its Article 88, in conjunction with Article 18 of the Act on International Treaties, ${ }^{54}$ requires international treaties to be adequately published in an official Journal of Laws for them to come into force. It seems that the need to ensure the priority of international conventions is met with the updating formula adopted selectively for some conventions ${ }^{55}$ and also used in non-code maritime safety regulations (Article 1 of the Act for the Prevention of Pollution from Ships of 1995 and Article 2 of the Maritime Safety Act of 2011). ${ }^{56}$ Unfortunately, the amendments to most maritime conventions are published in Polish with many years of delays. As a consequence, they may be found as not binding for private entities. This is one of the weaknesses of Polish maritime law.

Polish law includes criminal as well as administrative sanctions for maritime safety breaches as tools to provide proper enforcement. Criminal penalties are provided in the Criminal $\mathrm{Code}^{57}$ and include penalties for offences against transportation safety and for environmental crimes. The Maritime Safety Act of 2011 also sets a wide range of administrative sanctions, which are not, contrary to criminal sanctions, ordered by court, but by the

52 M. Dragun-Gertner, 'Polskie ustawodawstwo morskie a prawo międzynarodowe' in E. Kustra (ed.), Przemiany polskiego prawa (Toruń 2002) vol. II, pp. 131-153.

53 Journal of Laws 2015 item 1642.

54 Ustawa o umowach międzynarodowych, consolidated text in Journal of Laws 2020 item 127.

55 LLMC, CLC 92, FUND 92, Bunker Convention.

56 However, it is worth pointing out the lack of consistency of the legislator, who did not make an analogous provision in the Maritime Labour Act.

57 Consolidated text in Journal of Laws 2019 item 1950. 
administrative authorities. Most of the administrative sanctions are of a financial nature, acting in a preventive and disciplinary manner. ${ }^{58}$

Similar financial sanctions are provided by the Marine Equipment Act in relation to producers or importers of marine equipment and by the Act for the Prevention of Pollution from Ships. The latter also provides a criminal penalty in case of oil or noxious liquid substances discharged from ships. Apart from the instruments mentioned above (e.g. for pilots), the sanctions for safety breaches also include detention of a ship, denial of access to port or suspension of the right to practice the profession.

\subsection{Liability}

Poland is a party to several liability conventions which require a certificate of financial security. As stated before, according to the Polish Constitution, a ratified international agreement becomes part of Polish law and is to be applied directly (unless its application depends on the enactment of a statute). Moreover, in order to ensure the best possible compliance of internal law with international conventions, Poland has adopted a method of incorporating those conventions by making reference to them in the proper parts of the Maritime Code of 2001. Accordingly, the regime of an incorporated international convention, to which the Maritime Code only refers without duplicating its provisions, will further be used by virtue of Polish law applicability, also in cases when the convention itself would not be applicable due to its limitations (e.g. Article 2.1 of the Athens Convention). ${ }^{59}$ Provisions of a convention which has been incorporated into the Maritime Code become part of the Code itself and are in force in the same way as the other provisions of the Code. ${ }^{60}$

The maritime civil liability conventions which contain the obligation of financial security and have been ratified by Poland include CLC 1992, Bunker Convention and MLC 2006. In addition to the incorporating provisions, the Maritime Code also contains implementation norms necessary for the proper fulfilment of the obligations assumed with the ratification of international treaties. ${ }^{61}$ As maritime labour matters are governed by a separate act (the Labour at Sea Act of 2015), the norms implementing the issuance of MLC 2006 certificates are included therein. ${ }^{62}$ Most importantly, the implementation norms included in the Maritime Code of 2001 regulate the issuance of certificates attesting that the insurance or other financial security is in force in accordance with the provisions of a

58 According to the Maritime Safety Act of 2011, such financial sanctions can be imposed on a ship operator and a shipmaster in case of maritime safety breaches enumerated in Arts. 126 and 128 of the Maritime Safety Act of 2011. Administrative and financial sanctions may be imposed on anyone who breaches the maritime safety provisions enumerated in Art. 127 of the Act mentioned above (including natural persons, pilots and port management entities).

59 So far, Poland has not ratified the 2002 Athens Convention and remains bound by the Athens Convention of 1974, which does not require a compulsory financial insurance, see more below. Also incorporated into the Maritime Code are FUND 1992 and 2003 Protocol establishing Supplementary Fund.

60 J. Łopuski, 'Prawo morskie w dobie reformy ustawodawstwa' (1996) 3 Kwartalnik Prawa Prywatnego 574.

61 Ibid., 575.

62 Art. 62b of the Labour at Sea Act (Ustawa o pracy na morzu), consolidated text in Journal of Laws 2019 item 1889. 
particular convention. In Poland, the director of a maritime office is the authority responsible for the issuance of such certificates. In fulfilment of the obligations arising from the ratified conventions, the Maritime Code prohibits those ships under the Polish flag to which the financial security obligation applies from operating unless a proper certificate has been obtained. The Code also prohibits such ships from entering or leaving a Polish port (as well as arriving at or leaving an offshore terminal in the Polish territorial sea) without such a certificate. However, so far it has not provided for an administrative penalty for the breach of this obligation to obtain the certificate, which could be reconsidered as a tool strengthening the conventions' enforcement. Directors of maritime offices are obliged to control the observance of the norms on financial security.

Poland is party to neither the Nairobi Wreck Removal Convention nor HNS. National rules on wreck removal are included in the Maritime Code (Title VII, Part IV) and they require no sort of specific financial security covering wreck removal costs, nor any fund for wreck removal purposes. ${ }^{63}$ As this can be seen as a weakness of Polish maritime law, the Codification Commission for Maritime Law, in its proposal for the new maritime code delivered to the proper Ministry in June 2017, included provisions incorporating the Wreck Removal Convention, opting for its early ratification. The proposed provisions implementing the certification were largely drafted on the basis of the existing provisions referring to oil and bunker pollution certificates. In light of the advantages arising from the unified and thus predictable regime in the Polish maritime areas, the Codification Commission proposed provisions extending scope of the convention to the territorial sea. ${ }^{64}$ As far as the HNS is concerned, an act authorizing accession to the HNS 1996 was initially adopted by the Polish Council of Ministers, but was later suspended pending the 2010 Protocol. The Polish national regulation on the liability for pollution caused by substances other than oil or bunker oil (covered by the CLC and Bunker Convention) is included in the Maritime Code under the chapter "Miscellaneous pollution" (Articles 265-271). The scope of compensated damage as well as the basis and exclusion from liability are largely inspired by the CLC. It does not, however, contain any obligation in respect of specific compulsory insurance or creation of a compensation fund. Moreover, it attaches liability to the ship's operator, and not to the shipowner, as the latter solution is alien to Polish maritime law and exists only due to the ratification of certain liability conventions. The ship's operator will be able to invoke the limitation of liability under the LLMC 1976 as amended by the 1996 Protocol. So far, Poland has not ratified the 2002 Athens Convention and remains bound by the Athens Convention of 1974, which does not require a compulsory financial security. The 1974 Athens Convention is incorporated into the Maritime Code, and made applicable also to national carriages (with the exclusion of national carriages governed by Regulation (EC) No 392/2009). To remedy lack of insurance obligation under the 1974 Athens Convention, Polish Maritime Code

63 It is worth noting that Poland has made a reservation under Art. 18 (1) (a) LLMC 1976 as amended to exclude limitation of claims in respect of wreck removal.

64 See more in J. Nawrot, Z. Pepłowska-Dąbrowska, 'Environmental, Navigational and Regulatory Issues on Wrecks' in M. Musi (ed.), Port, Maritime and Transport Law Between Legacies of the Past and Modernization, Il Diritto Marittimo Quaderni (Bonomo Editore 2018), pp. 468-469. Authors are aware that works on the ratification of WRC and 2002 Athens Convention were started by the Ministry of Maritime Economy and Inland Navigation in September 2019 and continued in September 2020. At the time of delivering this chapter, the fate of both conventions in Poland is still unknown. 
requires a carrier who undertakes carriage of passengers to hold liability insurance up to carrier's liability limits provided in Articles 7 and 8 of the 1974 Athens Convention. At the same time Poland is bound by the Regulation (EC) No 392/2009, which incorporates 2002 Athens Convention. Thus, in relation to carriages governed by the Regulation, the Maritime Code implements norms on obligatory financial security. This inconsistency of applicable regimes should be seen as weakness of Polish law and the Codification Commission for Maritime Law has opted for ratification of 2002 Athens Convention. Works on ratification of the 2002 Athens Convention have been commenced in 2019 and still continues in September 2020.

Finally, Poland is bound by Directive 2009/20 on the insurance of shipowners against maritime claims, which has been implemented into Polish law in Articles 102a-102g of the Maritime Code together with the certification provisions shaped similarly to the norms of CLC and Bunker Convention certificates.

\subsection{Concluding remarks}

In recent decades, the form and scope of Polish maritime law has undergone an enormous evolution in terms of its adaptation to maritime safety standards. First, it should be stated that the matter of maritime safety was included in the first phase of the reform of Polish maritime law, which began with the change of the Polish system in the early 1990s. Adoption of the first Polish Maritime Safety Act in 2000 served that purpose. That act put an end to the practice of regulating maritime safety issues in the form of executive acts and gave it the appropriate statutory rank. The new Maritime Safety Act of 2011 is definitely more extensive and, within its framework, it includes numerous previously dispersed provisions in one piece of legislation. In addition, it regulates numerous additional issues, such as inspections (FSC and PSC), SafeSeaNet, search and rescue service and qualifications of seafarers. It also specifies financial penalties applied in Poland for violations of maritime safety regulations. The concept of separating private law issues (in the maritime code) and public law issues (in separate acts) has also been reinforced in Poland.

Maritime law in Poland has gone through a major revision in order to adapt national legislation to EU law. Poland joined the European Union in 2004 and since then it has been successively implementing and applying EU maritime legislation without any significant delay. The Maritime Safety Act of 2011 not only incorporates IMO conventions into the Polish legal system but also implements the EU directives.

In conclusion, it should be noted that the Polish legislator duly fulfils the obligation to apply international standards in the field of maritime safety. The strength of Polish solutions proves that the professional responsibility of seafarers is treated seriously. Irrespective of their criminal liability, seafarers in Poland are subject to an assessment carried out by specialized maritime chambers operating at the regional courts in Gdynia and Szczecin. It has an influence on the high work ethic of Polish seafarers. The model for investigating causes of maritime accidents also works well. It seems, however, that Polish legislation on maritime safety would benefit if the legislator made an effort to include maritime equipment and maritime security standards into the Maritime Safety Act of 2011, instead of regulating those issues separately, as is the case now.

Among the weaknesses of maritime law regulation in Poland, one should mention the lack of a well-designed method of incorporating amendments adopted through the tacit 
amendment procedure. It causes delays in their proper publication in Polish, being a premise for their effectiveness. It would be beneficial to implement a special and simplified method of adopting and enforcing the amendments introduced by tacit acceptance. Finally, the low level of the official translations of the maritime international and EU acts into Polish ought to be pointed to as a major deficiency. In some cases, the wording adopted in the Polish official translation of an act deviates from the authentic text so much that it substantially alters its meaning. 


\title{
Maritime safety and security in Spain ${ }^{1}$
}

\author{
Juan L. Pulido Begines and Achim Puetz
}

\subsection{Introduction}

Maritime safety regulations have a long tradition in Spanish maritime law. Even before the modern concept of public (international) law emerged, certain provisions of private maritime law already contained rules unequivocally aimed at guaranteeing the safety of navigation which are unparalleled in contemporary legal acts. Examples of such rules can be found in Articles 574 and 612(7) of the - now repealed - Book III of the Spanish Commercial Code of 1885. Pursuant to the former, shipbuilders were certainly allowed to use the materials and follow, with respect to the construction of the vessel, the systems that best suited their interests, but provided they abided by the rules on safety of ships contained in legal acts and regulations. Under the latter, the master was obliged to be on deck during landfall and take command for the entry into and departure from ports, canals, bays and rivers, at least when there was no pilot exercising his functions on board, and he was not permitted to spend the night off board the ship, except for serious grounds or by reason of his profession.

But even before the Commercial Code was enacted in 1885, there had already been manifestations of public intervention to promote safer navigation, particularly in Spain, where the control over maritime traffic was intense, in defence of the material interests of the Crown. The first regulations on maritime safety emerged after the industrial revolution and went hand in hand with the progressive intervention the Public Administration exerted on the lives and property of citizens, which is certainly paradoxical, since it was precisely this period that was characterized by a significant reduction of the risks and uncertainties related to maritime navigation. It is indeed well known that, for centuries, navigation has involved considerable economic and physical risks for stakeholders and that such risks are subject to a continuous evolutionary process aimed at their minimization in the technical, legal, economic and technological order.

Maritime transport has thus become the organized activity of professional shipowners, now generally organized in a corporate form, who compete on a continuous and global freight market and, thanks to their well-equipped fleets, are in a position to provide

1 The present study has been carried out in the framework of the research project 'Transport as a Motor of Socio-Economic Development: Protection of the Weak Contracting Party and Progress as regards Transport Sector Regulation' (Ref. DER2015-65424-C4-3-P MINECO/FEDER), financed by the Spanish Ministry of Economy and Competitiveness and the European Regional Development Fund (ERDF) (main researcher: M.V. Petit-Lavall). 
regular transport services. On the one hand, the possibility of knowing the cost of the journey beforehand and the existence of an adequate freight market contribute to the fact that, as regards maritime navigation, the idea of 'adventure' has lost part of its protagonism. On the other hand, the evolution of technical and geographical knowledge, the size and the materials used in the construction of ships, the means of propulsion, radar and modern rescue systems have had a notable impact on the safety of navigation. However, as a consequence of the increase in maritime traffic, the risk of collisions has increased as well, which, at the international level, led to the enactment of a convention for preventing such accidents at sea.

The achievement of higher levels of maritime safety has not, however, brought about a decrease in the intervention of the legislator, which is rather more and more relevant in this field, because the concept of safety in modern societies has evolved towards a higher level of demand, at an even faster pace than that undergone by technological development. As a result, despite the availability of technical means to make navigation increasingly safe, today there is a vast, heterogeneous and dispersed set of maritime safety standards, made up of provisions of very different rank and scope.

As to the meaning of 'maritime safety', the emergence of the idea of 'maritime security' at international level led also to the introduction of a new concept in Spain: while both aspects were previously subsumed under the expression 'seguridad maritima', maritime security is now referred to as 'protección maritima'. The distinction is made according to that established by Chapter XI of the Annex to the SOLAS Convention, although maritime security is often considered to be a part of the wider concept of maritime safety. For the purpose of this chapter, maritime safety in a narrow sense (safety of ships, on the one hand, and safety of navigation, on the other) and maritime security will be treated separately.

\subsection{National structure for the implementation of maritime safety law}

The Spanish Maritime Administration is divided into a central or state Administration, which is embodied mainly by the Ministry of Transports, Mobility and Urban Agenda (Ministerio de Transportes, Movilidad y Agenda Urbana, which as of 12 January 2020 replaced the former Ministry of Development or Ministerio de Fomento), and a peripheric Administration, represented by the Harbour Masters in certain ports. Furthermore, the 'Society of Salvage and Maritime Safety' (Salvamento Marítimo), a public business entity attached to the Ministry of Transports, provides the public services of rescue of human life at sea and the prevention and fight against marine pollution, as well as the services of monitoring and assistance to maritime traffic, of maritime and navigation safety and of towing and assistance to ships.

Within the Ministry of Transports, civil maritime affairs fall within the responsibilities of the Directorate-General for the Merchant Navy, which counts on three Sub-Directorates: for Safety, Pollution and Maritime Inspection; for Maritime Regulation and International Cooperation; and for Coordination and Administrative Management. The most relevant functions as regards maritime safety are performed by the Sub-Directorate General for Safety, Pollution and Maritime Inspection, e.g. those related to the control of maritime traffic, safety of navigation, coordination of maritime emergencies, the issuance and renewal of the Maritime Labour Certificate and the Declaration of Labour Compliance as referred to in the 2006 MLC, the coordination of the prevention of and fight against marine pollution 
from ships, as well as the manning requirements and the minimum equipment of ships according to SOLAS, MARPOL and other international, supranational or national standards derived therefrom. For its part, the Sub-Directorate General for Maritime Regulation and International Cooperation prepares the incorporation of European and international maritime regulations into national law, proposes sector-specific legislation, handles sanctions and disciplinary proceedings and issues reports and proposals for the resolution of administrative appeals against decisions of the Maritime Administration (see Article 7 of Royal Decree No. 953/2018, of 27 July).

\subsection{Prevention}

\subsubsection{Safety of ships}

The establishment of adequate mechanisms to ensure that ships are seaworthy at all times, as well as other aspects that are relevant for safe navigation (such as, for example, that the persons providing their services on board meet the mandatory training requirements) have become an urgent need in recent years to preserve the safety of navigation. To that end, many international instruments have been adopted (e.g. the SOLAS Convention, including the International Safety Management - ISM - Code, or the MARPOL, STCW and Torremolinos Conventions), which have been ratified by the Spanish State, and the European Union has also deployed intense legislative activity on this matter. These international and supranational standards have been developed and complemented by a vast number of domestic regulations, the basic rules of which have more recently been incorporated into the 2014 Maritime Navigation Act (Act No. 14/2014, of 24 July, on Maritime Navigation - MNA). Pursuant to its Article 97, the safety and pollution prevention requirements established in the national standards (e.g. Royal Decree 1247/1999, of 16 July, for passenger ships) are determined and controlled according to the nature and purpose of the services they provide and the navigation they perform. Spanish ships that meet the conditions set forth in the applicable regulations are granted the corresponding safety and pollution prevention certificates, which are issued by the Maritime Administration (Article 101 MNA).

As regards manning requirements, the number of crew and the conditions of professional training and qualification have to be adequate to guarantee the safety of the ship and of navigation at all times, as well as the protection of the marine environment. Based on its particular circumstances, the minimum safe manning requirements for each ship are established by the Maritime Administration, who also issues the Safe Manning Certificate which has to be carried on board and shall, where required, be displayed before the authorities of the port State (Article $161 \mathrm{MNA}$ ).

It is well known that the granting of nationality to a specific vessel implies the assumption by the flag State of certain obligations envisaged by the UNCLOS. According to its Article 94, every State must maintain a registry of ships and exercise its jurisdiction and control in administrative, technical and social matters over the ships flying its flag. Furthermore, in relation to innocent passage through the territorial Sea, the coastal State may enact laws and regulations related to the design, construction, manning or equipment of foreign vessels, provided that they give effect to generally accepted international rules or standards (Article 21(2) UNCLOS). Although the control of the safety of ships falls, 
in principle, within the exclusive competence of the flag State, and other States are not allowed to interfere in this field, the limitations inherent in this principle led, at the end of the last century, to the configuration of a mechanism which is complementary to that of flag State control: the control of the ship by the port State (see hereunder).

\subsubsection{Places of refuge}

The issue of places of refuge has been the subject of growing concern on the part of the international maritime community for some decades now. Since ancient times, sea rescuers have been pointing out the difficulties put by coastal authorities to accept that a severely damaged ship be transported to its ports. Recent events have only increased that interest and highlight the doubts and complications the issue presents in modern maritime traffic. It shall suffice to mention the case of the vessel Castor, which for six weeks at the end of the year 2000 requested successively to be admitted into the waters of five Mediterranean States in order to transfer its gasoline load. Since she was systematically rejected, she finally had to perform the transfer at sea. Other examples are the cases of the vessels Vicky (2003), Bizmita La (2001), Ventura (1999), Smirdan (1997), Protokletas (1992), Khark V (1989), Cristos Bitas (1978), Atlantic Empress (1979) and, finally, the well-known case of the vessel Prestige. These and other events have shown an undeniable reality, that is, when a damaged ship is successively rejected by various States, a situation of extreme danger to the vessel and the environment arises.

However, the legal regulation of the places of refuge presents important obstacles, which continue to delay the emergence of a complete and systematic uniform law on the subject. Many doubts and difficulties arise, and it can indeed be affirmed that the legal regime of these places is in an embryonic state. Much, almost everything, remains to be done, since the legal regulations in force on the matter are insufficient, both by their nature and by their scope.

In Spain, Royal Decree No. 210/2004, of 6 February, on the establishment of a monitoring and information system for maritime traffic (hereinafter RD 210/2004), sets up the rules and criteria by which the maritime authority has to abide when a ship in need of assistance requests entry, so that - as established in the Decree's Statement of Reasons - the damage that may foreseeably derive from the access to the place of refuge is lower than that which would arise if alternative measures to assist the ship were adopted. Its purpose is to establish an action procedure in case of emergency to assess all possible alternatives, and, where appropriate, grant refuge to the damaged ship.

Articles 20 to 24 of RD 210/2004 largely reproduce the provisions of Directive 2009/17/ EC. It is important to highlight that the Decree does not designate which are the Spanish places of refuge. This is not a trivial matter, because the designation of the places of refuge is a necessarily controversial measure, which provokes the hostility of the nearby coastal populations. It must therefore be the subject of an adequately motivated decision of a political nature.

Article 24 of the Decree carefully regulates the procedure for the authorization of the entry of a ship into a place of refuge. The authority competent to grant such authorization is the Director-General for the Merchant Navy. The procedure is initiated by the request of the master of the affected vessel or a representative of the operator or the shipping company, who must indicate the reasons why the vessel is in need of assistance, providing as 
much information as they deem relevant, as well as such information as may be required by the Harbour Master. Once the request is received, the Harbour Master will carry out as many acts of instruction as are deemed necessary to support the final decision, including, where appropriate, an inspection of the ship. In particular, he or she may propose that the entry of the vessel be conditioned to the weighting of the set of circumstances established in the second transitory provision of this Royal Decree.

The decision authorizing the access to a place of refuge must be expressly agreed and may, in case of urgent need, be adopted verbally and with no special formalities, without prejudice to the obligation to notify interested parties of the decision and its motivation in writing, as soon as possible and, in any case, within a period not exceeding 96 hours. Against the decision, which concludes the administrative procedure, the interested parties may file an appeal for reconsideration. In the event that the entry of the vessel into the place of refuge is not allowed, the Maritime Administration, if deemed necessary, will establish the alternative measures it considers appropriate in order to protect the - public and private - legal rights that might be endangered by the precarious situation of the ship or its cargo and by the external, mainly meteorological circumstances that affect or may affect the ship.

Article 22 of the Decree provides that in the cases in which a ship in need of assistance is received in a place of refuge, the financial guarantee, where required, must be presented by the operator, the shipping company, the ship's saviour, the shipper, the owner or the recipient of the cargo in a bank domiciled in Spain, in favour of the Directorate-General for the Merchant Navy and with express submission to the Spanish courts. It must clearly state that it is irrevocably constituted to cover, in any amount, the compensation claims arising from all possible damages caused to individuals, public entities or goods of any nature by the ship or its cargo as a result of catastrophic events such as fire, explosion, breakdown, including mechanical or structural failures, collision, pollution, decreased stability or stranding, among others.

It shall also cover the previous expenses incurred to avoid or minimize such damage, as well as the cost of the measures of extraction or removal of the ship or her cargo and of restoration of the coastal or marine environment that might be adopted as a result of the incident or during the entry or departure of the ship from the place of refuge or her stay therein.

If it is not possible to immediately establish the guarantee, because it is a bank holiday or a late hour, the operator, the shipper, the saviour, the agent or the person to whom they delegate shall offer any other guarantee of equivalent effects, at the discretion of the Directorate-General for the Merchant Navy, for the amount that corresponds according to the scale established in Article 23, until it is possible to provide the financial guarantee, at which time the former will be returned.

\subsubsection{Maritime security}

Until the end of the last century, the international community had not been overly concerned about terrorist attacks on or from ships, despite the fact that the issue had already been identified as a problem with the hijacking of the Italian passenger vessel Achille Lauro, on 7 October 1985, by the Palestine Liberation Front. However, full awareness of the need to address this threat was taken within the IMO after the 9/11 attacks in New York and, above all, following the attacks suffered by the American warship USS Cole in Aden and by the French tanker Limburg. These actions highlighted to what extent acts perpetrated 
against or from ships can harm the population. Indeed, the Organization addressed this issue in 2001, at the request of the US, assessed the globalization of threats to international trade and declared the common will to achieve regulatory development in this field through Resolution A.924(22), of 20 November 2001. In this Resolution, the Organization undertook to review the measures and procedures aimed at preventing terrorism threats that put at risk the security of passengers, crews and ships. Thus, a new concept, that of 'maritime security' (in Spanish, protección maritima), appears as a separate element, with its own substantivity, within the broader field of maritime safety.

As an immediate consequence, the IMO Maritime Safety Committee initiated the elaboration of regulations against terrorist threats by establishing an Expert Working Group on Maritime Security. These works led to the celebration of a conference of the Contracting States of the SOLAS Convention, held from 9 to 13 December 2002, which launched a set of measures aimed at improving the protection of maritime security, among which two should be mentioned here: Resolution 1, which introduces amendments to the SOLAS Convention that affect Chapters V and XI (modifications that were published in the Spanish Official Journal on 22 April 2004), and Resolution 2, which adopts the so-called International Ship and Port Facility Protection Code (ISPS Code). It entered into force in July 2004 (OJ of 21 August 2004).

Finally, it should also be borne in mind that Spain is a contracting party to both the 1988 Convention for the Suppression of Unlawful Acts Against the Safety of Maritime Navigation (SUA) and its 2005 Protocol.

\subsubsection{The International Ship and Port Facility Security (ISPS) Code}

As is well known, there are three main objectives of the ISPS Code: to prevent unauthorized persons from accessing a port facility or a ship, either while in port or during navigation; to impede the introduction of unauthorized weapons or goods on board a ship or inside a port facility; and to implement an alert system that allows the competent authorities to adopt measures when an incident that affects maritime security occurs.

To achieve these goals, the Code envisages a wide and ambitious series of measures. On the one hand, the establishment of an international framework that channels cooperation between Contracting Governments and encourages the detection of possible threats. On the other hand, it seeks to specify the respective roles and responsibilities of the Contracting Governments, local administrations and the shipping and port sectors, at national and international level, to guarantee maritime security and, in addition, to establish a methodology for security assessments that conclude with the formulation of plans and procedures that allow to react to changing security levels and ensure confidence in the sector that adequate security measures are in place.

The Code is structured in two parts. While the first part (A) establishes mandatory standards, the second one (B) contains a set of recommendations on security systems. It imposes the establishment of communication protocols for ships and port facilities, as well as access control to ships and facilities. In addition, it provides means of action in the face of signs of threats and requires the training of competent personnel, including the corresponding exercises and practices.

As regards port facilities, the Code obligates to implement three security levels, which must be established by the competent administration, that is, the Ministry of Internal Affairs in Spain (Article 14(2) of Royal Decree No. 1617/2007). The port facilities to which this 
regulation applies are those identified and defined by the Administration. In the case of port facilities located in so-called 'ports of general interest' as defined in the Act on State Ports and the Merchant Navy, approved by Royal Legislative Decree No. 2/2011, of 5 September (hereinafter SPMNA), the Designated Authority is the Port Authority managing the port in which each port facility is located.

According to the Code, the port facility must count on a Port Facility Security Officer, which is the person designated by the managing entity of the facility as responsible for the development, implementation, revision and maintenance of the security system. The officer must have specific training in all aspects related to this subject. In each port facility, a security assessment has to be performed in which the potential threats, their nature and extent, the degree of vulnerability and the level of consequences are to be determined. The assessment has to be approved by the Designated Authority and refers to aspects such as the identification of facilities, their limits and infrastructures, their operation or the organizations involved. As a result of the security assessment, a port facility security plan must be prepared that includes the measures aimed at avoiding the detected security risks in the port facility, which must be defined for each of the three security levels. The port facility security plan is also approved by the Designated Authority and, once it has been formulated, approved and implemented, its effectiveness has to be evaluated through exercises and drills, so that measures can be taken for its continuous improvement.

For their part, shipping companies are also required to comply with the requirements of Part A of the ISPS Code. Specifically, they must ensure that the master of the ship has on board the necessary information to identify the person responsible for appointing the members of the crew and for deciding the employment of the ship, as well as, where appropriate, who are the parties of the charter party under which the ship is employed. Each ship must have its own ship security plan and a ship security officer, i.e. the person on board, designated by the company and accountable to the master, who guarantees the security of the ship and coordinates the actions with the company security officer and port facility security officers.

Possible frictions are resolved in favour of the master's authority. At the operational level, the master remains ultimately responsible for making decisions about the security of the ship, and he or she cannot be forced by the company, the charterer or any other person to change his or her professional judgement. Consequently, the master is entitled to deny access on board to persons or their belongings or to refuse cargo and, what is more relevant, in case of conflict between the safety and security requirements, the master should give preference to the former. Furthermore, ships must be provided with a security alert system that, once activated, sends an alert signal (that does not raise any alarm on-board the ship itself) to the authorities designated by the flag State, identifying the ship and its location. The system must be capable of being activated from the bridge and in at least one additional location on the ship.

Compliance with maritime security standards is accredited by issuing the International Ship Security Certificate (ISSC), which must be presented to the corresponding authorities of the flag State and the port.

15.3.3.2 European regulations on maritime security and their implementation in Spain The European Union has also legislated on maritime security, through Regulation (EC) No. 725/2004, of 31 March 2004, on enhancing ship and port facility security, as amended by 
Regulation (EC) No. 219/2009 and Commission Decision 2009/83/EC. The purpose of this Regulation is to increase the acquis communautaire by incorporating the measures adopted by the IMO on protection of ships and port facilities, with some modifications and extensions. The application of the IMO regulations is thus extended to passenger ships destined for national traffic and belonging to class A, as well as to their companies and port facilities that provide services thereto. Furthermore, the application of some of the provisions contained in part B of the ISPS Code becomes mandatory.

Commission Regulation (EC) No. 324/2008 must also be taken into account, which establishes revised procedures for conducting inspections in the field of maritime security. Its purpose is to monitor the correct application by the Member States of Regulation No. 725/2004, through a series of surveys that shall be carried out in a transparent, effective, harmonized and consistent manner and allow verification of the effectiveness of quality control systems and national maritime security measures, procedures and structures.

Finally, mention should be made of Directive 2005/65/EC, of 26 October 2005, on enhancing port security, as amended by Regulation (EC) 219/2009 and Regulation (EU) 2019/1243, which continues along the lines established by Regulation No. 725/2004, but taking a new step in the regulation of this matter by expanding the scope of security measures. The Directive and its annexes devote special attention to roll-on roll-off traffic to ensure that appropriate safety measures are also introduced therein.

The Directive has been incorporated into Spanish national law by Royal Decree No. 1617/2007, of 7 December, establishing measures for the improvement of the security of ports and maritime transport, which aims at introducing measures with a view to increasing the protection of ports against the threat of deliberate illegal incidents or acts that affect maritime security, as well as determining the competent entities and bodies to apply the measures contained in the regulations on maritime security (Article 1). For this purpose, the Port Security Authority (Autoridad de Protección Portuaria) is created, which is the managing entity of the corresponding port, whose functions are specified in Article 7. The Port Security Authority must establish, for each of the ports it manages, a consultative port security committee that provides advice on the development of procedures or guidelines aimed at improving the implementation of port security measures.

Following the classification introduced by the ISPS Code, Royal Decree No. 1617/2007 establishes three security levels at ports: security level 1 , in which adequate minimum security measures must be maintained at all times; security level 2, with additional security measures that are deployed over a period of time, as a response to an increased threat of an incident affecting maritime security; and, finally, security level 3, which adds more security measures to those included in level 2, for a limited period of time, when an attack or incident that affects maritime security is probable or imminent, although it is not possible to determine the specific target.

Pursuant to Article 19 of the Royal Decree, certain ships (mainly passenger vessels and cargo carriers of more than 500 gross tonnage engaged in international traffic) have to transmit security-related information to the port prior to their arrival, by way of the so-called 'single document of call' (document único de escala or DUE), the content and presentation of which is further specified in the Order of the then Ministry of Development No. FOM/1194/2011. Furthermore, to adequately ensure the application of the Royal Decree, a system of inspections as regards the compliance with the regulations on maritime 
security in the port sector has been established by Order of the Ministry of Presidency No. PCI/1188/2018, of 15 November.

\subsection{Control and surveillance systems}

\subsubsection{Safety of navigation: the organization and control of maritime traffic}

The term 'safety of navigation' refers to a series of rules of very different origin intended for the same purpose: the organization and the control of maritime traffic with a view to the avoidance of accidents. While masters of ships have traditionally had complete autonomy when determining the course of their vessels and the other conditions under which navigation was performed, with no more limits than the instructions given by the owners, since there were no legal rules on this issue, more recently it has become apparent that it is convenient to establish a set of regulations that, especially in certain geographical areas with a high density of maritime traffic, determine the course or speed to be adopted by the vessels. Above all, such regulations aim at preventing accidents such as collisions or stranding. The UNCLOS contains certain provisions related to this matter, within the section dedicated to the innocent passage in the territorial sea (Article 22). This discipline, which operates as a general framework, has been developed by a set of Resolutions adopted by the IMO.

But the control of maritime traffic has also been addressed by regional organizations, especially by the EU, and by the internal laws of many States, including Spain, giving rise to a complex legal framework that, furthermore, is still in the making. The basic rule under Spanish law is Article 30 MNA, which enables the Government to establish, to replace or to remove ships' routeing and reporting systems, as well as vessel traffic systems. Once such systems have obtained, where necessary, approval and publication at international level, they are compulsory for all ships. In the following sections, we will briefly analyse the rules on the organization and control of maritime traffic which are in force in Spain.

\subsubsection{The legal regime in Spain: Royal Decree No. 210/2004}

The most important national regulation on this issue is the aforementioned Royal Decree No. 210/2004, since it incorporates Directive 2002/59/EC into domestic law. The Decree has subsequently been modified by Royal Decree No. 201/2012, of 23 January, and by the Order of the Department for Transport No. FOM/2380/2015, of 6 November, to reflect the amendments made by Directive 2009/17/EC and Commission Directive 2014/100/ EU, respectively. The most recent modification of Directive 2002/59/EC by virtue of Regulation (EU) 2019/1243 does not require incorporation into national law, since it only affects the amendment procedure of the Directive itself and the delegation of powers to the Commission.

RD 210/2004 establishes the sovereignty-related powers Spanish authorities may exercise on ships sailing on Spanish waters and that restrict the principle of freedom of navigation. It aims at increasing maritime safety and the effectiveness of such traffic; improving the responsiveness of the Maritime Administration to accidents and search and rescue operations; and contributing to an earlier detection and a better prevention of pollution that may be caused by ships.

Masters, operators and agents of ships, as well as the shippers or owners of dangerous or polluting goods transported on board such ships are obliged to comply with the 
requirements and conditions established by RD 210/2004, which sets up a complete and integrated monitoring and information system of vessel traffic. It also makes the use of technologic advances that are fundamental for maritime safety mandatory, such as those which allow the automatic identification of ships (AIS) or the recording of voyage data (VDR systems or 'black boxes') to facilitate the investigation following a maritime accident. Furthermore, assistance to ships in distress is regulated according to the guidelines approved by the IMO. The Maritime Administration, on its part, shall adopt the administrative police and sanctioning measures that are necessary to ensure compliance with the requirements established in the Decree. Article 27 specifies the administrative police measures that can be adopted:

The Maritime Administration may deny the entry into port of those ships that falsify, do not transmit, or incorrectly or incompletely transmit the information regulated in this Royal Decree, when this seriously compromises the safety of maritime navigation or poses a serious danger to the marine environment.

Although RD 210/2004 mostly reproduces - even literally - the provisions of Directive 2002/59 EC, on occasions it goes beyond the minimum required by European law and establishes a more complete and more detailed regime on maritime safety, which addresses points that are not treated by the Directive and further develops others.

\subsubsection{The use of traffic separation schemes}

Traffic organization systems - or 'ships' routing systems', following the terminology usually employed in the sector - are envisaged by the provisions of SOLAS, originally in its Rule V/8, amended in 1995 (which corresponds to rule V/10 in the text amended by the IMO Maritime Safety Committee in 2000), and in Resolution A.572(14), of the General Assembly, on General Provisions on Ships' Routeing. In addition, Rule 1.d and 10 COLREG establish provisions on traffic separation schemes (TSS). Such systems, which are established with the main purpose of allowing ships to follow certain routes where it is less likely that a collision, a stranding or any other type of accident will occur, must be approved by the IMO at the proposal of the governments concerned. In November 1997, the General Assembly of the IMO adopted Resolution A.858(20), under which said body delegates to the Maritime Safety Committee (MSC) the power to approve devices for traffic separation and similar measures, including the designation and substitution of archipelagic sea lanes. Once the approval has been issued, the proposing governments may begin to control maritime traffic, disseminating all the information necessary for its use in a safe and effective manner.

A partial regulation of traffic organization systems can also be found in Directive 2002/59/EC. In its Article 3(p), it defines a 'ship's routing system' as 'any system of one or more routes or routing measures aimed at reducing the risk of casualties; it includes traffic separation schemes, two-way routes, recommended tracks, areas to be avoided, inshore traffic zones, roundabouts, precautionary areas and deep-water routes'. A similar definition can be found in IMO documents (e.g. in Resolution A.857, rule 2.3.3).

Traffic organization systems thus contribute to the safety and effectiveness of navigation and the protection of the marine environment. Therefore, their use is recommended in certain cases. SOLAS Rule V/10 does not specify the geographical scope in which mandatory 
traffic separation devices are admissible. This gap raises some important questions. In particular, it is not clear whether such systems can be established only in the territorial sea of the coastal State or also beyond. The systematic interpretation of SOLAS Chapter V seems to lead to the conclusion that imperative traffic separation devices can also be established beyond the territorial sea. Note that, when referring to vessel traffic services (see infra), Rule 12 expressly states that imperative vessel traffic services can only be established within the territorial sea of the coastal State. Hence, the silence of the Convention in relation to mandatory traffic separation devices allows the opposite conclusion to be reached.

Both the SOLAS Convention and the mentioned IMO Resolutions thus allow the coastal State to establish imperative traffic separation devices for foreign vessels that navigate the waters under its sovereignty, provided that certain requirements are met. Firstly, they may only be established for certain types of traffic. In addition, the need for such a mechanism must have been clearly proven. Thirdly, there must have been a request by the coastal State, that is, by the government on its behalf, to the IMO. And finally, said request must have been expressly approved by the Organization.

In Spain, there are several traffic separation devices, located, e.g. in Finisterre in the northwest, the Strait of Gibraltar, Cabo de Gata in the southeast, as well as the Eastern and Western Canary Islands, respectively. The monitoring of ships which enter the area of a mandatory traffic separation scheme is performed by the Maritime Administration, which may also establish, under its own responsibility, traffic organization schemes not approved by the IMO, although the recommendations and criteria established by the IMO shall be taken into account and all information which is deemed necessary for the safety and the effective use of such system has to be promulgated (Article 7 RD 210/2004).

\subsubsection{Vessel Traffic Services (VTS)}

Vessel Traffic Services (VTS) are regulated in rule V/12 of the SOLAS Convention. The provision has been developed by the IMO through Resolution A.857(20) Guidelines for establishing VTS, including guidelines on recruitment, qualifications and training of VTS operators. On its part, Article 3(o) of Directive 2002/59/EC defines the 'vessel traffic service' (VTS) as 'a service designed to improve the safety and efficiency of vessel traffic and to protect the environment, which has the capability to interact with the traffic and to respond to traffic situations developing in the VTS area'. In Spain, the regulation of vessel traffic services is contained in Royal Decree 210/2004 and compliance with the specific rules of every one of them is entrusted to the Maritime Administration. These services may include a wide range of activities, such as traffic management, or the provision of information or navigation assistance. They respond to the need for the authorities of the coastal State to collect real-time information on traffic in heavily travelled waters, so that intervention is possible when necessary. Therefore, it has been said that they are the closest maritime equivalent to air control systems. The desirability of the introduction of VTS has been the subject of long debates within the international maritime community, which are still ongoing. In fact, there are still authorized voices that consider them impractical and undesirable.

Pursuant to the IMO Regulations mentioned above, it is an obligation of the affected States to establish a VTS when the volume or quality of maritime traffic make it necessary. For this purpose, the IMO rules must be followed, which establish that their use can only 
be made mandatory in waters within the territorial sea of the coastal State. Accordingly, Article 30(3) MNA establishes that VTS require approval by the IMO to be compulsory also within the exclusive economic zone. This is the case of ships which fly the flag of a Member State of the EU or are headed for an EU port, for which compliance with the rules associated to the VTS is mandatory even in Spanish waters different from the territorial sea, whenever such VTS are based on the guidelines developed by the IMO (Article 8(b) RD 210/2004). Finally, although ships flying the flag of a non-EU State and the destination of which is not an EU port are also held to abide by the VTS rules outside the territorial sea 'whenever possible', the Maritime Administration does not seem to be bound to adopt the necessary measures to ensure compliance therewith, but shall notify any serious infringement to the flag State (Article 8(c) RD 210/2004).

\subsubsection{Ship reporting systems}

Ship reporting systems (SRS) imply the obligation of the masters of certain ships to make radio contact with the vessel traffic service and provide a series of relevant information on the situation, course, speed and type of cargo transported. They are envisaged by SOLAS Rule V/11, as developed by IMO Resolution A.851(20) and by the Guidelines and criteria for ship reporting systems, approved by the IMO Maritime Safety Committee in document MSC.43(64), as amended by MSC.111(73) and MSC.189(79). In addition, there is a European regulation in Articles 4, 5, 6 and 10 of Directive 2002/59/EC.

Under the provisions of the Directive, ships must provide relevant information in certain cases: prior to entry into the port of a Member State; when they enter the area of a mandatory ship reporting system; when they use an automatic identification device; and when they use a data recording device. These information requirements have been transposed into Spanish law through Articles 4, 5, 6 and 10 of RD 210/2004.

\subsubsection{The control of dangerous substances on board}

Following the provisions contained in Directive 2002/59/EC, Spanish law imposes certain obligations in relation to dangerous goods carried by sea. No dangerous or polluting goods may be presented for transport or loaded on board a ship, regardless of its size, in a Spanish port without prior delivery to the master or operator of a declaration containing the information listed in Annex I of RD 210/2004. It shall be the responsibility of the shipper to provide the master or the operator with said declaration and ensure that the cargo presented for transport corresponds to the declaration that has been made.

In relation to the notification of dangerous or polluting goods transported on board, the operator, agent or master of a ship, regardless of its size, that carries dangerous or polluting goods and that leaves a Spanish port shall notify, at the latest at the time of departure, certain relevant information listed in the Annex to the competent Harbour Master. With regard to ships carrying dangerous or polluting goods the origin of which is a port located outside the EU and whose destination is a Spanish port (or which have to anchor in Spanish territorial waters), such information shall be notified to the competent Harbour Master, at the latest upon departure from the loading port or as soon as the port of destination (or anchorage) is known, if this information is not available at the moment of departure (Articles 12 and 13).

In addition, Directive 2002/59/EC refers to the establishment of an electronic data exchange system between the Member States, which must cooperate with a view to 
ensuring the interconnection and interoperability of national systems used to manage information on ships transporting dangerous goods. This possibility is envisaged by Article 14 RD 210/2014, which expressly refers to the use of the SafeSeaNet platform, as defined in Annex III to the Royal Decree.

15.4.1.6 The control of hazardous ships: intervention in case of accidents at sea

Following the provisions in the Directive, Royal Decree 210/2004 also establishes rules on the control of hazardous ships and on intervention in case of accidents at sea. These measures are intended to reinforce and, above all, to clarify the obligations contained in the IMO regulations on the information to be provided in the event of an accident.

\section{THE CONTROL OF HAZARDOUS SHIPS}

In this regard, the Decree establishes different measures aimed at increasing the intervention powers of the Spanish State in relation to ships that present a high degree of danger. For this purpose, certain vessels are to be considered per se as potentially hazardous for shipping, maritime safety or the marine environment.

The concept of 'hazardous ship' is established in Article 16(1), which refers to ships that, in the course of their voyage, have been involved in any of the incidents or accidents at sea referred to in Article 17; have failed to comply with the notification and reporting requirements imposed by the Decree; or have failed to comply with the rules applicable to ships' routeing systems and vessel traffic services placed under the responsibility of the Spanish Maritime Administration. Ships will also be considered as hazardous if there is proof or presumptive evidence of deliberate discharges of oil or other violations of the MARPOL Convention in waters under Spanish jurisdiction. Finally, ships that have been denied access to the ports of an EU Member State or that have been the subject of a report or notification by a Member State in accordance with point 1 of Annex I to the Regulation on the control of foreign ships in Spanish ports, approved by Royal Decree No. 91/2003, of 24 January (which transposes Council Directive 95/21/EC, on Port State Control of shipping), will also be classified as potentially hazardous; and the same is true for ships that have not notified or lack certificates of insurance or financial guarantees, in accordance to European legislation and international regulations, and ships that have been reported by pilots or port authorities as having apparent anomalies that may compromise the safety of navigation or pose a risk to the environment.

By defining what is a hazardous ship, what is really intended is the delimitation of a series of circumstances of emergency, a complex matter on which there are many doubts. This should be considered a risky but correct measure, as it can well serve as an instrument to legitimize the intervention powers of the State, which must face the dangers such situations imply. Accordingly, the Decree specifies the scope of the powers available to the Spanish Maritime Administration. Specifically, in relation to ships classified as hazardous, it assumes the obligation to inform and to control.

With regard to the obligation to inform, coastal stations that hold relevant information on such vessels shall communicate it to the coastal stations concerned in the other Member States located along the planned itinerary of the vessel. In addition, this information shall be transmitted to the corresponding port authorities and, where the case may be, to the organisms named by the latter (Article 16(2) and (3) RD 201/2004). 
The obligation to control, on its part, is very vaguely formulated. Within the limits of the available staff capacity, the Maritime Administration shall carry out any appropriate inspection or verification, either on its own initiative or at the request of another Member State, without prejudice to the obligations related to control by the port State. In such cases, all interested Member States shall be informed of the results of the actions that have been taken (Article 16(4) RD 210/2004).

\section{REPORTING OF INCIDENTS AND ACCIDENTS AT SEA}

The Directive requires Member States to monitor and take all appropriate measures to ensure that the master of a ship sailing within their search and rescue region (or exclusive economic zone or equivalent) immediately reports to the competent coastal station in that geographical area on any accident or incident occurred at sea. In particular, the provision requires information on:

(a) any incident or accident affecting the safety of the ship, such as collision, running aground, damage, malfunction or breakdown, flooding or shifting of cargo, any defects in the hull or structural failure; (b) any incident or accident which compromises shipping safety, such as failures likely to affect the ship's manoeuvrability or seaworthiness, or any defects affecting the propulsion system or steering gear, the electrical generating system, navigation equipment or communications equipment; (c) any situation liable to lead to pollution of the waters or shore of a Member State, such as the discharge or threat of discharge of polluting products into the sea;

(d) any slick of polluting materials and containers or packages seen drifting at sea.

This provision has been incorporated into Article 17(1) RD 210/2004.

However, there are no further indications on what should be considered an 'appropriate measure', but at least two clear limits are established: on the one hand, the measures must be in accordance with the requirements of international law; and, on the other hand, their purpose must be to prevent or reduce any significant risk to maritime safety, the safety of individuals or the environment. In any case, the matter continues to raise many doubts, although the provisions of both the Directive and the Royal Decree are more precise than rules 31 and 32 of Chapter V of the SOLAS Convention.

In relation to the obligation to inform, the warning message must include, at least, the identity of the ship, its position, the port of departure, the port of destination, the address at which information on dangerous and polluting goods transported on board can be obtained, the number of persons on board, details of the incident and any relevant information mentioned in IMO Resolution A.851(20) (Article 17(2) RD 210/2004).

\section{INTERVENTION MEASURES RELATING TO INCIDENTS AND ACCIDENTS AT SEA}

Article 221(1) of the UNCLOS recognizes the right of States, pursuant to both customary and conventional international law, to take and enforce measures beyond the territorial sea that are proportionate to the actual or threatened damage to protect their coastline or related interests, including fishing, from pollution or threat of pollution resulting from a maritime casualty or acts related to that casualty, which may reasonably be expected to result in major harmful consequences.

This right of intervention of the coastal States had previously been regulated by the 1969 Convention and the 1973 Protocol, regarding incidents related with oil and substances other than oil, respectively. But these treaties exclusively refer to the right to intervene on 
the high seas, since the concept of exclusive economic zone had not yet been legally recognized at the time they were signed. With the entry into force of the UNCLOS, the rules on the right of intervention of the coastal State established in these treaties should be considered applicable to the exclusive economic zone, too. Additionally, it should be borne in mind that Article 211(6) of the UNCLOS allows the coastal State to adopt special measures of an imperative nature for the prevention of pollution caused by ships in certain areas of the exclusive economic zone.

In this regard, the Royal Decree also recognizes the right of the Maritime Administration to intervene and contemplates different measures aimed at increasing its ability to act in relation to high-risk vessels, as defined in Articles 16 and 17, with the purpose of neutralizing the danger posed by such ships and keeping them away from the coast where necessary. These measures, which are envisaged by Article 19(1) and listed in a non-exhaustive manner in Annex IV to the Decree, are the following:

(a) restrict the movement of the ship or direct it to follow a specific course. This requirement does not affect the master's responsibility for the safe handling of his ship;

(b) give official notice to the master of the ship to put an end to the threat to the environment or maritime safety;

(c) send an evaluation team aboard the ship to assess the degree of risk, help the master to remedy the situation and keep the competent coastal station informed thereof;

(d) instruct the master to put in at a place of refuge in the event of imminent peril, or cause the ship to be piloted or towed.

Such practices are listed by way of example only, as the right of the Maritime Administration to take all necessary measures to achieve the intended purpose is expressly recognized. But, unlike what happens in the cases analysed hereabove, both the Directive and the Royal Decree provide some precise indications on what kind of measures can be adopted. The aforementioned Annex also specifies the limits that operate in this regard: the measures must be taken only when it is necessary to avert, lessen or remove a serious and imminent threat to the Spanish coastline or related interests, the safety of other ships and their crews and passengers or of persons on shore or to protect the marine environment. In addition, such measures must be taken within the framework of international law.

It becomes evident that, as a consequence of the provisions in Article 19 of the Royal Decree, the master of a ship may be obliged to restrict the movements of the ship or to direct it to a point, or over a particular route, or to enter a place of refuge. The ship may also be prevented from entering a specific port until the danger has disappeared. To that end, in accordance with their national law, the Spanish authorities shall take into account the relevant provisions of the IMO Guidelines on the fair treatment of the seafarers in the event of a maritime accident in the waters under Spanish jurisdiction (Article 19(5) RD 210/2004).

But, in addition, the aforementioned provision establishes some - certainly vague - obligations related to other interests which are present on board. It provides that the operator, the master of the ship and the owner of the dangerous or polluting goods must fully cooperate, in accordance with national and international law, with the maritime administration, at its request, with a view to reducing to a minimum the consequences of an incident or accident at sea (Article 19(3) RD 210/2004). Furthermore, the master of a ship to which the provisions of the ISM Code apply shall inform the company, pursuant to that Code, of any incident or 
accident referred to in the Decree. The company, as soon as it has been informed, must then contact the competent coastal station and make itself available as necessary (Article 19(4)). The obligation to cooperate should be considered a general rule of the Law of the Sea, but the scope of which is obscure, since it is not easy to specify in practice when that obligation has been correctly fulfilled or whether there is some discretion left to the master of the ship.

\subsubsection{Measures in the event of exceptionally bad weather}

Following the provisions of the Directive, Royal Decree 210/2004 establishes a series of measures or recommendations that can be applied if the harbour masters, in case of exceptionally unfavourable weather or sea conditions, consider that there is a serious threat of contamination of the Spanish maritime or coastal zones, or of the shipping or coastal zones of other States, or that the safety of human life is in danger.

The measures applicable in such cases are expressly mentioned in Article 18(1) of the Decree, although they are on occasions vague and ambiguous. In particular, while the Directive envisages rather clear instructions for the competent authorities (see the use of the terms should, may and shall in Article 18), the Harbour Masters under Spanish law may provide the master of a ship that is in the port area concerned and wishes to enter or leave the port all information on the state of the sea and weather conditions and, when relevant and possible, about the danger they may present to the ship, cargo, crew and passengers. They may also take, without prejudice to the obligation to assist ships in distress and in accordance with the provisions on places of refuge, any other appropriate measures, including a recommendation or a prohibition, both for a particular vessel and for all ships in general, to enter or leave the port in the affected areas, until it has been established that there is no longer any danger to human life or to the environment. Lastly, they may take the necessary measures to limit as much as possible or prohibit, if necessary, the bunkering of ships in their territorial waters.

It is important to underline that such decisions will in no case be mandatory for the master of the ship who, nonetheless, has to inform the shipowner about the measures and recommendations that have been adopted. But this requirement may not determine in any case the decision of the master based on his professional judgement, a faculty which is recognized by the SOLAS Convention. In those cases in which the decision taken by the master does not conform to the measures mentioned in the Decree, he or she shall inform the Harbour Master about the reasons that justify his or her decision (Article 18(2)).

The amendment of the Directive carried out in 2009 brought about the inclusion of a new article 18a, on Measures in case of risks posed by the presence of ice, under which the coastal authorities are obliged to adopt certain provisions when they consider that, due to ice conditions, there is a serious threat to the safety of human life at sea or to the protection of its shipping areas or coastal zones, or those of other States. The provision has not been incorporated into national law, probably due to the absence of such weather conditions on Spanish coasts.

\subsubsection{Control of ships}

\subsubsection{The control of ships in Spain}

The legal regime of this activity is basically contained in the State Ports and Merchant Navy Act, pursuant to which it is the responsibility of the Ministry of Transports, Mobility and 
Urban Agenda to regulate and carry out inspections and technical, radioelectric, safety and pollution prevention controls of all Spanish civil ships, those under construction in Spain, as well as those flying the flag of a foreign State, provided that international agreements authorize such control. Included are the (type) approval of the elements and devices of the ship or its materials or equipment, for reasons of protection of maritime safety, human life at sea and navigation. These inspections may be conducted, either directly by the Ministry or through collaborating entities, in the terms determined by law, which shall, in any case, act under the criteria and guidelines established by the competent Administration (Royal Decree No. 877/2011, of 24 June, on common rules and standards for entities dedicated to ship inspection and recognition and for the corresponding activities of the Maritime Administration, as amended) and may receive a financial compensation to cover their costs as consideration for their services.

The legal framework contained in the SPMNA has been developed by Royal Decree No. $1837 / 2000$, of 10 November, establishing the Regulation on inspection and certification of civil vessels, as amended by Royal Decrees No. 638/2007, of 18 May, and No. 804/2014, of 19 September. Pursuant to Article 1(3) of the Regulation, the objective of the inspection is to verify that the ship, her devices, elements, materials or equipment, her crew, her cargo and her operating procedures meet, with respect to the purpose for which the ship is intended, the applicable requirements and conditions established by national and international regulations in force in Spain regarding maritime safety - which, for the purposes of the Regulation, shall be understood as safety of human life at sea, of the ship and of maritime navigation - and the prevention of marine pollution of the marine environment produced by ships.

The aforementioned Regulation is structured in three Titles. Title I ('General principles and organization') determines the object and scope of application of the Regulation, the scope and content of the inspections and controls regulated therein, the applicable exemptions and exceptions, as well as the organization and regulation of the inspection activity. The second Title ('Inspection activity') establishes the rules and guiding principles of the inspection, its forms of initiation and completion, the survey activities to be performed during the process of building a ship, its transformation, repair, reform or modification, and during its service, as well as the general principles of (type) approval of devices, elements, materials and equipment that must be installed on board vessels flying the Spanish flag. The rules of this Title apply to ships flying the Spanish flag, those built in Spain for exportation, ships flying the flag of a foreign flag which enter a Spanish shipyard to be transformed or repaired, and those that call at Spanish ports. Finally, Title III ('Sanctions') envisages, in accordance with the general framework established by Title IV of the SPMNA, the exercise of the sanctioning power of the Maritime Administration with respect to ship inspection and certification activities.

The purpose of such surveys is diverse, but basically extends to the verification of the requirements established in national and international maritime safety regulations: SOLAS, MARPOL, STCW/95, ILO Conventions on working conditions and training, the International Regulations for Preventing Collisions at Sea, the 1966 International Convention on Load Lines, the Conventions on Minimum Standards applicable to Merchant Shipping, etc. The competence on this matter is attributed to the Ministry of Transports, Mobility and Urban Agenda, specifically, to the Sub-Directorate General for Maritime Inspection, a body which, as explained above, is attached to the Directorate-General for 
the Merchant Navy and assumes, among others, the functions related to the regulation and execution of inspections and radioelectric, technical (Royal Decree No. 1185/2006, of October 16, establishing the Regulation on maritime radiocommunications on board Spanish civil vessels, as amended), safety and pollution prevention controls.

Inspection activities cover various stages of the life of a ship: a stage prior to her construction, in which they will have as their object the revision of the ship's construction project and all the associated technical documentation; the stage corresponding to the entire process of construction of the ship, which will cover all activities carried out from the material collection phase until the end of the official tests, including the keeling of the ship and her launching; the stage during which the ship provides her services, which will cover all those performed from the moment the first certificates are issued to the ship, until the moment when her activities cease; and the final stage in which the vessel is scrapped or voluntarily sunk.

Article 6 of the Regulation specifies in detail the aspects to which the inspection activity is extended. Suffice it to say that it includes both the vessel and the devices, elements, materials and equipment installed therein, as well as the procedures and operational requirements related to loading, stowage and unloading of general cargo, lashing on board of cargo loaded in units, transport conditions of solid bulk cargo, special operations of emptying, filling or cleaning of tanks for liquid bulk, dangerous or highly polluting goods, with their special provisions on packaging, transport authorization, loading, stowage, unloading, lashing and any type of manipulation to which they may be subject to, communication between crew members, drills for procedures in case of fire or abandonment of the ship, procedures for damage control, plans associated to firefighting systems, command operations from the bridge, operation of the machines, information that must be provided through manuals, instructions or other documents related to the safety of operations on board and the prevention of pollution of the marine environment and the atmosphere, including the treatment and discharge of hydrocarbons and oily mixtures from the engine room, as well as garbage and sewage water to the sea, or the limited use of fuels polluting the atmosphere.

Inspection by the Administration will be directed, executed and supervised by the Directorate-General for the Merchant Navy, through its central and peripheral organs. Passing the established controls originates the right to obtain the corresponding certificates, which may be those provided in international or national regulations. To hold such certificates in force accredits compliance with the applicable regulations, so it can be presumed, at least prima facie, that the vessel is in proper conditions of maintenance and seaworthiness (Judgment of the Spanish Supreme Court of 28 November 2004). However, the inspection report, which is issued in the context of an administrative procedure, must be assessed, just like any other piece of evidence, according to the rules of reasoned judgment (Judgment of the Supreme Court of 18 October 2005).

According to the statistics elaborated by the Paris Memorandum of Understanding (MoU) on Port State Control, the Spanish flag meets the organization's 2018 low risk criteria, valid for the period from July 2019 through June 2020, and appears on its White List regarding Flag Performance.

\subsubsection{Port State Control (PSC)}

Under the current rule in international law of the sea, the vessel is subject exclusively to the jurisdiction of the flag State in all aspects that have to do with the design, the construction, 
the crew or its equipment. The safety control of the ship is, therefore, the exclusive competence of the flag State, and other States cannot interfere in this field.

In the event that the flag State does not adequately comply with its control obligations, a serious problem for maritime safety arises, as there will be ships that do not comply with the minimum international standards in this field, which are usually referred to as $s u b$ standard ships. The mechanisms established by international law of the sea to remedy this undesirable situation are clearly insufficient. As provided by Article 94(6) of the UNCLOS,

a State which has clear grounds to believe that proper jurisdiction and control with respect to a ship have not been exercised may report the facts to the flag State. Upon receiving such a report, the flag State shall investigate the matter and, if appropriate, take any action necessary to remedy the situation.

It is so evident that this rule fails to prevent navigation of substandard ships that some members of the international community reacted by providing alternative mechanisms for the protection of maritime safety, thus configuring the control of the ship by the port State.

All European Directives on this matter have been correctly transposed into Spanish Law by means of successive Royal Decrees, which contain all the requirements that ships must meet, certificates that must be carried on board and that have to be controlled, inspection procedures (inspection and detailed inspection), as well as the measures to be taken. The legal framework currently in force is contained in Royal Decree No. 1737/2010, of 23 December, establishing the Regulation on inspections of foreign ships in Spanish ports (as amended by Royal Decree No. 1004/2014, of 5 December, in order to adapt Spanish internal law to the requirements derived from Directive 2013/38/EU, of 12 August 2013, a modification that aims to include references to the 2006 Maritime Labour Convention). The latest amendment introduced in Directive 2009/16/EC by Directive (EU) 2017/2110, which refers to ro-ro passenger ships and high-speed passenger craft in regular service, has only recently been transposed into national law by Royal Decree No. 733/2019, of 20 December (the deadline to do so expired on 21 December 2019).

The purpose of Royal Decree No. 1737/2010 is the reduction of the number of vessels that fail to comply with the applicable standards in waters over which Spain exercises sovereignty, sovereign rights or jurisdiction, thus increasing the compliance with international rules and regulations on maritime safety, pollution prevention and living and working conditions on board ships. It also aims at establishing standards for ship control by harmonizing survey and detention procedures with regard to the commitments assumed by the maritime authorities of the Member States under the Paris MoU.

The Regulation on inspections of foreign ships in Spanish ports applies to any vessel that calls at or is anchored in a sea port or facility in waters over which Spain exercises sovereignty, sovereign rights or jurisdiction, as well as to the crew of said vessel, and to the off-port inspections of ro-ro and high-speed passenger vessels and crafts during regular navigation (Article 3). The competent authority in Spain for the inspection and survey of ships is the Ministry of Transports, Mobility and Urban Agenda, which will exercise it powers through the Directorate-General for the Merchant Navy, as well as the Harbour Masters as peripheral maritime administration.

The minimum content of initial inspections shall be the verification of the certificates and documents listed in Annex IV of the Royal Decree that may be required from the 
inspected vessel, as well as the examination of the general conditions of the vessel - in particular, those of the engine room and the accommodations - and the hygienic conditions. Inspectors may examine all certificates and documents, apart from those listed in Annex IV of the Royal Decree, that, in accordance with the conventions in force, must be carried on board. If the survey gives rise to well-founded reasons (clear grounds) to estimate that the conditions of the ship, her equipment or her crew substantially violate the requirements established by an agreement in force, a more detailed inspection will be carried out, including further control of compliance with the operational aspects of the ship. There are such clear grounds when the inspector finds such evidence that, according to his professional criteria, warrants a more detailed inspection of the ship, her equipment or her crew. An indicative list of clear grounds is established in Annex V of the Royal Decree. An expanded inspection is mandatory for certain vessels, which are determined in the Regulation. Once the inspection is completed, be it initial, more detailed or expanded, the surveyor will prepare an inspection report containing the data established in Annex IX of the Royal Decree, a copy of which will be delivered to the ship's master.

As a result of the inspection, rectification of any deficiencies which have been confirmed or detected may be required, in accordance with the international treaties in force and to the satisfaction of the competent authorities. Where such deficiencies are manifestly dangerous for maritime safety, health or the marine environment, the Harbour Master will proceed to immobilize the ship following the procedure established in Article 13(1) of the Regulation, notifying the port pilotage service thereof, or to paralyse the operation in which the deficiencies have been observed. The detention of the ship or the suspension of an operation shall not be lifted until the danger disappears, or until said authority decides that, under certain conditions, the ship may go to sea or may resume the interrupted operation, without risk to maritime safety or for the health of passengers and crew, or for other ships, or to the integrity of the marine environment.

Finally, the Royal Decree establishes the obligation of the Maritime Administration to act with prudence and proportionality. To this end, when said administration is to carry out any action of those provided for in the Regulation, it must avoid, as far as possible, that ships are immobilized or unduly delayed. In the event of undue detention or delay, the owner has a right to be compensated for the loss or damage suffered, provided that the requirements to declare the patrimonial liability of the Public Administration are fulfilled, as provided in Chapter IV of the Preliminary Title of Act No. 40/2015, of 1 October, on the Legal Regime of the Public Sector.

\subsection{The application and enforcement of maritime safety and security regulations}

The Spanish legislative framework on maritime safety and security regulations consists of international, EU and domestic legislation. The main regulation is the 2014 Maritime Navigation Act that addresses the indispensable co-ordination of Spanish maritime law with international maritime law, whilst adapting it to the present practice of sea transport. It puts an end to the shortcomings that had been detected with regard to multiple national interests whose protection shall be reinforced. That is the case of navigational safety, protection of the environment and the underwater cultural heritage, use of the territorial seas, combating pollution, Spanish interests in fishing matters, borders and immigration, or the fight against smuggling. Collisions, salvage and pollution are also addressed in the Maritime Navigation Act. 
Article 96 of the Spanish Constitution establishes that validly concluded international treaties become an integral part of the domestic legal order as soon as they are published in the Official Journal. From that moment on, the relevant provisions may only be repealed, amended or suspended in the manner provided in the treaties themselves or in accordance with the general rules of international law. As a consequence, the treaties and conventions which have been ratified, accessed or approved by Spain are binding upon their publication in the Official Journal, and no further internal regulations are needed to achieve this effect. However, especially as regards the amendments of the SOLAS Convention in accordance with its Article VIII (which do not require express acceptance by all contracting governments), publication on occasions occurs after entry into force of the instrument for Spain.

The foregoing is without prejudice to the possibility that national laws and regulations establish particularities regarding the application of certain conventions in Spain. Unfortunately, where this is the case, it has not been done by way of a single text - such as the MNA, as a sort of Spanish 'Maritime Code', or the SPMNA, as the fundamental act as regards the administrative organization of ports and maritime transport, but through rules of different rank and content, which cannot all be reproduced here. Paradigmatic is the case of the SOLAS Convention, whose scope of application is limited, in principle and as regards cargo ships, to ships of 500 gross tonnage or more (Reg. I-A3(a)(ii)). By virtue of Royal Decree 1661/1982, of 25 June, the provisions of the Convention are declared applicable to all Spanish civil ships and vessels, including fishing vessels and pleasure craft, whatever their size, although limitations can be established in view of the characteristics of such ships and vessels and the activities they carry out. To put this provision in practice, complementary regulations to the SOLAS Convention have been enacted by way of an Order of 10 June 1983. However, for most of the vessels to which the Convention does not apply per se - certain recreational and fishing vessels, fundamentally - other more specific safety rules now apply.

Finally, as regards infringements of the maritime safety and security regulations, the principle of legality enshrined in Article 25(1) of the Spanish Constitution requires that both the infringing behaviour and the sanctions that correspond thereto are established, in principle, in a provision enacted by the Parliament and not by the Government or other administrative bodies. Accordingly, the regime of infringements of the regulations on maritime safety and security is contained in Title IV SPMNA, which describes the punishable behaviour and classifies the infringements as minor, serious and very serious ones. The sanction to be imposed depends on the seriousness of the infringement and can be up to 60,000 euros in the case of minor infringements; up to 180,000 euros (infringements against maritime safety) or 601,000 euros (pollution of the marine environment) in the case of serious infringements; and up to 901,000 and 3,005,000 euros, respectively, for very serious infringements (Article 312 SPMNA), in addition to other possible penalties (e.g. retention of the ship). Apart from that, certain non-sanctioning measures may also be imposed, such as the refusal to perform calls or to depart, or to load or unload the ship.

\subsection{Liability}

The Kingdom of Spain is a party to most of the liability convention referring to financial security instruments: CLC (BOE n. 58, 8 March 1976), as well as its 1992 Protocol. Furthermore, Spain is a contracting party to the Convention establishing the International 
Fund for compensation of oil pollution, 1971, and to the 1992 and 2003 related Protocols (BOE n. 28, 2 February 2005). Moreover, the Kingdom of Spain is also a party to the Bunker Convention (BOE n. 43, 19 February 2008) and OPRC (BOE n. 113, 5 June 1995), as well as, regarding seafarers' rights, MLC 2006 (BOE n. 19, 22 January 2013).

Conversely, Spain has not ratified the International Convention on Liability and Compensation for Damage in Connection with the Carriage of Hazardous and Noxious Substances by Sea (1996 HNS Convention). Neither is it a party to the Nairobi Wreck Removal Convention of 2007, so that this matter is still governed by a specific provision in the State Ports and Merchant Navy Act (Article 304), according to which the owner of the vessel has the duty to remove the wreck. Act No. 14/2014, on Maritime Navigation, also establishes some obligations for ship-operators and masters: they must notify the Maritime Authorities of such events pursuant to the terms and to the ends determined by the implementing regulations. Maritime Authorities shall proceed of their own motion to inform the owners of ships and other damaged property within their territorial scope of competence so that the latter may adopt the urgent measures they deem convenient to their interests.

According to Article 389(1) MNA, civil liability insurance for damages due to pollution of the coast and navigable waters is compulsory. Accordingly, the Maritime Administration will prohibit the navigation of any ship or vessel without insurance cover, and it will deny the entry into or exit from any Spanish port or anchorage to any foreign ship or vessel that lacks the aforementioned insurance (Article 390 MNA). This general framework is complemented by Royal Decree No. 1892/2004, of 10 September, that adopts rules for the execution of the CLC, including compulsory insurance, and Royal Decree No. 1795/2008, of 3 November, with respect to bunker oil. The certificate evidencing the existence of insurance (or of a financial guarantee other than insurance) is issued by the DirectorateGeneral of the Merchant Marine.

\subsection{Concluding remarks}

As a general conclusion, it can be said that the compliance of Spanish national legislation and practice with the IMO legal framework is quite high. The 2014 Maritime Navigation Act brought about an ample reform of Spanish Maritime Law, considering all its aspects. It was meant as a renewal that did not seek a mere update and compilation, but, rather, also addressed the indispensable co-ordination thereof with international maritime law. The Act allowed the contradictions between the different international conventions in force in Spain and the disperse provisions governing the matter to be overcome. Its Preliminary Title is in line with the most modern views of maritime law, and Article 2 establishes a general rule that obliges the Act to be interpreted in the light of international conventions in force in Spain. Besides, that aim explains the legislative technique employed in 2014, based on a continuous reference to the current conventions for each matter, reserving to the Act the role of providing content to the space that is left by such international treaties to the legislative intervention of the contracting States.

The Spanish legal framework also adequately addresses specific issues, such as the traffic in the Strait of Gibraltar, one of the planet's major hotspots, in coordination with the Moroccan Authorities. The combination of an area with very dense traffic, a high concentration of crossing tracks and occasionally very unfavourable weather conditions within a narrow channel have forced the Spanish and Moroccan governments to promote, through 
the International Maritime Organization, the establishment of several maritime traffic organization and monitoring measures - traffic separation scheme, mandatory reporting system, precautionary areas, vessel traffic services - complemented by an extensive network of maritime signals covering both northern and southern coasts.

Of course, there is room for improvement, issues that should be studied in more detail, mainly those that have to do with new realities and emerging problems, such as illegal immigration and unmanned ships. As a maritime country with an immense coastline, Spanish public opinion is very aware of these problems and pressures the political powers in search of adequate solutions; for example, a large number of events, such as medical transfers, pollution incidents in port service waters, operations related to the use of recreational crafts and devices, swimmers, diving and other nature-related events, which require the deployment of specific marine search and rescue resources.

In this context, the Strait of Gibraltar is among Spain's biggest security headaches, as a crossroads for a range of illegal activities, notably drugs, arms and human trafficking. These country-specific problems, which affect maritime safety, are monitored by the Maritime Action Surveillance Operations Centre (COVAM), based in the Mediterranean port city of Cartagena. This centre monitors all activity not just in the Strait of Gibraltar, but anywhere that Spanish vessels operate, for instance, protecting fishing boats in the Gulf of Guinea or combating piracy in the Indian Ocean. All information is at the disposal of other agencies with responsibility over Spanish waters, such as the Civil Guard's National Centre for the Coordination of Maritime Surveillance of Coasts and Borders, located in Madrid. The information is also simultaneously cross-checked with data supplied by the EU's border agency (Frontex), along with Eurosur's drones, reconnaissance aircraft and satellites.

On the other hand, in many Spanish universities, in particular, the Jaume I-University of Castellon, the University of Cadiz and the University of the Basque Country, there are working groups that continuously propose and promote legislative improvements on these matters.

Finally, it should be noted that there is further legal work in preparation, dealing with maritime safety, protection of the environment and underwater cultural heritage, use of the territorial seas, combating pollution, Spanish interests in fishing matters, borders and immigration, or combating smuggling. But most of the regulations are still in a very embryonic state, within their respective ministries, and pending the necessary political stability in the Spanish Parliament. 


\title{
Maritime safety in Turkey
}

\author{
Ahmet Gelgeç
}

\subsection{Introduction}

Today safety is a very important aspect of the shipping industry that probably has impacts on all elements of it. As maritime transportation is by default international in character, it is fair to say that maritime safety should be considered very international as well. Since Turkey, being bathed by the Mediterranean Sea to the south, the Aegean Sea to the west, the Black Sea to the north, is situated in a location where maritime traffic is highly dense, maritime safety has the utmost importance not only for Turkey itself but also for the littoral states of these seas; though it is important to have a look at what falls within "maritime safety in Turkey", before closely scrutinising it in Turkey in general.

All the relevant legislation, which will be discussed below, in connection with safety at sea, is concerned with a set of measures that are taken to aim at protecting human life, vessels, cargo and the marine environment. This set of measures includes prevention of or reducing incidents that may cause marine environmental pollution, technological and operational safety of vessels, safety of navigation and vessel traffic monitoring and information systems. In the maritime context, this draws a line between safety and security in Turkey, as the latter in general is rather concerned with international peace and security, sovereignty, piracy, terrorist or unlawful acts in waters.

That is to say, this chapter does not deal with the security element but only with maritime safety in Turkey and is structured as follows: section 2 is a brief overview of national institutions in Turkey that are in charge of the implementation of maritime safety law; section 3 outlines the maritime safety law applicable in Turkey, including the implementation of international maritime conventions and other legal instruments related to maritime safety into national law, and whether they are combined within a single act. While section 4 deals with prevention, control and surveillance elements in the context of maritime safety, section 5 covers whether Turkey is a party to any liability convention related to financial security instruments. Eventually, section 6 involves a general assessment by drawing a number of conclusions on the status quo and future of maritime safety in Turkey.

\subsection{National institutions for the implementation of Maritime Law}

In Turkey, the Ministry of Transport and Infrastructure is the main governing authority on all maritime related affairs, including policymaking and acceding or signing international conventions. The Ministry has a number of general directories that are authorised, as to their corresponding subjects, on the implementation of maritime law. The Directorate 
General of Maritime and Inland Waters Regulation, ${ }^{1}$ the Directorate General of Dangerous Goods and Multimodal Transport Regulation ${ }^{2}$ and the Directorate General of Maritime Trade $^{3}$ are the sub-bodies controlling, monitoring and ensuring the accurate implementation of maritime law in Turkey.

The Directorate General of Maritime and Inland Waters Regulation has several duties, such as regulating the rights and obligations of service providers and the beneficiaries of those services in maritime transportation, keeping the registry of vessels as well as keeping the registries for seafarers. It also regulates the minimum safety standards for the management of vessels, issues safety documents and inspects vessels accordingly. It is also one of the main duties of the Directorate to aim at ensuring maritime safety and marine pollution prevention both in territorial seas and inland waters in a sustainable, convenient and free environment. It is also under a duty to determine the minimum standards of maritime safety as well as issuing those documents accordingly. The Directorate also sets procedures on the permissible level for seaworthiness of vessels and carries out inspections accordingly. It specifies the procedures and principles as to pilotage, towage and salvage services and authorises and inspects third parties that can provide such services in Turkish ports and coasts. It is also under a duty to publish all sorts of maps, books and necessary publications and services for marine navigation. In addition, the Directorate is authorised to regulate the procedures and rules for the prevention of marine pollution, and inspect vessels accordingly that are within Turkish territorial and inland waters. One of the most important duties of the Directorate is to take all necessary precautions that are within its power for the prevention of marine pollution and cooperate with the relevant international organisations in this regard.

On the other hand, the Directorate General of Dangerous Goods and Multimodal Transport Regulation is authorised to make sure that carriage of dangerous goods by sea, rail and road is performed in accordance with the national legislation and the international conventions under sustainable circumstances and that it sets minimum standards for all the necessary precautions for prevention of accidents and inspects those vehicles used for carriage of dangerous goods by sea, rail and road. It is also noteworthy to say that the Directorate General of Maritime Trade is authorised to carry out all maritime trade-related strategy and policymaking activities. Also, in the direction of Turkey's accession into the EU, in order to strengthen its administrative and institutional structure in maritime transport and to render them up to the EU standards, Turkey adopted a five-year maritime transport action plan in 2003 that ensured compatibility to some extent with the EU acquis in relation to maritime safety. In supporting this, in 2004, the Directorate General of Maritime and Inland Waters Regulation started to work on implementation of a comprehensive project (the Twining project) with the collaboration and participation of Spain, aiming to improve both the legislative and institutional structure of Turkey in maritime transport up to EU standards. Albeit being a private organisation, it is also worth noting that the Turkish

1 See Art. 9 of 655 numbered Statutory Decree on the Governance and Duties of Ministry of Transport, Maritime Affairs and Communication. By virtue of Art. 31 of 703 numbered Statutory Decree, the title of 655 numbered Decree was changed to 'The Regulations on Transport and Infrastructure'. For the other amendments made, see Art. 31 of 703 numbered Statutory Decree.

2 See, Art. 10 of 655 numbered Decree.

3 See, Art. 11 of 655 numbered Decree. 
Chamber of Shipping regularly provides substantial assistance to the Turkish maritime industry on the guidance and development of national policies and practices in sea trade. ${ }^{4}$

\subsection{Overview of the legislative framework and enforcement}

Legislation in Turkey is mostly made up of acts and statutory instruments of the Parliament. Maritime-related rules are not amalgamated under one set of a maritime act. The main sources of Turkish maritime law is the fifth book of 01.07.2012 and numbered 6102 Turkish Commercial Act (TCA), ${ }^{5}$ Cabotage Act No. 815, the Act on the Turkish International Ship Registry No. 4490 and Ports Act No. 618. As a result of being a completely international affair, maritime industry inherently obliges nations to work in close collaboration with each other both at regional and multinational level. Such collaborations include having an international regulatory framework concerning countries' rights and obligations in relation to maritime safety. Safety at sea is one of the elements that has drawn and in fact still draws a great deal of interest by all shipping nations around the world. In order to provide a comprehensive framework of subject-detailed regulations applicable throughout the world, the idea of improving safety at sea has spawned many international conventions.

Turkey, as a shipping nation, is a contracting state to many international conventions made in the maritime context and gives utmost importance to those conventions, normhierarchy-wise. Upon entering into force, in pursuant of Article 90, para. 5 of the Turkish Constitution, ${ }^{6}$ international conventions that are given effect by an act have the same statutory effect as the other local acts applicable under Turkish law, ensuring that the international conventions would prevail over the Articles of the TCA in case a discrepancy arose between their corresponding provisions. For the avoidance of such conflict of laws, the committee drafting the TCA adopted an approach ensuring the TCA (which entered into force in 2012) was up to date with the international trading requirements of the shipping industry, and accordingly took into consideration these international conventions when drafting maritime-related provisions. As a result, some of those conventions related to maritime safety were directly incorporated into the TCA. Turkey acceded to the International Convention on Salvage (Salvage Convention 1989) in 2014 and, save for some exceptions, its provisions were also directly incorporated into the TCA. ${ }^{7}$ The same can be said for the Convention for the Unification of Certain Rules of Law with respect to Collisions between Ships (Collision Convention 1910) and its provisions were also incorporated into the TCA. ${ }^{8}$

On the other hand, Turkey is a contracting state to the Convention on Limitation of Liability for Maritime Claims (LLMC 1976). The Convention and the Protocol of 1996 to amend the Convention are given effect as per Article 1328 of the TCA, in respect of conflicts over limitation of liability claims. Turkey is also a contracting state to the International Convention on the Establishment of an International Fund for Compensation for Oil Pollution Damage (FUND 1992) ${ }^{9}$ and the International Convention on Civil Liability for

4 See, www.deniticaretodasi.org.tr/en-en/pages/home.aspx.

5 Date of Official Gazette: 14.02.2011, Number of Official Gazette: 27846.

6 Date of Official Gazette: 18.10.1982, Number of Official Gazette: 17844.

7 Date of Official Gazette: 24.05.2014, Number of Official Gazette: 29009; from Art. 1298 to 1319.

8 Date of Official Gazette: 22.02.1955, Number of Official Gazette: 8937; from Art. 1286 to 1297.

9 Date of Official Gazette: 29.01.2000, Number of Official Gazette: 23948. 
Oil Pollution Damage (CLC 1992). ${ }^{10}$ Both are applicable in Turkey and given effect by Article 1336 of the TCA. It is also worth noting that, unlike CLC 1992, the 2872 numbered Environment Act $^{11}$ of which scope is not limited to oil pollution damage only, deals with liabilities arising from any kind of pollution or damage to the environment. In case of conflict between provisions of CLC 1992 and the Environment Act, as per Article 1336 of the TCA, CLC 1992 will overrule the application of the Act.

On the other hand, Turkey signed the founding convention of the IMO (Convention on the International Maritime Organization 1948) as well as the IMO 1991 and 1993 amendments. In 2011, Turkey volunteered to be part of the IMO's member audit scheme (VIMSAS), which is an initiative to ensure the implementation of IMO conventions by its member states. Turkey is a signatory to many IMO regulations as well. It is a contracting state to the International Convention for the Safety of Life at Sea (SOLAS 1974) ${ }^{12}$ as well as the International Convention for the Prevention of Pollution from Ships 1973, as modified by the protocol of 1978 (MARPOL 73/78). ${ }^{13}$ It is also noteworthy that Turkey acceded to all Annexes I, II, III, IV, V and VI of MARPOL 73/78. Turkey is also a contracting state to the International Convention on Load Lines 1966 (LOAD LINES 66). ${ }^{14}$ It also acceded to the International Convention on Tonnage Measurement of Ships (TONNAGE 69). International Convention on Civil Liability for Bunker Oil Pollution Damage (Bunker Convention 2001) has also been ratified by Turkey. Turkey is party to the Convention for the Suppression of Unlawful Acts against the Safety of Maritime Navigation, and the International Convention on Oil Pollution Preparedness, Response and Co-operation 1988 and the International Convention for the Control and Management of Ships' Ballast Water and Sediments as well. There is also an Act on Principles of Emergency Response and Compensation for Damages in Pollution of Marine Environment by Oil and Other Harmful Substances ${ }^{15}$ which in general aims to eliminate or reduce the risk of pollution in emergency cases generating from vessels or coastal facilities.

It should also be noted that Turkey has not signed the United Nations Convention on the Law of the Sea (UNCLOS). On the other hand, despite the fact that there is an adoption process under way, Turkey has yet to accede to the Maritime Labour Convention 2006 (MLC) or the Nairobi International Convention on the Removal of Wrecks 2007 (the Nairobi Convention). However, there is a Marine Labour Act ${ }^{16}$ numbered 854 that mainly deals with the rights of master and seafarers under the employment contract. Turkey is also a signatory to many ILO conventions in relation to seafarers and dockworkers: the Officers' Competency Certificates Convention 1936; Shipowners' Liability (Sick and Injured Seamen) Convention 1936; the Food and Catering (Ships' Crew) Convention 1946; the Accommodation of Crews Convention 1949; Seafarers' Identity Documents Convention 1958; the Accommodation of Crews (Supplementary Provisions) Convention 1970; and finally the Prevention of Accidents (seafarers) Convention 1970. There is also an

\footnotetext{
10 Ibid.

11 Date of Official Gazette: 11.08.1983, Number of Official Gazette: 18132.

12 Date of Official Gazette: 25.05.1980, Number of Official Gazette: 16985.

13 Date of Official Gazette: 24.06.1990, Number of Official Gazette: 20558.

14 Date of Official Gazette: 28.06.1968, Number of Official Gazette: 12936.

15 Date of Official Gazette: 11.03.2005, Number of Official Gazette: 25752.

16 Date of Official Gazette: 29.04.1967, Number of Official Gazette: 12586.
} 
Act on Protection of Life and Property at $\mathrm{Sea}^{17}$ in which its provisions generally deal with sea, cargo and voyage worthiness of vessels.

Some of the international conventions were given effect via by-laws in Turkey. The Convention on the International Regulations for Preventing Collisions at Sea (COLREG) ${ }^{18}$ was given effect by the 12.12.1977 dated and 7/14561 numbered By-law on Prevention of Collision at Sea. ${ }^{19}$ The Regulation on Seafarers ${ }^{20}$ is worded in accordance with the International Convention on Standards of Training, Certification and Watch-keeping for Seafarers (STCW 1978) as amended in 1995 (STCW 95) to which Turkey is a contracting state. ${ }^{21}$ The rules of COLREG are incorporated and specified in the relevant by-law. In addition, the Regulation on the Carriage of Dangerous Goods by Commercial Ships ${ }^{22}$ is worded in line with SOLAS 1974 and MARPOL 73/78. The Regulation on Investigation and Examination of Marine Accidents and Cases is also worded in line with the relevant Articles of SOLAS 1974, MARPOL 73/78, LOAD LINE 66 and STCW 95.

As for sanctions against breaches concerning maritime safety, the main legislations are the Environment Act, ${ }^{23}$ the Act on the Principles of Emergency Action and Indemnification of Losses in the Pollution of the Marine Environment by Oil and Other Hazardous Substances (5312 numbered Act) ${ }^{24}$ as well as the Turkish Criminal Act. ${ }^{25}$ The sanctions are mainly of an administrative and criminal nature. As a result of the lex superior principle, for breaches concerning the pollution of the marine environment by oil and other hazardous substances, the 5312 numbered Act prescribes monetary sanctions as well as administrative ones, including denial of the right of vessel access to Turkish ports. The authorities such as the Environmental Protection Agency, harbour masters and public prosecutors are entitled to issue fines for non-compliance by vessels with the legislation in case of pollution arising from oil or other hazardous substances. Any other breach concerning the environment falls within the scope of the Environment Act and most sanctions are of monetary nature thereunder.

On the other hand, according to the Turkish Criminal Act, regardless of whether the act is deliberate or negligent, causing damage to the environment is considered an offence and there are penalties for those offences accordingly. ${ }^{26}$ The same can be said for offences against transportation safety, irrespective of whether they result from negligence or deliberate act. $^{27}$

17 Date of Official Gazette: 14.06.1946, Number of Official Gazette: 6333.

18 Date of Official Gazette: 18.11.1984, Number of Official Gazette: 18579.

19 Date of Official Gazette: 29.04.1978, Number of Official Gazette: 16273.

20 Date of Official Gazette: 31.07.2002, Number of Official Gazette: 24832.

21 Turkey also adopted the 2010 Amendments of the STCW Convention; Date of Official Gazette: 23.08.2012, Number of Official Gazette: 28390.

22 Date of Official Gazette: 03.03.2015, Number of Official Gazette: 29284.

23 Date of Official Gazette: 09.08.1983, Number of Official Gazette: 2872.

24 Date of Official Gazette: 03.03.2005, Number of Official Gazette: 5312.

25 Date of Official Gazette: 26.09.2004, Number of Official Gazette: 5237.

26 By virtue of Art. 181 and 182.

27 By virtue of Art. 179 and 180. 


\subsection{Prevention, control and surveillance}

\subsubsection{Port State Control}

Port State Control (PSC), as evidenced from the wording, with the purpose of the preservation of the environment and protection of life, is the controlling and supervising mechanism of vessels - irrespective of their flag - that are intended to sail into or leave one of the ports in a state. PSC thus is said to be globally a significant mechanism to ensure maritime safety around the world. There are nine regional agreements on PSC signed by the states around the world. ${ }^{28}$

Turkey, as encircled by seas on three sides with some of the busiest ports in Europe, has an important role to play as a port state to ensure safety at sea. It should be noteworthy at this point that even well before those aforementioned memoranda of understandings, inspections would take place in Turkish ports, on board both Turkish flag and foreign flag merchant ships, ensuring that those ships met safety, security and environmental standards along with the living and working conditions of crew members as per the 10.06.1946 dated and 4922 numbered Act on Safety of Life and Goods at Sea. ${ }^{29}$ However, this Act only had a limited impact as being only a local law.

Today, the Paris MoU is considered as the most important PSC and each year an annual report is published, including a "White, Grey and Black list" which classifies states into black, grey or white lists in accordance with the performance of those states on the basis of the inspections and detentions combined over a three-year period. Since 2009, Turkey is regularly on the Paris MoU's white list. In order to update its regulations on maritime safety and the environment, in parallel with Directive 95/21/EC, in 2006, the By-Law on Port State Control came into force in Turkey, which effectively applies to 23 major ports in Turkey. Similarly, with Resolution A.739 of the IMO and Directive 94/57/EC, the Regulation on Selection and Authorization of Classification Societies Acting on Behalf of the Flag State for Turkish-Flagged Ships entered into force in 2003 which applies to Turkish and foreign companies that have submitted to the administration so as to undertake the testing, inspection, approval and certification of Turkish-flagged ships. Following the Authority Assignment Protocol, Turkey has authorised several members of International Association of Classification Societies (IACS) on the matter, including Bureau Veritas, Registro Italiano Navale, American Bureau of Shipping, Nippon Kaiji Kyokai, Lloyds Register, Det Norske Veritas. Although Turkish Lloyds is not a recognised classification society by the EU, the members of the Paris MoU consider Turkish Lloyds as a High Performance organisation and accordingly ships certified by Turkish Lloyds are subject to less inspection in Paris MoU ports. ${ }^{30}$

Turkey is also a signatory state on the establishment of a Port State Control agreement in the Mediterranean region (Mediterranean MoU) which has been in force since 1998. The relevant instruments to apply under the Mediterranean Mou are as follows: Load Lines

28 1. Europe and the north Atlantic (Paris MoU) 2. Asia and the Pacific (Tokyo MoU) 3. Latin America (Acuerdo de Viña del Mar) 4. Caribbean (Caribbean MoU) 5. West and Central Africa (Abuja MoU) 6. The Black Sea region (Black Sea MoU) 7. The Mediterranean (Mediterranean MoU) 8. The Indian Ocean (Indian Ocean MoU) 9. The Riyadh MoU.

29 As per Art. 6.

30 www.parismou.org/2018-performance-lists-paris-mou accessed 20.01.2020. 
1966, SOLAS 74 and SOLAS Protocol 1978, MARPOL 73/78/97, STCW 1978, COLREG 1972, ILO 147, MLC 2006.

On the other hand, Turkey is a member of another regional PSC with the main objective to eliminate sub-standard ships, which is the Black Sea MoU signed in Istanbul on 7 April 2000; the international instruments to apply under the Black Sea MoU are: Load Lines 1966, SOLAS 1974, MARPOL 73/78, STCW 1978, COLREG 1972, TONNAGE 1969, AFS 2001, BUNKER 2001, ILO 147, MLC 2006.

In order to ensure the implementation and incorporation of the relevant instruments into national law, including the international conventions that Turkey is party to - Resolution numbered A.1052(27) of the IMO for procedures for Port State Control alongside the Mediterranean MoU and Black Sea MoU - on 26.03.2006 the Regulation on Port State Control (PSC Regulation) came into force. ${ }^{31}$ Though to update its national instruments to international standards, Turkey amended the PSC Regulation in 2013 in accordance with Council Directive 95/21/EC of 19 June 1995 concerning the enforcement of international standards for ship safety, pollution prevention and the living and working conditions of seafarers. Additionally, the implementation of the International Ship and Port Facility Security Code (ISPS Code) Regulation on the Application of ISPS Code came into force in 2007, and to improve Turkey's standards up to the EU's level, the Regulation was worded in accordance with the relevant EU acquis, such as Regulation (EC) No. 725/2004 of the European Parliament and of the Council on enhancing ship and port facility security, Directive 2005/65/EC of the European Parliament and of the Council on enhancing port security and Commission Regulation (EC) no. 884/2005 on laying down procedures for conducting Commission inspections in the field of maritime security. ${ }^{32}$ In this regard, Turkey can be considered to have performed its obligations under SOLAS, Chapter XI/2. While the General Directorate of the Regulation of Seas and Inland Waters Regulation of the Ministry of Transport and Infrastructure is the main authority, Port State Controls are conducted by harbour master's offices in the relevant ports. At least 25 per cent of the total number of vessels entering in Turkish ports in a single year must be inspected by the relevant harbour master's offices.

Due to Turkey's work on harmonisation with both international conventions and EU rules and regulations in relation to PSC, it would not be wrong to conclude that Turkey has taken huge steps in order to align with these rules. Though, it is also opined that Turkey still appears to fall behind in the process of adoption and implementation of the EU's rules and regulations. First, in the long run, to maximise the maritime safety and security in its ports, Turkey should aim to be party to the Paris MoU. Also, the Regulation on Port State Control worded in accordance with Directive 95/21/EC should be amended as provided for in Directive 09/16/EC, which gave rise to a New Inspection Regime (NIR) developed by EC/EMSA that was eventually adopted by the Paris MoU in 2009.

31 For the Mediterranean MoU, save for the Protocol of 1997 (MARPOL), ILO 147 and MLC 06 - which has been ratified by Turkey and published in the Official Gazette numbered 30018 dated 25 March 2017, though it has not come into force yet - Turkey applies all the remaining instruments to all ships entering its ports. As is the case for the Mediterranean MoU, Turkey applies the relevant instruments of the Black Sea MoU, except for MLC 2006, ILO 147.

32 Art. 3 of the Regulation of ISPS Code. 


\subsubsection{Vessel traffic services and navigational safety}

Vessel traffic services (VTS) are shore-side systems, which provide significant contribution to safety at sea. The purpose of VTS is to enhance the safety and efficiency of navigation and protection of the marine environment by reducing or preventing the number of incidents, accidents and pollution by vessels or potentially dangerous situations at sea via a vessel traffic monitoring system. The importance of VTS was first recognised by the IMO in resolution A.158 (ES.IV) in 1968. In 1985, the IMO adopted resolution A.578 (14), 'Guidelines for Vessel Traffic Services'. Then these Guidelines were revised in A.857(20) in 1997 and in the same year the IMO's Maritime Safety Committee adopted a new regulation to Chapter V (Safety of Navigation), which set out when VTS could be implemented. ${ }^{33}$ On the other hand, for EU Member States, in an attempt to provide a greater level of collaboration and coordination within the EU, the guidelines for Vessel Traffic Monitoring and Information Services (VTMIS) were first adopted in Directive 2002/59/EC, then in Directive 2009/17/EC. Directive 2014/100/EU amended the previous directives, and incorporates the most up-to-date guidelines on the matter. ${ }^{34}$

Considering the fact that Turkey is surrounded by seas on three sides and has important straits including the Dardanelles and Bosporus Straits, VTS are considerably crucial to enhance the safety and efficiency of navigation and protection of the marine environment. In Turkey, in order to align legislation with the EU acquis on VTS, the Regulation on Establishment and Operation of Vessel Traffic Services came into force in 2007, which was drafted in parallel with Directive 2002/59/EC. Though the practices fall short to some extent, as VTMIS has only been in use in some regions like Izmit, and has yet to be fully implemented in other regions where maritime traffic is busy.

There is also a Practice Directive that is amended periodically by the General Directorate of the Regulation of Seas and Inland Waters Regulation with the purpose of minimising and preventing incidents within the Turkish Straits. Turkey also universally monitors Turkish-flagged as well as foreign-flagged ships that are within a 1,000 nautical miles radius of the Turkish coastline via the Long Range Identification and Tracking system (LRIT). Additionally, since 2007, the Automatic Identification System (AIS) has been in use. Although these regulations are consistent with the regulations of COLREG to a great extent, it must be emphasised that, in order to work in harmonisation with the EU on maritime safety, Turkey must amend the Regulation on VTS as consistent with Directive 2014/100/EU.

A few words must be also put in on navigational safety passage through the Turkish Straits, as they are considered one of the busiest ${ }^{35}$ and most perilous straits. The Dardanelles and Bosporus straits connect the Aegean sea to the Black Sea through the Sea of Marmara which is an inland sea as it is entirely located within the borders of Turkey. Factoring in the Sea of Marmara being an inland sea and the Bosporus Strait being situated on the coast of Istanbul which is one of the largest cities in Europe, an incident during passage through these straits resulting in pollution may have a large detrimental impact not only on the Sea

\footnotetext{
33 www.imo.org/en/OurWork/Safety/Navigation/Pages/VesselTrafficServices.aspx accessed 07.01.2020.

34 www.emsa.europa.eu/visits-to-member-states/vessel-traffic-monitoring-a-information-system.html accessed 07.01.2020.

35 https://atlantis.udhb.gov.tr/istatistik/gemi_gecis.aspx accessed 07.01.2020.
} 
of Marmara, but also on the Aegean and the Black Sea. It is therefore crucial to enable safe passage through these straits.

The main legislative work that governs passage through the Dardanelles and Bosporus Straits is the Montreux Convention Regarding the Regime of the Straits. Although the Montreux Convention in general sets out provisions on the manner of passage of merchant vessels and warships through the straits, it neither contains any provision dealing directly with the management of vessel traffic or navigational safety, nor includes a provision covering the protection of the marine environment or prevention of pollution in the Turkish Straits. To fill this gap in 1994, Turkey first enacted the Maritime Traffic Regulations on the Turkish Straits, dealing with vessel traffic management and a separation scheme in the Straits in general. The 1994 Regulation was later amended in the light of IMO recommendations in 1998 and recently in $2019 .{ }^{36}$ One of the key amendments is that the new Regulation addresses the transit of vessels carrying nuclear, dangerous or noxious goods and nuclear-powered vessels. Article 27 of the 2019 Regulations makes it clear that these vessels may transit through the Straits only in cooperation with the local authorities that are to plan their passage in advance, as they make sure these vessels do not pose any threat to the marine environment and traffic. Their passage is therefore made subject to the permission of the local authorities. In terms of maritime safety, another key amendment is provided by Article 30 of the 2019 Regulations, which permits passage through straits, provided that vessels must take all necessary precautions for marine protection and preventive measures for pollution that are set out in the local legislation and have the documentation evidencing this is ready. There is also a VTS in force since 2003, specifically dealing with the traffic management in the Straits, which provides navigational assistance to vessels during passage.

In relation to safety in the Straits, as there has been no major reported incident resulting in marine pollution in the Straits since VTS in the Straits was introduced in 2003 and Maritime Traffic Regulations on the Turkish Straits which first came into force in 1998, Turkey can be said to have taken a successful approach both in improving maritime safety and in reducing marine pollution in its Straits accordingly, as well as the littoral states on the coastline of the Aegean and the Black Sea.

\subsubsection{Prevention of casualties and marine pollution, collisions, salvage and wrecks}

In order to provide an international standard for prevention of casualties and marine pollution, the International Management Code for the Safe Operation of Ships and Pollution Prevention (ISM Code) was adopted by the IMO, which was also amended in Chapter IX of SOLAS that made its application mandatory. The ISM Code provides safety management objectives and requires companies ${ }^{37}$ to develop and maintain a Safety Management

36 Maritime Traffic Regulations on the Turkish Straits 2019; Date of Official Gazette: 15.08.2019, Number of Official Gazette: 30859 . The importance of the Turkish Straits in respect of VTS is also recognised by the IMO which adopted Resolution A.827(19) in 1995 on rules and recommendations on navigation through the Dardanelles, Bosporus Strait and the Sea of Marmara.

37 Company is considered as the owner or the charterer whichever has accepted responsibility for operation of the vessel. 
System (SMS), which is required to include functional requirements as prescribed in the ISM Code.

As Turkey did not apply the ISM Code effectively before 2009, the implementation of the ISM Code had adversely affected not only the ferry services between Turkey and the EU but also merchant vessels and tankers operating in-between their waters. First, in order to overcome the issues faced and to improve the ferry services provided, Turkey made a regulation in 1996. As it did not manage to address the problems entirely, Turkey eventually enacted the Regulation on the Application of ISM Code in $2009,{ }^{38}$ which can be said to have solved the previous problems to a great extent, and contributed to the harmonisation planned between the EU and Turkey in the context of maritime affairs.

In terms of salvage operations, as mentioned before, Turkey acceded to the International Convention on Salvage (Salvage Convention 1989) in 2014 and its provisions were also directly incorporated into the TCA. ${ }^{39}$ In the context of the prevention of marine pollution, salvage operations may often prove crucial for the prevention of marine pollution and accordingly a reward or special compensation may emerge as stipulated in Article 14 of the Convention. Turkey has accurately incorporated Article 14 of the Convention into the TCA to make it applicable as local law to encourage salvors to perform salvage operations to prevent or minimise damage to the environment. ${ }^{40}$ On the other hand, as all provisions of the 1910 Collision Convention were also incorporated into the TCA (from Article 1286 to 1297), the TCA will be applied when a collision occurs between two or more vessels. As to the removal of wrecks, despite the fact that there is no specific legislation on the removal of wrecks, there are some provisions as to wreck removal under the Turkish Port Act, which was amended in 2017.41 The harbour masters' offices are entitled to an extensive discretion in relation to removal of abandoned vessels or wrecks that pose threats to the safety of marine traffic or the environment. ${ }^{42}$

With regard to the recycling of vessels, as one of the five major ship recycling states in the world, Turkey signed the Hong Kong International Convention for the safe and environmentally sound recycling of ships (Hong Kong Convention) in 2010 and ratified it in 2019. The Hong Kong Convention is thought to aim to facilitate safe and environmentally sound recycling and to improve disposal practices of vessels environmentally. It will come into force after 24 months following ratification by 15 states that represent 40 per cent of the gross tonnage of world merchant shipping and average 3 per cent of recycling tonnage for the previous ten years. Turkey is one of the 15 states that have ratified the Convention. Though it has not yet come into force, as these 15 states only represent nearly 30 per cent of the gross tonnage of merchant shipping and 0.56 per cent of recycling tonnage. ${ }^{43}$

\footnotetext{
38 Date of Official Gazette: 27.10.2009, Number of Official Gazette: 27389.

39 Date of Official Gazette: 24.05.2014, Number of Official Gazette: 29009; from Art. 1298 to 1319.

40 Art. 1312 of TCA.

41 As per Art. 7 of the 618 numbered, 14/4/1341 dated Code.

42 As per Art. 7.

43 www.imo.org/en/MediaCentre/SecretaryGeneral/SpeechesByTheSecretaryGeneral/Pages/ship-recyclingseminar-2019.aspx accessed 13.01.2020.
} 


\subsubsection{Prevention of irregular migration}

In the last decade, Turkey has evolved into a regular destination for a massive inflow of irregular immigrants from Africa, the Middle East and Central Asia. For a considerable amount of these immigrants, as Turkey sits on the south-eastern point of Europe, with two EU members on the west, namely Greece and Bulgaria, it has also become a transit point for reaching EU nations. As controlling and monitoring over land borders has been beefed up in the last couple of decades, which has made it more difficult than ever for asylum seekers to cross, it is the seas that today dominate the inflow to Europe. This is also the case for Turkey. As the numbers prove this correct, the Aegean Sea is the main crossing point of illegal immigrants from Turkey to the EU. ${ }^{44}$ The other dominant crossing routes are the Black Sea via Istanbul to Romania or Bulgaria and the Mediterranean Sea via Mersin to Italy.

The flow of irregular immigrants from Turkey to the EU reached unprecedented levels in 2015, when 856,000 refugees crossed both the Aegean and the Mediterranean Sea to seek asylum in EU nations. ${ }^{45}$ First in 2015 to strengthen their cooperation, Turkey and the EU adopted a Joint Action Plan aimed at preventing crossing to EU states. In 2016, in order to tackle the influx of irregular immigration, the EU and Turkey eventually reached an agreement to end the flow of irregular immigration. Since then, having followed up on its commitment, Turkey has stepped up its measures to prevent all routes for irregular immigration opening from Turkey to the EU. In the implementation of the necessary measures, the Turkish Coast Guard capacity both in the Aegean Sea and the Mediterranean Sea was increased and enhanced by the addition of fast response boats and mobile radar systems in order to prevent crossings in advance. Turkey has also speeded up its close cooperation with the Greek and Bulgarian Coast Guards by sharing operational information. Since 2016, the Turkish Coast Guard has had access to the Turkish Ship Registry System provided by the Ministry of Transport and Infrastructure to enable a prominent monitoring power to fast track all ships. Turkey has also aimed at improving the cooperation between its General Directorate of Security and the Turkish Coast Guard and Gendarmerie General Command to improve efficiency in addressing the problem, and they have been trained specifically on the matter. In cooperation with the United Nations High Commissioner for Refugees (UNHCR), in order to watch over and take preventive measures in advance for the illegal immigration from Turkey to the EU in a concerted manner, the Turkish Coast Guard has established a 'Processing and Screening Centre' on the coast of Kusdasi which enhances the pre-screening capacity of the border authorities. ${ }^{46}$

As a result of Turkey's commitment in the last couple of years, there has been an immediate impact, which has resulted in a sharp decline in irregular crossings from Turkey to the EU by sea. By 2018, the arrivals from Turkey dropped by 97 per cent $(32,497)$ compared to $2015(856,000) .{ }^{47}$ As of 30 November 2019, the total recorded interceptions at sea are

$44 \mathrm{https}$ //data2.unhcr.org/en/situations/mediterranean/location/5179 accessed 07.02.2020.

45 https://ec.europa.eu/home-affairs/sites/homeaffairs/files/what-we-do/policies/european-agenda-migrat ion/20180314_eu-turkey-two-years-on_en.pdf accessed 07.02.2020.

46 www.unhcr.org/tr/wp-content/uploads/sites/14/2020/01/UNHCR-Turkey-Operational-Update-Novem ber-2019.pdf accessed 04.02.2020.

$47 \mathrm{https} / /$ ec.europa.eu/home-affairs/sites/homeaffairs/files/what-we-do/policies/european-agenda-migrat ion/20180314_eu-turkey-two-years-on_en.pdf accessed 07.02.2020. 
56,779 , while the total number of apprehension incidents at sea borders are recorded as 1,653. In 2019 a sharp drop was recorded in the number of deaths or missing persons in Turkish territorial waters, which is 32 , compared to the previous years. ${ }^{48}$ Though it must be emphasised that the same success may not be echoed for the crossings from Istanbul to Bulgaria or Romania through the Black Sea. The Montreux Convention entitles all vessels - regardless of their flag or cargo on board - to the freedom of transit and navigation through the Turkish Straits. In peacetime, all merchant vessels, which include any kind of vessels that do not fall within the category of warships, enjoy complete freedom of passage via the Straits..$^{49}$ Unless there is evidence indicating otherwise, in pursuant to the Montreux Convention, the Turkish Coast Guard are not entitled to detain or inspect those vessels that may carry irregular immigrants. Hence, the Black Sea route from Istanbul to Romania or Bulgaria can still be considered as open to abuse by immigrants.

Turkey's commitments have also had a massive impact on the prevention of marine pollution. In most cases immigrants cross the Aegean Sea on inflatable boats and wear lifejackets, inflatable plastic tubes which are in most cases left along the shores as piles of litter. Between 2015 and 2018, all these boats, lifejackets, tubes and clothing adversely affected the marine environment in the Aegean Sea, as they were found along the shores, on the seabed or floating on surface..$^{50}$ As the amount of irregular immigration via the Aegean Sea today is in massive decline, it is safe to say that this has also had an indirect positive impact on the prevention of pollution in the Aegean Sea.

Since hosting the highest number of refugees in the world and being in the south-easternmost tip of Europe and bordering the troubled areas to its south-east that are the main sources of the irregular immigration, it is fair to say that Turkey has had and still has a major role to play in tackling this issue. As evidenced by the aforementioned numbers, the measures introduced by Turkey and the expansion of institutional capacities since 2015 have proved undeniably effective in combatting the flow of irregular immigration by sea from Turkey to the EU. Although it is opined that such a sharp decline of crossings in a considerably short time should be considered an achievement for both Turkey and the EU, the other side of the story raises some concerns. Despite being a result of concerted actions between the EU and Turkey, it would not be wrong to say that the EU policy has focused on tackling this problem internally rather than enhancing safety at sea. The reduction in the influx of irregular immigration from Turkey to the EU and sending back those immigrants to Turkey can be considered a pragmatic result only in respect of the protection of its own borders. Maritime safety-wise, it is thought that this is an emergency policy acting as a painkiller to ease the pain of the EU rather than a policy aimed at saving lives at sea. Alongside the agreement reached with Turkey, in supporting this criticism, the other measures taken by the EU Council in 2015 and 2016 can also be regarded as emergency measures lacking judicial oversight. There are operations called Triton and Poseidon led by FRONTEX in order to provide military patrolling of the Mediterranean and Aegean Seas. For these operations, the goal has been focused on bringing down the mechanism

48 www.unhcr.org/tr/wp-content/uploads/sites/14/2020/01/UNHCR-Turkey-Operational-Update-Novem ber-2019.pdf accessed 04.02.2020.

49 Art. 2 of the Montreux Convention.

50 www.researchgate.net/figure/Life-jackets-tubes-and-clothing-abandoned-by-illegal-immigrants-on-arriv al-along-the_fig1_282365362 accessed 06.02.2020. 
run by traffickers rather than the rescue of immigrants at sea. ${ }^{51}$ It should not be forgotten that saving the lives of those in distress at sea is a long-standing and fundamental principle of international maritime law. It therefore follows that the EU policy appears to have slightly overlooked this core principle so far and rather focused on deterring or pushing back irregular immigrants than on the protection or safety of lives at sea.

\subsection{Liability regimes}

As Turkey is bathed by the Mediterranean Sea to the south, the Aegean Sea to the west, the Black Sea to the north and the Sea of Marmara bridging the Black Sea with the Aegean Sea via the Dardanelles and Bosporus Straits, it would be safe to say that Turkey is surrounded by one of the most important international waterways as well as one of the most congested and perilous ones. As a result of this, there have been a significant number of accidents in Turkish waters resulting in marine pollution such as Nassia in 1994, Tpao in 1997, Independenta in 1999, Volgoneft 247 in 1999 and most recently Vitaspirit in 2018.

Although it appears to be inevitable that Turkey should embrace a liability regime, regrettably, for a long period of time, Turkey preserved its indifferent stance to internationally acknowledged liability regimes. However, in the last couple of decades it can be said that the tide has turned, as Turkey has showed some significant readiness in order to accept and apply some of these liability conventions that provide financial security instruments. To start with, regarding LLMC, which enables an owner to limit his liability for claims arising out of a maritime incident, despite the fact that it was ratified in 1980, accession was only completed in 1998. Though it must be said that the Convention was directly incorporated into the new Turkish Commercial Act along with the Protocol of 1996 to Amend the Convention on Limitation of Liability for Maritime Claims 1976 which has also been ratified by Turkey. ${ }^{52}$ However, pursuant to Article 1 of LLMC 1976, amended by Article 7 of the Protocol of 1996, Turkey reserves the right to exclude the application of Article 2 1(d) and (e) and claims for damage within the meaning of the International Convention on Liability and Compensation for Damage in Connection with the Carriage of Hazardous and Noxious Substances by Sea (HNS) 1996, or of any amendment or protocol related thereto. ${ }^{53}$ That is to say, Turkey excludes owners' right to limit their liability on wreck and cargo removal claims under LLMC.

As for the HNS Convention, Turkey also excludes claims for damage arising under this Convention. Despite the fact that Turkey signed the 2010 Protocol to HNS Convention, it has not come into force due to the fact that signatory states have failed to meet the ratification requirements. It should also be noted that as Turkey has not reserved the right to exclude Article 3, claims for salvage, claims for oil pollution, claims for nuclear damage and claims by servants of the shipowner or salvor whose duties are connected with the ship

51 In 2017, FRONTEX director accused non-governmental organisations of encouraging illegal immigrants by saving lives (around 40 per cent of rescue operations) at sea; www.theguardian.com/world/2017/feb/27/ng o-rescues-off-libya-encourage-traffickers-eu-borders-chief accessed 09.02.2020.

52 TCC, Art. 1328.

53 www.imo.org/en/About/Conventions/StatusOfConventions/Documents/Status\%20-\%202019.pdf p. 404, accessed 11.01.2020. 
or the salvage operations are not exempt from limitation under Turkish law. In terms of tonnage limitation applicable under LLMC, Turkey applies the increased limits announced by the IMO on 19 April 2012, which entered into force on 8 June 2015.

Turkey is also party to several international conventions that cover liabilities in relation to pollution from ships: the Civil Liability Convention (CLC) $1992^{54}$ and the Fund Convention $1992^{55}$ - both of which came into force in 2002 in Turkey - and the International Convention on Civil Liability for Bunker Oil Pollution Damage (BUNKER) $2001^{56}$ which came into force in 2013. Turkey has also acceded to the 2000 Amendments in 2012 that raised the compensation limit by 50 per cent compared to the limits set in the CLC 1992 Protocol. ${ }^{57}$ Also, the 2003 Protocol establishing an International Oil Pollution Compensation Supplementary Fund with an aim to supplement the compensation available under CLC 1992 and the Fund Convention 1992 as a third tier of compensation, came into force in Turkey in 2013. As both CLC 1992 and the Fund Convention 1992 directly apply as domestic law, their provisions were not incorporated in the TCA; though it should be noted that the areas or the subjects that are left to national law or that are not covered by these conventions are dealt with by the TCA. ${ }^{58}$ In addition to this, under the Environment Act, ${ }^{59}$ a person that has caused pollution or damage to the environment shall be subject to a strict liability even in the absence of fault on his/her part. ${ }^{60}$ Furthermore, there is also another domestic legislation, which might be considered directly on the subject: the Act on the Principles of Emergency Action and Indemnification of Losses in the Pollution of the Marine Environment by Oil and Other Hazardous Substances (5312 numbered Act) ${ }^{61}$ The authorities such as the Environmental Protection Agency, harbour masters and public prosecutors are entitled to issue fines for non-compliance by vessels with the legislation in case of pollution arising from oil or other hazardous substances. A question may arise at this point whether both the Environment Act and 5312 numbered Act apply when matters also fall within the scope of the CLC 1992 and the Fund Convention 1992. The answer to this question is as per Article 1336 (1) para. (f) of the TCA: the application of the CLC 1992 and the Fund Convention 1992 prevail the application of the other national Acts, when the subject matter falls directly within those conventions, though this rule should be set aside when cases do not fall within the scope of the CLC 1992 and the Fund 1992.

Despite the fact that there is a process of adoption, Turkey has yet to accede to the MLC or the Nairobi Convention 2007. As mentioned before, even though there is no specific legislation on the removal of wrecks, there are some provisions as to wreck removal under the Turkish Port Act, which was amended in $2017 .{ }^{62}$ The harbour master is entitled to an extensive discretion in relation to the removal of abandoned vessels or wrecks that pose

54 Protocol of 1992 to Amend the International Convention on Civil Liability for Oil Pollution Damage, 1969. 55 Protocol of 1992 to Amend the International Convention on the Establishment of an International Fund for Compensation for Oil Pollution Damage 1971.

56 Turkey acceded to BUNKER 2001 in 2013 via the 6439 numbered and 26/02/2013 dated Act.

57 Came into force in 2012; Date of Official Gazette: 12.07.2012, Number of Official Gazette: 28351.

58 See, the Art. between 1336 and 1349 of the Commercial Code.

59 Date of Official Gazette: 09.08.1983, Number of Official Gazette: 2872.

60 Art. 28.

61 Date of Official Gazette: 03.03.2005, Number of Official Gazette: 5312.

62 As per Art. 7 of the Turkish Port Act: Date of Official Gazette: 14.04.1341, Number of Official Gazette: 618. 
threats to the safety of marine traffic or the environment. ${ }^{63}$ Though, considering the fact that the Nairobi Convention aims to establish uniform rules for the prompt and effective removal of wrecks that may be dangerous to navigation or to the environment, and that Turkey can be said to be surrounded by one of the most important international waterways as well as one of the most congested and perilous ones, it is opined that Turkey must speed up its adoption process of the Convention.

\subsection{Concluding remarks}

In the maritime context, international rules and conventions can be compiled under two headings: those regulating contractual and commercial relationships and those concerning safety and the environment. This chapter has sought to scrutinise and assess Turkey's position on the latter subject, namely maritime safety, whether those international rules and conventions are adequately embraced by Turkey and whether national legislation is in compliance with those international practices and rules in the context of maritime safety. Particularly with the effort put in during the last couple of decades, it would be fair to say that Turkey, to a great extent, has managed to harmonise its legislation with international rules and practices on maritime safety.

To start with the EU, the origin of the relationship between Turkey and the European Union can be traced back to the 1950s. Up to now, as a candidate and as a Custom Union state, Turkey has had a general policy for improving its relations with the EU in almost every field, including in the maritime context. One of the fruits of this policy was that in 2003 Turkey, in order improve its maritime safety policy, launched a five-year Transport Action Plan to align its national legislation with EU rules and practices and, accordingly in 2004, the Directorate General of Maritime and Inland Waters Regulation started to work with Spain as a partner state to update and align its institutions and legislation with the EU acquis on maritime safety. So far it is thought that Turkey can be considered to have improved both institutionally and legislatively on the matter. It should also be emphasised that Turkey has held one of the main keys to tackling the irregular immigration issue and it is opined that the measures taken in recent years have not been shy of generating positive impact in the eastern Mediterranean. However, in general, this does not necessarily mean that Turkey's commitments are not short of deficiencies, as it has failed to implement some rules such as the latest directives on VTS and PSCs; though it should be remembered that the aim is full harmonisation in the long term.

As to the implementation of the IMO conventions and practices, Turkey is party to nearly all major conventions or rules in relation to maritime safety such as the SOLAS, MARPOL, COLREG, STCW, ISPS and ISM codes. Despite not being compiled under one maritime act, many of these regulations are successfully incorporated into the TCA, whilst some others are applicable via local regulations or by-laws. In addition to its endeavour to improve its legislation, Turkey has also made some promising commitments within its power to improve maritime safety, including garbage collecting and ballast waste disposal, navigational aids to vessels and shore-based operational services to provide assistance to vessels. As Turkey only enacted the new Turkish Commercial Act in 2012, which is the

63 As per Art. 7. 
main legislation on maritime law, amendments in the maritime context are not forecasted within the foreseeable future, though this is not to say that Turkey has completed aligning with international conventions and rules. So, there is room for huge improvement, as the MLC and Nairobi Convention are yet to be ratified by Turkey. It is eventually opined that further steps should be taken to ratify these conventions by Turkey for further improvements on maritime safety in its waters. 
Taylor \& Francis

Taylor \& Francis Group

http://taylorandfrancis.com 


\section{IN DEX}

11 September 2001 159, 160

acceptance of IMO treaties 9-10, 15, 134 accession, IMO treaties 9-10, 13, 45n133, 46n137; Malta 191; Norway 212

accident investigation: Croatia 88-9, 93; EU

(European Union) 33-4; Germany 109; Greece 146n103, 47; Malta 178; Norway 212; Poland 217; United Kingdom 123-124 Accident Investigation Board Norway 212 accidents: Agia Zoni II 149; Amoco Cadiz (1978) 94, 103; Erika (1999) 29, 45, 94, 135n7, 169n47, 188, 206; Estonia (1994) 34, 35; Express Samina (2000) 34; Herald of Free Enterprises (1987) 35; human factors 74, 165; Independenta (1999) 264; Nassia (1994) 264; Pallas (1998) 121; Prestige (2002) 29, 45, 169n47, 188, 232; Slops (2000) 148; Titanic (1912) 160; Torrey Canyon (1967) xvii, 45; Tpao (1997) 264; Volgoneft 247 (1999) 264; Vitaspirit (2018) 264

Achille Lauro 233, 159

acquis communautaire 81-2, 92, 236

administration 43; Belgium 71; Croatia 75, 77, 88-89; Germany 108, Greece 137-39, 144;

Malta 177, 187; Norway 208, Poland 216-18, 221; Spain 230-233, 239; United Kingdom 127,130

adopting IMO treaties 4, 9

Adriatic Sea 75-6

Adriatic Traffic 168

Aegean Sea, migration flow 262-4

AFM (Armed Forces of Malta) 178; MALTA VTS 186

Agia Zoni II 149

amendments to IMO treaties 11-13

Amoco Cadiz (1978) 94, 103

Arctic Council 207

Armed Forces of Malta (AFM) 178

armed guards: Croatia 83-4; Greece 151-3;

The Netherlands 198
The Assembly 7n24

Athens Convention relating to the Carriage of Passengers and their Luggage by Sea, 1974

(PAL Convention 1974): Croatia 89; France 96n10; Poland 224, 225n59, 226-7

Athens Convention relating to the Carriage of Passengers and their Luggage by Sea, 2002

(PAL Convention 2002) 119; Croatia 79, 82, 89; EU (European Union) 46; Germany 119; Malta 190; Poland 224, 225n59, 226-7

Atlantic Empress (1979) 232

Aust, Anthony 9n34

Australia, Ballast Water Management

Convention 19, Biosecurity Act 201519

Austrian 'Maritime Proclamation' of 177475 authorities, empowerment of flag states, Greece 143-4

Authority, EFTA (European Free Trade Association) Convention (1960) 58-9 authorization, armed guards 152

Automatic Identification System (AIS) 168, 238; Croatia 86 ; Italy 168 ; Malta 183,186 ; Poland 222; Spain 238; Turkey 259

Ballast Water Management Convention (2004) 6, 17, 19; Croatia 81n27, 93; France 98; Germany 112; The Netherlands 199; Turkey 255

Barents Ship Reporting System, Norway 211

"Basic Law" (Germany) 107-9

Belgian Shipping Code 69-73

Belgium 73; control and surveillance 71-2; division of competences in maritime affairs 73; national structure for safety and law 65-9; prevention 69-71; regional authorities 71; regional policy competencies 66-7

"Better Regulation Guidelines" 49

Bizmita La (2001) 232

Black Sea MoU 258-9

BLU Code (Code of Practice for the Safe Loading and Unloading of Bulk Carriers): Greece 139; Malta 181 
Bonifacio Traffic 168

Bosporus Strait 259-60

Brussels Convention for the Unification of Certain Rules of Law with Respect to Assistance and Salvage at Sea of 1910, Italy 170

BSH (Federal Maritime and Hydrographic Agency), Germany 111-112, 118

Bunker Convention (International Convention on the Civil Liability for Bunker Oil Pollution Damage 2001) 6, 13, 90; Germany 118-119; Greece 147-148; Italy 171; The Netherlands 203-204; Norway 213; Malta 190; Poland 225-6; Spain 250; Turkey 255, 265; United Kingdom 130-131

carriage of dangerous goods: Greece 133; Italy 160; Malta 176, 182; The Netherlands 203; Turkey 253; United Kingdom 182

CASR (consolidated audit summary report) 43 Castor (2000) 232

Casualty Investigation Code 6n14; Malta 178 categories of IMO treaties 4-5

CCME (German Central Command for Maritime Emergencies) 121

certificates: France 99-100; ISSC

(International Ship Security Certificate) 235; Poland 218, 220; Spain 231

CISM (Committee for maritime security), Italy 166

civil liability: Belgium 72; Croatia 89-92; EU (European Union) 45-6; France 103; Germany 118-20; Italy 171-2; Malta 190-2; The Netherlands 203-4; Norway 212-3; Poland 225-7; Spain 249-250; Turkey

264-6; United Kingdom 130-1

civil liability conventions, legislative drafters 16

classical amendment procedure, amendments to IMO treaties 11

classification societies: Belgium 71; EU

(European Union) 23; France 100, 135, 138, Greece 143-4; Italy 161; Malta 182, 187; The Netherlands 195; Norway 208; Poland 217, 220; Turkey 257; United Kingdom 122, $125,127-8,130$

CLC (International Convention on Civil Liability for Oil Pollution Damage) 5-6, 13; Belgium 72; Croatia 89-90; France 103; Greece 147-8; Italy 171; Malta 190; The Netherlands 203; Norway 212; Poland 225-6; Spain 249; Turkey 254-5, 265; United Kingdom 130

CMI (International Maritime Committee) 81 coastal States 22-3, 40n109
Code of Navigation see Navigation Code of 1942

Code of Practice for the Safety of Commercial Vessels, Transport Malta 183-4

Code on Recognised Organisations (2013) 33 codes 6 n 14

Codification Commission for Maritime Law, Poland 226

Collision Convention of 1952 (International Convention On Certain Rules Concerning Civil Jurisdiction In Matters Of Collision), Italy 169

collisions: Italy 169-70; Turkey 260-1

COLREG (International Regulations for Preventing Collisions at Sea, 1972) 5, 12, 42n12; Belgium 70; Croatia 79, 84-5; France 96n10, 102; Italy 169; Malta 175, 186-7; The Netherlands 200n54; Norway 209; Poland 215, 221; Spain 245; Turkey 256, 258-9, 266 comitology $30 \mathrm{n} 50$

Commercial Code: Germany 114; The Netherlands 202; Spain 229

Commercial Vessels Regulations, Malta 183

Common Nautical Authority, The Netherlands 200

'A Common Policy of Safe Seas' 23

company security officers 235

compensation 6, 45-8; France 102-3; Germany 118; Greece 147-8; oil pollution 48; Poland 226; treaties 6; Turkey 265; United Kingdom 131

competence, EU (European Union) 26-8

complementarity of EU maritime safety rules 28-9

Compliance Document: France 99, The Netherlands 197

compliance with mandatory liability insurance, Germany 118-20

Consap, Italy 172

Constitutional Decision on the Sovereignty and Independence of the Republic of Croatia 78

construction of ships: Greece 139; Italy 163-4; The Netherlands 195-6; Poland 216; Spain 230; United Kingdom 125

Contingency Plan for Accidental Marine Pollution, Croatia 87

Contracting States of the SOLAS Convention 234

control: Belgium 71; Croatia 84-6; flag State control maritime surveillance systems 37-8; France 99-101; Greece 145-7; Italy 167-8; Malta 184-9; The Netherlands 198-202; Norway 210-11; Poland 221-3; Republic of Croatia 84-6; Spain 237-248; United Kingdom 127-30 
Convention for the Suppression of Unlawful Acts against the Safety of Maritime Navigation (SUA) 5; Croatia 79; The Netherlands 193n1; Poland 215n10, 216n15; Spain 234; Turkey 255

Convention on International Regulations for Preventing Collisions at Sea see COLREG

Convention on Limitation of Liability for Maritime Claims (LLMC 1976) 12-4; Croatia 89, EU (European Union) 82n34; France 96n10, 101, 103; Malta 190; The Netherlands 204; Norway 212; Poland 224, 226; Turkey 254, 264

Convention on the International Maritime Organization see IMO (International Maritime Organization)

cooperation agreements, Belgium 68

Corpo delle capitanerie di porto-Guardia costiera 163

COSS (Committee on Safe Seas and the Prevention of Pollution from Ships) 30

The Council 7n25

Criminal Code, Poland 224

criminal liability: Croatia 89; France 101-2; Germany 112-3; The Netherlands 201

criminal penalties, Greece 150-1, 157; Italy 168; Malta 189; Norway 206, 211; Poland 224, 227; Turkey 256

Cristos Bitas (1978) 232

Croatia: control 84 ; liability 88 ; maritime code 80-82; maritime security 83-84; national structure of maritime administration 74-76; places of refuge 87; prevention 78-83; vessel traffic management 86

Croatian Register of Shipping 84-5

Croatian Vessel Traffic Monitoring and Information (CVTMIS) System 86n53, 92

CROSS (Regional Operational Monitoring and Rescue Centres), France 95

DAM (Directorate of Maritime Affairs), France 95 damages, compensation see compensation Dangerous Cargo Ships, Marine Terminals and Facilities and Bunkering Regulations, Malta 182

Dardanelles 259-60

Declaration of Labour Compliance, Spain 230

delegation of authority to issue secondary legislation, IMO treaties 17

Department of Transport (DfT), United Kingdom 123

Department of Transport (France) 95

developing, IMO treaties 19

DfT (Department of Transport), United Kingdom 123
Directive, defined 26n23

Directorate General of Dangerous Goods and Multimodal Transport Regulation, Turkey 253

Directorate General of Maritime and Inland Waters Regulation, Turkey 252-3

Directorate General of Maritime Trade, Turkey 253

Directorate of Maritime Affairs (DAM), France 95

Directorate of the Safety of Navigation, Greece 138

Directorate-General for Shipping, Belgium 71

Directorate-General for the Merchant Navy, Spain 230, 232-3

Directorates of the Sea (DM), France 95

DIRM (Interregional Directorates of the Sea), France 95

discretion, EU (European Union) 26, 46

distressed vessels: Greece 146, 154; Malta 187; The Netherlands 198; Norway 210; Spain 238, 244; United Kingdom 126

DM (Directorates of the Sea), France 95

double-hull requirements for oil tankers 140 , 162,164

draft treaties $7 \mathrm{n} 25$

dualism 14-15

dualistic legal orders $54 \mathrm{n} 11$

Dutch Civil Code 202-3

EASA (European Aviation Safety Agency) 59

EEA (European Economic Area) Agreement 52-61; Norway 207

EEA EFTA States 53; EU internal market law versus EEA law 53-6

EEZ (Exclusive Economic Zone) 207

EFTA (European Free Trade Association) Convention (1960) 53; surveillance authority 58-9

ELD (Environmental Liability Directive) 47-9

Elka Aristotle 153

EMCIP (European Marine Casualty Information Platform) 33

EMSA (European Maritime Safety Agency) 25, 29, 38; EFTA (European Free Trade Association) Convention (1960) surveillance authority 58-9; EU (European Union) 36-7; Iceland 59-60; marine equipment 42; Norway 59-60, 207; United Kingdom 123; vessel traffic monitoring 40

EMSA Regulation 60

enforcement: Belgium 72; Croatia 88-9; EU rules 42-4; France 96-7; Germany 110; Greece 147-51; IMO treaties 19-20; Italy 168-70; Malta 189-90; The Netherlands 
202-3; Norway 211-12; Poland 223-5; Spain 248-50; Turkey 254-6; United Kingdom 125

English common law 122

Environmental Protection Agency 265

ERA (European Rail Agency) 59

'Erika I' 135n7

'Erika II' 135n7

'Erika III' 135n7

'Erika' legislative package 23, 206

EU (European Union) 122, 266; background and scope 22-4; competence 26-8; complementarity of EU maritime safety rules 28-9; construction and operation of vessels 139; enforcement of rules 42-4; internal market 53; internal market law versus EEA law 53-6; liability and insurance 45-9; maritime safety rules 24 , 49; maritime surveillance systems 37-42; migration 262-4; objectives of 24-5; Poland 218; preventative actions $31-7$; Regulations 139; special tools on maritime safety 29-30

EU Commission 44

EU Court of Justice 44

EU maritime policy 221

EU maritime safety policy $135 \mathrm{n} 7$

EU Member States 25, 29; recognised organisations 31

EU Operational Guidelines 41

EU Port State Control 38-40

EU waste legislation 135

EU waters 39

European Aviation Safety Agency (EASA) 59

European Coal and Steel Community 53

European Commission 23-4, 29-34, 46, 49, 53, 100, 144; ELD (Environmental Liability Directive) 49; EMSA 36, 42; flag States 144; Permanent Co-operation Framework 178

European Court of Human Rights, Poland 217

European Marine Casualty Information Platform (EMCIP) 33

European Maritime Investigators Forum 178

EU-wide maritime common information and exchange system see SafeSeaNe

Expert Working Group on Maritime Security 234

explicit acceptance procedure, amendments to IMO treaties 11-12

Express Samina (2000) 34

Facilitation Committee (FAL) 8

Federal Maritime and Hydrographic Agency (BSH), Germany 111-12, 118

Federation, Germany 107-9

ferry services, Greece 140

financial security rules, EU (European Union) 45-6 fishing vessels: The Netherlands 196; registry, Poland 223

flag State Directive 37-9

Flag State Service, Belgium 71

flag States 10n39, 22; Greece, empowerment of authorities 143-4; Malta 187; maritime safety rules 25; maritime surveillance systems 37-8; Spain 231-2, 247

'flag-blind' approach, recognised organisations 32

"Flaggenrechtsgestz" (1951), Germany 109

flagging, Norway 207

Flanders (Belgium) 66-7, 73; traffic management 72

Flemish Government, liability 73

Flemish legislative decreet, VTS (Vessel Traffic Service) 72-3

Flemish Parliament, control and surveillance 71-2

Flemish Shipping Decree 69

Food and Catering (Ships' Crew) Convention (1946), Turkey 255

France: civil liability 103; compensation 102-3; enforcement 96-7; French Transport Code 94, 97; law concerning maritime safety 95-7; maritime safety 94; maritime security 94; places of refuge 101; prevention 98-101; punishment 101-2; ship control 99

French Transport Code 94, 97

FRONTEX 263

FUND 1992 (International Convention on the Establishment of an International Fund for Compensation for Oil Pollution Damage) 45n133, 46; Belgium 72; Croatia 79, 89; France 96n10; Greece 147-9; Italy 171; Malta 190; Norway 212; Poland 224n55, 225n59; Spain 249-50; Turkey 254-5, 265

General Directorate of the Regulation of Seas and Inland Waters Regulation, Turkey 259

General Lighthouse Authorities (GLAs), United Kingdom 123

“General Regulation," 1984 Decree on safety of human life at sea, prevention of pollution, security and social certification of vessels (France) 97, 100

German Central command for Maritime Emergencies (CCME) 121

German Federal Ministry of Transport 110

German National Maritime Policy 105

Germany 105-106; "Basic Law" (Germany) 107-9; CCME (German Central Command for Maritime Emergencies) 121; compliance with mandatory liability insurance 118-20; enforcement 110; Federal Maritime and 
Hydrographic Agency (BSH) 111-12; federal level 106; German National Maritime Policy 105; monitoring 110; national structure for safety and law 107-13; non-compliance with safety laws 112-13; Occupational Accident Insurance Fund for Transport and Traffic 111; prevention 114-18; PSC (Port State Control) 118; "Seeaufgabengesetz" 108-9, 113, 120; "Seesicherheitsgesetz" 120; Ship Safety Division 111

GLAs (General Lighthouse Authorities), United Kingdom 123

Global Maritime Distress and Safety System (GMDSS): France 98; Malta 178

Greece 133-4; armed guards 151-3; control and surveillance 145-7; duty of assistance 155; enforcement and liability 147-51; flag States 143-4; illegal migrants 153-6; KDND (Greek Code of Public Maritime Law) 143; KIND (Greek Code of Private Maritime Law) 136; migration flow 153-7; MLC (Maritime Labour Convention) 142; national structure for safety and law 136-9; prevention 139-44; SafeSeaNet 146; SAR (Hellenic Search and Rescue) 155

“Grundgesetz” (1949) 107-9

Hague-Visby Rules 123

Harbour Masters: Croatia 75, 77-8, 85, 89, 91; Spain 230, 232

HAZMAT 23

hazardous ships, Spain 241-2

HBMCI (Hellenic Bureau for Marine Casualties Investigation) 146

Hellenic Chamber of Shipping 138n27

Hellenic Coast Guard, Greece 138, armed guards 153

Hellenic Ministry of Marine Affairs and Insular Policy 141

Hellenic Search and Rescue (SAR) 146

High Level Steering Group for Governance on the Digital Maritime System and Services (HLSG), EU (European Union) 30n50

High-Level Steering Group for SafeSeaNet 57 hijackings, $M / V$ Achille Lauro 159

history of EEA (European Economic Area) Agreement 52-3

HLSG (High Level Steering Group for Governance on the Digital Maritime System and Services), EU (European Union) 30n50

HNS 2010 see Protocol of 2010 to Amend the International Convention on Liability and Compensation for Damage to Connection with the Carriage of Hazardous and Noxious Substances by Sea, 1996
HNS Convention (1996): Greece 148; Italy 171; Poland 226; Spain 250; Turkey 264

homogeneity 61

human factors: accidents 74; Italy 165-6; Norway 209; Poland 216

human life, Greece 140-1; migration flow 153-7

IACS (International Association of Classification Societies), Turkey 257

IAMSAR 221

Iceland: dualistic legal orders 54n11; EMSA (European Maritime Safety Agency) 59-60

ICS (International Chamber of Shipping) 156

ILO (International Labour Organization): Croatia 78; Norway 207

IMCO (Inter-Governmental Maritime Consultative Organization) see IMO (International Maritime Organization)

IMO (International Maritime Organization) 3-4, 22n3, 133; Croatia 79-80; international uniform regulation 134-6; legal framework 4-7; Norway 207; organs 7-8; SubCommittee on Implementation of IMO Instruments 178; treaties see IMO treaties; treaty-making process $7-10$

IMO Audit Scheme 20, 37n91, 43; Germany 120

IMO Codes 6n14, 19, 182

IMO III Code 20, 37, 40n109, 43

IMO IMDG Code 6n14, 182

IMO Maritime Safety Committee 234

IMO Secretariat 43

IMO treaties 4-5, 9-10; amendments to 11-13; enforcement of 19-20; implementation process 14-19; incorporation by reference 18-19; interrelation between IMO treaties 13-14; legislative drafters $15-17$; non-selfexecuting treaties 15 ; protocols to 11

implementation process, IMO treaties 14-19

IMS (Integrated Maritime Services) 29n45

IMSAS see IMOAudit Scheme

IMSBC (International Maritime Solid Bulk

Cargoes) Code, Malta 181

Incident Response Plan North Sea, The Netherlands 198

incorporation by reference, IMO treaties 18-19 inspection activities, Spain 246

inspection bodies, Poland 217

Inspectorate, The Netherlands 194

Inspectorate for Human Environment and Transport, The Netherlands 194

Inspectorate for Transport and Water Management, The Netherlands 194 insurance 7n22, 24n12; Croatia 87, 90; EU (European Union) 45-9; France 103; 
Germany 118-20; Greece 149-50; Malta 191; The Netherlands 203-4; Norway 212; Poland 225-7; Spain 250; UK 130-131

Integrated Maritime Services (IMS) 29n45

Inter-Governmental Maritime Consultative Organization (IMCO) see IMO (International Maritime Organization)

internal market, EU (European Union 53

International Association of Classification Societies (IACS), Turkey 257

International Chamber of Shipping (ICS) 156

international civil liability, EU (European Union) 45-6

International Convention for the Control and Management of Ships' Ballast Water and Sediments see Ballast Water Management Convention

International Convention for the Prevention of Pollution from Ships (MARPOL) 5-6, 17, 19, 79, 92; amendments to 13; Greece 139; Italy 162; Malta 176-7; Spain 241; Turkey 256

International Convention for the Prevention of Pollution of the Sea by Oil (OILPOL) 5

International Convention for the Safety of Life at Sea see SOLAS

International Convention on Civil Liability for Bunker Oil Pollution Damage from 2001 see Bunker Convention

International Convention on Civil Liability for Oil Pollution Damage see CLC (International Convention on Civil Liability for Oil Pollution Damage)

International Convention on Liability and Compensation for Damage in Connection with the carriage of Hazardous and Noxious Substance by Sea (1996) see HNS Convention 1996

International Convention on Load Lines 1966: 12, 19; France 96n10; Greece 139; Italy 169 ; Malta 175-6, 180; The Netherlands 195-6; Norway 209; Poland 215n10; Spain 245; Turkey 255

International Convention on Oil Pollution Preparedness, Response and Cooperation (OPRC) 6, 17; Croatia 79; Spain 250; Turkey 255

International Convention on Salvage 1989 155-6; Italy 170; Turkey 254, 261

International Convention on Standards of Training, Certification and Watchkeeping for Seafarers (STCW) 1978 15; France 96n10; Greece 141; Italy 161, 166, 169; Malta 175, 177, 186-7; The Netherlands 196; Norway
209; Poland 215n10, 216, 219-20; Spain 231, 245; Turkey 256; United Kingdom 126

International Convention on the Establishment of an International Fund for Compensation for Oil Pollution Damage (FUND 1992) see FUND 1992

International Convention on the Removal of Wrecks (WRC 2007) 91 see Nairobi International Convention on the Removal of Wrecks (2007)

International Convention on Tonnage Measurement of Ships (1969): Malta 175n6; Norway 209; Turkey 255

International French Registry (RIF flag) 102

International Labour Organization 26, 49; Croatia 78-9; Greece 135; Malta 175, 185; Norway 207; United Kingdom 124

International Labour Organization, conventions: Croatia 78; France 96n11; Malta 185; Spain 245; Turkey 255, 258

international level, enforcement of EU rules 42-3 International Maritime Committee (CMI) 81

International Maritime Organization (IMO) see IMO

International Maritime Solid Bulk Cargoes (IMSBC) Code, Malta 181

International NAVTEX service 185

International Oil Pollution Compensation (IOPC) see FUND 1992

International Regulations for Preventing Collisions at Sea see COLREG

International Safety Management Code (ISM) see ISM Code

International SafetyNET service 185

International Ship and Port Facility Security (ISPS) Code 6n14, 94; Malta 178, 180n53; The Netherlands 202; Norway 209; Poland 216; Spain 231, 234-5; Turkey 258

International Ship Security Certificate (ISSC) 235

international uniform regulation 134-6

internationalism 135

Interregional Directorates of the Sea (DIRM), France 95

interrelation between IMO treaties 13-14

intervention measures, incidents/accidents at sea, Spain 242-3

IOPC Fund Convention 1992 see FUND 1992 147-9

irregular migration, Turkey 262-4

ISM Code 6n14, 38n94, 57; Germany 111; Italy 168; Malta 180, 183; The Netherlands 197; Poland 216, 220; Spain 230, 243; Turkey 260-1; United Kingdom 123, 126 
ISPS see International Ship and Port Facility Security Code

ISSC (International Ship Security Certificate) 235

Italian Code of Navigation see Navigation Code of 1942

Italian Pleasure Sailing Code 163

Italy: classification societies, RINA 161; collisions 169-170; control and surveillance 167-8; enforcement 168-70; implementation of maritime safety/security law 160-3; liability 171-3; National Maritime Security Program (PNSM) 166-7; passenger ships 165; Port State Control 167; prevention 163-7; salvage 170; seafarers' rights 170 , 172; VTS 167-8;

Journal of Laws, Poland 224

KDND (Greek Code of Public Maritime Law) 136-7, 143, 156

Khark V (1989) 232

KIND (Greek Code of Private Maritime Law) $136 \mathrm{jw}$

"Länder" (Germany), 107-8

law merchant 22

Legal Committee (LEG) 7-8, 8n27; The Netherlands 197; Poland 226-7

Legal Notices (L.Ns.) 176

legislative drafters, IMO treaties 15-17

liability: Belgian Shipping Code 72-3; Croatia 89-92; EU (European Union) 45-9; Germany 118-20; Greece 147-51; Italy 171-2; Malta 190-2; The Netherlands 203-4; Norway 212-13; Poland 225-7; ROs (Recognised Organisations) 129-30; Spain 249-50; Turkey 264-6; United Kingdom 130-1

Liechtenstein, monistic legal order $54 \mathrm{n} 11$ Lighthouses and Beacons Services, France 96 Limburg 233

limitation of liability 46

LLMC (Convention on Limitation of Liability for Maritime Claims, 1976) 13; France 103; Malta 190; Norway 212; Poland 226; Turkey 254, 264

L.Ns. (Legal Notices) 176

Load Lines Convention see International Convention on Load Lines 1966

London Convention on Salvage of 1989 see International Convention on Salvage 1989

Long-Range Identification and Tracking of Ships (LRIT) 146, 186; Croatia 87; France 98; Greece 146; Malta 186; Poland 222; Turkey 259
MAIB (Marine Accident Investigation Branch), United Kingdom 123-4

Malta 17-18, 175-177; control and surveillance 184-189; enforcement 189-90; liability 190-2; MARPOL (International Convention for the Prevention of Pollution from Ships) 176-7; national structure for safety and law 177-8; prevention 179-84

Maltese Designated Authority, Transport Malta 177

Maltese Hydrographic Office (MHO) 185

Maltese law, secondary legislation 17

manning: The Netherlands 196-7; Poland 220; Spain 231

Marine Accident Investigators International Forum 178

Marine Environment Protection Committee (MEPC) 8

marine equipment: EU (European Union) 42; France 98; Italy 164, 168; Malta 179n37; Poland 220

marine pollution 5-6; criminal liability (Greece) 150-1; oil, civil liability (Croatia) 89-90, (EU) 48-9, (France) 103; (Germany) 118-119, (Greece) 147-9, (Italy) 171, (Malta) 190, (The Netherlands) 203, (Norway) 212-3, (Poland) 225-6, (Spain) 249-50, (Turkey) 265, (United Kingdom) 130-1; prevention of 242-3, (Croatia) 75, (EU) 23, (France) 97, (Italy) 162, (Poland) 221, 224, (Turkey) 260-1

Marine Safety Investigation Unit (MSIU), Malta 178

Maritime Administration, Spain 231, 238, 242-3

Maritime and Coastguard Agency (MCA), United Kingdom 123-4

Maritime and Inland Navigation Act (1977), Yugoslavia 80n21

Maritime Assistance Service (MAS): Poland 221; Croatia 87

Maritime Authority: Italy 162-163; Norway 208

maritime autonomous surface ships (MASS) 29-30n46

maritime chambers, Poland 217

maritime claims 139

Maritime Code: Norway 206; Poland 214-15, 224, 226; Croatia 76-7, 80-3; Spain 249

Maritime Council, The Netherlands 194

Maritime Disciplinary Board, The Netherlands 194

Maritime Fitness Check, EU (European Union) 50 
maritime labour: Belgian Shipping Code 72;

Greece 142; Italy 165-6

Maritime Labour Certificate, Spain 230

Maritime Labour Convention (MLC) (2006):

Greece 142; Italy 166, 170, 172; Malta 177;

The Netherlands 204; Poland 216, 225;

Norway 213; Republic of Croatia, 78-9;

Spain 230; Turkey 255; United Kingdom 130

maritime prefects, France 97n9

'Maritime Proclamation' of 1774 (Austria) 75

Maritime Rescue and Coordination Centre (MRCC), Belgium 73

Maritime Rescue Coordination Centre (MRCC Rijeka) 87

"Maritime Safety Action Plan -Maritime safety matters. Moving Britain ahead" 124

Maritime Safety and Security Exchange Information System (SWIBZ), Poland 222

Maritime Safety Branch, France 95

Maritime Safety Committee (MSC) 7, 156, 238,240

Maritime Safety Directorate, Croatia 76-7

maritime safety rules: complementarity of EU 28-9; EU (European Union) 24, 49

maritime security: France 94; Greece 133n2; The Netherlands 198; Croatia 83-4; Spain 230, 233-7

maritime surveillance systems: control and EU-wide 37-42; flag States 37-8; see also surveillance

Maritime Traffic Regulations on the Turkish Straits 260

MARPOL see International Convention for the Prevention of Pollution from Ships

Mediterranean MoU, Turkey 257

Memoranda of Understanding (MoU) 20n66

Memorandum of Understanding on PSC in the Mediterranean Region (MMoU) 188

MEPC (Marine Environment Protection Committee) 8

MEPC Circular 307, 128

Merchant Navy Protection Act, The Netherlands 198

Merchant Shipping (Accident and Incident Safety Navigation) Regulations, Malta 178

Merchant Shipping Directorate (MSD), Malta 177

Merchant Shipping (International Safety Management (ISM) Code) Regulations 1998126

Merchant Shipping (Liability for Bunker Oil

Pollution Damage) Regulations 2009, 190

Merchant Shipping (Minimum Standards)

Convention, Republic of Croatia 84

Merchant Shipping Notice no. 60181 merchant ships, construction requirements, Italy 164

MHO (Maltese Hydrographic Office) 185

migration flow: Greece 153-7; Turkey 262-4

Minister of Maritime Economy and Inland Navigation, Poland 216

Ministry of Infrastructure and Transport, Italy 164,172

Ministry of Infrastructure and Water Management, The Netherlands 194

Ministry of Maritime Affairs and Insular Policy, Greece 137

Ministry of Maritime Affairs, Transport and Infrastructure, Republic of Croatia 76

Ministry of Sea, Transport and Infrastructure, Republic of Croatia 84

Ministry of Trade, Industry and Fisheries, Norway 208

Ministry of Transport and Infrastructure, Turkey 252

Ministry of Transports, Mobility and Urban Agenda, Spain 230, 244-5

MLC see Maritime Labour Convention (2006)

Model Agreement: Greece 144; United Kingdom 128

monism 14-15

monistic legal order, Liechtenstein 54n11

monitoring, Germany 110

Montreux Convention Regarding the Regime of the Straits 260, 263

MoU (Memoranda of Understanding) 20n66

MRCC (Maritime Rescue and Coordination Centre), Belgium 73

MRCC Rijeka (Maritime Rescue Coordination Centre), Republic of Croatia 87

MSC (Maritime Safety Committee) 7, 238, 240

MSD (Merchant Shipping Directorate), Malta 177, 187-8

MSIU (Marine Safety Investigation Unit), Malta 178

M/V Achille Lauro 159

Nairobi International Convention on the Removal of Wrecks (2007) 6, 13, 16n54; Croatia 79, 82, 89, 91; Germany 119; Italy 171-3; Malta 191; The Netherlands 204; Norway 212; Poland 226; Spain 250; Turkey 255, 265-6; United Kingdom 130-1

Nassia (1994) 264

National Collective Labour Agreements 170

National Competent Authority (NCA) 202

National Coordination Centre for Vessel Traffic Management and Information, Croatia 86 
National Legislative Alignment Programme, Croatia 92

National Maritime Security Program (PNSM), Italy $166-7$

National Strategic Plan for Ports and Logistics, Italy 162

national structure for safety and law, Republic of Croatia 75-8

nautical tourism, Italy 163

navigation 158; Croatia 85-6; France 99-102; Germany 107; Italy 162-3, 168-70; Malta 185-6; The Netherlands 197; Norway 210; Poland 220; Spain 229-30; Turkey 259-60;

Navigation Code of 1942, Italy 160-2, 168, 170-2

navigational warnings 185

NAVTEX 185

NCA (National Competent Authority) 202

need for treaties 8-9

negotiating state $9 \mathrm{n} 34$

The Netherlands 193; control and surveillance 198-202; enforcement 202-3; liability 203-4; national structure for safety law 194; prevention, 195-8; traffic management 72

New Inspection Regime (NIR), Turkey 258

NIS (Norwegian International Registry) 207

no more favourable treatment (NMFT) principle 7

non-compliance with safety laws, Germany $112-113$

non-self-executing treaties 15

non-statutory surveys 127

NOR (Norwegian Ordinary Registry) 207

Norway 206-8; Barents Ship Reporting System 211; control 210-11; dualistic legal orders 54n11; EMSA (European Maritime Safety Agency) 59-60; enforcement 211-12; liability $212-13$; national structure for safety law 208; prevention 208-10

Norwegian International Registry (NIS) 207

Norwegian Maritime Authority 208, 212

Norwegian National Coastal Administration 208, 210

Norwegian Ordinary Registry (NOR) 207

NSMDI Service, Croatia 76n8

Occupational Accident Insurance Fund for

Transport and Traffic, Germany 111

occupational activities 48

Off Brown Ridge 199

Officers' Competency Certificates Convention 1936, Turkey 255

oil spills 41n113, 46; Agia Zoni II 149

OILPOL (International Convention for the

Prevention of Pollution of the Sea by Oil) 5 operational-technical safety 158

OPRC see International Convention on Oil

Pollution Preparedness, Response and

Cooperation (OPRC)

Ordinance on Services of Armed Guards

Protection on board Ships of Croatian

Nationality, Republic of Croatia 83-4

"Ordinance on Ship Safety," Germany 114

organs of IMO 7-8

P\&I Clubs, United Kingdom 131

Package Meetings 59

pacta sunt servanda 20

Palestine Liberation Front 233

Pallas (1998) 121

Paris Memorandum of Understanding on Port State Control (PMoU): Croatia 84; EU (European Union) 38; Greece 138, 143; Malta 188; Poland 223; Spain 247; Turkey 257; United Kingdom 125-6

passenger ship safety: EU (European Union) 34-36; Italy 165; Malta 179

passenger ships: construction and equipment requirements, Italy 165; The Netherlands 197 penalties, Germany 110

Permanent Commission, The Netherlands 200

PHICS (Polish Harbours Information \& Control System) 222-3

Piano Strategico Nazionale della Portualita e della Logistica (National Strategic Plan for Ports and Logistics), Italy 162

piracy 159

PIRU (Pollution and Incidence Response Unit), Malta 184

place of refuge: France 101; Malta 184; The Netherlands 198; Poland 221; Republic of Croatia 87; Spain 232-3

Plan for Acceptance of Ships in Distress, Republic of Croatia 87

pleasure craft, Italy 163

PNSM (National Maritime Security Program), Italy $166-7$

Poland 214; classification societies 217; control and surveillance 221-3; enforcement 223-5; incorporation of international conventions 223-4, 225; liability 225-7; Maritime Code 226; national structure for safety and law 216-18; prevention 218-21; SafeSeaNet 222; tacit acceptance procedure 215

Polar Code, Norway 207, 210

Polish Harbours Information \& Control System (PHICS) 222-3

Polish Register of Shipping 217

Pollution and Incidence Response Unit (PIRU), Malta 184 
Pollution Control Act 1980, Norway 212 port facility security officers, Spain 235 port facility security plans, Spain 235

Port Security Authority, Spain 236

Port State Control (PSC) 20; Belgium 71; Croatia 84-6; EU (European Union) 23, 38-9; France 100-1; Germany 118; Greece 138, 145; Italy 167; The Netherlands 198-9; Poland 219, 223; Spain 246-8; Turkey 257-8

Port State Control officers (PSCO) 39 port States 22-3

Port System Authority, Italy 163

Ports and Yachting Directorate: Malta 181, 185; Transport Malta 178

ports of general interest 235

Poseidon, migration 263

preventative actions, EU (European Union) $31-7$

prevention: Belgium 69-71; France 98-101; Germany 114-18; Greece 139-44; Italy 163-7; Malta 179-84; The Netherlands 195-8; Norway 208-10; Poland 218-21; Republic of Croatia 78-84; Spain 231-7; Turkey 257-64; United Kingdom 125-7 Prevention of Accidents (Seafarers) Convention (1970), Turkey 255

primary legislation, IMO treaties 16 principle of proportionality $24 \mathrm{n} 15,26,152$ principle of subsidiarity $24 \mathrm{n} 16,26$ prior checks $99-100$

proposal of treaties 8-9

Protocol of 1978 Relating to the International Convention for the Prevention of Pollution from Ships, 1973, Norway 209

Protocol of 2003 to the International Convention on the Establishment of an International Fund for Compensation for Oil Pollution Damage, 1992: Croatia 89; EU (European Union) 46; Greece 147; Italy 171; Norway 212; Poland 225n59; Spain 250; Turkey 265

Protocol of 2010 to Amend the International Convention on Liability and Compensation for Damage to Connection with the Carriage of Hazardous and Noxious Substances by Sea, 1996 10n37; Croatia 89; EU (European Union) 45n133; France 103; Greece 148; The Netherlands 203; Norway 213; Poland 226; Turkey 264 protocols to IMO treaties 11

Protokletas (1992) 232

PSC White Lists 120 PSCO (Port State Control officers) 39 punishment, France 101-2 ratification of IMO treaties 9-10

RCCs (SAR Rescue and Coordination Centers) 155

Recognised Organisations (ROs) 31-3, 128; Belgium 71; Greece 138, 144; liability, United Kingdom 129-30

recording of voyage data 238 regional policy competencies, Belgium 66-7 regionalism 135

Registrar-General of Shipping and Seamen, Malta $177-8$

Regulation on Selection and Authorization of Classification Societies Acting on Behalf of the Flag State for Turkish-Flagged Ships 257

Regulations, defined 26n23; IMO treaties 134-6

Regulations on the Safety of Navigation Inspection Control 85

reporting obligations, The Netherlands 201-2 reporting of incidents/accidents at sea, Spain 242

RIF flag (International French Registry) 102 RINA, Italian classification societies 161 ro-ro passenger ships, EU (European Union) 35 routeing systems, The Netherlands 199

Rules and guidelines for consultative status of non-governmental international organizations with the International Maritime Organization $4 \mathrm{n} 4$

Rules for Statutory Certification of Ships 84

safe manning, Poland 220

Safe Manning Certificate, Spain 231

"Safer Ships, Cleaner Seas" report 126-7

SafeSeaNet 29, 40-1; Greece 146; High-Level Steering Group 57; National Competent Authority (NCA) 202; The Netherlands 201; Poland 222; Spain 241

safety, defined 74, 158-9, 193

Safety Investigation Board, The Netherlands 194

Safety Management Certificate, France 99

Safety Management System (SMS): The

Netherlands 197; Turkey 260-1

safety of navigation: Italy 168-169; The Netherlands 197; Spain 237; Turkey 259-60 safety of ships, Spain, 231-2

Salvage Convention 1989 see International Convention on Salvage 1989

sanctions: Belgium 72; France 101-2; Greece 136, 150-1; Italy 168 ; Norway $211-2$;

Poland 224-5; Spain 245; 249; treaties 20; Turkey 256

SAR (Search and Rescue) 35; Greece 146, 155

SAR Convention 155n173; Malta 178

SAR Rescue and Coordination Centers (RCCs) 155 
SAR services, Poland 221

sea fisheries 223

Sea of Marmara 259

Seafarers' Identity Documents Convention 1958, Turkey 255

seafarers' rights: Italy 170, 172; Spain 250

Seaworthiness Act 1903, Norway 206

seaworthiness 206

secondary legislation, delegation of authority 17

Secretary of State's Representative (SOSREP),

United Kingdom 126

security: Italy 159; The Netherlands 193;

Poland 216n14; Spain 230

security assessments 235

self-executing treaties 14

Service for Navigational Safety and Maritime

Domain Inspection, Croatia 77

Service for Technical Standards of the Croatian

Fleet 77

shared competence 26

ship construction, The Netherlands 195-6

ship control: France 99-101; Greece 148-9

ship recycling, Italy 172

ship registries, Spain 231

ship reporting systems (SRS), Spain 240

ship routeing, The Netherlands 199-200

Ship Safety Division, Germany 111

Ship Safety Plan, The Netherlands 197

ship security officers 235

ship security plans 235

Shipowners' Liability (Sick and Injured

Seamen) Convention 1936, Turkey 255

Shipping Inspectorate, The Netherlands 194

Shipping Regulations, The Netherlands 197

signatures on IMO treaties 9-10

sincere cooperation 27

single document of call 236

SMAIC (State Marine Accident Investigation Commission), Poland 217

Smirdan (1997) 232

Society of Salvage and Maritime Safety, Spain 230

SOLAS (International Convention for the Safety of Life at Sea, 1974) 5, 12, 19, 79; Chapter V 125n15, 155, 185, 209, 219-221, 239; Chapter $\mathrm{XI}$ of the Annex to the SOLAS Convention 230; distressed vessels 155; Greece, (1974)

139; Italy 160, 168; Malta 175, 179-81; navigational warnings 185; The Netherlands

197; Norway 208-10; Poland 216, 219-21;

Rule 12 239; Rule V/8 238; Rule V/10 238;

Turkey 255-6; United Kingdom 125-6

SOLAS 196012

SOLAS 1914160

SOSREP (Secretary of State's Representative), United Kingdom 126
Spain 229-30, 250-1; control and surveillance 237-48; enforcement 248-9; liability 249-50; maritime security 233-7; national structure for safety law 230-1; places of refuge 232-3; prevention 231-7; PSC 246-8; safety of ships 231-2; SRS 240; VTS 239-40

Spanish Commercial Code of 1885 , Book III 229

Spanish Constitution 249

Spanish Maritime Administration 230

special tools on maritime safety, EU (European Union) 29-30

SPMNA 249

stare decisis 122

State Marine Accident Investigation

Commission (SMAIC), Poland 217

statutory surveys 127,130

STCW Convention see International

Convention on Standards of Training,

Certification and Watchkeeping for Seafarers (STCW) 1978

Stockholm Agreement 35n79

SUA see Convention for the Suppression of Unlawful Acts against the Safety of Maritime Navigation (SUA)

Sub-Committee on Implementation of IMO Instruments, Malta 178

Sub-Directorate General for Maritime Inspection, Spain 245

Sub-Directorate General for Maritime Regulation and International Cooperation, Spain 231

Sub-Directorate General for Safety, Pollution and Maritime Inspection, Spain 230

subsidiarity see principle of subsidiarity

sub-standard ships, Spain 247

Supplementary Fund Protocol see Protocol of 2003 to the International Convention on the Establishment of an International Fund for Compensation for Oil Pollution Damage, 1992

surveillance: Belgium 71-2; Croatia 84-8; EFTA (European Free Trade Association) Convention (1960) 58-9; Greece 145-7; Italy 167-8; Malta 184-9; The Netherlands 198-202; Poland 221-3; Spain 237-48; United Kingdom 127-30

Switzerland, EEA (European Economic Area) Agreement 53n9

systems of control, Belgium 71-2

tacit acceptance procedures: amendments to IMO treaties 12-13; implementation of amendments 17; Poland 215

TC (Technical Co-operation Committee) 8 
Technical Co-operation Committee (TC) 8, 8 n29

technical rules, France 98-9

terrorism, hijackings 159

TFEU (Treaty on the Functioning of the

European Union) 26

thalassia asfaleia, Greece 133n2

THETIS 38n99, 167n41, 223

Titanic (1912) xvii, 160

Tonnage Convention see International Convention on Tonnage Measurement of Ships (1969)

Tonnage Regulations, Malta 180

Torremolinos Convention, Protocol 176n20, 196, 231

Torrey Canyon tanker (1967) xvii

Tpao (1997) 264

traffic management: Flanders and the

Netherlands 72; Malta 186

Traffic Order, The Netherlands 197

traffic organization systems $238-9$

Traffic Separation Schemes (TSS) 5; Croatia 86n53; France 102; The Netherlands 199-

200; Norway 211; Poland 223; Spain 238-9

traffic signs, The Netherlands 201

Transport Malta 177, 186; Code of Practice for the Safety of Commercial Vessels, 183

treaties: accession 9-10; adopting 9; amendments to 11-13; CLC (International Convention on Civil Liability for Oil Pollution Damage) 5; COLREGs (International Regulations for Preventing Collisions at Sea) 5; draft treaties 7n25; IMO (International Maritime Organization) 4; implementation process 14-19; incorporation 18-19, 180-1, 202, 223, 225; International Convention on the Civil Liability for Bunker Oil Pollution Damage (Bunker) 6; interrelation between IMO treaties 13-14; legislative drafters 15-17; MARPOL (International Convention for the Prevention of Pollution from Ships) 5-6; Nairobi International Convention on the Removal of Wrecks 6; non-self-executing treaties 15; OPRC (International Convention on Oil Pollution Preparedness, Response and Cooperation) 6; proposal and need for 8-9; SOLAS (International Convention for the Safety of Life at Sea) 5; SUA (Suppression of Unlawful Acts against the Safety of Navigation) 5; Treaty of Lisbon 23n7; Treaty of Lisbon 23n7; Treaty of Paris (1951) 53; Treaty on the Functioning of the European Union (TFEU) 26; see also IMO treaties treaty-making process, IMO (International Maritime Organization) 7-10
Triton, migration 263

TSCF Service, Republic of Croatia 76n7

Tunisia 185

Turkey 252; enforcement 254-6; legislative framework 254-6; liability 264-6; national institutions for implementation of maritime law 252-4; prevention 257-61, of irregular migration 262-4; PSC 257-8; VTS 259-60

Turkish Coast Guard 262-3

Turkish Constitution 254

Turkish Criminal Act 256

Turkish Lloyds 257

UNCLOS (United Nations Convention on the Law of the Sea), 1982 19-20, 25, 27-8, 139, 185; Article 221(1) 242-3; distressed vessels 154; Poland 221; Spain 231, 237, 247; Turkey 255

UNHCR (United Nations High Commissioner for Refugees) 156, 262

unilateralism 135

Union maritime Information and Exchange System see SafeSeaNet

United Kingdom 4n3, 122; 1995 Merchant Shipping Act 122, 130; classification societies 127-8; control and surveillance 127-30; delegation of authority to issue secondary legislation 17; dualism 15; implementation of maritime safety law 123-5; International Convention on Civil Liability for Bunker Oil Pollution Damage from 2001 131; ISM Code 126; liability 130-1; prevention 125-7; ROs 129-30; SOLAS (International Convention for the Safety of Life at Sea) 125-6; SOSREP (Secretary of State's Representative) 126; STCW Convention 126

United Nations Convention on the Law of the Sea see UNCLOS

United Nations High Commissioner for Refugees (UNHCR) 156, 262

United States, monism 14

USS Cole 233

Valletta Ports Vessel Traffic Service (Valletta VTS), Malta 185

VDR systems 238

Ventura (1999) 232

Vessel Protection Detachment 198

vessel traffic monitoring, EU (European Union) $23,40-1$

Vessels Safety Centres, France 96

Vicky (2003) 232

Vienna Convention of the Law of Treaties 9n34, 10-11, 20 
VIMSAS (Voluntary Member States Audit Scheme) 20; Turkey 255

Vitaspirit (2018) 264

Volgoneft 247 (1999) 264

VTMIS (Vessel Traffic Monitoring and Information System) 40-1; Republic of Croatia 86; Turkey 259

VTS (Vessel Traffic Service): Flemish 72-3; Italy 167; Malta 178, 185-6; The Netherlands 200-1; Norway 210-11; Poland 222; Spain 239-40; Turkey 259-60

VTS Centres, Republic of Croatia 86
Wallonia (Belgium) 67-8

West Friesland 199

working conditions, Greece 142

wreck removal: Belgium 72; Croatia 90-2;

Germany 119; Italy 171-2; Malta 191; The

Netherlands 204; Poland 226

Wreck Removal Convention see Nairobi

International Convention on the Removal of Wrecks (2007)

wrecks, Turkey 260-1 
